\title{
atmosphere
}

\section{Lower Atmosphere Meteorology}

\section{Edited by \\ Isidro A. Pérez and M. Ángeles García Printed Edition of the Special Issue Published in Atmosphere}




\section{Lower Atmosphere Meteorology}





\section{Lower Atmosphere Meteorology}

Editors

Isidro A. Pérez

M. Ángeles García

MDPI $\bullet$ Basel $\bullet$ Beijing $\bullet$ Wuhan $\bullet$ Barcelona $\bullet$ Belgrade $\bullet$ Manchester $\bullet$ Tokyo $\bullet$ Cluj $\bullet$ Tianjin 
Editors

Isidro A. Pérez

Universidad de Valladolid

Spain
M. Ángeles García

Universidad de Valladolid

Spain

\section{Editorial Office}

MDPI

St. Alban-Anlage 66

4052 Basel, Switzerland

This is a reprint of articles from the Special Issue published online in the open access journal Atmosphere (ISSN 2073-4433) (available at: https://www.mdpi.com/journal/atmosphere/special_ issues/lower_atmosphere_meteorology).

For citation purposes, cite each article independently as indicated on the article page online and as indicated below:

LastName, A.A.; LastName, B.B.; LastName, C.C. Article Title. Journal Name Year, Volume Number, Page Range.

ISBN 978-3-0365-2960-8 (Hbk)

ISBN 978-3-0365-2961-5 (PDF)

Cover image courtesy of Javier Martínez de Orueta

(C) 2022 by the authors. Articles in this book are Open Access and distributed under the Creative Commons Attribution (CC BY) license, which allows users to download, copy and build upon published articles, as long as the author and publisher are properly credited, which ensures maximum dissemination and a wider impact of our publications.

The book as a whole is distributed by MDPI under the terms and conditions of the Creative Commons license CC BY-NC-ND. 


\section{Contents}

About the Editors $\ldots \ldots \ldots \ldots \ldots \ldots \ldots \ldots \ldots \ldots$ vii

\section{M. Ángeles García and Isidro A. Pérez}

Lower Atmosphere Meteorology

Reprinted from: Atmosphere 2019, 10, 609, doi:10.3390/atmos10100609 . . . . . . . . . . . . 1

Zeeshan Javed, Cheng Liu, Kalim Ullah, Wei Tan, Chengzhi Xing and Haoran Liu

Investigating the Effect of Different Meteorological Conditions on MAX-DOAS Observations of $\mathrm{NO}_{2}$ and $\mathrm{CHOCHO}$ in Hefei, China

Reprinted from: Atmosphere 2019, 10,353, doi:10.3390/atmos10070353 _ . . . . . . . . . . . 5

Jin Maruhashi, Pedro Serrão and Margarida Belo-Pereira

Analysis of Mountain Wave Effects on a Hard Landing Incident in Pico Aerodrome Using the AROME Model and Airborne Observations

Reprinted from: Atmosphere 2019, 10, 350, doi:10.3390/atmos10070350 . . . . . . . . . . . . . 19

Yifang Ren, Jun A. Zhang, Stephen R. Guimond and Xiang Wang

Hurricane Boundary Layer Height Relative to Storm Motion from GPS Dropsonde Composites

Reprinted from: Atmosphere 2019, 10, 339, doi:10.3390/atmos10060339 . . . . . . . . . . . . 43

Cuicui Gao, Yunying Li and Haowei Chen

Diurnal Variations of Different Cloud Types and the Relationship between the Diurnal Variations of Clouds and Precipitation in Central and East China

Reprinted from: Atmosphere 2019, 10, 304, doi:10.3390/atmos10060304 . . . . . . . . . . . . . 57

Jose Manuel Jiménez-Gutiérrez, Francisco Valero, Sonia Jerez and Juan Pedro Montávez Impacts of Green Vegetation Fraction Derivation Methods on Regional Climate Simulations Reprinted from: Atmosphere 2019, 10, 281, doi:10.3390/atmos10050281 . . . . . . . . . . . . .

Nina Zhu, Jianhua Xu, Kaiming Li, Yang Luo, Dongyang Yang and Cheng Zhou

Spatiotemporal Change of Plum Rains in the Yangtze River Delta and Its Relation with EASM, ENSO, and PDO During the Period of 1960-2012

Reprinted from: Atmosphere 2019, 10, 258, doi:10.3390/atmos10050258 . . . . . . . . . . . . .

Miguel Ángel Hernández-Ceballos and Luca De Felice

Air Mass Trajectories to Estimate the "Most Likely" Areas to Be Affected by the Release of Hazardous Materials in the Atmosphere-Feasibility Study

Reprinted from: Atmosphere 2019, 10, 253, doi:10.3390/atmos10050253 . . . . . . . . . . . . . . 109

Fan Song, Xiaohua Yang and Feifei Wu

Suitable Pattern of the Natural Environment of Human Settlements in the Lower Reaches of the Yangtze River

Reprinted from: Atmosphere 2019, 10, 200, doi:10.3390/atmos10040200 . . . . . . . . . . . . . 121

Wenjing Huang, Wei Xiao, Mi Zhang, Wei Wang, Jingzheng Xu, Yongbo Hu, Cheng Hu, Shoudong Liu and Xuhui Lee

Anthropogenic $\mathrm{CH}_{4}$ Emissions in the Yangtze River Delta Based on A "Top-Down" Method

Reprinted from: Atmosphere 2019, 10, 185, doi:10.3390/atmos10040185 . . . . . . . . . . . . . 137 
Qian Wang, Haiming Xu, Leying Zhang and Jiechun Deng

Seasonal and Interannual Variation Characteristics of Low-Cloud Fraction in Different North Pacific Regions

Reprinted from: Atmosphere 2019, 10, 126, doi:10.3390/atmos10030126 . . . . . . . . . . . . . . 159

Yufei Zhao, Jianping Li, Qiang Zhang, Xiaowei Jiang and Aixia Feng

Diurnal Variations in Surface Wind over the Tibetan Plateau

Reprinted from: Atmosphere 2019, 10, 112, doi:10.3390/atmos10030112 . . . . . . . . . . . . . . . 175

Chi Zhang, Ying Zhang, Zhengqiang Li, Yongqian Wang, Hua Xu, Kaitao Li, Donghui Li, Yisong Xie and Yang Zhang

Sub-Mode Aerosol Volume Size Distribution and Complex Refractive Index from the Three-Year Ground-Based Measurements in Chengdu China

Reprinted from: Atmosphere 2019, 10,46, doi:10.3390/atmos10020046 . . . . . . . . . . . . . 187

Ventsislav Danchovski

Summertime Urban Mixing Layer Height over Sofia, Bulgaria

Reprinted from: Atmosphere 2019, 10, 36, doi:10.3390/atmos10010036 . . . . . . . . . . . . . . 201 


\section{About the Editors}

Isidro A. Pérez His scientific career began with photochemical oxidant measurements and modelling. The following research line was the management of RASS sodar data, which led to different papers. This device analyses the low boundary layer beyond the heights investigated by any meteorological tower. After that, $\mathrm{CO}_{2}$ concentrations were studied at a rural site and several papers that combined RASS sodar observations with concentrations present the results of this research. Moreover, parametric and nonparametric procedures were used to investigate the daily and annual cycles of greenhouse gases. The analysis of air parcel trajectories was later considered, and the contrast between Atlantic and continental trajectories was observed on the greenhouse gas concentration recorded. Finally, his research is oriented towards the trend determination by parametric and nonparametric procedures, as well as the origin of greenhouse gas outliers and their influence on this trend.

M. Ángeles García Her research included photochemical oxidant measurements and modelling. Special attention was devoted to ozone-analysing temporal variations, air quality, and the influence of meteorological variables. Another research topic in which she has participated emphasizes the greenhouse gases included in some projects with the aim of studying the climate variability and the need to quantify the sources and sinks of $\mathrm{CO}_{2}$ of natural ecosystems. Different procedures have been applied to investigate temporal cycles and trends of greenhouse gases, the influence of the air masses, and the atmosphere evolution on the concentrations recorded. The research has also included the study of $\mathrm{CO}_{2}$ fluxes in an agricultural soil. 



\title{
Editorial
}

\section{Lower Atmosphere Meteorology}

\author{
M. Ángeles García * and Isidro A. Pérez * \\ Department of Applied Physics, Universidad de Valladolid, Valladolid 47011, Spain \\ * Correspondence: magperez@fa1.uva.es (M.A.G.); iaperez@fa1.uva.es (I.A.P.)
}

Received: 30 September 2019; Accepted: 9 October 2019; Published: 10 October 2019

The Atmosphere Special Issue "Lower Atmosphere Meteorology" comprises thirteen original papers dealing with different meteorological processes that occur in the layer of the atmosphere close to the surface and which can greatly affect living beings and materials. This issue was conceived because of the key role that the lower atmosphere plays in that intensive interaction.

This special issue is made up of three groups of papers. The first group focuses on three meteorological variables. One is the mixing layer height, which is an important parameter vis-à-vis gaining a better understanding of the processes involved in air pollution, climate, and weather. This layer is not usually measured and must be calculated and compared with experimental values. The second variable is wind speed, which is one of the most important parameters used as an indicator of changes in atmospheric circulation. The third variable is the air parcel trajectory for estimating atmospheric transport pathways. This is an important tool for obtaining a better understanding of processes within the lower atmosphere.

The mixing layer height's influence on pollutant dispersion is noticeable in urban areas. In this issue, Danchovski [1] evaluated the algorithms used to calculate this variable based on radiosonde and ceilometer data, and a comparison between the procedures was made. The atmospheric boundary layer plays an important role in the study of meteorology and when modelling the weather. Turbulence mixing in the atmosphere near the surface is determined by the height of the atmospheric boundary layer and data remains scarce in hurricane conditions. Under such extreme conditions, Ren et al. [2] investigated the asymmetric distribution of atmospheric boundary layer height scales using dropsondes.

Meteorological parameters are subject to variations as a consequence of atmospheric turbulence. Daily evolution in the surface wind was analysed by Zhao et al. [3], considering observation data from a noticeable spatial and temporal extension. They found large diurnal variations in surface wind and significant regional features. Maruhaashi et al. [4] addressed the topic of mountain waves caused by disturbance in the air flow around a topographic obstacle. They categorized the severity of the wind shear into classes based on airborne observations from two flights and forecasts of a model considering the Froude number and turbulent indicators.

The dispersion and transport of gases and particles in the atmosphere is characterised by important parameters, such as temperature, precipitation, and wind direction and speed. Transport may have a major impact on living beings and materials when toxic substances are released. Analysis of air mass trajectories improves the response so as to minimize the environmental impact of harmful releases into the atmosphere. Air parcel trajectory models prove particularly useful in these situations. This issue presents one study carried out by Hernández-Ceballos et al. [5], who investigated areas probably affected by air masses of hazardous materials released into the atmosphere. Long-term forward trajectories, with the corresponding end-point positions and density maps, were used to show the influence of orography and height release on the dispersion and transport of materials in the atmosphere.

The content in this group is expanded taking into account that meteorological variables together with additional factors can be used to establish suitable environments for human settlements. This object was quantitatively evaluated and analysed in this issue by Song et al. [6]. The superposition of 
six key natural factors, including temperature-humidity index and land surface-temperature index, was considered. Results were expressed in levels as a function of the most suitable pattern. Topography and vegetation were the dominant factors while for the perspective of time the dominant factors were temperature and water resource.

Characterizing vegetation also plays an important role in modelling the atmospheric processes involved in climate simulations. The research carried out by Jiménez et al. [7] contributes further in this matter. Remote sensing was used to obtain the nearest different vegetation index database which represents vegetation in land surface models. Three methods were considered to derive the fractional vegetation cover assessing the impact of this parameter on near-surface temperature.

The second group of papers considers aerosols, clouds, and precipitation. Intensive research has been devoted in recent years to aerosols due to their influence on radiative processes and on human health. Moreover, aerosols may be cloud condensation nuclei. Atmospheric optics is represented by the analysis carried out by Zhang et al. [8], where aerosol optical depth evolution was investigated together with the determination of the volume size distribution. In this issue, the paper by Wang et al. [9] presents the seasonal and interannual variation of low-cloud fraction and some of its meteorological controlling factors such as the estimated inversion strength and sea surface temperature by means of a long-term database.

Precipitation is represented by the analysis made by Gao et al. [10], where several cycles were determined in a temporal analysis and two patterns in spatial analysis. The relationship between the diurnal variations of clouds and precipitation was also considered.

Persistent rain in a subtropical monsoon region is a complex process that demands in-depth research. The results obtained by Zhu et al. [11] are included in this issue. These authors studied the spatiotemporal variations of the Plum Rains and the influencing factors on different time scales that have thus far scarcely been considered in this perspective.

The final set of papers addresses fundamental features of gases in the atmosphere and anthropogenic greenhouse emission estimates whose concentration and evolution are measured worldwide. Trace gases retrieved using ground-based remote sensing instruments are presented in Javed et al. [12], who discuss the relationship between $\mathrm{NO}_{2}$ and $\mathrm{CHOCHO}$ with different meteorological parameters and show the significant decreasing trend of these trace gases in the afternoon. Huang et al. [13] analysed a correlation "top-down" procedure to estimate anthropogenic $\mathrm{CH}_{4}$ emission using long-term atmospheric $\mathrm{CH}_{4}$ and $\mathrm{CO}_{2}$ concentration data. Moreover, the results were compared with the frequent "bottom-up" IPCC inventory procedure.

Acknowledgments: The editors would like to thank the authors for their contributions, the reviewers for their comments and the editorial office for the support in publishing this issue.

Conflicts of Interest: The authors declare no conflict of interest.

\section{References}

1. Danchovski, V. Summertime urban mixing layer height over Sofia, Bulgaria. Atmosphere 2019, 10, 36. [CrossRef]

2. Ren, Y.; Zhang, J.A.; Guimond, S.R.; Wang, X. Hurricane boundary layer height relative to storm motion from GPS dropsonde composites. Atmosphere 2019, 10, 339. [CrossRef]

3. Zhao, Y.; Li, J.; Zhang, Q.; Jiang, X.; Feng, A. Diurnal variations in surface wind over the Tibetan plateau. Atmosphere 2019, 10, 112. [CrossRef]

4. Maruhashi, J.; Serrào, P.; Belo-Pereira, M. Analysis of mountain wave effects on a hard landing incident in Pico Aerodrome using the AEROME model and airborne observations. Atmosphere 2019, 10, 350. [CrossRef]

5. Hernández-Ceballos, M.A.; De Felice, L. Air mass trajectories to estimate the "most likely" areas to be affected by the release of hazardous materials in the atmosphere-feasibility study. Atmosphere 2019, 10, 253. [CrossRef]

6. Song, F.; Yang, X.; Wu, F. Suitable pattern of the natural environment of human settlements in the lower reaches of the Yangtze river. Atmosphere 2019, 10, 200. [CrossRef] 
7. Jiménez-Gutiérrez, J.M.; Valero, F.; Jerez, S.; Montávez, J.P. Impacts of green vegetation fraction derivation methods on regional climate simulations. Atmosphere 2019, 10, 281. [CrossRef]

8. Zhang, C.H.; Zhang, Y.; Li, Z.; Wang, Y.; Xu, H.; Li, K.; Li, D.; Xie, Y.; Zhang, Y. Sub-mode aerosol volume size distribution and complex refractive index from the three-year ground-based measurements in Chengdu China. Atmosphere 2019, 10, 46. [CrossRef]

9. Wang, Q.; Xu, H.; Zhang, L.; Deng, J. Seasonal and interannual variation characteristics of low-cloud fraction in different north pacific regions. Atmosphere 2019, 10, 126. [CrossRef]

10. Gao, C.; Li, Y.; Chen, H. Diurnal variations of different cloud types and the relationship between the diurnal variations of clouds and precipitation in central and east China. Atmosphere 2019, 10, 304. [CrossRef]

11. Zhu, N.; Xu, J.; Li, K.; Luo, Y.; Yang, D.; Zhou, C. Spatiotemporal change of plum rains in the Yangtze River Delta and its relation with EASM, ENSO, and PDO during the period of 1960-2012. Atmosphere 2019, 10, 258. [CrossRef]

12. Javez, Z.; Lui, C.; Ullah, K.; Xing, C.H.; Lui, H. Investigating the effect of different meteorological conditions on MAX-DOAS observations of $\mathrm{NO}_{2}$ and $\mathrm{CHOCHO}$ in Hefei, China. Atmosphere 2019, 10, 353.

13. Huang, W.; Xiao, H.; Zhang, M.; Wang, W.; Xu, J.; Hu, Y.; Hu, C.; Liu, S.; Lee, X. Anthropogenic $\mathrm{CH}_{4}$ emissions in the Yangtze River delta based on a "top-down" method. Atmosphere 2019, 10, 185. [CrossRef]

(C) 2019 by the authors. Licensee MDPI, Basel, Switzerland. This article is an open access article distributed under the terms and conditions of the Creative Commons Attribution (CC BY) license (http://creativecommons.org/licenses/by/4.0/). 

Article

\title{
Investigating the Effect of Different Meteorological Conditions on MAX-DOAS Observations of $\mathrm{NO}_{2}$ and $\mathrm{CHOCHO}$ in Hefei, China
}

\author{
Zeeshan Javed ${ }^{1}$, Cheng Liu ${ }^{1,2,3,4, *}$, Kalim Ullah ${ }^{5, *}$, Wei Tan ${ }^{3}$, Chengzhi Xing ${ }^{1}$ and Haoran Liu ${ }^{1}$ \\ 1 School of Earth and Space Sciences, University of Science and Technology of China, Hefei 230026, China \\ 2 Key Lab of Environmental Optics \& Technology, Anhui Institute of Optics and Fine Mechanics, Chinese \\ Academy of Sciences, Hefei 230031, China \\ 3 Center for Excellence in Regional Atmospheric Environment, Institute of Urban Environment, Chinese \\ Academy of Sciences, Xiamen 361021, China \\ 4 Anhui Province Key Laboratory of Polar Environment and Global Change, USTC, Hefei 230026, China \\ 5 Department of Meteorology, COMSATS University Islamabad, Islamabad 44000, Pakistan \\ * Correspondence: chliu81@ustc.edu.cn (C.L.); kalim_ullah@comsats.edu.pk (K.U.); \\ Tel.: +86-183-2667-9137(C.L.)
}

Received: 9 May 2019; Accepted: 22 June 2019; Published: 27 June 2019

\begin{abstract}
In this work, a ground-based remote sensing instrument was used for observation of the trace gases $\mathrm{NO}_{2}$ and $\mathrm{CHOCHO}$ in Hefei, China. Excessive development and rapid economic growth over the years have resulted in the compromising of air quality in this city, with haze being the most prominent environmental problem. This is first study covering observation of $\mathrm{CHOCHO}$ in Hefei $\left(31.783^{\circ} \mathrm{N}, 117.201^{\circ} \mathrm{E}\right)$. The observation period of this study, i.e., July 2018 to December 2018, is divided into three different categories: (1) clear days, (2) haze days, and (3) severe haze days. The quality of the differential optical absorption spectroscopy (DOAS) fit for both $\mathrm{CHOCHO}$ and $\mathrm{NO}_{2}$ was low during severe haze days due to a reduced signal to noise ratio. $\mathrm{NO}_{2}$ and $\mathrm{CHOCHO}$ showed positive correlations with PM2.5, producing $\mathrm{R}$ values of 0.95 and 0.98 , respectively. $\mathrm{NO}_{2}$ showed strong negative correlations with visibility and air temperature, obtaining $R$ values of 0.97 and 0.98 , respectively. $\mathrm{CHOCHO}$ also exhibited strong negative correlations with temperature and visibility, displaying $\mathrm{R}$ values of 0.83 and 0.91 , respectively. The average concentration of $\mathrm{NO}_{2}, \mathrm{CHOCHO}$, and PM2.5 during haze days was larger compared to that of clear days. Diurnal variation of both $\mathrm{CHOCHO}$ and $\mathrm{NO}_{2}$ showed a significant decreasing trend in the afternoons during clear days due to photolysis, while during haze days these two gases started to accumulate as their residence time increases in the absence of photolysis. There was no prominent weekly cycle for both trace gases.
\end{abstract}

Keywords: MAX-DOAS; $\mathrm{CHOCHO}$; $\mathrm{NO}_{2}$; meteorological conditions; haze days

\section{Introduction}

China has been ranked near the bottom of the Global Environmental Sustainability Index due to its persistent and extensive air pollution [1]. Widespread air pollution in China can be attributed to a variety of factors: high output from production and manufacturing, an extensive rise in the number of automobiles, a massive economic boom, and high population growth. Poor air quality results in the degradation of human health as well as negative impacts on terrestrial ecosystems and the built environment.

Nitrogen dioxide $\left(\mathrm{NO}_{2}\right)$ and glyoxal $(\mathrm{CHOCHO})$ have significant roles in varying the chemistry of the troposphere [2]. Glyoxal may originate from natural as well as anthropogenic activities [3-5]. The molecule is the smallest alpha-dicarbonyl with the highest predominance in the troposphere [6]. Glyoxal is generated as an intermediate product in most volatile organic compound (VOC) 
oxidation cycles $[5,7,8]$ and acts as an indicator for secondary organic aerosol (SOA) formation in the atmosphere $[4,7,9]$. In addition, $\mathrm{CHOCHO}$ is also produced as an oxidation product for alkyne, isoprene, and various aromatic hydrocarbons. The concentrations of $\mathrm{CHOCHO}$ are not directly impacted by vehicular discharges [5] because they are only in fractions.

The formation of tropospheric ozone and the destruction of stratospheric ozone are catalyzed by nitrogen dioxide $\left(\mathrm{NO}_{2}\right)$ along with other species in the troposphere [10]. The oxidation of nitrogen dioxide forms nitric acid under favorable circumstances in the atmosphere [11]. It increases the risk and incidence of infections related to the respiratory tract [12]. Combustion of fossil fuels in urban settlements has been regarded as the main source of nitrogen dioxide [13]. Additionally, nitrogen dioxide may act as a precursor for the formation of aerosols under certain meteorological conditions. Nitrate aerosols constitute a significant proportion of fine particulates in the urban environment.

In the lower atmosphere, a substantial driving factor towards pollutant distribution in terms of chemical behavior and residence time is believed to be the meteorological condition of the locality. There exist several pieces of evidence in the literature that highlight the effect of various meteorological factors on the distribution of trace gases and aerosols in the atmosphere [14]. The overall tropospheric profile including gaseous pollutants and a variety of particles along with their meteorological parameters present a dynamic and multidimensional picture of the atmosphere, aiding towards a better understanding of pollutant sources, features, and sinks, as well as their dependence on weather conditions.

Multi-axis differential optical absorption spectroscopy (MAX-DOAS) is a type of passive spectroscopy system that has been in use to observe tropospheric trace gases over the past decade. There have been some reported studies on monitoring air quality in China using MAX-DOAS instruments. Long-term observations have resulted in the demonstration of monthly, weekly, and diurnal cycles of $\mathrm{SO}_{2}, \mathrm{NO}_{2}$, and $\mathrm{HCHO}$ in China, and these long-term based observations have been published in Ma et al. [15], Wang et al. [16], and Hendrick et al. [17]. Concentrations of tropospheric nitrogen dioxide were obtained using MAX-DOAS mounted at four different locations in Shanghai in 2010 during the Shanghai World Expo [18]. A MAX-DOAS system was deployed in the Eastern part of China to monitor $\mathrm{NO}_{2}, \mathrm{HCHO}$, and $\mathrm{SO}_{2}$ in the Yangtze River Delta (YRD) region. Shanghai, Hefei, and Nanjing were designated for long-term monitoring. Vertical profiles and vertical column densities (VCDs) of tropospheric trace gases were monitored. Minimum values of $\mathrm{SO}_{2}$ and $\mathrm{NO}_{2}$ were observed at noon, whereas maxima for $\mathrm{HCHO}$ occurred during noontime. The broad-spectrum concentration of the pollutants was observed to gradually decrease from Shanghai to Hefei [19]. The effect of haze and non-haze conditions on the retrieval of $\mathrm{CHOCHO}$ from MAX-DOAS observations in Beijing has been investigated [20].

The city of Hefei, which supports a population of 683 people $/ \mathrm{km}^{2}$, is the capital city of Anhui Province. Excessive development and rapid economic growth over the years have resulted in the compromising of air quality in this city, with haze being the most prominent environmental problem. The prevalence of haze has dramatically impacted public health and has cast negative impressions on transportation networks and production systems. The city usually witnesses hazy days during the autumn and winter months of the year. This can be understood by taking into account the crop burning practices which occur during these months.

In addition, the location of the city makes it more prone to cold and dry air, with relatively gentle winds resulting in less chance for dust and other particulates to be diffused, causing the formation of haze.

Keeping in mind the aforementioned facts, Hefei may be considered a potential site for the observation of pollutants like $\mathrm{NO}_{2}$ and $\mathrm{CHOCHO}$. However, there have been no studies which have reported on the monitoring of $\mathrm{CHOCHO}$ and effects of different meteorological conditions on the retrieval of $\mathrm{NO}_{2}$ and $\mathrm{CHOCHO}$.

In this study we primarily focused on retrieval of $\mathrm{CHOCHO}$ and $\mathrm{NO}_{2}$ from MAX-DOAS observations. Time series and weekly and diurnal cycles of $\mathrm{VCDs}$ of $\mathrm{NO}_{2}$ and $\mathrm{CHOCHO}$ were 
generated. The dependence of $\mathrm{CHOCHO}$ and $\mathrm{NO}_{2}$ VCDs on different meteorological parameters is discussed. As a quick overview of the arguments discussed above, the current research claims the unique contribution of monitoring the air quality of Hefei, China.

\section{Materials and Methods}

\subsection{Instrument}

Ground-based observations of several trace gases were carried out using a remote sensing MAX-DOAS instrument. The instrument contains a spectrometer which has a resolution of $0.6 \mathrm{~nm}$ and a spectral range of 300-490 $\mathrm{nm}$. The major source of light employed by the instrument is dispersed sunlight, while spectral observations can be taken at different viewing angles depending on the concerned atmospheric species [21]. An inbuilt processor automatically controls the day-to-day measurements of the instrument. The spectral measurements were recorded at elevation viewing angles of $1^{\circ}, 2^{\circ}, 3^{\circ}, 4^{\circ}, 5^{\circ}, 6^{\circ}, 8^{\circ}, 10^{\circ}, 15^{\circ}, 30^{\circ}$, and $90^{\circ}$. The average time span for single measurement was $60 \mathrm{~s}$.

\subsection{Observation Site}

Anhui Province is situated in Eastern Central China with Hefei $\left(31.783^{\circ} \mathrm{N}, 117.201^{\circ} \mathrm{E}\right)$ as the capital. The climate of the region is subtropical and humid with the existence of four distinct seasons: summer, fall, winter, and spring. The locality is dominated by southeasterly winds during summer and northwesterly during the winter season. Following a general trend, Hefei has experienced a boom in growth and development over the past two decades. At present, the city supports a permanent population of about 7.7 million. For the current study, the MAX-DOAS instrument was fitted on the building of the Hefei Environmental Protection Bureau. The observation site was almost in the center of city. Figure 1 shows the location of the observation site for MAX-DOAS measurements in Hefei, China.

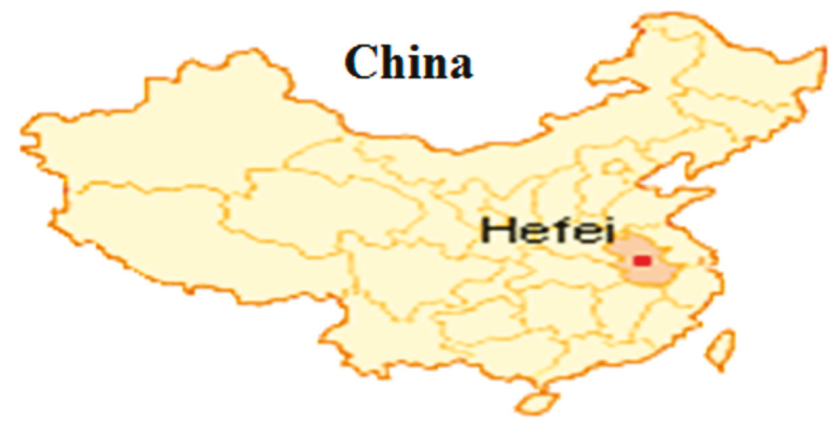

Figure 1. Location of Hefei observation site for multi-axis differential optical absorption spectroscopy (MAX-DOAS) measurements in China.

\subsection{DOAS Analysis}

The application of DOAS provides differential slant column densities (dSCDs) for a variety of trace gases [22]. The current study analyzes MAX-DOAS spectra by employing QDOAS software developed by the Royal Belgian Institute for Space Aeronomy (BIRA-IASB) [23]. The spectra were employed to correct the measurement spectra prior to further analysis. A variety of absorption cross sections for trace gas [24-28], a low order polynomial, a Fraunhofer reference spectrum, and a Ring spectrum were included in the DOAS fit. Comprehensive details for the DOAS fit settings have been depicted in Table 1. 
Table 1. The parameter settings used in MAX-DOAS observations.

\begin{tabular}{cccc}
\hline \multirow{2}{*}{ Parameter } & Data Source & \multicolumn{2}{c}{ Trace Gases } \\
\cline { 3 - 3 } & & $\mathrm{NO}_{2}$ & CHOCHO \\
\hline Wavelength & $298 \mathrm{~K}$, Vandaele et al. [24] & $\checkmark 25-490(\mathrm{~nm})$ & $438-457(\mathrm{~nm})$ \\
$\mathrm{NO}_{2}$ & $220 \mathrm{~K}$, Vandaele et al. [25] & $\checkmark$ & $\checkmark$ \\
$\mathrm{NO}_{2}$ & 223K, Serdyuchenko et al. [26] & $\checkmark$ & $\checkmark$ \\
$\mathrm{O}_{3}$ & 296K, Volkamer et al. [8] & $\mathrm{x}$ & $\checkmark$ \\
$\mathrm{CHOCHO}$ & 293 K, Thalman and Volkamer [27] & $\checkmark$ & $\checkmark$ \\
$\mathrm{O}_{4}$ & 296 K, HITEMP (High-temperature & & $\checkmark$ \\
$\mathrm{H}_{2} \mathrm{O}$ & spectroscopic absorption parameters), & $\checkmark$ & $\checkmark$ \\
& Rothman et al. [28] & $\checkmark$ & 5 \\
Ring & Calculated with QDOAS & 5 & $\checkmark$ \\
\hline
\end{tabular}

Figure 2 displays a characteristic DOAS spectral fitting of the spectrum obtained at a viewing angle of $30^{\circ}$ on 11 November 2018. The fitting shows obvious absorption structures and low residuals, revealing that the spectral fitting is of good quality.
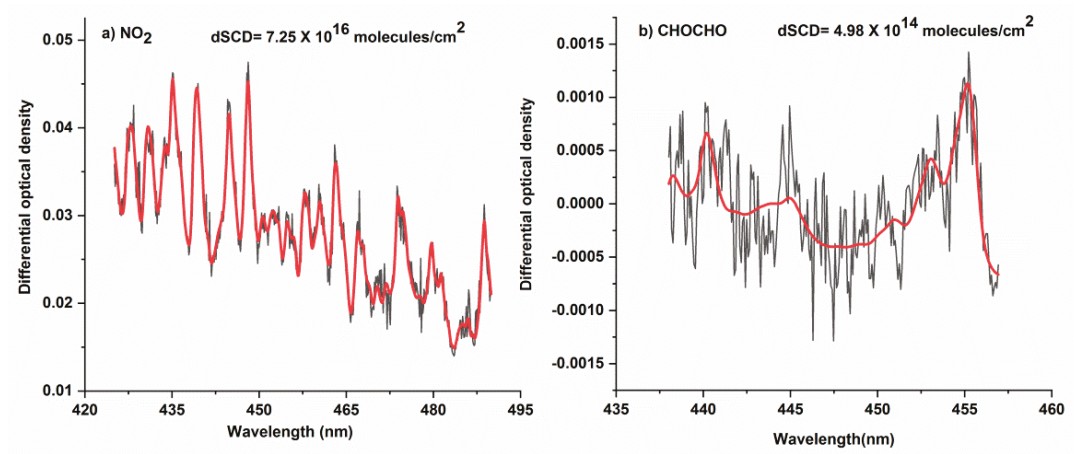

Figure 2. Characteristic DOAS spectral fitting of the spectrum obtained at a viewing angle of $30^{\circ}$ on 11 November 2018 for (a) $\mathrm{NO}_{2}$ and (b) CHOCHO. Legend: dSCD, differential slant column density.

Vertical column densities were generated using an air mass factor (AMF) [29].

For the current study, a differential air mass factor (dAMF) was applied.

$$
V C D_{\text {trop }}=\frac{d S C D_{\alpha}}{d A M F_{\alpha}}
$$

The difference in AMF between $\alpha \neq 90^{\circ}$ and $\alpha=90^{\circ}$ is actually referred to as dAMF.

$$
\begin{aligned}
d A M F_{\alpha} & =A M F_{\alpha}-A M F_{90^{\circ}} \\
V C D_{\text {trop }} & =\frac{d S C D_{\alpha}}{A M F_{\alpha}-A M F_{90^{\circ}}}
\end{aligned}
$$

AMF can be estimated using a geometrical approximation approach [30,31].

$$
A M F=\frac{1}{\sin (\alpha)}
$$

Equation (4) then becomes:

$$
V C D_{\text {trop }}=\frac{d S C D_{\alpha}}{1 / \sin (\alpha)-1}
$$




\section{Results and Discussion}

\subsection{Meteorological Conditions}

The observation period of this study, i.e., July 2018 to December 2018, has been divided into three different categories of meteorological conditions based on meteorological parameters. These three categories are (1) clear days, (2) haze days, and (3) severe haze days. The clear days are days with visibility greater than $10 \mathrm{~km}$ and a PM2.5 concentration less than $70 \mu \mathrm{g} / \mathrm{m}^{3}$. The haze days are days with visibility less than $10 \mathrm{~km}$ and greater than $5 \mathrm{~km}$ and where the PM2.5 concentration is greater than $70 \mu \mathrm{g} / \mathrm{m}^{3}$ and less than $115 \mu \mathrm{g} / \mathrm{m}^{3}$. The severe haze days are days with visibility less than 5 $\mathrm{km}$ and a PM2.5 concentration greater than $115 \mu \mathrm{g} / \mathrm{m}^{3}$ [32,33]. Table 2 shows a summary of different meteorological conditions. The data for meteorological parameters like temperature, humidity, and visibility was downloaded from (http://www.wunderground.com/). The data for meteorological parameters was obtained from a weather station installed at Hefei airport. The data for PM2.5 was downloaded from (http://beijingair.sinaapp.com/).

Table 2. Different meteorological conditions.

\begin{tabular}{ccc}
\hline Meteorological Condition & Visibility $(\mathbf{k m})$ & PM2.5 $\left(\boldsymbol{\mu g} / \mathbf{m}^{3}\right)$ \\
\hline Clear days & $>10$ & $<70$ \\
Haze days & $>5$ and $<10$ & $>70$ and $<115$ \\
Severe haze days & $<5$ & $>115$ \\
\hline
\end{tabular}

\subsection{Impact of Meteorological Conditions on DOAS Fit of $\mathrm{CHOCHO}$ and $\mathrm{NO}_{2}$}

The measurements of MAX-DOAS in the ultraviolet as well as the visible spectral range largely rely on the intensity of sunlight. The excellence of the DOAS fit is characterized by the structure of the residual left after subtracting numerous absorbers using a numerical least square fitting method $[22,34]$ which is usually expressed using the root mean square (RMS). It is a measure of mean "instrument error" which is largely subjected to many specific parameters like limitations of the instruments (such as dark current and spectral resolution, etc.), along with limitations in illustrating the actual state of the atmosphere (for instance aerosols and scattering processes, etc.).

Figure 3 shows the average RMS and dSCD errors during different weather conditions. A higher RMS is observed during severe haze and haze days while on clear days the RMS is low. A similar trend is observed for the dSCD error with higher values during severe haze and haze days and lower values during clear days. These results can be related to the fact that during haze days the intensity of light is low, resulting in a lower signal to noise ratio. The quality of the DOAS fit is affected during severe haze days, which can be observed from the RMS and dSCD errors for both $\mathrm{CHOCHO}$ and $\mathrm{NO}_{2}$. This can result in an underestimation of $\mathrm{CHOCHO}$ and $\mathrm{NO}_{2}$ levels. By contrast, the RMS and dSCD errors during haze and clear days are in an acceptable range and do not have any significant effect on the levels of $\mathrm{CHOCHO}$ and $\mathrm{NO}_{2}$. 

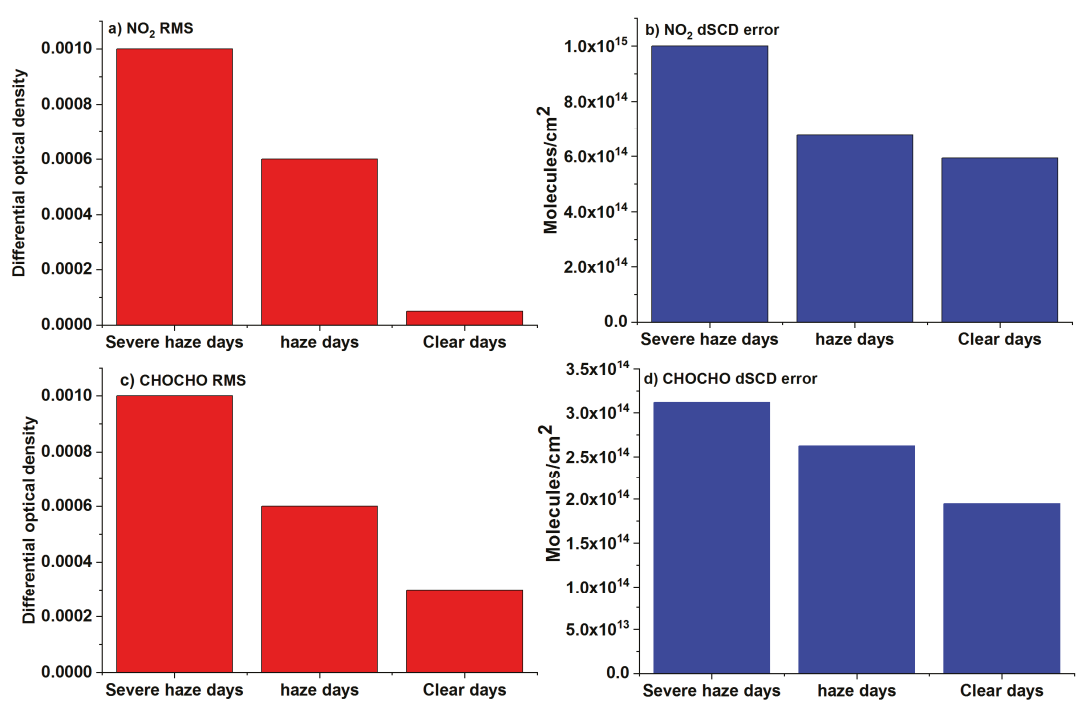

Figure 3. (a) $\mathrm{NO}_{2}$ RMS (b) $\mathrm{NO}_{2}$ dSCD error, (c) $\mathrm{CHOCHO} \mathrm{RMS}$ and (d) $\mathrm{CHOCHO}$ dSCD error under different weather conditions.

\subsection{Time Series of $\mathrm{NO}_{2}, \mathrm{CHOCHO}$, and Meteorological Parameters}

Observations of the trace gases $\mathrm{NO}_{2}$ and $\mathrm{CHOCHO}$ were performed from July 2018 to 31 December 2018 in Hefei, China. QDOAS software was used for analysis of the spectrum to obtain dSCDs. VCDs were generated from these dSCDs using a geometric approximation approach. Data for meteorological parameters like temperature, humidity, and visibility was downloaded from (http://www.wunderground.com/). Data for PM2.5 was downloaded from (http://beijingair.sinaapp.com/). This website belongs to the national environmental monitoring network. Figure 4 shows time series of $\mathrm{NO}_{2}$ and $\mathrm{CHOCHO}$.

(a)

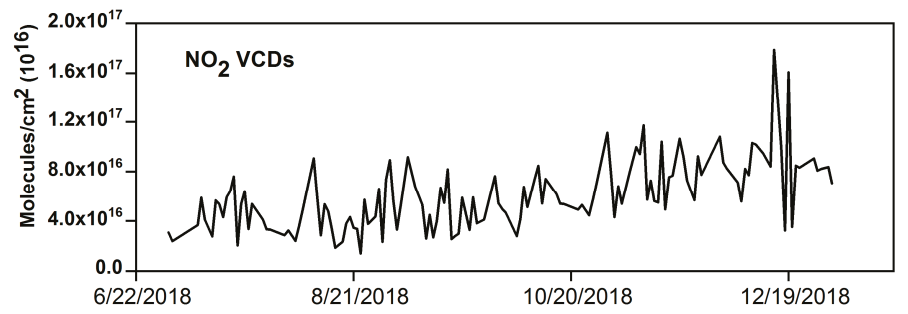

(b)

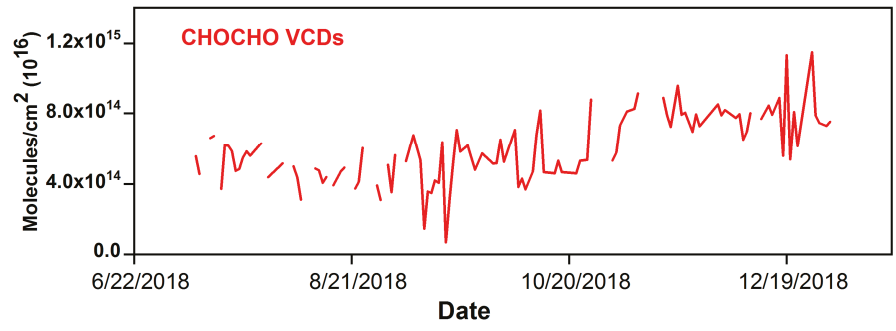

Figure 4. Time series of (a) $\mathrm{NO}_{2}$ and (b) $\mathrm{CHOCHO}$ from 1 July 2018 to 31 December 2018. Legend: VCDs, vertical column densities. 


\subsection{Dependence of Trace Gases on Meteorological Parameters}

In the lower atmosphere, a substantial driving factor of pollutant distribution in terms of chemical behavior and residence time is the meteorological condition of the locality. Hence, the relation of trace gases, i.e., $\mathrm{NO}_{2}$ and $\mathrm{CHOCHO}$, with different meteorological parameters is discussed here. Figure 5 shows monthly variations of PM2.5, temperature, visibility, $\mathrm{NO}_{2}$, and $\mathrm{CHOCHO}$. The average concentration of PM2.5 is seen to increase gradually from July to December. A similar trend is observed for the concentration of $\mathrm{NO}_{2}$ and $\mathrm{CHOCHO}$, whereas air temperature and visibility show a decreasing trend. The decrease in visibility due to an increase in PM2.5 is obviously to have resulted in the more frequent occurrence of haze days in the month of December.
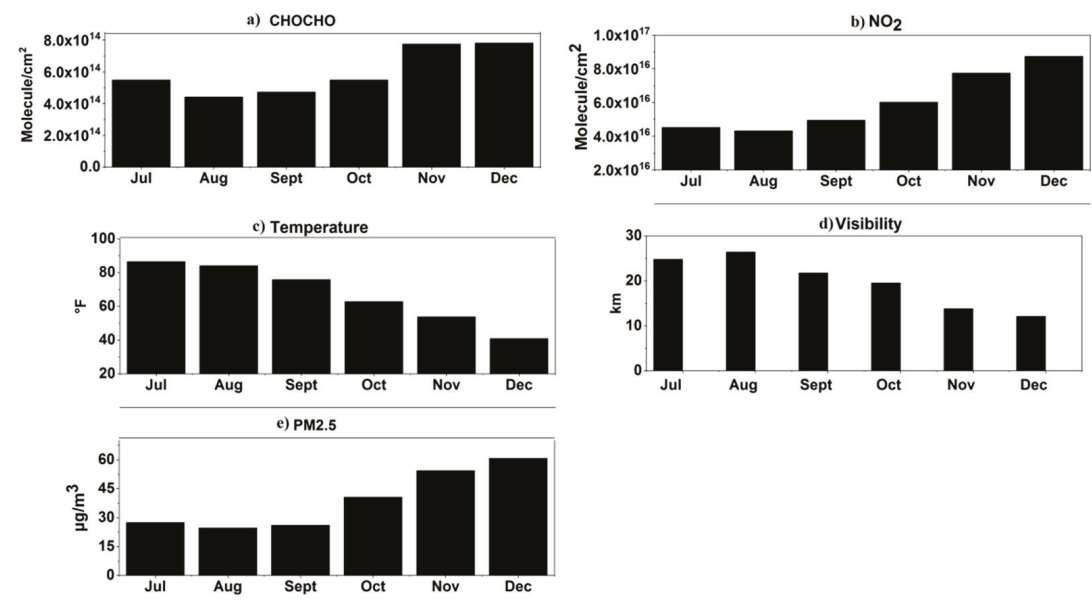

Figure 5. Monthly variations in (a) $\mathrm{CHOCHO},(\mathbf{b}) \mathrm{NO}_{2}$, (c) temperature, (d) visibility, and (e) PM2.5.

The increasing trend of $\mathrm{CHOCHO}$ and $\mathrm{NO}_{2}$ VCDs can be explained by the fact that photolysis is a major sink of both these trace gases. During the winter months when haze conditions start to occur more frequently due to an increase in PM2.5, visibility decreases. The rate of photolysis decreases, as visibility is low. This results in the accumulation of $\mathrm{NO}_{2}$ and $\mathrm{CHOCHO}$ because their major sink, i.e., the rate of photolysis, is very low. The observed increase in $\mathrm{CHOCHO}$ from October may also be related to heating during winter. This finding is consistent with glyoxal retrieved over Beijing and Northern China from OMI (Ozone monitoring instrument) satellite data [35,36]. The increase in the concentration of $\mathrm{NO}_{2}$ may also be related to an increase in the burning of fossil fuels during the winter months. Figure 6 shows correlation plots of $\mathrm{NO}_{2}$ and $\mathrm{CHOCHO}$ with meteorological parameters. 

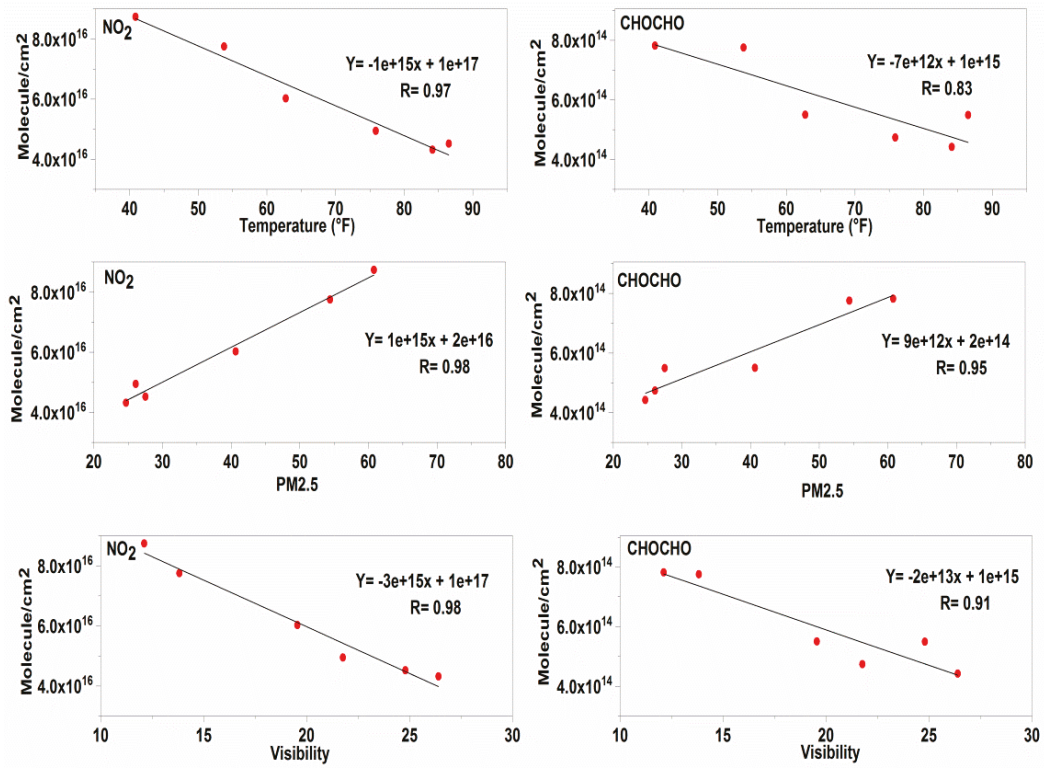

Figure 6. Correlation plots of $\mathrm{NO}_{2}$ and $\mathrm{CHOCHO}$ with PM2.5, temperature, and visibility.

$\mathrm{NO}_{2}$ shows strong negative correlations with temperature and visibility, producing $\mathrm{R}$ values of 0.97 and 0.98 , respectively. $\mathrm{CHOCHO}$ also exhibits strong negative correlations with temperature and visibility, giving $\mathrm{R}$ values of 0.83 and 0.91 , respectively. However, both $\mathrm{CHOCHO}$ and $\mathrm{NO}_{2}$ show positive correlations with PM2.5, having $R$ values of 0.95 and 0.98 , respectively. Table 3 shows the average concentration of $\mathrm{NO}_{2}, \mathrm{CHOCHO}$, and $\mathrm{PM} 2.5$ during clear days, haze days, and severe haze days. It can be observed that the average concentration of $\mathrm{NO}_{2}$ and $\mathrm{CHOCHO}$ is higher during haze days and heavy days compared to clear days, which is due to reduced photolytic activity, with photolytic activity acting as a major sink for $\mathrm{NO}_{2}$ and $\mathrm{CHOCHO}$. During heavy haze days the values are lower when compared with those of haze days.

The most likely reason for this trend is the fact that the quality of the DOAS fit is affected during severe haze days due to higher RMS and dSCD errors which result in the underestimation of $\mathrm{NO}_{2}$ and $\mathrm{CHOCHO}$ during severe haze days.

Table 3. Average concentrations of $\mathrm{NO}_{2}, \mathrm{CHOCHO}, \mathrm{PM} 2.5$, and visibility under different meteorological conditions.

\begin{tabular}{|c|c|c|c|c|}
\hline $\begin{array}{l}\text { Meteorological } \\
\text { Condition }\end{array}$ & $\begin{array}{c}\mathrm{NO}_{2} \\
\text { (molecules/cm²) }\end{array}$ & $\begin{array}{c}\text { CHOCHO } \\
\left.\text { (molecules } / \mathrm{cm}^{2}\right)\end{array}$ & Visibility (km) & PM2.5 $\left(\mu \mathrm{g} / \mathrm{m}^{3}\right)$ \\
\hline Clear days & $1.92 \times 10^{16}$ & $4.70 \times 10^{14}$ & 22 & 36 \\
\hline Haze days & $4.38 \times 10^{16}$ & $7.62 \times 10^{14}$ & 8.8 & 103 \\
\hline Severe haze days & $3.30 \times 10^{16}$ & $5.25 \times 10^{14}$ & 3.9 & 151 \\
\hline
\end{tabular}

\subsection{Diurnal Variation}

Atmospheric trace gases may come from a variety of natural sources of chemical and biological nature as well as from agricultural and industrial practices. The concentration of such gases in the atmosphere and their variation depends upon emission sources, transport routes, and removal mechanisms [37]. In urban centers, the concentration of trace gases is directly or indirectly linked to anthropogenic activities. Specific trends can be seen when looking at the diurnal cycle of these trace 
gases in the atmosphere at different times of the day. The diurnal cycle is critical for understanding the atmospheric profile of these pollutants as well as vital for understanding the emission sources and atmospheric chemistry of these trace gases. The study of atmospheric trace gases can be employed to address various contemporary environmental problems [38]. In this study, the mean diurnal variation of both trace gases was calculated. Figure 7 represents the diurnal variation of $\mathrm{CHOCHO}$ and $\mathrm{NO}_{2}$.
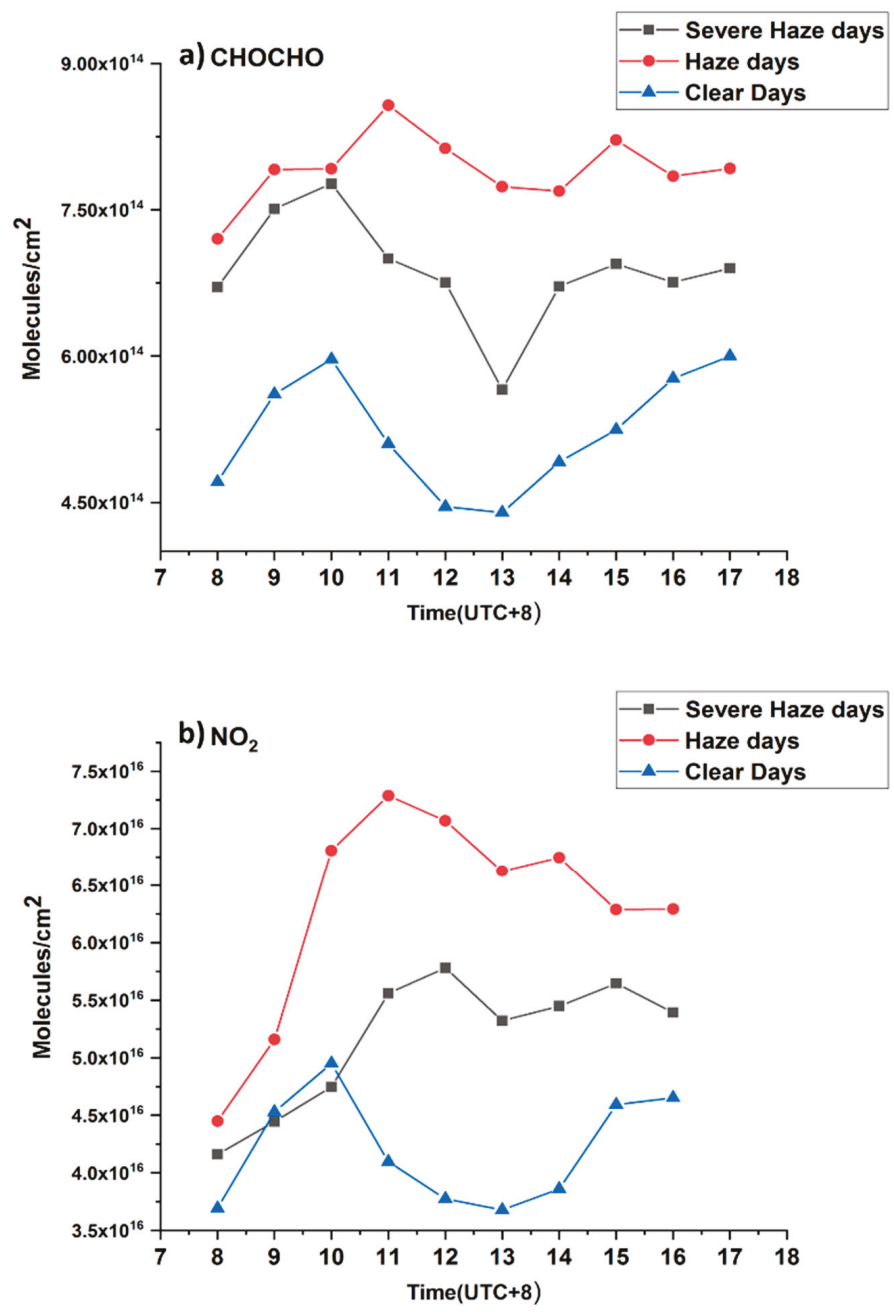

Figure 7. Diurnal cycles for (a) $\mathrm{CHOCHO}$ and (b) $\mathrm{NO}_{2}$ VCDs monitored in Hefei, China.

Diurnal variation of $\mathrm{NO}_{2} \mathrm{VCDs}$ is observed to follow a typical pattern during clear days. Higher values occur during the morning and evening whereas lower values occur during noontime. In the morning $\mathrm{NO}_{2}$ levels increase with a peak at around 10 a.m. local time, which can be attributed to increased traffic-related NOx emissions. The lower values during noontime can be attributed to the enhanced rate of photolysis, along with the oxidation of $\mathrm{NO}_{2}$ by $\mathrm{OH}$ radicals. However, this reduction in $\mathrm{NO}_{2}$ levels is very small because our observation period took place during the winter season, when the rate of photolysis is very low. The level of $\mathrm{NO}_{2} \mathrm{VCDs}$ again starts to rise during the late afternoon because rate of photolysis decreases and $\mathrm{NO}_{2}$ begins to accumulate as the load of traffic 
again increases during the evening. It is worth noting that our results are in agreement with other MAX-DOAS measurements for megacities [17-19,39].

For haze and severe haze days there is no reduction in the level of $\mathrm{NO}_{2}$ during the afternoon. This is obviously because the major sink for $\mathrm{NO}_{2}$, i.e. photolysis, is absent during these days, which results in a slight increase in residence time of the trace gas. During severe haze days, a lower concentration of $\mathrm{NO}_{2}$ is observed as compared to haze days. These results may be ascribed to an underestimation of trace gases during severe haze days due to a lower signal to noise ratio.

During clear days, due to a faster photolysis rate, a certain decrease in $\mathrm{CHOCHO}$ emissions is observed during the afternoon; haze and heavy haze days do not depict such a trend. $\mathrm{CHOCHO}$ concentrations during severe haze days are lower than during haze days, which can be explained by taking into account the fact that DOAS retrieval for $\mathrm{CHOCHO}$ is very sensitive and is underestimated during severe haze days.

\subsection{Weekly Cycles}

Human activities can be categorically divided according to weekly cycles. During weekends, because of reduced industrial activities and transport, the emissions of atmospheric pollutants normally decline [40] in comparison to week days, with peak anthropogenic activities at industrial as well as personal levels (including more use of public and private transport). This factor may have a significant effect on weekly cycles of various atmospheric species. However, in China, because of continuous industrial activity throughout the week and no formal weekly breaks, the weekend effect for various atmospheric species has been observed to be non-significant $[15,18,19,41]$. Figure 8 shows the results of our weekly cycle. There is no meaningful conclusion which can be drawn from these results. These results are consistent with the findings of previous studies.

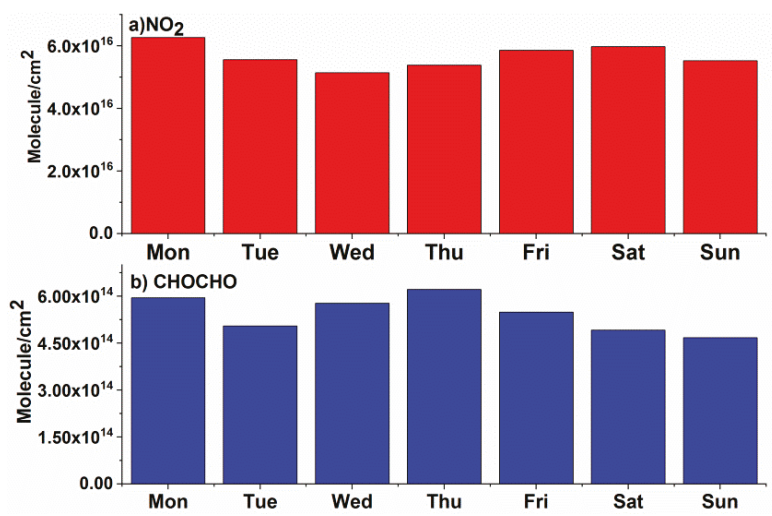

Figure 8. Weekly cycles for (a) $\mathrm{NO}_{2}$ and (b) $\mathrm{CHOCHO}$ VCDs monitored in Hefei, China.

\section{Conclusions}

In this work, MAX-DOAS observations for $\mathrm{NO}_{2}$ and $\mathrm{CHOCHO}$ were performed from 1 July 2018 to 31 December 2018 in Hefei, China. Hefei is the capital of Anhui Province and has a population of around 7.80 million. Hefei is becoming a potential site for air quality monitoring. Because of the development and growth of its economy its air quality is deteriorating and haze days are occurring more frequently. There have been fairly sparse studies reporting the monitoring of $\mathrm{CHOCHO}$ throughout China. This is first study to observe $\mathrm{CHOCHO}$ in Hefei. $\mathrm{NO}_{2}$ is well known for its significance in tropospheric chemistry. The observation time of our study was divided into three different categories based on meteorological parameters and PM2.5 levels. These categories were named clear days, haze days, and severe haze days. The excellence of the DOAS fit was not good during the severe haze days 
for both $\mathrm{CHOCHO}$ and $\mathrm{NO}_{2}$. RMS and $\mathrm{dSCD}$ errors were higher during severe haze days due to a low signal to noise ratio. This therefore resulted in the underestimation of $\mathrm{NO}_{2}$ and $\mathrm{CHOCHO}$ during severe haze days. $\mathrm{NO}_{2}$ and $\mathrm{CHOCHO}$ showed positive correlations with PM2.5, giving $\mathrm{R}$ values of 0.95 and 0.98 , respectively. $\mathrm{NO}_{2}$ showed strong negative correlations with visibility and air temperature, displaying $\mathrm{R}$ values of 0.97 and 0.98 , respectively. $\mathrm{CHOCHO}$ also exhibited strong negative correlations with temperature and visibility, producing $R$ values of 0.83 and 0.91 , respectively. These outcomes can be accredited to the fact that photolysis is the main sink for both $\mathrm{NO}_{2}$ and $\mathrm{CHOCHO}$. An increase in PM2.5 concentration caused a reduction in visibility and hence resulted in the reduction of the rate of photolysis. The average concentrations of $\mathrm{NO}_{2}, \mathrm{CHOCHO}$, and PM2.5 during haze days were higher when compared to those of clear days. Diurnal variations of both $\mathrm{CHOCHO}$ and $\mathrm{NO}_{2}$ showed significant decreasing trends during clear days due to photolysis, while during haze days the trace gases started to accumulate as the residence time of these gases increased. There was no prominent weekly cycle for both trace gases because of continuous industrial activity throughout the week and no formal weekly breaks; the weekend effect for various atmospheric species has been observed to be non-significant.

Author Contributions: Conceptualization, Z.J. and C.L.; formal analysis, Z.J.; methodology, C.L., W.T., and H.L.; resources, C.L.; validation, W.T. and C.X.; writing, review, and editing, Z.J., K.U., and C.L.

Funding: This research was funded by grants from the National Key Research and Development Program of China (2018YFC0213104), the National Natural Science Foundation of China (41722501, 91544212, 51778596, and 41575021) and the National Key Research and Development Program of China (2016YFC0203302).

Acknowledgments: We are indebted to Aimon Tanvir for their useful communications.

Conflicts of Interest: The authors declare no conflict of interest.

\section{References}

1. Liu, J.; Diamond, J. China's environment in a globalizing world. Nature. 2005, 435, 1179. [CrossRef] [PubMed]

2. Hong, Q.; Liu, C.; Chan, K.L.; Hu, Q.; Xie, Z.; Liu, H.; Si, F.; Liu, J. Ship-based MAX-DOAS measurements of tropospheric $\mathrm{NO}_{2}, \mathrm{SO}_{2}$, and $\mathrm{HCHO}$ distribution along the Yangtze River. Atmos. Chem. Phys. 2018, 18, 5931-5951. [CrossRef]

3. Stavrakou, T.; Müller, J.F.; Smedt, I.D.; Roozendael, M.V.; Kanakidou, M.; Vrekoussis, M.; Wittrock, F.; Richter, A.; Burrows, J.P. The continental source of glyoxal estimated by the synergistic use of spaceborne measurements and inverse modelling. Atmos. Chem. Phys. 2009, 9, 8431-8446. [CrossRef]

4. Fu, T.M.; Jacob, D.J.; Wittrock, F.; Burrows, J.P.; Vrekoussis, M.; Henze, D.K. Global budgets of atmospheric glyoxal and methylglyoxal, and implications for formation of secondary organic aerosols. Geophys.Res. Atmos. 2008, 113, D15. [CrossRef]

5. Wittrock, F.; Richter, A.; Oetjen, H.; Burrows, J.P.; Kanakidou, M.; Myriokefalitakis, S.; Volkamer, R.; Beirle, S.; Platt, U.; Wagner, T. Simultaneous global observations of glyoxal and formaldehyde from space. Geophys.Res. Lett. 2006, 33, 16. [CrossRef]

6. Myriokefalitakis, S.; Vrekoussis, M.; Tsigaridis, K.; Wittrock, F.; Richter, A.; Brühl, C.; Volkamer, R.; Burrows, J.P.; Kanakidou, M. The influence of natural and anthropogenic secondary sources on the glyoxal global distribution. Atmos. Chem. Phys. 2008, 8, 4965-4981. [CrossRef]

7. Sinreich, R.; Volkamer, R.; Filsinger, F.; Frieß, U.; Kern, C.; Platt, U.; Sebastián, O.; Wagner, T. MAX-DOAS detection of glyoxal during ICARTT 2004. Atmos. Chem. Phys. 2007, 7, 1293-1303. [CrossRef]

8. Volkamer, R.; Molina, L.T.; Molina, M.J.; Shirley, T.; Brune, W.H. DOAS measurement of glyoxal as an indicator for fast VOC chemistry in urban air. Geophys.Res. Lett. 2005, 32, 8. [CrossRef]

9. Vrekoussis, M.; Wittrock, F.; Richter, A.; Burrows, J.P. Temporal and spatial variability of glyoxal as observed from space. Atmos. Chem. Phys. 2009, 9, 4485-4504.

10. Crutzen, P.J. The influence of nitrogen oxides on the atmospheric ozone content. Q. J. R. Meteorol. Soc. 1970, 96, 320-325. [CrossRef]

11. Seinfeld, J.H.; Pandis, S.N. Atmospheric Chemistry and Physics: From Air Pollution to Climate Change, 2nd ed.; John Willey \& Sons. Inc.: New York, NY, USA, 2006. 
12. Chaloulakou, A.; Mavroidis, I.; Gavriil, I. Compliance with the annual $\mathrm{NO}_{2}$ air quality standard in Athens. Required NOx levels and expected health implications. Atmos. Environ. 2008, 42, 454-465. [CrossRef]

13. Noxon, J.F. Stratospheric $\mathrm{NO}_{2}$ in the Antarctic winter. Geophys.Res. Lett. 1978, 5, 1021-1022. [CrossRef]

14. Sahu, L.K.; Tripathi, N.; Yadav, R. Contribution of biogenic and photochemical sources to ambient VOCs during winter to summer transition at a semi-arid urban site in India. Environ. Pollut. 2017, 229, 595-606. [CrossRef] [PubMed]

15. Ma, J.Z.; Beirle, S.; Jin, J.L.; Shaiganfar, R.; Yan, P.; Wagner, T. Tropospheric $\mathrm{NO}_{2}$ vertical column densities over Beijing: results of the first three years of ground-based MAX-DOAS measurements (2008-2011) and satellite validation. Atmos. Chem. Phys. 2013, 13, 1547-1567. [CrossRef]

16. Wang, Y.; Ying, Q.; Hu, J.; Zhang, H. Spatial and temporal variations of six criteria air pollutants in 31 provincial capital cities in China during 2013-2014. Environ. Int. 2014, 73, 413-422. [CrossRef] [PubMed]

17. Hendrick, F.; Müller, J.F.; Clémer, K.; Wang, P.; Mazière, M.D.; Fayt, C.; Gielen, C.; Hermans, C.; Ma, J.Z.; Pinardi, G.; et al. Four years of ground-based MAX-DOAS observations of $\mathrm{HONO}$ and $\mathrm{NO}_{2}$ in the Beijing area. Atmos. Chem. Phys. 2014, 14, 765-781. [CrossRef]

18. Chan, K.L.; Hartl, A.; Lam, Y.F.; Xie, P.H.; Liu, W.Q.; Cheung, H.M.; Lampel, J.; Pöhler, D.; Li, A.; Xu, J.; et al. Observations of tropospheric $\mathrm{NO}_{2}$ using ground based MAX-DOAS and OMI measurements during the Shanghai World Expo 2010. Atmos. Environ. 2015, 119, 45-58. [CrossRef]

19. Tian, X.; Xie, P.; Xu, J.; Li, A.; Wang, Y.; Qin, M.; Hu, Z. Long-term observations of tropospheric $\mathrm{NO}_{2}, \mathrm{SO}_{2}$ and HCHO by MAX-DOAS in Yangtze River Delta area, China. J. Environ. Sci. 2018, 71, 207-221. [CrossRef]

20. Javed, Z.; Liu, C.; Khokhar, M.F.; Xing, C.; Tan, W.; Subhani, M.A.; Rehman, A.; Tanvir, A. Investigating the impact of Glyoxal retrieval from MAX-DOAS observations during haze and non-haze conditions in Beijing. J. Environ. Sci. 2019. [CrossRef]

21. Plane, J.M.; Saiz-Lopez, A. UV-visible differential optical absorption spectroscopy (DOAS). In Analytical Techniques for Atmospheric Measurement; Oxford publisher: Oxford, UK, 2006; pp. 147-188.

22. Platt, U.; Stutz, J. Differential absorption spectroscopy. In Differential Optical Absorption Spectroscopy; Springer: Berlin/Heidelberg, Germany, 2008; pp. 135-174.

23. Danckaert, T.; Fayt, C.; Van Roozendael, M.; De Smedt, I.; Letocart, V.; Merlaud, A.; Pinardi, G. QDOAS Software User Manual; Belgian Institute for Space Aeronomy: Brussels, Belgium, 2013.

24. Vandaele, A.C.; Hermans, C.; Simon, P.C.; Carleer, M.; Colin, R.; Fally, S.; Merienne, M.F.; Jenouvrier, A.; Coquart, B. Measurements of the $\mathrm{NO}_{2}$ absorption cross-section from $42,000 \mathrm{~cm}^{-1}$ to $10,000 \mathrm{~cm}^{-1}(238-1000 \mathrm{~nm})$ at $220 \mathrm{~K}$ and 294 K. J. Quant. Spectrosc. Radiat. Transf. 1998, 59, 171-184. [CrossRef]

25. Vandaele, A.C.; Hermans, C.; Fally, S. Fourier transform measurements of $\mathrm{SO}_{2}$ absorption cross sections: II.: Temperature dependence in the $29,000-44,000 \mathrm{~cm}^{-1}(227-345 \mathrm{~nm})$ region. J. Quant. Spectrosc. Radiat. Transf. 2009, 110, 2115-2126. [CrossRef]

26. Serdyuchenko, A.; Gorshelev, V.; Weber, M.; Chehade, W.; Burrows, J.P. High spectral resolution ozone absorption cross-sections-Part 2: Temperature dependence. Atmos. Meas. Tech. 2014, 7, 625-636. [CrossRef]

27. Thalman, R.; Volkamer, $\mathrm{R}$. Temperature dependent absorption cross-sections of $\mathrm{O}_{2}-\mathrm{O}_{2}$ collision pairs between 340 and $630 \mathrm{~nm}$ and at atmospherically relevant pressure. Phys. Chem. Chem. Phys. 2013, 15, 15371-15381. [CrossRef] [PubMed]

28. Rothman, L.S.; Gordon, I.E.; Barber, R.J.; Dothe, H.; Gamache, R.R.; Goldman, A.; Perevalov, V.I.; Tashkun, S.A.; Tennyson, J. HITEMP, the high-temperature molecular spectroscopic database. J. Quant. Spectrosc. Radiat. Transf. 2010, 111, 2139-2150. [CrossRef]

29. Solomon, S.; Schmeltekopf, A.L.; Sanders, R.W. On the interpretation of zenith sky absorption measurements. Geophys. Res. Atmos. 1987, 92, 8311-8319. [CrossRef]

30. Hönninger, G.; Friedeburg, C.V.; Platt, U. Multi axis differential optical absorption spectroscopy (MAX-DOAS). Atmos. Chem. Phys. 2004, 4, 231-254. [CrossRef]

31. Celarier, E.A.; Brinksma, E.J.; Gleason, J.F.; Veefkind, J.P.; Cede, A.; Herman, J.R. Validation of ozone monitoring instrument nitrogen dioxide columns. J. Geophys. Res. Atmos. 2008, 113, D15. [CrossRef]

32. Zheng, G.J.; Duan, F.K.; Su, H.; Ma, Y.L.; Cheng, Y.; Zheng, B.; Zhang, Q.; Huang, T.; Kimoto, T.; Chang, D.; et al. Exploring the severe winter haze in Beijing: the impact of synoptic weather, regional transport and heterogeneous reactions. Atmos. Chem. Phys. 2015, 15, 2969-2983. [CrossRef]

33. Duan, L.; Xiu, G.; Feng, L.; Cheng, N.; Wang, C. The mercury species and their association with carbonaceous compositions, bromine and iodine in PM2.5 in Shanghai. Chemosphere 2016, 146, 263-271. [CrossRef] 
34. Wagner, T.; Burrows, J.P.; Deutschmann, T.; Dix, B.; Friedeburg, C.V.; Frieß, U.; Hendrick, F.; Heue, K.P.; Irie, H.; Iwabuchi, H.; et al. Comparison of box-air-mass-factors and radiances for Multiple-Axis Differential Optical Absorption Spectroscopy (MAX-DOAS) geometries calculated from different UV/visible radiative transfer models. Atmos. Chem. Phys. 2007, 7, 1809-1833. [CrossRef]

35. Alvarado, L.M.A.; Richter, A.; Vrekoussis, M.; Wittrock, F.; Hilboll, A.; Schreier, S.F.; Burrows, J.P. An improved glyoxal retrieval from OMI measurements. Atmos. Meas. Tech. 2014, 7, 4133. [CrossRef]

36. Wang, Y.; Tao, J.; Cheng, L.; Yu, C.; Wang, Z.; Chen, L. A Retrieval of Glyoxal from OMI over China: Investigation of the Effects of Tropospheric $\mathrm{NO}_{2}$. Remote Sens. 2019, 11, 137. [CrossRef]

37. Rasmussen, R.A.; Khalil, M.A.K. Atmospheric trace gases: trends and distributions over the last decade. Science 1986, 232, 1623-1624. [CrossRef] [PubMed]

38. Wilkniss, P.E.; Lamontagne, R.A.; Larson, R.E.; Swinnerton, J.W.; Dickson, C.R.; Thompson, T. Atmospheric trace gases in the southern hemisphere. Nat. Phys. Sci. 1973, 245, 45-47. [CrossRef]

39. Gratsea, M.; Vrekoussis, M.; Richter, A.; Wittrock, F.; Schönhardt, A.; Burrows, J.; Kazadzis, S.; Mihalopoulos, N.; Gerasopoulos, E. Slant column MAX-DOAS measurements of nitrogen dioxide, formaldehyde, glyoxal and oxygen dimer in the urban environment of Athens. Atmos. Environ. 2016, 135, 118-131. [CrossRef]

40. Cleveland, W.S.; Graedel, T.E.; Kleiner, B.; Warner, J.L. Sunday and workday variations in photochemical air pollutants in New Jersey and New York. Science 1974, 186, 1037-1038. [CrossRef] [PubMed]

41. Beirle, S.; Platt, U.; Wenig, M.; Wagner, T. Weekly cycle of $\mathrm{NO}_{2}$ by GOME measurements: a signature of anthropogenic sources. Atmos. Chem. Phys. 2003, 3, 2225-2232. [CrossRef]

(C) 2019 by the authors. Licensee MDPI, Basel, Switzerland. This article is an open access article distributed under the terms and conditions of the Creative Commons Attribution (CC BY) license (http://creativecommons.org/licenses/by/4.0/). 

Article

\title{
Analysis of Mountain Wave Effects on a Hard Landing Incident in Pico Aerodrome Using the AROME Model and Airborne Observations
}

\author{
Jin Maruhashi ${ }^{1}$, Pedro Serrão ${ }^{2}$ and Margarida Belo-Pereira ${ }^{3,4, *}$ \\ 1 Aerospace Group, Instituto Superior Técnico, Lisbon University, 1049-001 Lisboa, Portugal \\ 2 LAETA/CCTAE (Centro de Ciências e Tecnologias Aeronáuticas e Espaciais), Instituto Superior Técnico, \\ Lisbon University, 1049-001 Lisboa, Portugal \\ 3 Aviation Meteorology Division, Portuguese Institute for Sea and Atmosphere, 1749-077 Lisboa, Portugal \\ 4 Centre for the Research and Technology of Agro-Environmental and Biological Sciences (CITAB), University \\ of Trás-os-Montes and Alto Douro, 5001-801 Vila Real, Portugal \\ * Correspondence: margarida.belo@ipma.pt; Tel.: +351-218-447123
}

Received: 22 May 2019; Accepted: 24 June 2019; Published: 26 June 2019

\begin{abstract}
A hard landing incident in Pico Aerodrome (LPPI) involving an Airbus A320-200 aircraft is investigated using airborne observations and forecasts of the AROME (Applications of Research to Operations at Mesoscale) model. A second flight is also analyzed. The severity of the wind shear during both flights is quantified using the intensity factor " $\mathrm{I}$ " that is based on aerial data and recommended by ICAO (International Civil Aviation Organization). During Flight 1, 36\% of the landing phase (below $2100 \mathrm{ft}$ ) occurred under "severe" wind shear conditions and $16 \%$ occurred under "strong" conditions. Upstream characteristics included southwest winds, stable stratification and a Froude number close to 1 . According to the AROME model, these circumstances triggered the development of vertically propagating mountain waves, with maximum vertical velocities above $400 \mathrm{ft} / \mathrm{min}$ and exceeding $200 \mathrm{ft} / \mathrm{min}$ in the flight path. These conditions, together with the severe wind shear, may have caused the incident. During the second flight, a wake with lee vortices and reversed flow developed in the region of the flight path, which is consistent with a low upstream Froude number and/or with the flow regime diagram of previous studies. During the approach phase of this flight, "severe" wind shear conditions were absent, with "strong" ones occurring $4 \%$ of the time. It predominantly displayed "light" conditions during $68 \%$ of this phase. As a result of the comparison between "I" and the AROME turbulence indicators, preliminary thresholds are proposed for these indexes. Lastly, this study provides an objective verification of AROME wind forecasts, showing a good agreement with airborne observations for wind speeds above $10 \mathrm{kt}$, but a poor skill for weaker winds.
\end{abstract}

Keywords: mountain waves; wake; AROME model; turbulence indicators; Azores Island; Froude number; model objective verification; aircraft observations

\section{Introduction}

In a stably stratified atmosphere, the airflow towards a topographic obstacle may trigger gravity (or buoyancy) waves downstream of the obstacle, known as mountain waves [1]. The flow response to the obstacle depends on several factors like the mountain shape and the Froude number [2]. At a low Froude number, several phenomena have been observed: the flow may be blocked upwind [3] or it may also pass around the obstacle rather than over it (flow splitting phenomenon) [2,4]. In association with the flow splitting phenomenon, a low-level wake may develop on the leeside of the obstacle [4-7]. The wake can be expressed as a quasi-steady pair of counter-rotating vortices circulating about vertical 
axes or can present an unstable pattern in which vortices of alternating sign are periodically shed downstream to form a vortex street $[4,5]$. Also at a low Froude number, wave breaking, indicating the breakdown of laminar flow, may occur above the obstacle [2,4]. On the other hand, at high Froude numbers, airflow will overcome the topographic obstacle and vertically propagating mountain waves may exist depending on the relation between stability, wind and mountain width [8].

The study of such orographic phenomena is of paramount importance in the realm of aeronautics as they have been known to cause a variety of aviation accidents worldwide $[9,10]$ and are especially hazardous to light aircraft during their takeoff and landing phases. Therefore, several authors analyzed aircraft accidents and incidents in various parts of the world, with special attention given to airports or aerodromes directly exposed to orographic flow interference. Aircraft observations have often been compared to NWP (numerical weather prediction) models in an attempt to not only establish their reliability as forecasting tools but to also better comprehend the main causes behind these incidents. Keller et al. [9], for instance, investigated a Continental Airlines aircraft that caught fire after veering violently off of the runway in Denver International Airport (DIA) during takeoff. High-resolution numerical simulations enabled them to conclude that lee waves were the probable cause behind the strong crosswinds that caused the accident. Another study published in 2013 by Parker and Lane [10] revealed that turbulence engendered by orographic flow resulted in a fatal lightweight aircraft accident in Australia.

In Portugal, the behavior of Madeira's wake has been the subject of several studies [5,11,12]. However, mountain waves associated to Pico Mountain (the highest of Portugal), to the authors' best knowledge, has only been addressed previously by Barata et al. [13] in a characterization of the surrounding wind regime and validation of the existence of leeside vortices through a scaled physical model of the island placed within a wind tunnel.

Pico Island is one of nine constituents of the Azorean archipelago, situated in the Atlantic Ocean $1500 \mathrm{~km}$ from Lisbon (Figure 1). Pico Aerodrome (LPPI) lies on the north coast of the island (Figure S1), north of Pico Mountain with a maximum height of $2351 \mathrm{~m}(7710 \mathrm{ft})$. In the presence of southwesterly winds in the southern region of the Island, which are frequent [13], the likelihood that takeoff and landing phases will be affected by a plethora of orographic phenomena ranging from severe mountain waves, leeside vortices and overall LLWS (low-level wind shear) is increased $[13,14]$.

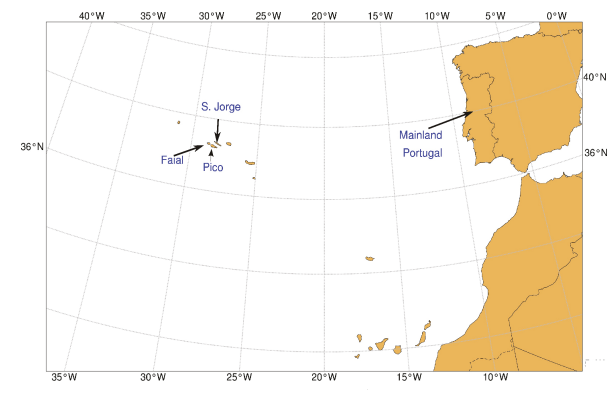

Figure 1. Macroscopic view of Pico Island's location relative to Mainland Portugal.

Forecasts of mountain wave induced turbulence rely on algorithms based on outputs of numerical weather prediction (NWP) models. Many of these algorithms rely on wind, temperature and turbulent kinetic energy [15]. Therefore, the accuracy of these fields is a key issue. However, an accurate simulation of such atmospheric variables is particularly challenging in the atmospheric boundary layer (ABL) due to its unsteady and turbulent nature [16]. Several factors may influence the model accuracy, namely, unresolved topographic features [17], turbulence closure schemes [18,19] as well as the representation of turbulence mixing [20,21]. The dynamical core also plays a key role. Ricard et al. [22] for instance, in analyzing the kinetic energy spectra of AROME and Meso-NH models (which have the 
same physical parameterizations), concluded that a model using a Semi-Implicit Semi-Lagrangian (SISL) scheme has a coarser effective resolution than a model using an Eulerian explicit scheme (less efficient).

The current article focuses on the orographic flow associated to Pico Mountain in two different synoptic backgrounds, using forecasts from the operational AROME (Applications of Research to Operations at Mesoscale) model and airborne measurements collected by SATA (SATA Internacional-Azores Airlines, S.A.) Airbus A320-200 aircraft. Two flights were considered, where the first one represents the hard landing incident (henceforth referred to as Flight 1). Upon touchdown, the aircraft bounced and registered a vertical acceleration above $2 \mathrm{G}$. No fatalities or serious injuries were reported. The second one, labeled Flight 2, will serve as a control parameter that is representative of a flight in which no incidents were reported.

This study has three goals. The first goal is to characterize the nature of the orographic phenomenon involved during the two flights. The second is to provide an assessment of the agreement between AROME wind forecasts and airborne observations. The third objective is to establish a correspondence between AROME turbulence indicators and the wind shear severity registered by the aircraft. For this purpose, five turbulence indicators (Brown, Ellrod T11, Ellrod TI2, CAT1 and EDR or Eddy Dissipation Rate) are computed from AROME forecasts. The wind shear perceived by the aircraft is quantified using the wind shear intensity factor "I", as originally suggested by Woodfield and Woods [23]. This assessment is also of great importance because the Portuguese Institute for Sea and Atmosphere (IPMA) routinely provides AROME forecasts of the wind and EDR for Pico and Faial Islands to SATA on an experimental basis. This test phase started in November 2017.

\section{Data and Methodology}

This section characterizes the wind from aerial data gathered by SATA A320-200 aircraft during both flights. The method of calculation of the wind shear intensity factor "I", which is a function of these airborne measurements, is established. A brief description of the AROME model is also provided. The Froude number and turbulence indicators, which are based on forecasts, are then defined. Lastly, definitions for the RMSE (root mean square error) and MAE (mean absolute error) concerning wind magnitude and direction are included.

\subsection{SATA Airborne Measurements}

For each flight, wind intensity and direction were recorded approximately every $4 \mathrm{~s}$ along with the corresponding altitude and geographical coordinates (latitude and longitude). Only the approach and landing phases (approximately final $10 \mathrm{~min}$ of flight or altitudes below $5000 \mathrm{ft}$ ) were perused since these are the most pertinent to understanding the incident. The average trajectory for both flights along with Pico's orography in the AROME model are mapped in Figure 2.

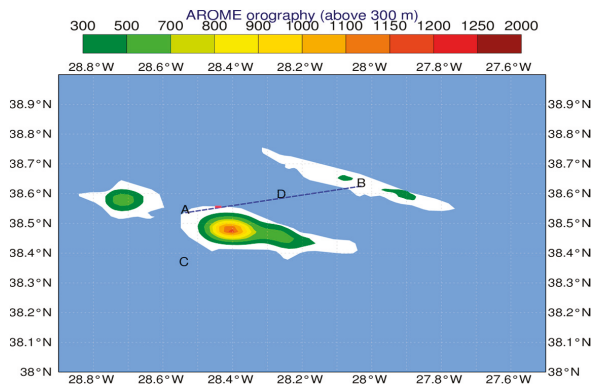

Figure 2. Approximate flight path (blue dashed line) and AROME orography. Shading shows elevation in meters. Pink marker shows the aerodrome location. "AB" and "CD" are endpoints of cross-sections analyzed in subsequent sections. 


\subsection{Wind Shear Intensity Factor " $\mathrm{I}$ "}

The severity of wind shear intensity, as perceived by the aircraft, will be measured according to the wind shear intensity factor "I", detailed in ICAO's (International Civil Aviation Organization) Manual on Low-level Wind Shear [24]. Following Guan and Yong's study [25], wind shear is classified as "light", "moderate", "strong" or "severe" based on the variation of the airspeed with time $\frac{d V_{T A S}}{d t}$ and on the airspeed proportion $\frac{\Delta V_{T A S}}{V_{T A S}}$. The intensity factor "I" itself may be expressed as follows:

$$
I=\frac{d V_{T A S}}{d t} \cdot\left(\frac{\Delta V_{T A S}}{V_{T A S}}\right)^{2}
$$

The computation of the true airspeed, $V_{T A S}$, is based on the following relation:

$$
G S=V_{T A S}+V_{H T}
$$

where GS represents the ground speed of the aircraft and was computed by employing the three-dimensional distance formula between any two points described by their altitude and geographic coordinates (latitude and longitude). Note that $\Delta V_{T A S}$ is simply the difference between true airspeeds at the $n^{\text {th }}$ and $(n+1)^{\text {th }}$ instants. The head or tailwind component (see Equation S2.1 and Figure S2, from Supplementary Materials) is then subtracted from the ground speed to obtain the true airspeed.

Once $\frac{d V_{T A S}}{d t}$ and $\frac{\Delta V_{T A S}}{V_{T A S}}$ are known, the wind shear intensity may be classified by consulting the proper boundaries specified in Figure S3 from the Supplementary Materials. In both flights, this was performed for altitudes approximately below $2000 \mathrm{ft}(610 \mathrm{~m})$, which according to Guan and Yong [25], represents the appropriate range for low-level wind shear considerations.

\subsection{Description of the AROME Model}

The AROME model that runs operationally at IPMA uses a horizontal grid spacing of $2.5 \mathrm{~km}$. It uses a SISL scheme and employs a three-class ice scheme with ECMWF (European Center for Medium-Range Weather Forecasts) radiation parameterizations, as was described by Seity et al. [26]. The representation of turbulence in the ABL is based on a prognostic TKE (Turbulent Kinetic Energy) equation [27], combined with a diagnostic mixing length. AROME initial and boundary conditions emanate from the ARPEGE (Action de Recherche Petite Échelle Grande Échelle) model. At the time of Flight 1, the operational AROME model was integrated with 46 levels, while at the time of Flight 2, additional vertical levels were incorporated, leading to a total of 60 levels.

\subsection{Froude Number Definitions}

The Froude number is a dimensionless parameter that may be utilized to describe the interaction mechanism between kinetic and potential energies as air flows past orography, according to Sutherland [28]. The Froude number can be interpreted as the ratio of the inertial to gravity forces in the flow (Lynch and Cassano [29]). This ratio may also be interpreted physically as the ratio between the mean flow velocity and the shallow water gravity wave speed (Holton [30]). The Froude number has also been applied to infer the type of flow phenomenon that may occur in the lee of a mountain when paired with a flow regime diagram, as was done by Sheridan and Vosper [31].

Three definitions of the Froude number were considered in this study. The first is the classical form, the second is based on Sheppard's dividing-streamline concept [32] and the third is applicable when a temperature inversion is present in the vicinity of the upstream region of the mountain. The exact upstream location at which Froude numbers were computed in both flights is indicated by point $\mathrm{C}$ in Figure 2. 


\subsubsection{Classical Froude Number, Fr}

The classical Froude number, Fr, may be defined as:

$$
\mathrm{Fr}=\frac{\bar{U}}{N h_{m}},
$$

where $\bar{U}$ is upstream flow speed, $N$ is the Brunt-Väisälä frequency and $h_{m}$ is the mountain height $[6,7,33]$. Vosper et al. [34] provide an additional definition, $F_{L}$, that is based on a horizontal length scale $L$, such that $F_{L}=U / N L$. In this study, $h_{m}$ is $1200 \mathrm{~m}$, which is the maximum height of Pico Mountain according to AROME topography and $L=21 \mathrm{~km}$. Some authors [2,4,35], alternatively, refer to the non-dimensional mountain height $M$ as:

$$
M=\frac{1}{\mathrm{Fr}}=\frac{N h_{m}}{U_{n m}},
$$

where $N$ would now represent an average value for the Brunt-Väisälä frequency below $h_{m}$ and $U_{n m}$ a cross-mountain wind speed average also under $h_{m}$, as is done similarly by Jiang et al. [35].

Several authors summarize their results from laboratory, numerical and theoretical studies in a schematic regime diagram showing that for Fr $>1$ mostly small-amplitude gravity waves are expected, while for Fr $<1$, flow splitting, lee vortices and/or wave breaking may occur depending also on the horizontal aspect ratio of the obstacle. This is seen in Figure 2 from [4] and in Figure 13 from [2], the latter of which is shown here as Figure A1a.

For the parameter $F_{L}$, whenever $F_{L} \leq 1$ vertically propagating waves are expected, but are evanescent if $F_{L}>1$ [34].

\subsubsection{Froude Number $\left(\mathrm{Fr}_{\mathrm{h}}\right)$ in Terms of the Dividing-Streamline Height $h_{c}$}

Under stable conditions and with varying wind speed and stratification, according to Sheppard [32] and Heinze et al. [6], it is possible to determine the dividing-streamline height $h_{c}$ (also called the critical height) as follows:

$$
\frac{1}{2} \bar{V}_{h}^{2}\left(h_{c}\right)=\int_{h_{c}}^{h_{m}} N^{2}(z)\left(h_{m}-z\right) d z
$$

where Heinze et al. [6] define $\bar{V}_{h}$ as the mean horizontal velocity as a function of the horizontal velocity components $u$ and $v: V_{h}=\sqrt{u^{2}+v^{2}}$. It is assumed in Equation (5) that all the kinetic energy of the flow is converted into potential energy [6]. As was done in [6], Equation (5) will be solved iteratively for $h_{c}$ via the trapezoidal rule to numerically compute the integral.

As noted by Heinze et al. [6], if Fr $>1$, all fluid parcels, even near the surface, can flow over the obstacle. On the other hand, when $\mathrm{Fr}<1$, the fluid may stagnate in the upstream region below a certain critical height $h_{c}$, passing primarily around the orographic obstacle rather than over it (flow splitting phenomenon). Above $h_{c}$, the flow would be able to ascend the obstacle [6]. An illustration of flow splitting and of the critical height $h_{c}$ is provided in Figure 3.

So, when flow splitting occurs, an expression for the Froude number in terms of the dividing-streamline height may then be obtained, as is noted by Trombetti and Tampieri [36]:

$$
\mathrm{Fr}_{\mathrm{h}}=1-\frac{h_{c}}{h_{m}}
$$

According to Wooldridge et al. [37], Equation (6) may also be used to find the critical height $h_{c}$ if $\mathrm{Fr}_{\mathrm{h}}$ is replaced by Fr (defined by Equation (3)), which is applicable when Fr $<1$. 


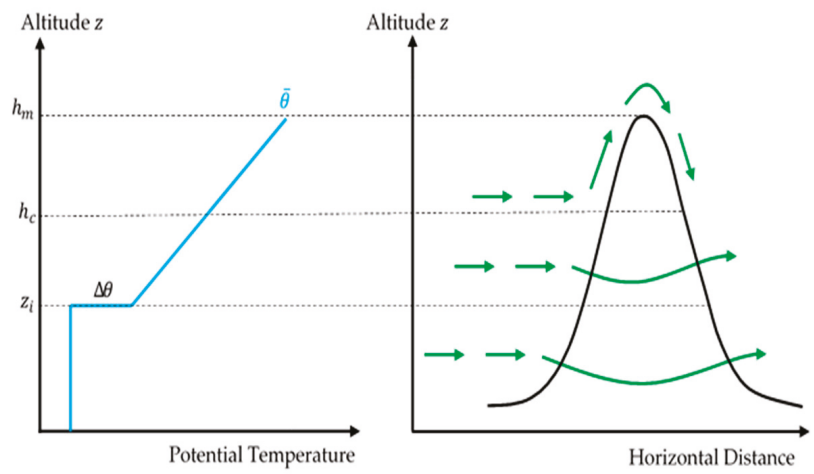

Figure 3. Theoretical illustration of the flow splitting phenomenon with green arrows depicting airflow. Potential temperature profile is shown in blue. The critical and inversion heights, $h_{c}$ and $z_{i}$ respectively, are also illustrated.

\subsubsection{Inversion Froude Number $\left(\mathrm{Fr}_{\mathrm{i}}\right)$}

The inversion Froude number may be computed in the presence of an inversion by adopting Vosper's [38] definition:

$$
\mathrm{Fr}_{\mathrm{i}}=\frac{U_{n m}}{\sqrt{g^{\prime} z_{i}}}, g^{\prime}=g \frac{\Delta \theta}{\theta_{m}} .
$$

where $z_{i}$ is the inversion height, $\Delta \theta$ is the magnitude of the potential temperature difference across the inversion, $\theta_{m}$ is the mean potential temperature below the inversion base and $U_{n m}$ is the cross-mountain wind speed (averaged below $z_{i}$ ). See Figure 3 for a visual representation of some of these parameters.

In the presence of a temperature inversion, several authors $[5,38,39]$ provide a regime diagram for a two-layer flow over mountains as a function of the inversion Froude number (Equation (7)) and of the ratio $\frac{h_{m}}{z_{i}}$, as is shown in Figure A1b from Appendix A.

\subsection{Turbulence Indicators}

Five turbulence indicators commonly used in aviation meteorology applications [40,41] are used in this study: Brown, Ellrod TI1, Ellrod TI2, CAT1 and EDR. These parameters were calculated using AROME forecasts.

\subsubsection{Brown Index $\Phi$}

According to Gill and Buchanan [40] and Sharman et al. [41], the Brown Index $\Phi$ may be defined as:

$$
\Phi=\sqrt{0.3 \zeta_{a}^{2}+\left(\frac{\partial v}{\partial x}+\frac{\partial u}{\partial y}\right)^{2}+\left(\frac{\partial u}{\partial x}-\frac{\partial v}{\partial y}\right)^{2}}, \quad \zeta_{a}=\left(\frac{\partial v}{\partial x}-\frac{\partial u}{\partial y}\right)+f
$$

with $u$ and $v$ denoting the zonal and meridional components of the wind respectively. The vertical component of the absolute vorticity is represented by $\zeta_{a}$, which is the sum of the vertical component of the relative vorticity and the Coriolis frequency $f$.

The form applied in this work, $\Phi_{\varepsilon}$, was based on Equation (8) and is expressed as energy dissipation in the following manner:

$$
\Phi_{\varepsilon}=\frac{1}{24} \Phi S_{V}^{2}, S_{V}=\sqrt{\left(\frac{\partial u}{\partial z}\right)^{2}+\left(\frac{\partial v}{\partial z}\right)^{2}}
$$

where $S_{V}$ is the vertical wind shear. 


\subsubsection{Ellrod TI Indexes}

As is mentioned in [40], the Ellrod indicators can be used to quantify turbulence. The first version, Ellrod TI1, is defined as:

$$
\text { Ellrod TI }=\mathrm{S}_{\mathrm{v}} \sqrt{\left(\frac{\partial u}{\partial x}-\frac{\partial v}{\partial y}\right)^{2}+\left(\frac{\partial v}{\partial x}+\frac{\partial u}{\partial y}\right)^{2}}
$$

where $S_{v}$ is the vertical wind shear. The Ellrod TI2 index is similar to the Ellrod TI1, except that it incorporates a convergence term in the form of $-\left(\frac{\partial u}{\partial x}+\frac{\partial v}{\partial y}\right)$, as is shown in Equation (11):

$$
\text { Ellrod TI2 }=\mathrm{S}_{\mathrm{v}}\left[\sqrt{\left(\frac{\partial u}{\partial x}-\frac{\partial v}{\partial y}\right)^{2}+\left(\frac{\partial v}{\partial x}+\frac{\partial u}{\partial y}\right)^{2}}-\left(\frac{\partial u}{\partial x}+\frac{\partial v}{\partial y}\right)\right] .
$$

\subsubsection{CAT1 Indicator}

The CAT1 turbulence indicator, as is denoted in this study, is referred to as "MOS (Model Output Statistics) probability forecast" by Sharman et al. [41] and is defined as:

$$
\mathrm{CAT} 1=V_{h} \sqrt{\left(\frac{\partial u}{\partial x}-\frac{\partial v}{\partial y}\right)^{2}+\left(\frac{\partial v}{\partial x}+\frac{\partial u}{\partial y}\right)^{2}}
$$

where $V_{h}$ is the horizontal wind speed.

\subsubsection{EDR Indicator}

The Eddy Dissipation Rate, $\varepsilon$, may also be used as a quantifier for turbulence. The method of calculation for this parameter in the current study followed the empirical formula delineated in Frech et al. [42]:

$$
\varepsilon=\frac{\mathrm{TKE}^{1.5}}{L_{e}}
$$

where $L_{e}=311 \mathrm{~m}$, which is the chosen length scale [42]. TKE represents the turbulent kinetic energy, which is a prognostic variable from the AROME model. The EDR indicator itself, however, was defined as the cube root of $\varepsilon$ according to ICAO [43]:

$$
\mathrm{EDR}=\varepsilon^{\frac{1}{3}}
$$

This study presents EDR because it is the standard measure to quantify turbulence in aviation applications. Nevertheless, for other scientific communities, it is relevant to show TKE forecasts, which are presented in the supplementary materials.

\subsection{RMSE and MAE for Wind Speed and Direction}

The quantitative comparison between observed (from aircraft) and forecast (from AROME) wind data is established using the root mean square error (RMSE) and the mean absolute error (MAE). The calculation of the wind speed error, RMSE $E_{W S D}$, is performed following the method employed by Grubišić et al. [5] for a dataset with $n$ points, as follows:

$$
\mathrm{RMSE}_{\mathrm{WSPD}}=\sqrt{\frac{1}{n} \sum_{i=1}^{n}\left[V_{h}(i)_{o b s}-V_{h}(i)_{s i m}\right]^{2}} .
$$


$\mathrm{MAE}_{\mathrm{WSPD}}$ is similarly defined as follows:

$$
\operatorname{MAE}_{W S P D}=\frac{1}{n} \sum_{i=1}^{n}\left|V_{h}(i)_{o b s}-V_{h}(i)_{s i m}\right| .
$$

The root mean square error and the mean absolute error for the wind direction, RMSE $E_{W D I R}$ and MAE WDIR respectively, are determined using the method described in Jiménez et al. [44]:

$$
\begin{aligned}
\mathrm{RMSE}_{\mathrm{WDIR}} & =\sqrt{\frac{1}{n} \sum_{i=1}^{n}\left[\Delta_{\mathrm{WDIR}}(i)\right]^{2},} \\
\mathrm{MAE}_{\mathrm{WDIR}} & =\frac{1}{n} \sum_{i=1}^{n}\left|\Delta_{\mathrm{WDIR}}(i)\right|
\end{aligned}
$$

where $\Delta_{\mathrm{WDIR}}(i)$ in degrees is given by:

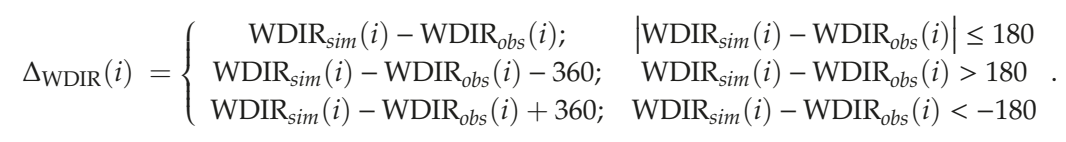

The comparison between model and observation was done according to the following two-step approach in order to find corresponding values for a given airborne observation:

1. The absolute difference between all AROME levels for each recorded flight altitude, expressed as $\mid$ Altitude $_{\text {Flight }}-$ Altitude $_{\text {AROME }} \mid$, is computed and the level with the minimum difference is selected as the best match. This process is repeated for each available flight altitude.

2. Once every flight altitude is paired with an AROME level, a latitude and longitude pair must be chosen at each one of these correspondences. Following a similar logic, the best coordinate pair from the model was deemed to minimize the distance relative to the flight coordinates at each altitude.

\section{Results and Discussion}

This section begins by illustrating results based on aerial observations. The wind shear intensity factor "I" is then analyzed. Next, outcomes based primarily on AROME forecasts like Froude numbers and turbulence indicators are discussed. Finally, the accuracy of AROME wind predictions is assessed by comparing them with data that was collected by SATA aircraft, using objective scores.

\subsection{Observations}

\subsubsection{Aerodrome Wind Data}

At the LPPI aerodrome, wind was predominantly from the southwest at two instants close to the time of both flights (Table 1). A headwind $\left(W_{H D}\right)$ of $12 / 13 \mathrm{kt}\left(6 / 7 \mathrm{~ms}^{-1}\right)$ and a crosswind $\left(W_{C H}\right)$ of $14 / 16 \mathrm{kt}\left(7 / 8 \mathrm{~ms}^{-1}\right)$ were registered on the day of Flight 1 . In regard to gusts, the aircraft experienced a headwind $\left(G W_{H D}\right)$ of $18 / 20 \mathrm{kt}\left(9 / 10 \mathrm{~ms}^{-1}\right)$ and a crosswind $\left(G W_{C H}\right)$ of $21 / 24 \mathrm{kt}\left(11 / 12 \mathrm{~ms}^{-1}\right)$ incoming from the left. 
Table 1. Wind data (velocity in knots) based on METAR (Meteorological Aerodrome Reports) at Pico aerodrome at the time of flights. The crosswind $\left(W_{C H}\right)$ is from the left if negative. Negative values of $W_{H D}$ indicate headwinds. $\mathrm{T}_{1}$ and $\mathrm{T}_{2}$ are approximate landing times for Flights 1 and 2.

\begin{tabular}{ccccccccc}
\hline \multirow{2}{*}{ Flight } & Time & $\begin{array}{c}\text { Wind } \\
\text { Direction }\end{array}$ & $\begin{array}{c}\text { Wind } \\
\text { Speed }\end{array}$ & Gust & $W_{H D}$ & $W_{C H}$ & $G W_{H D}$ & $G W_{C H}$ \\
\hline \multirow{2}{*}{ Flight 1 } & $\mathrm{T}_{1}$ & $220^{\circ}$ & 18 & 28 & -12 & -14 & -18 & -21 \\
& $\mathrm{~T}_{1}+1 \mathrm{hr}$ & $220^{\circ}$ & 21 & 31 & -13 & -16 & -20 & -24 \\
\cline { 2 - 8 } Flight 2 & $\mathrm{T}_{2}$ & $200^{\circ}$ & 13 & - & -4 & -12 & - & - \\
& $\mathrm{T}_{2}+0.5 \mathrm{hr}$ & $210^{\circ}$ & 12 & - & -6 & -10 & - & - \\
\hline
\end{tabular}

\subsubsection{Characterization of Wind Profiles}

The wind speed profile based on airborne observations along its path (see Figure 2 and Figure S1) is presented in Figure 4, for Flights 1 and 2. During Flight 1, the aircraft experienced strong winds oscillating between $10 \mathrm{kt}\left(5 \mathrm{~ms}^{-1}\right)$ and nearly $40 \mathrm{kt}\left(21 \mathrm{~ms}^{-1}\right)$. At $440 \mathrm{ft}(107 \mathrm{~m})$, for instance, the aircraft experienced a wind of $38 \mathrm{kt}\left(19.5 \mathrm{~ms}^{-1}\right)$. During Flight 2, in the approach phase, the wind speed reaches its maximum of nearly $22 \mathrm{kt}\left(11 \mathrm{~ms}^{-1}\right)$ at $600 \mathrm{ft}(183 \mathrm{~m})$, at a distance of $1.67 \mathrm{NM}$ of the aerodrome. Closer to the aerodrome, the wind decreases to $5 \mathrm{kt}\left(3 \mathrm{~ms}^{-1}\right)$ near the surface. Above $1000 \mathrm{ft}(305 \mathrm{~m})$ at a distance of nearly $4 \mathrm{NM}$ of the aerodrome, the wind is weak (below $8 \mathrm{kt}$ or $4 \mathrm{~ms}$ ), due to the wake in the lee of Pico Mountain, as will be shown in the next sections. During both flights, the wind was predominantly from the southwest below $1500 \mathrm{ft}$ or $457 \mathrm{~m}$ (Figure S4).

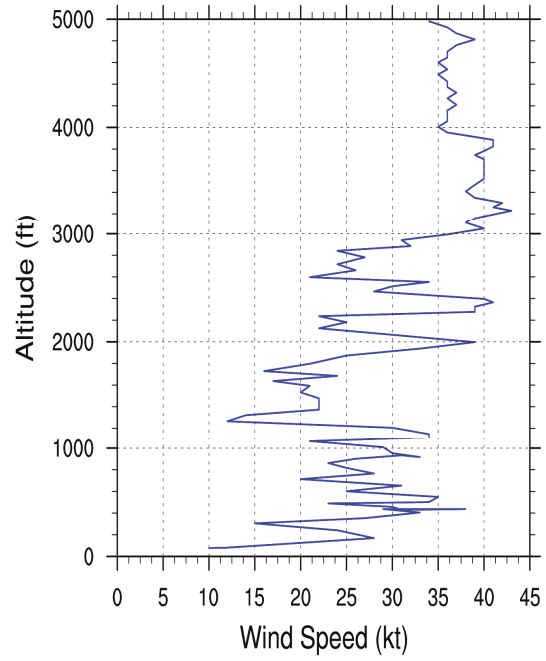

(a)

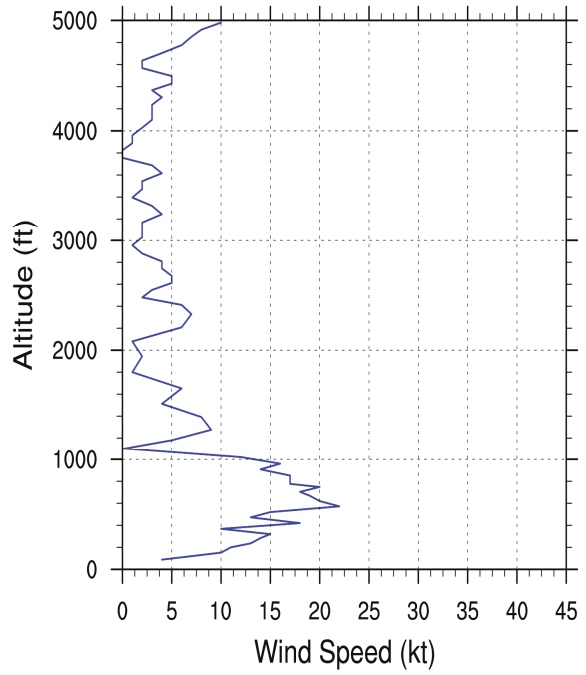

(b)

Figure 4. Variation of wind speed with altitude along the flight path, below $5000 \mathrm{ft}$ (1524 m), for: (a) Flight 1 ; (b) Flight 2.

\subsubsection{Wind Shear Intensity Factor " $\mathrm{I}$ "}

Figure 5a,b detail the relative frequency distributions in both flights for altitudes only below 2100 $\mathrm{ft}(640 \mathrm{~m})$ in order to focus on the effects of low-level wind shear as is suggested in [25]. During Flight 1 , about $36 \%$ of the approach phase was carried out under "severe" wind shear conditions and over $15 \%$ under "strong". In other words, more than 50\% of it experienced "strong" to "severe" wind shear, which is consistent with the occurrence of the hard landing incident. During Flight 2, "severe" wind shear conditions were absent, with only $4 \%$ being classified as "strong" and nearly $29 \%$ as "moderate" 
(Figure 5b). Table 2 lists wind shear levels of the first three lowest levels as functions of $\frac{d V}{d t}$ and $\frac{\Delta V}{V}$ for both flights. By comparing them, it is clear that within the three closest levels to the ground, the hard landing incident (Flight 1) exclusively experiences "severe" wind shear, whereas in Flight 2, a "light" intensity is prevalent.

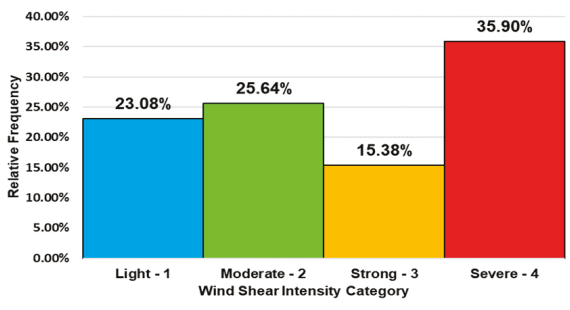

(a)

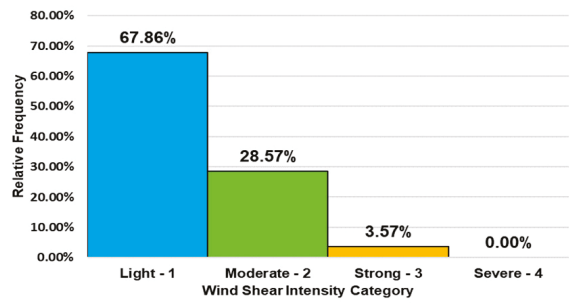

(b)

Figure 5. Relative frequency per wind shear intensity category for: (a) Flight 1; and (b) Flight 2.

Table 2. Classification of wind shear intensity for three lowest altitudes in Flights 1 and 2.

\begin{tabular}{cccccc}
\hline Flight & Altitude & $\frac{d V}{d t}\left(\mathrm{~ms}^{-2}\right)$ & $\frac{\Delta V}{V}$ & Classification & Rating \\
\hline \multirow{3}{*}{ Flight 1 } & $228 \mathrm{ft}(69 \mathrm{~m})$ & 1.649 & 0.170 & Severe & 4 \\
& $164 \mathrm{ft}(50 \mathrm{~m})$ & 8.820 & 0.476 & Severe & 4 \\
& $90 \mathrm{ft}(27 \mathrm{~m})$ & 2.962 & 0.138 & Severe & 4 \\
\cline { 2 - 5 } Flight 2 & $214 \mathrm{ft}(65 \mathrm{~m})$ & 0.265 & 0.015 & Light & 1 \\
& $169 \mathrm{ft}(52 \mathrm{~m})$ & 0.264 & 0.015 & Light & 1 \\
& $128 \mathrm{ft}(39 \mathrm{~m})$ & 0.729 & 0.042 & Moderate & 2 \\
\hline
\end{tabular}

\subsection{Synoptic Analysis}

During Flight 1, the flow in Pico Island was influenced by the presence of a depression located northwest of the Azores and by a subtropical anticyclone to its west/southeast. Consequently, southwesterly winds of around $20 \mathrm{kt}\left(10 \mathrm{~ms}^{-1}\right)$ were visible south of the island, according to an ECMWF analysis (Figure 6a). For Flight 2, an anticyclone was present south of the Azores, causing southwesterly winds of approximately $10 \mathrm{kt}\left(5 \mathrm{~ms}^{-1}\right)$ south of Pico Island (Figure 6b).

\subsection{Mesoscale Analysis}

During Flight 1 , according to AROME forecasts, the upstream conditions are characterized by a stable stratification, with $N$ varying from 0.012 to $0.015 \mathrm{~s}^{-1}$ and by the absence of an inversion (Figure S5a). The Froude number varies between 0.7 and 0.9 below $400 \mathrm{~m}$, reaching a maximum value of 1.2 at about $1600 \mathrm{~m}$ (Figure 7), which coincides with a wind speed of nearly $18 \mathrm{~ms}^{-1}$ (Figure S5c). Above this level, $F r$ varies between 1 and 1.2. Consistently, $F r$ and $F r_{h}$ are 0.95 and 0.9, respectively (Table 3). Therefore, according to previous studies [2,4], no wave breaking, upstream blocking or lee vortex formation are expected (see Figure A1a). The critical height defined in Section 2 is $107 \mathrm{~m}$ or $60 \mathrm{~m}$, depending on the method. Consequently, it is expected that air will flow nearly horizontally around the mountain below this level, but will overcome the obstacle above it. Moreover, the parameter $F_{L}$ is always below 0.08 (Figure S5c) and so, according to the analysis of $F_{L}$ and the Froude number, vertically propagating waves are expected [34]. 


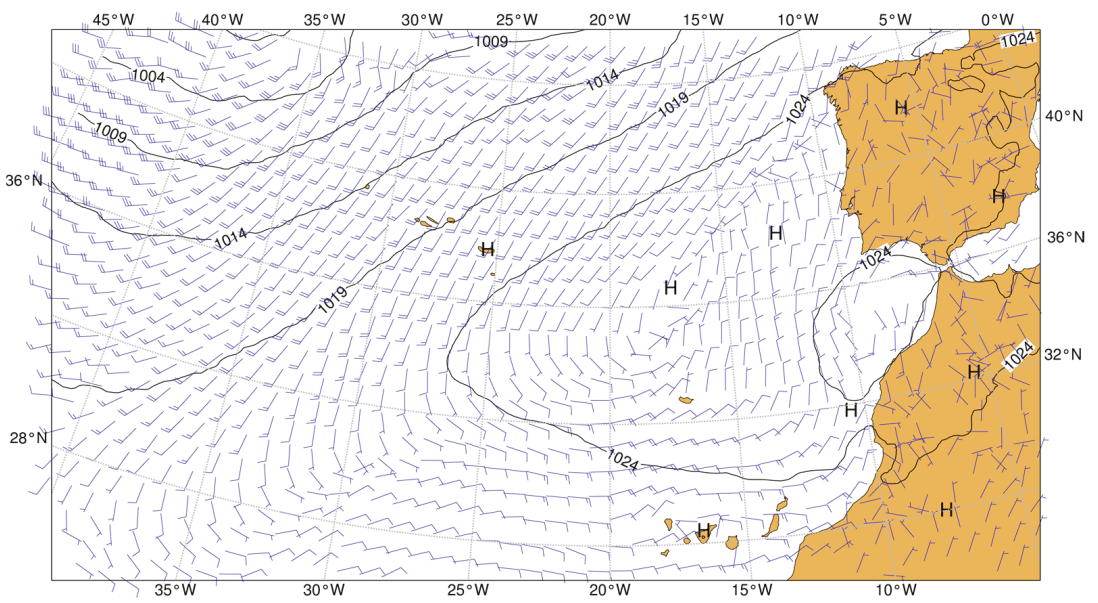

(a)

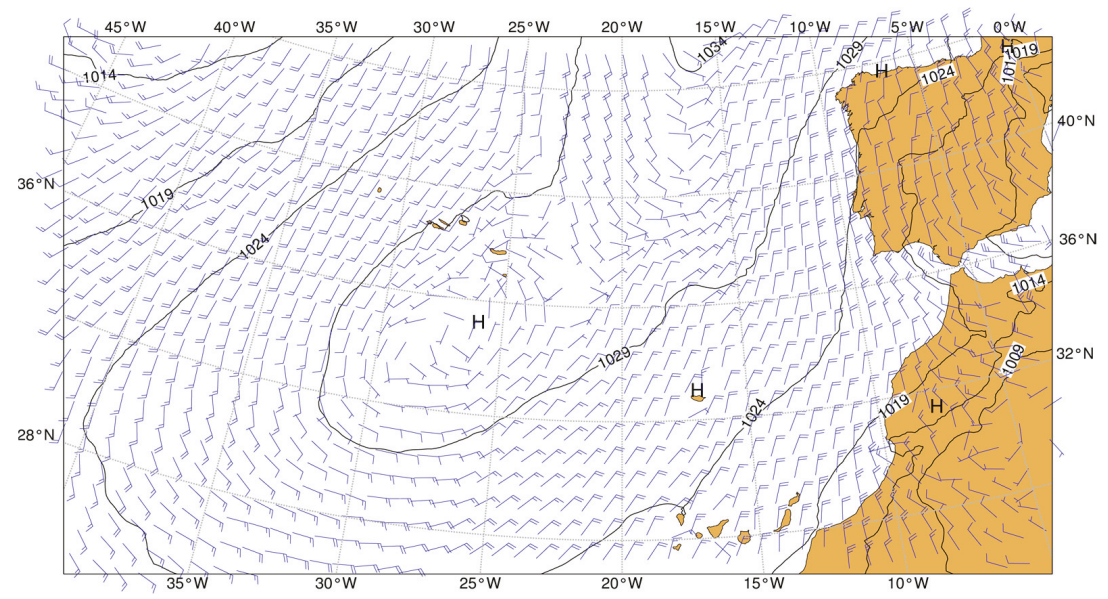

(b)

Figure 6. Mean sea level pressure (in $\mathrm{hPa}$ ) and $10 \mathrm{~m}$ wind (kt) based on ECMWF analysis for: (a) Flight 1; (b) Flight 2.

Table 3. Froude number and related results by flight for Point $C$ in Figure 2 with $h_{c 1}, h_{c 2}, z_{i}$ in meters.

\begin{tabular}{ccc}
\hline Parameter & Flight $\mathbf{1}$ & Flight $\mathbf{2}$ \\
\hline Fr (Equation (3)) & 0.95 & 0.42 \\
$\mathbf{F r}_{\mathbf{h}}$ (Equation (6)) & 0.90 & 0.31 \\
$\mathbf{F r}_{\mathbf{i}}$ (Equation (7)) & $\infty$ & 0.92 \\
$\boldsymbol{h}_{c \mathbf{1}}$ (Equation (5)) & 107 & 855 \\
$h_{c 2}$ (Equations (3),(6)) & 60 & 696 \\
$z_{i}$ & - & 872 \\
\hline
\end{tabular}




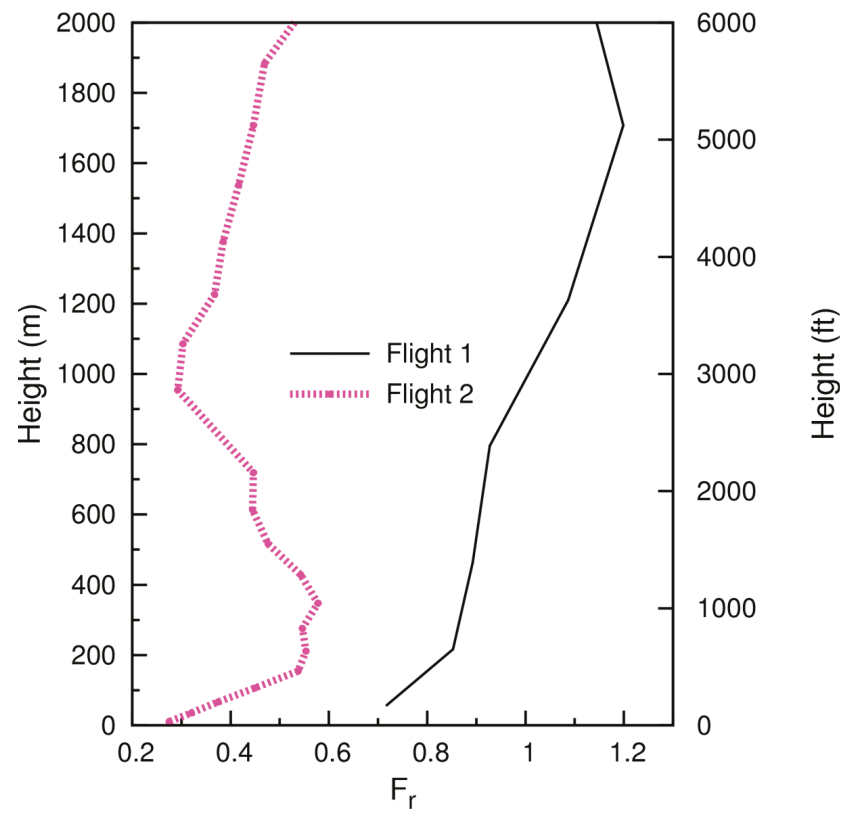

Figure 7. Vertical profile of Froude number (from AROME forecasts) for both flights.

During Flight 2, the upstream conditions are characterized by the presence of a short inversion close to $3000 \mathrm{ft}\left(872 \mathrm{~m}\right.$ ), where $N$ varies between 0.015 and $0.018 \mathrm{~s}^{-1}$ (Figure S5b). The Froude number has values smaller than 0.6 below $2 \mathrm{~km}$ (Figure 7). Consistently, $F r$ and $F r_{h}$ are 0.42 and 0.31 , respectively (Table 3). According to the flow regime diagram presented in Figure A1b, flow splitting and lee vortex formation with reversed flow are expected.

\subsubsection{Characterization of Orographic Flow during Flight 1}

The horizontal wind and vertical component of the absolute vorticity predicted by the AROME model are depicted in Figure 8 for Flight 1 . At $30 \mathrm{~m}$, the flow is partially deflected laterally (mostly on the west side), which is denounced by the curvature of the wind vectors. This deflection is still present at $200 \mathrm{~m}$ but is barely visible at $300 \mathrm{~m}$ (not shown), while at $500 \mathrm{~m}$ (Figure $8 \mathrm{~b}$ ) it is no longer discernible at all. This implies that the critical altitude $\left(h_{c}\right)$ should lie somewhere between 200 and $300 \mathrm{~m}$. From Table 3, it may be seen that $h_{c 1}=107 \mathrm{~m}$ and $h_{c 2}=60 \mathrm{~m}$, revealing that the estimate based on Equation (5) is more accurate. However, it underestimates $h_{c}$, possibly due to an insufficient vertical resolution of the AROME model.

Until $2800 \mathrm{ft}(853 \mathrm{~m})$, a pair of positive and negative vertical vorticities is visible over the mountain and on the leeward region, illustrated in Figure $8 \mathrm{a}$ for a height of $30 \mathrm{~m}$. However, no signs of reversed flow or vortex formation are present, which is consistent with the results of Bauer et al. [2] and Epifanio [4].

The horizontal wind speed at $680 \mathrm{ft}(207 \mathrm{~m})$ shows a stagnation area on the upstream region of Pico Mountain and a maximum wind speed $\left(>40 \mathrm{kt}\right.$ or $21 \mathrm{~ms}^{-1}$ ) over it with weak winds on the leeward side (Figure 9a). This pattern is coherent with previous studies like in Bauer et al. [2] with their Figure 2.a2. Near Pico Aerodrome, AROME forecast winds with speeds above $35 \mathrm{kt}\left(18 \mathrm{~ms}^{-1}\right)$. Ergo, during the approach to the aerodrome, the aircraft passes a region of elevated wind shear. Figure $9 \mathrm{~b}$ presents the maximum and minimum vertical velocities in the layer from the surface up to $6000 \mathrm{ft}(1829 \mathrm{~m})$, illustrating a wave pattern over Pico and Faial Islands. Figure 10a displays the 
vertical cross-section through the flight path in the approach phase (line A-B in Figure 2), showing that AROME forecasts the upward vertical velocity in the order of $100 \mathrm{ft} / \mathrm{min}\left(0.5 \mathrm{~ms}^{-1}\right)$ near $2000 \mathrm{ft}$ $(610 \mathrm{~m})$ and a downward vertical velocity of $100-150 \mathrm{ft} / \mathrm{min}\left(0.50-0.76 \mathrm{~ms}^{-1}\right)$ near the aerodrome. This is associated with pronounced vertically propagating waves, which are illustrated in Figure $10 \mathrm{~b}$ (up to $10000 \mathrm{ft}$ or $3048 \mathrm{~m}$ ) and in Figure S6a (up to $42000 \mathrm{ft}$ or $12802 \mathrm{~m}$ ), where the highest values exceed $400 \mathrm{ft} / \mathrm{min}\left(2 \mathrm{~ms}^{-1}\right)$, and then propagate to the vicinity of the aerodrome.

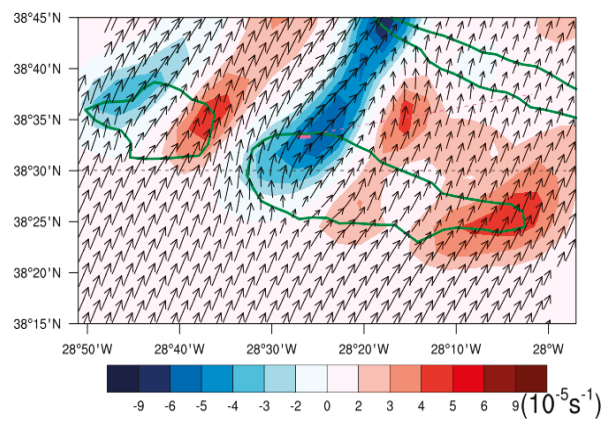

(a)

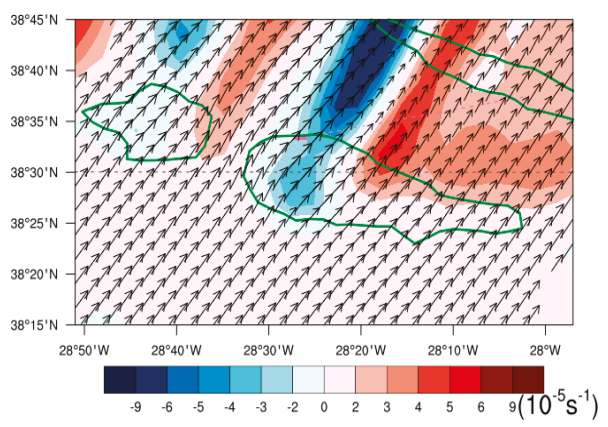

(b)

Figure 8. AROME absolute vorticity and wind vectors for Flight 1 at an altitude of: (a) $30 \mathrm{~m}$; (b) $500 \mathrm{~m}$. Dark arrows represent wind vectors.

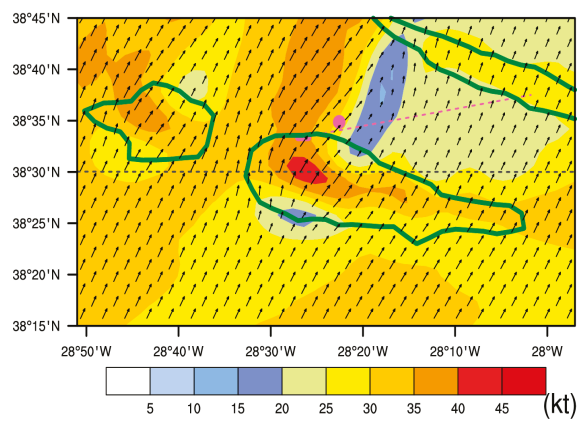

(a)

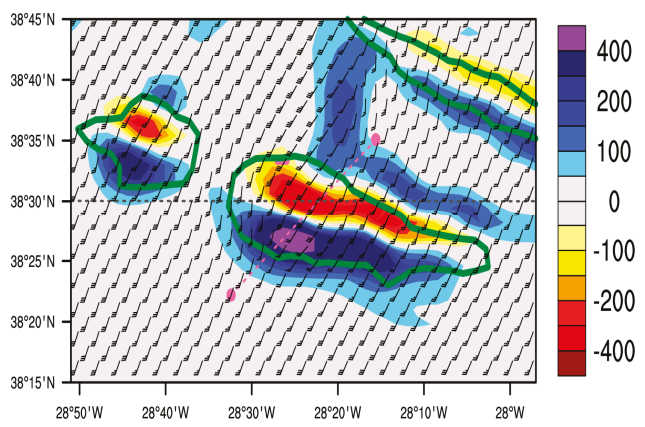

(b)

Figure 9. (a) Horizontal wind at $680 \mathrm{ft}(207 \mathrm{~m})$ for Flight 1; (b) Maximum vertical velocity under 6000 $\mathrm{ft}(1829 \mathrm{~m})$ for Flight 1. Both fields are from AROME forecasts. Shading in (a) represents the wind speed in kt and the pink dot identifies the approximate aircraft position at this level. Pink dashed line identifies the approximate aircraft trajectory. Shading in (b) represents intensity in $\mathrm{ft} / \mathrm{min}$, positive values indicate upward vertical velocity and negative values represent downward vertical velocity. The pink dots are the points $C$ and D shown in Figure 2, which are the endpoints of the cross-section (dashed pink line) used in the next figures.

During Flight 1 , the mean wind speed at point $C$ (from Figure 2) is $12.76 \mathrm{~ms}^{-1}(U)$ and the average value of the buoyancy frequency is $0.0129 \mathrm{~s}^{-1}(N)$. Since the horizontal scale $(L)$ for Pico Mountain is of the order of $21 \mathrm{~km}$, the condition for vertically propagating gravity waves $\left(N^{2}>U^{2} k^{2}\right)$ applies $[1,29]$. See also Figure 13.3 in Cassano and Lynch [29], which illustrates the alternating pattern between upward and downward motion associated with vertically propagating gravity waves. 


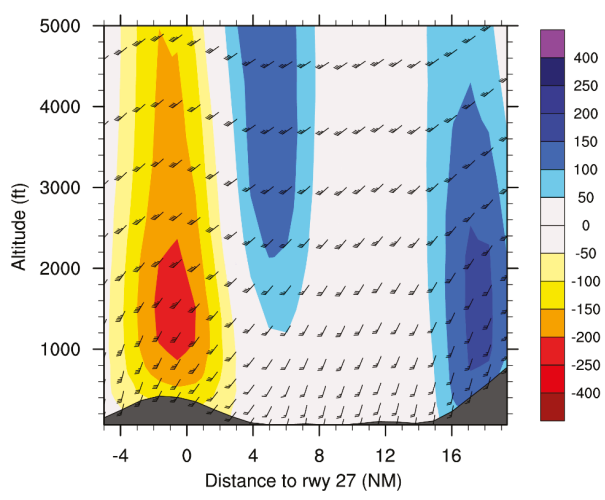

(a)

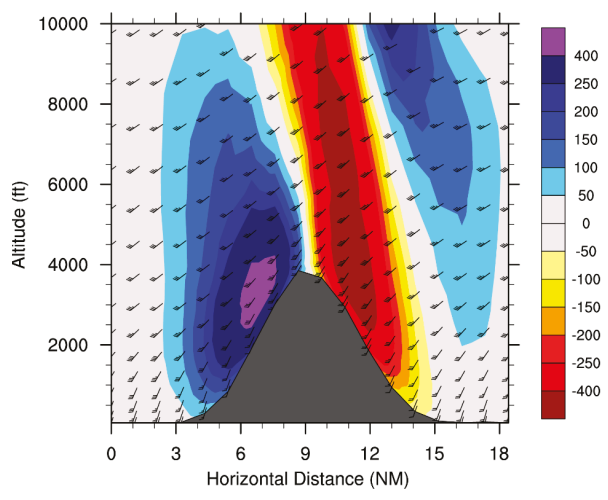

(b)

Figure 10. Vertical cross-section of the vertical velocity of AROME through (a) line A-B on Figure 2 and (b) line C-D on Figure 2, for Flight 1 . Shading represents intensity in $\mathrm{ft} / \mathrm{min}$, positive values indicate upward vertical velocity and negative values represent downward vertical velocity. The altitude scale of (a) is half of the corresponding scale of $(\mathbf{b})$.

\subsubsection{Characterization of Orographic Flow during Flight 2}

The horizontal wind and vertical component of the absolute vorticity predicted by the AROME model at several heights are presented in Figure 11 for Flight 2. Figure 11a depicts a stagnation area in the windward direction of Pico Mountain and the occurrence of a flow splitting phenomenon in addition to a wake with reversed flow in the lee of the hill. This wake (at $40 \mathrm{~m}$ ) consists of a pair of vortices, one with a clockwise rotation and negative absolute vorticity and another with a counter-clockwise rotation and positive vorticity. The wake structure exemplified in Figure 11a, which is visible below $600 \mathrm{~m}$ (not shown), resembles the results obtained by Smith and Grubišić [45] (p. 3747) in their study of Hawaii's wake, which is described as comprising "two large, nearly steady vortices". A similar structure with a pair of counter-rotating vortices downstream of the obstacle was also documented by Smolarkiewicz and Rotunno [7] (see their Figure 1c) and by Epifanio [4] (their Figure 3c). Moreover, the regime flow diagram of Figure A1b in Appendix A, which was used by Schär and Smith [39] and Grubišić et al. [5], accurately estimates this situation in which a wake displays reversed flow.

At higher levels, between $600 \mathrm{~m}$ and $850 \mathrm{~m}$ (Figure 11b,c), no lee vortices are present and the dipole of positive and negative vorticities is weaker and shifted to the east relative to lower levels, mainly at $850 \mathrm{~m}$. At $1100 \mathrm{~m}$, the incoming flow is mainly from the west and overcomes the mountain (Figure 11d). Finally, the analysis of Figure 11 suggests that the critical height in Flight 2 should be approximately $850 \mathrm{~m}$, which is close to the estimate of the dividing streamline concept (see Table 3 ).

The horizontal wind speed at $40 \mathrm{~m}$ is depicted in Figure 12a, which shows that near the aircraft position, the wind speed varies between 15 and $20 \mathrm{kt}\left(8-10 \mathrm{~ms}^{-1}\right)$. It is also visible from this figure that the aircraft during the approach phase (pink dashed line in Figure 12a) has passed through the wake. Figures 12a and 13 also show signs of a vertically propagating mountain wave, however, less energetic than the one seen on the day of Flight 1 (compared to Figure 10) and propagating to lower levels (up to $25000 \mathrm{ft}$ or $7620 \mathrm{~m}$ ), as is illustrated in Figure S6b. During Flight 2, the maximum vertical velocity on the leeward side of Pico Mountain (Figure 13b) is less than $150 \mathrm{ft} / \mathrm{min}\left(0.8 \mathrm{~ms}^{-1}\right)$, while during Flight 1 the maximum vertical velocity was above $400 \mathrm{ft} / \mathrm{min}\left(2 \mathrm{~ms}^{-1}\right)$. Upon propagation of this wave to the aerodrome (Figure 13a), it is seen that only a weak downdraft (less than $100 \mathrm{ft} / \mathrm{min}$ or $0.5 \mathrm{~ms}^{-1}$ ) lies atop it with no hints of updrafts along the flight path. In Figure 13b, the reversed flow associated with the lee vortices is also visible until about $2000 \mathrm{ft}(610 \mathrm{~m})$. 


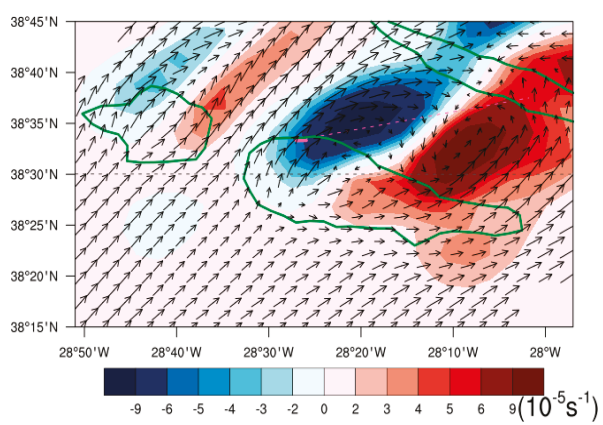

(a)

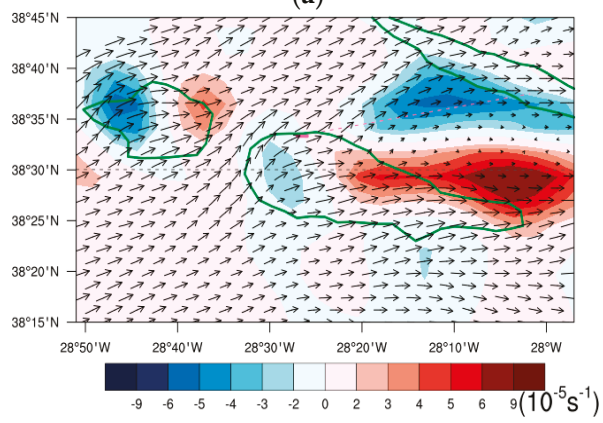

(c)

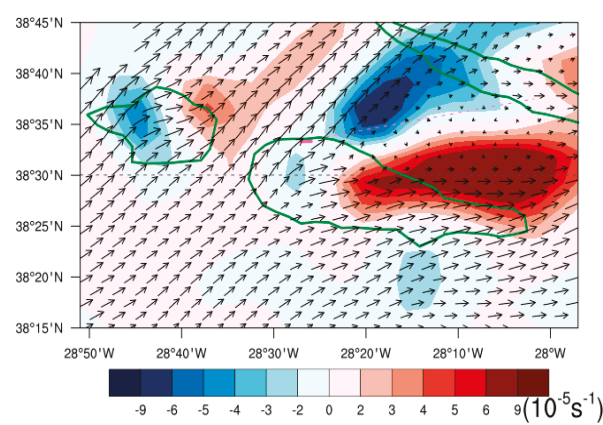

(b)

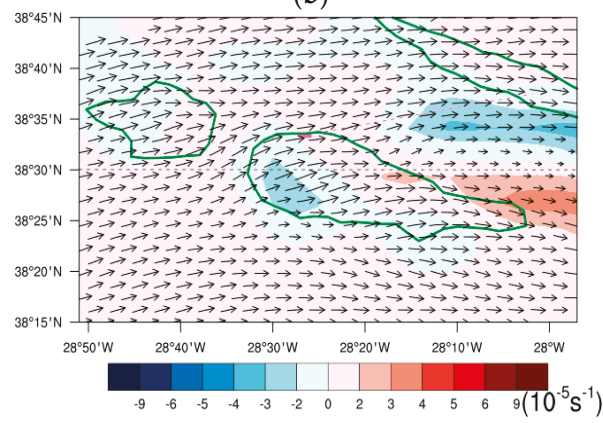

(d)

Figure 11. AROME absolute vorticity and wind vectors for Flight 2 at an altitude of: (a) 40 m; (b) 640 m; (c) 850 m; (d) 1100 m. Dark arrows represent wind vectors.

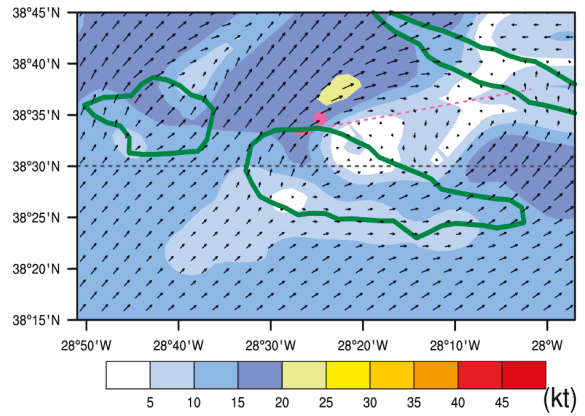

(a)

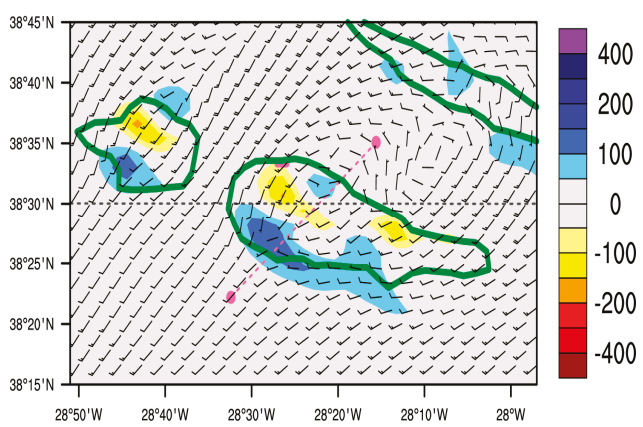

(b)

Figure 12. (a) Horizontal wind at $135 \mathrm{ft}(40 \mathrm{~m})$ for Flight 2.; (b) Maximum vertical velocity component under $6000 \mathrm{ft}(1829 \mathrm{~m})$ for Flight 2. Both fields are from AROME forecasts. Shading in (a) represents the wind speed in kt and the pink dot identifies the approximate aircraft position at this level. Pink dashed line identifies the approximate aircraft trajectory. Shading in (b) represents intensity in $\mathrm{ft} / \mathrm{min}$, positive values indicate upward vertical velocity and negative values represent downward vertical velocity. The pink dots are the points $C$ and D shown in Figure 2, which are the endpoints of cross-section (dashed pink line) used in the next figures. 


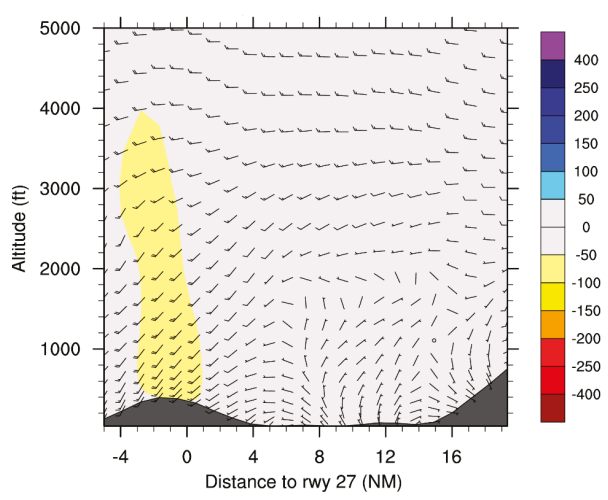

(a)

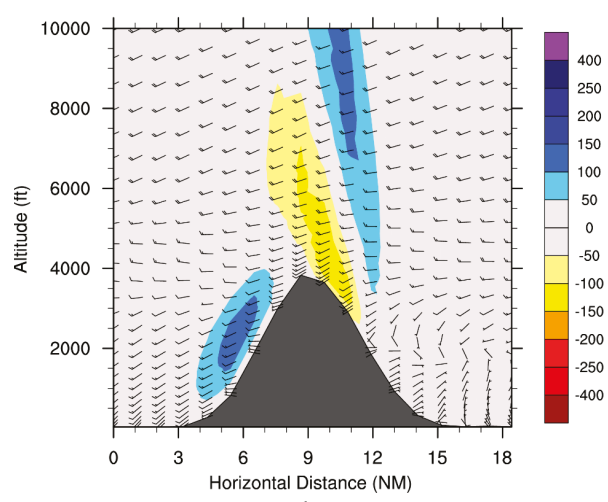

(b)

Figure 13. Vertical cross-section of the vertical velocity of AROME through (a) line A-B in Figure 2 and (b) line C-D in Figure 2, for Flight 2. Shading represents intensity in $\mathrm{ft} / \mathrm{min}$, positive values indicate upward vertical velocity and negative values represent downward vertical velocity. The altitude scale of (a) is half of the corresponding scale of $(\mathbf{b})$.

\subsection{Turbulence Indicators}

Turbulence indicators Ellrod TI2 and CAT1 at $66 \mathrm{~m}$ are presented in Figure 14a,b, for Flight 1. Both indicators show maximum values leeward of Pico mountain, with TI2 exceeding $18 \times 10^{-6} \mathrm{~s}^{-2}$ and CAT1 exceeding $8 \times 10^{-3} \mathrm{~ms}^{-2}$ in the proximity of the aerodrome where the incident occurred. The cross-section along the flight path shows that for a distance less than $5 \mathrm{NM}(9.3 \mathrm{~km})$ of the runway, between 300 and $1600 \mathrm{ft}$, TI2 and CAT1 reach values above $18 \times 10^{-6} \mathrm{~s}^{-2}$ and $8 \times 10^{-3} \mathrm{~ms}^{-2}$, respectively (Figure 14c,d). Comparing the indicators with the wind shear Intensity Factor "I" (Figure 15a,b), the aircraft experienced severe wind shear at these levels, suggesting that these values for TI2 and CAT1 could be tested as thresholds indicative of severe wind shear conditions. Ellrod TI1 (not shown in Figure 14) has a similar spatial pattern to TI2, but with lower values (Figure 15a). The Brown index is maximum over land near the LPPI aerodrome (not shown in Figure 14), exceeding $20 \times 10^{-9} \mathrm{~s}^{-3}$ near the surface and decreasing drastically with height, reaching a value of $13 \times 10^{-9} \mathrm{~s}^{-3}$ at $600 \mathrm{ft}$ (Figure 15c).

The EDR indicator shows a different pattern when compared to others. EDR shows higher values over land than over sea, depicting a maximum value above $0.4 \mathrm{~m}^{2 / 3} \mathrm{~s}^{-1}$ near the top of Pico Mountain (Figure 16a). The higher values over land are consistent with higher roughness lengths (than over sea), which contribute to a higher mechanical production of turbulence [16]. At $66 \mathrm{~m}$, EDR reaches a value between 0.35 and $0.4 \mathrm{~m}^{2 / 3} \mathrm{~s}^{-1}$ near the aerodrome (corresponding to moderate turbulence). Figure $16 \mathrm{~b}$ shows that along the flight path, EDR decreases with height, varying from $0.35-0.4 \mathrm{~m}^{2 / 3} \mathrm{~s}^{-1}$ near the surface to $0.15-0.2 \mathrm{~m}^{2 / 3} \mathrm{~s}^{-1}$ at $2000 \mathrm{ft}(610 \mathrm{~m})$. It is interesting to mention that the thresholds applied in Figure 16 are lower than those presented in ICAO [43] but are those proposed recently [46], after a study by Sharman et al. [47] that showed that the thresholds in reference [43] were overestimated. According to reference [46], turbulence is severe when EDR $\geq 0.45 \mathrm{~m}^{2 / 3} \mathrm{~s}^{-1}$ and is moderate for EDR between 0.2 and $0.45 \mathrm{~m}^{2 / 3} \mathrm{~s}^{-1}$. Comparing EDR to the wind shear Intensity Factor "I" (Figure 15d), it is clear that in the presence of severe wind shear conditions, EDR has values between 0.2 and $0.25 \mathrm{~m}^{2 / 3} \mathrm{~s}^{-1}$ above $700 \mathrm{ft}$. For heights under $200 \mathrm{ft}(61 \mathrm{~m})$, EDR is close to 0.3, which suggests an underestimation of the severe wind shear conditions. 


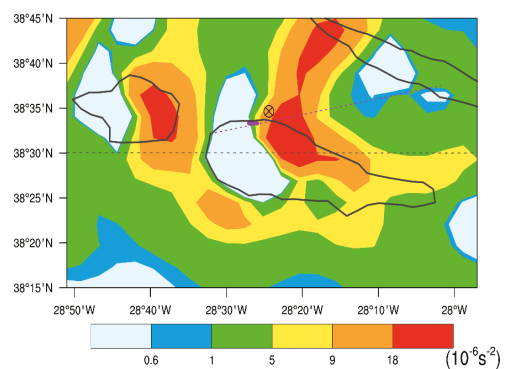

(a)

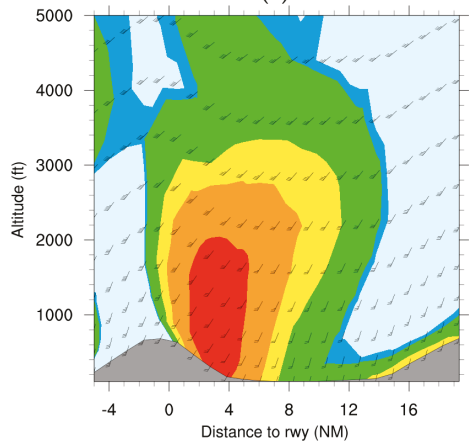

(c)

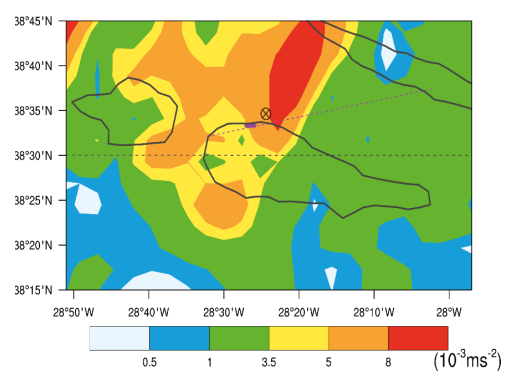

(b)

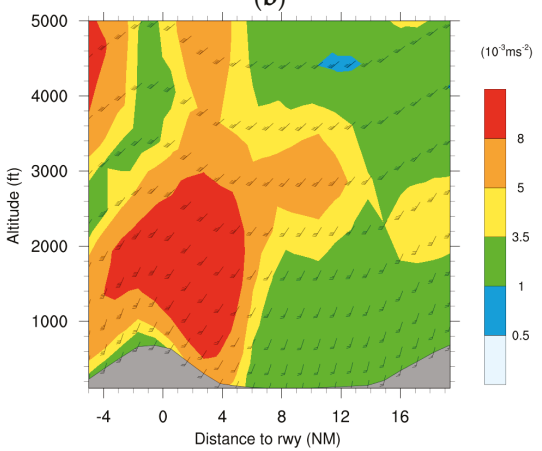

(d)

Figure 14. Horizontal variation of (a) Ellrod TI2 and (b) CAT1 at $66 \mathrm{~m}$ for Flight 1. Dotted pink line shows aircraft trajectory and pink bar locates the aerodrome. The circled " $x$ " mark identifies the approximate aircraft position at $66 \mathrm{~m}$. Cross-sectional variation of (c) Ellrod TI2 and (d) CAT1.
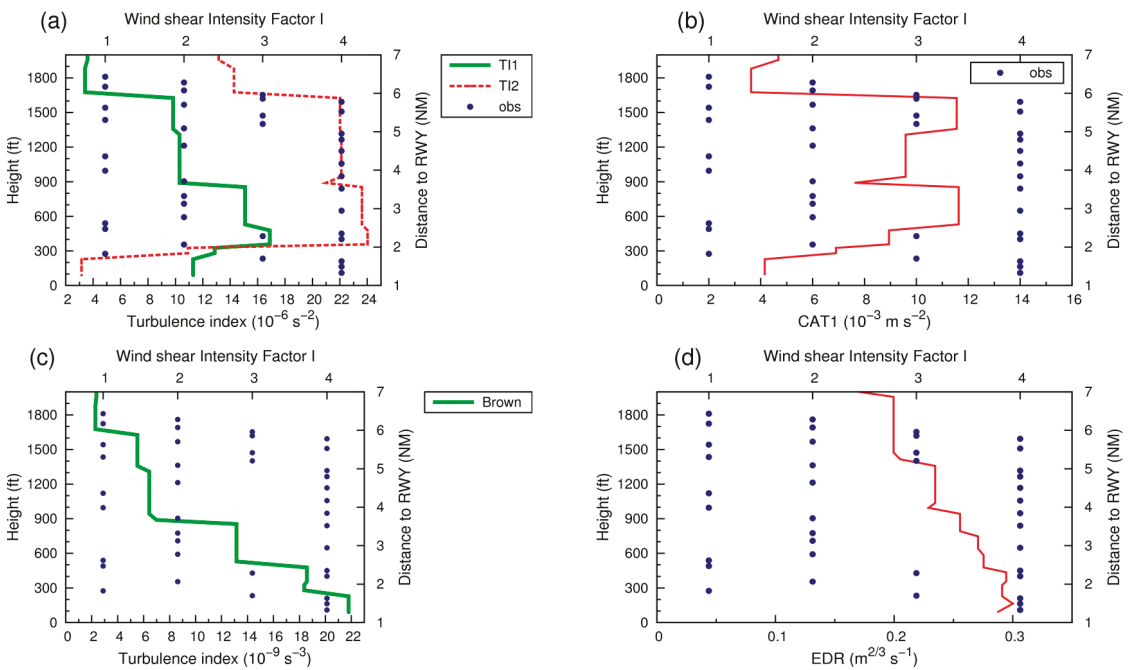

Figure 15. AROME turbulence indicators (bottom x-axis) vs. the wind shear intensity factor "I" (top $\mathrm{x}$-axis), along the flight path during Flight 1. Ellrod TI1, TI2 and Brown indicators are shown in (a) and (c), respectively. Solid red lines in (b) and (d) indicate CAT1 and EDR values, respectively. 


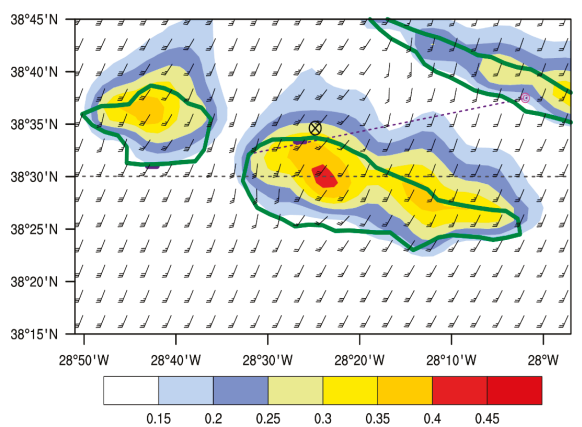

(a)

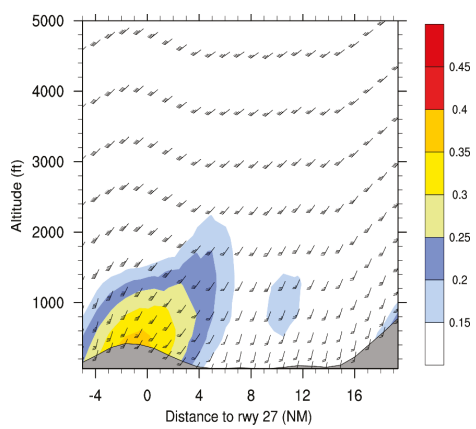

(b)

Figure 16. (a) Horizontal representation of EDR during Flight 1 . The circled " $X$ " mark identifies aircraft position at $66 \mathrm{~m}$. (b) Cross-sectional representation of EDR.

During Flight 2, the index Ellrod TI2 shows maximum values in the leeward region of the mountain and exhibits a value of $9 \times 10^{-6} \mathrm{~s}^{-2}$ near the aircraft position (Figure 17a). The index CAT1 shows maximum values above $5 \times 10^{-3} \mathrm{~ms}^{-2}$ downstream of Pico Aerodrome, close to the flight path (Figure 17b). Along the flight path itself, Ellrod TI2 reaches values above $9 \times 10^{-6} \mathrm{~s}^{-2}$ below $500 \mathrm{ft}$ $(152 \mathrm{~m})$, while CAT1 attains values between $4 \times 10^{-3} \mathrm{~ms}^{-2}$ and $8 \times 10^{-3} \mathrm{~ms}^{-2}$ below $900 \mathrm{ft}$ or $274 \mathrm{~m}$ (Figure 17c,d and Figure S7), which are predominantly "moderate" wind shear conditions. The TI1 indicator is very similar to TI2 and the Brown index decreases again drastically with height, exhibiting values below $4 \times 10^{-9} \mathrm{~s}^{-3}$ above $300 \mathrm{ft}$ (Figure S7).

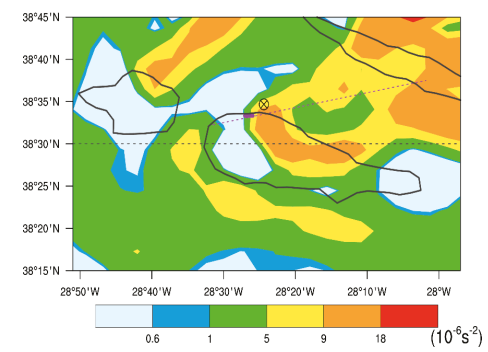

(a)

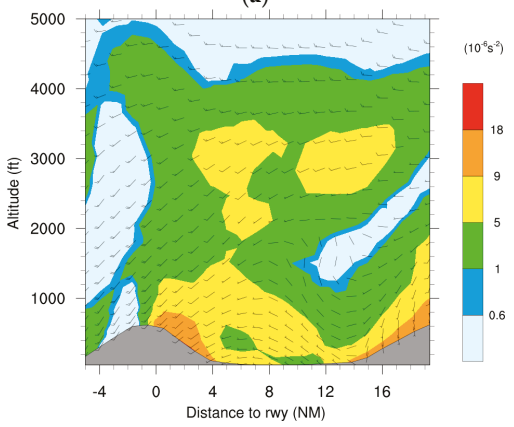

(c)

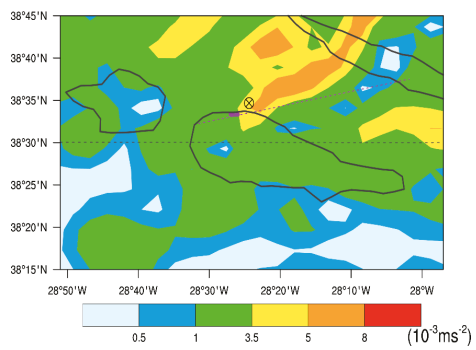

(b)

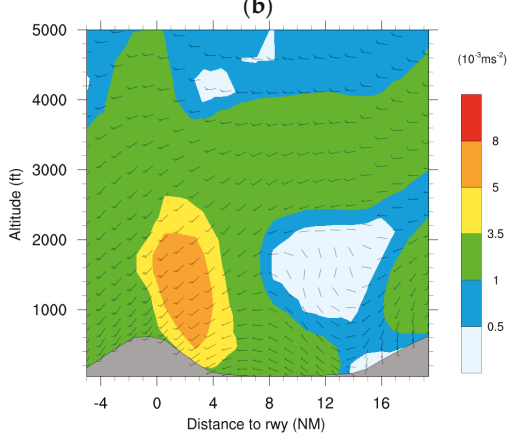

(d)

Figure 17. Horizontal variation of (a) Ellrod TI2 and (b) CAT1 at $66 \mathrm{~m}$ for Flight 2. Dotted pink line shows the aircraft trajectory and pink bar indicates the aerodrome. The circled " $X$ " mark identifies the approximate aircraft position at $66 \mathrm{~m}$. Cross-sectional variation of (c) Ellrod TI2 and (d) CAT1. 
Analysis of EDR depicts the occurrence of "light" turbulence near the aerodrome for Flight 2 (Figure 18). The " $\mathrm{I}$ " factor is mostly consistent with this categorization as wind shear conditions reach intensities that are predominantly "light" for heights between 200-500 ft (61-152 m). Nevertheless, in some instants the wind shear was classified as "moderate", while the EDR values above $400 \mathrm{ft}$ are below $0.1 \mathrm{~m}^{2 / 3} \mathrm{~s}^{-1}$ suggesting the absence of turbulence or wind shear (Figure $\mathrm{S} 7 \mathrm{~d}$ ).

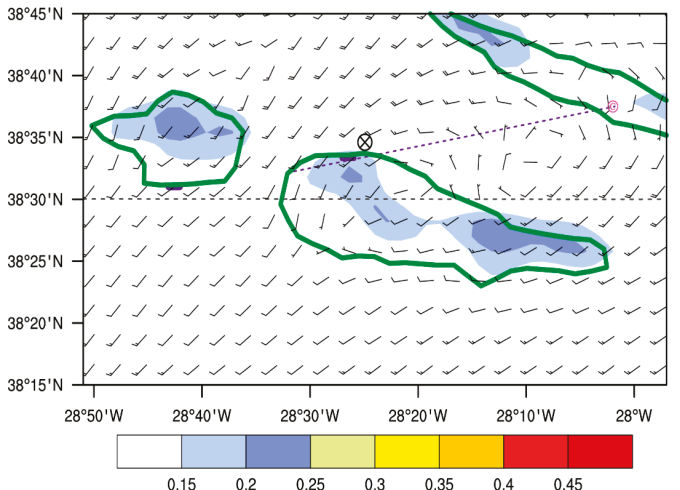

(a)

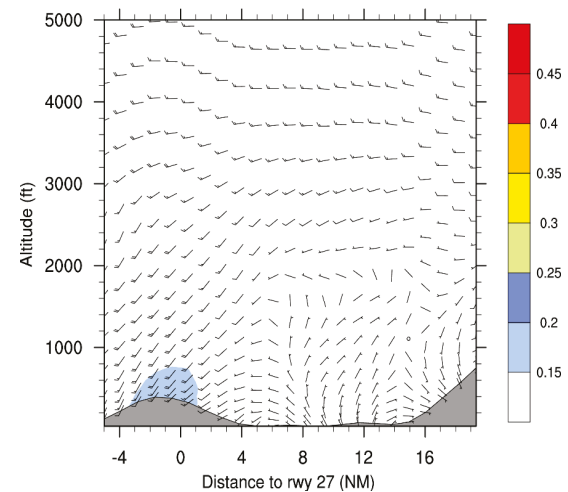

(b)

Figure 18. (a) Horizontal representation of EDR during Flight 2. The circled " $X$ " mark identifies approximate aircraft position at $66 \mathrm{~m}$. (b) Cross-sectional representation of EDR.

This preliminary scrutiny of turbulence indicators suggests that CAT1, Ellrod TI2 and EDR could be applied together to arrive at a classification for the hazard level of turbulence. Moreover, preliminary thresholds for these indicators are proposed (Table A1), which should be subject to further validation, using more flight data.

As expected from their similarity in mathematical construction, both TKE and EDR evolve analogously during both flights (Figure S8a,b). In Flight 1, when the EDR indicator attains values of around $0.3 \mathrm{~m}^{2 / 3} \mathrm{~s}^{-1}$ (coinciding with "severe" wind shear conditions according to the " $\mathrm{I}$ " factor), TKE has values close to $4 \mathrm{~m}^{2} \mathrm{~s}^{-2}$. During Flight 2, an EDR hovering near $0.1 \mathrm{~m}^{2 / 3} \mathrm{~s}^{-1}$ translated to a TKE value of about $0.5 \mathrm{~m}^{2} \mathrm{~s}^{-2}$.

In order to certify that the turbulence was indeed predominantly greater for Flight 1 than for Flight 2, independently of the discrepant mean flow speeds in each case, the dimensionless turbulence intensity parameter $\left(T I=\sqrt{T K E} / V_{h}\right)$, defined by Stull [16], was also plotted (Figure S9). It is clear from these results that the TI of Flight 1, with two maxima slightly above 0.25 (near $200 \mathrm{ft}$ or $61 \mathrm{~m}$ and $1200 \mathrm{ft}$ or $366 \mathrm{~m}$ ), mostly exceeds that of Flight 2, with a maximum slightly above 0.15 (near $300 \mathrm{ft}$ or $91 \mathrm{~m})$.

\subsection{Objective Verification of Wind Forecasts from AROME}

The accuracy of AROME wind predictions is assessed by comparing them with data that was collected by SATA aircraft during Flights 1 and 2. Absolute errors of wind speed and direction are also mapped for each observation and forecast pair in Figure 19. The color coding for wind magnitude and its direction is based on ICAO guidelines [43] for operationally acceptable levels of forecast errors. For wind speed, an absolute value error of up to $5 \mathrm{kt}\left(2.6 \mathrm{~ms}^{-1}\right)$ was deemed operationally desirable. For the direction, this value is $20^{\circ}$. For Flight 1 , there is a good agreement between observations and forecasts. 


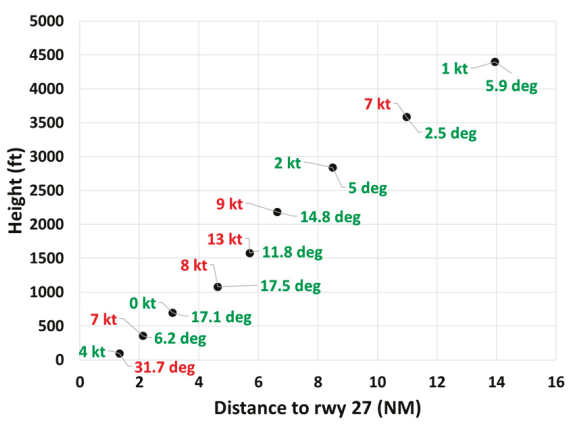

(a)

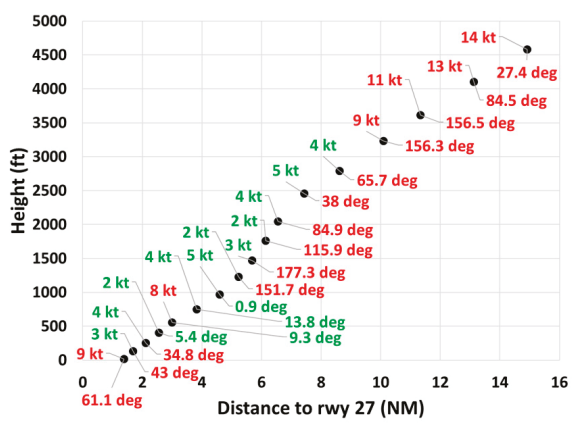

(b)

Figure 19. Absolute value differences for wind speed and direction for: (a) Flight 1 and (b) Flight 2.

Values for the root mean square error (RMSE) and mean absolute error (MAE) regarding wind speed and direction are displayed in Table 4, showing that wind speed RMSE for Flight 1 is only slightly above operational recommendations (about 30\% larger) and the RMSE for wind direction is $11.4^{\circ}$, well within the acceptable limits. The Flight $1 \mathrm{MAE}$ for wind speed shows that the $2.6 \mathrm{~ms}^{-1}$ recommendation is exceeded by only $7 \%$ and the wind direction MAE is again within limits with a value of $8.1^{\circ}$.

Table 4. Summary of RMSE and MAE for wind speed and direction for both flights.

\begin{tabular}{ccccc}
\hline Flight & RMSE $_{\text {WSPD }}\left[\mathrm{ms}^{-\mathbf{1}}\right]$ & RMSE $_{\text {WDIR }}[\mathrm{deg}]$ & $\begin{array}{c}\text { MAE }_{\text {WSPD }} \\
{\left[\mathbf{m s}^{\mathbf{- 1}}\right]}\end{array}$ & MAE $_{\text {WDIR }}$ [deg] \\
\hline Flight 1 & 3.4 & 11.4 & 2.8 & 8.1 \\
Flight 2 & 4.4 & 83.3 & 3.8 & 65.4 \\
\hline
\end{tabular}

During Flight 2, the RMSE and MAE for wind speed are $4.43 \mathrm{~ms}^{-1}$ and $3.77 \mathrm{~ms}^{-1}$ respectively, slightly over 30\% larger than Flight 1 errors. For Flight 2 wind direction errors, the RMSE and MAE are around $83.3^{\circ}$ and $65.4^{\circ}$. It is important to mention that when the wind speed is above $10 \mathrm{kt}$, the wind direction errors are inferior to $45^{\circ}$ (see Figure S10). However, during Flight 2 at altitudes above $1200 \mathrm{ft}$, the wind is below $10 \mathrm{kt}$ (Figure S4b) and at these levels, large errors $\left(>120^{\circ}\right)$ are found in the wind direction (Figure $4 \mathrm{~b}$, Figure S10). The limitations of NWP models in accurately forecasting the wind direction for weak winds was previously documented by Jiménez et al. [44], who showed that RMSE $E_{W D I R}$ increases with decreasing wind speeds, reaching values over $70^{\circ}$ for speeds under $2 \mathrm{kt}$ $\left(1 \mathrm{~ms}^{-1}\right)$. It is also important to note that during Flight 2, a wake developed in the lee of Pico mountain in the vicinity of the flight path. In the wake region, the wind varies strongly over short distances (see Figure 12), implying that a small phase error may cause large errors in wind speed and/or wind direction. According to Ricard et al. [22], the effective resolution of the AROME model is about 9 times the grid spacing (i.e., $22 \mathrm{~km}$ ), which may be insufficient to correctly resolve the wind variations within the lee wake.

\section{Summary and Conclusions}

The present article focuses on the orographic flow associated with Pico Mountain in the Azores in two different synoptic environments, using SATA airborne measurements and AROME forecasts. Aerial measurements were used to compute the wind shear intensity factor "I" according to Guan and Yong [25] and to categorize its severity according to four classes: "light", "moderate", "strong" and "severe". 
During the first scenario, a hard landing incident (Flight 1) occurred in Pico's aerodrome. On this day, according to the AROME model, the upstream conditions were characterized by southwest winds with speeds of up to $40 \mathrm{kt}\left(20 \mathrm{~ms}^{-1}\right)$ in the ABL and stable stratification, which translated to a Froude number slightly above 1 near the mountain top. These conditions triggered the development of vertically propagating mountain waves, which created an undulation pattern of upward and downward motion downstream of Pico Mountain, leading to maximum vertical velocities above $400 \mathrm{ft} / \mathrm{min}\left(2 \mathrm{~ms}^{-1}\right)$ and above $200 \mathrm{ft} / \mathrm{min}$ in the flight path. Based on ICAO Annex 3 guidelines [43], a mountain wave is deemed "severe" whenever downdrafts exceed $600 \mathrm{ft} / \mathrm{min}\left(3 \mathrm{~ms}^{-1}\right)$ and "moderate" whenever they vary between 350 to $600 \mathrm{ft} / \mathrm{min}\left(1.75-3.0 \mathrm{~ms}^{-1}\right)$. However, it is important to note that the AROME model may have underestimated the intensity of the vertical velocities, so this pattern of oscillating updraft/downdraft may have strongly contributed to the hard landing event. Furthermore, large wind speeds ( $38 \mathrm{kt}$ or $20 \mathrm{~ms}^{-1}$ ) were registered close to $440 \mathrm{ft}(107 \mathrm{~m})$ and the wind shear intensity factor " $\mathrm{I}$ " based on airborne data showed that $36 \%$ of the approach phase (below $2100 \mathrm{ft}$ or $640 \mathrm{~m}$ ) occurred under "severe" wind shear conditions and 16\% under "strong". At the aerodrome, METAR observations showed southwest winds (18-21 kt or 9-11 ms ${ }^{-1}$ ) with gusts between 28 and $31 \mathrm{kt}$ (14 and $16 \mathrm{~ms}^{-1}$ ).

During the second flight, the upstream conditions were characterized by southwest winds with speeds below $20 \mathrm{kt}\left(10 \mathrm{~ms}^{-1}\right)$ in the PBL and a temperature inversion in the layer between 860 to 1100 $\mathrm{m}$. In this range, the Froude number is less than 0.5. According to previous studies, these conditions promote upstream stagnation and flow splitting with the formation of lee vortices in low levels with reversed flow, which was predicted by the AROME model. AROME forecasts for Flight 2 also showed a pattern of vertically propagating waves, but with smaller vertical velocities and shorter vertical propagation compared to Flight 1 . According to airborne observations, Flight 2 occurred under wind shear conditions predominantly rated as "light" $(68 \%)$ or "moderate" $(29 \%)$, with its most intense class being "strong" (only during less than $4 \%$ of the landing phase).

Moreover, the pattern of several turbulence indicators derived from AROME forecasts was analyzed for both flights. All these indicators forecast higher values for Flight 1 than for Flight 2, which is consistent with the wind shear intensity factor "I" derived from airborne observations. As a result of the comparison between "I" and the AROME turbulence indicators, preliminary thresholds have been proposed for three indexes. In the future, however, more flights should be perused in order to verify the validity of such thresholds. The use of other wind shear and turbulence indicators derived from airborne data should also be tested.

Lastly, this study provides an objective verification of AROME wind forecasts, showing a good agreement with airborne observations for wind speeds above $10 \mathrm{kt}$, but a poor skill for weaker winds. For Flight 1, characterized by wind speeds over $30 \mathrm{kt}\left(15 \mathrm{~ms}^{-1}\right)$ during several instants, AROME forecasts show a good agreement with observations in terms of wind speed and direction, with an RMSE of $3.4 \mathrm{~ms}^{-1}$ and $11.4^{\circ}$, respectively. The MAE score is $2.8 \mathrm{~ms}^{-1}$ and $8.1^{\circ}$ for wind speed and direction, respectively. During Flight 2, in the approach phase, the maximum wind speed is $22 \mathrm{kt}$ $\left(11 \mathrm{~ms}^{-1}\right)$. In this case, AROME has an RMSE of $4.4 \mathrm{~ms}^{-1}$ and $83.3^{\circ}$ for wind speed and wind direction. MAE revealed values of $3.8 \mathrm{~ms}^{-1}$ and $65.4^{\circ}$ for the wind speed and direction. In particular, when the wind speed is below $10 \mathrm{kt}\left(5 \mathrm{~ms}^{-1}\right)$, large errors $\left(>120^{\circ}\right)$ in the wind direction can be found. This is a limitation of NWP models that was previously documented by Jiménez et al. [44] for the WRF model.

Strong ageostrophic winds often develop in coastal gaps or channels when an along-gap pressure gradient is created [48]. A gap flow may also contribute to reinforce the winds downstream of the strait between Faial and Pico islands. This hypothesis should be subject to future research.

Supplementary Materials: The following are available online at http://www.mdpi.com/2073-4433/10/7/350/s1, Figure S1: (a) Enlarged view of Pico Mountain and its Aerodrome (LPPI), (b) Location of Pico Aerodrome (LPPI) relative to Pico Mountain, Figure S2: Cross and headwind components, Figure S3: Boundaries for the classification of wind shear intensity, Figure S4: Wind profile along flight path according to aerial observations and AROME for (a) Flight 1, and (b) Flight 2, Figure S5: Absolute temperature and N profiles at point $C$ for (a) Flight 1 and (b) Flight 2, Figure S6: (a) Vertically propagating mountain waves predicted by AROME during Flight 1, and (b) 
Flight 2, Figure S7: AROME turbulence indicators vs. the wind shear intensity factor $I$ along the flight path during Flight 2. Figure S8: Variation of Turbulent Kinetic Energy (TKE) and Eddy Dissipation Rate (EDR) with Height for (a): Flight 1 and (b) Flight 2. Figure S9: Turbulence Intensity for both Flights. Figure S10: Absolute Value Wind Direction Errors versus Wind Speed for both Flights.

Author Contributions: Conceptualization, J.M., M.B.-P. and P.S.; software, J.M. and M.B.-P.; Analysis, J.M., M.B.-P. and P.S.; writing — original draft preparation, J.M. and M.B.-P.; writing—review and editing, J.M., M.B.-P. and P.S.; Figures, J.M. and M.B.-P.; supervision, M.B.-P. and P.S.

Funding: FCT - Portuguese Foundation for Science and Technology, under the project UID/AGR/04033/2019.

Acknowledgments: This work is supported by National Funds by FCT - Portuguese Foundation for Science and Technology, under the project UID/AGR/04033/2019. The authors are also thankful to SATA International - Azores Airlines, S.A. for providing the airborne data.

Conflicts of Interest: The authors declare no conflict of interest.

\section{Appendix A}

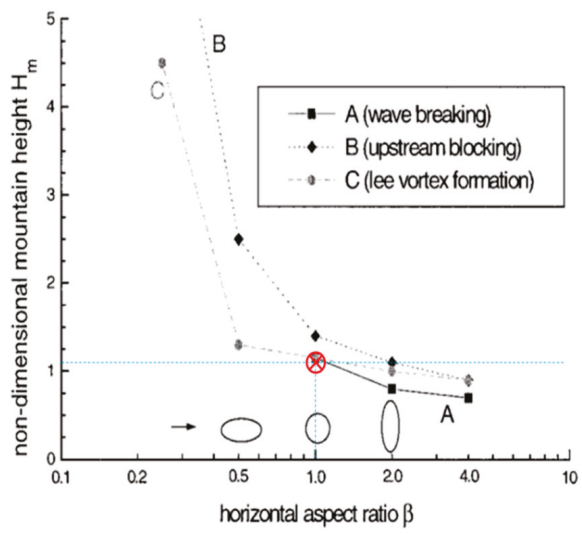

(a)

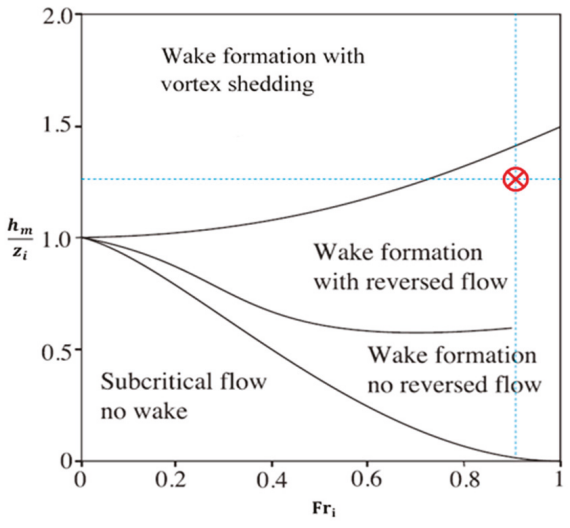

(b)

Figure A1. (a) Regime flow diagram adapted from Bauer et al. [2] for conditions of Flight 1; (b) Regime flow diagram adapted from Grubišić et al. [5] for conditions of Flight 2. Red mark indicates predicted states according to results from this study. Pico's orography is approximately circular (unitary horizontal aspect ratio).

Table A1. Suggested preliminary thresholds for three turbulence indicators. The thresholds values of EDR are only valid for heights below $500 \mathrm{ft}$ (152 m).

\begin{tabular}{ccc}
\hline Indicator & "Strong" & "Severe" \\
\hline Ellrod TI2 $\left[10^{-6} \mathrm{~s}^{-2}\right]$ & {$[9,16[$} & {$[16,+\infty[$} \\
CAT1 $\left[10^{-3} \mathrm{~ms}^{-2}\right]$ & {$[5,8[$} & {$[8,+\infty[$} \\
EDR & {$[0.3,0.35[$} & {$[0.35,+\infty[$} \\
\hline
\end{tabular}

\section{References}

1. Markowski, P.; Richardson, Y. Mesoscale Gravity Waves. In Mesoscale Meteorology in Midlatitudes, 1st ed.; Wiley-Blackwell: Hoboken, NJ, USA, 2010; pp. 161-180.

2. Bauer, M.H.; Mayr, G.J.; Vergeiner, I.; Pichler, H. Strongly Nonlinear Flow over and around a Three-Dimensional Mountain as a Function of the Horizontal Aspect Ratio. J. Atmos. Sci. 2000, 57, 3971-3991. [CrossRef] 
3. Ólafsson, H.; Bougeault, P. Nonlinear Flow Past an Elliptic Mountain Ridge. J. Atmos. Sci. 1996, 53, $2465-2489$. [CrossRef]

4. Epifanio, C.C. Lee Vortices. In Encyclopedia of the Atmospheric Sciences; Cambridge University Press: Cambridge, UK, 2014; pp. 1150-1160.

5. Grubišić, V.; Sachsperger, J.; Caldeira, R.M. Atmospheric Wake of Madeira: First Aerial Observations and Numerical Simulations. J. Atmos. Sci. 2015, 72, 4755-4776. [CrossRef]

6. Heinze, R.; Raasch, S.; Etling, D. The Structure of Kármán Vortex Streets in the Atmospheric Boundary Layer derived from Large Eddy Simulation. Meteorol. Z. 2012, 21, 221-237. [CrossRef]

7. Smolarkiewicz, P.K.; Rotunno, R. Low Froude-Number Flow Past Three-dimensional Obstacles. Part I: Baroclinically Generated Lee Vortices. J. Atmos. Sci. 1989, 46, 1154-1164. [CrossRef]

8. Li, L.; Chen, Y.-L. Numerical Simulations of Two Trapped Mountain Lee Waves Downstream of Oahu. J. Appl. Meteorol. Climatol. 2017, 56, 1305-1324. [CrossRef]

9. Keller, T.L.; Trier, S.B.; Hall, W.D.; Sharman, R.D.; Xu, M.; Liu, Y. Lee Waves Associated with a Commercial Jetliner Accident at Denver International Airport. J. Appl. Meteorol. Climatol. 2015, 54, 1373-1392. [CrossRef]

10. Parker, T.J.; Lane, T.P. Trapped Mountain Waves during a Light Aircraft Accident. Aust. Meteorol. Oceanogr. J. 2013, 63, 377-389. [CrossRef]

11. Caldeira, R.M.A.; Tomé, R. Wake Response to an Ocean-Feedback Mechanism: Madeira Island Case Study. Bound. Layer Meteorol. 2013, 148, 419-436. [CrossRef]

12. Couvelard, X.; Caldeira, R.M.A.; Araújo, I.B.; Tomé, R. Wind Meditated Vorticity-generation and Eddy-confinement, Leeward of the Madeira Island: 2008 Numerical Case Study. Dyn. Atmos. Oceans 2012, 58, 128-149. [CrossRef]

13. Barata, J.M.M.; Medeiros, R.C.; Silva, A.R.R. An Experimental Study of Terrain-Induced Airflow at the LPPI Airport. In Proceedings of the 10th AIAA Aviation Technology, Integration, and Operations (ATIO) Conference, Fort Worth, TX, USA, 13-15 September 2010; American Institute of Aeronautics and Astronautics: Reston, VA, USA, 2010; pp. 1-8.

14. Sayers, D.; Stewart, M. Background Information. In Azores, 6th ed.; The Globe Pequot Press Inc.: Guilford, CT, USA, 2016; pp. $2-3$.

15. Sharman, R.D.; Pearson, J.M. Prediction of Energy Dissipation Rates for Aviation Turbulence. Part I: Forecasting Nonconvective Turbulence. J. Appl. Meteor. Climatol. 2017, 56, 317-337. [CrossRef]

16. Stull, R.B. An Introduction to Boundary Layer Meteorology; Springer: Berlin, Germany, 1988; 666p.

17. Jiménez, P.A.; Dudhia, J. Improving the Representation of Resolved and Unresolved Topographic Effects on Surface Wind in the WRF Model. J. Appl. Meteorol. Climatol. 2012, 51, 300-316. [CrossRef]

18. Chow, F.K.; Street, R.L. Evaluation of Turbulence Closure Models for Large-Eddy Simulation over Complex Terrain: Flow over Askervein Hill. J. Appl. Meteorol. Climatol. 2009, 48, 1050-1065. [CrossRef]

19. Svensson, G.; Holtslag, A.A.M. Analysis of Model Results for the Turning of the Wind and Related Momentum Fluxes in the Stable Boundary Layer. Bound. Layer Meteorol. 2009, 132, 261-277. [CrossRef]

20. Brown, A.R.; Beljaars, A.C.M.; Hersbach, H.; Hollingsworth, A.; Miller, M.; Vasiljevic, D. Wind turning across the marine atmospheric boundary layer. Q. J. R. Meteorol. Soc. 2005, 131, 1233-1250. [CrossRef]

21. Brown, A.R.; Beare, R.J.; Edwards, J.M.; Lock, A.P.; Keogh, S.J.; Milton, S.F.; Walters, D.N. Upgrades to the boundary-layer scheme in the Met Office numerical weather prediction model. Bound. Layer Meteor. 2008, 128, 117-132. [CrossRef]

22. Ricard, D.; Lac, C.; Riette, S.; Legrand, R.; Mary, A. Kinetic energy spectra characteristics of two convection-permitting limited-area models AROME and Meso-NH. Q. J. R. Meteorol. Soc. 2013, 139, 1327-1341. [CrossRef]

23. Woodfield, A.A.; Woods, J.F. Worldwide experience of windshear during 1981-1982. In AGARD Flight Mechanics Panel Conf. on Flight Mechanics and System Design Lessons from Operational Experience; AGARD CP; NATO-STO: Brussel, Belgium, 1983; Volume 347, 28p.

24. International Civil Aviation Organization (ICAO). Manual on Low-level Wind Shear, 1st ed.; International Civil Aviation Organization: Montreal, QC, Canada, 2005; p. 213.

25. Guan, W.-L.; Yong, K. Review of Aviation Accidents Caused by Wind Shear and Identification Methods. J. Chin. Soc. Mech. Eng. 2002, 23, 99-110.

26. Seity, Y.; Brousseau, P.; Malardel, S.; Hello, G.; Bénard, P.; Bouttier, F.; Lac, C.; Masson, V. The AROME-France Convective-Scale Operational Model. Mon. Weather Rev. 2011, 139, 976-991. [CrossRef] 
27. Cuxart, J.; Bougeault, P.; Redelsperger, J.-L. A Turbulence Scheme Allowing for Mesoscale and Large-eddy Simulations. Q. J. R. Meteorol. Soc. 2006, 126, 1-30. [CrossRef]

28. Sutherland, B.R. Generation Mechanisms. In Internal Gravity Waves; Cambridge University Press: Cambridge, UK, 2018; pp. 284-285.

29. Lynch, A.H.; Cassano, J.J. Mountain Weather. In Atmospheric Dynamics; Wiley: Hoboken, NJ, USA, 2006; pp. 209-232.

30. Holton, J. An Introduction to Dynamic Meteorology, 4th ed.; Elsevier Inc.: Amsterdam, The Netherlands, 2004; Volume 88, 535p.

31. Sheridan, P.F.; Vosper, S.B. A Flow Regime Diagram for Forecasting Lee Waves, Rotors and Downslope Winds. Meteorol. Appl. 2006, 13, 179-195. [CrossRef]

32. Sheppard, P.A. Airflow over Mountains. Q. J. R. Meteorol. Soc. 1956, 82, 528-529. [CrossRef]

33. Sha, W.; Nakabayashi, K.; Ueda, H. Numerical Study on Flow Pass of a Three-dimensional Obstacle under a Strong Stratification Condition. J. Appl. Meteorol. 1998, 37, 1047-1054. [CrossRef]

34. Vosper, S.B.; Gardner, B.A. Measurements of the Near Surface Flow over a Hill. Q. J. R. Meteorol. Soc. 2002, 128, 2257-2280. [CrossRef]

35. Jiang, Q.; Doyle, J.D.; Smith, R.B. Blocking, Descent and Gravity Waves: Observations and Modelling of a MAP Northerly Föhn Event. Q. J. R. Meteorol. Soc. 2005, 131, 675-701. [CrossRef]

36. Trombetti, F.; Tampieri, F. An Application of the Dividing-Streamline Concept to the Stable Airflow over Mesoscale Mountains. Mon. Weather Rev. 1987, 115, 1802-1806. [CrossRef]

37. Wooldridge, G.L.; Fox, D.G.; Furman, R.W. Air-Flow Patterns over and around a Large 3-Dimensional Hill. Meteorol. Atmos. Phys. 1987, 37, 259-270. [CrossRef]

38. Vosper, S.B. Inversion Effects on Mountain Lee Waves. Q. J. R. Meteorol. Soc. 2004, 130, 1723-1748. [CrossRef]

39. Schär, C.; Smith, R.B. Shallow-Water Flow past Isolated Topography. Part I: Vorticity Production and Wake Formation. J. Atmos. Sci. 1993, 50, 1373-1400.

40. Gill, P.G.; Buchanan, P. An Ensemble based Turbulence Forecasting System. Meteorol. Appl. 2014, 21, 12-19. [CrossRef]

41. Sharman, R.; Tebaldi, C.; Wiener, G.; Wolff, J. An Integrated Approach to Mid- and Upper-Level Turbulence Forecasting. Weather Forecast. 2006, 21, 268-287. [CrossRef]

42. Frech, M.; Holzäpfel, F.; Tafferner, A.; Gerz, T. High-Resolution Weather Database for the Terminal Area of Frankfurt Airport. Am. Meteorol. Soc. 2007, 46, 1913-1932. [CrossRef]

43. International Civil Aviation Organization (ICAO). Meteorological Service for International Air Navigation: Annex 3 to the Convention on International Civil Aviation, 20th ed.; International Standards and Recommended Practices Technical Report; International Civil Aviation Organization: Montreal, QC, Canada, 2007; p. 218.

44. Jiménez, P.A.; Dudhia, J. On the Ability of the WRF Model to Reproduce the Surface Wind Direction over Complex Terrain. J. Appl. Meteorol. Climatol. 2013, 52, 1610-1617. [CrossRef]

45. Smith, R.B.; Grubišić, V. Aerial Observations of Hawaii's Wake. J. Atmos. Sci. 1993, 50, 3728-3750. [CrossRef]

46. International Civil Aviation Organization (ICAO). Meeting of the Meteorology Panel (METP): Proposed Revision to Eddy Dissipation Rate (EDR) Values in Annex 3; International Civil Aviation Organization: Montreal, QC, Canada, 2018; pp. 1-6.

47. Sharman, R.D.; Cornman, L.B.; Meymaris, G.; Pearson, J.; Farrar, T. Descriptions and Derived Climatologies of Automated in Situ Eddy-Dissipation-Rate Reports of Atmospheric Turbulence. J. Appl. Meteorol. Climatol. 2014, 53, 1416-1432. [CrossRef]

48. Colle, B.A.; Mass, C.F. High-Resolution Observations and Numerical Simulations of Easterly Gap Flow through the Strait of Juan de Fuca on 9-10 December 1995. Mon. Weather Rev. 2000, 128, 2398-2422. [CrossRef] 
Article

\title{
Hurricane Boundary Layer Height Relative to Storm Motion from GPS Dropsonde Composites
}

\author{
Yifang Ren ${ }^{1}$, Jun A. Zhang ${ }^{2,3, *}$, Stephen R. Guimond ${ }^{4,5}$ and Xiang Wang ${ }^{6}$ \\ 1 The Center of Jiangsu Meteorological Service, Nanjing 21008, China; renyifang2006@126.com \\ 2 Cooperative Institute for Marine and Atmospheric Studies, University of Miami, Miami, FL 33149, USA \\ 3 NOAA/AOML/Hurricane Research Division, Miami, FL 33149, USA \\ 4 Joint Center for Earth Systems Technology, University of Maryland Baltimore County, \\ Baltimore, MD 21250, USA; stephen.guimond@nasa.gov \\ 5 NASA Goddard Space Flight Center (GSFC), Greenbelt, MD 20771, USA \\ 6 Centre of Data Assimilation for Research and Application, Nanjing University of Information Science \& \\ Technology, Nanjing 210044, China; wangxiang@nuist.edu.cn \\ * Correspondence: jun.zhang@noaa.gov
}

Received: 9 May 2019; Accepted: 10 June 2019; Published: 21 June 2019

\begin{abstract}
This study investigates the asymmetric distribution of hurricane boundary layer height scales in a storm-motion-relative framework using global positioning system (GPS) dropsonde observations. Data from a total of 1916 dropsondes collected within four times the radius of maximum wind speed of 37 named hurricanes over the Atlantic basin from 1998 to 2015 are analyzed in the composite framework. Motion-relative quadrant mean composite analyses show that both the kinematic and thermodynamic boundary layer height scales tend to increase with increasing radius in all four motion-relative quadrants. It is also found that the thermodynamic mixed layer depth and height of maximum tangential wind speed are within the inflow layer in all motion-relative quadrants. The inflow layer depth and height of the maximum tangential wind are both found to be deeper in the two front quadrants, and they are largest in the right-front quadrant. The difference in the thermodynamic mixed layer depth between the front and back quadrants is smaller than that in the kinematic boundary layer height. The thermodynamic mixed layer is shallowest in the right-rear quadrant, which may be due to the cold wake phenomena. The boundary layer height derived using the critical Richardson number $\left(R_{i c}\right)$ method shows a similar front-back asymmetry as the kinematic boundary layer height.
\end{abstract}

Keywords: atmospheric boundary layer; tropical cyclone; storm motion; asymmetry; hurricane; aircraft; dropsonde

\section{Introduction}

The atmospheric boundary layer (ABL) is the turbulent layer close to the Earth's surface that is influenced by surface friction. Physical processes in the ABL play an important role in regulating the atmosphere at both weather and climate scales, including hurricanes. The top of the ABL (i.e., the boundary layer height) is a key parameter that determines the vertical distribution of turbulent mixing in numerical models that require a boundary layer parameterization. In numerical models where turbulent fluxes are parameterized using a first-order K-profile method, the boundary layer height is usually defined as the height at which the bulk Richardson number $\left(R_{i c}\right)$ reaches a threshold (typically 0.25 ), where $R_{\text {ic }}$ is defined as the ratio of buoyancy to shear forcing [1-3]. Note that this Richardson number method was also previously used in observational studies to determine the boundary layer height in non-hurricane conditions [4-8]. 
Under non-hurricane conditions when vertical profiles of turbulent intensity and/or flux are measured, the boundary layer height is usually taken as the height where the magnitude of the turbulence parameter is much smaller $(\sim 95 \%)$ than that in the surface layer. Note that the surface layer height is usually taken as $10 \%$ of the ABL height [9]. Without turbulence data, the height of the temperature inversion layer is generally used to define the boundary layer height, in particular, under unstable conditions [9-12]. Since passive scalars are accumulated in the ABL, large gradients of temperature and water vapor occur at the inversion layer capping the ABL [13,14]. Above the inversion layer, a rising air parcel typically becomes neutrally buoyant.

The top of the stable or neutral boundary layer is more difficult to determine than the unstable convective boundary layer. The boundary layer height is typically defined using the vertical gradient of virtual potential temperature with a threshold [4,15-17], when flux data are not available. This method has been widely used when radiosonde data are available. The parcel method developed by Holzworth [18] was also used in previous studies to estimate the boundary layer height using radiosonde data $[15,19,20]$. Remote sensing data (e.g., lidars, radars, sodas, and wind profilers), although sometimes ambiguous, can also be used to determine the boundary layer height when other types of data are not available [21-24].

In hurricane conditions, it is even more difficult to acquire direct turbulence measurements due to safety issues and measurement constraints. Multi-level turbulent intensity and flux data that can be used to estimate the boundary layer height are scarce in hurricane conditions. The only in situ data of this kind was collected in regions either $100 \mathrm{~km}$ away from the hurricane eyewall or in weak tropical storms [25-28]. Note that a new airborne Doppler radar dataset from the Imaging Wind and Rain Airborne Profiler (IWRAP) is able to provide three-dimensional winds, deep into the hurricane boundary layer, at high resolution ( $200 \mathrm{~m}$ horizontal and $30 \mathrm{~m}$ vertical), which will be useful for characterizing the boundary layer height using dynamical metrics $[29,30]$.

Dropsonde data have been used to estimate the hurricane boundary layer height scales in previous studies [31]. Zhang et al. [31] pointed out differences between the kinematic boundary layer height denoted by the height of the maximum tangential wind speed $\left(h_{\mathrm{vtmax}}\right)$ or inflow layer depth $\left(h_{\text {inflow }}\right)$, and the thermodynamic boundary layer height denoted by the mixed layer depth $\left(z_{\mathrm{i}}\right)$. Of note, $h_{\text {inflow }}$ is taken as the height of strong inflow layer where the inflow strength is equal to $10 \%$ of the maximum inflow [32]. Furthermore, $z_{\mathrm{i}}$ is taken as the height where the vertical gradient of the virtual potential temperature (theta-v) is equal to $3 \mathrm{~K} \mathrm{~km}^{-1}$, a widely used approach in non-hurricane ABL studies [4]. Ming et al. [33] confirmed the result of Zhang et al. [31] by analyzing a smaller number of dropsonde data in Pacific typhoons.

Previous modeling studies on air-sea coupling processes of individual tropical cyclones (TCs) showed an asymmetric distribution of the boundary layer structure relative to the storm motion, suggesting that the boundary layer is more stable in the right-rear quadrant [34,35]. Although a significant number of observational studies have documented the mean boundary layer structure of individual hurricanes [27,36-41], the variability of the ABL structure as a function of azimuth remains to be explored. The objective of the present study is to investigate the asymmetry of the boundary layer structure in a storm-motion-relative framework with a focus on the boundary layer height scales. This study is a first attempt to analyze the motion-induced asymmetry of the boundary layer heights in a climatological sense by compositing dropsonde data collected in multiple hurricanes. The results of this study will be useful for improving our understanding of the low-level structure of hurricanes and providing composite analyses that can be used for model evaluation and physics improvements [42].

This paper is organized as follows. Section 2 describes the dropsonde data and the composite analysis methodology. The dropsonde composites used to compute the boundary layer heights are shown in Section 3, which is followed by the discussion and conclusion in Section 4. 


\section{Data and Composite Methodology}

Dropsondes are typically deployed from research or reconnaissance aircraft at a height of $\sim 3 \mathrm{~km}$ (i.e., $700 \mathrm{hPa}$ ), with a descending rate of $\sim 10 \mathrm{~m} \mathrm{~s}^{-1}$ and a vertical sampling resolution of $\sim 7 \mathrm{~m}$. During the process of descent, atmospheric profiles of pressure, temperature, relative humidity, and horizontal winds are collected by the dropsonde. The accuracy of pressure, temperature, relative humidity and horizontal wind speed are $\pm 1.0 \mathrm{hPa}, \pm 0.2{ }^{\circ} \mathrm{C}, \pm 5 \%$, and $\pm 0.5 \mathrm{~ms}^{-1}$, respectively [43]. The dropsonde data used in this study are from the Hurricane Research Division (HRD) archives and have been quality controlled using the Editsonde and/or ASPEN programs.

In this study, a total of 7326 GPS dropsonde profiles collected by research aircraft in 37 TCs from 1998 to 2015 are analyzed. The storm intensity is obtained from the hurricane best track database produced by the National Hurricane Center (NHC). The storm tracks processed by HRD, which combine the best track storm locations with aircraft center fixes, are used in the analysis. We linearly interpolate the storm intensity, center and motion from the track data to the dropsonde time. For the composite analysis of the inner-core structure, the dropsonde profiles must meet the following requirements: (i) They have measurements of wind speed, temperature, and humidity from flight-level all the way to the surface with no data gaps, (ii) the maximum sustained wind speed (i.e., storm intensity) from NHC's best track is larger than $64 \mathrm{kt}$ (Cat 1 strength), and (iii) the sondes are deployed within four times the radius of maximum wind speed (RMW). A total of 1916 dropsonde profiles are used in the final composite analysis after this screening. Note that the RMW data used in this study are calculated based on the flight-level data following [44]. Table 1 summarizes the storm information and numbers of dropsondes used in this work.

Table 1. Storm information and number of dropsondes (1916).

\begin{tabular}{|c|c|c|c|}
\hline ID & Storm & Intensity Range (kt) & No. of Sondes \\
\hline 0298 & BONNIE & $98.6-100.0$ & 101 \\
\hline 0498 & DANIELLE & $65.0-73.1$ & 43 \\
\hline 0598 & EARL & $79.6-83.0$ & 3 \\
\hline 0798 & GEORGES & $65.0-131.1$ & 106 \\
\hline 1398 & MITCH & $139.1-139.6$ & 6 \\
\hline 0399 & BRET & 101.9-111.4 & 9 \\
\hline 0599 & DENNIS & 67.1-90.0 & 19 \\
\hline 0899 & FLOYD & $81.3-122.5$ & 23 \\
\hline 1399 & IRENE & 65.0 & 4 \\
\hline 1002 & ISIDORE & $66.1-110.0$ & 14 \\
\hline 1003 & FABIAN & $100.0-125.0$ & 154 \\
\hline 1303 & ISABEL & $79.6-140.0$ & 271 \\
\hline 0304 & CHARLEY & $64.1-120.4$ & 49 \\
\hline 0604 & FRANCES & $87.6-124.7$ & 128 \\
\hline 0904 & IVAN & $105.0-145.0$ & 158 \\
\hline 1104 & JEANNE & $85.0-105.0$ & 11 \\
\hline 0405 & DENNIS & $71.6-84.5$ & 21 \\
\hline 1205 & KATRINA & $100.0-150.0$ & 60 \\
\hline 1805 & RITA & $123.4-146.5$ & 13 \\
\hline 0906 & HELENE & $80.0-98.3$ & 42 \\
\hline 0708 & GUSTAV & $75.3-111.7$ & 23 \\
\hline 1708 & PALOMA & $79.1-125.0$ & 20 \\
\hline 0309 & BILL & $105.1-115.0$ & 37 \\
\hline 0710 & EARL & 71.8-121.1 & 41 \\
\hline 1310 & KARL & $71.6-76.9$ & 9 \\
\hline 0911 & IRENE & $72.7-104.6$ & 91 \\
\hline 1811 & RINA & $81.8-100.0$ & 7 \\
\hline 0912 & ISAAC & $64.0-70.0$ & 42 \\
\hline 1812 & SANDY & $65.0-74.5$ & 90 \\
\hline 1013 & INGRID & $65.0-70.9$ & 35 \\
\hline 0114 & ARTHUR & $67.8-82.4$ & 46 \\
\hline 0314 & BERTHA & $64.6-70.0$ & 23 \\
\hline 0414 & CRISTOBAL & $65.0-67.0$ & 28 \\
\hline 0614 & EDOUARD & $72.5-101.5$ & 73 \\
\hline 0814 & GONZALO & $106.9-125.0$ & 40 \\
\hline 0415 & DANNY & 105.7-106.4 & 10 \\
\hline 1115 & JOAQUIN & $75.0-120.0$ & 66 \\
\hline
\end{tabular}


The dropsonde distribution relative to the storm center is shown in Figure 1, with observation locations rotated with respect to the storm motion direction to the top of the figure. Figure 1 shows nearly evenly distributed data at motion-relative azimuths at all radii, although more dropsonde data are located close to the RMW (i.e., $r / R M W=1$ ). The dropsonde data are composited in four motion-relative quadrants defined clockwise from the storm motion direction, as right-front, right-rear, left-rear and left-front (Figure 2). The storm characteristics in terms of frequency distribution, including the storm intensity $V_{\max }, \mathrm{RMW}$, storm translational direction, and storm speed are presented in Figure 3. Storm intensities range from 65-150 kt, sizes in terms of RMW range from 10-65 km, and translational speed ranges from $2-20 \mathrm{~ms}^{-1}$. The mean storm intensity for the whole sample is $105.5 \mathrm{kt}$, the mean RMW is $28.5 \mathrm{~km}$, and the mean storm translational speed is $5.27 \mathrm{~ms}^{-1}$.

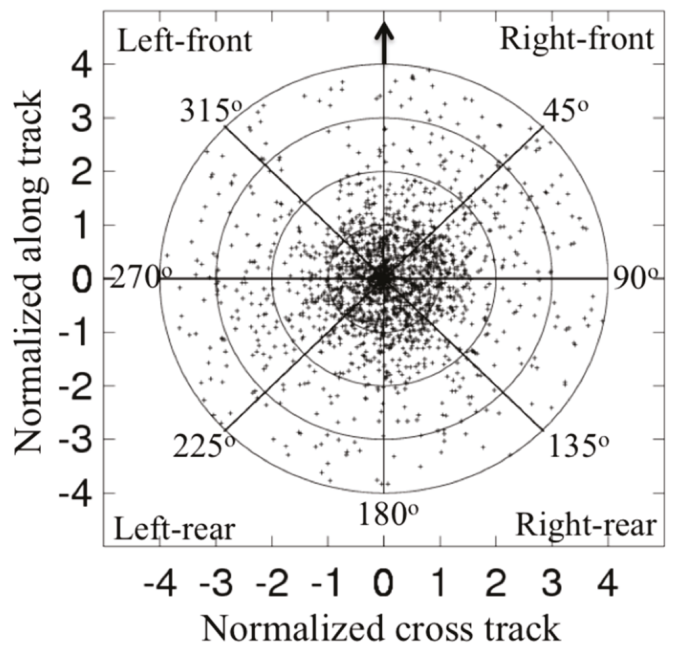

Figure 1. Storm-relative two-dimensional distribution of dropsonde surface observation locations. Cross- and along-track positions are normalized by the radius of maximum wind at the time of observation. The arrow indicates the storm motion direction.

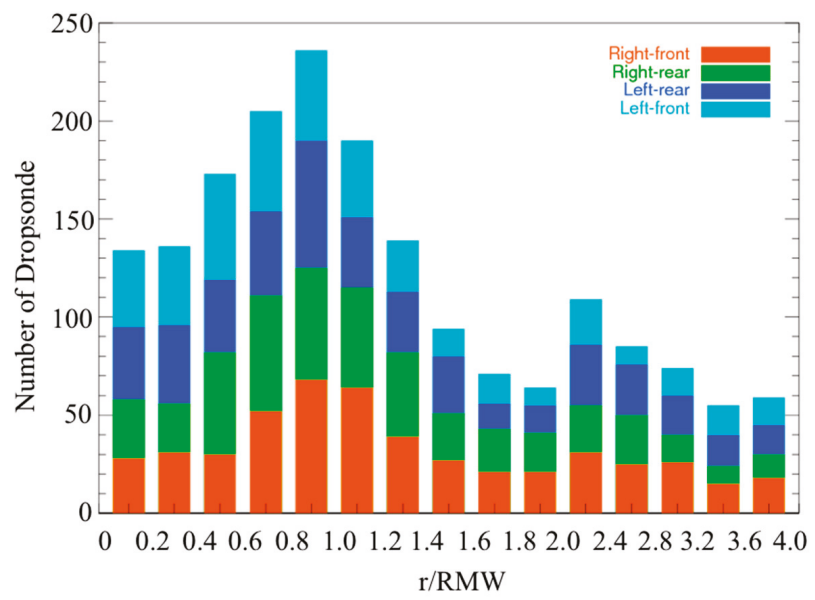

Figure 2. Radial distribution of dropsonde counts per bin as a function of normalized distance by radius of maximum wind speed (RMW). 
In this study, we use the same composite methodology as Zhang et al. [31] to construct the radial-vertical profiles of virtual temperature $\left(\theta_{v}\right)$, tangential wind, radial wind, and Richardson number in four quadrants relative to the storm motion. When compositing the data, the radial bin width is $0.2 r^{*}\left(r^{*}=r / \mathrm{RMW}\right)$ for the inner core $\left(r^{*}<2\right)$, and it is $0.4 r^{*}$ for the outer part. The data are also bin averaged vertically at $10 \mathrm{~m}$ resolution. The final averaged data are also smoothed with three passes of a 1-2-1 filter, instead of five passes as in Zhang et al. [31]. The data sampling sizes for different quadrants are displayed in Figure 2 as a function of normalized radius and height. The largest sample size is located in the vicinity of the eyewall as expected. Figure 2 also indicates that the data samples for the four motion-relative quadrants are similar.
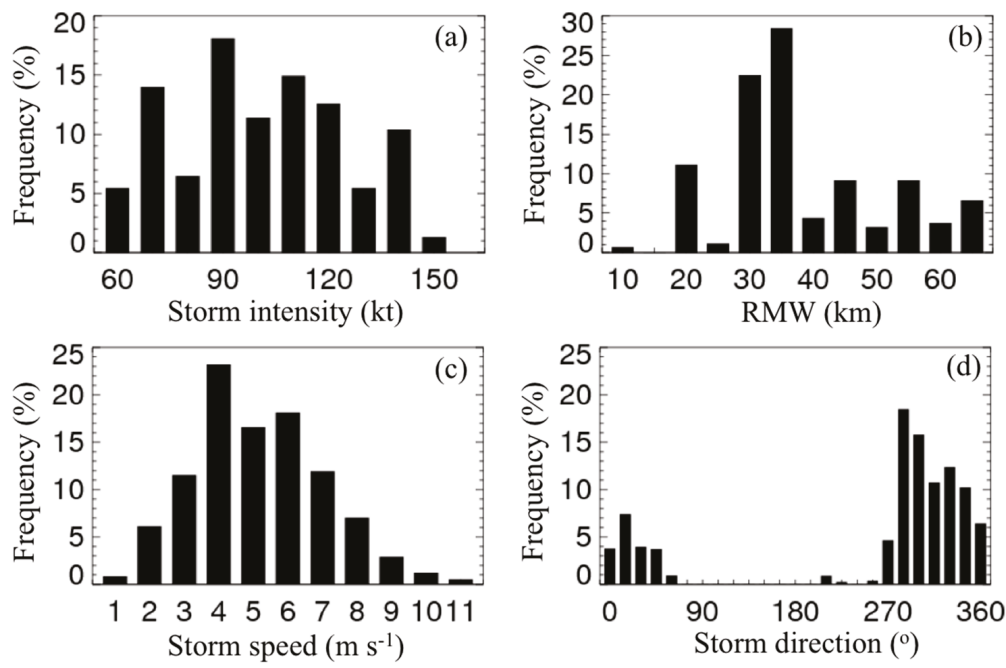

Figure 3. Frequency distribution of dropsondes according to the corresponding (a) storm intensity, (b) radius of maximum wind speed (RMW), (c) storm speed, and (d) storm direction rotated clockwise with $0^{\circ}$ pointing to the north.

\section{Results}

The storm-motion-relative normalized radius-height representation of the tangential wind speed is displayed in Figure 4. The tangential wind first increases with height to a maximum value then decreases with height in all four motion-relative quadrants. This tangential wind maximum has been called the boundary layer jet $[45,46]$. The maximum tangential wind speed is largest in the right-front quadrant and it is smallest at the right-rear quadrant. Specifically, the peak values of the tangential wind speed are 53.5, 55.8, 52.6, and $44.3 \mathrm{~ms}^{-1}$ for left-front, right-front, left-rear and right-rear quadrant, respectively. The fact that the front quadrants have stronger tangential wind speeds than the rear quadrants in a storm-relative framework is consistent with previous theoretical studies [45-48].

It is also evident from Figure 4 that the jet height, $h_{\mathrm{vtmax}}$, has a trend of decreasing with smaller $\mathrm{r}^{*}$ values in all four motion-relative quadrants. This result further supports the findings of Zhang et al. [31] in terms of the radial variation of the hurricane boundary layer height, which may be applied in the asymmetric sense. Interestingly, $h_{\mathrm{vtmax}}$ is higher in the front quadrants than in the rear quadrants, which may be associated with the stronger tangential wind speed in the front quadrants. Specifically, $h_{\mathrm{vtmax}}$ increases from $\sim 600 \mathrm{~m}$ at a radius of $r^{*}=1$ to $\sim 1200 \mathrm{~m}$ at a radius of $r^{*}=2$, then slightly increases with increasing radius in the front two quadrants. In the left-rear quadrant, $h_{\mathrm{vtmax}}$ is $\sim 100 \mathrm{~m}$ smaller than in the front two quadrants at $\mathrm{r}^{*}=1$, and increases with radius to $\sim 800 \mathrm{~m}$ at $\mathrm{r}^{*}=2$, then increases to $\sim 900 \mathrm{~m}$ at $\mathrm{r}^{*}=4$. In the right-rear quadrant, $h_{\mathrm{vtmax}}$ is the lowest among all four quadrants, and it 
gradually increases from $\sim 400 \mathrm{~m}$ at radius of $r^{*}=1$ to $\sim 600 \mathrm{~m}$ at radius of $r^{*}=2$, and increases to $\sim 800 \mathrm{~m}$ at $\mathrm{r}^{*}=4$.

The normalized radius-height representation of the radial velocity for the four motion-relative quadrants is displayed in Figure 5. The peak values of the radial wind speed are $-18.5,-18.7,-13.5$ and $-15.4 \mathrm{~ms}^{-1}$ for left-front, right-front, left-rear and right-rear quadrant, respectively. These peak inflow values are located at $\sim 100 \mathrm{~m}$ altitude between $\mathrm{r}^{*}=1-2$ and closer to $\mathrm{r}^{*}=1$, which is consistent with the axisymmetric structure documented by Zhang et al. [31]. In addition, a pronounced outflow of 5-10 $\mathrm{m} \mathrm{s}^{-1}$ can be seen in all the four quadrants above the inflow layer. The inflow is stronger in the front quadrants compared to the rear quadrants, which is consistent with previous theoretical and numerical studies [46-48]. Observational studies of individual hurricanes also showed similar front-back wind asymmetry $[37,38,49]$.

The inflow layer depth, $h_{\text {inflow }}$, which is depicted by the white line in Figure 5 , shows a decreasing trend with decreasing radius in all four motion-relative quadrants. It is also evident from Figure 5 that, $h_{\text {inflow }}$ is larger in the front two quadrants than in the rear two quadrants. Specifically, $h_{\text {inflow }}$ evolves similarly in left-front, right-front and right-rear quadrants from an altitude of $\sim 600 \mathrm{~m}$ to an altitude of 900-1200 m with highest heights in the right-front quadrant and lowest heights in the right-rear quadrant. However, $h_{\text {inflow }}$ remains nearly constant $(\sim 500 \mathrm{~m})$ with a slightly negative trend in the left-rear quadrant. This result suggests that the asymmetric distribution of $h_{\text {inflow }}$ follows that of $h_{\mathrm{vtmax}}$. From Figures 4 and 5, the maximum tangential wind speed in the eyewall region is close to the top of the inflow layer in all quadrants.

The thermodynamic mixed layer depth, $z_{i}$, is depicted by the white line in Figure 6 that shows the normalized radius-height representation of the vertical gradient of theta-v $\left(d \theta_{v} / d z\right)$. In all quadrants, the boundary layer is unstable near the surface as indicated by the negative value of $d \theta_{v} / d z$. Above this very shallow unstable layer, the boundary layer becomes nearly neutral up to the mixed layer depth and then becomes stable. There is a strong stable layer inside the RMW above the mixed layer at heights of 600-2000 m with $d \theta_{v} / d z>5 \mathrm{~K} / \mathrm{km}$. This strong stable layer is shallowest at the right-rear quadrant among the four motion-relative quadrants, which may be tied to the cold wake phenomena observed in the sea surface temperature (SST) field [50-52]. On average when the storm motion of a hurricane is $\sim 6 \mathrm{~ms}^{-1}$, which is the average value of our data, the typical SST close to the cold wake region at the right-rear quadrant is of the order of 1-2 K smaller than the front quadrants based on in-situ data [53]. The smaller SST in the right-rear quadrant would stabilize the low-level boundary layer due to a reduction in surface enthalpy fluxes.

In all four quadrants, $z_{i}$ decreases with distance toward the storm center, in a similar manner as the kinematic boundary layer heights. This result again supports that of Zhang et al. [31] and Zhang et al. [54]. From Figures $4-6$, it is clear that $z_{\mathrm{i}}$ is much smaller than $h_{\text {inflow }}$ and $h_{\mathrm{vtmax}}$ in all quadrants, the kinematic and thermodynamic boundary layer heights largely depart from each other, as noted by Zhang et al. [31]. This structure is different from that of the ABL in non-hurricane conditions. Close to the eyewall region $\left(\mathrm{r}^{*}<1.5\right), \mathrm{z}_{\mathrm{i}}$ is nearly symmetric with a value of $\sim 200 \mathrm{~m}$. Outside the eyewall, the left-front quadrant has the largest $z_{i}$ while the other three quadrants have similar magnitudes of $z_{i}$. In the outer radii $\left(r^{*}>3\right), z_{i}$ is largest in the left-front quadrant and is smallest in the right-rear quadrant. There is a weak front-back asymmetry in $z_{\mathrm{i}}$, which is similar to the asymmetric distribution of the kinematic boundary layer height, but the mixed layer depth difference is less than $\sim 100 \mathrm{~m}$.

The storm-motion-relative normalized radius-height representation of the bulk Richardson number is displayed in Figure 7. Here the height of $R_{i c}=0.25$ is taken as the top of the boundary layer $\left(\mathrm{h}_{\text {Ric }}\right.$ ), which is depicted by the solid white line in Figure 7 . The front-back difference in $\mathrm{h}_{\text {Ric }}$ is clearly shown in Figure 7 with the front two quadrants displaying a deeper boundary layer, consistent with the other height scales investigated earlier. Combining Figures 4-7, it appears that $h_{\text {Ric }}$ lies between the thermodynamic mixed layer depth and the kinematic boundary layer height, which agrees with the axisymmetric structure documented by Zhang et al. [31]. The left-front quadrant has the deepest boundary layer while the right-rear quadrant has the shallowest boundary layer, in terms of $h_{\text {Ric }}$. 
(a) Left-front

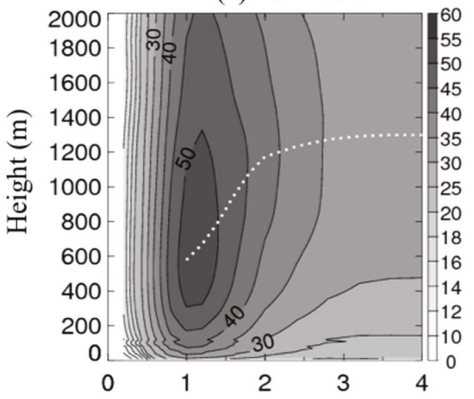

(c) Left-rear

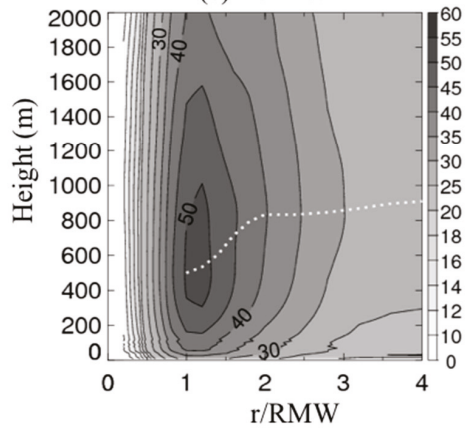

(b) Right-front

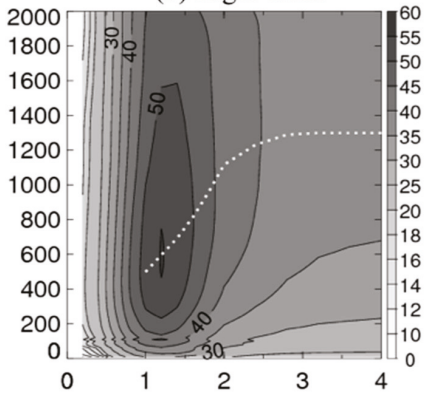

(d) Right-rear

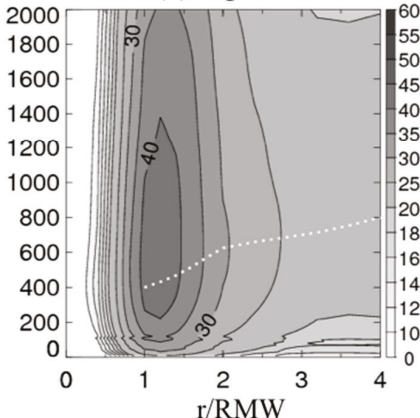

Figure 4. Composite analysis result of the relative tangential wind velocity as a function of altitude and the normalized radius to the storm center for the four quadrants relative to the motion direction. The panels show the left-front (a), right-front (b), left-rear (c) and right-rear (d) quadrants. The white dashed line in each panel depicts the height of the maximum tangential wind speed varying with radius.
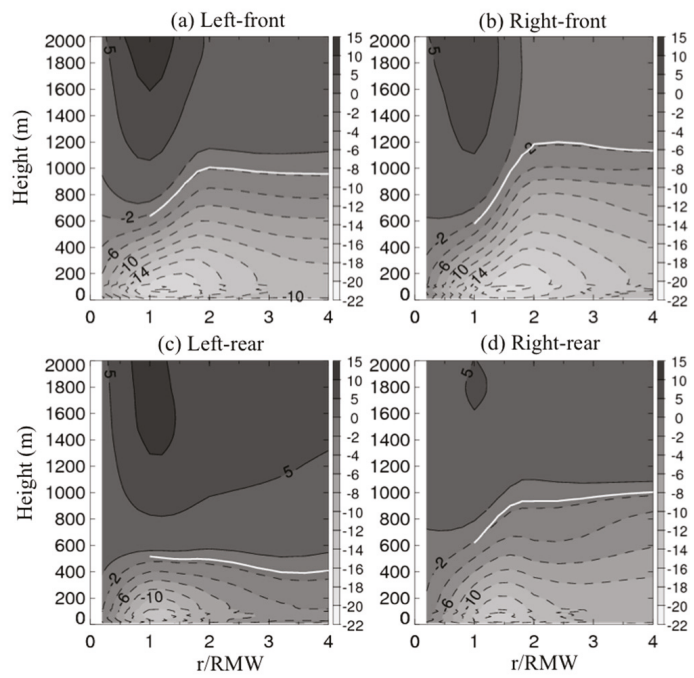

Figure 5. Same as in Figure 4 but the results are for the relative radial wind velocity as a function of altitude and the normalized radius to the storm center for the four quadrants relative to the shear direction. The panels show the left-front (a), right-front (b), left-rear (c) and right-rear (d) quadrants. The white line in each panel represents the height of $10 \%$ peak inflow. 
(a) Left-front

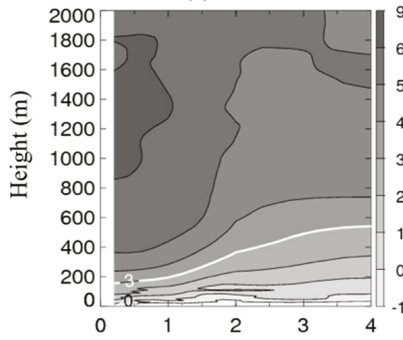

(c) Left-rear

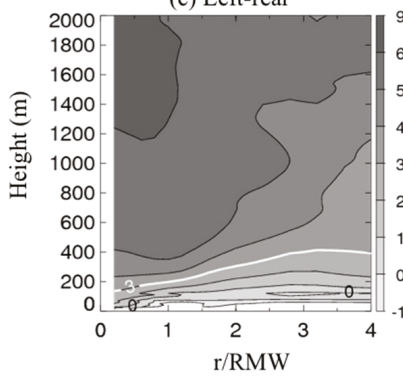

(b) Right-front

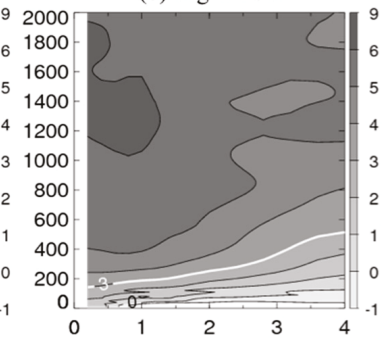

(d) Right-rear

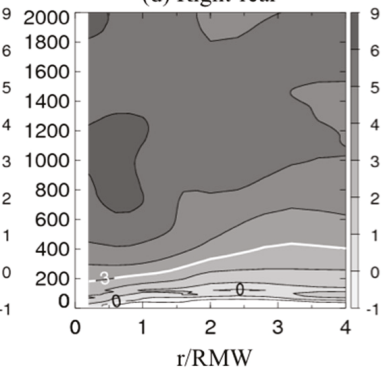

Figure 6. Same as in Figure 4 but the results show the lapse rate of the virtual potential temperature. The panels show the left-front (a), right-front (b), left-rear (c) and right-rear (d) quadrants. The thick white line denotes the contour. The contour denotes the constant contour of $d \theta_{v} / d z=3 \mathrm{~K} \mathrm{~km}^{-1}$.

(a) Left-front

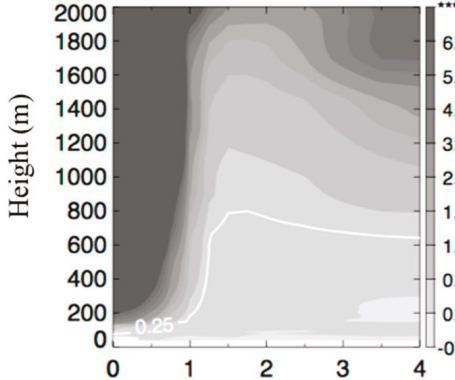

(c) Left-rear

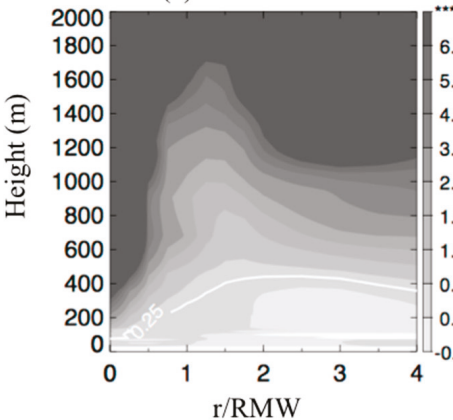

(b) Right-front

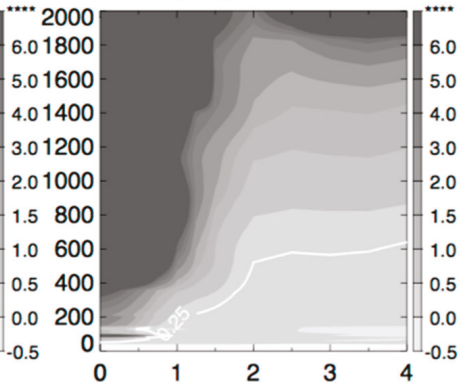

(d) Right-rear

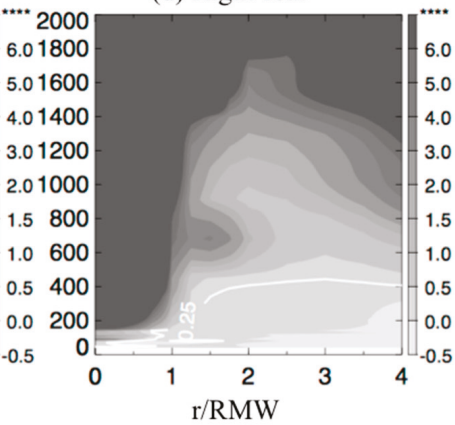

Figure 7. Same as in Figure 4 but the results are for the Richardson numbers as a function of altitude and the normalized radius to the storm center. The panels show the left-front (a), right-front (b), left-rear (c) and right-rear (d) quadrants. The white line shows the contour of 0.25 . 


\section{Discussion and Conclusions}

The ABL plays an important role in the energy transport processes related to hurricane intensification and maximum intensity [32,55-60] and it is essential to understand the ABL structure. This paper analyzes a total of 1916 GPS dropsondes within four times the RMW distance from 37 hurricanes over the tropical Atlantic basin from 1998 to 2015 to study the characteristic height scales of the ABL with respect to the storm-motion direction. Figure 8 is a schematic diagram that summarizes the height scales investigated in this study based on the composite dropsonde analysis. The results show a clear departure between thermodynamic and kinematic boundary layer heights with the thermodynamic boundary layer height much shallower than the kinematic boundary layer height. Supporting the findings of Zhang et al. [31] based on the symmetric analysis of the dropsonde data, our results show that the hurricane boundary layer height increases with increasing radius in a storm-relative framework. This observed variation of boundary layer height with radius supports the theoretical scaling of a rotating boundary layer [46,59,61-64] in an axisymmetric framework. Our results indicate that this scaling also holds in a motion-relative asymmetric distribution of the boundary layer height.

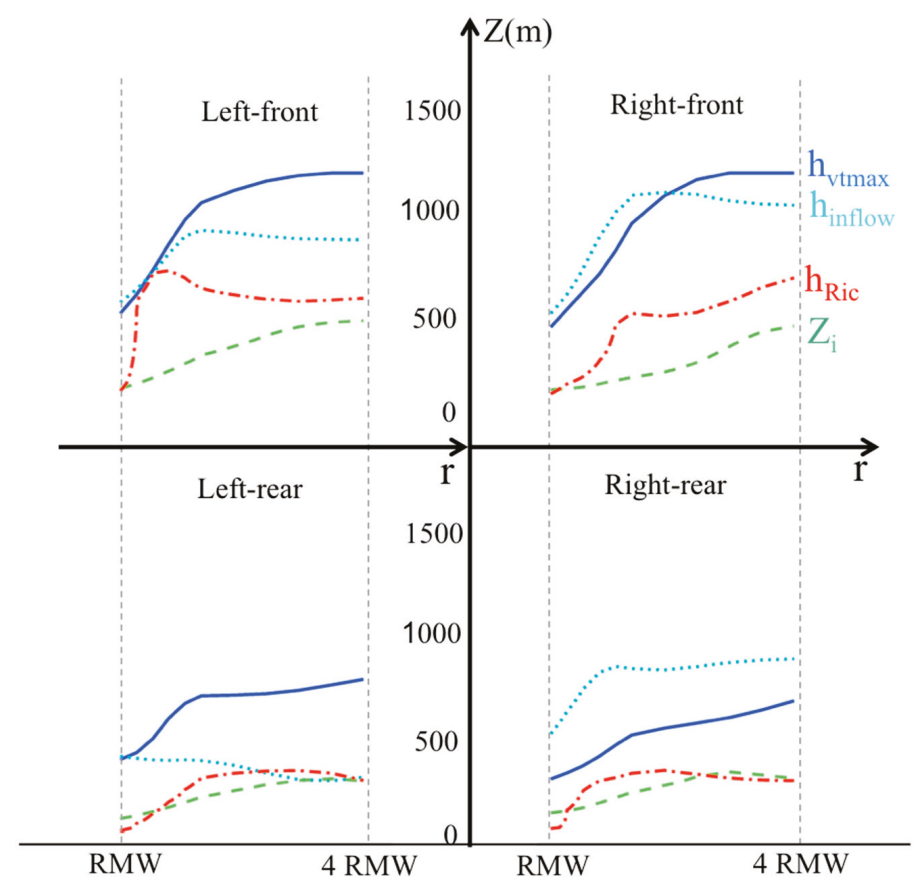

Figure 8. Schematic diagram of the characteristic height scales of the hurricane boundary layer for the four quadrants relative to the storm motion. The height scales are based on the composite analysis of the dropsonde data. $h \mathrm{i}_{\text {nflow }}$ is the inflow layer depth (cyan dotted line); $\mathrm{z}_{\mathrm{i}}$ is the mixed layer depth (green dashed line); $h_{\mathrm{vtmax}}$ is the height of the maximum tangential wind speed (blue solid line) and; $\mathrm{h}_{\text {Ric }}$ is the height of the bulk Richardson number value of 0.25 .

In the eyewall region, all height scales show relatively small asymmetric distribution. The weak asymmetry is found in the kinematic boundary layer heights $\left(h_{\mathrm{vtmax}}\right.$ and $\left.h_{\text {inflow }}\right)$ that are slightly smaller in the left-rear quadrant than in other quadrants. All height scales demonstrate similar front-back asymmetry outside the eyewall region, in that the two front motion-relative quadrants have a deeper boundary layer. The front-back difference in the thermodynamic boundary layer height is smaller than 
that in the kinematic boundary layer height. The mixed layer depth being smallest in the right-rear quadrant may be due to the SST cooling effect in this quadrant where the cold wake is located, following the argument of previous modeling studies [35,52].

The boundary layer height derived using the critical Richardson number $\left(R_{i c}\right)$ method shows a similar asymmetry as the kinematic boundary layer height, confirming that turbulence in the hurricane boundary layer is mainly shear driven. Consistent with Zhang et al. [31], our results suggest that the hurricane research community should use the kinematic height scales to represent the top of the boundary layer instead of the thermodynamic mixed layer depth typically used in non-hurricane conditions. Kepert [65] and Kepert et al. [66] discussed the limitation of using thermodynamic mixed layer depth to represent the boundary layer height in numerical models, which is in agreement with our observational findings here.

Our results in terms of the asymmetry of maximum tangential and radial wind speeds in the boundary layer generally agree with previous theoretical and numerical studies [46-48] Our result in terms of front-back asymmetry in the velocity fields also agrees with previous observational case studies such as the ABL structure in Hurricanes Mitch (1998), George (1998), Isabel (2003) and Daniel (2008) as shown by Kepert $[37,38]$. Although previous studies did not focus on the boundary layer height asymmetry, their results indicate a similar structure of the inflow and inflow layer depth as well as the height of the boundary layer jet. The surface wind asymmetry is consistent with Uhlhorn et al. [67] who analyzed stepped frequency microwave radiometer (SFMR) data, as well as Klotz and Jiang [68] who analyzed satellite data. The inflow asymmetry near the surface is consistent with the result of Zhang and Uhlhorn [69], who studied the characteristics of surface inflow angle in both axisymmetric and asymmetric framework.

Note that Zhang et al. [54] investigated the asymmetric structure of the hurricane boundary layer in relation to the environmental vertical wind shear. They focused on investigating how boundary layer thermodynamic structure is tied to the upper-level convection in an energy-cycling paradigm. They also studied the asymmetry of the boundary layer height scales relative to the environmental shear direction and found that the kinematic boundary layer height scales are larger in the downshear direction than in the upshear direction, while the thermodynamic boundary layer height scale is slightly larger left of the shear than right of the shear. The boundary layer being deeper in the downshear quadrants may be tied to the asymmetric distribution of convection that is usually initiated in the downshear-right quadrant and propagates to downshear-left quadrant [70]. The boundary layer is deeper in the quadrants where stronger convection occurs. Following this argument, storm-motion induced asymmetry of the boundary layer height scales may also be linked to asymmetric distribution of convective activity relative to storm motion, although storm motion and environmental wind shear are very different parameters.

The asymmetric structure above the boundary layer (i.e., convection) in tropical cyclones with respect to storm motion have been extensively studied using radar observations in both case studies and composite analysis studies. For instance, Jorgensen et al. [71] utilized flight-level data and found maximum upward mass transport in slow-moving storms occurred to the right of motion, with equal amounts occurring in the front and rear of the inner core. Our composite analysis supports strong convection occurs in the right-front quadrant, as both the maximum tangential wind speed and maximum inflow strength occur in this quadrant. Marks et al. [72] found that the maximum upward vertical velocities were in the left-front quadrant of Hurricane Norbert (1984). Marks [73] found that the maximum precipitation of Hurricane Allen (1980) in the eyewall region was in the left-front quadrant, while the maximum precipitation of Hurricane Elena (1985) was in the right-front quadrant. Through examining the patterns of reflectivity in the eyewall region of Hurricane Olivia (1994), Reasor et al. [74] found that the maximum radar reflectivity was located in the left quadrants relative to the motion direction, which was consistent with the structure in Hurricane Gloria (1985) documented by Franklin et al. [75]. Our composite analysis shows that the strongest inflow in the boundary layer is located in the front quadrants, which support large vertical motion and strong 
convection due to mass continuity. Overall, it is hypothesized that the asymmetry of boundary layer inflow and jet strength are tied to the asymmetry of convection and precipitation.

Furthermore, the composite analysis result showing the front-back asymmetry of the boundary layer heights supports the theoretical argument that the boundary-layer convergence is larger in the front quadrants relative to the storm motion direction $[45,47]$. The surface wind asymmetry related to storm-motion effect induces the asymmetry of surface drag forcing, which in turn affects the distribution of boundary layer convergence and convection. Larger wind speed observed in the front quadrants induces larger turbulent mixing in the boundary layer, which supports larger kinematic boundary layer height according to dynamic scaling [42,45].

Of note, the combined effects of storm motion and environmental wind shear on the asymmetry of the boundary layer structure remains to be understood due to the limitation of data sampling size at the current stage. Future studies will combine the dropsonde and Doppler radar data to investigate the linkage between the boundary layer and convective processes and their asymmetry relative to both the storm motion and environmental wind shear. The extent of asymmetry of the boundary layer structure to the storm motion speed will also be evaluated when more observational data are available than those used in the present study.

Author Contributions: Conceptualization, J.A.Z., X.W.; methodology, Y.R., J.A.Z.; software, X.W.; validation, Y.R., J.A.Z., S.R.G. and X.W.; formal analysis, Y.R., X.W.; resources, J.A.Z., X.W.; data curation, Y.R.; writing-original draft preparation, Y.R., J.A.Z., S.R.G., X.W.; writing-review and editing, J.A.Z., S.R.G., X.W.; visualization, X.W.; supervision, J.A.Z.; project administration, Y.R.; funding acquisition, J.A.Z., S.R.G., X.W.

Funding: This study was partially supported by NSF Grant AGS1822128, NOAA Grant NA14NWS4680030, NASA Grant NNX14AM69G, and NASA Weather and Atmospheric Dynamics program (Grant NNH16ZDA001N-WEATHER) directed by Ramesh Kakar.

Acknowledgments: The authors would like to thank all the scientists and crew members who have been involved in the hurricane field program and operational reconnaissance hurricane missions to help collect the dropsonde data used in this study. This paper is a follow-up work of the first author's Master thesis and she would like to acknowledge Prof. Xiaolei Zou and Prof. Ming Cai for their helpful discussions. We also wish to thank the reviewers for their comments that led to improvement of the paper.

Conflicts of Interest: The authors declare no conflict of interest.

\section{References}

1. Troen, I.B.; Mahrt, L. A simple model of the atmospheric boundary layer; sensitivity to surface evaporation. Bound. Layer Meteorol. 1986, 37, 129-148. [CrossRef]

2. Hong, S.-Y.; Pan, H.-L. Nonlocal Boundary Layer Vertical Diffusion in a Medium-Range Forecast Model. Mon. Weather Rev. 1996, 124, 2322-2339. [CrossRef]

3. Hong, S.-Y.; Noh, Y.; Dudhia, J. A New Vertical Diffusion Package with an Explicit Treatment of Entrainment Processes. Mon. Weather Rev. 2006, 134, 2318-2341. [CrossRef]

4. Zeng, X.; Brunke, M.A.; Zhou, M.; Fairall, C.; Bond, N.A.; Lenschow, D.H. Marine Atmospheric Boundary Layer Height over the Eastern Pacific: Data Analysis and Model Evaluation. J. Clim. 2004, 17, 4159-4170. [CrossRef]

5. Balsley, B.B.; Frehlich, R.G.; Jensen, M.L.; Meillier, Y. High-Resolution In Situ Profiling through the Stable Boundary Layer: Examination of the SBL Top in Terms of Minimum Shear, Maximum Stratification, and Turbulence Decrease. J. Atmos. Sci. 2006, 63, 1291-1307. [CrossRef]

6. Hennemuth, B.; Lammert, A. Determination of the Atmospheric Boundary Layer Height from Radiosonde and Lidar Backscatter. Bound. Layer Meteorol. 2006, 120, 181-200. [CrossRef]

7. Sicard, M.; Pérez, C.; Rocadenbosch, F.; Baldasano, J.M.; García-Vizcaino, D. Mixed-layer depth determination in the Barcelona coastal area from regular lidar measurements: methods, results and limitations. Bound. Layer Meteorol. 2006, 119, 135-157. [CrossRef]

8. Georgoulias, A.K.; Papanastasiou, D.K.; Melas, D.; Amiridis, V.; Alexandri, G.; Georgoulias, A. Statistical analysis of boundary layer heights in a suburban environment. Theor. Appl. Clim. 2009, 104, 103-111. [CrossRef] 
9. Stull, R.B. An Introduction to Boundary-layer Meteorology; Kluwer Academic Publishers: Dordrecht, The Netherlands; Boston, MA, USA; London, UK, 1988; 666p.

10. Fetzer, E.J.; Teixeira, J.; Olsen, E.T.; Fishbein, E.F. Satellite remote sounding of atmospheric boundary layer temperature inversions over the subtropical eastern Pacific. Geophys. Res. Lett. 2004, 31. [CrossRef]

11. Wood, R.; Bretherton, C.S. Boundary Layer Depth, Entrainment, and Decoupling in the Cloud-Capped Subtropical and Tropical Marine Boundary Layer. J. Clim. 2004, 17, 3576-3588. [CrossRef]

12. Medeiros, B.; Hall, A.; Stevens, B. What Controls the Mean Depth of the PBL? J. Clim. 2005, 18, 3157-3172. [CrossRef]

13. Palm, S.P.; Spinhirne, J.; Benedetti, A. Validation of ECMWF global forecast model parameters using GLAS atmospheric channel measurements. Geophys. Res. Lett. 2005, 32, 109-127. [CrossRef]

14. Sokolovskiy, S.; Röcken, C.; Hunt, D.; Schreiner, W.; Johnson, J.; Masters, D.; Esterhuizen, S. GPS profiling of the lower troposphere from space: Inversion and demodulation of the open-loop radio occultation signals. Geophys. Res. Lett. 2006, 33. [CrossRef]

15. Beyrich, F. Mixing height estimation from sodar data-A critical discussion. Atmos. Environ. 1997, 31, 3941-3953. [CrossRef]

16. Dupont, E.; Menut, L.; Carissimo, B.; Pelon, J.; Flamant, P. Comparison between the atmospheric boundary layer in Paris and its rural suburbs during the ECLAP experiment. Atmos. Environ. 1999, 33, 979-994. [CrossRef]

17. Bianco, L.; Wilczak, J.M. Convective Boundary Layer Depth: Improved Measurement by Doppler Radar Wind Profiler Using Fuzzy Logic Methods. J. Atmos. Ocean. Technol. 2002, 19, 1745-1758. [CrossRef]

18. Holzworth, C.G. Estimates of mean maximum mixing depths in the contiguous United States. Mon. Weather Rev. 1964, 92, 235-242. [CrossRef]

19. Coulter, R.L. A Comparison of Three Methods for Measuring Mixing-Layer Height. J. Appl. Meteorol. 1979, 18, 1495-1499. [CrossRef]

20. Lokoshchenko, M.A. Long-Term Sodar Observations in Moscow and a New Approach to Potential Mixing Determination by Radiosonde Data. J. Atmos. Ocean. Technol. 2002, 19, 1151-1162. [CrossRef]

21. Emeis, S.; Münkel, C.; Vogt, S.; Müller, W.J.; Schäfer, K. Atmospheric boundary-layer structure from simultaneous SODAR, RASS, and ceilometer measurements. Atmos. Environ. 2004, 38, 273-286. [CrossRef]

22. Nielsen-Gammon, J.W.; Powell, C.L.; Mahoney, M.J.; Angevine, W.M.; Senff, C.; White, A.; Berkowitz, C.; Doran, C.; Knupp, K. Multisensor Estimation of Mixing Heights over a Coastal City. J. Appl. Meteorol. Clim. 2008, 47, 27-43. [CrossRef]

23. Guo, P.; Kuo, Y.-H.; Sokolovskiy, S.V.; Lenschow, D. Estimating Atmospheric Boundary Layer Depth Using COSMIC Radio Occultation Data. J. Atmos. Sci. 2011, 68, 1703-1713. [CrossRef]

24. Seidel, D.J.; Ao, C.O.; Li, K. Estimating climatological planetary boundary layer heights from radiosonde observations: Comparison of methods and uncertainty analysis. J. Geophys. Res. Space Phys. 2010, 115. [CrossRef]

25. Moss, M.S. Low-level turbulence structure in the vicinity of a hurricane. Mon. Weather Rev. 1978, 106, 841-849. [CrossRef]

26. French, J.R.; Drennan, W.M.; Zhang, J.A.; Black, P.G. Turbulent fluxes in the hurricane boundary layer. Part I: Momentum flux. J. Atmos. Sci. 2007, 64, 1089-1102. [CrossRef]

27. Zhang, J.A.; Drennan, W.M.; Black, P.G.; French, J.R. Turbulence Structure of the Hurricane Boundary Layer between the Outer Rainbands. J. Atmos. Sci. 2009, 66, 2455-2467. [CrossRef]

28. Zhang, J.A.; Drennan, W.M. An Observational Study of Vertical Eddy Diffusivity in the Hurricane Boundary Layer. J. Atmos. Sci. 2012, 69, 3223-3236. [CrossRef]

29. Guimond, S.R.; Tian, L.; Heymsfield, G.M.; Frasier, S.J. Wind Retrieval Algorithms for the IWRAP and HIWRAP Airborne Doppler Radars with Applications to Hurricanes. J. Atmos. Ocean. Technol. 2014, 31, 1189-1215. [CrossRef]

30. Guimond, S.R.; Zhang, J.A.; Sapp, J.W.; Frasier, S.J. Coherent turbulence in the boundary layer of Hurricane Rita (2005) during an eyewall replacement cycle. J. Atmos. Sci. 2018, 75, 3071-3093. [CrossRef]

31. Zhang, J.A.; Rogers, R.F.; Nolan, D.S.; Marks, F.D. On the Characteristic Height Scales of the Hurricane Boundary Layer. Mon. Weather Rev. 2011, 139, 2523-2535. [CrossRef]

32. Smith, R.K.; Montgomery, M.T.; Nguyen, S.V. Tropical cyclone spinup revisited. Q. J. R. Meteor. Soc. 2009, 135, 1321-1335. [CrossRef] 
33. Ming, J.; Zhang, J.A.; Rogers, R.F. Typhoon kinematic and thermodynamic boundary layer structure from dropsonde composites. J. Geophys. Res. Atmos. 2015, 120, 3158-3172. [CrossRef]

34. Lee, C.-Y.; Chen, S.S. Symmetric and Asymmetric Structures of Hurricane Boundary Layer in Coupled Atmosphere-Wave-Ocean Models and Observations. J. Atmos. Sci. 2012, 69, 3576-3594. [CrossRef]

35. Wu, C.; Tu, W.; Pun, I.; Lin, I.; Peng, M.S. Tropical cyclone-ocean interaction in Typhoon Megi (2010)A synergy study based on ITOP observations and atmosphere-ocean coupled model simulations. J. Geophys. Res. Atmos. 2016, 121, 153-167. [CrossRef]

36. Powell, M.D. Boundary layer structure and dynamics in outer hurricane rainbands. Part II: Downdraft modification and mixed layer recovery. Mon. Weather Rev. 1990, 118, 918-938. [CrossRef]

37. Kepert, J.D. Observed boundary layer wind structure and balance in the hurricane core. Part I: Hurricane Georges. J. Atmos. Sci. 2006, 63, 2169-2193. [CrossRef]

38. Kepert, J.D. Observed boundary layer wind structure and balance in the hurricane core. Part II: Hurricane Mitch. J. Atmos. Sci. 2006, 63, 2194-2211. [CrossRef]

39. Bell, M.M.; Montgomery, M.T. Observed structure, evolution, and potential intensity of category 5 Hurricane Isabel (2003) from 12 to 14 September. Mon. Weather Rev. 2008, 136, 2023-2046. [CrossRef]

40. Barnes, G.M. Atypical Thermodynamic Profiles in Hurricanes. Mon. Weather Rev. 2008, 136, 631-643. [CrossRef]

41. Lokoshchenko, M.T.; Zhang, J.A.; Smith, R.K. An analysis of the observed low-level structure of rapidly intensifying and mature hurricane Earl (2010). Q. J. R. Meteorol. Soc. 2014, 140, 2132-2146.

42. Zhang, J.A.; Nolan, D.S.; Rogers, R.F.; Tallapragada, V. Evaluating the impact of improvements in the boundary layer parameterization on hurricane intensity and structure forecasts in HWRF. Mon. Weather Rev. 2015, 143, 3136-3155. [CrossRef]

43. Hock, T.F.; Franklin, J.L. The NCAR GPS dropwindsonde. Bull. Am. Meteor. Soc. 1999, 80, 407-420. [CrossRef]

44. Vigh, J.L.; Dorst, N.M.; Williams, C.L.; Uhlhorn, E.W.; Klotz, B.W.; Martinez, J.; Willoughby, H.E.; Marks, F.D., Jr.; Chavas, D.R. FLIGHT+: The Extended Flight Level Dataset for Tropical Cyclones (Version 1.0); Tropical Cyclone Data Project; National Center for Atmospheric Research, Research Applications Laboratory: Boulder, CO, USA, 2015. Available online: http://dx.doi.org/10.5065/D6WS8R93 (accessed on 21 January 2015).

45. Kepert, J.D. The Dynamics of Boundary Layer Jets within the Tropical Cyclone Core. Part I: Linear Theory. J. Atmos. Sci. 2001, 58, 2485-2501. [CrossRef]

46. Kepert, J.D.; Wang, Y. The dynamics of boundary layer jets within the tropical cyclone core. Part II: Nonlinear enhancement. J. Atmos. Sci. 2001, 58, 2485-2501. [CrossRef]

47. Shapiro, L.J. The Asymmetric Boundary layer Flow Under a Translating Hurricane. J. Atmos. Sci. 1983, 40, 1984-1998. [CrossRef]

48. Thomsen, G.L.; Smith, R.K.; Montgomery, M.T. Tropical cyclone flow asymmetries induced by a uniform flow revisited. J. Adv. Model. Earth Syst. 2015, 7, 1265-1284. [CrossRef]

49. Schwendike, J.; Kepert, J.D. The boundary layer winds in hurricanes Danielle (1998) and Isabel (2003). Mon. Weather Rev. 2008, 136, 3168-3192. [CrossRef]

50. Price, J.F. Upper Ocean Response to a Hurricane. J. Phys. Oceanogr. 1981, 11, 153-175. [CrossRef]

51. Shay, L.K.; Black, P.G.; Mariano, A.J.; Hawkins, J.D.; Elsberry, R.L. Upper ocean response to Hurricane Gilbert. J. Geophys. Res. Space Phys. 1992, 97, 20227. [CrossRef]

52. Lee, C.-Y.; Chen, S.S. Stable Boundary Layer and Its Impact on Tropical Cyclone Structure in a Coupled Atmosphere-Ocean Model. Mon. Weather Rev. 2014, 142, 1927-1944. [CrossRef]

53. Cione, J.J.; Kalina, E.A.; Zhang, J.A.; Uhlhorn, E.W. Observations of Air-Sea Interaction and Intensity Change in Hurricanes. Mon. Weather Rev. 2013, 141, 2368-2382. [CrossRef]

54. Zhang, J.A.; Rogers, R.F.; Reasor, P.D.; Uhlhorn, E.W.; Marks, F.D. Asymmetric Hurricane Boundary Layer Structure from Dropsonde Composites in Relation to the Environmental Vertical Wind Shear. Mon. Weather Rev. 2013, 141, 3968-3984. [CrossRef]

55. Ooyama, K.V. Numerical simulation of the life cycle of tropical cyclones. J. Atmos. Sci. 1969, 26, 3-40. [CrossRef]

56. Emanuel, K.A. An Air-Sea Interaction Theory for Tropical Cyclones. Part I: Steady-State Maintenance. J. Atmos. Sci. 1986, 43, 585-605. [CrossRef] 
57. Emanuel, K.A. Sensitivity of Tropical Cyclones to Surface Exchange Coefficients and a Revised Steady-State Model incorporating Eye Dynamics. J. Atmos. Sci. 1995, 52, 3969-3976. [CrossRef]

58. Bryan, G.H.; Rotunno, R. The maximum intensity of tropical cyclones in axisymmetry numerical model simulations. Mon. Weather Rev. 2009, 137, 1770-1789. [CrossRef]

59. Foster, R.C. Boundary-Layer Similarity Under an Axisymmetric, Gradient Wind Vortex. Bound. Layer Meteorol. 2009, 131, 321-344. [CrossRef]

60. Montgomery, M.T.; Smith, R.K. Recent Developments in the Fluid Dynamics of Tropical Cyclones. Annu. Rev. Fluid Mech. 2017, 49, 541-574. [CrossRef]

61. Eliassen, A. On the Ekman Layer in a circular Vortex. J. Meteorol. Soc. Jpn. 1971, 49, 784-789. [CrossRef]

62. Carrier, G.F. Swirling flow boundary layers. J. Fluid Mech. 1971, 49, 133-144. [CrossRef]

63. Montgomery, M.T.; Snell, H.D.; Yang, Z. Axisymmetric Spindown Dynamics of Hurricane-like Vortices. J. Atmos. Sci. 2001, 58, 421-435. [CrossRef]

64. Nolan, D.S. Instabilities in hurricane-like boundary layers. Dyn. Atmos. Oceans 2005, 40, 209-236. [CrossRef]

65. Kepert, J.D. Slab- and height-resolving models of the tropical cyclone boundary layer. Part I: Comparing the simulations. Q. J. R. Meteorol. Soc. 2010, 136, 1686-1699. [CrossRef]

66. Kepert, J.D.; Schwendike, J.; Ramsay, H. Why is the tropical cyclone boundary layer not "well mixed"? J. Atmos. Sci. 2016, 73, 957-973. [CrossRef]

67. Uhlhorn, E.W.; Klotz, B.W.; Vukićević, T.; Reasor, P.D.; Rogers, R.F. Observed Hurricane Wind Speed Asymmetries and Relationships to Motion and Environmental Shear. Mon. Weather Rev. 2014, 142, 1290-1311. [CrossRef]

68. Klotz, B.W.; Jiang, H. Global composites of surface wind speeds in tropical cyclones based on a 12-year scatterometer database. Geophys. Res. Lett. 2016, 43, 10480-10488. [CrossRef]

69. Zhang, J.A.; Uhlhorn, E.W. Hurricane Sea Surface Inflow Angle and an Observation-Based Parametric Model. Mon. Weather Rev. 2012, 140, 3587-3605. [CrossRef]

70. Reasor, P.D.; Rogers, R.; Lorsolo, S. Environmental Flow Impacts on Tropical Cyclone Structure Diagnosed from Airborne Doppler Radar Composites. Mon. Weather Rev. 2013, 141, 2949-2969. [CrossRef]

71. Jorgensen, D.P.; Zipser, E.J.; LeMone, M.A. Vertical Motions in Intense Hurricanes. J. Atmos. Sci. 1985, 42, 839-856. [CrossRef]

72. Marks, F.D., Jr.; Houze, R.A., Jr.; Gamache, J.F. Dual-aircraft investigation of the inner core of Hurricane Norbert. Part I: Kinematic structure. J. Atmos. Sci. 1992, 49, 919-942. [CrossRef]

73. Marks, F.D. Evolution of the Structure of Precipitation in Hurricane Allen (1980). Mon. Weather Rev. 1985, 113, 909-930. [CrossRef]

74. Reasor, P.D.; Montgomery, M.T.; Marks, F.D.; Gamache, J.F. Low-Wavenumber Structure and Evolution of the Hurricane Inner Core Observed by Airborne Dual-Doppler Radar. Mon. Weather Rev. 2000, 128, 1653-1680. [CrossRef]

75. Franklin, J.L.; Lord, S.J.; Feuer, S.E.; Marks, F.D. The Kinematic Structure of Hurricane Gloria (1985) Determined from Nested Analyses of Dropwindsonde and Doppler Radar Data. Mon. Weather Rev. 1993, 121, 2433-2451. [CrossRef]

(C) 2019 by the authors. Licensee MDPI, Basel, Switzerland. This article is an open access article distributed under the terms and conditions of the Creative Commons Attribution (CC BY) license (http://creativecommons.org/licenses/by/4.0/). 
Article

\title{
Diurnal Variations of Different Cloud Types and the Relationship between the Diurnal Variations of Clouds and Precipitation in Central and East China
}

\author{
Cuicui Gao ${ }^{1,2}$, Yunying $\mathrm{Li}^{1, *}$ and Haowei Chen ${ }^{2}$ \\ 1 College of Meteorology and Oceanography, National University of Defense Technology, Nanjing 211101, \\ China; gaocc2016@foxmail.com \\ 2 Shaoguan Meteorological Office, Shaoguan, Guangdong 512000, China; chen_haowei@foxmail.com \\ * Correspondence: ghlyy@mail.iap.ac.cn
}

Received: 19 April 2019; Accepted: 25 May 2019; Published: 3 June 2019

\begin{abstract}
In this paper, the diurnal variations of various clouds are analyzed using hourly cloud observations at weather stations in China from 1985 to 2011. In combination with merged hourly precipitation data, the relationship between the diurnal variations of clouds and precipitation in the summers from 2008 to 2011 are studied. The results show that the occurrence frequencies of total cloud and various cloud types exhibit significant diurnal variations. The diurnal variations of the occurrence frequencies of altocumulus and stratocumulus show a bimodal pattern, with peaks appearing in the early morning and late afternoon. The early morning peaks of altocumulus and stratocumulus appear earlier in the summer than in the other seasons, while the late afternoon maxima show an opposite trend. The occurrence frequency of nimbostratus peaks in the morning between 07 and 12 LST (local solar time), and the peak value lags 2 to $3 \mathrm{~h}$ from west to east along the Yangtze River valley; meanwhile, the diurnal variation shows no clear differences caused by changes in the latitude or seasons. Cumulus shows an afternoon (14 LST) maximum, while cumulonimbus peaks in the late afternoon during 16-20 LST, and both of them present a great diurnal range. Cirrus usually reaches its peak at 17-18 LST, and it differs by 1 to $2 \mathrm{~h}$ with a change in the latitude. The results of the study first show that the diurnal variations of precipitation among different regions are dominated by different clouds. The upper reaches of the Yangtze River valley present a midnight precipitation maximum that is mainly dominated by cumulonimbus. For the middle reaches of the Yangtze River valley impacted by nimbostratus, the precipitation peaks in the early morning. In South and Northeast China, the precipitation peaks in the afternoon and is determined by the diurnal variations of convective clouds. In the region between the Yangtze River valley and Yellow River valley, the precipitation peaks in the early morning and afternoon; the early morning peak is mainly determined by stratiform clouds, while the afternoon peak is closely related to convective clouds.
\end{abstract}

Keywords: clouds; precipitation; diurnal variation

\section{Introduction}

Diurnal variations are the most basic period of change in the Earth's climate system, the most important driving force of which is solar radiation. Various meteorological parameters, such as the temperature, wind, pressure and precipitation, all show significant diurnal variations. Rutledge noted that stratiform and convective precipitation are produced by different cloud microphysical processes [1]. The formation mechanism of precipitation is complex, but it ultimately originates from clouds. Clouds are the external manifestation of dynamic and thermodynamic processes in the atmosphere, and there are many differences in the nature of precipitation sourced from different types of clouds. The diurnal variation of clouds reflects the changes in the internal movements throughout the atmosphere. 
However, the diurnal cycle of clouds also plays a feedback role in the movements of the atmosphere in addition to the radiation process and the water cycle [2]. Furthermore, the diurnal variation of clouds also reflects the atmospheric stability and changes in the weather. Therefore, studying the diurnal variation of clouds is of significance for understanding the diurnal cycle of the internal movements throughout the atmosphere. In addition, understanding the relationship between the diurnal variations of clouds and precipitation is beneficial to provide a physical basis and observe relevant facts for cloud parameterization schemes in weather and climate models, which is helpful for improving the ability to simulate weather and climate models.

Precipitation exhibits significant diurnal variation characteristics. Consequently, many scholars have carried out a great deal of research [3-9]. Yu et al. noted that the summer precipitation over contiguous China has large diurnal variations with considerable regional features [10]. Over southern inland China and northeastern China, the summer precipitation peaks in the late afternoon, while the precipitation in some regions peaks between midnight and the early hours of the morning. Zhou et al. verified the above results by comparing satellite to rain gauge observations, showing that the diurnal phase of rainfall frequency and intensity were similar to those of the rainfall amount in southern China [11]. A study by Li et al. showed the clear differences in the diurnal cycle of precipitation between southwestern China and southeastern China [12]. The diurnal cycle of the annual mean precipitation in southwestern China tends to reach a maximum either at midnight or during the early morning, while the precipitation in eastern China peaks in the late afternoon. Yuan et al. analyzed the sub-seasonal characteristics of the diurnal variation of summer monsoon rainfall over eastern central China and found that the early-morning diurnal peaks experience sub-seasonal movements similar to those of the monsoon rain belt [13]. The aforementioned scholars have obtained many meaningful conclusions about the diurnal variation of precipitation. Moreover, since precipitation originates from clouds, the diurnal variation of precipitation is closely related to the diurnal variations of different types of clouds, and therefore, studying the relationships between the diurnal variations of clouds and precipitation could be helpful for further understanding the mechanism of precipitation.

William et al. presents observational evidence in support of the existence of a large diurnal cycle of oceanic, tropical, deep cumulus convections [14]. Zheng et al. used satellite infrared temperature of black body (TBB) data to explore the climatological characteristics of deep convection over southern China and the adjacent seas during the June-August periods of 1966-2007 [15]. They found that sea-land and mountain-valley breezes accounted for the propagation of deep convection from sea to land in the afternoon and from land to sea after midnight. Based on hourly infrared brightness temperature data acquired by the FY-2C satellite to classify clouds into cold clouds, middle clouds and warm clouds according to the cloud top temperature, Chen et al. analyzed the diurnal variations of three types of clouds in southern China during the summer periods from 2005 to 2008 and the seasonal changes in the diurnal variations of those clouds [16]. Fujinami et al. studied the diurnal variations of high clouds and precipitation over the Tibetan Plateau, where observation stations are sparse, using satellite observations. He noted that the cloud cover frequency for high clouds increased in the afternoon along the ridges and reached a maximum near 18 LST, after which high cloud cover frequencies moved over the valley and persisted until early morning [17]. In addition, a similar evolution occurred in the frequency of rainfall. Zhao et al. based on MODIS observations, showed the statistical characteristics of cloud properties, along with the difference between morning and afternoon [18]. These conclusions have promoted the understanding of the diurnal variations of clouds; however, the corresponding research is relatively fragmented, and the relationship between the diurnal variations of clouds and precipitation has not yet been established. Therefore, this paper aims to analyze the climatic characteristics of the diurnal changes of clouds over China in addition to the relationship between the diurnal variations of clouds and precipitation to deepen the existing understanding of the correlation between clouds and precipitation and to provide the basis for a simulation of the diurnal variations of clouds and precipitation in weather and climate models. 


\section{Data and Analysis Method}

\subsection{Data}

In this study, hourly cloud data during 1985-2011 are acquired from 114 surface observation stations after a quality-control procedure is performed. Since the distribution of stations to the west of $105^{\circ} \mathrm{E}$ is sparse, this study mainly analyzes the diurnal variations of clouds over eastern and central China. The dataset includes the information of total cloud (TC), and 10 cloud genera (cirrus (Ci), cirrocumulus (Cc), cirrostratus (Cs), altocumulus (Ac), altostratus (As), nimbostratus (Ns), stratocumulus $(\mathrm{Sc})$, stratus $(\mathrm{St})$, cumulus $(\mathrm{Cu})$, and cumulonimbus $(\mathrm{Cb}))$. Due to the light intensity and visual reasons, artificial observations on the ground will produce some random observation errors, however, many years of climatological normal results can significantly reduce the instabilities of artificial observations. In addition, the reliability of the dataset has been tested and verified [19]. From the perspective of surface observations, the diurnal variation of low clouds is relatively accurate. High clouds and middle clouds are sometimes blocked by low clouds, and the article therefore analyzes the diurnal variation of a certain type of high (middle) cloud when it appears.

Hourly merged precipitation data during 2008-2011 were obtained from the National Meteorological Information Center of the China Meteorological Administration with a spatial resolution of $0.1^{\circ} \times 0.1^{\circ}$. These hourly precipitation data were merged with more than 30,000 automatic weather stations over China in addition to global Climate Prediction Center morphing technique (CMORPH) precipitation estimates with a temporal interval of $30 \mathrm{~min}$ and a resolution of $8 \mathrm{~km}$ provided by the American Climate Prediction Center. The merged precipitation product effectively combines the advantages of surface precipitation observations with satellite retrieved precipitation products. The overall error of the product is less than $10 \%$, which is better than the same type of product worldwide [20]. The quality of the merged precipitation products in the sparse station areas still needs improvement. However, the stations in eastern and central China studied in this paper are densely and effectively distributed, and the precipitation values are accurate since station data were utilized as the main data source in the fusion process. Since 56.5 percent of the precipitation falls during the summertime throughout most of China [21], this paper mainly analyzes the relationship between the diurnal variations of clouds and precipitation during the summer.

The diurnal variation of clouds is the average of the data from the stations from 1985 to 2011. Since the precipitation data range from 2008 to 2011, to match the precipitation data, the cloud data are truncated from 2008 to 2011, when the relationship between the diurnal variations of clouds and precipitation is analyzed.

\subsection{Analysis Method}

The diurnal variations of the meteorological parameters are the changes in the meteorological parameters with the local solar time (LST) $[5,22]$. Therefore, statistical work on the diurnal variations of clouds and precipitation should be conducted according to the local solar time. The time system for the hourly cloud data used in this paper corresponds to China Standard Time (CST), and the method used to convert CST into LST is as follows:

$$
\begin{gathered}
T 1=\left[\frac{\text { lon }+7.5}{15}\right]-8+\mathrm{T} \\
\mathrm{LST}=\left\{\begin{array}{lc}
T 1 & 0<T 1 \leq 24 \\
24+T 1 & T 1 \leq 0 \\
T 1-24 & T 1>24
\end{array}\right.
\end{gathered}
$$

where lon represents the longitude of the station, and the unit of lon is degree, T denotes CST, LST is the local solar time, and [] indicates an operation to change the number into an integer. 
The time system for the precipitation data used in this paper corresponds to Greenwich Mean Time (GMT), and the method used to convert GMT into LST is similar to CST, and it just don't need to subtract the time zone in the first step. The time used hereafter in this study is LST.

The occurrence frequency of a cloud is defined as $\mathrm{F}=\left(\mathrm{rec}_{\mathrm{cld}} / \mathrm{rec}\right) \times 100 \%$, where $\mathrm{F}$ represents the occurrence frequency of a cloud at a certain time, rec $_{\mathrm{cld}}$ represents the number of cloud occurrences at a certain time within the analysis period, rec is the number of observations at a certain time, and the definition of the occurrence frequency is suitable for all types of cloud, including TC. The maximum occurrence frequency of a cloud from 01 to 24 LST in a day is the daily peak. The amplitude of the diurnal variation of clouds reflects the magnitude of the maximum and minimum occurrence frequency of cloud in $24 \mathrm{~h}$ and is defined as $\mathrm{A}=\mathrm{cld}_{\max } / \mathrm{cld}_{\mathrm{avg}}$, where $\mathrm{A}$ is the amplitude, cld $\max$ is the daily peak of the cloud occurrence frequency, and $\operatorname{cld}_{\mathrm{avg}}$ is the daily occurrence frequency of the cloud. When analyzing the diurnal variation of clouds in different seasons, to eliminate the differences in the occurrence frequencies of cloud among the different seasons, this paper calculates the anomalies in the occurrence frequencies of clouds in each month from 01 to 24 LST.

\section{Climatic Characteristic of Diurnal Variation of Clouds}

\subsection{Diurnal Variation of Different Types of Clouds}

To obtain an overall understanding of the diurnal variations of the total clouds (TC) and of the various types of clouds over central and eastern China, this paper first analyzes the diurnal variations of the average occurrence frequencies of the TC and various clouds at 114 stations over central and eastern China. The diurnal variation of the frequency of TC shows a bimodal pattern; the main peak appears in the late afternoon, and the second peak appears in the early morning (Figure 1a). During the day, the occurrence frequency of the TC is significantly greater than that of nocturnal clouds. After 04 LST, the occurrence frequency of the TC increases rapidly and reaches a peak at 07 LST. The frequency of the TC changes slightly during 07-09 LST, and it begins to increase again after 09 LST and reaches the main peak at 14-15 LST. Ac also shows a diurnal variation with a bimodal pattern with peaks at 07 LST and 18 LST, and the morning peak is larger. As occurs at a frequency of less than $3.5 \%$ but at a relatively high frequency in the afternoon.
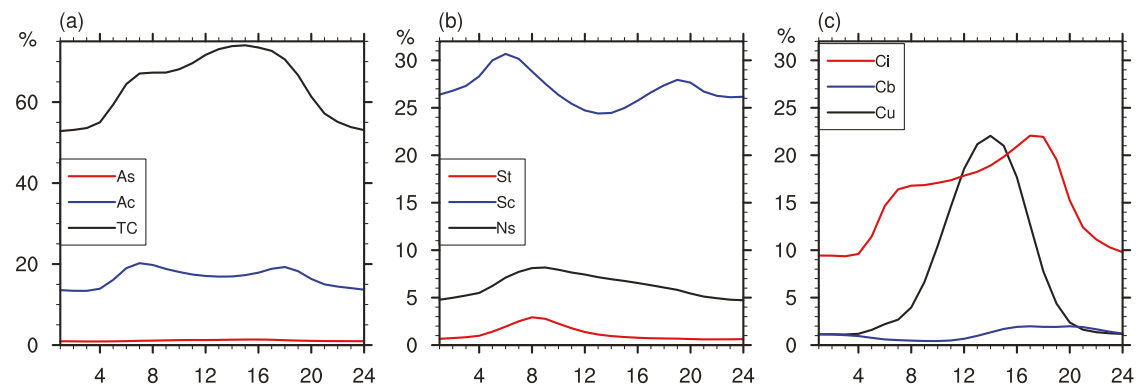

Figure 1. The diurnal variation of the occurrence frequencies (\%) of various cloud types in central and east China during 1981-2011: (a) TC, Ac, As, (b) Ns, Sc, St, (c) Cu, Cb, Ci(the horizontal axis represents the local solar time, and the vertical axis represents the occurrence frequency of clouds).

The diurnal cycle of the occurrence frequency of Ns is unimodal, and it occurs at approximately 08 LST. Ns is a component of frontal clouds, which are mainly formed as deep, moist air rises along the front surface; the relative humidity of the air is larger in the morning and is saturated more easily and condensed, and thus, Ns appears more frequently in the early morning. The diurnal variation of St is consistent with that of Ns, and its diurnal peak appears at 08 LST. St, whose formation mechanism is the same as that of fog, is generally formed by fog rising. Fog usually appears during the night until 
$08 \mathrm{LST}$, and it especially occurs throughout most of the morning; St also shows such a pattern in the morning. The diurnal variation of the occurrence frequency of Sc presents a bimodal pattern with a main diurnal peak at 06 LST and a second peak at 17 LST. As a typical boundary layer cloud, the diurnal variation of $\mathrm{Sc}$ reflects the diurnal variation of the boundary layer. The low temperature in the boundary layer and the stable atmospheric stratification in the morning are beneficial for water vapor below the top of the boundary layer to accumulate and form Sc. When the atmosphere stability deteriorates, the conditions are no longer favorable to the formation of stratiform clouds and the occurrence of Sc. As the solar radiation weakens in the evening and the atmosphere stratification tends to become stable, the frequency of Sc starts to increase again and reaches the second peak at approximately 19 LST.

The diurnal variation of $\mathrm{Cu}$ is also unimodal (Figure 1c). During the daytime, as the solar radiation gradually enhances, the atmosphere temperature around and above the ground surface gradually rises while the instability of the atmospheric stratification increases, and thus, the occurrence frequency of $\mathrm{Cu}$ begins to increase beginning in the early morning and reaches a peak at $14 \mathrm{LST}$, after which it decreases. The diurnal variation of the occurrence frequency of $\mathrm{Cb}$ shows a unimodal pattern as well. The occurrence frequency of $\mathrm{Cb}$ is high at 16-20 LST, and its main diurnal peak appears at 16-17 LST, which is $4-6 \mathrm{~h}$ behind the time when $\mathrm{Cu}$ reaches its diurnal peak, indicating that it takes some time for shallow convection clouds to develop into deep clouds. The frequency of Ci increases from 04 to 05 LST continuously, and it reaches a maximum at 17 LST, after which it rapidly decreases after 18 LST. Sometimes, $\mathrm{Ci}$ acts as an anvil to the development of $\mathrm{Cb}$ to a mature stage, and thus, there is a lag in the time required for $\mathrm{Cu}, \mathrm{Cb}$ to $\mathrm{Ci}$ to reach their diurnal peaks.

Figure 2 shows the times of the diurnal peaks of different clouds and the spatial distribution of the amplitudes of their diurnal variations over central and eastern China. The figure shows the time when the occurrence frequency peaks at each station in the form of a clock, and the number indicates the amplitude of the diurnal variation of the cloud occurrence frequency. Figure 2a shows that the diurnal peak of the TC appears from the afternoon to the late afternoon, but it appears in the early morning at some stations. For example, at most of the stations to the north of $32^{\circ} \mathrm{N}$ in China, the diurnal peak appears at 15-18 LST; meanwhile, over the Liaodong Peninsula and Shandong Peninsula, the diurnal peak appears a little earlier at 13-14 LST. However, to the south of $32^{\circ} \mathrm{N}$, the diurnal peak appears in two periods at 14-18 LST and 06-07 LST. For instance, the diurnal peak of the TC in the southeastern coastal areas of China mainly occurs in the early morning at 06-07 LST. The amplitude of the occurrence frequency of the TC is large in northern China (approximately 1.2-1.3), while that at most stations in southern China is approximately 1.1, indicating that the diurnal variations of the occurrence frequencies of clouds in northern China are greater than those in southern China.

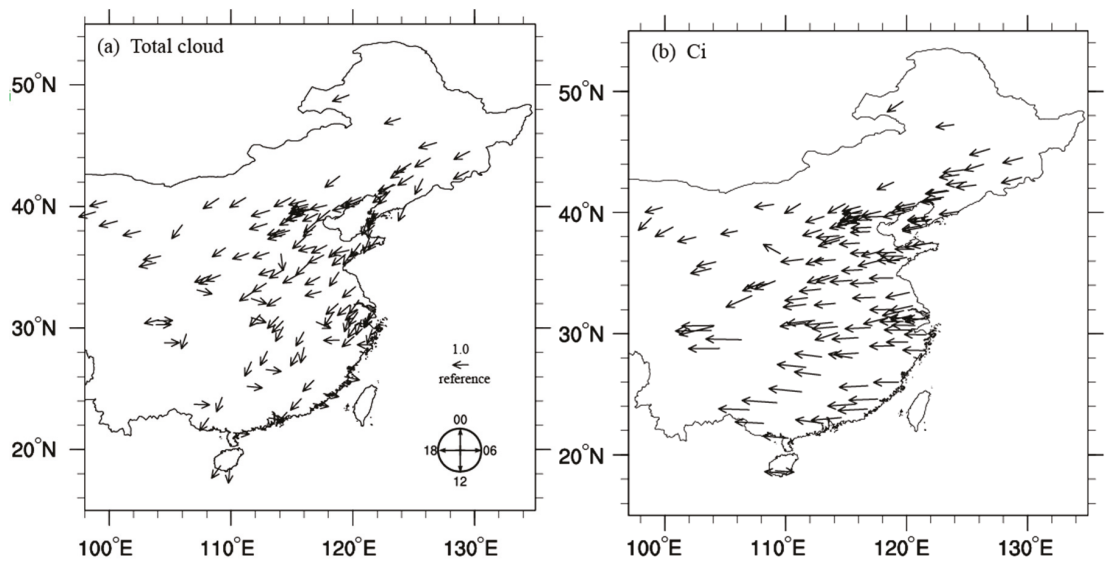

Figure 2. Cont. 

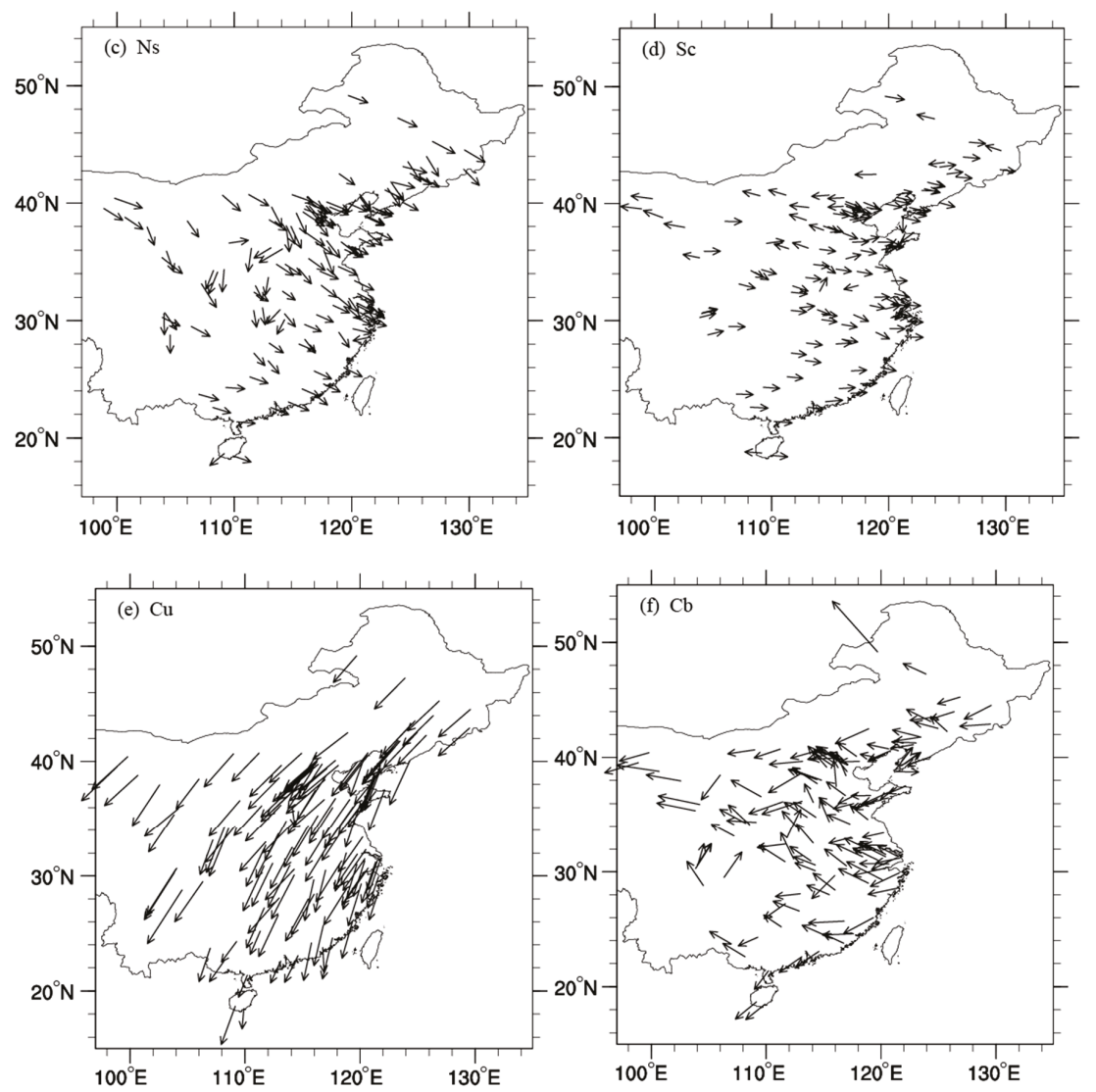

Figure 2. Spatial distributions of the phases and amplitudes of the diurnal cycles of various clouds: (a) TC, (b) Ci, (c) Ns, (d) Sc, (e) Cu, and (f) Cb. The directions of the vectors denote the local solar time (LST) of the maximum cloud occurrence frequency (phase clock in (b)), while the length of the vectors represent the amplitude of the diurnal cycle, the reference arrow represents the amplitude of diurnal cycle is 1.0 .

According to this study, the diurnal peak of Ci appears at 17-18 LST consistently at each station (Figure 2b), and the diurnal variation amplitude is larger in South China and in the Sichuan Basin.

The diurnal peak of Ns occurs in the morning (08-09 LST) (Figure 2c), but those of some stations in Shanxi Province, western Henan Province, and Hubei Province and in the Sichuan basin occur around noon (11-14 LST). The Meiyu front near the Yangtze River valley is also a frequent area of Ns formation, yet the diurnal variation amplitude of Ns in this area is small. Sc is the cloud with the highest occurrence frequency over China. Its diurnal peak over most stations occurs at 06-07 LST (Figure 2d), but those in western Inner Mongolia and North China usually occur at 18-19 LST.

The diurnal peak of $\mathrm{Cu}$ over all stations appears in the afternoon (12-14 LST) (Figure 2e). The diurnal variation of $\mathrm{Cu}$ in most areas throughout China is large, and its amplitudes are basically above 2.9, while the diurnal variation of $\mathrm{Cu}$ in South China is relatively small with amplitudes between 1.9 and 3.1. The frequency of $\mathrm{Cb}$ usually reaches a peak value at 16-20 LST (Figure 2f); however, at very few stations, the peak occurs at 02-04 LST. In addition, the diurnal variation of $\mathrm{Cb}$ is large with the second-largest amplitude (approximately 1.5 to 2.7 ) following that of $\mathrm{Cu}$. 
The analysis above shows that there are regional differences among the diurnal peaks of Ac and Sc that are mainly due to the frequent occurrences of both cloud types in the early morning and evening with different peak times at different stations. As Ac and Sc occur more frequently, they have a great impact on the diurnal variation of the TC occurrence frequency, and thus, the TC shows a similar diurnal changing pattern with these two types of clouds. The diurnal peak of Ns mainly appears in the morning (07-12 LST), and the time difference in the diurnal peaks between different stations does not exceed $5 \mathrm{~h}$. The diurnal peak of Ci usually appears in the evening (17-18 LST) while that of Cu appears in the afternoon but shows no clear regional difference. Finally, the diurnal peak of $\mathrm{Cb}$ mainly appears at 16-20 LST with slight differences among different regions. The diurnal variations of $\mathrm{Cu}$ and $\mathrm{Cb}$ are both relatively enormous.

\subsection{Diurnal Variation Cycles of Clouds with the Latitude and Longitude}

Figure 3 shows the diurnal variations of the TC and of various cloud types with the latitude; the zonal average of $110-120^{\circ}$ E represents the occurrence frequency of cloud types at each latitude. Figure $3 \mathrm{a}$ illustrates that the diurnal peak of the TC to the south of $20^{\circ} \mathrm{N}$ appears in the afternoon (12-15 LST), which is closely related to the diurnal variation of convective clouds. Meanwhile, the diurnal peak of the TC at $20-26^{\circ} \mathrm{N}$ (i.e., southern China) appears in two periods during the early morning (06-08 LST) and afternoon (11-16 LST). This is probably due to the diurnal peaks of Ac and $\mathrm{Sc}_{\mathrm{c}}$ in these areas that occur in the early morning and evening and have a great impact on the diurnal variation of the TC occurrence frequency. The diurnal peak of the TC at $26-36^{\circ} \mathrm{N}$ appears mainly in the afternoon. The occurrence frequency of the TC to the north of $36^{\circ} \mathrm{N}$ increases with the latitude with a maximum at 16 LST.

(a) Total cloud
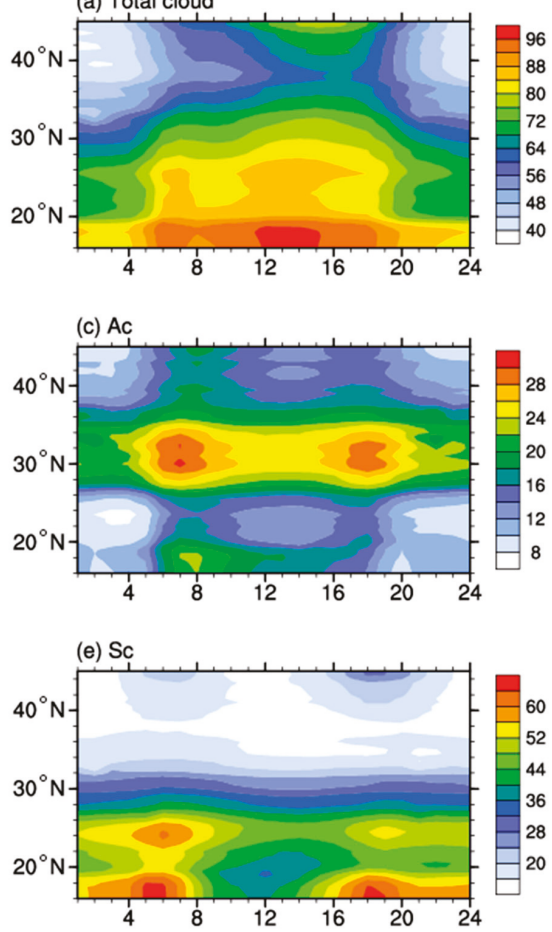

(b) $\mathrm{Ci}$
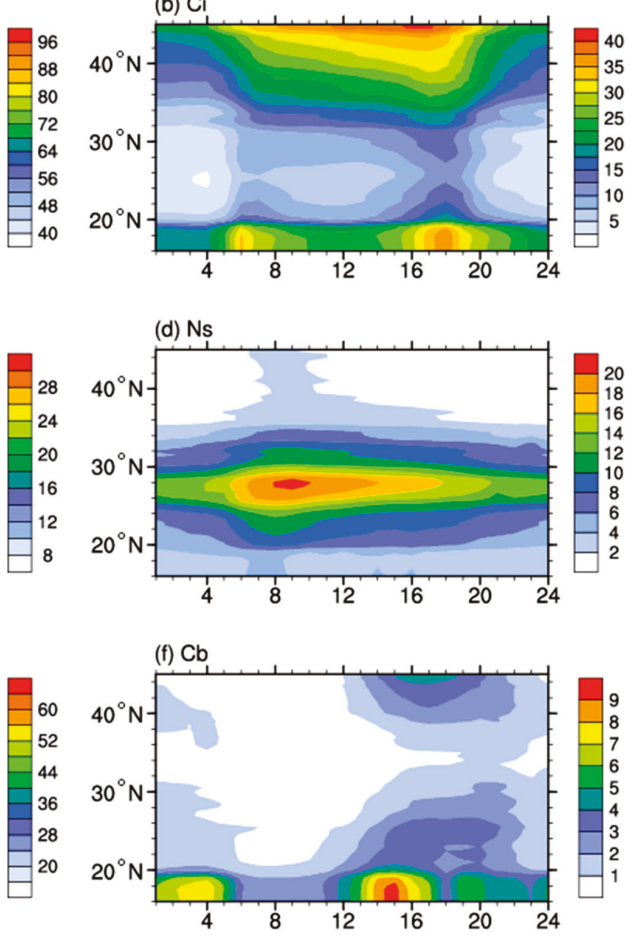

Figure 3. Diurnal variation cycles of occurrence frequency (\%) of clouds with the latitude averaged over $110-120^{\circ} \mathrm{E}$ : (a) TC, (b) Ci, (c) Ac, (d) Ns, (e) Sc, and (f) $\mathrm{Cb}$ (the horizontal axis is the local solar time in hours, and the vertical axis represents the latitude). 
The occurrence frequency of $\mathrm{Ci}$ at $20-32^{\circ} \mathrm{N}$ over China is small, but the occurrence frequencies over Hainan Province and to the north of $32^{\circ} \mathrm{N}$ are large, and the frequency of the latter area increases with the latitude (Figure 3b). Moreover, there is a slight difference in the diurnal peak of Ci between the two areas. The occurrence frequency of Ci over Hainan Province is large (approximately 35\%), and the peak appears at 06 LST and 18 LST. The diurnal peak of Ci to the north of $32^{\circ} \mathrm{N}$ occurs at $16-17$ LST, and the occurrence frequency of $\mathrm{Ci}$ near $45^{\circ} \mathrm{N}$ reaches $40 \%$ at $16 \mathrm{LST}$. The occurrence frequency of Ac increases with the latitude from south to north (Figure $3 \mathrm{c}$ ); it reaches a maximum at $28-36^{\circ} \mathrm{N}$ and then decreases. At $28-36^{\circ} \mathrm{N}$, the diurnal peak of Ac appears at 07 LST and 18 LST, while in other areas the diurnal peak of Ac appears at approximately 08 LST, indicating that its maximum daily peak appears at a difference of 1 to $2 \mathrm{~h}$ with a change in the latitude.

Figure $3 \mathrm{~d}$ shows a high occurrence frequency of Ns within $26-29^{\circ} \mathrm{N}$. After $04 \mathrm{LST}$, the high value of the frequency of Ns begins to expand to the south and to the north. In addition, a frequency of $10 \%$ expands to the south to $22^{\circ} \mathrm{N}$ at 08 LST and to the north to $32^{\circ} \mathrm{N}$ at 09 LST. After 09 LST, the frequency of Ns begins to shrink, as the maximum frequency of Ns occurs at 09 LST. The diurnal peak of Ns does not change significantly with the latitude. The diurnal peak of Sc occurs in two periods during the early morning (approximately 06 LST) and the late afternoon (18-19 LST) (Figure 3e). The diurnal peak of Sc over Hainan Province appears at 05 LST and 18 LST while that at 20-28 $\mathrm{N}$ over China occurs at 06 LST and 19 LST. Moreover, the diurnal peak of Sc at $18-25^{\circ} \mathrm{N}$ lags behind by approximately $1 \mathrm{~h}$. The diurnal peak of $\mathrm{Cb}$ over Hainan Province is reached at 09 LST while that of $\mathrm{Cb}$ to the north of $20^{\circ}$ $\mathrm{N}$ mainly occurs in the period of 16-20 LST, and its appearance time lags behind with the latitude (Figure 3f). There is no difference in the diurnal peak of $\mathrm{Cu}$ with the latitude, as it consistently occurs at 13-14 LST (figure omitted).

The diurnal variation cycles of clouds with the longitude are not as clear as that with the latitude. Ns shows clear zonal difference over the Yangtze River valley and its south side, where the occurrence frequency of Ns is the largest. In the upper reaches of the Yangtze River, the diurnal peak of Ns occurs at 06-09 LST, while the diurnal peaks over the middle and lower reaches of the Yangtze River appear at 07-13 LST (Figure 4a). The occurrence frequency of $\mathrm{Cu}$ is the largest in south China. And the diurnal variation of the occurrence frequency of $\mathrm{Cu}$ does not change with the longitude (Figure $4 \mathrm{~b}$ ) in south China. The peak occurrence frequency appears in the afternoon (13-14 LST); however, at $22-26^{\circ} \mathrm{N}$, the frequency of $\mathrm{Cu}$ decreases clearly from west to east. The diurnal variations of the TC and the other types of clouds show no significant change with the longitude.

(a) Ns

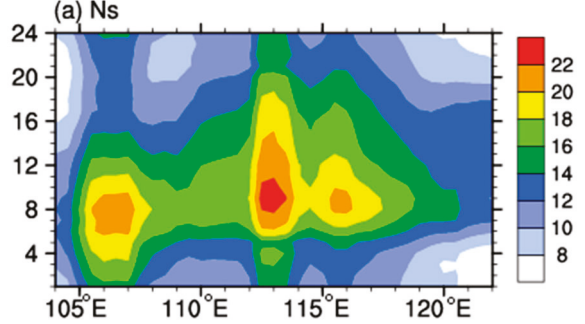

(b) $\mathrm{Cu}$

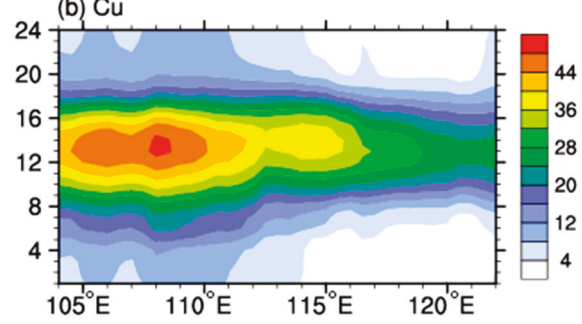

Figure 4. Diurnal variation cycles of clouds with the longitude: (a) Ns (averaged over $26-30^{\circ} \mathrm{N}$ ) and (b) $\mathrm{Cu}$ (averaged over $22-26^{\circ} \mathrm{N}$ ) (the horizontal axis represents the longitude, and the vertical axis is the local solar time in hours).

\subsection{Diurnal Variation Cycles of Clouds with the Season}

The diurnal peak of the TC over China during the spring occurs at approximately 16 LST (Figure 5a). In addition, there is a clear diurnal variation of the TC in the summer and autumn (i.e., from June to November). The maximum occurrence frequency occurs at 14 LST while the minimum occurs at 23 LST, and the difference between them reaches $28 \%$. In addition, the amplitude of the diurnal 
variation of the TC in the winter is small; at 13-15 LST, however, the occurrence frequency is relatively large. In contrast, the occurrence frequency of the TC during the summer reaches a peak time $1-2 \mathrm{~h}$ earlier than that during the spring, which may occur because the mean temperature increases more rapidly in the summer than in the spring, and thus, the conditions that are unstable for cloud formation are reached earlier.

(a) Total cloud

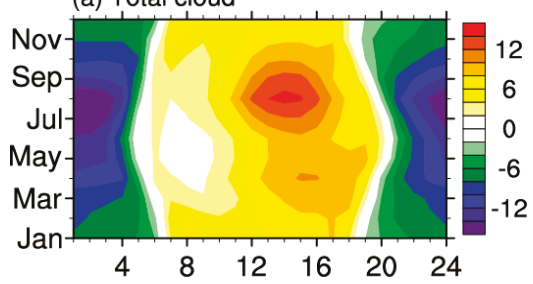

(c) Ac

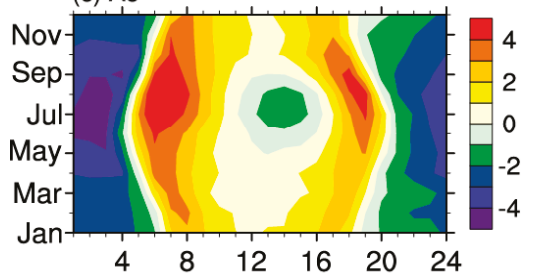

(e) Sc

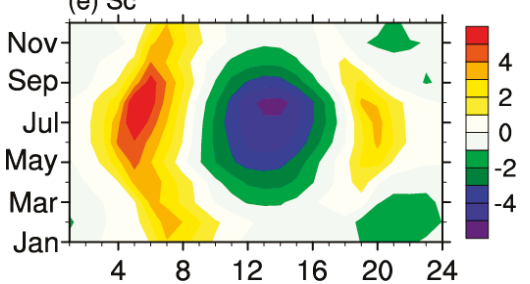

(b) $\mathrm{Ci}$

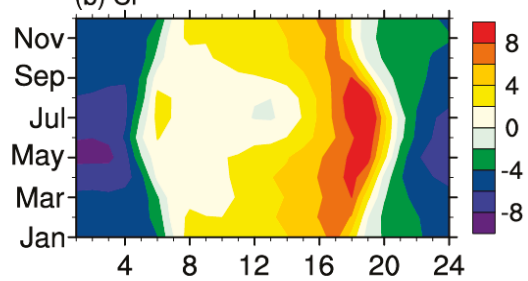

(d) Ns
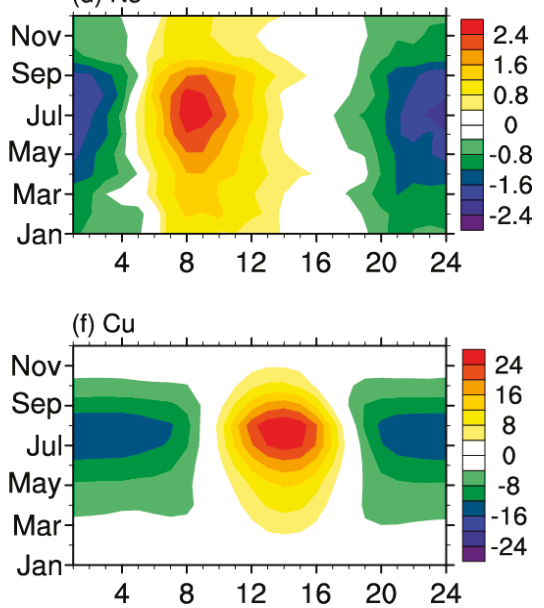

Figure 5. Seasonal variations in the diurnal cycle of anomalous values of the occurrence frequencies of clouds: (a) TC, (b) Ci, (c) Ac, (d) Ns, (e) Sc, (f) Cu (the horizontal axis is the local solar time in hours, and the vertical axis represents the month).

The diurnal peak of $\mathrm{Ci}$ also changes with the season (Figure $5 \mathrm{~b}$ ). Ci reaches its maximum at 16-17 LST in December and at 18-19 LST in July, thereby lagging 1-2 $\mathrm{h}$ between the winter and summer. The changes in the peak times of Ac are the most clear from June to September (Figure 5c). The peak times of the two peaks appear from early winter to summer, while the early morning peak appears earlier and the evening peak appears later in the summertime. The diurnal peak times of $\mathrm{Ns}$ and $\mathrm{Cu}$ do not change with the seasons (Figure $5 \mathrm{~d}, \mathrm{f}$ ), but both of the amplitudes of their diurnal variations are relatively large in the summer. The diurnal variation of $\mathrm{Sc}$ with the seasons is somewhat similar to that of Ac (Figure 5e), but the minimum occurrence frequency always appears at 14 LST and does not change with the seasons. The occurrence frequency of $\mathrm{Cb}$ in the winter is very small, and its seasonal variation is also not clear and therefore is not discussed here. 


\section{The Relationship between the Diurnal Variations of Clouds and Precipitation}

\subsection{Diurnal Variation of Precipitation}

The study of Yu et al. showed that the regional differences in the diurnal variation of summer precipitation is significant across the Chinese mainland [10]. Therefore, in order to analyze the relationship between the diurnal variations of clouds and precipitation, the following analysis is based on the regional division of central and eastern China into five sub-regions (Table 1) by Yu et al. , who studied the diurnal variation of precipitation.

Table 1. The information of five regions in eastern China.

\begin{tabular}{cccccc}
\hline & Region 1 & Region 2 & Region 3 & Region 4 & Region 5 \\
\hline Latitude Range & $27-32^{\circ} \mathrm{N}$ & $27-30^{\circ} \mathrm{N}$ & $23-26^{\circ} \mathrm{N}$ & $40-50^{\circ} \mathrm{N}$ & $30-40^{\circ} \mathrm{N}$ \\
\hline $\begin{array}{c}\text { Longitude } \\
\text { Range }\end{array}$ & $100-107^{\circ} \mathrm{E}$ & $108-113^{\circ} \mathrm{E}$ & $110-117^{\circ} \mathrm{E}$ & $110-130^{\circ} \mathrm{E}$ & $110-120^{\circ} \mathrm{E}$ \\
\hline Region & $\begin{array}{c}\text { The upper } \\
\text { reaches of the } \\
\text { Yangtze River } \\
\text { (Sichuan Basin) }\end{array}$ & $\begin{array}{c}\text { The middle } \\
\text { reaches of the } \\
\text { Yangtze River }\end{array}$ & South China & $\begin{array}{c}\text { Northeast } \\
\text { China }\end{array}$ & $\begin{array}{c}\text { The area between } \\
\text { the Yangtze River } \\
\text { and the Yellow } \\
\text { River }\end{array}$ \\
\hline
\end{tabular}

The reliability of the hourly merged precipitation data has been verified by Shen et al. [23]. To compare the error of the hourly merged precipitation data and rain-gauge data, we first analyzed the diurnal variation of the precipitation in each of the five regions by using the hourly merged precipitation data from 2008 to 2011 in summer (June-August). The diurnal variation of precipitation in each of the five regions is the average of grid data of each regions. Figure 6a shows that the maximum precipitation in the upper reaches of the Yangtze River occurs at midnight (24-02 LST), while the minimum precipitation falls at noon (12 LST). Meanwhile, the precipitation in the middle reaches of the Yangtze River reaches a diurnal peak in the early morning (06-07 LST) and a sub-peak in the afternoon (14-16 LST) (Figure 6b). The diurnal peaks of precipitation in South and Northeast China appear in the afternoon (16-17 LST) (Figure 6c,d). Although the peak precipitation between the Yangtze River valley and the Yellow River valley (region 5) differs among different stations (figure omitted), the diurnal variation of precipitation in this region is generally bimodal with peaks in the early morning (06-08 LST) and afternoon (16-18 LST). By comparing our results with the diurnal variation characteristics of the precipitation in the five regions from 1991 to 2004 reported by Yu et al. (Figure 2 in Yu's article), it is found that the hourly merged precipitation data can effectively reflect the diurnal variation of the precipitation in each region. However, the amounts of precipitation in these data are smaller than those observed by the stations. Therefore, in the following discussion, we mainly analyze the corresponding relationship between the diurnal cycles of clouds and precipitation regardless of the diurnal variation of the precipitation amount. 
(a) Reg1

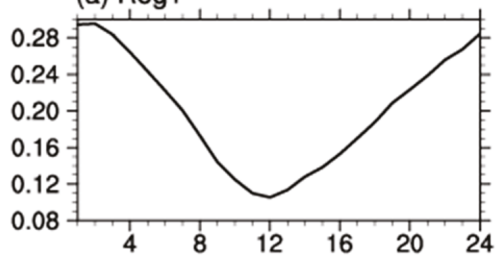

(c) Reg3

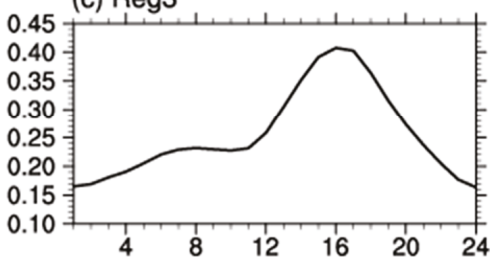

(e) Reg5

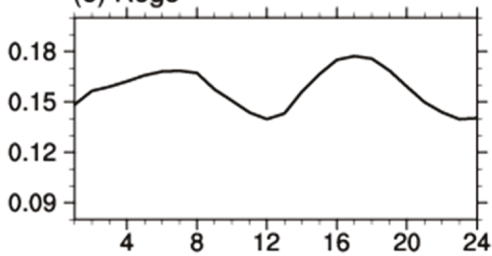

(b) Reg2

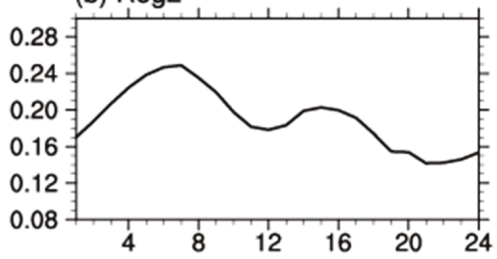

(d) Reg4

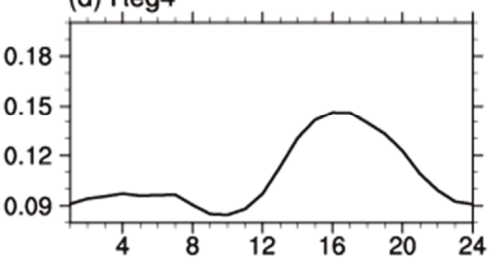

Figure 6. Diurnal variation of the 2008-2011 mean summer precipitation averaged over the five regions in Table 1 (the horizontal axis corresponds to the local solar time, units: $\mathrm{mm} / \mathrm{h}$ ).

\subsection{The Relationship between the Diurnal Variations of Clouds and Precipitation}

The probability occurrence of $\mathrm{Ci}$ and Ac with precipitation is relatively small, and thus, they are classified as non-precipitation clouds [19]. Therefore, this paper mainly discusses the correspondence between the diurnal variations of $\mathrm{Ns}, \mathrm{Sc}, \mathrm{Cu}$ and $\mathrm{Cb}$ and that of precipitation. Table 2 shows the correlation coefficients between the diurnal variations of various clouds and precipitation, where P_Ns represents the correlation coefficient between the diurnal variation of the occurrence frequency of Ns and that of precipitation, and it has a similar meaning for P_Sc, P_Cu and P_Cb, while the clouds are different.

Table 2. Correlation coefficient between the diurnal cycle of precipitation and the occurrence frequency of clouds in summer.

\begin{tabular}{cccccc}
\hline Precipitation_Cloud & Region $\mathbf{1}$ & Region 2 & Region 3 & Region 4 & Region 5 \\
\hline P_Ns & $\mathbf{- 0 . 8 2}$ & $\mathbf{0 . 5 1}$ & 0.16 & -0.13 & 0.17 \\
P_Sc & $\mathbf{0 . 8 2}$ & 0.42 & $-\mathbf{0 . 5 1}$ & -0.27 & 0.13 \\
P_Cu & $\mathbf{- 0 . 7 8}$ & 0.04 & $\mathbf{0 . 7 0}$ & $\mathbf{0 . 5 5}$ & 0.05 \\
P_Cb & $\mathbf{0 . 9 0}$ & $\mathbf{- 0 . 5 7}$ & $\mathbf{0 . 6 8}$ & $\mathbf{0 . 8 8}$ & 0.09 \\
\hline
\end{tabular}

Note: Bold font indicates a 0.05 significance level.

Figure 7a1 shows that the diurnal variation of $\mathrm{Cb}$ is in good agreement with that of precipitation in the upper reaches of the Yangtze River; both reach a peak around midnight with a significant positive correlation coefficient of 0.90 (Table 2). While there is a clear negative correlation between the diurnal variations of $\mathrm{Cu}$ and precipitation, there is also a consistent correlation between the diurnal variations of Sc and precipitation (Figure 7a2), but the diurnal peak of Sc occurs slightly later than that of precipitation. This shows that the diurnal variation of precipitation in the upper reaches of the 
Yangtze River relies upon the diurnal variations of $\mathrm{Cb}$ and Sc. Moreover, the correspondence between the diurnal variations of $\mathrm{Cb}$ and precipitation is better, and $\mathrm{Cb}$ may evolve into Sc after precipitation falls; thus, the diurnal peak of Sc lags behind that of precipitation by approximately $2 \mathrm{~h}$.

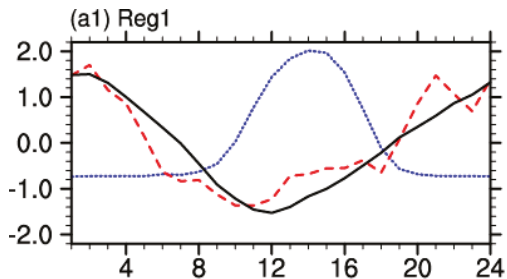

(b1) Reg2

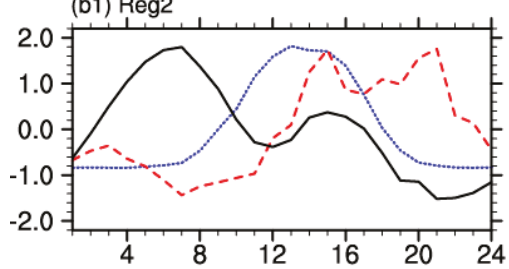

(c1) Reg3

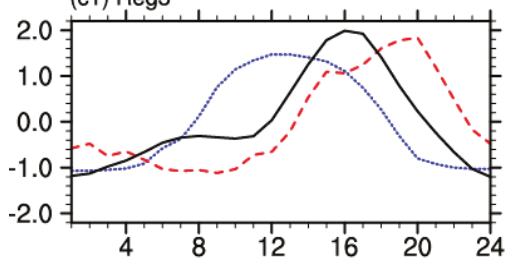

(d1) Reg4

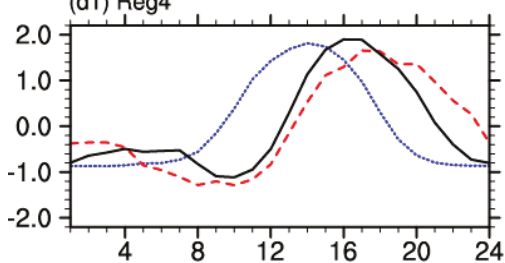

(e1) Reg5

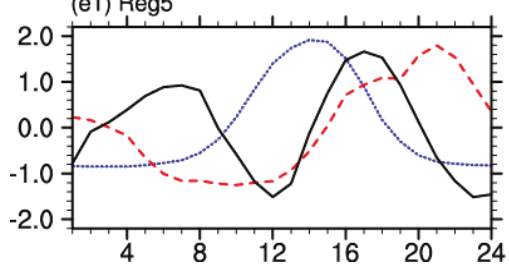

(a2) Reg1

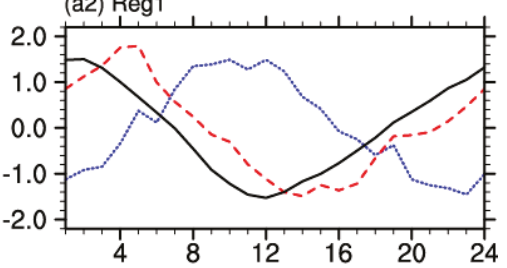

(b2) Reg2

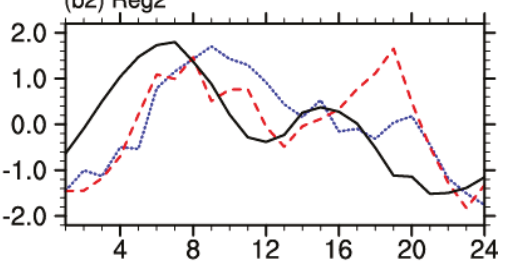

(c2) Reg3

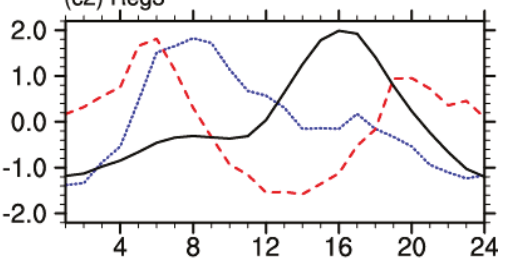

(d2) Reg4

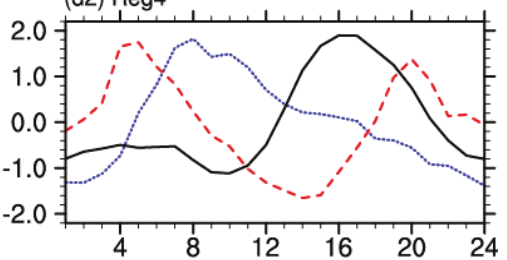

(e2) Reg5

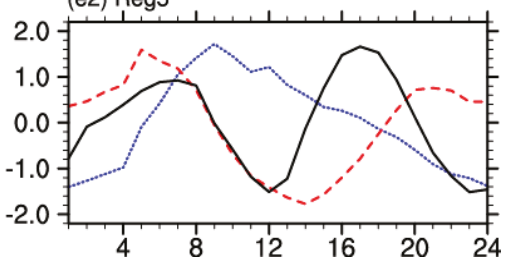

Figure 7. Diurnal variations of the standardized occurrence frequencies of $\mathrm{Cu}, \mathrm{Cb}$ and precipitation (in a1-e1) and of the standardized occurrence frequencies of Ns, Sc and precipitation (in a2-e2) (the black solid line corresponds to precipitation, while the blue dotted line and red dashed line represent the occurrence frequencies of $\mathrm{Cu}$ and $\mathrm{Cb}$, respectively, in a1-e1; meanwhile, the blue dotted line and red dashed line represent the occurrence frequencies of Ns and Sc, respectively in a2-e2).

The precipitation in the middle reaches of the Yangtze River mainly occurs in the early morning (Figure 7b1). There is a sub-peak at approximately 15 LST, the occurrence of which corresponds to the sub-peaks of both $\mathrm{Cu}$ and $\mathrm{Cb}$, indicating that the afternoon rainfall in the middle reaches of the 
Yangtze River mainly originates from $\mathrm{Cu}$ and $\mathrm{Cb}$. Figure $\mathrm{7b} 2$ shows that the corresponding relationship between the diurnal variations of precipitation and stratiform clouds in the middle reaches of the Yangtze River is good, and there is a notable positive correlation between precipitation and Ns with a correlation coefficient of 0.51 . These results show that the peak of early morning rainfall in the middle reaches of the Yangtze River is mainly caused by stratiform clouds, while the sub-peak of afternoon rainfall mainly depends upon $\mathrm{Cu}$ and $\mathrm{Cb}$.

The diurnal peaks of $\mathrm{Cu}$, precipitation and $\mathrm{Cb}$ appear sequentially over southern China (Figure 7c1). The peak frequency of Cu occurs at 12 LST, while those of precipitation and Cb occur at 16 LST and 20 LST, respectively. In addition, the occurrence frequency of Cu decreases during 12-16 LST, but those of precipitation and $\mathrm{Cb}$ rapidly increase during this period, implying that $\mathrm{Cu}$ begins to produce precipitation during this period and that a part of $\mathrm{Cu}$ develops vigorously into $\mathrm{Cb}$ under the favorable conditions. However, the corresponding relationship between the diurnal variations of stratiform clouds and precipitation is poor over South China (Figure 7c2). In conclusion, both $\mathrm{Cu}$ and $\mathrm{Cb}$ over southern China show a good correspondence with the diurnal variation of precipitation, indicating that the diurnal variation of precipitation in southern China is mainly attributed to the diurnal variations of convective clouds.

There is a significant positive correlation between the diurnal cycles of $\mathrm{Cu}$ and precipitation in Northeast China with a correlation coefficient of 0.55 . Cb shows a better correspondence with the diurnal variation of precipitation (Figure $7 \mathrm{~d} 1$ ), with a significant positive correlation of 0.88 . For example, the diurnal peaks of $\mathrm{Cb}$ and precipitation are both almost synchronous at $09-16 \mathrm{LST}$, although the diurnal peak of $\mathrm{Cb}$ that occurs during 01-09 LST is a little earlier than that of precipitation, and the occurrence frequency of $\mathrm{Cb}$ peaks one hour later than that of precipitation. In addition, the correspondence between the diurnal variations of stratiform clouds and precipitation is also poor in these areas (Figure 7d2). This shows that the diurnal variation of precipitation in Northeast China is primarily dominated by convective clouds, especially $\mathrm{Cb}$.

There are two peaks in the diurnal variation of precipitation in the region between the Yangtze River and the Yellow River (region 5). In the afternoon, $\mathrm{Cu}$, precipitation and $\mathrm{Cb}$ reach their peaks sequentially (Figure 7e1). Cu peaks at $14 \mathrm{LST}$, while the occurrence frequencies of precipitation and $\mathrm{Cb}$ increase rapidly after $12 \mathrm{LST} . \mathrm{Cb}$ and precipitation both peak at $17 \mathrm{LST}$, indicating that the afternoon peak of precipitation is determined by convective clouds. Figure $7 \mathrm{e} 2$ shows that the diurnal peaks of Sc and Ns occur at 05 LST and 09 LST, respectively, while the precipitation peaks at 07 LST, meaning that the morning precipitation peak in the area is dominated by stratiform clouds. Therefore, the results show that the diurnal variation of precipitation in the area is comparatively complicated and is closely related to both convective and stratiform clouds. The morning precipitation is closely related to stratiform clouds, while the afternoon precipitation is dominated by convective clouds.

All of the above analysis shows that the precipitation peak in central and eastern China usually occurs in the early morning or afternoon. The precipitation peak in early morning is dominated by stratiform clouds, while the peak in the afternoon is dominated by convective clouds.

\section{Discussions and Conclusions}

Based on hourly cloud observations at weather stations in combination with merged hourly precipitation data, the diurnal climatic features of different types of clouds in central and eastern China are revealed and the relationship between the diurnal variations of clouds and precipitation are analyzed. The primary conclusions are as follows:

The TC and the occurrence frequencies of all types of clouds show significant diurnal variations. The diurnal variation of the TC shows a bimodal pattern with a main peak in the late afternoon. Ac, Sc and $\mathrm{Ci}$ contribute the most to the diurnal variation of the TC. The diurnal cycles of the occurrence frequencies of Ac and Sc also show a bimodal pattern with peaks appearing in the early morning and late afternoon. The occurrence frequency of nimbostratus peaks in the morning between 07 and 12 LST, and the daily difference is weaker. The diurnal peak of Ci usually appears at 17-18 LST in the late 
afternoon, $\mathrm{Cu}$ peaks in the afternoon, and $\mathrm{Cb}$ peaks in the late afternoon during 16-20 LST, and there are slight differences among different regions. In addition, the diurnal variation amplitudes of $\mathrm{Cu}$ and $\mathrm{Cb}$ are larger, indicating that they both have significant diurnal variations.

The diurnal variations of clouds vary with both the latitude and the longitude. There is a slight difference in the time when the occurrence frequency of the TC reaches its peak value at different latitudes, while there is a difference of $1-2 \mathrm{~h}$ with a change in the latitude for both $\mathrm{Ci}$ and Ac. The peak times of $\mathrm{Ns}, \mathrm{Sc}, \mathrm{Cu}$ and $\mathrm{Cb}$ do not change with the latitude. In addition, the peak appearance time of the occurrence frequency of Ns in the Yangtze River valley lags by $1-2 \mathrm{~h}$ from west to east.

The diurnal features of clouds change with the seasons. All of the types of clouds show the largest diurnal amplitudes in the summer and autumn, and the time when the TC and Ci reach their maximum values tend to lag by $1-2 \mathrm{~h}$ from the spring to the summer. Ac and Sc present bimodal patterns with early morning peaks that appear earlier in the summer, while their late afternoon peaks appear later in the summer than in the other seasons. The maximum peak appearance times of $\mathrm{Ns}$ and $\mathrm{Cu}$ do not change with the seasons.

The diurnal variations of precipitation among the different regions are dominated by convective or stratiform clouds. The upper reaches of the Yangtze River valley present a midnight precipitation maximum that is mainly dominated by $\mathrm{Cb}$. Both precipitation and $\mathrm{Cb}$ reach a peak around midnight with a significant positive correlation coefficient of 0.90 . In other regions, the precipitation usually peaks in the early morning or in the afternoon, and there is a notable positive correlation between the early morning peak of precipitation and stratiform clouds, while the afternoon peak of precipitation shows positive relationship with convective clouds. The diurnal peak in the Yangtze River valley and the region between the Yangtze River valley and the Yellow River valley is mainly dominated by stratiform clouds, while it is mainly determined by convective clouds in South and Northeast China. The peak appearing in the afternoon over the Yangtze River valley is also dominated by convective clouds.

Nesbitt and Zipser suggested that the nocturnal rain is often caused by meso-scale convective systems (MCS) rather than isolated convection, and the MCSs are the strongest systems after midnight [24]. Lin et al. indicated that the nocturnal maximum rainfall is enhanced by instability due to nocturnal radiative cooling at cloud top [25]. This explains that the midnight precipitation maximum is mainly dominated by $\mathrm{Cb}$ in the upper reaches of the Yangtze River valley. The afternoon peaks of convective clouds and precipitation can be explained by the highest surface air temperature and the strongest instability in the lower troposphere occurring in the afternoon, which are beneficial to the trigger of the convection [22].

The study points out the relationship of diurnal variations of clouds and precipitation among different regions for the first time. However, the research on the physical mechanism of the diurnal variations of clouds and precipitation is not deep. We will study the diurnal variation of cloud microphysical characteristics, and analyze the influence of terrain, atmospheric stability and atmospheric circulation on the diurnal variation of clouds and precipitation in the next step. This is helpful for understanding the mechanism of clouds and precipitation, and for improving the ability to simulate weather and climate models.

Author Contributions: Conceptualization, C.G.; Data curation, C.G. and H.C.; Formal analysis, C.G.; Funding acquisition, Y.L.; Project administration, Y.L.; Validation, H.C.; Visualization, C.G. and H.C.; Writing - original draft, C.G.; Writing - review and editing, Y.L.

Funding: This research was funded by the National Key Research and Development Program of China, Grant /Award Number 2018YFC1507604; National Natural Science Foundation of China, Grant/Award Number 41475069.

Conflicts of Interest: The authors declare no conflict of interest. 


\section{References}

1. Rutledge, S.A.; Houze, R.A. A diagnostic modeling study of the trailing stratiform region of a midlatitude squall line. J. Atmos. Sci. 1987, 44, 2640-2656. [CrossRef]

2. Bao, S.H.; Letu, H.; Zhao, C.F.; Tana, G.; Shang, H.; Wang, T.; Lige, B.; Bao, Y.; Purevjav, G.; He, J.; et al. Spatiotemporal distributions of cloud parameters and the temperature response over the Mongolian Plateau during 2006-2015 based on MODIS data. IEEE J. Sel. Top. Appl. Earth Obs. Remote Sens. 2018, 12, 549-558. [CrossRef]

3. Wallace, J.M. Diurnal variations in precipitation and thunderstorm frequency over the conterminous United States. Mon. Weather Rev. 1975, 103, 406-419. [CrossRef]

4. Higgins, R.W.; Janowiak, J.E.; Yao, Y.P. A gridded hourly precipitation data base for the United States (1963-1993). NCEP Clim. Predict. Center ATLAS 1996, 1, 47.

5. Dai, A.G. Global precipitation and thunderstorm frequencies. Part II: Diurnal variations. J. Climate 2010, 14, 1112-1128. [CrossRef]

6. Sorooshian, S.; Gao, X.; Maddox, R.A.; Hong, Y.; Imam, B. Diurnal variability of tropical precipitation retrieved from combined GOES and TRMM satellite information. J. Clim. 2002, 15, 983-1001. [CrossRef]

7. Liang, X.Z.; Li, L.; Dai, A.G. Regional climate model simulation of summer precipitation diurnal cycle over the United States. Geophys. Res. Lett. 2004, 31, L24208. [CrossRef]

8. Lolli, S.; Di Girolamo, P.; Demoz, B.; Li, X.; Welton, E.J. Rain evaporation rate estimates from dual-wavelength lidar measurements and intercomparison against a model analytical solution. J. Atmos. Ocean. Technol. 2017, 34, 829-839. [CrossRef]

9. Lolli, S.; D'Adderio, L.; Campbell, J.; Sicard, M.; Welton, E.; Binci, A.; Rea, A.; Tokay, A.; Comeron, A.; Barragan, R.; et al. Vertically resolved precipitation intensity retrieved through a synergy between the ground-based NASA MPLNET lidar network measurements, surface disdrometer datasets and an analytical model solution. Remote Sens. 2018, 10, 1102. [CrossRef]

10. Yu, R.C.; Zhou, T.J.; Xiong, A.Y.; Zhu, Y.J.; Li, J.M. Diurnal variations of summer precipitation over contiguous China. Geophys. Res. Lett. 2007, 34, L01704. [CrossRef]

11. Zhou, T.J.; Yu, R.C.; Chen, H.M. Summer precipitation frequency, intensity, and diurnal cycle over China: A comparison of satellite data with rain gauge observations. J. Climate 2008, 21, 3997-4010. [CrossRef]

12. Li, J.; Yu, R.C.; Wang, J.J. Seasonal variation of the diurnal cycle of rainfall in the southern contiguous China. J. Climate 2008, 21, 6036-6043. [CrossRef]

13. Yuan, W.H.; Yu, R.C.; Chen, H.M.; Li, J.; Zhang, M.H. Subseasonal characteristics of diurnal variation in summer monsoon rainfall over central eastern China. J. Climate 2010, 23, 6684-6695. [CrossRef]

14. Gray, W.M.; Jacobson, R.W., Jr. Diurnal variation of deep cumulus convection. Mon. Weather Rev. 1977, 105, 1171-1188. [CrossRef]

15. Zheng, Y.G.; Chen, J. A climatology of deep convection over south China and adjacent seas during summer. J. Trop. Meteor. 2011, 27, 495-508.

16. Chen, H.M.; Yu, R.C.; Wu, B.Y. FY-2C derived diurnal features of clouds in the southern contiguous China. J. Geophys. Res. 2012, 117, D18101. [CrossRef]

17. Fujinami, H.; Nomura, S.; Yasunari, T. Characteristics of diurnal variations in convection and precipitation over the southern Tibetan Plateau during summer. SOLA 2005, 1, 49-52. [CrossRef]

18. Zhao, C.F.; Chen, Y.Y.; Li, J.M.; Letu, H.; Su, Y.; Chen, T.; Wu, X. Fifteen-year statistical analysis of cloud characteristics over China using Terra and Aqua moderate resolution imaging spectroradiometer observations. Int. J. Climatol. 2018, 39, 2612-2629. [CrossRef]

19. Gao, C.C.; Fang, L.X.; Li, Y.Y.; Kou, X.W. Cloud occurrence frequency, duration time and accompanying rainfall probability in China during 1985-2011. Torrential Rain Disaster 2015, 34, 206-214.

20. Shen, Y.; Zhao, P.; Pan, Y.; Yu, J.J. A high spatiotemporal gauge-satellite merged precipitation analysis over China. J. Geophys. Res. 2014, 119, 3063-3075. [CrossRef]

21. Yao, S.B.; Jiang, D.B.; Fan, G.Z. Seasonality of precipitation over China. Chin. J. Atmos. Sci. 2017, 41, 1191-1203. [CrossRef]

22. Yu, R.C.; Xu, Y.P.; Zhou, T.J.; Li, J. Relation between rainfall duration and diurnal variation in the warm season precipitation over central eastern China. Geophys. Res. Lett. 2007, 34, L13703. [CrossRef] 
23. Shen, Y.; Pan, Y.; Yu, J.J.; Zhao, P.; Zhou, Z.J. Quality assessment of hourly merged precipitation product over China. Trans. Atmos. Sci. 2013, 36, 37-46.

24. Nesbitt, S.W.; Zipser, E.J. The diurnal cycle of rainfall and convective intensity according to three years of TRMM measurements. J. Climate 2003, 16, 1456-1475. [CrossRef]

25. Lin, X.; Randall, D.A.; Fowler, L.D. Diurnal variability of the hydrologic cycle and radiative fluxes: Comparisons between observations and a GCM. J. Climate 2000, 13, 4159-4179. [CrossRef]

(C) 2019 by the authors. Licensee MDPI, Basel, Switzerland. This article is an open access article distributed under the terms and conditions of the Creative Commons Attribution (CC BY) license (http://creativecommons.org/licenses/by/4.0/). 
Article

\title{
Impacts of Green Vegetation Fraction Derivation Methods on Regional Climate Simulations
}

\author{
Jose Manuel Jiménez-Gutiérrez ${ }^{1}$, Francisco Valero ${ }^{1}$, Sonia Jerez ${ }^{2}$ and Juan Pedro Montávez ${ }^{2, *}$ \\ 1 Departamento de Astrofísica y Ciencias de la Atmósfera, Universidad Complutense de Madrid, \\ 28040 Madrid, Spain; jimenezg1980@gmail.com (J.M.J.-G.); valero@ucm.es (F.V.) \\ 2 Departamento de Física, Universidad de Murcia, 30100 Murcia, Spain; Sonia.Jerez@gmail.com \\ * Correspondence: montavez@um.es; Tel.: +34-868-88-7005
}

Received: 8 March 2019; Accepted: 15 May 2019; Published: 21 May 2019

\begin{abstract}
The representation of vegetation in land surface models (LSM) is crucial for modeling atmospheric processes in regional climate models (RCMs). Vegetation is characterized by the green fractional vegetation cover (FVC) and/or the leaf area index (LAI) that are obtained from nearest difference vegetation index (NDVI) data. Most regional climate models use a constant FVC for each month and grid cell. In this work, three FVC datasets have been constructed using three methods: ZENG, WETZEL and GUTMAN. These datasets have been implemented in a RCM to explore, through sensitivity experiments over the Iberian Peninsula (IP), the effects of the differences among the FVC data-sets on the near surface temperature (T2m). Firstly, we noted that the selection of the NDVI database is of crucial importance, because there are important bias in mean and variability among them. The comparison between the three methods extracted from the same NDVI database, the global inventory modeling and mapping studies (GIMMS), reveals important differences reaching up to $12 \%$ in spatial average and and 35\% locally. Such differences depend on the FVC magnitude and type of biome. The methods that use the frequency distribution of NDVI (ZENG and GUTMAN) are more similar, and the differences mainly depends on the land type. The comparison of the RCM experiments exhibits a not negligible effect of the FVC uncertainty on the monthly T2m values. Differences of $30 \%$ in FVC can produce bias of $1{ }^{\circ} \mathrm{C}$ in monthly $\mathrm{T} 2 \mathrm{~m}$, although they depend on the time of the year. Therefore, the selection of a certain FVC dataset will introduce bias in $\mathrm{T} 2 \mathrm{~m}$ and will affect the annual cycle. On the other hand, fixing a FVC database, the use of synchronized FVC instead of climatological values produces differences up to $1^{\circ} \mathrm{C}$, that will modify the $\mathrm{T} 2 \mathrm{~m}$ interannual variability.
\end{abstract}

Keywords: fraction vegetation cover; regional climate model; near surface temperature

\section{Introduction}

Land surface features play a very important role in modulating surface-atmosphere interactions. This is an overlooked issue in climate simulations [1] and short-term weather forecasting [2]. Surface components like soil moisture, albedo, emissivity, surface roughness, vegetation type and amount are fundamental since they control the energy partition at surface [3]. Therefore, the representation of all these variables in land surface models (LSM) is crucial for modeling atmospheric processes.

Atmosphere and vegetation interact in different ways, controlling evapotranspiration, moisture availability, momentum transfer, partitioning radiation, etc. Vegetation is characterized within numerical weather prediction models (NWPM) and RCMs by FVC, LAI and the vegetation class [4]. Therefore, realistic characterization of these parameters should lead to a better reproduction of atmosphere-surface processes.

Different methodologies have been reported for obtaining FVC and LAI through satellite NDVI data [5-8]. According to Gutman and Ignatov [6] both parameters should not be used simultaneously in the same parameterization. Therefore, it is necessary to prescribe one of the indices and derive 
the other. Gutman and Ignatov [6] and Carlson et al. [9] argued that is preferable to derive FVC and prescribe LAI, because the exponential dependence of LAI and NDVI saturates after a certain threshold, becoming LAI insensitive to changes in NDVI. Some other authors $[7,10]$ recommend to derive LAI (fixing FVC), because they assume that spatial and seasonal variations of NDVI are related with variations of LAI and validation of FVC is problematical because of the requirement of information at the scale of individual plant elements. Anyway, Godfrey et al. [2] argue that errors introduced by the dual specification of vegetation parameters from a single NDVI observation are likely smaller than uncertainties associated to initial conditions.

The role of vegetation parameters (FVC and LAI) is relevant for weather forecasting and climate change assessments [11]. Their impact on land surface processes has been studied in the Eta operational model [12-14] and the Weather Research and Forecasting model (WRF) [15-20]. The relevance of using realistic information of the vegetation state on RCM performance has been analyzed in several works. Meng et al. [21] and Müller et al. [22] study the impact of vegetation in concrete cases of droughts in Australia and South America. Other works investigate the contribution of near real time values of vegetation fraction to simulated precipitation. For instance, vegetation-atmosphere feedback in monsoon systems [23,24], severe convection episodes [25], or improving model performance in oasis-desert systems [26]. Other interesting studies focus on vegetation effects on regional climate simulations in complex urban areas like Los Angeles [27,28].

However, the characterization of vegetation is subjected to several sources of uncertainty. On one hand, there are several NDVI database available for obtaining FVC data. They differ in aspects such as the methods for correcting errors, type of satellite, etc. The differences among these NDVI databases reach, for example, similar values to the observed trends in the phenological phases [29]. On the other hand, several methodologies can be used to obtain FVC or LAI from NDVI data $[4,6,13,30]$. Crawford et al. [31] points out that differences up to $25 \%$ in LAI and FVC can easily occur among the different methodologies, similar values to the FVC interannual variability.

In addition, most of the standard configurations of NWPM and RCM use climatological values of vegetation parameters. However, the vegetation has a strong inter-annual variability $[18,21,31]$, leading this to a non-suitable characterization of surface properties. A known limitation is that surface properties can vary at several time scales depending on climate conditions and other processes such as urbanization, forest fires or changes in crops [32].

As an example of the impact of using different approaches with FVC datasets in a LSM, Miller et al. [30] describe, using the Noah LSM, noteworthy differences in surface fluxes, comparing a five-year climatology data from the Advanced Very High Resolution Radiometer (AVHRR) and NASA's Moderate Resolution Imaging Spectrometers (MODIS) data from the year 2000. With differences of $25 \%$ in FVC in monthly-averaged values for all pixels of dry land and cropland of the same two-degree box, transpiration was modified in $30 \mathrm{~W} \mathrm{~m}^{-2}$, latent heat fluxes in $10 \mathrm{~W} \mathrm{~m}^{-2}$, and sensible heat fluxes in $-20 \mathrm{~W} \mathrm{~m}^{-2}$. Other works, where real-time satellite data have been used instead of climatological values, have found improvements in the forecasts of T2m in RCM simulations [13,33]. While other studies, indicates that the model sensitivity is not reliable with improved vegetation parameters $[2,15,23]$, stressing the significance of minimizing errors in surface initial conditions (especially soil moisture) or canopy resistance parameterization.

The objective of this work is to assess the impact on T2m simulated by a RCM, of the uncertainty associated to the use of different NDVI data, different methodologies for obtaining FVC, as well as the temporal variability of surface properties in regional climate simulations. Our work will focus on IP, since it is characterized by a large variety of vegetation classes, with a strong seasonal and interannual climate variability that leads to important changes in the state of vegetation. 


\section{Methods and Data}

\subsection{NDVI Data}

The NDVI is defined as:

$$
N D V I=N I R-\frac{V I S}{N I R}+V I S
$$

where NIR and VIS are the amounts of near-infrared and red visible, respectively, reflected by the vegetation and captured by the satellite sensor [34]. This index was highly correlated with the photo synthetically active biomass, chlorophyll abundance and energy absorption [35] and has been widely used in studies involving land-biosphere interactions [6,13,30,31,36].

There are several global coarse-resolution satellite spectral vegetation index datasets [37]. For example, Satellite Pour l'Observation de la Terre (SPOT Vegetation) and MODIS datasets which have higher resolution and significant improvements with regard to the 1981-2004 record of the AVHRR dataset. However, the latter is an invaluable and irreplaceable archive of historical land surface information and the most used dataset for deriving NDVI due to its long record. Since 1984 several global land surface NDVI data have been derived from AVHRR, as can be the global vegetation index (GVI) dataset [38,39], the NASA Pathfinder 8-km dataset [40] and the GIMMS-NDVI[37,41]. Other datasets, such as the EFAI-NDVI [29], were derived from the NASA Pathfinder $8 \mathrm{~km}$ data. These datasets were corrected by taking into account artifacts from sensors, orbital drifting, atmospheric corrections and cloud screening.

Therefore, NDVI values can vary from a database to another in an remarkable way. The GIMMS-NDVI and EFAI-NDVI datasets were chosen to perform our analysis. The selection was done following criteria of NDVI data already processed, easily/free availability and temporal extension.

The EFAI-NDVI covers the period 1982-2001 and corrects the original AVHRR data to create a continuous dataset of 10 -day temporal and $0.1^{\circ}$ spatial resolutions with global coverage. The correction method implies a spatial interpolation of missing values and processing artifacts as well as a temporal interpolation of the NDVI series throughout a Fourier adjustment algorithm [10,29].

The GIMMS-NDVI [42] from the AVHRR dataset covers from 1982 to 2006 with a spatial resolution of $8 \mathrm{~km}$. This database has been corrected for calibration, view geometry, volcanic aerosols, and other effects non related to vegetation change. In particular, NOAA-9 descending node data from September 1994 to January 1995, volcanic stratospheric aerosol correction for 1982-1984 and 1991-1994, and improved NDVI using empirical mode decomposition/reconstruction to minimize effects of the orbital drift.

\subsection{Deriving FVC from NDVI Data}

FVC is defined as the fraction of horizontal area associated with the photosynthetically active green vegetation that occupies a model grid cell [43]. In our experiments we derive FVC and use prescribed LAI, because of our LSM, Noah, considers this option in its configuration.

FVC calculation from NDVI data [44] can be based on linear models [6] or quadratic models [45]. These methods take as reference bare soil $\left(N D V I_{0}\right)$ and dense green vegetation $\left(N D V I_{\infty}\right)$. Such values can be prescribed or estimated from the actual NDVI data. For instance, Montandon and Small [44] studied the impact of varying $N D V I_{0}$, showing how its underestimation yields a FVC overestimation.

In this study, three linear models, WETZEL, GUTMAN and ZENG have been selected as a basis to study the uncertainty in FVC calculation and its impacts on RCMs runs. These methods present different degrees of complexity, being the WETZEL/ZENG method the most simple/complex, while GUTMAN is of intermediate complexity. This latter has been extensively used in generating data for NWPMs.

The three methodologies have been applied to the GIMMS-NDVI data. Monthly FVC values have been calculated from 1982 to 2006 with a spatial resolution of $0.1^{\circ}$. 


\subsubsection{Wetzel Method}

In Chang and Wetzel [5] a two-line-segment method is presented. The slope of the linear relationship between NDVI and FVC changes when NDVI exceeds 0.547 . The relation is as follows:

$$
F V C=\left\{\begin{array}{l}
1.5(N D V I-0.1), N D V I \leq 0.547 \\
3.2(N D V I)-1.08, N D V I>0.547
\end{array}\right.
$$

being that the FVC is constrained to be between 0 and 1 .

The FVC data obtained by this method is used in the MM5 LSM model by Crawford et al. [31] and in the ETA model by Kurkowski et al. [13].

\subsubsection{Gutman Method}

This method uses the following simple linear relationship between NDVI and FVC:

$$
F V C=\frac{N D V I_{\text {val }}-N D V I_{0}}{N D V I_{\infty}-N D V I_{0}}
$$

where $N D V I_{0}$ and $N D V I_{\infty}$ are the values for bare soil and dense green vegetation.

Gutman and Ignatov [6] take $N D V I_{0}=0.04$ and $N D V I_{\infty}=0.52$, which correspond respectively to the minimum NDVI value of the desert cluster and the maximum NDVI value of the evergreen cluster in their study with GVI data. These values are in principle, region and season specific, since they depend on the soil and vegetation types and the vegetation chlorophyll content [46]. However, the authors take this assumption because there are many intermediate cases that make the evaluation difficult for other surface types. In this work, $N D V I_{0}$ and $N D V I_{\infty}$, have been set to 0.1 ( $2 \%$ percentile of bare soil) and 0.91 ( $98 \%$ Evergreen vegetation) using the GIMMS-NDVI database.

\subsubsection{Zeng Method}

This method includes procedures that involve the analysis of NDVI data as a function of biome or land cover type. This approach has been used in several works $[7,15,30,43]$. It follows the simple relationship between FVC and NDVI described by Gutman and Ignatov [6] (Equation (3)). The values of $N D V I_{\infty}$ are calculated analyzing the frequency distribution of maximum NDVI for each land cover type.

This study uses the University of Maryland Department (UMD) global land cover classification [47,48]. This land cover database has been chosen because it was created using the same NDVI data as the GIMMS-NDVI database. Figures 1a (forest types) and 2a (shrubland, cropland and grassland) show the spatial distribution as well as the relative frequency distributions of NDVI.

According to Zeng et al. [7] $N D V I_{\infty}$ is low sensitive to the exact percentile used for a given vegetation type. In this work the $N D V I_{\infty}$ is chosen getting the 98th percentile as adopted in other studies $([10,43])$. For $N D V I_{0}$, the 5 th percentile of the no-vegetation category is taken for all vegetation types. North Africa has been included to have a more suitable value for bare soil. Regarding $N D V I_{\text {val }}$, Zeng et al. [7] estimated FVC as independent of season, then $N D V I_{\text {val }}$ (Equation (3)) is the annual maximum in a given pixel in order to minimize the effects of cloud contamination. However, in our case, $N D V I_{\text {val }}$ corresponded with each of the 15-day values of the GIMMS-NDVI database in a given pixel, since we precisely wanted that FVC varies with time. 


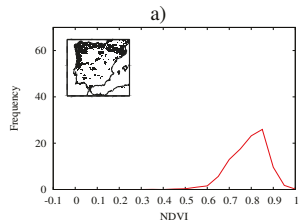

NDV
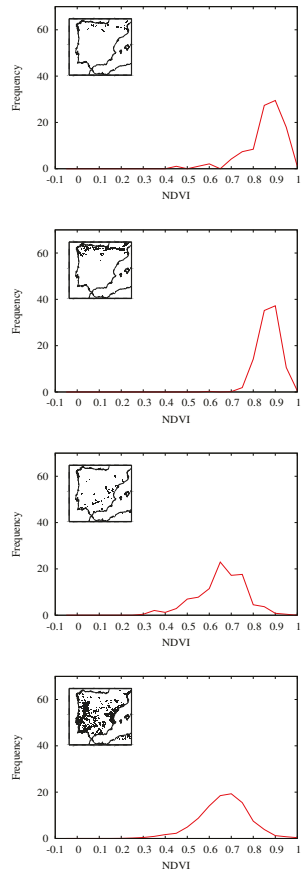

造

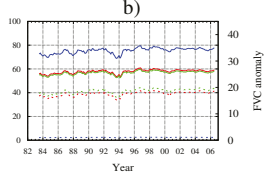

Year

$\underset{\substack{\text { GUTAN } \\ \text { WETZEL }}}{\substack{\text { WERZELLZNG } \\ \text { WETZEL-GGTMAN } \\ \text { ZENG-GUTMAN }}}$

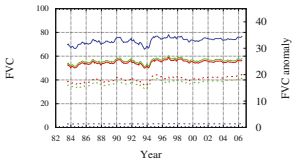

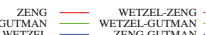

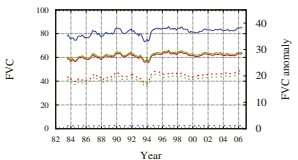

$\underset{\substack{\text { ZENG } \\ \text { GUTMAN } \\ \text { WETZEL }}}{\substack{\text { WETZEL-ZENG } \\ \text { WEIZEL-GUTMAN } \\ \text { ZENG-GUTMAN }}}$

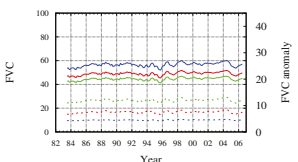

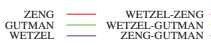

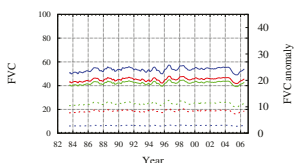

$\underset{\substack{\text { GUTMN } \\ \text { WETZEL }}}{\text { ZENG }}=\begin{gathered}\text { WETELL-ZENG } \\ \text { WEITELL-GUTMAN } \\ \text { ZENG-GUTMAN }\end{gathered}$

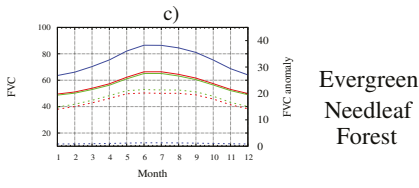

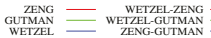

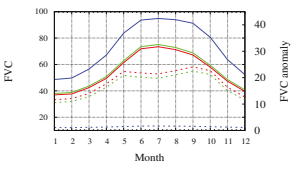

Deciduous

Broadleaf

Forest

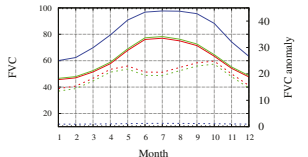

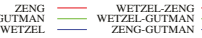

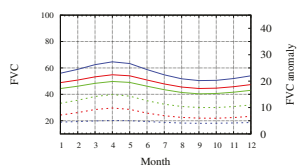

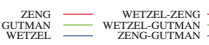

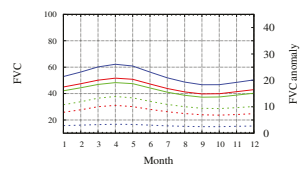

$\begin{gathered}\text { ZENG } \\ \text { GUTMAN } \\ \text { WETZEL }\end{gathered}=\begin{gathered}\text { WETZEL-ZENG } \\ \text { WETZTL-GUTMAN } \\ \text { ZENG-GUTMAN }\end{gathered}$
Mixed

Forest

Woodland

Wooded

Grassland

Figure 1. (a) Area covered by land type. Relative frequency distributions of NDVI in the IP by land types according to UMD global landcover. (b) FVC time series in forest land types calculated with the GUTMAN (green solid line), WETZEL (blue solid line) and ZENG (red solid line) methods (spatial average by land type). Differences between FVC methods: WETZEL-ZENG (red dashed line), WETZEL-GUTMAN (green dashed line), ZENG-GUTMAN (blue dashed line). (c) Same as b but monthly averaged values by land type for the period 1982-2006. 

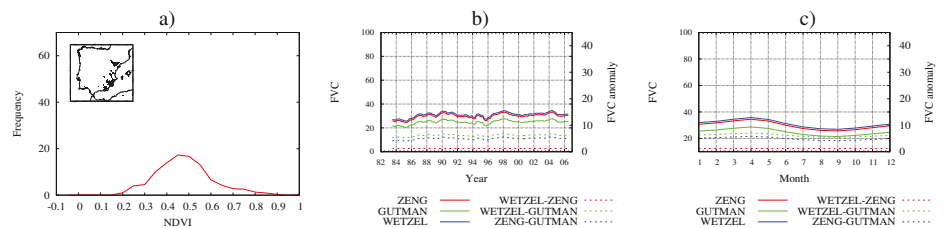

Closed

Shubland
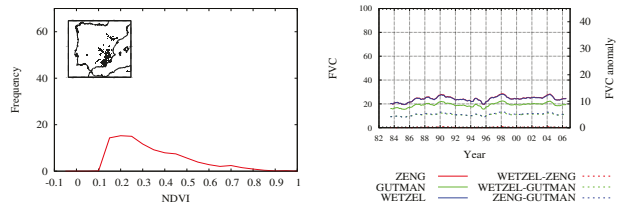

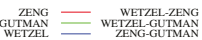
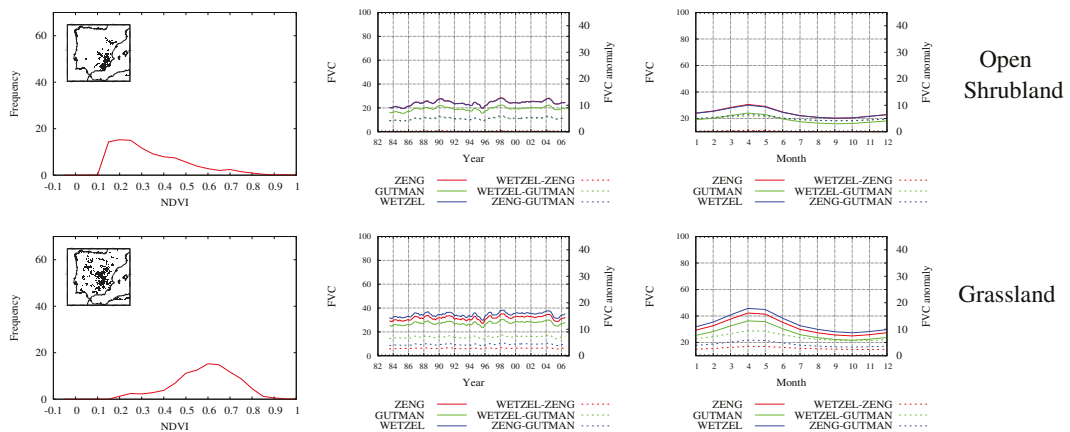

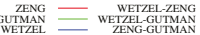

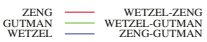
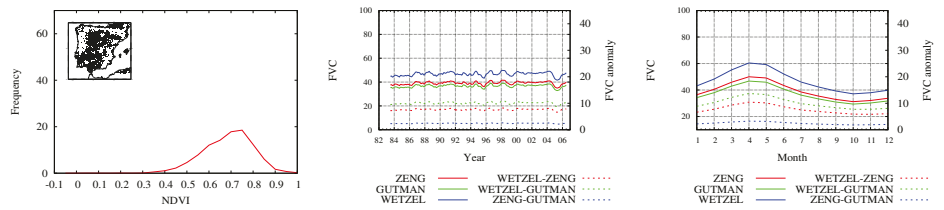

Cropland

Figure 2. As Figure 1 for closed and open shrubland, grassland and croplands.

As a help for understanding differences between the methods, Figure 3 shows the relationships between FVC and NDVI for the three methods. The ZENG method (red area) provides a wider range of values of FVC depending of land type frequency distribution of NDVI. The GUTMAN method (green line) agrees with the lower correspondence between NDVI and FVC of the ZENG method, explaining the lower values of FVC. On the other hand, the WETZEL method produce higher FVC values in areas where NDVI is larger than the rupture point (0.547), especially in the north of IP.

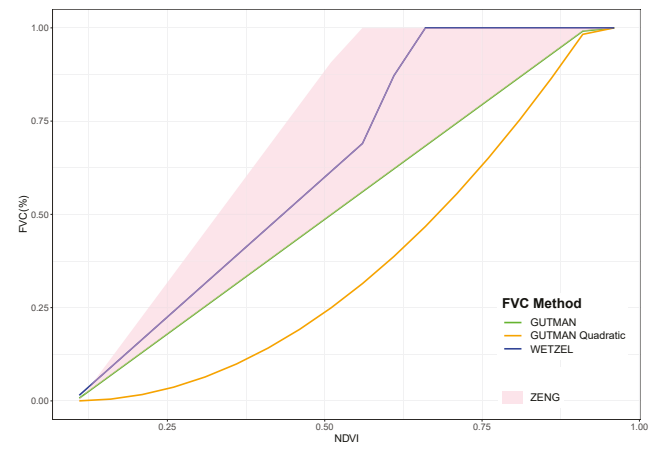

Figure 3. Relationship between fractional vegetation cover (FVC) and nearest difference vegetation index (NDVI) for the ZENG (red area), GUTMAN, WETZEL, and GUTMAN quadratic methods.

\subsection{Regional Climate Model Experiments}

In order to gain some insight about the sensitivity of a RCM to changes in FVC a set of simulations have been performed using a climate version of the MM5 mesoscale model $[49,50]$. The spatial 
configuration consists of two-way nested domains with 30 and $10 \mathrm{~km}$ horizontal resolution respectively (Figure 4) and 24 sigma levels in the vertical up to $100 \mathrm{mb}$. ERA-Interim reanalysis [51] were used to provide initial and boundary conditions, which were updated every six hours. The physics configuration consisted of Grell cumulus parameterization [52], simple ice for microphysics [53], rapid radiative transfer mode (RRTM) radiation scheme [54] and the medium-range forecast (MRF) planet boundary layer scheme [55]. The Noah LSM [56] used in this simulations was based on the coupling of the diurnally dependent Penman potential evaporation approach of Mahrt and Ek [57], the multilayer soil model of Mahrt and Pan [58], and the primitive canopy model of Pan and Mahrt [59]. It was extended by Chen and Coauthors [60] to include a complex canopy resistance approach [61,62] and a surface runoff scheme. The prognostic variables in the Noah LSM are soil moisture and temperature as well as canopy moisture and water-equivalent snow depth. Four soil layers were used with thicknesses of 10, 30, 60 and $100 \mathrm{~cm}$, and an additional canopy layer for the soil model. The total soil depth was $2 \mathrm{~m}$, with the root zone in the upper $1 \mathrm{~m}$ of soil. The lower 1-m soil layer acted as a reservoir with gravity drainage at the bottom. Ground heat flux was controlled by the usual diffusion equation for soil temperature, with heat capacity and thermal conductivity formulated as functions of the soil water content. The diffusive form of Richard's equation was used as the prognostic equation for the volumetric soil moisture content, where the hydraulic conductivity and the soil water diffusivity are also functions of the soil water content. In this LSM, vegetation type and soil texture were primary variables upon which other secondary parameters (such as minimal canopy resistance and soil hydraulic and thermal properties) were determined. Landuse-vegetation category is specified from 25-category $1 \mathrm{~km}$ data from USGS version 2 land cover data. The dominant vegetation type in each grid box is selected to represent the "grid level" vegetation characteristic. In Noah LSM, the FVC acts as a fundamental weighting coefficient in partitioning the total evaporation into direct evaporation from the top shallow soil layer, evaporation of precipitation intercepted by the canopy, and transpiration via canopy and roots.

The runs have been performed running the model for one year with four additional months of spin-up period. The outputs during this spin-up period, integrated only to guarantee that soil variables reach dynamic equilibrium, are ignored. The RCM used here, employing similar configurations, provided satisfactory results in climatic simulations [50,63-65].

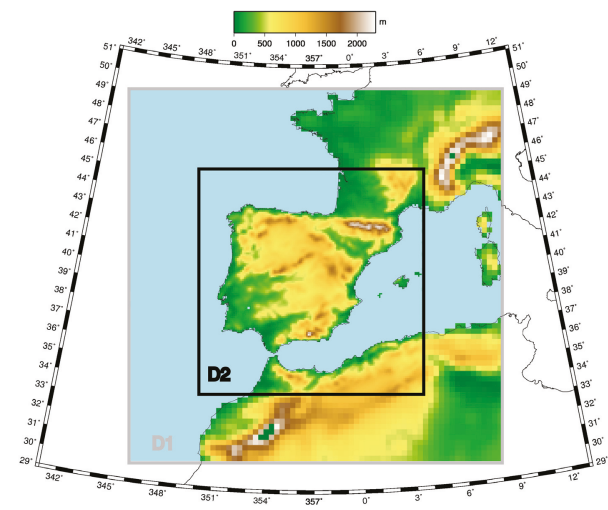

Figure 4. Regional climate model (RCM) spatial domains. Mother domain, D1 (30 km), and inner domain, D2 $(10 \mathrm{~km})$. Topography of the spatial domains.

Most regional models such as WRF or MM5 (Noah LSM) use a default FVC monthly climatological data calculated in a given period. A commonly used database is described in Gutman and Ignatov [6] which consist of a 5-year FVC climatology derived from AVHRR, for the period April-December of 
1985, from 1986 to 1990 and the period January-March of 1991 with a spatial resolution of $0.15^{\circ}$. In this work, the database generated had a resolution of $0.1^{\circ} \times 0.1^{\circ}$.

Two set of experiments have been carried out. The first set investigated the effect of using different methodologies in constructing the FVC database used in the simulations. For this task, firstly a five-year FVC climatology has been constructed for the same period of Gutman and Ignatov [6] (April 1985-March 1991) with the ZENG, GUTMAN and WETZEL methods from the GIMMS-NDVI data. Then three runs for the year 1995 were performed using such FVC climatologies. The second set of simulations explored the role of introducing synchronous FVC data for a given year respect to the use of climatological values of this variable. For this case, two pairs of runs were carried out, choosing the ZENG method for the years 1995 (a dry year) and 1996 (a wet year). Each pair consists of a simulation using the period of the five-year FVC climatology (CLIM) described before and the other one using the FVC values for such year (YEAR). The ZENG method has been chosen, among the three options, because it presents an intermediate behaviour between WETZEL and GUTMAN (see Figure 5) as well as the fact that it has been evaluated in previous works [7].
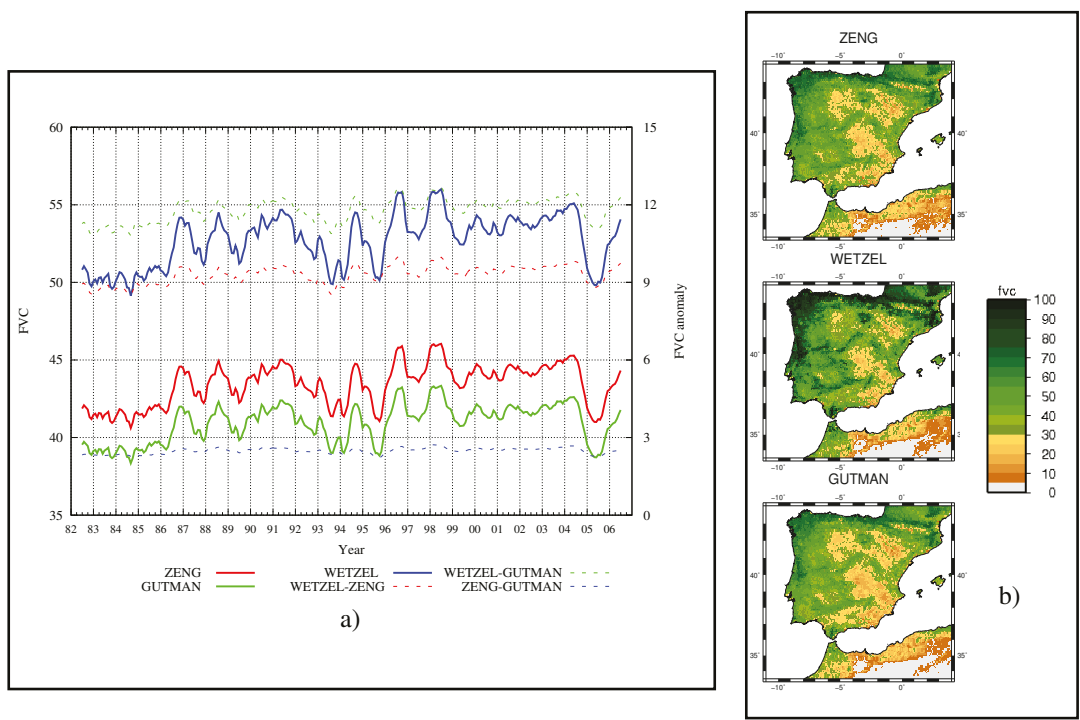

Figure 5. (a) FVC spatial averaged time series (solid lines) and differences between them (dashed lines) for the whole IP calculated by the WETZEL (blue line), GUTMAN (green line) and ZENG (red line) methods. (b) FVC temporal averaged over the whole period (1982-2006) for the IP for the ZENG, WETZEL and GUTMAN methods.

\section{Results}

\subsection{NDVI Database Comparison}

Figure 6 shows the NDVI for the two datasets in a dry year (1995) and a wet year (1996) for January and July over the IP. It is remarkable that they differed in magnitude but that spatial variability was quite similar (spatial correlation over 0.97). The differences were higher when comparing years with different precipitation regime, where NDVI values differed up to $30 \%$ in the summer (not shown).

The 12 month run-mean series of the spatially averaged NDVI over the IP for the period 1982-1998 is shown in Figure 7a. The series shows a quite different interannual variability for the whole period; the EFAI-NDVI had a greater variability and lower mean values than the GIMMS-NDVI. We attributed the disagreement (almost a periodical signal not attributable to natural variability) to the solar zenith angle correction implemented in the GIMSS-NDVI that avoids artificial trends derived from orbital 
drifting. At this point we concluded that the EFAI-NDVI should not be used for characterizing the vegetation properties in RCMs. Therefore, we focused our study on the GIMMS-NDVI data. In addition, GIMMS-NDVI had a longer record, because of the compatibility with AVHRR data with MODIS and SPOT vegetation satellite data, that have continued until nowadays.
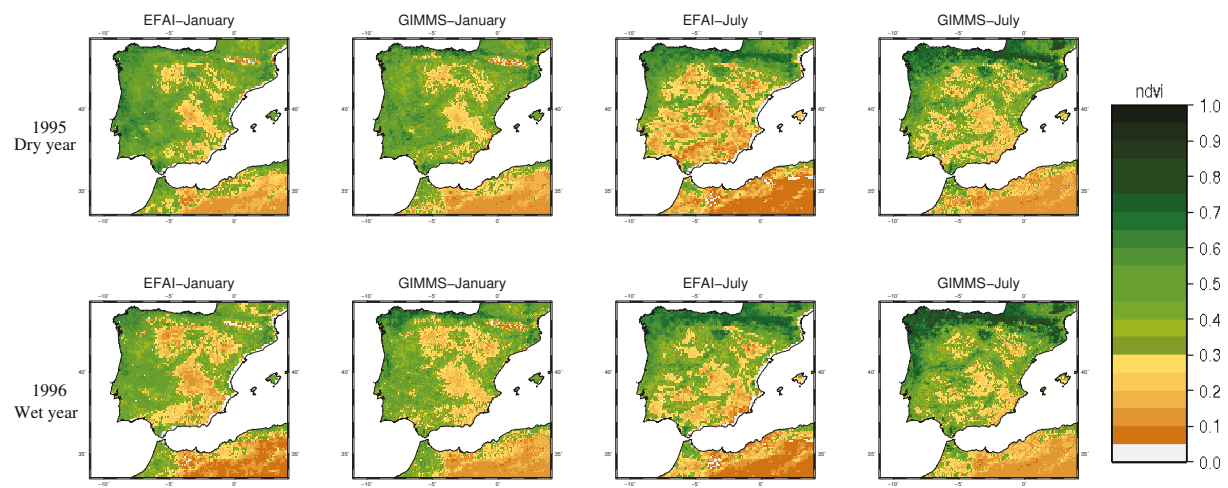

Figure 6. EFAI-NDVI and GIMMS-NDVI for January and July for a wet year (1996) and a dry year (1995) in the Iberian Peninsula (IP).
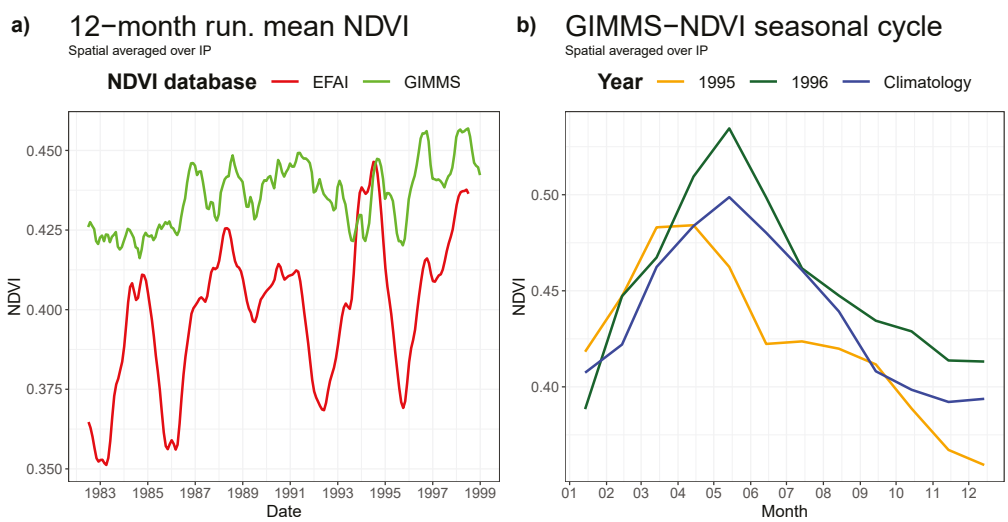

Figure 7. (a) NDVI 12 month run-mean of the spatially averaged series for the IP derived from the EFAI-NDVI (red line) and GIMMS-NDVI (green line); (b) GIMMS-NDVI monthly values for a wet year (1996, green line), a dry year (1995, orange line) and climatology (blue line).

Usually FVC is implemented using climatological values in NWPMs and RCMs. We compared the spatially averaged NDVI over the IP, with monthly climatological values calculated on a seven year period (1985-1991) with the monthly evolution on a specific dry (1995) and wet year (1996) (Figure $7 \mathrm{~b}$ ). The biggest NDVI differences between the dry and wet year were observed in spring, when the maximum of vegetation productivity occurred, prevailing these NDVI differences in a lesser way the rest of the year. The spatial average NDVI difference between wet and dry years was about $5 \%$ reaching values up to $15 \%$ in some areas. This elucidates that taking into account the interannual variability could be important when implementing these data in RCMs.

\subsection{Analysis of FVC Retrieval Methods}

FVC data were obtained for the 25 year of available NDVI data using the three methods. Figure 5a shows the temporal evolution of the FVC data spatially averaged over the IP and Figure $5 b$ the temporal 
means of FVC values over the domain. Since the three methods used the same NDVI, there was a very good agreement in the temporal variation of FVC, however some important differences appear. The most remarkable difference comparing the magnitude of FVC was that WETZEL method presented FVC values $10 \%$ greater than the others. The ZENG and GUTMAN methods only differed around a $3 \%$ in magnitude. This large difference was due to the fact that when applying WETZEL method the frequency distribution of NDVI was not taken into account. Regarding the spatial variability, the ZENG and GUTMAN show very similar patterns although the ZENG method achieves a larger range of FVC values, reaching values near $10 \%$ and over $80 \%$ more frequently.

The differences between the methods depended on the land type by construction. Figures $1 \mathrm{~b}$ and $2 \mathrm{~b}$ depict the time series of the FVC spatially averaged by land types calculated with the GUTMAN (green solid line), WETZEL (blue solid line) and ZENG (red solid line) methods as well as the differences between them (dashed lines). The GUTMAN and ZENG methods showed very similar FVC values in forest land types (Figure 1), while the WETZEL method showed significant differences of around 20\% respect to the other methods. Land types with low values of FVC, such as shrubland, cropland and grassland (Figure 2) present smaller differences. In the case of closed and open shrubland, the WETZEL method presents the closest values to the other methods. This can be explained because NDVI values below the rupture point of the WETZEL method were more frequent for this land types (Figure 2a).

Therefore, in general, places with high FVC values exhibited a good agreement between the methods that take into account the NDVI frequency distribution (GUTMAN and ZENG), showing larger differences with the WETZEL method. While in places with medium and low values of FVC, the spread among the methods was lower.

Another interesting feature was to evaluate is the differences in phenology. Figures 1 and 2 show the relative frequency distribution if NDVI (a), temporal evolution (b) and FVC annual cycle (c) for each biome and the differences between them. In the biomes where the maximum of FVC occurred in summer, forest vegetation with low hydric stress, the GUTMAN and ZENG methods had a quite similar behavior (maximum value of $60-80 \%$ in summer) while the WETZEL method gave greater values. In the rest of the biomes, the maximum of FVC occurred in spring (irrigated lands or places with summer hydric stress) and the differences between the methods were smaller than for forest land types, although there were differences that could be remarkable in cropland, grasslands and woodland areas.

\subsection{Sensitivity to the FVC Estimation Method}

Here we assessed the sensitivity of climate simulations to the use of different FVC data presented above. For the sake of clarity, we only present the comparisons between the ZENG and WETZEL experiments, because they show the largest FVC differences. Figure 8a depicts the FVC monthly means of ZENG for some months representative of each season (January, April, July and October) and Figure $8 \mathrm{~b}$ the FVC differences between the ZENG and WETZEL methods. There is a clear negative difference in the FVC estimated (ZENG-WETZEL) with higher FVC values for the WETZEL data, especially in areas with the highest FVC. The biggest difference was in April, when the vegetation productivity presented the maximum rate of generation of biomass.

The effect of such differences between the ZENG and WETZEL data on the regional climate simulations for monthly mean T2m is depicted in Figure 8c,d. In general, lower FVC values led to higher temperatures, but this relationship depended on the time of the year (Figure 8d). This result was directly related to the sensible and latent heat partitioning (not shown). An increase/decrease of vegetation led to a larger/lower evapotranspiration and therefore, a higher/smaller latent heat production. This led to a reduced/intensified sensible heat manifested in a decrease/increase in $\mathrm{T} 2 \mathrm{~m}$. Besides, there was an additional effect due to the modification of soil thermal conductivity by the presence of a vegetation canopy. Heat flux from soil was reduced when FVC increases because of heat conductivity was diminished $[12,66]$. This effect was of importance mostly during night when these fluxes had a dominant role and can cause higher night temperatures with reduced FVC. 
It is worth noting that $\mathrm{T} 2 \mathrm{~m}$ differences were higher in April and July than in January and October with similar FVC differences (Figure 8). In January differences of $30 \%$ in FVC led to changes smaller than $0.5{ }^{\circ} \mathrm{C}$, while in July or April can reach $1{ }^{\circ} \mathrm{C}$ in some places. This was mainly due to the greater availability of energy at these months. In addition, the greater dispersion in the quasi-linear relationship between changes in FVC and T2m (Figure 8d) for higher $\triangle F V C$ values may be relevant. Therefore, it was clear that changing the FVC database modified the climatology reproduced by a $\mathrm{RCM}$, both the spatial patterns and the amplitude of the annual cycle.

a) FVC (ZENG)

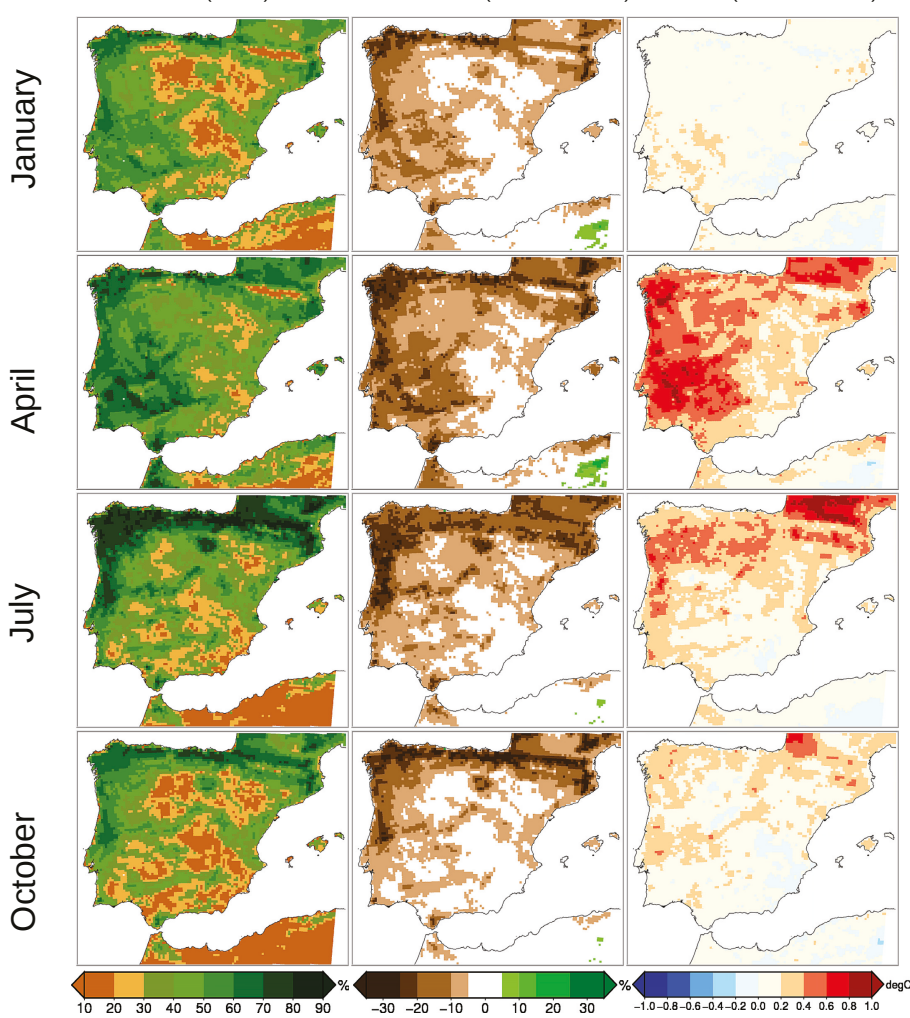

d) $\Delta \mathrm{FVC}$ vs $\Delta \mathrm{T}$
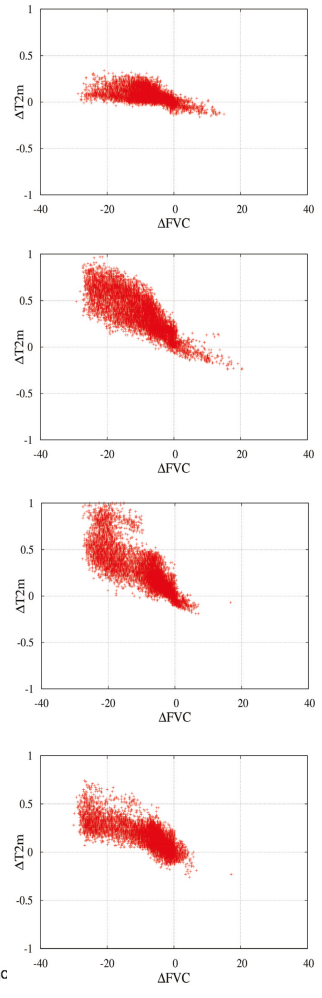

Figure 8. (a) Monthly means of FVC for the ZENG method. (b) Differences of monthly means of FVC between the ZENG and WETZEL methods. (c) Differences in monthly means of T2m between the ZENG and WETZEL regional climate simulations. (d) $x-y$ scatter plot graph between differences of FVC (x-axis) and differences in T2m between ZENG and WETZEL methods(y-axis).

\subsection{Sensitivity to FVC Interannual Variations}

As mentioned above, in RCM experiments, FVC values are usually prescribed using climatologies, so they do not vary from year to year. But vegetation depended on the climate conditions as well as other factors, and it had a non negligible interannual variability. In this section we analyze the effect of varying the FVC according to the observations (real FVC) versus fixed monthly climatological/prescribed values.

Figure 9 shows the differences between the FVC 5-year climatology simulation (CLIM) and the reconstructed (YEAR) for January, April, July and October for two years, the dry 1995 and wet 1996. These years were selected because of their quite different climate conditions. Dry conditions prevailed during 1995, while 1996 was characterized for abundant precipitation that favored higher biomass production. 


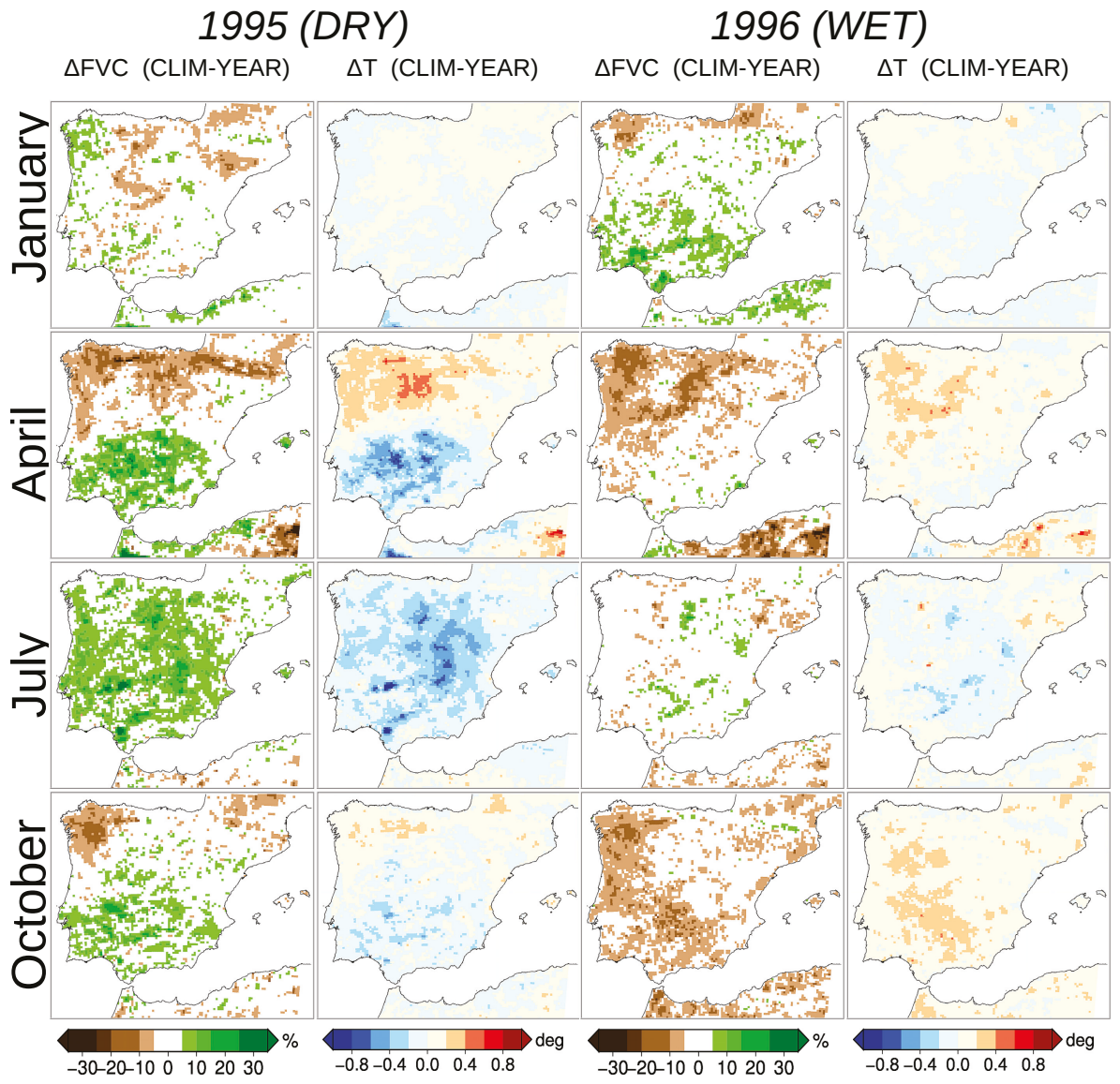

Figure 9. Differences between five-year FVC climatology (CLIM) simulation (climatology-based FVC) and FVC values for such year (YEAR) simulation (inter-annual varying FVC) for FVC and T2m in a dry year (1995) and a wet year (1996).

During the dry year, the prescribed FVC was much higher that the estimated for this year, finding large areas with $\triangle F V C$ over $10 \%$, especially in April and July that locally reached values around $30 \%$. The $\mathrm{T} 2 \mathrm{~m}$ temperature patterns resembled the spatial structure of $\triangle F V C$ with a clear negative bias. The largest T2m differences appeared again in July and April, with values larger than $0.4{ }^{\circ} \mathrm{C}$ in large areas that locally were over $0.8^{\circ} \mathrm{C}$.

During the wet year the largest $\triangle F V C$ appeared in April in the north-west part of the IP, and October over the South and Western Iberia. In this case differences were negative, i.e., the prescribed FVC underestimates the YEAR FVC. Interestingly, the absolute T2m differences were smaller, with slightly lower absolute $\triangle F V C$. This is due to the fact that in July (highest sensitivity) $\triangle F V C$ is quite small, and that in April advection phenomena prevailed in the area with the largest $\triangle F V C$.

Adding both effects at the different times suggest that interannual variability can change more that $1{ }^{\circ} \mathrm{C}$ in some areas for a given month. 


\section{Discussion and Conclusions}

Three database of monthly FVC from 1982 to 2006 has been created for a domain covering the whole IP with a spatial resolution of $0.1^{\circ}$ with the aim of being implemented in RCMs to improve climate simulations by providing more realistic soil physical conditions. Three different methodologies, WETZEL, GUTMAN and ZENG, were applied to the same NDVI database. The GIMMS-NDVI data was selected because it has better interannual behavior, longer record and is compatible with MODIS and SPOT vegetation data, which facilitates its temporal extension.

The comparison between the FVC databases reveals important differences between them that depend on the FVC value and the biome, being especially relevant for forest land types. Methods that use the frequency distribution of NVDI (ZENG and GUTMAN) are more similar although some differences can be found between them depending of the land type. In addition the FVC series reveal a important interannual variability, consequently prescribed FVC values can present important differences regarding the "real" FVC. These facts can be important when FVC are used in RCMs coupled to LSMs. The magnitude of the differences found causes a noteworthy impact on surface fluxes and hence modifying the regional climate.

The RCM experiments performed exhibit a not negligible effect of FVC uncertainty on the monthly climatological values. The results showed that differences of 30\% of FVC, that appear in the two sensitivity experiments, can produce bias of $1^{\circ}$ in T2m monthly values. Therefore, depending on the spatial structure of the FVC differences, the climatological patters are modified. In addition, the magnitude of the model response depends on the time of the year. This implies that the annual cycle reproduced by the model is also sensible to the FVC data used. Finally, the role of the interannual variability of the FVC series can also change the interannual variability of climatological series (T2m in our study). In the experiment showed here, the differences for some times of the year, especially spring and summer could reach $1{ }^{\circ} \mathrm{C}$.

It is known that changes in vegetation also modifies the albedo. This was not taken into account in our experiments. Therefore, it can be expected an impact on the regional climate simulations. In fact, this impacts can be opposite to our findings since a decrease of the vegetation leads to an increase of albedo and then, less radiation is trapped by the surface and temperature could decrease. However, Crawford et al. [31] show that the impact of changing albedo on surface heat fluxes is much smaller, an order of magnitude, than changing FVC.

In this paper we just analyze the sensitivity of RCM simulations to changes in FVC. A question remaining is if the RCM simulations with these new FVC datasets can better capture the climate over the IP. The sensitivity of the model to the FVC changes is much smaller than the deviations of the model respect to the observations (not shown), therefore it is difficult to find any improvement using only one or two years of data. This is not a surprising result. For example, Gómez-Navarro et al. [67] shows that the skill score of different RCMs depends on the data-base chosen for evaluating the model. Other examples can be found in Fernández et al. [68] and Jerez et al. [64] where the authors did not find any combination of physical parameterizations that always reproduce better the observed climate. However, changing FVC with time instead of using climatological data should improve the simulation of inter-annual regional climate variability. For instance, the mean temperature differences between the dry and the wet year are better represented by the YEAR simulations (not shown).

In this work, just linear models have been tested for obtaining FVC from NDVI, because they have been more frequently used (for instance, in most of works cited along the work). Some examples are the NOAH land-surface model and the NAM Eta model. However, some authors use quadratics models. Figure 3 shows the relationship between FVC and NDVI for the linear models analyzed and a quadratic model (GUTMAN Quadratic). The quadratic methodology drives to lower values of FVC. Anyway, the FVC differences obtained with linear methods covers the range of the differences in FVC that we found. 
Author Contributions: Conceptualization, J.M.J.-G. and J.P.M. Methodology, J.M.J.-G. and J.P.M. Software, J.M.J.-G. and J.P.M. and S.J. Investigation, J.M.J.-G. Formal Analysis, J.M.J.-G., J.P.M. and S.J. Data curation, J.M.J.-G., J.P.M. and S.J. Writing-original draft preparation, J.M.J.-G. and J.P.M. Writing-review and editing, J.M.J.-G., J.P.M., S.J. and F.V. Visualization, J.M.J.-G. Supervision, J.P.M. and F.V.

Funding: The authors acknowledge projects REPAIR-CGL2014-59677-R and ACEX-CGL2017-87921-R of the Spanish Ministry of Economy and Competitiveness PCIN-2014-013-C07-04, PCIN2016-080 (UE ERA-NET Plus NEWA Project), CGL2016-78702, and the Instituto de Matemática Interdisciplinar (IMI) of the Universidad Complutense that partially support this work. S. Jerez has received funding from the Plan Propio de Investigación of the University of Murcia (grant No. UMU-2017-10604) and the Fundación Séneca-Regional Agency for Science and Technology of Murcia (CLIMAX project 20642/JLI/18).

Acknowledgments: We acknowledge all the institutions and communities that provided free software, R community, CDO (Climate Data Operators), GMT (Generic Mapping Tools), MM5, Gnuplot, gfortran as well as the institutions supplying data (ECMWF, NASA).

Conflicts of Interest: The authors declare no conflicts of interest.

\section{References}

1. Pielke, R.A. Overlooked issues in the U.S. National Climate and IPCC assesments. Clim. Chang. 2002, 52,1-11.

2. Godfrey, C.M.; Stensrud, D.J.; Leslie, L.M. The influence of improved land surface and soil data on mesoscale model predictions. CD-ROM. In Proceedings of the 19th Conference on Hydrology; American Meteorological Society: Boston, MA, USA, 2002; Paper 4.7.

3. Jerez, S.; Montavez, J.; Gomez-Navarro, J.; Jimenez, P.; Jimenez-Guerrero, P.; Lorente, R.; Gonzalez-Rouco, J.F. The role of the land-surface model for climate change projections over the Iberian Peninsula. J. Geophys. Res. Atmos. 2012, 117. [CrossRef]

4. Stensrud, D.J. Parameterization Schemes: Keys to Understanding Numerical Weather Prediction Models; Cambridge University Press: Cambridge, UK, 2007.

5. Chang, J.T.; Wetzel, P.J. Effects of spatial variations of soil moisture and vegetation on the evolution of a prestorm environment: A numerical case study. Mon. Weather Rev. 1991, 119, 1368-1390. [CrossRef]

6. Gutman, G.; Ignatov, A. The derivation of the green vegetation fraction from NOAA/AVHRR data for use in numerical weather prediction models. Int. J. Remote Sens. 1998, 19, 1533-1543. [CrossRef]

7. Zeng, X.; Dickinson, R.E.; Walker, A.; Shaikh, M. Derivation and evaluation of global 1-km fractional vegetation cover data for land modelling. J. Appl. Meteorol. 2000, 39, 826-839. [CrossRef]

8. Li, X.; Zhang, J. Derivation of the Green Vegetation Fraction of the Whole China from 2000 to 2010 from MODIS Data. Earth Interact. 2016, 20, 1-16. [CrossRef]

9. Carlson, T.N.; Perry, E.M.; Schmugge, T.J. Remote estimates of soil moisture availability and fractional vegetation cover for agricultural fields. Remote Sens. Environ. 1990, 52, 45-70.

10. Sellers, P.J.; Los, S.O.; Tucker, C.J.; Justice, C.O.; Dazlich, D.A.; Collatz, G.J.; Randall, D.A. A revised land surface parameterization (SiB2) for atmospheric GCMs. Part II: The generation of global fields of terrestrial biophysical parameters from satellite data. J. Clim. 1996, 9, 706-737. [CrossRef]

11. Hanamean, J.M., Jr.; Pielke, R.A., Sr.; Castro, C.L.; Ojima, D.S.; Reed, B.C.; Gao, Z. Vegetation greenness impacts on maximum and minimum temperatures in northeast Colorado. Meteorol. Appl. 2003, 10, $203-215$. [CrossRef]

12. Ek, M.B.; Mitchell, K.E.; Lin, Y.; Rogers, E.; Grunmann, P.; Koren, V.; Gayno, G.; Tarpley, J.D. Implementation of Noah land surface model advances in the National Centers for Environmental Prediction operational mesoscale Eta model. J. Geophys. Res. Atmos. 2003, 108, 8851. [CrossRef]

13. Kurkowski, N.P.; Stensrud, D.J.; Baldwin, M.E. Assessment of Implementing Satellite-Derived Land Cover Data in the Eta Model. Weather Forecast. 2003, 18, 404-416. [CrossRef]

14. Marshall, C.H.; Crawford, K.C.; Mitchell, K.E.; Stensrud, D.J. The impact of the land surface physics in the operational NCEP Eta model on simulating the diurnal cycle: Evaluation and testing using Oklahoma Mesonet data. Weather Forecast. 2003, 18, 748-768. [CrossRef]

15. Hong, S.; Lakshmi, V.; Small, E.; Chen, F.; Tewari, M.; Manning, K.W. Effects of vegetation and soil moisture on the simulated land surface processes from the coupled WRF/Noah model. J. Geophys. Res. Atmos. 2009, 114, D18118. [CrossRef] 
16. Limei, R.; Gilliam, R.; Binkowski, F.; Xiu, A.; Pleim, J.; Band, L. Sensitivity of the Weather Research and Forecast/Community Multiscale Air Quality modeling system to MODIS LAI, FPAR, and albedo. J. Geophys. Res. Atmos. 2015, 120, 8491-8511.

17. Cao, Q.; Yu, D.; Georgescu, M.; Han, Z.; Wu, J. Impacts of land use and land cover change on regional climate: A case study in the agro-pastoral transitional zone of China. Environ. Res. Lett. 2015, 10, 124025. [CrossRef]

18. Xu, L.; Pyles, R.D.; Snyder, R.H.; Monier, E.; Falk, M.; Chen, S.-H. Impact of canopy representations on regional modeling of evapotranspiration using the WRF-ACASA coupled model. Agric. For. Meteorol. 2017, 247, 79-92. [CrossRef]

19. Zhang, M.; Geping, L.; Maeyer, P.D.; Cai, P.; Kurban, A. Improved Atmospheric Modelling of the Oasis-Desert System in Central Asia Using WRF with Actual Satellite Products. Remote Sens. 2017, 9, 1273. [CrossRef]

20. Wen, J.; Lai, X.; Shi, X.; Pan, X. Numerical simulations of fractional vegetation coverage influences on the convective environment over the source region of the Yellow River. Meteorol. Atmos. Phys. 2013, 120, 1-10. [CrossRef]

21. Meng, X.H.; Evans, J.P.; McCabe, M.F. The Impact of Observed Vegetation Changes on Land-Atmosphere Feedbacks During Drought. J. Hydrometeorol. 2014, 15, 759-776. [CrossRef]

22. Müller, O.V.; Berbery, E.H.; Alcaraz-Segura, D.; Ek, M.B. Regional model simulations of the 2008 drought in southern South America using a consistent set of land surface properties. J. Clim. 2014, 27, 6754-6778. [CrossRef]

23. Matsui, T.; Lakshmi, V.; Small, E.E. The effects of satellite-derived vegetation cover variability on simulated land-atmosphere interactions in the NAMS. J. Clim. 2005, 18, 21-40. [CrossRef]

24. Notaro, M.; Chen, G.; Yu, Y.; Wang, F.; Tawfik, A. Regional Climate Modeling of Vegetation Feedbacks on the Asian-Australian Monsoon Systems. J. Clim. 2017, 30, 1553-1582. [CrossRef]

25. James, K.A.; Stensrud, D.J.; Yussouf, N. Value of real-time vegetation fraction to forecasts of severe convection in high-resolution models. Weather Forecast. 2009, 24, 187-210. [CrossRef]

26. Zhang, G.; Zhou, G.; Chen, F.; Barlage, M.; Xue, L. A Trial to Improve Surface Heat Exchange Simulation through Sensitivity Experiments over a Desert Steppe Site. J. Hydrometeorol. 2014, 15, 664-684. [CrossRef]

27. Vahmani, P.; Hogue, T. High-resolution land surface modeling utilizing remote sensing parameters and the Noah UCM: A case study in the Los Angeles Basin. Hydrol. Earth Syst. Sci. 2014, 18, 4791-4806. [CrossRef]

28. Vahmani, P.; Ban-Weiss, G. Climatic consequences of adopting drought-tolerant vegetation over Los Angeles as a response to California drought. Geophys. Res. Lett. 2016, 43, 8240-8249. [CrossRef]

29. Stockli, R.; Vidale, P.L. European plant phenology and climate as seen in a 20 year AVHRR land-surface parameter dataset. Int. J. Remote Sens. 2004, 17, 3303-3330. [CrossRef]

30. Miller, J.; Barlage, M.; Zeng, X.; Wei, H.; Mitchell, K. Sensitivity of the NCEP/Noah land surface model to the MODIS green vegetation fraction data set. Geophys. Res. Lett. 2006, 33, 237-250. [CrossRef]

31. Crawford, T.M.; Stensrud, D.J.; Mora, F.; Merchant, J.W.; Wetzel, P.J. Value of Incorporating Satellite-Derived Land Cover Data in MM5/PLACE for Simulating Surface Temperatures. J. Hydrometeorol. 2001, 2, 453-468. [CrossRef]

32. Myneni, R.B.; Keeling, C.D.; Tucker, C.J.; Asrar, G.; Nemani, R.R. Increased plant growth in the northern high latitudes from 1981 to 1991. Nature 1997, 386, 698-702. [CrossRef]

33. Refslund, J.; Dellwik, E.; Hahmann, A.; Barlage, M.; Boegh, E. Development of satellite green vegetation fraction time series for use in mesoscale modeling: Application to the European heat wave 2006. Theor. Appl. Clim. 2014, 117, 377-392. [CrossRef]

34. Pettorelli, N.; Olav, V.J.; Atle, M.; Gaillard, J.M.; Tucker, C.J.; Stenseth, N.C. Using the satellite-derived NDVI to assess ecological responses to enviromental change. IEEE Trans. Geosci. Remote Sens. 2005, 20, 503-510.

35. Myneni, R.B.; Hall, F.G.; Sellers, P.J.; Marshak, A.L. The interpretation of spectral vegetation indexes. IEEE Trans. Geosci. Remote Sens. 1995, 33, 481-486. [CrossRef]

36. Zhou, L.; Kaufmann, R.K.; Tian, Y.; Mineny, R.B.; Tucker, C.J. Relation between interannual variations in satellite measures of northern forest greenness and climate between 1982 and 1999. J. Geophys. Res. 2003, 108, ACL 3-1-ACL 3-16. [CrossRef]

37. Tucker, C.J.; Pinzon, J.E.; Brown, M.E.; Slayback, D.; Pak, E.W.; Mahoney, R.; Vermote, E.; Saleous, N.E. An Extended AVHRR 8-km NDVI Data Set Compatible with MODIS and SPOT Vegetation NDVI Data. Int. J. Remote Sens. 2005, 26, 4485-4498. 
38. Tarpley, J.P.; Schneider, S.R.; Money, R.L. Global vegetation indices from NOAA-7 meteorological satellite. J. Clim. Appl. Meteorol. 1984, 23, 491-494.

39. Gutman, G.; Tarpley, D.; Ignatov, A.; Olson, S. The enhanced NOAA Global Land datasets from the Advanced Very High Resolution Radiometer. Int. J. Remote Sens. 1995, 76, 1141-1156. [CrossRef]

40. James, M.E.; Kalluri, S.N.V. The Pathfinder AVHRR land dataset:an improved coarse resolution dataset for terrestrial monitoring. Int. J. Remote Sens. 1994, 15, 3347-3363. [CrossRef]

41. Pinzon, J. Using HHT to successfully uncouple seasonal and interannual components in remotely sensed data. In Proceedings of the 6th World Multiconference on Systemics, Cybernetics and Informatics, Orlando, FL, USA, 14-18 July 2002.

42. Tucker, C.J.; Pinzon, J.E.; Brown, M.E. Global Inventory Modeling and Mapping Studies 2.0, 2004. Digital Media. Available online: http://staff.glcf.umd.edu/sns/htdocs/data/gimms/ (accessed on 8 March 2019).

43. Gallo, K.; Tarpley, D.; Mitchell, K.; Csiszar, I.; Owen, T.; Reed, B. Monthly fractional green vegetation cover associated with land cover classes of the Conterminous USA. Geophys. Res. Lett. 2001, 28, 2089-2092. [CrossRef]

44. Montandon, L.M.; Small, E.E. The impact of soil reflectance on the quantification of the green vegetation fraction from NDVI. Remote Sens. Environ. 2008, 112, 1835-1845. [CrossRef]

45. Carlson, T.N.; Rypley, D.A. On the relation between NDVI, fractional vegetation cover, and leaf area index. Remote Sens. Environ. 1997, 62, 241-252. [CrossRef]

46. Price, J.C. Estimating vegetation amount from visible and near infrared reflectances. Remote Sens. Environ. 1992, 41, 29-34. [CrossRef]

47. Hansen, M.; DeFries, R.; Townshend, J.R.G.; Sohlberg, R. UMD Global Land Cover Classification. 8 Kilometer. Version 1.0. 1981-1994; Department of Geography, University of Maryland: College Park, MD, USA, 1998.

48. Hansen, M.; DeFries, R.; Townshend, J.R.G.; Sohlberg, R. Global land cover classification at $1 \mathrm{~km}$ resolution using a decision tree classifier. Int. J. Remote Sens. 2000, 21, 1331-1365. [CrossRef]

49. Grell, G.; Dudhia, J.; Stauffer, D. A Description of the Fifth-Generation Penn State/NCAR Mesoscale Model (MM5); NCAR Technik Note; NCAR: Boulder, CO, USA, 1994.

50. Jerez, S.; Montavez, J.P.; Gomez-Navarro, J.J.; Jimenez-Guerrrero, P.; Jimenez, J.M.; Gonzalez-Rouco, J.F. Temperature sensitivity to the land-surface model in MM5 climate simulations over the Iberian Peninsula. Meteorol. Z. 2010, 19, 363-374. [CrossRef]

51. Dee, D.P.; Uppala, S.M.; Simmons, A.; Berrisford, P.; Poli, P.; Kobayashi, S.; Andrae, U.; Balmaseda, M.A.; Balsamo, G.; Bauer, P.; et al. The ERA-Interim reanalysis: Configuration and performance of the data assimilation system. Quart. J. R. Meteorol. Soc. 2011, 137, 553-597. [CrossRef]

52. Grell, G.A. Prognostic evaluation of assumptions used by cumulus parameterizations. Mon. Weather Rev. 1993, 121, 764-787. [CrossRef]

53. Dudhia, J. Numerical study of convection observed during the winter monsoon experiment using a mesoscale two-dimensional model. J. Atmos. Sci. 1989, 46, 3077-3107. [CrossRef]

54. Mlawer, E.; Taubman, S.; Brown, P.; Iacono, M.; Clough, S. Radiative transfer for inhomogeneous atmospheres: RRTM, a validated correlated-k model for the longwave. J. Geophys. Res. 1997, 102, 16663-16682. [CrossRef]

55. Hong, S.; Pan, H. Nonlocal boundary layer vertical diffusion in a Medium-Range Forecast Model. Mon. Weather Rev. 1996, 124, 2322-2339. [CrossRef]

56. Chen, F.; Dudhia, J. Coupling an advanced land-surface/hydrology model with the Penn State/NCAR MM5 modeling system. Part I: Model implementation and sensitivity. Mon. Weather Rev. 2001, 129, 569-585. [CrossRef]

57. Mahrt, L.; Ek, M. The influence of atmospheric stability on potential evaporation. J. Appl. Meteorol. 1984, 23, 222-234. [CrossRef]

58. Mahrt, L.; Pan, H. A two-layer model of soil hydrology. Bound. Layer Meteorol. 1984, 29, 1-20. [CrossRef]

59. Pan, H.L.; Mahrt, L. Interaction between soil hydrology and boundary-layer development. Bound. Layer Meteorol. 1987, 38, 185-202. [CrossRef]

60. Chen, F.; Mitchell, K.; Schaake, J.; Xue, Y.; Pan, H.L.; Koren, V.; Duan, Q.Y.; Ek, M.; Betts, A. Modeling of land surface evaporation by four schemes and comparison with FIFE observations. J. Geophys. Res. Atmos. 1996, 101, 7251-7268. [CrossRef]

61. Noilhan, J.; Planton, S. A simple parameterization of land surface processes for meteorological models. Mon. Weather Rev. 1989, 117, 536-549. [CrossRef] 
62. Jacquemin, B.; Noilhan, J. Sensitivity study and validation of a land surface parameterization using the HAPEX-MOBILHY data set. Bound. Layer. Meteorol. 1990, 52, 93-134. [CrossRef]

63. Gómez-Navarro, J.; Montávez, J.; Jiménez-Guerrero, P.; Jerez, S.; Lorente-Plazas, R.; González-Rouco, J.; Zorita, E. Internal and external variability in regional simulations of the Iberian Peninsula climate over the last millennium. Clim. Past 2012, 8, 25. [CrossRef]

64. Jerez, S.; Montavez, J.P.; Jimenez-Guerrero, P.; Gomez-Navarro, J.J.; Lorente-Plazas, R.; Zorita, E. A multi-physics ensemble of present-day climate regional simulations over the Iberian Peninsula. Clim. Dyn. 2013, 40, 3023-3046. [CrossRef]

65. Lorente-Plazas, R.; Montávez, J.; Jerez, S.; Gómez-Navarro, J.; Jiménez-Guerrero, P.; Jiménez, P. A 49 year hindcast of surface winds over the Iberian Peninsula. Int. J. Climatol. 2015, 35, 3007-3023. [CrossRef]

66. Peters-Lidard, C.D.; Zion, M.S.; Wood, E.F. A soil-vegetation-atmosphere transfer scheme for modeling spatially variable water and energy balance processes. J. Geophys. Res. Atmos. 1997, 102, 4303-4324. [CrossRef]

67. Gómez-Navarro, J.; Montávez, J.; Jerez, S.; Jiménez-Guerrero, P.; Zorita, E. What is the role of the observational dataset in the evaluation and scoring of climate models? Geophys. Res. Lett. 2012, 39. [CrossRef]

68. Fernández, J.; Montávez, J.; Sáenz, J.; González-Rouco, J.; Zorita, E. Sensitivity of the MM5 mesoscale model to physical parameterizations for regional climate studies: Annual cycle. J. Geophys. Res. Atmos. 2007, 112. [CrossRef]

(c) 2019 by the authors. Licensee MDPI, Basel, Switzerland. This article is an open access article distributed under the terms and conditions of the Creative Commons Attribution (CC BY) license (http:/ / creativecommons.org/licenses/by/4.0/). 



\title{
Article \\ Spatiotemporal Change of Plum Rains in the Yangtze River Delta and Its Relation with EASM, ENSO, and PDO During the Period of 1960-2012
}

\author{
Nina Zhu ${ }^{1,2,3}$, Jianhua Xu ${ }^{1,2,3, *}$, Kaiming $\mathrm{Li}^{4}$, Yang Luo ${ }^{5}$, Dongyang Yang ${ }^{1,2,3}$ and Cheng Zhou ${ }^{6}$ \\ 1 Key Laboratory of Geographic Information Science (Ministry of Education), East China Normal University, \\ Shanghai 200241, China; ninaecnu@126.com (N.Z.); yangdy@lreis.ac.cn (D.Y.) \\ 2 Research Center for East-West Cooperation in China, East China Normal University, Shanghai 200241, China \\ 3 School of Geographic Sciences, East China Normal University, Shanghai 200241, China \\ 4 School of Urban and Geography, Lanzhou City College, Lanzhou 730070, China; 1km_wd@126.com \\ 5 Jianhu Data Technology (Shanghai) Co., Ltd, Shanghai 201700, China; luoyang@jianhushuju.com \\ 6 Faculty of Tourism Management, Shanxi University of Finance \& Economics, Taiyuan 030006, China; \\ zhoutravel@163.com \\ * Correspondence: jhxu@geo.ecnu.edu.cn; Tel.: +86-21-54341187
}

Received: 16 April 2019; Accepted: 7 May 2019; Published: 9 May 2019

\begin{abstract}
The Plum Rains process is a complex process, and its spatiotemporal variations and influencing factors on different time scales still need further study. Based on a dataset on the Plum Rains in the Yangtze River Delta, from 33 meteorological stations during the period of 1960 to 2012, we investigated the spatiotemporal variations of Plum Rains and their relation with the East Asian Summer Monsoon (EASM), the El Niño-Southern Oscillation (ENSO), and the Pacific Decadal Oscillation (PDO) using an integrated approach that combines ensemble empirical mode decomposition (EEMD), empirical orthogonal function (EOF), and correlation analysis. The main conclusions were as follows: (1) the plum rainfall (i.e., the rainfall during the period of Plum Rains) showed a trend of increasing first and then decreasing, and it had a three-year and six-year cycle on the inter-annual scale and a 13-year and 33-year cycle on the inter-decadal scale. The effect of the onset and termination of Plum Rains and the daily intensity of plum rainfall on plum rainfall on the inter-annual scale was greater than the inter-decadal scale, (2) the EOF analysis of plum rainfall revealed a dominant basin-wide in-phase pattern (EOF1) and a north-south out-of-phase pattern (EOF2), and (3) ENSO and EASM were the main influencing factors in the three-year and six-year periods, respectively.
\end{abstract}

Keywords: plum rains; ensemble empirical mode decomposition (EEMD); empirical orthogonal function (EOF); East Asian summer monsoon; El Niño-southern oscillation; pacific decadal oscillation; the Yangtze River Delta; multi-time scales

\section{Introduction}

The Plum Rains are one of the typical climatic phenomena in the subtropical monsoon region. They refer to persistent rain in June and July every year in the Yangtze-Huaihe River region, Southern Taiwan, Liaodong Peninsula of China, and Southern Japan [1]. Every year in the spring, warm and humid air of the tropical ocean will enter the mainland from the sea, and the forces of the warm and humid air will gradually strengthen. Especially at the low altitude of two or three kilometers, there is often a very humid and strong southerly airflow from the ocean [1]. When it enters mainland China, it will meet the cold air from the north to the south [2,3]. When the warm and cold air meets, the junction will form a frontal surface, and precipitation will occur near the frontal surface. This forms the Plum Rains [4]. The Plum Rains are also called "Meiyu" in China, "Baiu" in Japan, and "changma" 
in Korea $[2,5,6]$. The temperature and humidity are very high during this period. In the 1930s, scholars began to study Plum Rains from different perspectives [7-12]. In a previous study, scholars have mainly concentrated on some typical large or medium regions (such as the middle and lower reaches of the Yangtze River Delta, located at the longitude of $110-122^{\circ}$ E and the latitude of $26^{\circ}-34^{\circ} \mathrm{N}$ ) [13-15]. As for the research methods applied in the previous studies, the classical statistical regression, wavelet analysis, neural network, and mechanism models have been used [16-18]. As for the research content, meteorological scholars in the previous studies have mainly focused on the internal dynamic process and external forcing factors of the atmosphere (such as sea temperature) influencing the degree and change mechanisms of the Plum Rains [19-23].

Yu et al. [24] built a new index of Plum Rains' intensity (IPRI) to analyze the spatiotemporal variation characteristics of Plum Rains in the areas along the Huaihe River in the Anhui province. The results were of great help in analyzing, assessing, and identifying flooding disasters. Chen et al. [25] simulated a heavy rainfall event during the period of Plum Rains using the Penn State-NCAR Mesoscale Model Version 5 (MM5). They found that there were strong interaction and positive feedback between the convective rainstorms embedded within the Mei-Yu front and the Mei-Yu front itself. Zhang et al. [26] developed indicators for the onset and retreat dates, duration, and Meiyu precipitation and analyzed the variations of Meiyu in the Yangtze-Huaihe River valley, which points out that Meiyu rainfall showed an increased trend during the period from 1954 to 2003. Zhu et al. [27] analyzed the Meiyu onset dates (MODs) in the middle and lower reaches of the Yangtze River valley and found that the beginning of June displays the average MOD in this region. However, due to the complexity of the Plum Rains process, there are still many issues that require further research, especially the relationship between the atmospheric circulation and the Plum Rains along with the spatiotemporal variations of the Plum Rains.

In previous studies, when analyzing the relationship between atmospheric circulation and Plum Rains, most meteorologists studied them from an overall perspective and rarely analyzed them on different time scales [28-30]. The relationship between atmospheric circulation and Plum Rains may be different on multi-time scales. Therefore, it is necessary to specifically analyze the relationship between them from the perspective of multi-time scales. In addition, due to regional differences, how to determine the characteristic of local Plum Rains and analyze its climate change, as well as study the consistency and particularity of local Plum Rains and regional Plum Rains climate change, is important. Industry and agriculture of the Yangtze River Delta play major roles in China's economy [31,32]. Frequent floods and droughts in the summer are harmful to agricultural production, transportation, and life, which will all cause huge economic losses [33,34]. Damage caused by Plum Rains is one of the main factors responsible for flood and drought disasters [35]. Therefore, the study of Plum Rains is not only conducive to industrial and agricultural production, but is also advantageous for improving the governments' awareness of disaster prevention. Thus, it can reduce loss of life and property during the period of floods and droughts and promote economic and social development.

When facing global climate change and frequent extreme climate events [36], how to understand the particularity and generality of the local Plum Rains and the relationship between the Plum Rains and atmospheric circulation on different time scales is an important scientific issue. For the above reasons, we select Shanghai, the Jiangsu province, and the Zhejiang province as a typical region. Based on a dataset from 33 meteorological stations during the period of 1960 to 2012, this study applies selected methods, including ensemble empirical mode decomposition (EEMD), empirical orthogonal function (EOF), and correlation analysis to investigate the spatiotemporal changes of plum rainfall and the relationship between plum rainfall and the East Asian Summer Monsoon (EASM), the El Niño-Southern Oscillation (ENSO), and the Pacific Decadal Oscillation (PDO). 


\section{Materials and Methods}

\subsection{Study Area and Data}

The study area includes most of the Jiangsu province, the Zhejiang province, and Shanghai, which are part of the middle and lower regions of the Yangtze River Delta. It is situated at a longitude of $116^{\circ} 18^{\prime} \mathrm{E}-123^{\circ} 00^{\prime} \mathrm{E}$ and latitude of $27^{\circ} 12^{\prime} \mathrm{N}-35^{\circ} 20^{\prime} \mathrm{N}$. Its climate belongs to the sub-tropical monsoon climate, and the average temperature ranges from 2 to $4{ }^{\circ} \mathrm{C}$ in January and is above $28^{\circ} \mathrm{C}$ in July. Annual precipitation is above $800 \mathrm{~mm}$ and the precipitation is mainly concentrated in the period of Plum Rains. The precipitation during the period of Plum Rains accounts for approximately $22.5 \%$ of the total annual precipitation. In addition, there are numerous lakes, and the recharge of the water mainly comes from atmospheric precipitation. It is well-known that this study area is one of the most developed areas in China with high levels of urbanization and industrialization. According to the Bulletin of the Sixth National Census, in 2010, the resident population had reached approximately 156 million [37].

Figure 1 shows the distribution of 33 meteorological stations, which are fairly uniformly distributed. The daily precipitation of 33 meteorological stations in the Yangtze River Delta from 1960 to 2012 comes from the China meteorological data network (http://data.cma.com). A uniform standard concerning the onset and termination of the Plum Rains was published on 12 May 2017 and implemented on 1 December 2017 (GB/T 33671-2017 Mei-yu Monitoring Indicators) [38]. From the first rainy day, the second day, the third day, etc., to the tenth day, if the ratio of the number of rainy days to the total number of days in the corresponding period is greater than or equal to $50 \%$, the first rainy day is the beginning of Plum Rains. There is no new rainy beginning date after July 20. From the last rainy day of the rainy season, 2 days ago, 3 days ago, etc., to 10 days ago, if the number of rainy-day accounts for more than or equal to $50 \%$ of the number of rainy days in the corresponding period, the last rainy day is the termination of Plum Rains. If the number of rainy days accounts for less than $50 \%$ of the number of rainy days in the corresponding period, the last rainy day cannot be the termination of Plum Rains. It is necessary to push one day forward from the last rainy day of the rainy season, and then calculate whether the day is the termination of the Plum Rains, according to the conditions of the termination of the Plum Rains. If it is still not, this method is followed until the termination of the Plum Rains is found. For the abnormal rain season, the termination of Plum Rains occurs the day before the first non-rainy day after the rain period enters August. The termination of Plum Rains should appear before the start of the fall. For the sake of simplicity, it was assumed that the onset and termination of the Plum Rains were the same for each station, and the plum rainfall of each station for every year accumulated, according to the daily rainfall and the onset and termination of the Plum Rains, while the annual plum rainfall in the whole area was the average of the 33 stations. According to previous studies [25-27], we selected the PDO index, ENSO index, and EASM index to investigate the relationship between them and plum rainfall. The PDO index was obtained from http://research.jisao.washington.edu/pdo/PDO.latest. The ENSO data were gathered from http://research.jisao.washington.edu/datasets/globalsstenso. EASM index was defined as an area-averaged seasonally dynamic normalized seasonality index at $850 \mathrm{hPa}$ within the East Asian monsoon domain $\left(10^{\circ}-40^{\circ} \mathrm{N}, 110^{\circ}-140^{\circ} \mathrm{E}\right)$. The EASM index data were from the literature $[39,40]$. 


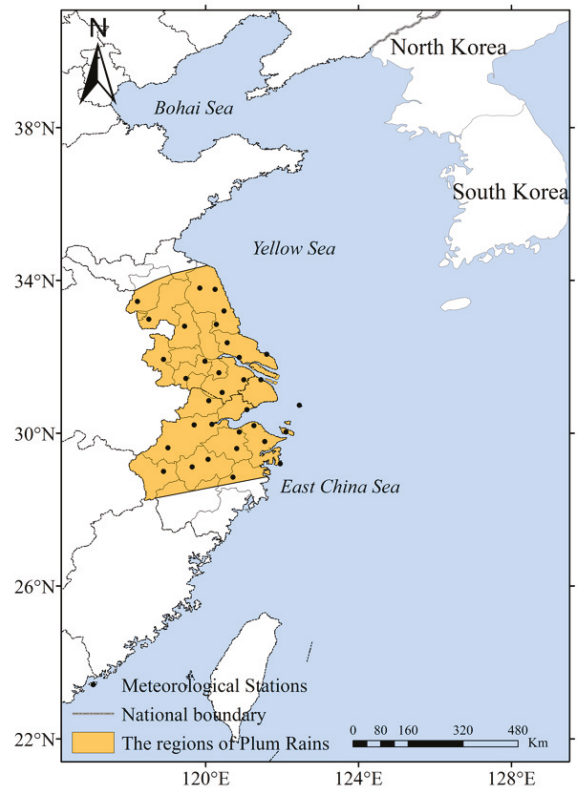

Figure 1. The spatial distribution of 33 meteorological stations and the study area.

\subsection{Methodology}

To investigate the spatiotemporal variation of Plum Rains and its relation to EASM, ENSO, and PDO, we used an integrated approach combining the EEMD, EOF, and correlation analysis (Figure 2). We first showed the features of plum rainfall. Then, we used the EEMD method to decompose the plum rainfall into four intrinsic mode functions (i.e., IMF1, IMF2, IMF3, and IMF4) and a trend (RES). The influencing factors of the plum rainfall were also studied. We revealed the spatial pattern of the plum rainfall over the Yangtze River Delta during the period of 1960 to 2012. Lastly, we assessed the relationship between the EASM, ENSO, PDO, and plum rainfall on different time scales.

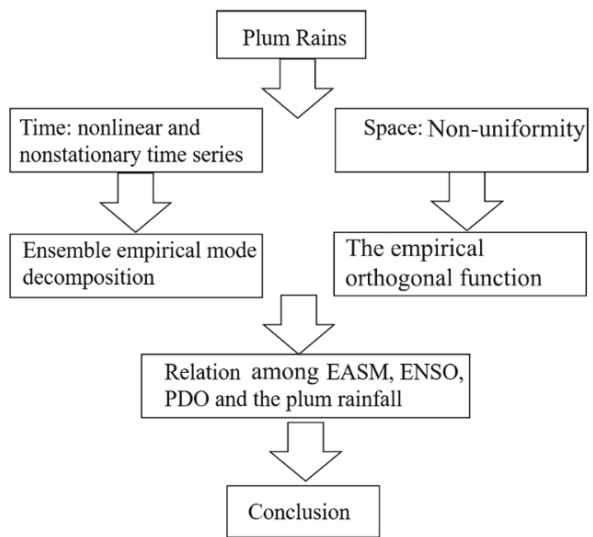

Figure 2. The framework of this study. 


\subsubsection{Ensemble Empirical Mode Decomposition}

Ensemble empirical mode decomposition (EEMD) is utilized to analyze the nonlinear and periodic characteristics of the plum rainfall. It is based on empirical mode decomposition (EMD), and improvement of the EMD [41,42]. EMD is an effective method for dealing with the nonlinear and nonstationary time series problem, and it also has some advantages, such as self-adaptability, orthogonality, and completeness, etc. [43]. However, some defects still exist. One of the biggest defects is mode mixing, which makes a signal have different scales or frequencies in the same component or be decomposed into different components [44]. In order to solve this problem, Wu and Huang [45] proposed a new method, known as the EEMD, to better solve nonlinear problems. It can adaptively decompose the time-frequency, according to the local time variation features, and is completely free from the constraints of the Fourier transform so that it can obtain a high time-frequency resolution [41]. Therefore, we use the EEMD, which is the best decomposition method to extract the changes of various scales in the plum rainfall signal from the plum rainfall time series. The steps of the EEMD are as follows.

1. White noise with specified amplitude is added to the sequence of the original signal:

$$
x_{i}(t)=x(t)+n_{i}(t)
$$

where $x_{i}(t)$ is the new signal after adding the white noise, $x(t)$ is the original signal, and $n_{i}(t)$ is white noise.

2. By decomposing the signal, to which white noise has been added, using the EMD can result in IMF1 (the first Intrinsic Mode Function).

3. Adding the same white noise in the sequence that has separated out the IMF1 can result in IMF2 (the Second Intrinsic Mode Function) by using the EMD.

4. Repeating the above steps can result in different IMFs (the Intrinsic Mode Functions). In general, the standard deviation (SD) (generally be set as $0.2-0.3$ ) between two consecutive results is used as a criterion for stopping the generation of IMFs [45]. When the SD reaches a certain threshold, the generation of IMFs is stopped. In this study, we set the threshold to 0.2 according to a previous study [18] and obtained four IMFs.

5. The IMFs obtained by each decomposition are collectively averaged so that the added white noises cancel each other out and can be used as the final decomposition result.

$$
C_{j}(t)=\frac{1}{N} \sum_{i=1}^{N} C_{i j}(t)
$$

where $C_{j}(t)$ is the final $j$ th IMF component, $N$ is the number of white noise series, and $C_{i j}(t)$ denotes the $j$ th IMF from the added white noise trial. From the above decomposition, the IMFs and trend term can be obtained at different scales. Next, the original signal is reconstructed.

$$
\mathrm{x}(\mathrm{t})=\sum_{j=1}^{n} C_{j}(t)+r_{n}(t)
$$

After decomposing the original signal, each component should be tested for its significance. They can be tested by means of a set of white noise ensemble disturbance to obtain each IMF's credibility [33]. The energy spectral density of the $\mathrm{k} t h$ IMF is assumed to be the following.

$$
E_{k}=\frac{1}{N} \sum_{j=1}^{N}\left|I_{k}(j)\right|^{2}
$$


where $\mathrm{N}$ is the length of the IMF component and $I_{k}(j)$ denotes the kth IMF component. The white noise sequence is tested by the Monte Carlo method [44]. Then, a simple equation that relates the averaged energy density $\bar{E}_{k}$ to the averaged period $\bar{T}_{k}$ is obtained.

$$
\bar{E}_{k}+\ln \left\{\bar{T}_{k}\right\}=0
$$

In a figure of $\ln \left(\bar{T}_{k}\right)$ as the $\mathrm{x}$-axis and $\ln \left(E_{k}\right)$ as the $\mathrm{y}$-axis, the relations between them can be expressed by a straight line whose slope is -1 . The IMF component of the white noise series should, in theory, be distributed in a line. However, a little actual deviation is produced, so the confidence interval for the energy spectrum distribution of the white noise is presented as follows.

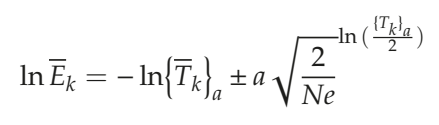

where $a$ is the significance level. If the energy of the IMF is located above the confidence curve at a given significance level (e.g., $a=0.05$ ), periodic oscillation has passed the significance test, and it can be assumed that the information at the selected confidence level contains physical meaning. Its corresponding oscillation period is the main oscillation period of the original sequence. However, if the energy of the IMFs falls outside the confidence curve at a given significance, it is considered to have not passed the significance test $[42,46]$.

\subsubsection{The Empirical Orthogonal Function}

The spatiotemporal variation of plum rainfall has always been a hot issue. Different methods have been used to analyze it. The empirical orthogonal function (EOF), also known as the eigenvector analysis or principal component analysis (PCA), can describe the original variable field with fewer spatial distribution modalities and can cover most of the information in the original variable field [47,48]. It is helpful to analyze the spatiotemporal variations of the climate element field, and has become an important method for analyzing the characteristics of the variable field in climate research. The method was first proposed by the statistician Pearson in 1902, and then introduced into the analysis of climate problems by Lorenz (1956) [49]. Its analysis principle is as follows.

A climate variable field can be seen as a function of time and space. Suppose a climate variable field has $m$ elements, and the time length is $n$, then the following is true.

$$
X=\left[\begin{array}{cccc}
x_{11} & x_{12} & \ldots & x_{1 n} \\
x_{21} & x_{22} & \ldots & x_{2 n} \\
\vdots & \vdots & \vdots & \vdots \\
& & & \\
x_{m 1} & x_{m 2} & \ldots & x_{m n}
\end{array}\right](i=1,2, \ldots, m ; j=1,2, \ldots, n)
$$

where $m$ is the spatial point, which can be the grid point or the observation point, $n$ is the point in time, which is the number of samples, and $x_{i j}$ represents the observation value of the point $i$ at the point $j$. EOF expansion is employed to decompose the above equation into the sum of the product of the space function and the time function, which is shown below.

$$
\mathrm{X}=V T=\sum_{k=1}^{m} v_{k j} t_{k j}, i=1,2, \ldots, m ; j=1,2, \ldots, n
$$

where $V$ represents the eigenvector matrix, and $T$ represents the time coefficient matrix. According to the orthogonality, $V$ and $T$ satisfy the following conditions. 


$$
\left\{\begin{array}{l}
\sum_{i=1}^{m} v_{i k} v_{i l}=1 \quad k=l \\
\sum_{i=1}^{m} v_{i k} v_{i l}=0 \quad k \neq l
\end{array}\right.
$$

Next, according to Equation (10), the eigenvector, the eigenvalue, and the time coefficient matrix $T$ can be obtained. The eigenvalues are arranged in descending order $\left(\lambda_{1} \geq \lambda_{2} \geq \ldots \geq \lambda_{m} \geq 0\right)$, and the variance contribution rate of each eigenvector $\left(R_{k}\right)$ can be obtained by the following formula.

$$
R_{k}=\lambda_{k} / \sum_{i=1}^{m} \lambda_{i}, k=1,2, \ldots, p(p<m)
$$

\section{Results}

\subsection{The Time Variation of Plum Rainfall}

As seen in Figure 3, the plum rainfall in the Yangtze River Delta over the period of 1960 to 2012 presented an increasing and then decreasing trend. A turning point appeared in the 1990s. Before that, the plum rainfall showed an increasing trend, and after that, the plum rainfall showed a decreasing trend. The plum rainfall was higher in the years of 1969, 1982, 1996, and 1998, and lower in the years of $1965,1971,1978$, and 2006. In addition, it can be seen that the plum rainfall was not linear, but shows a nonlinear variation trend (see Figure 3). Therefore, a nonlinear method should be used to analyze the nonlinear and non-stationary variations of plum rainfall.

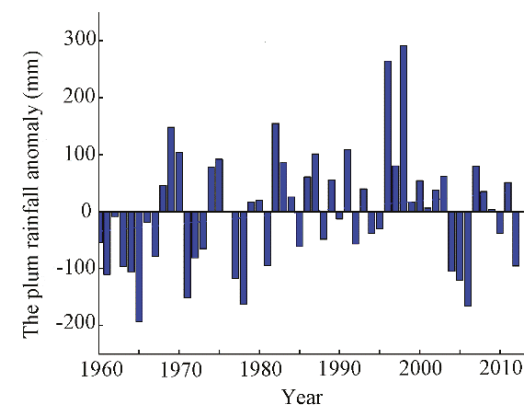

Figure 3. Anomaly in plum rainfall during the period of 1960 to 2012 (The axis of abscissas represents the years, and the axis of ordinates represents a plum rainfall anomaly, which is the result of subtracting the mean from the original value).

As we know, the formation process of Plum Rains is a complex nonlinear system, which is influenced by natural factors and human activities [50], and has many uncertainties, such as ambiguity and randomness. Simple statistical analysis, such as linear regression analysis and correlation analysis, can only describe linear time series, and cannot reveal the regularity of nonlinear and non-stationary time series. Studies have shown that EEMD is an improvement of EMD [41] and exhibits a stronger local performance than wavelet analysis [51,52]. Therefore, we used the EEMD to extract the variations of various scales in terms of the plum rainfall, the onset of Plum Rains, the termination of Plum Rains, and the daily intensity of the plum rainfall signal from their original time series to reveal the oscillating mode structure characteristics at different time scales and explore evolution characteristics of these different scale oscillations.

Figure 4 shows the EEMD results of the four-time series. There were four IMFs (IMF1-4) and one trend component (RES) of plum rainfall, the onset of Plum Rains, the termination of Plum Rains, and the daily intensity of plum rainfall, respectively. The components represent the oscillation characteristics 
from high to low frequency of the original sequence on different scales and all have a specific physical meaning, while the tendency term represents the variation characteristic as a whole [42]. As shown in Figure 4a, plum rainfall displayed three-year (IMF1) and six-year (IMF 2) periodic fluctuation at the inter-annual scale and 14-year (IMF3) and 33-year (IMF4) periodic variation at the inter-decadal scale. In other words, there may be some dry Plum Rains seasons after a few wet Plum Rains seasons. The result is useful for local governments and farmers to predict and mitigate the effects of droughts and floods. The trend term reflects the variations of plum rainfall, which increased gradually before the 1990s and then decreased gradually. However, previous studies showed that the plum rainfall in the YRD presented an increasing trend in past decades $[28,53]$. The difference is that they analyzed the variations of plum rainfall from the perspective of the linear trend, but we used the nonlinear method. It can be seen that previous studies did not reflect details of the variations of plum rainfall, which illustrates that the EEMD is an optimal method for dealing with nonlinear problems. In addition, we produced EEMD results for the onset and termination of Plum Rains and the daily intensity of plum rainfall (Figure 4b-d). The onset of Plum Rains exhibited three-year (IMF1) and six-year (IMF2) periodic fluctuation at the inter-annual scale and 14-year (IMF3) and 49-year (IMF4) periodic variation at the inter-decadal scale. The termination of Plum Rains displayed three-year (IMF1), six-year (IMF2), and nine-year (IMF3) periodic fluctuation at the inter-annual scale and 24-year (IMF4) periodic variation at the inter-decadal scale. The daily intensity of plum rainfall showed three-year (IMF1) and five-year (IMF2) periodic fluctuation at the inter-annual scale and 27-year (IMF3) and 51-year (IMF4) periodic variation at the inter-decadal scale. It can be seen that the plum rainfall had similar cycles with the onset and termination of Plum Rains and the daily intensity of plum rainfall on the inter-annual scale. Their trend terms were the same as those for plum rainfall, which means that the variation of plum rainfall is mainly affected by the onset and termination of Plum Rains and the daily intensity of plum rainfall, and the result was consistent with previous studies [13,15]. However, unlike previous studies, the effect of the onset and termination of Plum Rains and the daily intensity of plum rainfall on the inter-annual scale is greater than on the inter-decadal scale.

It is necessary to conduct significant tests in order to determine whether each component is a result of simple noise, or a signal that has physical meaning. In Figure 5, the horizontal coordinate represents periodic data and the vertical coordinate represents the energy spectrum density with four confidence levels, which are $80 \%, 90 \%, 95 \%$, and $99 \%$. It indicates that the IMF passes the significance test and has many physical meanings if it falls above the confidence level. Otherwise, IMF contains pure white noise. In other words, more or less physical meaning actually means strong or weak oscillations within a certain range. IMF1, IMF2, and IMF3 of plum rainfall fell above the confidence level of $90 \%$ and IMF4 of plum rainfall fell between the confidence level of $80 \%$ and 90\%. IMF1, IMF2, and IMF3 comprised a more definite physical meaning but not white noise, and IMF4 contained less physical meaning. IMF1 and IMF4 of the onset of Plum Rains fell above the confidence level of 95\%, while IMF2 and IMF3 of the onset of Plum Rains fell below the confidence level of 90\%. IMF1, IMF2, and IMF3 of the termination of Plum Rains fell above the confidence level of $90 \%$ while IMF4 fell below the confidence level of $90 \%$. IMF1, IMF2, and IMF3 of the intensity of plum rainfall fell above the confidence level of $90 \%$, while IMF4 fell below the confidence level of $80 \%$.

Each component's variation contribution rate was calculated to compare each component and the inherent oscillation characteristics in the original sequence. Table 1 presents the results of the variance contribution rates of the EEMD for the plum rainfall, the onset and termination of Plum Rains, and the intensity of plum rainfall. Significant IMFs are shown in bold in Table 1 . The changes of each component are the common consequences of the internal dynamic process and the external force factors of the atmosphere. We can note that the largest variance contribution rate was IMF1, followed by IMF2, RES, IMF3, and IMF4 for plum rainfall and the intensity of plum rainfall. The largest variance contribution rate was IMF1, followed by IMF2, RES, IMF4, and IMF3 for the onset of plum rainfall. Additionality, the largest variance contribution rate was IMF1, followed by IMF2, IMF3, IMF4, and RES for the termination of Plum Rains. Although the variance contribution rate of each component is 
different for plum rainfall, the onset and termination of Plum Rains, and the intensity of plum rainfall, their common point is that the variance contribution rate on the inter-annual scale is greater than the inter-decadal scale.
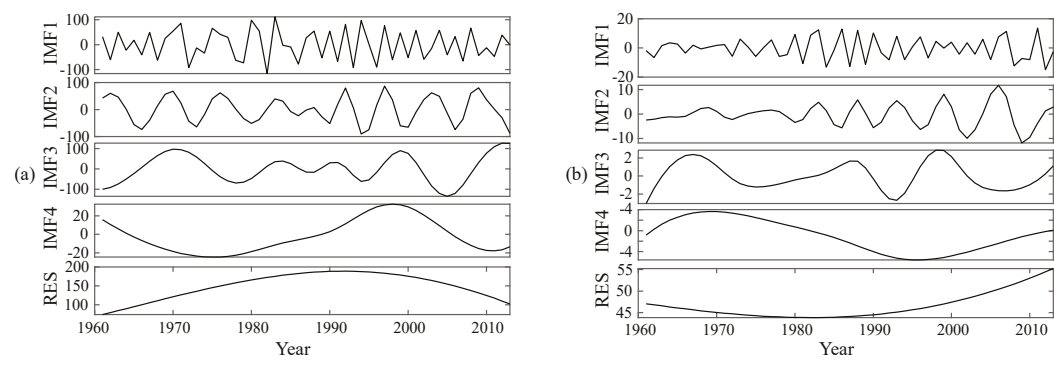

(b)
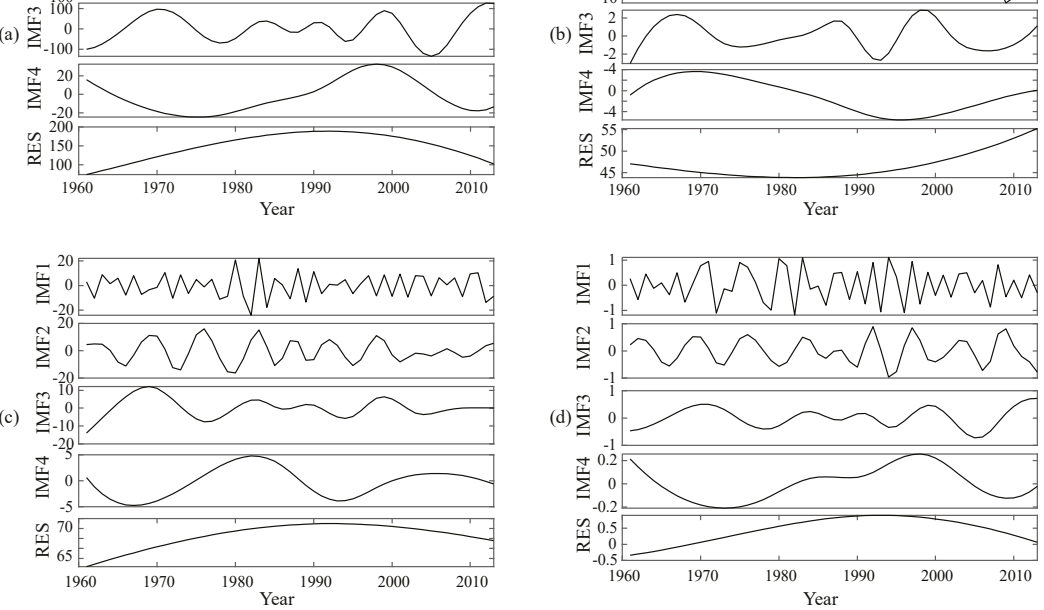

Figure 4. IMFs and the trend component of (a) The plum rainfall. (b) The onset of Plum Rains. (c) The termination of Plum Rains. (d) The daily intensity of plum rainfall during the period of 1960 to 2012.
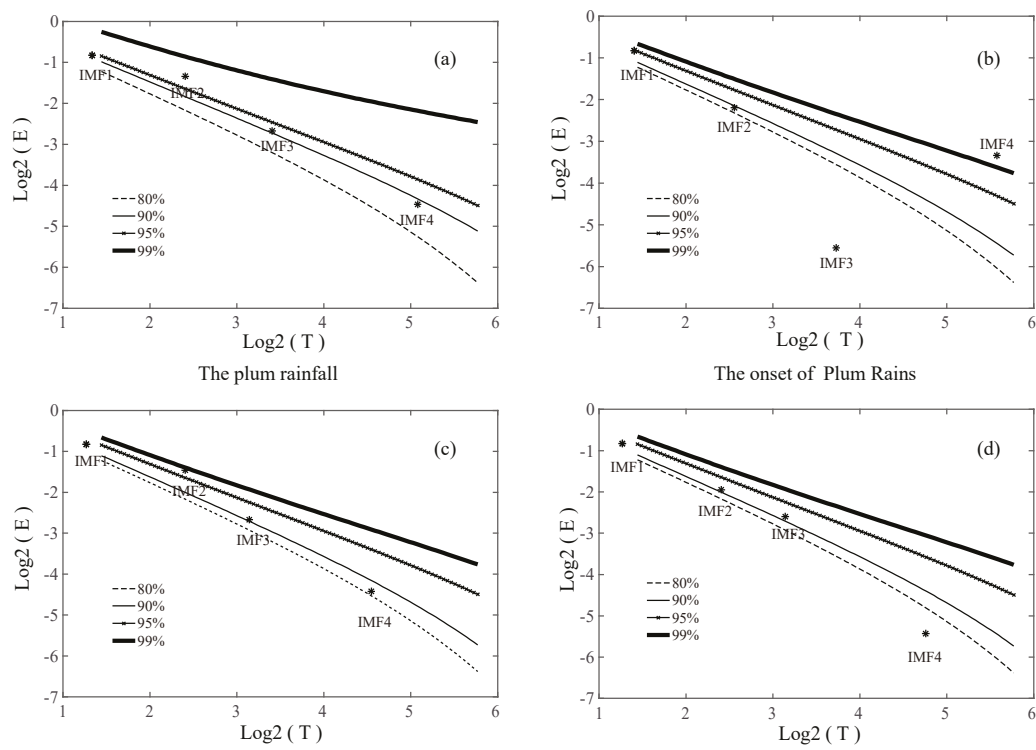

The termination of Plum Rains

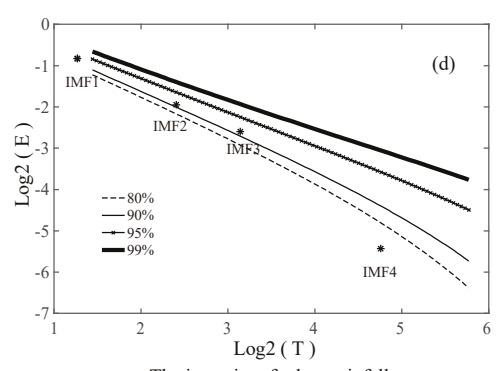

The intensity of plum rainfall

Figure 5. Significance test for the IMFs of (a) the plum rainfall, (b) the onset of Plum Rains, (c) the termination of Plum Rains, and (d) the intensity of plum rainfall during the period of 1960 to 2012. 
Table 1. The variance contribution rates of EEMD for plum rainfall, the onset and termination of Plum Rains, and the intensity of plum rainfall.

\begin{tabular}{cccccc}
\hline & \multicolumn{5}{c}{ Variance Contribution Rate (\%) } \\
\cline { 2 - 5 } & IMF1 & IMF2 & IMF3 & IMF4 & RES \\
\hline The plum rainfall & $\mathbf{4 1 . 0 4}$ & $\mathbf{2 8 . 3 3}$ & $\mathbf{1 4 . 2 0}$ & 2.63 & 16.14 \\
The onset of Plum Rains & $\mathbf{5 5 . 9 1}$ & 21.21 & 2.23 & $\mathbf{9 . 1 7}$ & 9.22 \\
The termination of Plum Rains & $\mathbf{5 1 . 9 1}$ & $\mathbf{3 3 . 8 5}$ & $\mathbf{1 5 . 2 0}$ & 4.19 & 3.12 \\
The intensity of plum rainfall & $\mathbf{4 3 . 6 1}$ & $\mathbf{2 0 . 4 3}$ & $\mathbf{1 2 . 8 0}$ & 1.93 & 14.31 \\
\hline
\end{tabular}

\subsection{Spatial Pattern of Plum Rainfall}

In order to explore the spatial pattern variation of plum rainfall during the period of 1960 to 2012, the EOF method is used. First, we obtained six principal components and they passed the North test [54]. The main results are shown in Table 2. It can be seen that the variance contribution rate of the first principal component was the largest, which was 50.48. The variance contribution rate of the second principal component decreased rapidly, and the variance contribution rate of the third and other principal components was small. The variance contribution rate of the first two principal components reached $70 \%$. Therefore, we only gave the eigenvector fields corresponding to the first two principal components.

Table 2. The variance contribution rates and the cumulative variance contribution rates of six principle components.

\begin{tabular}{ccc}
\hline Principal Component & Variance Contribution Rate (\%) & Cumulative Variance Contribution Rate (\%) \\
\hline 1 & 50.48 & 50.48 \\
2 & 18.57 & 69.05 \\
3 & 8.05 & 77.10 \\
4 & 5.23 & 82.33 \\
5 & 3.72 & 86.05 \\
6 & 1.53 & 87.58 \\
\hline
\end{tabular}

Figure 6a shows the first eigenvector field and all values are positive. This means that the increase or decrease of plum rainfall is consistent in the entire region. That is, if the value is positive, the plum rainfall in the entire study region will increase, and, if the value is negative, the plum rainfall in the entire study region will decrease, so it can be said that it is affected by the large-scale atmospheric circulation. The high value was mainly distributed in the northern part of the region, which indicates that it was the region with the highest variability of plum rainfall and it was the most sensitive region of drought and flood. The low value was mainly distributed in the southwest part of this region, which indicates that it was the region with a low variability of plum rainfall. These results illustrate that the plum rainfall is also affected by local factors. The related temporal coefficient curve (Figure 6c) mostly depicts variations on 4-year to 6-year time scales, which are similar to the EEMD result. Results of EOF and EEMD can be verified with each other. The results of EOF can prove the rationality of EEMD, and the results of EEMD can also prove the rationality of EOF. In addition, the time coefficient in 1996 was the largest and positive, which indicates that the plum rainfall in this year was the highest. This was a typical rainy year, followed by 1982 and 1991. The time coefficients in 1965, 1971, 1978, and 2006 were the smallest and negative, which indicates that they were the typical years of little plum rainfall.

It can be seen from Figure $6 \mathrm{~b}$ that there was a large difference between the first eigenvector field and the second eigenvector field. From Figure $6 \mathrm{~b}$, we can see that the positive values were distributed in the north of the region, while the negative values were distributed in the south of the region. This indicates that the plum rainfall showed an out-of-phase pattern of about $30^{\circ} \mathrm{N}$ between the north and south area. This means that there is less plum rainfall in the south when there is more plum rainfall in the north and there is more plum rainfall in the south when there is less plum rainfall 
in the north. The reason for this phenomenon is mainly due to the different location of the Plum Rains' belt every year. When the Plum Rains' belt stays in the south of the Yangtze River for a long time, there is a lot of plum rainfall in the south. When the Plum Rains' belt stays in the Jiang-Huai area for a long time, there is more plum rainfall in the north. Figure 6d shows that the time coefficient in 1991 was the largest and positive, which meant that it was the typical year with more plum rainfall in the north and less plum rainfall in the south, which was followed by 1996 and 2003. The time coefficient in 1992 was the smallest and negative, which meant that it was the typical year with more plum rainfall in the south and less plum rainfall in the north.

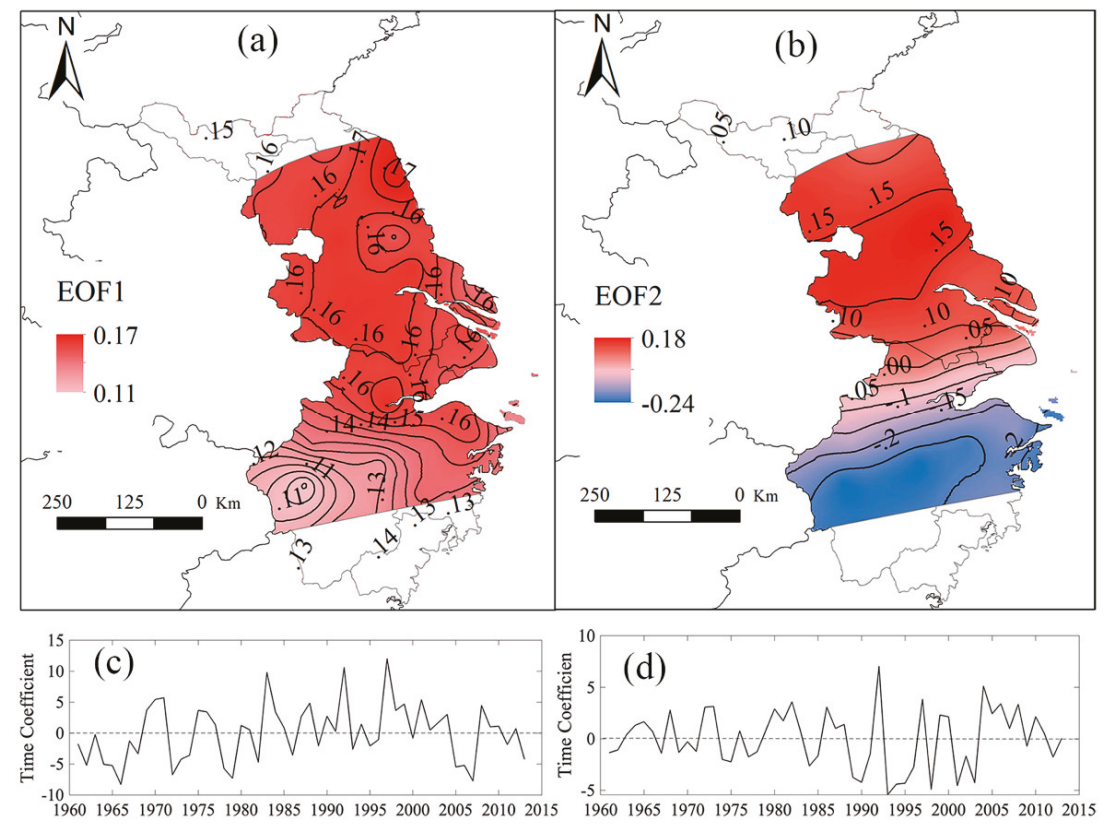

Figure 6. The spatial patterns of the two leading EOF modes of plum rainfall: (a) EOF 1, (b) EOF 2, and the corresponding $(\mathbf{c}, \mathbf{d})$ normalized temporal coefficients.

\subsection{The Relation among EASM, ENSO, PDO, and Plum Rainfall}

The variations of plum rainfall are complex and have a direct relationship with atmospheric circulation. Previous studies have analyzed the influencing factors of plum rainfall on the whole [55-57], while ignoring the relationship between them in detail. Therefore, we have tried to explore the impact of EASM, ENSO, and PDO on plum rainfall from multi-time scales. Table 3 shows the EEMD results for plum rainfall, EASM, ENSO, and PDO. There were four IMF components for each index and they all had similar periods on both the inter-annual scale and the inter-decadal scale. This means that there is a relationship between EASM, ENSO, PDO, and plum rainfall, but the specific relationship between them at different time scales still needs to be discussed. However, the fourth IMF component of plum rainfall was different from EASM and ENSO, and the period of EASM and ENSO was longer than the period of plum rainfall. The period of PDO was shorter than the period of plum rainfall.

We performed significance tests to determine whether each component of EASM, ENSO, and PDO is a physically meaningful signal, or the result of simple noise. In Figure 7, IMF2 and IMF4 of EASM fell above the confidence level of $90 \%$, while IMF1 and IMF3 fell below the confidence level of $90 \%$, which meant that IMF2 and IMF4 contained more physical meaning and IMF1 and IMF3 contained more white noise. IMF1 and IMF4 of ENSO fell above the confidence level of $90 \%$, while IMF2 and IMF3 of ENSO fell below the confidence level of $80 \%$, which meant that IMF1 and IMF4 contained 
more physical meaning while IMF2 and IMF3 contained less physical meaning. IMF1, IMF2, and IMF4 of PDO fell above the confidence level of $90 \%$ and IMF3 of PDO fell between the confidence level of $80 \%$ and $90 \%$. This meant that IMF1, IMF2, and IMF4 comprised a more definite physical meaning, and IMF3 contained a less physical meaning. Significant IMFs are shown in bold in Table 3.

Table 3. The EEMD results of the plum rainfall, EASM, ENSO, and PDO (The numbers in the table represent the cycle of the plum rainfall, EASM, ENSO, and PDO on the four components (IMF1-4), respectively).

\begin{tabular}{ccccc}
\hline & \multicolumn{4}{c}{ Cycle (Year) } \\
\cline { 2 - 5 } & IMF1 & IMF2 & IMF3 & IMF4 \\
\hline Plum rainfall & 3 & $\mathbf{6}$ & $\mathbf{1 4}$ & 33 \\
EASM & 3 & $\mathbf{6}$ & 14 & $\mathbf{4 8}$ \\
ENSO & $\mathbf{4}$ & 6 & 11 & $\mathbf{4 9}$ \\
PDO & $\mathbf{4}$ & 7 & 14 & $\mathbf{2 8}$ \\
\hline
\end{tabular}
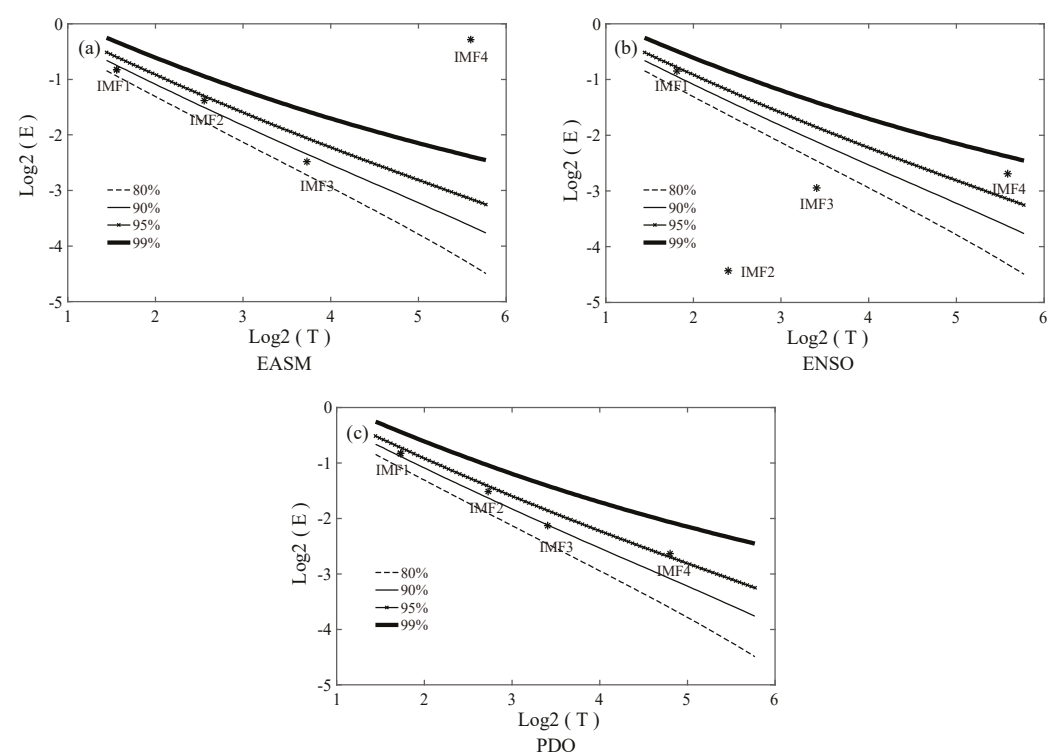

Figure 7. Significance test for the IMFs of (a) EASM, (b) ENSO, and (c) PDO during the period of 1960 to 2012.

Then, the correlation analysis was applied in order to understand the relation between plum rainfall and EASM, ENSO, and PDO more clearly. We first obtained the components of plum rainfall, EASM, ENSO, and PDO on four-time scales, and then calculated the correlation of plum rainfall and EASM, ENSO, and PDO on each time scale, respectively. The results are shown in Table 4. Significant correlations are shown in bold. On the inter-annual scale, IMF2 of plum rainfall had a negative and significant correlation with IMF2 of EASM. The result was similar to the results of some previous studies [58-60], but the difference was that they did not discuss the relation between plum rainfall and EASM on multi-time scales. Our result indicated that EASM had a significant impact on plum rainfall on an interannual scale rather than on the entire time scale. The correlation between IMF1 of plum rainfall and IMF1 of ENSO was positive and significant, which indicated that ENSO had a significant influence on plum rainfall in a three-year periodic fluctuation. On the inter-decadal scale, although all components of plum rainfall had some association with the components of EASM and 
ENSO, neither of them passed the significance test. It can be said that EASM and ENSO were not the main influencing factors of plum rainfall on the inter-decadal scale. The correlation between IMF4 of plum rainfall and IMF4 of PDO was positive, but the correlation between IMF3 of plum rainfall and IMF3 of PDO was negative. From the above results, we know that IMF4 of plum rainfall and IMF3 of PDO were not significant. Therefore, we cannot say that PDO was the main influencing factor of plum rainfall on the inter-decadal scale during the period of 1960 to 2012, and the relationship between plum rainfall and PDO needs to be further confirmed. This study gives a simple correlation between them. In summary, ENSO and EASM were the main influencing factors in the three-year and six-year periods, respectively, and the main influencing factors on the inter-decadal scale remains to be further studied. This means that on the time scale of three years, the plum rainfall is mainly affected by ENSO. On the time scale of six years, the plum rainfall is mainly affected by EASM. Therefore, it is necessary to separate the diverse time scales when forecast and climate changes are studied.

Table 4. The Pearson correlation coefficients between plum rainfall and EASM, ENSO, and PDO (1960 to 2012).

\begin{tabular}{ccccc}
\hline & IMF1 & IMF2 & IMF3 & IMF4 \\
\hline \multirow{2}{*}{ EASM } & 0.05 & $\mathbf{- 0 . 1 8}$ & -0.18 & 0.11 \\
& $(0.37)$ & $\mathbf{( 0 . 0 9 )}$ & $(0.10)$ & $(0.21)$ \\
\hline \multirow{2}{*}{ ENSO } & $\mathbf{0 . 2 4}$ & 0.04 & 0.16 & -0.00 \\
& $\mathbf{( 0 . 0 9 )}$ & $(0.78)$ & $(0.26)$ & $(0.98)$ \\
\hline \multirow{2}{*}{ PDO } & 0.07 & -0.01 & $\mathbf{- 0 . 2 4}$ & $\mathbf{0 . 2 4}$ \\
& $(0.60)$ & $(0.96)$ & $\mathbf{( 0 . 0 8 )}$ & $\mathbf{( 0 . 0 8 )}$ \\
\hline
\end{tabular}

Notes: The value in parentheses indicates the $p$ value.

\section{Discussion}

This study first investigated the multi-time scale temporal variation of plum rainfall in the YRD by using the EEMD method and then analyzed the spatial pattern of plum rainfall by using the EOF method. Lastly, we showed the relationship between plum rainfall and EASM, ENSO, and PDO. We found that, in the past 53 years, plum rainfall has three-year and six-year cycles on the inter-annual scale and 14-year and 33-year cycles on the inter-decadal scale. The plum rainfall variability was dominated by the inter-annual scale. In addition, the first EOF showed in-phase changes of plum rainfall across the whole study region and the second EOF showed an out-of-phase plum rainfall pattern between the north and south areas of about $30^{\circ} \mathrm{N}$. The changes of plum rainfall were affected by ENSO and EASM in the three-year and six-year periods, respectively. Whether PDO was the main influencing factor on the inter-decadal scale remains to be further studied.

Few studies have analyzed variations of the Plum Rains from multi-time scales, and most of them have used the wavelet analysis method and rarely used the EEMD method $[17,26]$. It has been proven that the EEMD method is superior to the wavelet analysis method [51,52]. Our study used the EEMD method to analyze the multi-time-scale variations of plum rainfall, the multi-time-scale variations of the onset of Plum Rains, the termination of Plum Rains, and the intensity of plum rainfall, which can, more accurately, identify their variation periods. We found that plum rainfall had three-year and six-year cycles on the inter-annual scale and 14-year and 33-year cycles on the inter-decadal scale. IMF1, IMF2, and IMF3 all passed the significance test. However, IMF4 of plum rainfall was not significant, even though it accounted for a large fraction of the variance, which meant that it was not possible to say whether there was a 33-year cycle in plum rainfall. Wei and Xie [17] used the wavelet analysis method to analyze the multi-time scales variations of plum rainfall, and they found that the plum rainfall had cycles of 2 to 3 years, 6 to 7 years, 23 to 24 years, and 36 to 37 years in the entire Yangtze-Huaihe River region. Zhang et al. [26] pointed out that plum rainfall existed for about a three-year to six-year short cycle and 11-year and 20-year-long cycles by using the wavelet analysis method in the entire Yangtze-Huaihe River region. Bai et al. [18] showed that the plum rainfall had three-year, six-year, 
13-year, and 24-year cycles in the Middle-Lower Reaches of the Yangtze River. Compared with previous studies, we found that plum rainfall has similar variations on the interannual scale, but the variation on the interdecadal scale is very large in different regions. This is mainly due to the fact that, on the interdecadal scale, the influence of various factors on plum rainfall in different regions is more complicated, which illustrates the importance of regional differences. In addition, we also found that the onset of Plum Rains had three-year, six-year, 14-year, and 49-year cycles, but six-year and 14-year cycles were not significant, even though they accounted for a large fraction of the variance, which meant that the onset of Plum Rains only had significant three-year and 49-year cycles. Similarly, the termination of Plum Rains had significant three-year, six-year, and nine-year cycles (IMF4 is not significant), and the intensity of plum rainfall had significant three-year, five-year, and 27-year cycles (IMF4 is not significant). It can be seen that the onset of Plum Rains, the termination of Plum Rains, and the intensity of plum rainfall had similar cycles with plum rainfall, which reveals their relationship with plum rainfall on multi-time scales. Previous studies have analyzed the relationship between the onset of Plum Rains, the termination of Plum Rains, and the intensity of plum rainfall as well as plum rainfall from the perspective of the linear trend [61,62]. Prior studies did not discuss it from multi-time scales. We can see from the above results that variations of the onset of Plum Rains, the termination of Plum Rains, and the intensity of plum rainfall are nonlinear, so it is necessary to explore their relationship at multi-time scales.

As far as the spatial pattern of plum rainfall is concerned, Chen and Li [63] analyzed the spatial pattern in the Yangtze-Huaihe River region during the period of 1960 to 2012 using the EOF method. They found that there were four modes, the first of which was characterized by the simultaneous increase or decrease of the plum rainfall in the whole region, and the second of which was characterized by more plum rainfall in the north (south) and less plum rainfall in the south (north). Our result was consistent with this. However, the difference was that there were two other local spatial patterns in their study. It may be because our study region is small, which cannot recognize the smaller spatial pattern. Li et al. [64] found a different spatial pattern of plum rainfall. They pointed out that the first mode of plum rainfall showed a spatial pattern of more (less) plum rainfall in the south and less (more) plum rainfall in the north, and the second mode showed a spatial pattern of more (less) plum rainfall in the middle and less (more) plum rainfall on both sides, which was different from our results. This is mainly due to regional differences and differences in research times. Therefore, it can be seen that, although the Plum Rains season is formed by some common factors, it does not mean that the plum rainfall has completely consistent variation. Therefore, it is necessary to study the spatiotemporal variations of plum rainfall in different sub-regions. The sub-regional analysis of the spatiotemporal variations of the plum rainfall is meaningful to formulate agricultural and industrial development policies, according to local conditions. In addition, it is worth mentioning that our study only analyzes an average state for a period of 53 years, and does not discuss the spatial pattern of plum rainfall in different time periods, which needs to be further studied in the future.

In addition, we also assessed the relationship between ENSO, EASM, PDO, and plum rainfall on multi-time scales. Many studies have explored the effects of atmospheric circulation on Plum Rains from statistical methods or physics-based methods [58-60]. The difference between our study and previous studies was that previous studies studied the relationship between plum rainfall and EASM, ENSO, and PDO from the average state, and we explored the relationship between ENSO, EASM, $\mathrm{PDO}$, and plum rainfall from multi-time scales. It was also found that ENSO and EASM are the main influencing factors in the three-year and six-year periods, respectively. In addition, the correlation between IMF3 of plum rainfall and IMF3 of PDO and the correlation between IMF4 of plum rainfall and IMF4 of PDO were significant. However, the IMF4 of plum rainfall and IMF3 of PDO were not significant. Therefore, we cannot say that PDO was the main influencing factor of plum rainfall during the period of 1960 to 2012. Jiang and Gao [61] pointed out that the amount of plum rainfall would increase when PDO was in a positive phase compared to a normal year. In this study, we did not get the same results, and the difference is that Jiang and Gao did not study the relationship between 
plum rainfall and PDO on multi-time scales, as we did. Due to the short observational record in this study, we will study the relationship between plum rainfall and PDO at multi-time scales for longer observational records. Whether PDO is the main influencing factor of plum rainfall on the inter-decadal scale remains to be further studied. This study builds on previous ones by exploring different aspects of the Plum Rains onset and withdrawal variability. However, this study has only analyzed the relationship between ENSO, EASM, PDO, and plum rainfall at multi-time scales by using statistical methods and has not explained the reasons for the different relationships at different time scales in terms of the physical mechanism, which requires further research.

\section{Conclusions}

The spatiotemporal variation of plum rainfall and its relation to EASM, ENSO, and PDO was investigated using a dataset from 33 meteorological stations on the onset and termination of Plum Rains as well as daily precipitation during the period of 1960 to 2012. An integrated approach combining the EEMD, EOF, and correlation analysis was employed. The main conclusions are reproduced below.

(1) By analyzing the time series at the onset and termination of Plum Rains, the daily intensity of plum rainfall, and plum rainfall, we found that, in the past 53 years, the plum rainfall had three-year and six-year cycles on the inter-annual scale and 14-year and 33-year cycles on the inter-decadal scale. Additionally, it showed a trend of increasing first and then decreasing. In addition, the onset of Plum Rains, the termination of Plum Rains, and the daily intensity of plum rainfall had similar cycles and trends to plum rainfall. Furthermore, the effect of the onset and termination of Plum Rains and the daily intensity of plum rainfall on plum rainfall on the inter-annual scale was greater than on the inter-decadal scale.

(2) There are two obvious characteristics of the spatial pattern of plum rainfall. The first EOF was characterized by in-phase changes across the whole study region. The second EOF showed an out-of-phase plum rainfall pattern of about $30^{\circ} \mathrm{N}$ between the areas north and south. It is necessary to analyze the spatiotemporal variations of plum rainfall in different sub-regions.

(3) The changes in plum rainfall were affected by different factors on different time scales. The difference was that ENSO and EASM were the main influencing factors in the three-year and six-year periods, respectively, and whether PDO was the main influencing factor on the inter-decadal scale remains to be further studied. Studying the influence of atmospheric circulation on plum rainfall at multi-time scales can give us a deeper understanding of it.

Author Contributions: N.Z. designed, carried out the analysis, and wrote the manuscript. J.X. revised the paper and refined the results, conclusion, and abstract. K.L. and C.Z. discussed the results. Y.L. edited the figures. All authors approved the manuscript.

Funding: This research received no external funding.

Acknowledgments: The authors are grateful to the Resource and Environmental Science Data Center (http://www. resdc.cn) of the Chinese Academy of Sciences and the China Meteorological Data Sharing Service System (http: //cdc.cma.gov.cn/) for providing data. The authors appreciate the insightful comments of anonymous reviewers.

Conflicts of Interest: The authors declare no conflict of interest.

\section{References}

1. Ninomiya, K. Characteristics of Baiu front as a predominant subtropical front in the summer Northern Hemisphere. J. Meteor. Soc. Jpn. 1984, 62, 880-894. [CrossRef]

2. Akiyama, T. The large-scale aspects of the characteristic features of the Baiu front. Meteor. Geophys. 1973, 24, 157-188. [CrossRef]

3. Kodama, Y.-M. Large-scale common features of subtropical precipitation zones (the Baiu frontal zone, the SPCZ, and the SACZ). Part I: Characteristics of subtropical frontal zones. J. Meteorol. Soc. Jpn. 1992, 70, 813-836. [CrossRef] 
4. Sampe, T.; Xie, S.P. Large-scale dynamics of the Meiyu-Baiu rainband: Environmental forcing by the westerly jet. J. Climatol. 2010, 23, 113-134. [CrossRef]

5. Huang, Z.; Xu, H.; Hu, J. Review and Discussion on the Plum Rain Research in China. Meteorol. Environ. Res. 2011, 2, 25-29. [CrossRef]

6. You, C.H.; Lee, D.I.; Jang, S.M.; Jang, M.; Uyeda, H.; Shinoda, T.; Kobayashi, F. Characteristics of rainfall systems accompanied with Changma front at Chujado in Korea. Asia-Pac. J. Atmos. Sci. 2010, 46, 41-51. [CrossRef]

7. Zhu, K.Z. The southeast summer monsoon and precipitation of China. J. Geogr. Sci. 1934, 1, 1-27.

8. Tu, C.W. Chinese air mass properties. Q. J. R. Meteorol. Soc. 1939, 65, 33-51. [CrossRef]

9. Lu, A. Precipitation in the South Chinese-Tibetan Borderland. Geogr. Rev. 1947, 37, 88-93. [CrossRef]

10. Kang, I.S.; Ho, C.H.; Lim, Y.K. Principle modes of climatological seasonal and intraseasonal variations of the Asian summer monsoon. Mon. Weather Rev. 1999, 127, 322-340. [CrossRef]

11. Zhou, H. Study on the mesoscale structure of the heavy rainfall on Meiyu front with dual-Doppler RADAR. Atmos. Res. 2009, 93, 335-357. [CrossRef]

12. Huang, D.Q.; Qian, Y.F.; Zhu, J. The heterogeneity of Meiyu rainfall over Yangtze-Huaihe River vally and its relationship with oceanic surface heating and intraseasonal variability. Theor. Appl. Climatol. 2012, 108, 601-611. [CrossRef]

13. Gao, Q.; Sun, Y.; You, Q. The northward shift of Meiyu rain belt and its possible association with rainfall intensity changes and the Pacific-Japan pattern. Dyn. Atmos. Ocean. 2016, 76, 52-62. [CrossRef]

14. Matsumoto, J. Heavy rainfall over East Asia. Int. J. Climatol. 1988, 9, 407-423. [CrossRef]

15. Lee, D.K.; Kim, Y.A. Variability of the East Asian summer monsoon during the period of 1980-1989. J. Korean Meteorol. Soc. 1992, 28, 315-331.

16. Chen, C. Investigation of a heavy rainfall event over southwestern Taiwan associated with a sub-synoptic cyclone during the 2003 Mei-Yu season. Atmos. Res. 2010, 95, 235-254. [CrossRef]

17. Wei, F.Y.; Xie, Y. Interannual and interdecadal oscillations of Meiyu over the middle-lower reaches of the Changjiang River for 1885-2000. J. Appl. Meteorol. Climtol. 2005, 16, 492-499. [CrossRef]

18. Bai, L.; Chen, Z.S.; Zhao, B.F. Application of Ensemble Empirical Mode Decomposition Method in Multiscale analysis of Meiyu in Middle-Lower Reaches of Yangtze River. Resour. Environ. Yangtze Basin 2015, 24, 482-488. [CrossRef]

19. Jiang, J.Y.; Ni, Y.Q. Diagnostic study on the structural characteristics of a typical Meiyu front system and its maintenance mechanism. Adv. Atmos. Sci. 2004, 21, 802-813. [CrossRef]

20. Shinoda, T.; Uyeda, H.; Yoshimura, K. Structure of moist layer and sources of water over the southern region far from the Meiyu/Baiu front. J. Meteorol. Soc. Jpn. 2005, 83, 137-152. [CrossRef]

21. Zhou, X.J.; Zha, P.; Liu, G.; Zhou, T.J. Characteristics of decadal-centennial-scale changes in East Asian summer monsoon circulation and precipitation during the medieval warm period and little ice age and in the present day. Chin. Sci. Bull. 2011, 56, 3003-3011. [CrossRef]

22. Liu, D.N.; He, J.H.; Yao, Y.H.; Qi, L. Characteristics and Evolution of Atmospheric Circulation Patterns during Meiyu over the Jianghuai valley. Asia-Pac. J. Atmos. Sci. 2012, 48, 145-152. [CrossRef]

23. Wu, Y.T.; Shaw, T.A. The Impact of the Asian Summer Monsoon Circulation on the Tropopause. J. Climatol. 2016, 8, 8689-8701. [CrossRef]

24. Yu, J.; Huang, X.; Yu, Y.; Guo, X.; Dong, B.; Lu, T.; Wang, H. Analysis on the new index of plum rains intensity and its spatio-temporal characteristics: A case study on the reaches of the region along Huaihe River in Anhui Province. Sci. Agric. Sin. 2009, 42, 1325-1330.

25. Chen, S.J.; Kuo, Y.W.; Wang, W.; Tao, Z.Y.; Cui, B. A Modeling Case Study of Heavy Rainstorms along the Mei-Yu Front. Mon. Weather Rev. 1998, 126, 2330. [CrossRef]

26. Zhang, Y.; Zhai, P.; Qian, Y. Variations of Meiyu indicators in the Yangtze-Huaihe River basin during 1954-2003. Acta Meteorol. Sin. 2005, 19, 479-484.

27. Zhu, X.; Wu, Z.; He, J. Anomalous Meiyu onset averaged over the Yangtze River valley. Theor. Appl. Climatol. 2008, 94, 81-95. [CrossRef]

28. Zhu, J.; Huang, D.Q.; Zhang, Y.C.; Huang, A.N.; Kuang, X.Y.; Huang, Y. Decadal changes of Meiyu rainfall around 1991 and its relationship with two types of ENSO. J. Geophys Res. Atmos. 2013, 118, 9766-9777. [CrossRef] 
29. Xue, F.; Liu, C.Z. The influence of moderate ENSO on summer rainfall in eastern China and its comparison with strong ENSO. Chin. Sci. Bull. 2008, 53, 791-800. [CrossRef]

30. Wang, H.; Yao, J.Q.; Shi, C.H.; Chen, B.M. The relationship between Meiyu and the intensity of East Asian Summer Monsoon. Plateau Meteorol. 2008, 27, 109-117.

31. Zhang, N.; Gao, Z.; Wang, X.; Chen, Y. Modeling the impact of urbanization on the local and regional climate in Yangtze River Delta, China. Theor. Appl. Climatol. 2010, 102, 331-342. [CrossRef]

32. Feng, Z.; Jin, M.; Zhang, F.; Huang, Y. Effects of ground-level ozone (O3) pollution on the yields of rice and winter wheat in the Yangtze River Delta. J. Environ. Sci. China 2003, 15, 360-362. [CrossRef]

33. Zhang, Q.; Gemmer, M.; Chen, J. Climate changes and flood/drought risk in the Yangtze Delta, China, during the past millennium. Quat. Int. 2008, 176, 62-69. [CrossRef]

34. Wang, Y.; Xu, Y.; Lei, C.; Li, G.; Han, L.; Song, S.; Yang, L.; Deng, X. Spatio-temporal characteristics of precipitation and dryness/wetness in Yangtze River Delta, eastern China, during 1960-2012. Atmos. Res. 2016, 172, 196-205. [CrossRef]

35. Chen, W.; Cutter, S.L.; Emrivh, C.T.; Shi, P. Measuring social vulnerability to natural hazards in the Yangtze River Delta region, China. Int. J. Disaster Risk Sci. 2013, 4, 169-181. [CrossRef]

36. Zhu, N.; Xu, J.; Li, W.; Li, K.; Zhou, C. A Comprehensive Approach to Assess the Hydrological Drought of Inland River Basin in Northwest China. Atmosphere 2018, 9, 370. [CrossRef]

37. The Sixth Census Commission. The Main Data Bulletin for the Sixth National Census in 2010 (No. 1); Sixth Census Commission: Beijing, China, 2010.

38. General Administration of Quality Supervision, Inspection and Quarantine of the People's Republic of China and China National Standardization Management Committee. Mei-Yu Monitoring Indicators; Standards Press of China: Beijing, China, 2017.

39. Li, J.P.; Zeng, Q.C. A new monsoon index and the geographical distribution of the global monsoons. Adv. Atmos. Sci. 2003, 20, 299-302. [CrossRef]

40. Li, J.P.; Zeng, Q.C. A unified monsoon index. Geophys. Res. Lett. 2002, 29, 1274. [CrossRef]

41. Chu, W.; Qiu, S.; Xu, J. Temperature change of Shanghai and its response to global warming and urbanization. Atmosphere 2016, 7, 114. [CrossRef]

42. Xu, J.; Chen, Y.; Bai, L.; Xu, Y. A hybrid model to simulate the annual runoff of the Kaidu River in northwest China. Hydrol. Earth Syst. Sci. 2016, 20, 1447-1457. [CrossRef]

43. Bai, L.; Xu, J.; Chen, Z.; Li, W.; Liu, Z.; Zhao, B.; Wang, Z. The regional features of temperature variation trends over Xinjiang in China by the ensemble empirical mode decomposition method. Int. J. Climatol. 2015, 35, 3229-3237. [CrossRef]

44. Wu, Z.H.; Huang, N.E. Ensemble empirical mode decomposition: A noise-assisted data analysis method. Adv. Adap. Data Anal. 2009, 1,1-41. [CrossRef]

45. Huang, N.E.; Shen, Z.; Long, S.R.; Wu, M.C.; Shih, H.H.; Zheng, Q.; Yen, N.C.; Tung, C.C.; Liu, H.H. The empirical mode decomposition and the Hilbert spectrum for nonlinear and non-stationary time series analysis. Proceedings of the Royal Society of London. Series A: Mathematical. Phys. Eng. Sci. 1998, 454, 903-995. [CrossRef]

46. Zhu, N.; Xu, J.; Wang, C.; Chen, Z.; Luo, Y. Modeling the multiple time scale response of hydrological drought to climate change in the data-scarce inland river basin of Northwest China. Arab. J. Geosci. 2019, 12, 225. [CrossRef]

47. Xoplaki, E.; Luterbacher, J.; Burkard, R.; Patrikas, I.; Maheras, P. Connection between the large-scale $500 \mathrm{hPa}$ geopotential height fields and precipitation over Greece during wintertime. Climatol. Res. 2000, 14, 129-146. [CrossRef]

48. Kikuchi, K.; Wang, B. Diurnal precipitation regimes in the global tropics. J. Climate 2008, 21, 2680-2696. [CrossRef]

49. Lorenz, E.N. Empirical orthogonal functions and statistical weather prediction. In Technical Report; Statistical Forecast Project Report 1; Dept. of Meteor. MIT: Cambridge, MA, USA, 1956; p. 49.

50. Fu, C. Potential impacts of human-induced land cover change on East Asia monsoon. Glob. Planet. Chang. 2003, 37, 219-229. [CrossRef]

51. Ayenu-Prah, A.Y.; Attoh-Okine, N.O. Comparative study of Hilbert-Huang transform, Fourier transform and wavelet transform in pavement profile analysis. Veh. Syst. Dyn. 2009, 47, 437-456. [CrossRef]

52. Alexandrov, T. A method of trend extraction using singular spectrum analysis. Rev. Stat. J. 2009, 7, 1-22. 
53. He, J.H.; Wu, Z.W.; Jiang, Z.H.; Miao, C.S.; Han, G.R. "Climate effect" of the northeast cold vortex and its influences on Meiyu. Chin. Sci. Bull. 2007, 52, 671-679. [CrossRef]

54. North, G.R.; Bell, T.L.; Cahalan, R.F. Sampling errors in the estimation of the empirical orthogonal functions. Mon. Weather Rev. 1982, 110, 699-706. [CrossRef]

55. Hao, Z.; Zheng, J.; Ge, Q. Variations in the summer monsoon rainbands across eastern China over the past 300 years. Adv. Atmos. Sci. 2009, 26, 614-620. [CrossRef]

56. Gao, H.; Jiang, W.; Li, W.J. Changed Relationships Between the East Asian Summer Monsoon Circulations and the Summer Rainfall in Eastern China. Acta Meteorol. Sin. (Engl. Ed.) 2014, 28, 1075-1084. [CrossRef]

57. Gong, D.; Wang, S. Impacts of ENSO on rainfall of global land and China. Chin. Sci. Bull. 1999, 44, 852-857. [CrossRef]

58. Liu, C.Z.; Wang, H.J.; Jiang, D.B. The Configurable Relationships between Summer Monsoon and Precipitation over East Asia. Chin. J. Atmos. Sci. 2004, 28, 700-712.

59. Ge, Q.S.; Guo, X.F.; Zheng, J.Y.; He, Z.X. Meiyu in the middle and lower reaches of the Yangtze River since 1736. Chin. Sci. Bull. 2007, 52, 2792-2797. [CrossRef]

60. Hu, C.S.; Xu, Y.P.; Han, L.F.; Yang, L. Long-term trends in daily precipitation over the Yangtze River Delta region during 1960-2012, Eastern China. Theor. Appl. Climatol. 2016, 125, 131-147. [CrossRef]

61. Jiang, W.; Gao, H. New features of Meiyu over middle-lower reaches of Yangtze River in the 21st century and the possible causes. Meteorol. Mon. 2013, 39, 1139-1144.

62. Zhao, J.; Chen, L.; Xiong, K. Climate characteristics and influential systems of Meiyu to the south of the Yangtze River based on the new monitoring rules. Acta Meteorol. Sin. 2018, 76, 680-698. [CrossRef]

63. Chen, X.; Li, D. The features of Meiyu under the new standard. J. Meteorol. Sci. 2016, 36, 165-175. [CrossRef]

64. Li, K.; Yu, J.; Wang, Y.; Song, J.; Zhuang, Y. Abnormal distribution of Meiyu precipitation over Jianghuai region and its relation with East Asia subtropical westerly jet. J. Meteorol. Sci. 2018, 38, 302-309. [CrossRef]

(C) 2019 by the authors. Licensee MDPI, Basel, Switzerland. This article is an open access article distributed under the terms and conditions of the Creative Commons Attribution (CC BY) license (http://creativecommons.org/licenses/by/4.0/). 
Article

\title{
Air Mass Trajectories to Estimate the "Most Likely" Areas to Be Affected by the Release of Hazardous Materials in the Atmosphere-Feasibility Study
}

\author{
Miguel Ángel Hernández-Ceballos * and Luca De Felice \\ European Commission, Joint Research Centre, 21027 Ispra, Italy; Luca.DE-FELICE@ec.europa.eu \\ * Correspondence: miguelhceballos@gmail.com; Tel.: +39-033-278-3721
}

Received: 25 April 2019; Accepted: 7 May 2019; Published: 8 May 2019

\begin{abstract}
Countries continuously review and improve their Emergency Preparedness and Response $(E P \& R)$ arrangements and capabilities to take agile and rapid actions with the intent of minimizing health, environmental and economic impacts of potential harmful releases into the atmosphere. One of the specific topics within the EP\&R field is the estimation of the areas that might be affected. A proposal is presented to estimate the spatial distribution of the released material. The methodology combines the computation of air mass trajectories and the elaboration of density maps from the corresponding end-point positions. To this purpose, density maps are created in a three-way procedure; first, forward trajectories are calculated from a certain location and for a long period of time, e.g., a decade; second, the selected end-point positions are aggregated in a density field by applying the kernel density estimation method, and then the density field is visualized. The final product reports the areas with the longest residence time of air masses, and hence, the areas "most likely" to be affected and where the deposit may be substantial. The usefulness of this method is evaluated taking as reference a ten-year period (2007-2016) and against two different radioactive release scenarios, such as the Chernobyl accident and the Algeciras release. While far from being fully comprehensive, as only meteorological data are used, the performance of this method is reasonably efficient, and hence, it is a desirable alternative to estimating those areas potentially affected by a substantial deposit following the releases of a harmful material in the atmosphere.
\end{abstract}

Keywords: Nuclear Emergency Preparedness and Response; air mass trajectory; density maps

\section{Introduction}

In the context of the effective management of crises and disasters, which is a global challenge, the risk of an accident releasing airborne harmful material to the atmosphere, like radioactive, chemical or bacteriological active substances, cannot be ruled out. To face these kinds of events, it is well recognized that good preparedness substantially improves the emergency response. In this line, efforts to promote and enhance global safety, and to limit and mitigate any consequences associated with these kinds of releases are continuously triggered at national and international levels [1].

The early phase of a harmful release to the atmosphere is a period usually characterized by large uncertainty in the source term release characteristics and the lack of field measurements. Within this period, to have available a prior estimation of the possible atmospheric transport and dispersion of the released material, and hence, the likely areas to be affected by the plume, is of importance to decision makers and emergency managers in an attempt at minimizing its health and environmental impacts.

Meteorological conditions determine the dispersion and transport of substances in the atmosphere. Rainfall, wind speed, wind direction and temperature are relevant parameters in establishing their temporal and spatial variability. Once in the atmosphere, the primary process favoring the transport and dispersion of substances is wind regimes, which is characterized by wind direction and wind speed, 
e.g., the greater the wind velocity is, then the greater the dispersion of the contaminants, and the lower their concentration is [2]. Many studies [3,4] have outlined the need of characterizing wind regimes to understand air pollution scenarios. This direct link makes the knowledge and characterization of wind regimes at a site become key information in estimating the atmospheric transport and dispersion of harmful substances and, therefore, in forecasting the likely areas affected by the plume passage.

Air trajectory analysis is a central scientific tool to characterize synoptic and regional wind regimes [5]. The basic methodological approach in this kind of analysis is to generate massive amounts of air mass trajectories with the purpose of considering a large number of transport and dispersion scenarios so that the statistical analysis leads to the extraction of representative information about flow patterns (e.g., residence time, range, distance, speed, etc.). When compiled and studied over multiple years $[6,7]$, the outcome of this trajectory analysis is used to generate an estimation of future wind scenarios.

With this in mind, the aim of this paper is to describe and to evaluate a method to estimate the likely areas to be affected by a hypothetical release to the atmosphere. The present methodology, which is based on the influence that lower atmosphere meteorology has on the dispersion and transport of substances in the atmosphere, is based on the calculation of density maps from air mass trajectories by applying the kernel density estimation (KDE) method [8]. KDE's strength is its ability to provide an estimate of density at any location in the spatial frame. In this present framework, these density maps report the areas with the longest residence time of air masses, and hence, the areas where the deposit may be substantial. Residence time analysis [9] identifies the likelihood that an air mass will traverse a given region in its movement to or from the site of interest over a given time period $[7,10]$. The longer the residence time over certain areas is, the more favorable the situation for significant surface dry deposition from contaminant plumes is.

Considering that the calculation of air mass trajectories is purely based on meteorological fields, i.e., we are not considering any release to the atmosphere (source term) in the calculation, we can only address a qualitative comparison to evaluate the outcomes of this method, e.g., between areas of high residence time and high deposit. To estimate the bias of this meteorological approach, we have evaluated it against the period 2006-2017 and two radioactive dispersion events, such as Chernobyl accident and Algeciras release. The corresponding density maps for each case study, which identify those areas with the longest residence time of air masses, are then qualitatively compared with those areas affected by high deposits in each release scenario. Reasonable estimation of the areas affected by both releases would prove the usefulness of this method and the number of years selected in the estimation of likely areas to be affected by a hypothetical release.

While far from being fully comprehensive of the complexity behind the simulation and prediction of atmospheric dispersion, as only meteorological data are used, this method would provide useful guidance in estimating the transport and dispersion that might result if harmful material reaches the atmosphere, and hence, in increasing knowledge of crisis and disaster management for improving responsiveness. Being only based on the analysis of the wind field, this method can be used, for instance, for any kind of airborne material.

The article is structured as followed. In Section 2, we describe the methodology applied to obtain density maps from air mass end-point positions, while Section 3 is dedicated to showing and discussing the results obtained in the two study cases taken as reference. To finalize, the conclusions obtained from this work are shown in Section 4.

\section{Materials and Methods}

\subsection{Trajectory Modelling}

Air mass trajectory shows the pathway of an infinitesimal air parcel through a centerline of an advected air mass having vertical and horizontal dispersion [11]. Forward trajectory estimates the pathway to be followed by an air parcel downwind from the selected coordinates in due course of time. 
The National Oceanic and Atmospheric Administration (NOAA) Air Resources Laboratory's (ARL) Hybrid Single-Particle Lagrangian Integrated Trajectory model (HYSPLIT 4.9) [12] is used to calculate forward kinematic three-dimensional trajectories. The computation of three-dimensional trajectories is based on the use of the vertical velocity field included in publicly available meteorological datafiles, such as the 3-hourly meteorological archive data from NCEP's GDAS (National Weather Service's National Centers for Environmental Prediction-Global Data Assimilation System) [13]. The GDAS covers from 2004 to the present, which is a big advantage in favor of using them in research studies, as they span 10 years or more. The GDAS is run 4 times a day, i.e., at 0000, 0600, 1200, and 1800 UTC. These data are archived and made available by the NOAA's ARL as a global and 1-degree latitude-longitude dataset on pressure surface.

Our method uses forward trajectories with duration of 120 hours (length of the trajectory). A complete description of all the equations and HYSPLIT calculation methods for trajectories can be seen in [14]. HYSPLIT provides the coordinates (longitude and latitude) and height (in meters above ground level, a.g.l) of every trajectory calculated at 1-h intervals. Therefore, each trajectory of $120 \mathrm{~h}$ is composed of 120 end-point positions. In our study, we work these 120 end-point positions, which are the position of the lagrangian particles, at a certain hour within the duration of $120 \mathrm{~h}$.

\subsection{Kernel Density Estimation}

Kernel density estimation (KDE) [8] is an important method in visualizing and analyzing spatial data, with application in many fields (ecology, public health, etc.), with the objective of understanding and potentially predicting event patterns [15-17]. KDE is a non-parametric approach to the estimation of probability density functions using a finite number of cases [18]. This method compensates for in distance the influence of a case in its vicinity. To this purpose, it incorporates a decay function that assigns smaller values to locations which are still in the neighborhood, but further way from a case [15]. To achieve this, KDE fits a curved surface over each case such that the surface is highest above the center and zero at a specified distance from the case (the bandwidth, i.e., the distance around a case at which its influence is felt). The influence of a number of cases at a certain location, over a two-dimensional space, can be represented as the following definition $[8,19]$ :

$$
f(x, y)=\frac{1}{n h^{2}} \sum_{i=1}^{n} K\left(\frac{d_{i}}{h}\right),
$$

where $f(x, y)$ is the density value at location $(x, y), n$ is the total number of cases under concern, $h$ is the bandwidth, $d_{i}$ is the geographical distance between case $i$ and the location and $K$ is a density function (generally a radially symmetric unimodal probability density function) which integrates to one. Different density functions (K) can be used, e.g., Cauchy [20], Epanechnikov [21], Gaussian [22]. More information about different kernel-smoothing algorithms can be found in [23].

The KDE refers to high or low density of points, i.e., cases per unit area. Therefore, KDE method detects the highs and lows of cases densities of the pattern, and is useful for detecting hot spots. Figure 1 graphically shows an example of the procedure use in our method to determine the density value $f(x, y)$ (grey squared) over the raster data by considering two cases (red circles). 


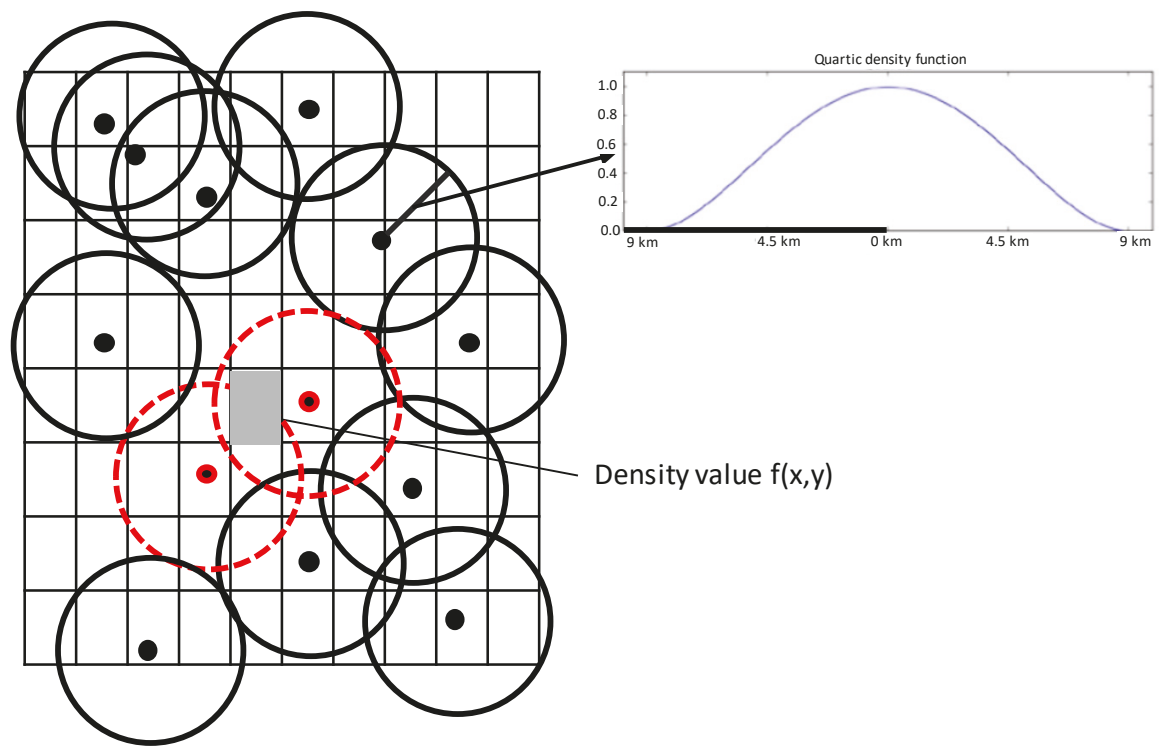

Figure 1. An illustration of the density value $f(x, y)$ calculations over raster data and the quartic kernel function used $(K)$, with a bandwidth of $9 \mathrm{~km}$.

\subsection{Method}

Figure 2 shows the procedure applied in our method to determine the corresponding density maps. Once calculated, the trajectories for the period 2007-2016 (Figure 2a), and the corresponding end-point positions (i.e., cases in Section 2.2), the subset of end-point positions within the analyzed period (hereafter, time window), are extracted (Figure 2b). We define the "time window" as the reference period for which end-point positions are collected and to which, as a result, the density map refers. This time window refers to one reference time (e.g., a specific day, such as the release date or the maximum concentration date). The definition of the time window is based on the fact of having evidences that cyclicality plays a significant role in the weather we experience, i.e., weather appears to be a regularly cycling pattern over short and long-range time. In the present method, we consider three different temporal cycling patterns of weather, e.g., two weeks, one month and two months. As an example, if the event date is 7 May, we work with all end-point positions within the period 2007-2016 from 1 May to 14 May (one week before and after the release date), from 24 April to 21 May (two weeks before and after), and from 7 April to 7 June (one month before and after).

Based on the end-point positions extracted, we provide a comprehensive analysis of the residence time of air masses. In order to accommodate as much as possible the residence time with hypothetical deposits from the plume, the present analysis is carried out by selecting the number of end-point positions below a vertical level, which is set to $100 \mathrm{~m}$ a.g.l., within the selected time window

Once the subset of end-point positions within the time window and with a height less than $100 \mathrm{~m}$ a.g.l are selected, these are then displayed as a density map using the KDE method indicated in Section 2.2 (Figure 2c,d). To make a KDE, the challenge is to select the kernel function, the bandwidth and the cell size. However, there are no rules and standards concerning this selection, and they are predominantly taken as the results of experimental studies [24]. After several analyses, in the present work, end-point positions are displayed on a map with a fixed grid cell size of $3 \times 3 \mathrm{~km}$ and we have defined a bandwidth of $9 \mathrm{~km}$, while the kernel function is based on the quartic kernel function described in [8], i.e., an inverse distance weighting (Figure 1). We have used the free and open source QGIS geographic information system [25]. 
(a) Trajectory lines
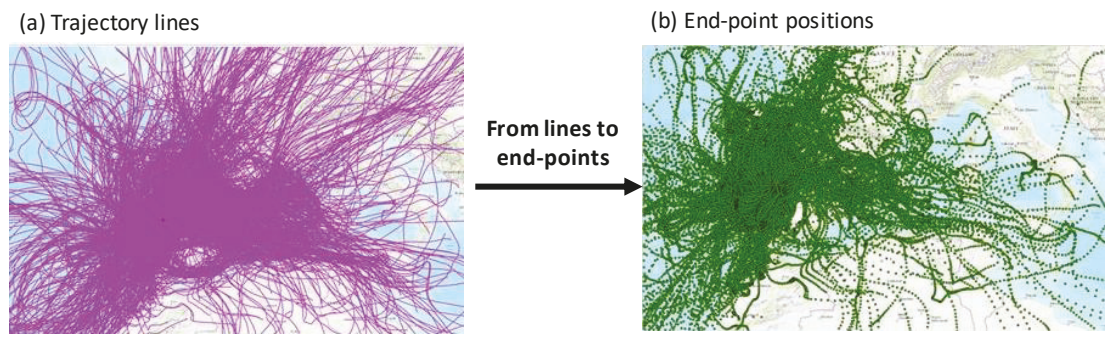

Time window of 2 months

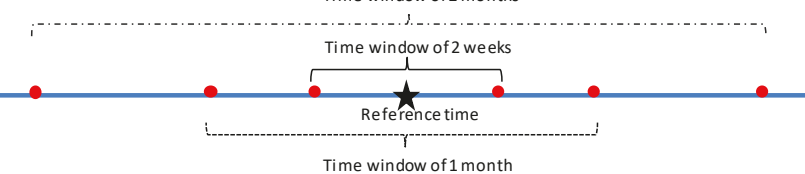

Time window of 1 month

(d) Density map for 2 weeks' time window (e.g. from 1 May to 14 May)

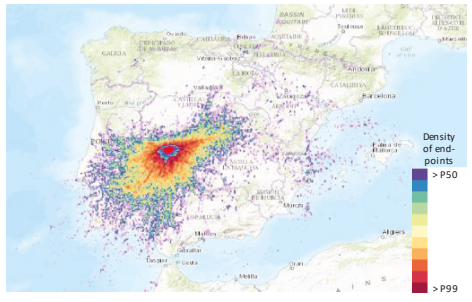

(c) End-point positions for 2 weeks' time window (e.g. from 1 May to 14 May)

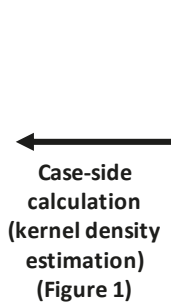

Figure 2. Steps and information used to produce the density maps: (a) Set of trajectory lines, (b) end-point positions for the 2007-2016 period, (c) definition of time windows and extraction of end-point positions for the defined time window ( 2 weeks) and (d) example of density map, which expresses the density of end-point positions estimated above $50 \%$.

\section{Case Studies}

Two case studies, the Chernobyl accident (25-26 April 1986) and the Algeciras release (30 May 1998), have been taken as reference in order to evaluate the use of trajectories and density maps as valuable information in the preparedness phase of an atmospheric event release.

An explosive accident took place at the Chernobyl nuclear power plant unit IV in Ukraine on 25 April 1986 at 2123 UTC. This accident led to a widespread dispersion of radioactive materials released at different times in the atmosphere at a continental scale. The meteorological conditions caused the various plumes to take different directions according to the release date [26], and therefore, contaminated clouds flew all around the world.

On 30 May, 1998, a ${ }^{137}$ Cs medical source was accidentally melted in one of the furnaces at the Acerinox stainless steel production plant near Algeciras, southern Spain. An unknown amount of contaminated air was dispersed over the western coast of Spain and travelled all the way north, reaching the southern coast of France and northern Italy two to three days after the release. The International Atomic Energy Agency (IAEA) Emergency Response Centre reported the occurrence of a radiological accident on June 12.

Following the methodology explained in Section 2.3, we have calculated the forward trajectories and the corresponding end-point positions for the 10-year period (2007-2016) at Chernobyl (51 $23^{\prime} 23.47^{\prime \prime}$ $\left.\mathrm{N}, 30^{\circ} 5^{\prime} 38.57^{\prime \prime} \mathrm{E}\right)$ and Algeciras (6 $\left.6^{\prime} 39^{\prime \prime} \mathrm{N}, 5^{\circ} 27^{\prime} 14^{\prime \prime} \mathrm{W}\right)$. 
In accordance with the release characteristic of each release scenario $[27,28]$, the initial height applied in the calculation of trajectories differs: Chernobyl at $1000 \mathrm{~m}$ a.g.l and Algeciras release at $100 \mathrm{~m}$ a.g.l. For each scenario, over 97\% of 1-h trajectories in the period 2007-2016 are completed for all $120 \mathrm{~h}$ (an incomplete trajectory is due to missing data in the initialization fields).

Table 1 shows the three time windows defined for each case study, taking as reference the corresponding release date to calculate the associated density map.

Table 1. Time windows defined for Chernobyl and Algeciras case studies to extract the end-point positions in the period 2007-2016.

\begin{tabular}{cccc}
\hline & Time Window of Two Weeks & Time Window of One Month & $\begin{array}{c}\text { Time Window of Two } \\
\text { Months }\end{array}$ \\
\hline $\begin{array}{c}\text { Chernobyl } \\
\text { (reference date: 25 April) }\end{array}$ & From 18 April to 3 May & From 11 April to 9 May & From 25 March to 25 May \\
\hline $\begin{array}{c}\text { Algeciras } \\
\text { (reference date: 30 May) }\end{array}$ & From 23 May to 6 June & From 16 May to 13 June & From 30 April to 30 June \\
\hline
\end{tabular}

\section{Results and Discussion}

This section presents the set of density maps calculated for each case study. To evaluate the bias of our meteorological approach, the results obtained in the density maps are qualitatively compared with bibliography regarding the depositional analysis of each case study. We need to point out that our method does not aim to estimate the deposit, but the areas affected.

\subsection{Chernobyl Accident}

Figure 3 shows the density maps produced applying each one of the three time windows (Table 1) for the period 2007-2016 from the Chernobyl site. The three maps display a large spatial dispersion from the release point. Our analysis finds high-density values (above the 90th percentile, P90) in central Europe and Scandinavia. This large dispersion provides an example of the differences in flow regimes, with areas being affected to the south (from southwest to southeast) and to the north of the release point. This spatial spread is in agreement with the variation in the meteorological conditions according to the release date. The emissions on 26 April were transported in the western and northern directions [29], while the plume released in the following days started to move in a south-westerly direction, towards central Europe [30], as well as towards Asia [31].

The highest density values (above the 99th Percentile (P99); the blue circles in Figure 3) in the three density maps are located to the southwest of the source region. This region covers areas of Romania and Bulgaria, such as the Western Romanian Carpathians, as well as the landmass formed inside the mountain circle, the Transylvanian Plateau and the Western Plain and Hills. The geographical distribution of elevated residence times in Figure 3 is in agreement with most of the areas identified in the "Atlas of cesium deposition on Europe after the Chernobyl accident" [32]. Figure 4 shows the high-resolution map of the total cumulative deposition of ${ }^{137} \mathrm{C}$ s throughout Europe as a result of the Chernobyl accident, which is used in this paper to validate the areas identified in Figure 3. Figure 4 shows that high deposits occurred in Eastern Europe and the Balkan countries, following the dominant precipitation. These areas are well identified in our density maps, which report the highest residence time values on the northern and southern borders of Romania. 
(a) Time window: 2 weeks

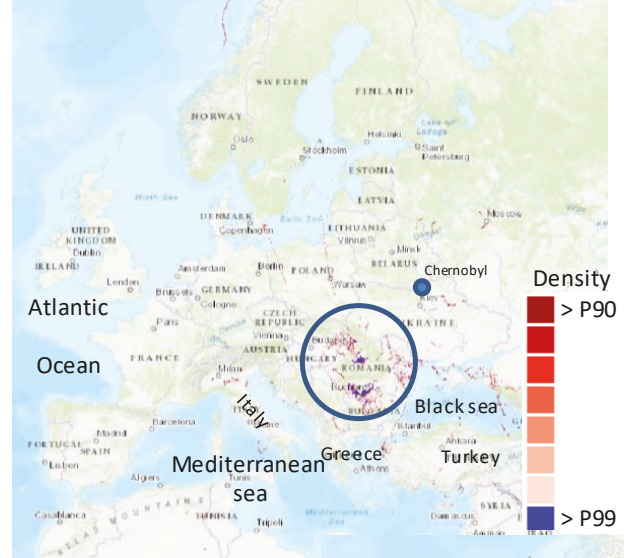

(b) Time window: 1 month

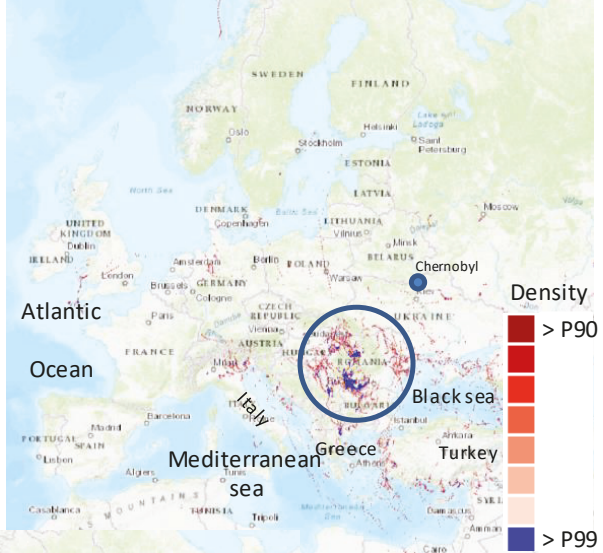

(c) Time window: 2 months

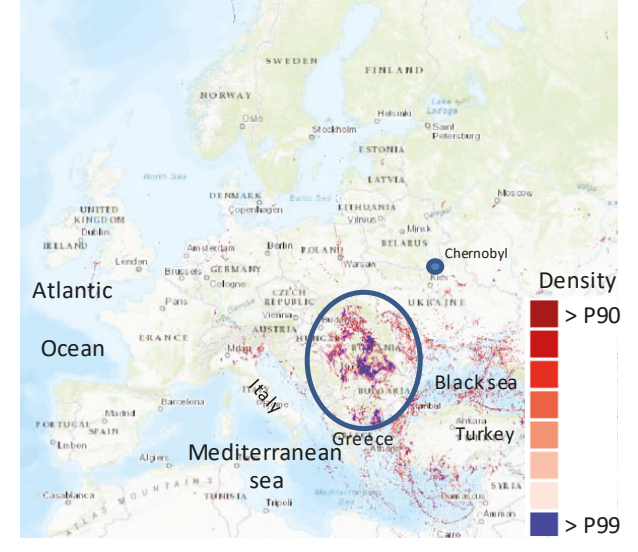

Figure 3. Density plots for 120-h trajectories starting at Chernobyl (blue point) and with a height below $100 \mathrm{~m}$ above ground level for (a) 2 weeks, (b) 1 month and (c) 2 months' time window (reference date of April 25) for the period 2007-2016 (Table 1). The density maps express the density of end-point positions estimated above $90 \%$; quartic kernel function bandwidth $9 \mathrm{~km}$. Blue circles express those areas with a density value above the 99 th percentile.

Comparing the three maps (Figure 3), the area with the highest density values is better identified on increasing the time window from two weeks to two months, i.e., the number of end-point positions, and hence, the meteorological scenarios. The impact of the time window on results is well observed by comparing the greater spread of spots with values above P90 between Figure 3a (time window of two weeks) and Figure 3c (time window of two months). This impact is especially seen to the south of the release site, as high-density values show up in the Black and Aegean seas, and northern Italy-southern Austria. In addition, zones in northern Germany and in the United Kingdom are identified by using a longer time window. In contrast, the set of areas identified in northern countries does not vary with the time window. In this region, few spots can be identified over continental areas, such as southern and eastern coastal areas of Sweden. In contrast, Figure 4 displays a large spread of high ${ }^{137} \mathrm{Cs}$ in specific areas of Sweden and Finland. One of the reasons of this difference can be associated with the selection of density values up to P90. 


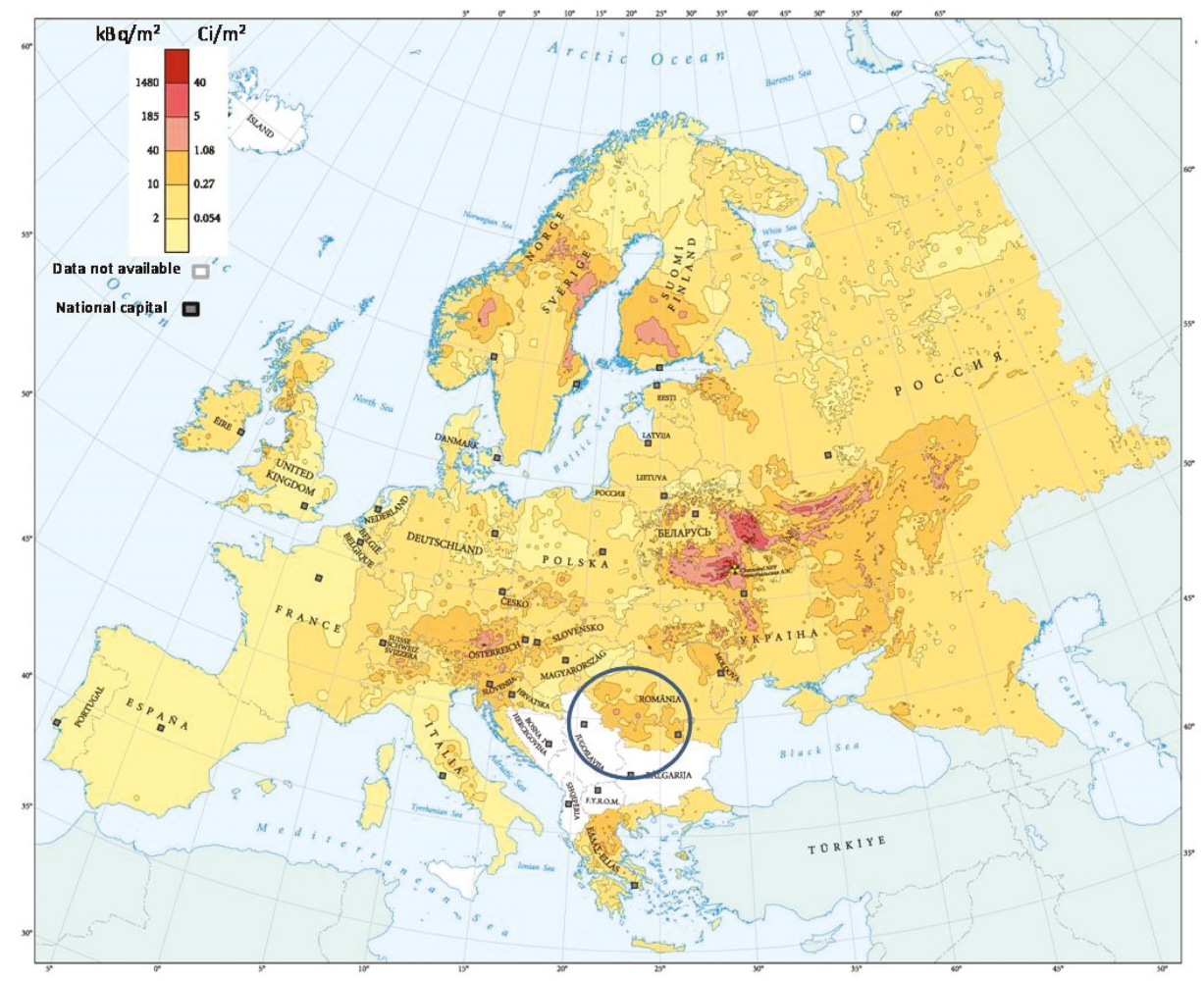

Figure 4. The Atlas map (using the Lambert azimuthal projection) depicting the total cumulative deposition of ${ }^{137} \mathrm{Cs}$ throughout Europe as a result of the Chernobyl accident from all available data of the REM database corrected for radioactive decay to 10 May 1986 [31]. Blue circle expresses the areas with a density value above the 99th Percentile obtained in Figure 3.

\subsection{Algeciras Release}

Figure 5 shows the corresponding density maps for the three time windows defined for the Algeciras case study. Density maps look similar for the three "time windows", with the increase in the most affected area (>P90) easily seen by increasing the time window considered. The trajectories have either an eastern or southwestern component, displaying two main branches of the possible dispersion of the plume released at Algeciras. While the branch to the east, over the Alboran Sea, turns to the northeast following the Spanish coastline, the one to the west veers to the southwest following the northwestern coast of Africa. In both cases, after the channeling effect created by the southern Iberian Peninsula and northern African mountain chains, there is a wide area over the Atlantic and Mediterranean covered by high-density values.

The three maps display a wider area corresponding to the highest density values (above P99) to the east of the release site, along the southern Mediterranean coast of the Iberian Peninsula. It is interesting to highlight how this Mediterranean branch also presents areas over central Italy and northern Africa with high-density values.

This distribution is completely in agreement with the wind dynamics in this area, which is clearly conditioned by the channeling effect of the strait of Gibraltar [33]. The highest density values are obtained to the east of the release site, over the Mediterranean Sea, being consistent with previous studies dealing with this event [34], which reported an easterly movement of the plume. According to the measurements of ${ }^{137} \mathrm{C}$ s registered in southern France and northern Italy at the beginning of June, 
the radioactive plume continued its movement to the north-west over the Mediterranean Sea the following days. The density maps suggest this displacement, although the consideration of trajectories with a duration of $120 \mathrm{~h}$ limits the possible identification of continental areas affected.

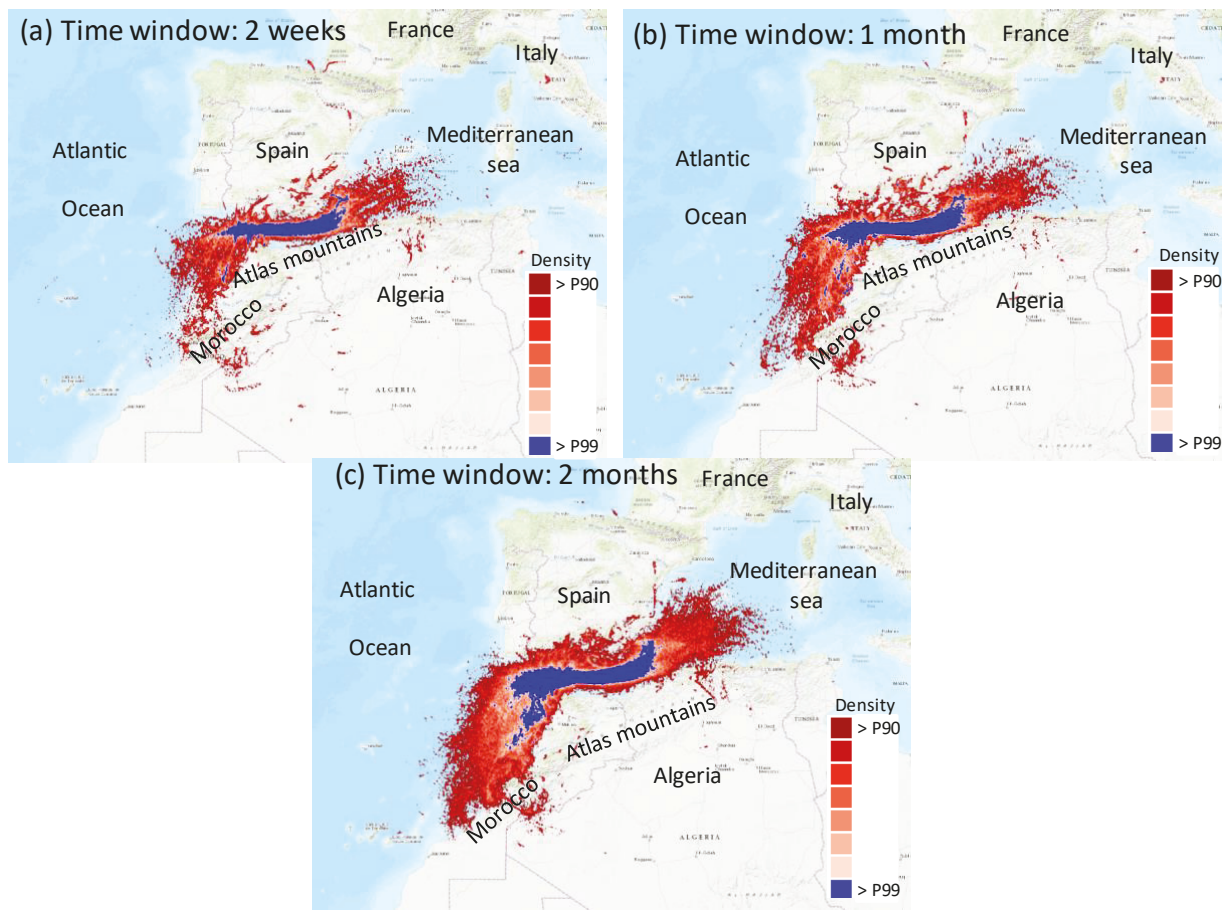

Figure 5. Density plots for 120-h trajectories starting at Algeciras and with a height below $100 \mathrm{~m}$ above ground level for (a) 2 weeks, (b) 1 month and (c) 2 months' time window (reference date of 30 May) for the period 2007-2016 (Table 1). The density maps express the density of end-point positions estimated above $90 \%$; quartic kernel function bandwidth $9 \mathrm{~km}$.

\section{Conclusions}

This paper addresses the method developed to estimate the areas that could be most affected by harmful airborne releases to the atmosphere. To the author's knowledge, this is the first study in which a long-term set of trajectories is used as part of an emergency preparedness infrastructure to early estimate areas likely to be affected by the release of harmful substances in the atmosphere. The bases for this approach are 5-days forward trajectories departing every $1 \mathrm{~h}$ at different heights above ground (in accordance with the study case) for the period 2007-2016.

We have qualitatively evaluated the method by comparing the results from density maps against the air concentration and deposition maps of ${ }^{137} \mathrm{Cs}$ from the Chernobyl and Algeciras releases. The comparison reports a reasonable agreement in the identification of both the atmospheric dispersion patterns and the areas most affected by ${ }^{137} \mathrm{Cs}$ activity concentrations.

Differences in the spatial coverage of the potential affected areas between these two events highlight the influence of the orography and of the release height in the transport and dispersion of substances in the atmosphere. While in Chernobyl (initial height of $1000 \mathrm{~m}$ a.g.l.), the transport occurs mainly above the boundary layer (1-2 km above surface) and hence, surface features affect the wind less (e.g., frictional drag); in Algeciras the wind is forced to move in a certain direction by the presence of mountains. In this sense, the Chernobyl map is a good example of the orographic blocking caused 
by the mountains, forcing the winds to slow down and/or change direction much more. The highest density values for the Chernobyl case study are found within the arc of the Carpathians and in the southern part of the country, in the Danube Plain, between the sub-Carpathians and Balkans. The main transport direction in the Algeciras case study is to the east, in agreement with previous studies.

The comparisons of density maps produced by different time windows (from weeks to months) have shown similarities in the identification of areas highly affected (>P99) by the air mass passage. The use of long time windows has produced the increase of the spatial coverage of these areas, but not the clear identification of new ones. The use of long time windows (more than one week before and after the release date), therefore, could not be necessary, as it could include the consideration of inhomogeneous and noisy trajectory endpoints.

While this method is far from being fully comprehensive, as only meteorological data are used, by building on the current results, future work with the purpose of including more years and measured concentrations into the analysis will help to further improve the present method, and to perform a quantitative evaluation.

Author Contributions: Conceptualization, M.Á.H.-C.; methodology, M.Á.H.-C. and L.D.F; formal analysis, M.Á.H.-C. and L.D.F; investigation, M.Á.H.-C. and L.D.F; resources, M.Á.H.-C. and L.D.F.; visualization, L.D.F.; data curation, L.D.F.; writing-original draft preparation, M.Á.H.-C.; writing—review and editing, M.Á.H.-C. and L.D.F; supervision, M.Á.H.-C.

Funding: This research received no external funding.

Acknowledgments: The authors gratefully acknowledge the NOAA Air Resources Laboratory (ARL) for the provision of the HYSPLIT transport and dispersion model and/or READY website (http://www.ready.noaa.gov) used in this publication. The authors also acknowledge the Open Source Geospatial Foundation (OSGeo) for the provision of the QGIS project.

Conflicts of Interest: The authors declare no conflict of interest.

\section{References}

1. International Atomic Energy Agency (IAEA). Preparedness and Response for a Nuclear or Radiological Emergency; IAEA Safety Standards Series No. GSR Part 7; IAEA: Vienna, Austria, 2015.

2. Cooper, J.R.; Randle, K.; Sokhi, R.S. Radioactive Releases in the Environment: Impact and Assessment; John Wiley \&Sons: Hoboken, NJ, USA, 2003; ISBN 978-0-471-89924-2.

3. Yang, X.; Wang, T.; Xi, M.; Gao, X.; Li, Q.; Zhang, N.; Gao, Y.; Lee, S.; Wang, X.; Xye, L.; et al. Abundance and origin of fine particulate chloride in continental China. Sci. Total. Environ. 2018, 624, 1041-4051. [CrossRef]

4. Wang, W.; Yu, J.; Cui, Y.; He, J.; Xue, P.; Cao, W.; Ying, H.; Gao, W.; Yan, Y.; Hu, B.; et al. Characteristics of fine particulate matter and its sources in an industrialized coastal city, Ningbo, Yangtze River Delta, China. Atmos. Res. 2018, 203, 105-117. [CrossRef]

5. Pérez, I.A.; Artuso, F.; Mahmud, M.; Kulshrestha, U.; Sánchez, M.L.; García, M.A. Applications of Air Mass Trajectories. Adv. Meteorol. 2015. [CrossRef]

6. Toledano, C.; Cachorro, V.E.; De Frutos, A.M.; Torres, B.; Berjón, A.; Sorribas, M.; Stone, R.S. Airmass classification and analysis of aerosol types at El Arenosillo (Spain). J. Appl. Meteorol. Climatol. 2009, 48, 962-981. [CrossRef]

7. Hondula, D.M.; Sitka, L.; Davis, R.E.; Knight, D.B.; Gawtry, S.D.; Deaton, M.L.; Lee, T.R.; Normile, C.P.; Stenger, P.J. A back-trajectory and air mass climatology for the Northern Shenandoah Valley, USA. Int. J. Climatol. 2010, 30, 569-581. [CrossRef]

8. Silverman, B.W. Density Estimation for Statistics and Data Analysis; Chapman and Hall: New York, NY, USA, 1986.

9. Ashbaugh, L.L. A statistical trajectory technique for determining air pollution source regions. APCAJ 1983, 33, 1096-1098. [CrossRef]

10. Fleming, Z.L.; Monks, P.S.; Manning, A.J. Review: Untangling the influence of air-mass history in interpreting observed atmospheric composition. Atmos. Res. 2012, 104-105, 1-39. [CrossRef]

11. Kulshrestha, U.; Kumar, B. Airmass Trajectories and Long Range Transport of Pollutants: Review of Wet Deposition Scenario in South Asia. Adv. Meteorol. 2014. [CrossRef] 
12. Stein, A.F.; Draxler, R.R.; Rolph, G.D.; Stunder, B.J.B.; Cohen, M.D.; Ngan, F. NOAA's HYSPLIT atmospheric transport and dispersion modeling system. Bull. Amer. Meteor. Soc. 2015, 96, 2059-2077. [CrossRef]

13. Meteorological Archive Data from NCEP's GDAS. Available online: https://www.ready.noaa.gov/gdas1.php (accessed on 20 January 2019).

14. Draxler, R.; Hess, G. Description of the HYSPLIT_4 Modeling System; National Oceanic and Atmospheric Administration: Silver Spring, MD, USA, 1997.

15. Carlos, H.A.; Shi, X.; Sargent, J.; Tanski, S.; Berke, E.M. Density estimation and adaptive bandwidths: A primer for public health practitioners. Int. J. Health Geogr. 2010, 9, 39. [CrossRef]

16. Smith, M.-J.; Goodchild, M.-F.; Longley, P.-A. Geospatial Analysis: A Comprehensive Guide to Principles; Techniques and Software Tools; The Winchelsea Press: Winchelsea, UK, 2015.

17. Bartolini, S.; Cappello, A.; Martí, J.; Del Negro, C. QVAST: A new Quantum GIS plugin for estimating volcanic susceptibility. Nat. Hazards Earth Syst. Sci. 2013, 13, 3031-3042. [CrossRef]

18. Krisp, J.M.; Peters, S.; Murphy, C.E.; Fan, H. Visual Bandwidth Selection for Kernel Density Maps. Photogramm. Fernerkund. Geoinf. 2009, 5, 441-450. [CrossRef]

19. Shi, X. Selection of bandwidth type and adjustment side in kernel density estimation over inhomogeneous backgrounds. J. Int. J. Geogr. Inf. Sci. 2010, 24, 643-660. [CrossRef]

20. Martin, A.J.; Umeda, K.; Connor, C.B.; Weller, J.N.; Zhao, D.; Takahashi, M. Modeling long-term volcanic hazards through Bayesian inference: An example from the Tohuku volcanic arc Japan. J. Geophys. Res. 2004, 109. [CrossRef]

21. Lutz, T.M.; Gutmann, J.T. An improved method for determining and characterizing alignments of point-like features and its implications for the Pinacate volcanic field, Sonoran, Mexico. J. Geophys. Res. 1995, 100, 17659-17670. [CrossRef]

22. Connor, C.B.; Hill, B.E. Three nonhomogenous Poisson models for the probability of basaltic volcanism: Application to the Yucca Mountain region, Nevada. J. Geophys. Res. 1995, 100, 10107-10125. [CrossRef]

23. Wand, M.P.; Jones, M.C. Kernel Smoothing Monographs on Statistics and Applied Probability; Chapman \& Hall/CRC. Taylor \&Francis Group: Boca Raton, FL, USA, 1995.

24. Wolf, M.; Asche, H. Exploring Crime Hotspots: Geospatial Analysis and 3D Mapping. In Proceedings of the 14th International Conference on Urban Planning, Regional Development and Information Society, Schwechat, Austria, 22-25 April 2009.

25. QGIS Development Team. QGIS Geographic Information System. Open Source Geospatial Foundation. Available online: http://qgis.org (accessed on 20 September 2018).

26. Institute De Radioprotection et de Surete Nucleaire (ISRN), Chernobyl 25 years on. 2011. Available online: https:/www.irsn.fr/EN/publications/thematicsafety/chernobyl/Documents/irsn_booklet_ chernobyl_2011.pdf (accessed on 10 January 2019).

27. Bartnicki, J.; Salbu, B.; Saltbones, J.; Foss, A.; Lind, O.L. Gravitational Settling of Particles in Dispersion Model Simulations Using the Chernobyl Accident as a Test Case; Research Report; Norwegian Meteorological Institute: Oslo, Norway, 2001; ISSN 0332-9879.

28. Kaviani, F.; Memarian, M.H.; Eslami-Kalantari, M. Simulation of atmospheric dispersion, transport and deposition of nuclear pollutants released from a hypothetical accident at Bushehr Power Plant. J. Earth Space Phys. 2017, 43, 635-650. [CrossRef]

29. Langner, J.; Robertson, L.; Persson, C.; Ullerstig, A. Validation of the operational emergency response model at the Swedish meteorological and hydrological institute using data from ETEX and the Chernobyl accident. Atmos. Environ. 1998, 32, 4325-4333. [CrossRef]

30. Talerko, N. Mesoscale modelling of radioactive contamination formation in the Ukraine caused by the Chernobyl accident. J. Environ. Radioact. 2005, 78, 311-329. [CrossRef] [PubMed]

31. Simsek, V.; Pozzoli, L.; Unal, A.; Kindap, T.; Karaca, M. Simulation of 137Cs transport and deposition after Chernobyl Nuclear Power Plant accident and radiological doses over the Anatolian Peninsula. Sci. Total Environ. 2014, 499, 74-88. [CrossRef] [PubMed]

32. De Cort, M.; Dubois, G.; Fridman, S.D.; Germenchuk, M.G.; Izrael, Y.A.; Janssens, A.; Jones, A.R.; Kelly, G.N.; Kvasnikova, E.V.; Matveenko, I.I.; et al. Atlas of Caesium Deposition on Europe after the Chernobyl Accident; Office of the European Union: Luxembourg, 1998; p. 176. 
33. Dorman, C.E.; Beardsley, R.C.; Limeburner, R. Winds in the strait of Gibraltar. Quaterly J. R. Meteorol. Soc. 1995, 121, 1093-1921. [CrossRef]

34. Vogt, P.J.; Pobanz, B.M.; Aluzzi, F.J.; Baskett, R.L.; Sullivan, T.J. ARAC Modeling of the Algeciras, Spain Steel Mill CS-137 Release. Available online: https://www.osti.gov/servlets/purl/15013432 (accessed on 20 January 2019).

(C) (

(C) 2019 by the authors. Licensee MDPI, Basel, Switzerland. This article is an open access article distributed under the terms and conditions of the Creative Commons Attribution (CC BY) license (http://creativecommons.org/licenses/by/4.0/). 


\title{
Article \\ Suitable Pattern of the Natural Environment of Human Settlements in the Lower Reaches of the Yangtze River
}

\author{
Fan Song, Xiaohua Yang * and Feifei Wu \\ State Key Laboratory of Water Environment Simulation, School of Environment, Beijing Normal University, \\ Beijing 100875, China; 201621180014@mail.bnu.edu.cn (F.S.); wufeifei_bnu@163.com (F.W.) \\ * Correspondence: xiaohuayang@bnu.edu.cn; Tel.: +86-010-5880-6050
}

Received: 27 February 2019; Accepted: 9 April 2019; Published: 12 April 2019

\begin{abstract}
The human settlement environment is the object on which human survival depends. In this study, six single factor suitability models and a comprehensive index model of the human settlement natural environment were established. The six single factor models included topography, hydrology, vegetation, soil, temperature and humidity, and land surface temperature. This study took $1 \mathrm{~km} \times 1 \mathrm{~km}$ as the pixel size and relied on the ArcGIS platform to systematically and quantitatively evaluate the human settlement environment of the lower reaches of the Yangtze river. The results show that: (1) From the evaluation results of single natural elements, the topography of the study area is relatively flat, with a small number of hydraulic erosion areas. Besides, there are significant differences between the north and the south in temperature and humidity, hydrology, vegetation, and land surface temperature. (2) In 2015, the most suitable areas of human settlement environment were mainly distributed in the plains along the Yangtze river, the plain of northern Zhejiang, and the Poyang plain. The most unsuitable areas are mainly distributed in mountainous areas, such as the mountain area of southern Zhejiang and Dabie mountain area. Topography and vegetation are the dominant factors for classification. (3) From the perspective of space, the score of the human settlement natural environment in Shanghai is above the average, and the best among the other provinces is Jiangsu province, while Zhejiang, Jiangxi, and Anhui provinces have little difference. From the perspective of time, the overall level of the suitability in the lower reaches of the Yangtze river has been improved from 2005 to 2015, mainly due to the influence of temperature and humidity index and water resource index.
\end{abstract}

Keywords: human settlement suitability; human settlement natural environment index; GIS; lower reaches of Yangtze River

\section{Introduction}

The human settlement environment is the place where people work, live, and play. It is also the dependent object of human survival and the main transformation object of human activities [1]. The quality of the human settlement environment not only directly affects the residents' living experience, but also indirectly affects the economic and social progress of a region. The earliest research on the human settlement environment was in 1958, when the Greek scholar Doxiadis established the science of human settlement and conducted a lot of basic research on the problems of the human settlement environment [2]. The second Habitat Conference of United Nations in the 1990s put forward the "Habitat Agenda"; there were two important issues: "comfortable housing for everyone" and "sustainable development of human settlements in the process of urbanization". This indicated that sustainable human settlements should be established in a human living environment so that human beings can enjoy a harmonious, healthy, and fulfilling life with nature. In the 21st century, the 
concept of sustainable development has become the guiding ideology of the research on the human settlement environment. In recent years, many international scholars have done a lot of research on the sustainable development of a human settlement environment from multiple perspectives. For example, Muhammad Rusdi et al. [3] assessed the land suitability of the Banda Aceh, Indonesia region 10 years after the tsunami. The study was conducted primarily from the perspective of soil permeability, topography, and geology, so as to determine the level of suitability of the area for human habitat. Safa Mazahreh et al. [4] made a land suitability map in Jordan through an approach that integrated soil and climatic data. The analyses not only identified key factors limiting land use but also provided the type of land use for which the region was suitable. Walter Musakwa [5] and Ingrida Bagdanavičiūtè [6], respectively, established evaluation standards from the perspectives of nature-society and pollution sources, and then selected the most suitable areas for human settlement in their respective study areas, so as to provide a basis for land reform and creation of smart cities. Although their researches have their own emphases, they all make great contributions to the study of human settlement.

In China, the research on the human settlement environment started in the 1990s. Tsinghua University established the research center for human settlements in 1995. Professor Wu Liang-yong classified the human settlement environment system into five systems: natural system, human system, social system, residential system, and supporting system [7,8]. Around these five systems, scholars in different fields have conducted a lot of studies from different perspectives. Scholars in the field of architecture are more focused on the study of the residential system and support system, among the five major systems, while sociologists are more concerned with human systems and social systems [9], and environmental and ecologists are more inclined to study natural systems. There are also some scholars who study complex systems [10]. A review article by MA Ren-feng gave a detailed description of the history and current situation of research on the human settlement environment in China [11], and the evaluation method of human settlement natural environment suitability, introduced in the article, is also the main idea of this paper.

In addition to the system divisions described above, the research on the human settlement environment can also be divided from the spatial scale, which can be divided into five scales including global, regional, urban, community, and architecture [12]. Numerous classifications have also generated numerous research methods. Currently, the commonly used method is analysis in Geographic Information System. At the same time, many mathematical methods such as fuzzy comprehensive evaluation [13], factor analysis [14], and genetic algorithm [15] have been applied in this field. With the development and maturity of Geographic Information System and Remote Sensing technology, it is possible to show the advantages and disadvantages of the human settlement environment with pictures and texts. The joint analysis of GIS tool and other methods is also gradually developed [16], which is of great significance to the research on the human settlement environment suitability.

Natural system is the basic system of the human settlement environment, which directly relates to human health and body surface feeling, and indirectly constitutes the construction foundation of other systems. Among the numerous natural factors, this study selects some basic elements that are most closely related to human survival and life, including six natural elements: topography, hydrology, vegetation, soil, temperature and humidity, and land surface temperature. On the basis of the study of each individual element, the model of the human settlement natural environment index (HNEI) is established, and different weights are assigned to each element according to the actual situation of the research area. The lower reaches of the Yangtze river are one of the most developed regions in China. During a long period of economic development, a series of resource and environmental problems have emerged. The purpose of this study is as follows: 1 . To reveal the spatial pattern of the human settlement natural environment suitability of five provinces in the lower reaches of the Yangtze river; 2. to explore the advantage and restriction of the human settlement environment in this region, so as to provide the corresponding research basis and decision-making support for local population spatial planning and land function planning. 


\section{Study Area}

The study area covered the lower reaches of the Yangtze river, including five provincial-level administrative regions of Jiangxi, Anhui, Jiangsu, Zhejiang and Shanghai, with a total of 51 prefecture-level cities and one municipality directly under the central government. The region is located in longitude $\mathrm{E} 113^{\circ} 34^{\prime}-\mathrm{E} 123^{\circ} 25^{\prime}$ and latitude $\mathrm{N} 24^{\circ} 29^{\prime}-\mathrm{N} 35^{\circ} 20^{\prime}$. The total area is about $526,080 \mathrm{~km}^{2}$. The location of the study area is shown in Figure 1. At the end of 2016, the permanent resident population of the five provinces was about 267.82 million, accounting for $19.37 \%$ of the total population of China, with a high population density. Most of the region is located in the economic radiation zone of the urban agglomeration of the Yangtze river delta. Relying on the excellent geographical advantages and economic foundation, the study area has become the region with the highest urbanization level and the most developed economy in China. Most of the region belongs to the subtropical monsoon climate zone, with obvious monsoon characteristics. In the process of rapid urbanization in this region, a lot of resources and environmental problems have been caused, resulting in great changes in the natural environment. In this study, the grid of $1 \times 1 \mathrm{~km}$ was taken as the basic unit, which can satisfy the analysis of different spatial scales, so as to make an appropriate evaluation of the natural suitability of human settlement.

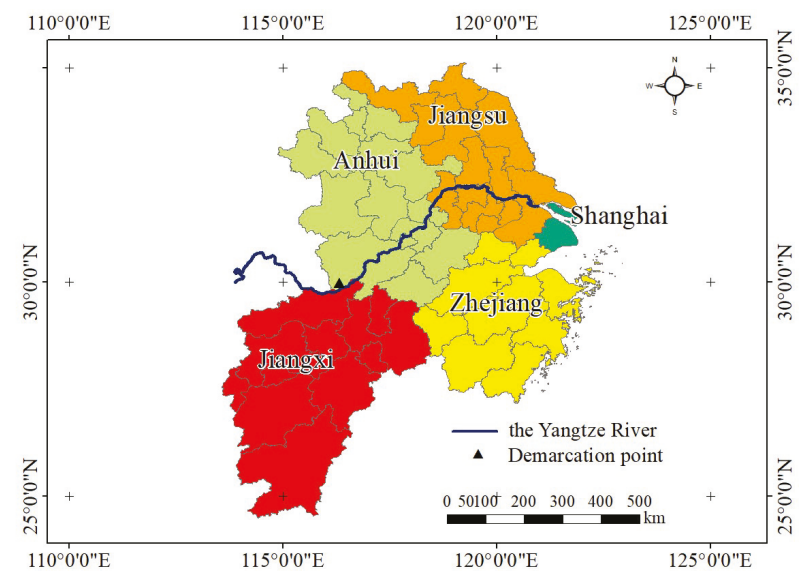

Figure 1. Location of study area.

\section{Materials and Methods}

\subsection{Data Sources}

The six indexes selected in this study were: relief degree of land surface (RDLS), water resource index (WRI), land cover index (LCI), soil suitability index (SSI), temperature-humidity index (THI), and land surface temperature index (LSTI). The data used for calculation included: digital elevation model data, land use data, annual precipitation spatial interpolation data, normalized difference vegetation index data [17], soil erosion spatial distribution data [18], annual data for natural indicators of weather stations, and MODIS land surface temperature data. The data types, year of data, and data source are shown in the Table 1. 


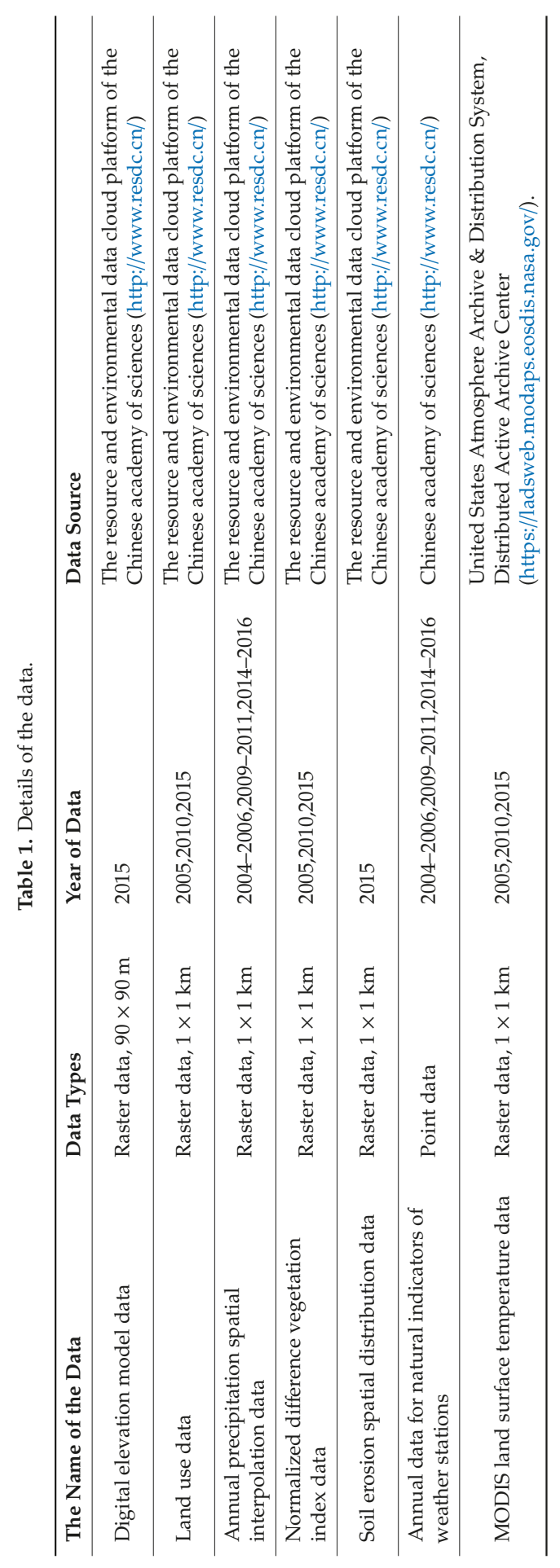




\subsection{Methods of Single Factor Model}

\subsubsection{Relief Degree of Land Surface}

Relief degree of land surface refers to the difference between the highest and lowest elevations in an area. It reflects the macroscopic changes of the region's terrain, which is of great reference value for the site selection of human settlements [19]. The key to calculate RDLS is to determine the size of the reference area, which can well express the topographic characteristics of the study area. Referring to the research results of Feng Zhi-ming [20], Wang Yong-li [21], and other scholars, the formula of RDLS established in this paper is as follows:

$$
R D L S=A L T / 1000+\{[\max (\mathrm{H})-\min (\mathrm{H})] \times[1-\mathrm{P}(\mathrm{A}) / \mathrm{A}]\} / 500
$$

where, ALT refers to the average altitude within the selected reference area; $\operatorname{Max}(\mathrm{H})$ and $\min (\mathrm{H})$ refer to the highest and lowest elevations within the reference area; $\mathrm{P}(\mathrm{A})$ refers to the flat area within the reference area, whose slope is less than $5^{\circ}$; A refers to the total area of the reference area; and 500 refers to China's benchmark mountain height.

The neighborhood analysis method based on raster data was used to calculate the size of the reference area [22]. The neighborhood analysis tool of ArcGIS was used to analyze the altitude difference within the grid, from $3 \times 3$ pixels to $69 \times 69$ pixels. According to the calculation results, the scatter diagram of the corresponding relationship between the grid size and the altitude difference was established, and the logarithmic function of the curve equation was determined. The size of the reference area grid can be determined according to the change of curve growth rate. In this study, the determined optimal grid size was $19 \times 19\left(2.92 \mathrm{~km}^{2}\right)$. According to Formula (1), the RDLS of the lower reaches of the Yangtze river can be obtained. The result in 2015 is shown in Figure 3a.

\subsubsection{Water Resource Index}

Water is the source of life, and the basic need of human settlement construction and development. Although the lower reaches of the Yangtze river are relatively rich in water resources, they are unevenly distributed. In order to express this difference, referred to the environmental assessment standards of the ministry of environmental protection of the People's Republic of China, and relevant research results [23,24], we selected two indexes of "rainfall" and "distance from water source" to build the water resource index model. The formula of WRI is as follows:

$$
W R I=\alpha \mathrm{P}+\beta \mathrm{D}
$$

where $\mathrm{P}$ is the normalized rainfall; $\mathrm{D}$ is the normalized distance from the water source; $\mathrm{A}$ and $\mathrm{B}$ are the weights of two factors, which are respectively 0.8 and 0.2 in this study. In order to reduce the contingency of data, the average rainfall in 2004-2006, 2009-2011, and 2014-2016 was used as the values in 2005, 2010, and 2015, respectively. The required water source location was obtained by extracting the "water area" type in the land use data and the "Euclidean Distance" in ArcGIS was used to calculate the "distance from water source". In this paper, the distance within $10 \mathrm{~km}$ from the water source was calculated and reversely normalized, and the value of the remaining areas was assigned to zero. The calculation result in 2015 is shown in Figure 3b.

\subsubsection{Land Cover Index}

Land is an important material for human survival and development. Land coverage and utilization not only affect the stability of natural ecosystem, but also continuously affect the development of social economy [25]. In recent years, with the rapid development of urbanization, inappropriate land use has become more and more serious. Inappropriate land use has become a problem of universal concern, among which vegetation cover has been a hot topic. Vegetation is an important intermediate link 
connecting the atmospheric environment, soil environment, and water environment, which can regulate the climate and have a significant impact on the human settlement environment [26]. In this paper, the land cover index model was constructed by referring to the ecological environment evaluation standard of the State Environmental Protection Administration [27] and previous research results [24]:

$$
L C I=L T_{i} \times N D V I
$$

where, $L T_{i}$ refers to the weight of each land use type, and NDVI refers to the normalized difference vegetation index.

According to the research purpose, relevant literatures $[28,29]$ and technical specifications, weight was assigned to each land use type, and the results are shown in Table 2. Then, the land cover index can be obtained according to Formula (3). The calculation result in 2015 is shown in Figure 3c.

Table 2. Weight of each land use type.

\begin{tabular}{|c|c|c|c|}
\hline Land-Use Type & Weight & Classification & Weight \\
\hline \multirow[t]{2}{*}{ Arable land } & 0.25 & Paddy field & 0.65 \\
\hline & & Dry field & 0.35 \\
\hline \multirow[t]{4}{*}{ Woodland } & 0.18 & Forest land & 0.34 \\
\hline & & Shrub land & 0.26 \\
\hline & & Sparse wood & 0.2 \\
\hline & & Other woodland & 0.2 \\
\hline \multirow[t]{3}{*}{ Grass land } & 0.15 & Grassland with high coverage & 0.4 \\
\hline & & Grassland with moderate coverage & 0.33 \\
\hline & & Grassland with low coverage & 0.27 \\
\hline \multirow[t]{5}{*}{ Water area } & 0.17 & Canal & 0.31 \\
\hline & & Lake & 0.29 \\
\hline & & Reservoir and pit-pond & 0.2 \\
\hline & & Mudflat & 0.1 \\
\hline & & Bottomland & 0.1 \\
\hline \multirow[t]{3}{*}{ Construction land } & 0.2 & Urban and town land & 0.44 \\
\hline & & Village land & 0.35 \\
\hline & & Other construction land & 0.21 \\
\hline \multirow[t]{3}{*}{ Unused land } & 0.05 & Wetland & 0.48 \\
\hline & & Bare land & 0.28 \\
\hline & & Bare rock & 0.24 \\
\hline
\end{tabular}

\subsubsection{Soil Suitability Index}

Soil erosion is a serious environmental problem, which not only damages land resources and affects normal industrial and agricultural behaviors, but also may aggravate drought and waterlogging. It is one of the important evaluation indexes of the human settlement environment [30]. China is one of the countries with serious soil erosion, which has affected the economic and social development. It can be known from the existing studies that soil erosion exists in some areas of the study area, especially in Jiangxi province [31,32]. Therefore, soil erosion was taken as an evaluation index in this study. We used soil erosion data for reclassification to obtain soil suitability index of five provinces in the lower reaches of the Yangtze river, as shown in Figure 3d.

\subsubsection{Temperature-Humidity Index}

Among the many climatic elements, air temperature directly affects the exchange of heat and water between human body and the outside world, so the air temperature directly affects the comfort degree of human body. Due to the difference in humidity between the north and the south, there will be a difference in apparent temperature [33]. Therefore, this study adopted the widely used temperature-humidity index (THI) to express this effect [34,35], so as to reflect the temperature 
suitability through the comprehensive effect of temperature and humidity. The calculation formula is as follows:

$$
\begin{aligned}
& \text { THI }=\mathrm{T}-0.55(1-f)(\mathrm{T}-58) \\
& \mathrm{T}=1.8 \mathrm{t}+32
\end{aligned}
$$

where $\mathrm{t}$ is Celsius, $\mathrm{T}$ is Fahrenheit, and $f$ is relative humidity. In order to reduce the contingency of data, the average temperature and relative humidity data in 2004-2006, 2009-2011, and 2014-2016 was used as the values in 2005, 2010, and 2015, respectively. Firstly, the location of weather stations in the study area and the corresponding temperature and humidity information were input in ArcGIS. The locations of weather stations are shown in Figure 2. After data processing, the kriging interpolating model was used to carry out spatial interpolation processing in five provinces, and the spatial distribution data of various climatic elements were obtained. We mainly used the "Spatial Analyst tools-interpolation-Kriging" function in ArcGIS. Finally, according to Formula (4), the 2015 result is shown in Figure 3e.

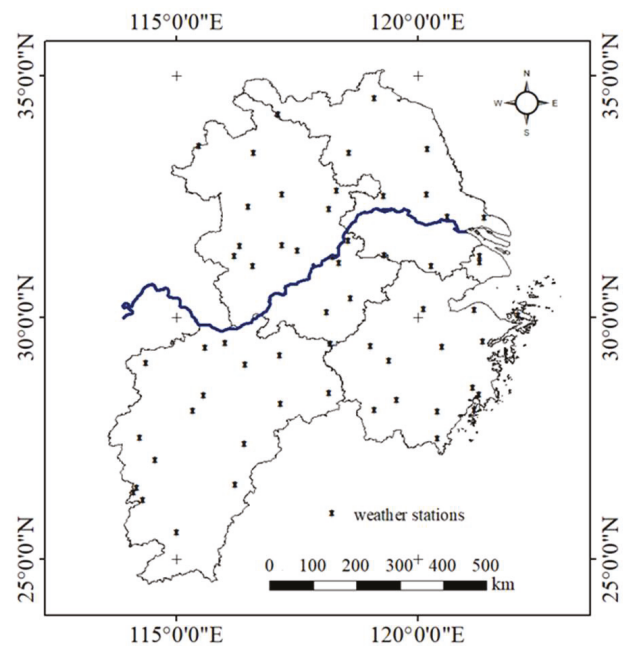

Figure 2. Locations of weather stations.

\subsubsection{Land Surface Temperature Index}

The rapid development of urbanization has changed the urban climate, and one of the remarkable characteristics is the urban heat island effect. On the one hand, the urban heat island effect directly affects the energy utilization, hydrological environment, and air quality. On the other hand, the urban heat island effect also indirectly affects the quality of urban living environment and the health status of residents [36]. Land surface temperature is a key parameter of urban surface energy balance and a very important parameter for monitoring urban heat island effect.

The classification method of land surface temperature was to segment the temperature density on the basis of the original land surface temperature data [37]. The surface temperature in the region was divided into five grades, which were: low temperature $\left(\mathrm{T}<\mathrm{T}_{\text {mean }}-1.5 \mathrm{~T}_{\text {std }}\right)$; sub-low temperature $\left(\mathrm{T}_{\text {mean }}-1.5 \mathrm{~T}_{\text {std }}<\mathrm{T}<\mathrm{T}_{\text {mean }}-0.5 \mathrm{~T}_{\text {std }}\right)$; medium temperature $\left(\mathrm{T}_{\text {mean }}-0.5 \mathrm{~T}_{\text {std }}<\mathrm{T}<\mathrm{T}_{\text {mean }}+0.5 \mathrm{~T}_{\text {std }}\right)$; sub-high temperature $\left(\mathrm{T}_{\text {mean }}+0.5 \mathrm{~T}_{\text {std }}<\mathrm{T}<\mathrm{T}_{\text {mean }}+1.5 \mathrm{~T}_{\text {std }}\right)$; high temperature $\left(\mathrm{T}>\mathrm{T}_{\text {mean }}+1.5 \mathrm{~T}_{\text {std }}\right)$. Where $\mathrm{T}_{\text {mean }}$ is the average value of land surface temperature and $\mathrm{T}_{\text {std }}$ is the standard deviation of land surface temperature. The result of land surface temperature index in 2015 is shown in Figure $3 f$. 


\subsection{Methods of Human Settlement Natural Environment Model}

\subsubsection{Scoring Criteria}

After the completion of the single factor evaluation, it is necessary to carry out the graph superposition to complete the evaluation of human settlement natural environment. Therefore, each single factor model should be graded according to the actual situation of the study area and existing studies [38]. The single factor evaluation results in 2015 were divided into five grades and assigned with scoring values, as shown in Table 3.

Table 3. Scoring criteria of the single factors.

\begin{tabular}{cccc}
\hline & RDLS & WRI & LCI \\
\hline I (90 grades) & {$[-0.02,0.15]$} & $(0.67,0.96]$ & $(0.1209,0.1495]$ \\
II (70 grades) & $(0.15,0.44]$ & $(0.54,0.67]$ & $(0.0807,0.1209]$ \\
III (50 grades) & $(0.44,1.03]$ & $(0.41,0.54]$ & $(0.0562,0.0807]$ \\
IV (30 grades) & $(1.03,1.68]$ & $(0.25,0.41]$ & $(0.0323,0.0562]$ \\
V (10 grades) & $(1.68,3.30]$ & {$[0,0.25]$} & {$[-0.004,0.0323]$} \\
\hline & SSI & THI & LSTI \\
\hline I (90 grades) & mired & $(61,63]$ & low temperature \\
II (70 grades) & mild & $(59,61],(63,66]$ & sub-low temperature \\
III (50 grades) & moderate & $(57,59]$ & medium temperature \\
IV (30 grades) & strong & $(55,57]$ & sub-high temperature \\
V (10 grades) & very strong and violent & {$[46,55]$} & high temperature \\
\hline
\end{tabular}

Note: RDLS refers to Relief Degree of Land Surface; WRI refers to Water Resource Index; LCI refers to Land Cover Index; SSI refers to Soil Suitability Index; THI refers to Temperature-Humidity Index; LSTI refers to Land Surface Temperature Index.

\subsubsection{Establishment of Human Settlement Natural Environment Index}

On the basis of single factor evaluation, a human settlement natural environment index (HNEI) model was constructed to evaluate the natural suitability of human settlement in five provinces of the lower reaches of the Yangtze river. The formula is as follows:

$$
H N E I=\alpha R D L S+\beta W R I+\chi L C I+\delta S S I+\gamma T H I+\varepsilon L S T I+0.2 G D P I
$$

where $\alpha \beta \chi \delta \gamma \varepsilon$ are the corresponding weights of each index respectively, which were obtained by referring to existing studies $[4,28,38]$ through the analytic hierarchy process. The results were as follows: $\alpha=0.2324, \beta=0.0794, \chi=0.3579, \delta=0.0435, \gamma=0.1697, \varepsilon=0.1172$.

0.2GDPI (Gross Domestic Product Index) is the economic correction coefficient. Since selected natural indexes such as LCI and LSTI are affected largely by population distribution, the economic coefficient was added to eliminate such influence. At the same time, economically developed areas have relatively complete residential infrastructure, which is also one of the necessary conditions for human settlement. The classification of GDPI is shown in Table 4. 
Table 4. The classification of Gross Domestic Product Index (GDPI).

\begin{tabular}{cc}
\hline Grades & Classification of GDP (unit: Yuan per $\mathbf{~ k m}^{\mathbf{2}}$ ) \\
\hline 10 & {$[0,424]$} \\
20 & $(425,558]$ \\
30 & $(558,983]$ \\
40 & $(983,2337]$ \\
50 & $(2337,6654]$ \\
60 & $(6654,20,415]$ \\
70 & $(20,415,64,282]$ \\
80 & $(64,282,204,114]$ \\
90 & $(204,114,649,851]$ \\
100 & $(649,851,2,070,711]$ \\
\hline
\end{tabular}

\section{Results and Discussion}

\subsection{Results of Single Natural Factor}

(1) RDLS: As can be seen from Figure 3a, the RDLS in most areas was low, with the maximum of 3.3 and the minimum of -0.03 . From the perspective of province, there were some high-RDLS areas in Anhui, Zhejiang, and Jiangxi provinces, which were distributed in the Dabie Mountain area, mountainous area of southern Anhui, mountain area of southern Zhejiang, and the Mufu Mountain, Jiuling Mountain in northwest Jiangxi province.

(2) WRI: As can be seen from Figure 3b, the WRI showed a trend of gradual decrease from south to north, with high suitability areas concentrated in central and northern Jiangxi, southern Anhui, and most areas of southwest Zhejiang. The low suitability areas were mainly concentrated in the central and northern Anhui and most areas of Jiangsu province.

(3) LCI: As shown in Figure 3c, the LCI had the following characteristics: 1. In terms of spatial distribution, a medium-high-low pattern was formed from north to south. The dominant vegetation types in the three regions were dry field, paddy field, and woodland, respectively. 2. In terms of provinces, Jiangsu province had the best suitability. Except for the uninhabitable lake areas, the scores of the other regions were all above the average. The LCI of Anhui from north to south also presented a medium-high-low distribution. Because the built-up areas in Shanghai were too concentrated, the LCI of the northern Shanghai was poor. The most suitable areas of Jiangxi and Zhejiang were the areas of basins and plains.

(4) SSI: As can be seen from Figure 3d, soil erosion in the lower reaches of the Yangtze river was only caused by hydraulic erosion without wind erosion and freeze-thaw erosion, which was related to the geographical location of the region. The numerous tributaries along the Yangtze river and the abundant rainfall contributed to this phenomenon.

(5) THI: According to Figure 3e and the reference standard, the THI of the lower reaches of the Yangtze river was suitable for human habitation. From the perspective of distribution, the THI basically increased with the increase of latitude. The overall temperature-humidity index of Jiangxi province was the highest, while that of Anhui province and Jiangsu province was lower. In addition, the THI of mountainous areas was obviously lower than that of plain areas at the same latitude.

(6) LSTI: According to the actual situation of the research area, we believed that the lower the land surface temperature is, the better the habitability is. Figure 3f shows that Shanghai had the highest land surface temperature among the five provinces, because Shanghai had a high population density and a high proportion of built-up area. Due to the existence of a large number of lakes, such as Tai Lake and Hongze Lake, Jiangsu province had reserved a large area of low temperature area, while the high temperature area was mostly concentrated in the urban agglomeration in southern Jiangsu. There was a close relationship between land surface temperature and topography in Zhejiang and Anhui provinces. High temperature areas were mainly concentrated in plain and basin areas; low 
temperatures areas were concentrated in hilly and mountainous areas. Jiangxi province is located in the south of the five provinces, the sun is the strongest, so the land surface temperature was relatively high.
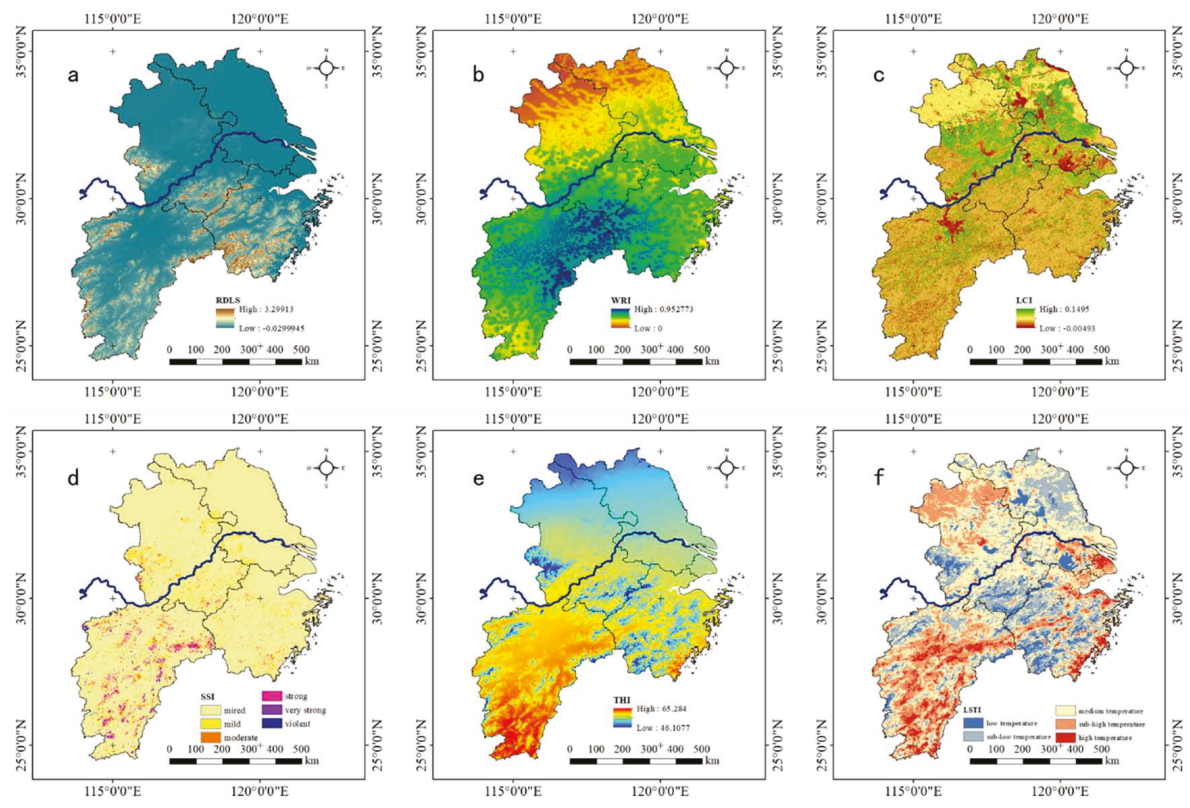

Figure 3. Suitability evaluation of single natural elements. (a) RDLS; (b) WRI; (c) LCI; (d) SSI; (e) THI; (f) LSTI.

\subsection{Results of Human Settlement Natural Environment}

The distribution diagram of Human Settlement Natural Environment Index (HNEI) obtained after superposition calculation is shown in Figure 4a. It can be seen from the figure that the range of HNEI was 22.2-99.3. The results are expressed in five levels respectively: very unsuitable $(22 \leq \mathrm{HNEI} \leq 48)$, unsuitable $(48<\mathrm{HNEI} \leq 57)$, medium suitable $(57<\mathrm{HNEI} \leq 66)$, suitable $(66<\mathrm{HNEI} \leq 77)$, and very suitable $(77<\mathrm{HNEI} \leq 100)$.
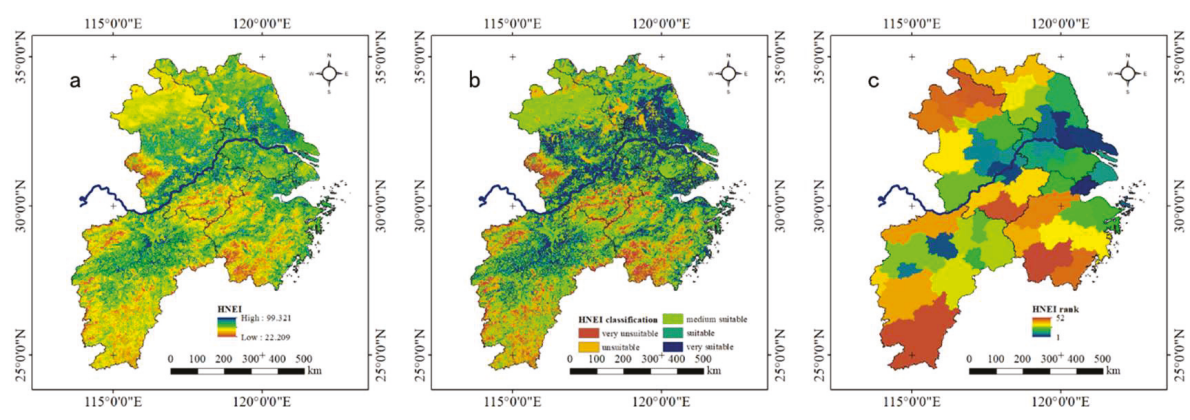

Figure 4. Evaluation results of Human Settlement Natural Environment Index (HNEI). (a) HNEI; (b) HNEI classification; (c) HNEI rank.

As can be seen from Figure $4 \mathrm{~b}$, the regions with high HNEI were mainly distributed along the Yangtze river, the northern Zhejiang plain, and the Poyang lake plain. The specific analysis is as follows: 
(1) Very unsuitable area: This area was the most unsuitable area for human habitation in the study area, which was not suitable for development and had a fragile ecological environment. This area accounted for $7.27 \%$ of the total area. As can be seen from the figure, this part of the region was mainly distributed in southern Zhejiang mountain, Dabie mountain, and southern Anhui mountain. Besides, there was Mufu mountain and Jiuling mountain in northwest Jiangxi province. The dominant factor in these areas was RDLS. In addition, these areas also tended to be consistent in other single factor evaluation results. As for the LCI, most of these areas were covered by forest, and the scoring criteria was IV (30 grades). In terms of LSTI, due to the high vegetation coverage, most scoring criteria in these areas were II (70 grades) or above. In terms of THI, due to the high terrain, the somatosensory temperature in these areas was relatively cold, and most of the scoring criteria were III (50 grades) or below. Finally, in addition to the southern Zhejiang mountains, other areas had varying degrees of erosion.

(2) Unsuitable area: This area accounted for $20.14 \%$ of the total area and was widely distributed. The reasons for the formation of such areas were complex and can be roughly divided into five categories: The first category was the surrounding area of the very unsuitable area. The terrain and other factors in this area were better than those in the very unsuitable area. The second category was distributed in mountainous and hilly areas in southern Jiangxi. The terrain of this category was between mountain and plain, and the score of RDLS increased, but correspondingly, the score of LSTI decreased. The WRI of this area differed widely, there was less rainfall in southern Jiangxi and more in eastern Jiangxi. The biggest difference from the first category was in the THI. Such a category had lower latitudes and higher temperatures, making it more suitable for settlement. The third category was the western Zhejiang hilly region and the eastern Zhejiang hilly region. Similar to the first category, the dominant factors were RDLS and LCI. In general, this category was limited by THI, so the natural ecological conditions were slightly worse than those of the second category. However, the GDP of this area was higher than that of the second category; there was a strong ability to construct and transform the residential environment. After correction, they were all in the unsuitable area. The fourth category was located in the lake area of northern Anhui and northern Jiangsu. The water area itself was uninhabitable and the temperature was low, so it was in the unsuitable area. The fifth category was the northern region of the study area. The limiting factor in this category was the THI, and the temperature was relatively cold.

(3) Very suitable area: This area had the most harmonious combination of various natural factors, and was the most suitable place for human production and life. This category accounted for $21.19 \%$ of the total area, mostly distributed in the plain areas along the Yangtze river, the plain areas in northern Zhejiang, and the Poyang lake plain. There were two dominant factors in this area. The first one was LCI, with scores of 70 or above. The vegetation coverage in these regions was basically paddy fields, which were suitable for living. The second was RDLS. These areas were all flat and suitable for large-scale group living.

(4) Suitable area: This category was also suitable for human habitation, accounting for $16.91 \%$ of the total area. This area was relatively complex, which can be roughly divided into three categories: The first category was the area around the Yangtze river basin, which was distributed around the very suitable area. The dominant factor in this region was the LCI, and most of the vegetation was paddy field. The second category was parts of Nantong city, Yancheng city, and part of northern Jiangsu. The dominant factor of this region was still the LCI, and most of them were dryland regions with relatively good hydrothermal conditions. In addition, the correlation degree between this category and the LSTI was relatively high, and most of them were located in the region with medium temperature. The third category was the area around Poyang lake plain in Jiangxi province and the basin area in the south of Poyang lake. The dominant factors in this part were WRI and RDLS, and most of them were in flat areas and areas with abundant water resources.

(5) Medium suitable area: This category covered the largest area among the five categories, accounting for $34.56 \%$ of the total area, with a large distribution in each province. Generally, there 
were the following distribution areas: The first category was the part of northern Anhui and northern Zhejiang province, the dominant factor was the land cover index, and the land use type was mostly dry land. The limiting factors were the THI and WRI. The temperature in most regions was low and the amount of water resources was small; the score of the two indexes were mostly below 30 points. The second category covered most of Shanghai and some parts of southern Jiangsu province. The dominant factor of this category was LCI, and the limiting factor was LSTI. The main land use type was construction land, and the natural conditions of this region were more suitable for living. However, it was located in the Yangtze river delta region, and the built-up area had a large population density, so the LSTI was higher. In fact, it was no longer suitable for adding too many people, so it was classified in the medium suitable area. The third category was Tai lake, Poyang lake, and other lake areas, which were similar to the lake in unsuitable areas. The fourth category was the area between the suitable areas and the unsuitable areas. If such areas can follow the local development rules and make rational development and utilization in the development process, they are highly likely to become suitable areas. On the contrary, if the ecological environment is damaged or the climate changes greatly, they are also likely to become unsuitable areas.

The ranking of HNEI in 2015 is shown in Figure 4c. Similar to Figure 4b, cities with a high index were mainly distributed along the Yangtze river, the northern Zhejiang plain, and the Poyang lake plain. Shanghai's HNEI ranked twelfth. Among the other four provinces, Jiangsu province had the best HNEI. There were six cities in the top 15: Taizhou, Nantong, Yangzhou, Zhenjiang, Changzhou, and Nanjing. The overall scores of the other three provinces were similar. The top 15 cities in Zhejiang province are Jiaxing and Zhoushan. Jiangxi province had Nanchang, Xinyu. Anhui province had Wuhu, Hefei, Ma'anshan, and Tongling.

\subsection{Time Evolution Analysis of HNEI}

In order to explore the evolution of HNEI in the study area, WRI, LCI, THI, and LSTI in 2010 and 2005 were recalculated using relevant data to obtain the HNEI of 2010 and 2005. The results were graded using the same criteria as in 2015, as shown in Figure 5 and Table 5.
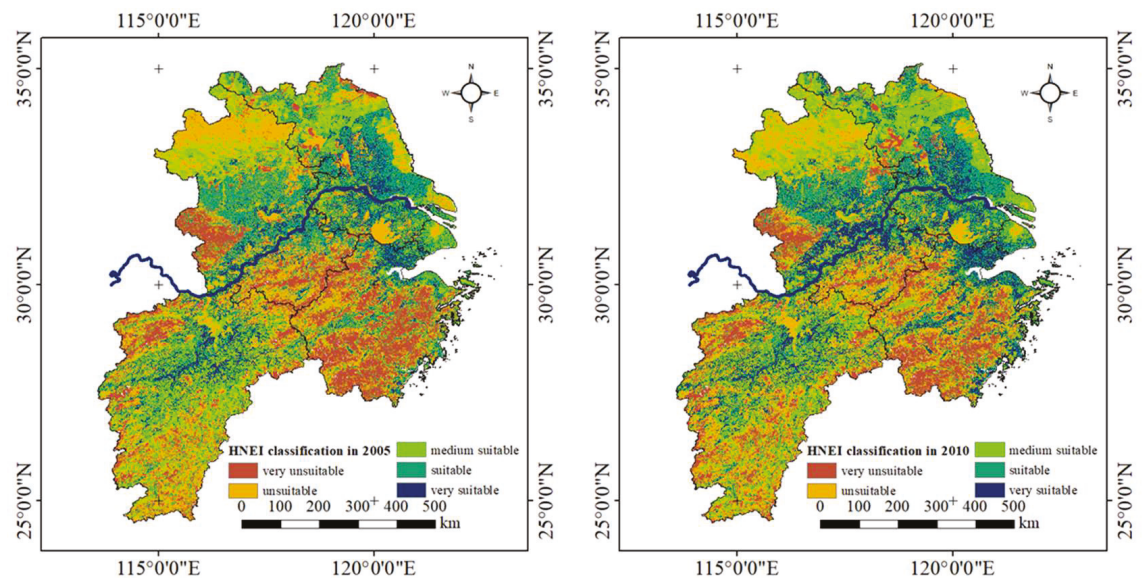

Figure 5. Results of natural suitability of human settlements in 2005 and 2010. HNEI classification in 2005; HNEI classification in 2010.

According to the results in Figure 5 and the result of 2015, the natural suitability of human settlement in the lower reaches of the Yangtze river showed little change, and the high suitability areas were still concentrated along the Yangtze river, the northern Zhejiang plain, and the Poyang lake plain. However, the overall level of HENI was slightly improved; it can be seen from the results in 
Table 5 that the area of very unsuitable was significantly reduced, while the area of very suitable was significantly increased. It was found that the leading factors are THI and WRI, and the improvement of these two indexes increased the overall score, making the natural suitability of human settlement somewhat improved compared with that of ten years ago.

Table 5. The change of area proportion of each district.

\begin{tabular}{cccccc}
\hline & $\begin{array}{c}\text { Very } \\
\text { Unsuitable }\end{array}$ & Unsuitable & $\begin{array}{c}\text { Medium } \\
\text { Suitable }\end{array}$ & Suitable & Very Suitable \\
\hline 2015 & $7.20 \%$ & $20.14 \%$ & $34.56 \%$ & $16.91 \%$ & $21.19 \%$ \\
2010 & $14.30 \%$ & $30.82 \%$ & $22.29 \%$ & $18.31 \%$ & $14.28 \%$ \\
2005 & $17.80 \%$ & $31.93 \%$ & $20.04 \%$ & $20.59 \%$ & $9.64 \%$ \\
\hline
\end{tabular}

\section{Conclusions}

(1) In this paper, six natural factors, including relief degree of land surface (RDLS), water resource index (WRI), land cover index (LCI), soil suitability index (SSI), temperature-humidity index (THI), and land surface temperature index (LSTI), were selected to establish the human settlement natural environment index (HNEI) model. With ArcGIS as a tool, the natural suitability of human settlement in five provinces in the lower reaches of the Yangtze river was quantitatively evaluated and analyzed.

(2) The human settlement environment includes five major systems: nature, human, society, residence, and support. There is a strong correlation between each system. The main research object of this study is the natural system, and the GDP Index was used to correct the repeated interference of human factors on various elements. The method is feasible to restore the human ecological system objectively and truly from the angle of nature.

(3) In 2015, the most suitable areas accounted for $22.06 \%$ of the total area. The areas with the highest suitability index were mainly distributed in the plains along the Yangtze river, the northern Zhejiang plain, and the Poyang lake plain. The dominant factors were RDLS and LCI, and the vegetation cover was basically paddy field, which is suitable for living. Suitable areas accounted for $16.85 \%$ of the total area. Some areas were distributed around very suitable areas. In addition, there were parts of paddy fields and dry lands in Jiangsu province, and areas with better hydrothermal conditions in Jiangxi province. The most unsuitable areas accounted for $7.27 \%$ of the total area, and were mainly distributed in southern Zhejiang mountain, Dabie mountain, southern Anhui mountain, Mufu mountain, and Jiuling mountain. Relief degree of land surface (RDLS) was the dominant factor, and soil erosion areas were also mainly distributed in these areas. The unsuitable areas accounted for $20.49 \%$ of the total area. Some areas were distributed around the very unsuitable areas, while others were mainly distributed in southern Jiangxi (the dominant factors were RDLS and THI), western and eastern Zhejiang (the dominant factor was RDLS), and northern Anhui (the dominant factor was THI). The area of medium suitable area accounted for $33.33 \%$, which was widely distributed in each province. Whether these areas will develop into suitable or unsuitable areas in the future depends, to a great extent, on urban development policies and means, which are the key areas that should be paid attention to.

(4) From the perspective of space, the human settlement natural environment index of Shanghai in 2015 was above the average. The best among the rest of the provinces was Jiangsu province, with six cities ranking in the top 15. Zhejiang province, Jiangxi province, and Anhui province had two, two, and four cities, respectively. From the perspective of time, the spatial distribution of the natural suitability of human settlements did not change much from 2005 to 2015, but the overall suitability level was improved for a certain extent, mainly due to the improvement of the temperature-humidity index (THI) and the water resource index (WRI).

Author Contributions: Conceptualization, F.S. and X.H.Y.; methodology, F.S. and F.F.W.; data curation, F.S.; writing, F.S.; visualization, F.S.; project administration, X.H.Y. 
Funding: This research was funded by the Project of the National Key Research Program of China (Nos. 2017YFC0506603, 2016YFC0401305), National Natural Foundation of China (No. 51679007), and the State Key Program of National Natural Science of China (No. 41530635).

Conflicts of Interest: The authors declare no conflict of interest.

\section{References}

1. Aynur, M.; Shi, P.; Zhao, G.J.; Yan, F.; Xue, G.L. Evaluations of living environment suitability of Hotan Prefecture in Xinjiang based on GIS. Arid Land Geogr. 2012, 35, 847-855. (In Chinese)

2. Xie, X.Y.; Zeng, X.; Li, J. Evaluation of Nature Suitability for Human Settlement in Chongqing. Resour. Environ. Yangtze Basin 2014, 23, 1351-1359. (In Chinese)

3. Muhammad, R.; Ruhizal, R.; Mohd, S.; Ahamad, S. Land evaluation suitability for settlement based on soil permeability, topography and geology ten years after tsunami in Banda Aceh, Indonesia. Egypt. J. Remot Sens. Space Sci. 2015, 18, 207-215.

4. Safa, M.; Majed, B.; Doaa, A.H. GIS approach for assessment of land suitability for different land use alternatives in semi arid environment in Jordan: Case study (Al Gadeer Alabyad-Mafraq). Inf. Proc. Agric. 2019, 6, 91-108.

5. Walter, M.R.; Tshesane, M.; Kangethe, M. The strategically located land index support system for human settlements land reform in South Africa. Cities 2017, 60, 91-101.

6. Bagdanavičiūtè, I.; Valiūnas, J. GIS-based land suitability analysis integrating multi-criteria evaluation for the allocation of potential pollution sources. Environ. Earth Sci. 2013, 68, 1797-1812. [CrossRef]

7. Wu, L.Y. Search for the Theory of Science of Human Settlement. Planners 2001, 17, 5-8. (In Chinese)

8. Wu, L.Y. Introduction to Sciences of Human Settlements; China Architecture \& Building Press: Beijing, China, 2001. (In Chinese)

9. Wei, W.; Shi, P.J.; Feng, H.C.; Wang, X.F. Study on the Suitability Evaluation of the Human Settlements Environment in Arid Inland River Basin-A Case Study on the Shiyang River Basin. J. Nat. Resour. 2012, 27, 1940-1950. (In Chinese)

10. Wang, Y.; Jin, C.; Lu, M.Q.; Lu, Y.Q. Assessing the suitability of regional human settlements environment from a different preferences perspective: A case study of Zhejiang Province, China. Habitat Int. 2017, 70, 1-12. [CrossRef]

11. Ma, R.F.; Wang, T.F.; Zhang, W.Z.; Yu, J.H.; Wang, D.; Chen, L.; Jiang, Y.P.; Feng, G.Q. Overview and progress of Chinese geographical human settlement research. J. Geogr. Sci. 2016, 26, 1159-1175. [CrossRef]

12. Deng, M.L.; Zhang, B.; Gao, Y.R.; Yu, B. Assessment of Human Settlements in Prefecture-level Cities of Sichuan Province. Sichuan Environ. 2009, 28, 42-47. (In Chinese)

13. Xia, Y.; Lin, A.W.; Zhu, H.J. Evolvement of Spatial Pattern of Urban Human Settlement Environment Suitability in Yangtze River Delta. Ecol. Econ. 2017, 33, 112-117. (In Chinese)

14. Li, X.; Li, X.X.; Wang, T.; Li, L. Human Settlement Assessment in Yellow River Valley Based on Factor Analysis. Environ. Sci. Technol. 2010, 33, 189-193. (In Chinese)

15. Li, M.; Li, X.M. Application Research on Quality Evaluation of Urban Human Settlements Based on The BP Neural Network Improved by GA. Econ. Geogr. 2007, 32, 99-103. (In Chinese)

16. Zhang, X.R.; Fang, C.L.; Wang, Z.B.; Ma, H.T. Urban Construction Land Suitability Evaluation Based on Improved Multi-criteria Evaluation Based on GIS (MCE-GIS): Case of New Hefei City, China. Chin. Geogr. Sci. 2013, 23, 740-753. [CrossRef]

17. Xu, X.L. China Annual Normalized Difference Vegetation Index Spatial Distribution Data. Resource and Environment Data Cloud Platform, Chinese Academy of Sciences. Available online: http://www.resdc.cn/ DOI/doi.aspx?DOIid=49 (accessed on 2 November 2018). (In Chinese).

18. Xu, X.L. Spatial Distribution Data of Soil Erosion in China. Resource and Environment Data Cloud Platform, Chinese Academy of Sciences. Available online: http://www.resdc.cn/DOI/doi.aspx?DOIid=47 (accessed on 2 November 2018). (In Chinese).

19. Cheng, S.J.; Zhu, Z.L.; Bai, L.B. GIS-based Assessment on Ecological Suitability for Human Settlement-A Case Study in the Central Arid Zone in Ningxia. Arid Zone Res. 2015, 32, 176-183. (In Chinese)

20. Feng, Z.M.; Tang, Y.; Yang, Y.Z.; Zhang, D. Relief degree of land surface and its influence on population distribution in China. J. Geogr. Sci. 2008, 18, 237-246. [CrossRef] 
21. Wang, Y.L.; Qi, P.C.; Li, D.; Ma, X.L. Relief and Suitability Evaluation of the Human Settlements in Shaanxi Province. J. Northwest Normal Univ. 2013, 49, 96-101. (In Chinese)

22. Lang, L.L.; Cheng, W.M.; Zhu, Q.J.; Long, E. A Comparative Analysis of the Multi-criteria DEM Extracted Relief-Taking Fujian Low Mountainous Region as an Example. Geo-Inf. Sci. 2007, 1, 135-136. (In Chinese)

23. Hao, H.M.; Ren, Z.Y. Evaluation of Nature Suitability for Human Settlement in Shaanxi Province Based on Grid Data. Acta Geogr. Sin. 2009, 64, 498-506. (In Chinese)

24. Feng, Z.M.; Yang, Y.Z.; Zhang, D.; Tang, Y. Natural environment suitability for human settlements in China based on GIS. J. Geogr. Sci. 2009, 19, 437-446. [CrossRef]

25. Hao, H.M.; Ren, Z.Y.; Xue, L.; Jiang, Y.F. Quantitative Study on Response of Ecosystem to Land Use/Cover Changes in Yulin Area Based on 3S Technology. Prog. Geogr. 2007, 96, 106-130. (In Chinese)

26. Peng, S.Z.; Yu, K.L.; Li, Z.; Wen, Z.M.; Zhang, C. Integrating potential natural vegetation and habitat suitability into revegetation programs for sustainable ecosystems under future climate change. Agric. For. Meteorol. 2019, 269, 270-284. [CrossRef]

27. State Environmental Protection Administration. Environmental Protection Industry Standard of the People's Republic of China: Technical Criterion for Ecosystem Status Evaluation; China Environmental Science Press: Beijing, China, 2006. (In Chinese)

28. Deng, S.B.; Zhang, Q.N. GIS-Based Evaluation of Natural Suitability of Human Settlement Environment in Guangdong Province. Acta Scientiarum Nat. Univ. Sunyatseni 2014, 53, 127-134. (In Chinese)

29. Li, Y.C.; Liu, C.X.; Zhang, H.; Gao, X. Evaluation on the human settlements environment suitability in the Three Gorges Reservoir Area of Chongqing based on RS and GIS. J. Geogr. Sci. 2011, 21, 346-358. [CrossRef]

30. Qiao, H.J.; Ding, M.J.; Li, L.H.; Chen, Z.P.; Hou, H.Y. Design and Achievement of Soil Erosion Assessment System of Jiangxi Province. Soil Water Conserv. China 2014, 46, 63-69. (In Chinese)

31. Teng, H.F.; Hu, J.; Zhou, Y.; Zhou, L.Q.; Shi, Z. Modelling and mapping soil erosion potential in China. J. Integr. Agric. 2019, 18, 251-264. [CrossRef]

32. Zhao, J.L.; Yang, Z.Q.; Gerard, G. Soil and water conservation measures reduce soil and water losses in China but not down to background levels: Evidence from erosion plot data. Geoderma 2019, 337, 729-741. [CrossRef]

33. Yu, S.; Dai, W.Y. Fujian Province Tour Climate Evaluation. J. Fujian Normal Univ. 2005, 103-106. (In Chinese)

34. Aynur, M.; Wahap, H.; Gulgena, H.; Rebiyam, M. Assessment of residential environment suitability for southern Xinjiang based on GIS. J. Arid Land Resour. Environ. 2012, 26, 11-17. (In Chinese)

35. Halik, W.; Mamat, A.; Dang, J.H.; Deng, B.S.; Tiyip, T. Suitability analysis of human settlement environment within the Tarim Basin in Northwestern China. Quatern. Int. 2013, 311, 175-180. [CrossRef]

36. Bokaie, M.; Zarkesh, M.K.; Arasteh, P.D.; Hosseini, A. Assessment of Urban Heat Island based on the relationship between land surface temperature and Land Use/ Land Cover in Tehran. Sustain. Cities Soc. 2016, 23, 94-104. [CrossRef]

37. Qiao, Z.; Sun, Z.Y.; Sun, X.H.; Xu, X.L.; Yang, J. Prediction and analysis of urban thermal environment risk and its spatio-temporal pattern. Acta Econ. Sin. 2019, 39, 1-10. (In Chinese)

38. Zhu, B.Y.; Li, G.Z.; Liu, C.Y.; Liu, J.F.; Xu, C.H. Evaluation of the natural suitability of human settlements environment in Jilin Province based on RS and GIS. Remot Sens. Land Resour. 2013, 25, 138-142. (In Chinese)

(C) 2019 by the authors. Licensee MDPI, Basel, Switzerland. This article is an open access article distributed under the terms and conditions of the Creative Commons Attribution (CC BY) license (http://creativecommons.org/licenses/by/4.0/). 



\title{
Article \\ Anthropogenic $\mathrm{CH}_{4}$ Emissions in the Yangtze River Delta Based on A "Top-Down" Method
}

\author{
Wenjing Huang ${ }^{1,2}$, Wei Xiao ${ }^{1,2}$, Mi Zhang ${ }^{1}$, Wei Wang ${ }^{1}$, Jingzheng $\mathrm{Xu}^{3}$, Yongbo Hu ${ }^{1}$, \\ Cheng Hu ${ }^{1,4}$, Shoudong Liu ${ }^{1}$ and Xuhui Lee ${ }^{1,2,5, *}$ \\ 1 Yale-NUIST Center on Atmospheric Environment, Nanjing University of Information, Science and \\ Technology, Nanjing 210044, China; 20181108059@nuist.edu.cn (W.H.); wei.xiao@nuist.edu.cn (W.X.); \\ zhangm.80@nuist.edu.cn (M.Z.); wangw@nuist.edu.cn (W.W.); 20171103089@nuist.edu.cn (Y.H.); \\ huxxx991@umn.edu (C.H.); lsd@nuist.edu.cn (S.L.) \\ 2 NUIST-Wuxi Research Institute, Wuxi 214073, China \\ 3 Radio Science Research Institute Inc., Wuxi 214073, China; xu.jingzheng@js1959.com \\ 4 Department of Soil, Water, and Climate, University of Minnesota-Twin Cities, St. Paul, MN 55108, USA \\ 5 School of Forestry and Environmental Studies, Yale University, New Haven, CT 06511, USA \\ * Correspondence: Xuhui.lee@yale.edu (X.L.)
}

Received: 3 March 2019; Accepted: 2 April 2019; Published: 5 April 2019

\begin{abstract}
There remains significant uncertainty in the estimation of anthropogenic $\mathrm{CH}_{4}$ emissions at local and regional scales. We used atmospheric $\mathrm{CH}_{4}$ and $\mathrm{CO}_{2}$ concentration data to constrain the anthropogenic $\mathrm{CH}_{4}$ emission in the Yangtze River Delta one of the most populated and economically important regions in China. The observation of atmospheric $\mathrm{CH}_{4}$ and $\mathrm{CO}_{2}$ concentration was carried out from May 2012 to April 2017 at a rural site. A tracer correlation method was used to estimate the anthropogenic $\mathrm{CH}_{4}$ emission in this region, and compared this "top-down" estimate with that obtained with the IPCC inventory method. The annual growth rates of the atmospheric $\mathrm{CO}_{2}$ and $\mathrm{CH}_{4}$ mole fractions are $2.5 \pm 0.7 \mathrm{ppm}_{\text {year }}{ }^{-1}$ and $9.5 \pm 4.7 \mathrm{ppb} \mathrm{year}^{-1}$, respectively, which are $9 \%$ and $53 \%$ higher than the values obtained at Waliguan (WLG) station. The average annual anthropogenic $\mathrm{CH}_{4}$ emission is $4.37( \pm 0.61) \times 10^{9} \mathrm{~kg}$ in the YRD (excluding rice cultivation). This "top-down" estimate is $20-70 \%$ greater than the estimate based on the IPCC method. We suggest that possible sources for the discrepancy include low biases in the IPCC calculation of emission from landfills, ruminants and the transport sector.
\end{abstract}

Keywords: "top-down" method; the Yangtze River Delta; $\mathrm{CO}_{2} ; \mathrm{CH}_{4}$; annual growth rate; anthropogenic $\mathrm{CH}_{4}$ emissions

\section{Introduction}

The source apportionment of $\mathrm{CH}_{4}$ is important for the study of carbon cycle and climate change. The mole fraction of $\mathrm{CH}_{4}$ in the atmosphere increased by $157 \%$ from 1750 to 2011 [1,2]. As the second largest greenhouse gas next to $\mathrm{CO}_{2}, \mathrm{CH}_{4}$ has a warming potential of 28 times that of $\mathrm{CO}_{2}$ with a 100-year time horizon [2]. In addition to the greenhouse effect, $\mathrm{CH}_{4}$ also affects the chemical and photochemical reactions in the atmosphere [3]. The annual growth rate of atmospheric $\mathrm{CH}_{4}$ was $6.9 \pm 2.4 \mathrm{ppb}$ year $^{-1}$ from 2007 to 2017 [4]. However, the source contributions of $\mathrm{CH}_{4}$ have so far not been accurately quantified, especially at the regional and the city scale [5].

Anthropogenic $\mathrm{CH}_{4}$ emissions account for $50-65 \%$ of the global $\mathrm{CH}_{4}$ emissions of $5.82( \pm 0.5)$ $\times 10^{11} \mathrm{~kg}$ year $^{-1}[6,7]$. Large uncertainties still exist in regional anthropogenic emission estimates. These estimates are usually based on the Intergovernmental Panel on Climate Change (IPCC) inventory method. The IPCC method aggregates the $\mathrm{CH}_{4}$ emissions generated by different anthropogenic activities and sums up the individual components to the domain of interest. One problem is that 
activity data, such as landfill and livestock, and emission factors cannot be accurately determined at the regional and the city scale [8-10]. A study in Beijing found that the uncertainty caused by landfill accounts for nearly half of the total uncertainty in the $\mathrm{CH}_{4}$ emission estimate [11]. Accurate and timely calculations of anthropogenic $\mathrm{CH}_{4}$ emissions at the regional scale are necessary for assessing the effectiveness of emission reduction policies.

Anthropogenic greenhouse gas emissions can also be estimated from observations of the gaseous concentrations in the atmosphere ("top-down" methods). The "atmospheric method" used in this study is one of the "top-down" approaches. One reason for using the atmospheric method is that many sources of anthropogenic $\mathrm{CH}_{4}$ cannot be quantified with traditional methods, such as the chamber method [12-14]. The atmospheric method requires simultaneous concentration measurements of the target gas $\left(\mathrm{CH}_{4}\right)$ and a tracer gas (usually $\left.\mathrm{CO}_{2}\right)$ when there is no disturbance from sinks or other natural sources [15]. In an observational study using aircraft profile measurement over a broad region of Alaska and Canada, the concentrations of $\mathrm{CH}_{4}$ and $\mathrm{CO}_{2}$ increase synchronously with height, showing a strong positive correlation between the two gases [16]. A similar positive relationship also exists in the surface air in a moderately polluted urban atmosphere of Boulder, USA [16]. The explanation for the positive relationship is that the two gases share common source areas and undergo the same long-range transport $[17,18]$. The concentration ratio between the two gases were used to estimate the $\mathrm{CH}_{4}$ emissions in the densely populated urban areas in Southern California, showing that inventory $\mathrm{CH}_{4}$ emission estimates for these urban areas are lower in comparison to the "top-down" atmospheric estimate [19]. In a study of anthropogenic $\mathrm{CH}_{4}$ emissions in the Los Angeles megacity, a ground-based remote sensing concentration measurement with 29 different surface targets was used to spatially resolve $\mathrm{CH}_{4}: \mathrm{CO}_{2}$ emission ratio, once again relying on the linear relationship between the two gaseous concentrations [20].

The atmospheric method is based on a strong correlation between the observed concentration values of two relatively inert gases $\mathrm{CH}_{4}$ and $\mathrm{CO}_{2}$. Because the lifetime of these two gases in the atmosphere (7-11 years and 50-200 years, respectively) [21] is much longer than hourly time scales at which the observations are made, the linear slope value of the regression is essentially equivalent to the ratio of their anthropogenic emission strengths. In the applications cited above, the $\mathrm{CH}_{4}$ emission flux is computed as the product of the concentration regression slope and the anthropogenic $\mathrm{CO}_{2}$ emission flux, the latter of which can be obtained reliably with the IPCC inventory method [22].

The atmospheric method has been used to track emissions of other gas species besides $\mathrm{CH}_{4}$. This method was used to infer anthropogenic $\mathrm{Hg}$ emissions in Northeast USA, with wintertime $\mathrm{Hg}$ and $\mathrm{CO}_{2}$ concentration data and $\mathrm{CO}_{2}$ as the tracer [23]. Simultaneous observations of the $\mathrm{CO}_{2}$ and $\mathrm{CO}$ concentrations in a suburban site outside Beijing was used to determine the efficiency of fossil fuel combustion [24]. The concentrations of $\mathrm{CO}_{2}$ and $\mathrm{CO}$ observed in the Asian outflow air combined with a three-dimensional global chemical transport model were used to quantify $\mathrm{CO}_{2}$ emissions in East Asia [25].

In this paper, we report long-term (five years), near-continuous, and simultaneous observations of atmospheric $\mathrm{CH}_{4}$ and $\mathrm{CO}_{2}$ at a lake site near Wuxi, Jiangsu Province, China. Our main objective was to quantify the $\mathrm{CH}_{4}$ emission in the Yangtze River Delta (YRD) and its interannual variability, using the atmospheric tracer method described above. The second objective was to evaluate the validity of the $\mathrm{CH}_{4}$ emissions calculated with the "bottom-up" IPCC inventory method against the atmospheric or "top-down" emission estimates.

\section{Experiments}

\subsection{Study Area and Observational Site}

The YRD in East China occupies only 2.1\% of the land area of China (including Jiangsu Province, Zhejiang Province, Anhui Province and Shanghai), but contributes 1/4 of the total economic output [26]. 
The Wuxi Municipality is located roughly in the middle of the Yangtze River Delta, with a population of about 5 million. Other major cities in this region are Shanghai, Nanjing, Hangzhou, Ningbo and Hefei.

The observational site is located at the Taihu Lake Ecosystem Observatory of the Chinese Academy of Sciences $\left(31.4197^{\circ} \mathrm{N}, 120.2139^{\circ} \mathrm{E}\right)$ in Wuxi. Measurements of the $\mathrm{CO}_{2}$ and $\mathrm{CH}_{4}$ concentrations were made on a platform about $200 \mathrm{~m}$ from the north shore of the lake (Figure 1). The platform was once also part of the Lake Taihu Eddy Flux Network (site id MLW) [27]. The site is surrounded by water, scattered farmlands and residential buildings. The closest traffic road is about $10 \mathrm{~km}$ away. The prevailing wind is northwesterly in the winter (Figure S1) and southerly in the summer. In the winter season, the landscape upwind is mostly rural (Figure S1).

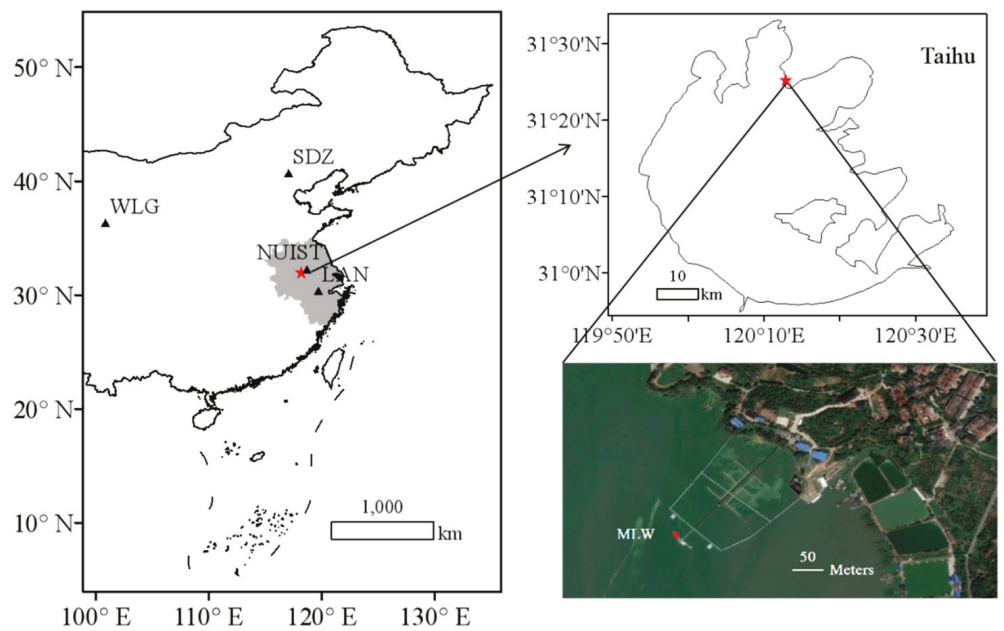

Figure 1. Location of the MLW site (pentagram in red color), Nanjing University of Information Science and Technology (NUIST) and three Chinese WMO/GAW stations, including Lin'an (LAN), Shangdianzi (SDZ) and Waliguang (WLG).

\subsection{Trace Gas Analyzer}

The analyzer we used was based on wavelength scanning cavity ring-down spectroscopy (model G1301 from 14 May 2012 to 6 July 2013 and model G2301 from 20 October 2013 until now, Picarro Inc., Sunnyvale, CA, USA). The measurement frequency is $1 \mathrm{~Hz}$ (sampling rate) and the precision (5-s mean) is $0.15 \mathrm{ppm}$ for $\mathrm{CO}_{2}$ and $1 \mathrm{ppb}$ for $\mathrm{CH}_{4}$. The air inlet is placed at a height of $3.5 \mathrm{~m}$ above the water surface. The water vapor concentration measured by the instrument was used to remove the water vapor dilution effect so the concentrations of $\mathrm{CH}_{4}$ and $\mathrm{CO}_{2}$ are expressed as molar ratio of $\mathrm{CH}_{4}$ or $\mathrm{CO}_{2}$ to dry air.

The observation period in this study was from May 2012 to April 2017. A large data gap occurred between July and October 2013 owing to instrument malfunction. In the second half of 2016, some data were lost because of loss of power on the platform.

The data from the analyzer were averaged to half-hour intervals. Standard deviation in half an hour and a five-point moving average method with a threshold of 1.5 times the standard deviation were used to filter the outliers. The daily average was achieved when daily data exceeded $75 \%$.

For model G1301, the $\mathrm{CO}_{2}$ and $\mathrm{CH}_{4}$ measurements were calibrated twice (2 May 2012 and 22 June 2012) and the details can be found in the supplementary materials of a previously published paper [28]. Model G2301 was calibrated three times on 11 September 2013, 4 November 2015 and 25 August 2016, respectively. The mole fractions of $\mathrm{CO}_{2}$ and $\mathrm{CH}_{4}$ were calibrated against two standard $\mathrm{CO}_{2}$ gases (concentration: $490 \mathrm{ppm}$ or $491 \mathrm{ppm}$ and $385 \mathrm{ppm}$, National Primary Standard prepared by the National Institute of Meteorology (NIM), China) and two standard $\mathrm{CH}_{4}$ gases (2.02 ppm and $3.05 \mathrm{ppm}$ 
or $3.52 \mathrm{ppm}$, National Primary Standard) each time. The relative error is $0.62-0.37 \%$ for $\mathrm{CO}_{2}$ and 0.81-0.41\% for $\mathrm{CH}_{4}$. We used a dew-point generator (model 610, LI-COR, Inc., Lincoln, NE, USA) to correct the analyzers humidity measurement. The humidity level of the air coming out of the dew-point generator was regulated at five levels and measurement at each humidity level lasted $15 \mathrm{~min}$. The first several minutes when the measurement was transitional were excluded from the analysis. A linear regression fit generated from saturation vapor mixing ratio and observed vapor mixing ratio resulted in a slope value of $0.97-0.99$.

No standards were available for us to trace our calibration gases to the WMO scale. NIM participated in two inter-agency comparison experiments on calibration standards including standards traceable to the WMO scale. The results can be found in references $[29,30]$.

\subsection{The IPCC Inventory Calculation}

The IPCC emissions inventory is a "bottom-up" approach. It takes emission activity data from different economic sectors into account and multiplies them by the corresponding emission factors to estimate the emission. The activity data used in this study were obtained from China Energy Statistical Yearbook [31-34], China Statistical Yearbook [35-38], China Rural Statistical Yearbook [39-42], Jiangsu Statistical Bureau, Auhui Statistical Bureau, Zhejiang Statistical Bureau, Shanghai Statistical Bureau and Wuxi Statistical Bureau. The data on crop straw burning were derived from crop yields combined with grain-to-straw ratio [43]. The data on firewood usage from 1991 to 2006 were estimated with the ratio of firewood usage in the YRD combined with the total firewood usage [44]. Then a time-varying line of the firewood usage was fitted to estimate the 2012-2015 firewood usage in the YRD. We used the default emission factors provided by IPCC if no domestic values are available, such as industry energy consumption, industry processes and livestock. $\mathrm{CH}_{4}$ emissions from landfills were based on the first order decay model provided by IPCC, taking into account local climatic conditions, the landfill waste volume, organic carbon content and waste age [11,45,46]. $\mathrm{CH}_{4}$ emissions from rice paddies accounted for different varieties of rice acreage and the corresponding growth period [47-49]. The proportion of open-pit mining to the total mining volume has increased year by year in the YRD region [50]. The $\mathrm{CH}_{4}$ fugitive emissions in the YRD mainly come from coal mining in Xuzhou in Jiangsu Province and Huainan, Huaibei, Fuyang, etc. in Anhui Province. The remaining emission factors for other sectors not listed here were obtained from the relevant literature [51,52].

The Monte Carlo method [52,53] was used to obtain uncertainty ranges of the inventory calculations. The uncertainties of the IPCC method arise from the choice of emission factors and from uncertainties in the activity data. These uncertainties were assumed to follow uniform distributions. The range of variations of the emission factors were given by IPCC or domestic values. For the activity data, an uncertainty range of $10 \%$ was assumed. A total of 400,000 ensemble members were calculated to determine a probability distribution function and estimate the emission uncertainties. A 95\% confidence interval was used to quantify the random errors.

The $\mathrm{CO}_{2}$ inventory is well quantified and with less uncertainty. For example, in Austria, Norway, the Netherlands, the UK and the USA, the uncertainty of $\mathrm{CO}_{2}$ emission factors and activity data for main sources is between $\pm 0.5 \%$ and $\pm 7 \%$ of the means [54]. In comparison, the uncertainty of the $\mathrm{CH}_{4}$ factors sector is $\pm 20 \%$ to $\pm 50 \%$ of the means [54]. The overall uncertainty of the $\mathrm{CO}_{2}$ emission estimates is $2-4 \%$, much smaller than that of $\mathrm{CH}_{4}(17-48 \%)$ or $\mathrm{N}_{2} \mathrm{O}(34-230 \%)$ [54-56].

\subsection{Application of the Atmospheric Method}

We used a geometric mean regression to determine the slope of the $\mathrm{CH}_{4}$ molar mixing ratio against the $\mathrm{CO}_{2}$ molar mixing ratio. Because uncertainties exist in both $\mathrm{CO}_{2}$ and $\mathrm{CH}_{4}$ concentration measurements, geometric mean regression gives more robust parameter estimates than the ordinary least squares regression [57]. Moreover, there is slight variations between the four seasons according to the national level fuel consumption [58], so we focused on wintertime (December to February inclusive) measurements because plant photosynthesis is minimal and atmospheric $\mathrm{CO}_{2}$ variations are driven 
primarily by anthropogenic sources. The annual anthropogenic $\mathrm{CH}_{4}$ emission flux is the product of the regression slope in winter and the anthropogenic $\mathrm{CO}_{2}$ flux derived from the IPCC inventory method. We refer to this flux as the "top-down" estimate.

The uncertainty of the atmospheric method comes from two aspects. The first is a result of the regression procedure, and is characterized by the standard deviation of the regression estimate of the geometric mean slope. The second source of uncertainty is caused by the anthropogenic $\mathrm{CO}_{2}$ emission calculation using the IPCC method. The overall uncertainty of the atmospheric $\mathrm{CH}_{4}$ emission estimate was calculated with the Monte Carlo method that combines these two sources of uncertainty.

The daytime $\mathrm{CO}_{2}$ and $\mathrm{CH}_{4}$ concentrations are indicative of source contributions at the regional scale if there are no direct nearby emissions. This is because the daytime atmospheric boundary layer (ABL) is well mixed and there is no nearby direct emission disturbance. At a suburban site in Xiamen in southeastern China, the vertical profile of $\mathrm{CO}_{2}$ concentration shows little variation with altitude (below $350 \mathrm{~m}$ ) between 8:40 and 15:45 [59]. At the Zotino Tall Tower Observatory, $\mathrm{CO}_{2}$ and $\mathrm{CH}_{4}$ in the atmosphere becomes well-mixed and their concentrations become nearly indistinguishable at six height levels $(4,52,92,157,227$ and $301 \mathrm{~m})$ during day in summer [60]. The ABL height at the MLW site in the winters of 2014-2016, simulated with the Meteoinfo open-source software [61], varies between $570 \mathrm{~m}$ and $970 \mathrm{~m}$ in the midday period (10:00-17:00; Figure 2). The Meteoinfo program used the Data Assimilation System (GDAS1) as input data, and the predicted ABL height was interpolated spatially to the MLW site. The analysis of Potential Source Contribution Function (PSCF) calculated with the HYSPLIT trajectory model with the 500-m height, the approximate mean height of the mid-point of the ABL, as the end point is shown in Figure 3. The PSCF value can be interpreted as the conditional probability for the specific grid cell, or the ratio of the number of endpoints falling in the grid cell with high concentration (>85th percentile concentration at the receptor site) to the total number of endpoints falling in the grid cell. Grid points having high PSCF values are likely to be potential source regions contributing to the observed concentrations [62]. A weighting function was introduced to deal with the bias brought by PSCF value when the number of endpoints falling in the grid cell was small. The choice of the function was set according to that reported by Sigler and Lee [63]. The calculation was performed for December 2014 with 48-h backward trajectories at 10:00, 13:00 and 16:00 LST each day. In Figure 3, the area with the PSCF value greater than the typical threshold of $0.1[51,64]$ is $3.8 \times 10^{5} \mathrm{~km}^{2}$, of which $76 \%$ fall in the political boundary of the YRD. As a result, the daytime observational data at the MLW site can represent the source signatures of the YRD, consistent with a similar study conducted in Nanjing [51].

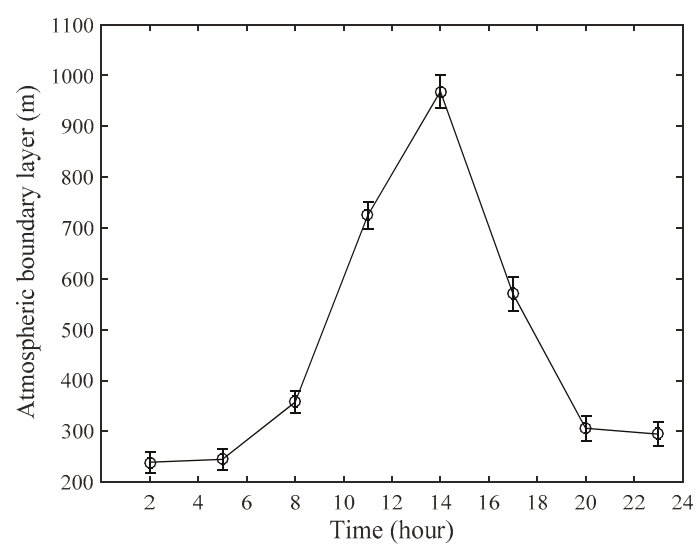

Figure 2. Diurnal variation of the boundary layer height at the MLW site. Error bars are \pm 1 standard deviation of the mean. 


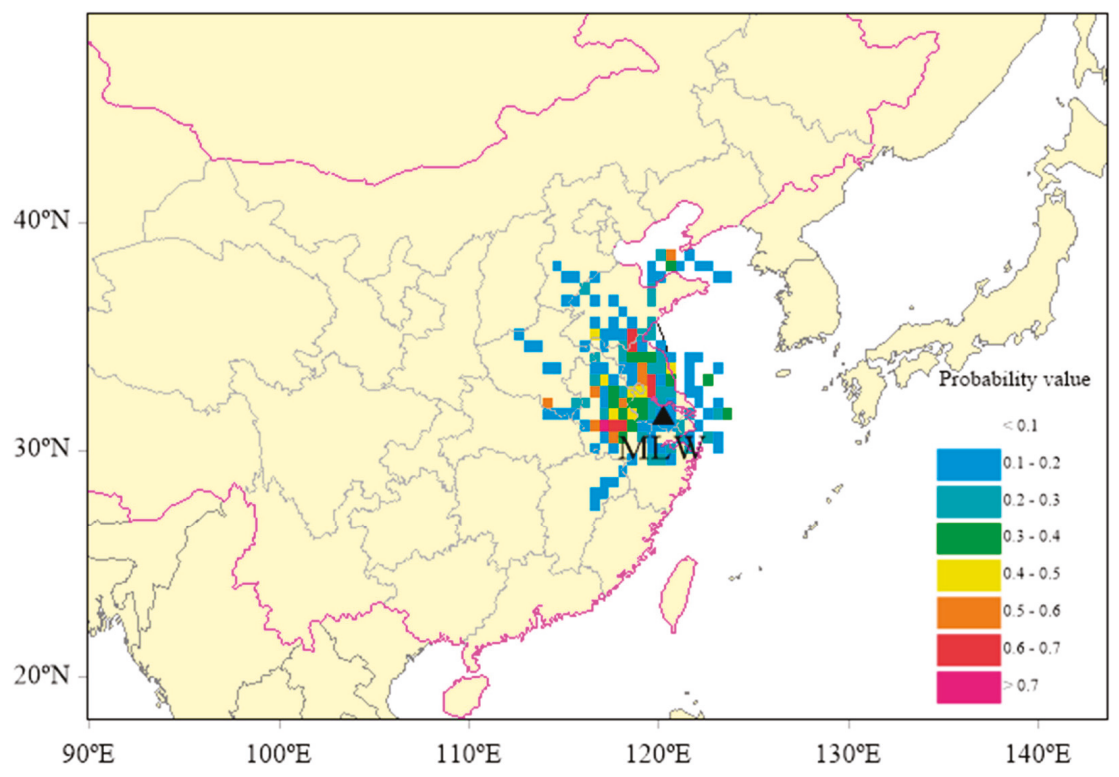

Figure 3. Spatial distribution of the potential source region contributions simulated for December 2014.

The footprint analysis revealed the source region mostly likely to have impacted the daytime measurement at MLW. The actual probability value, or weighting factor, was not used later when we aggregated the inventory emission data to the whole YRD region.

At night (23:00-05:00), an inversion layer typically prevails near the ground surface, with high atmospheric stability. The mean height of the boundary layer is $260 \mathrm{~m}$ (Figure 2). Because of the strong stability, the $\mathrm{CO}_{2}$ and $\mathrm{CH}_{4}$ emitted by anthropogenic sources are trapped near the surface. The lack of mixing implies that the source areas of the observed concentration may span only several kilometers [65]. In other words, the regression slope represents more the emission ratio of local sources than the emission ratio of regional sources, although the exact spatial representation of nighttime observations needs to be further studied.

\section{Results}

\subsection{Temporal Variations of $\mathrm{CO}_{2}$ and $\mathrm{CH}_{4}$ Concentrations}

Figure 4 shows the temporal variations of half-hourly atmospheric $\mathrm{CH}_{4}$ and $\mathrm{CO}_{2}$ mole fractions during the observation period. The data show significant periodic fluctuations through the 24-h cycle, especially for $\mathrm{CO}_{2}$. Data for 2014 and 2015 are nearly gap-free and are representative of seasonal variations. 

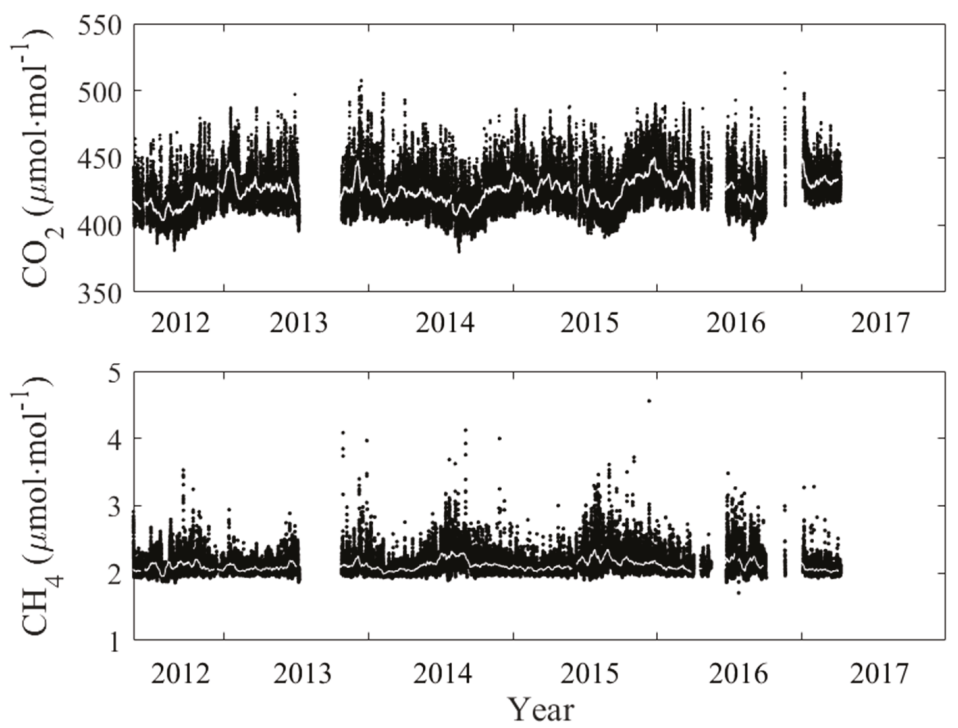

Figure 4. The half-hourly $\mathrm{CO}_{2}$ and $\mathrm{CH}_{4}$ mole fractions during the observation period (black dots). The white points are 14-day moving averages.

Figure 5 shows the diurnal composite concentrations for each of the four seasons in 2014. The diurnal variations of $\mathrm{CO}_{2}$ and $\mathrm{CH}_{4}$ show similar patterns in all seasons. In the spring (March, April and May) and autumn (June, July and August), the peaks appear at about 07:00 and the troughs appear at around 17:00. In the summer, the peaks occur at 04:00 and the minimum still appear around 17:00. In the winter (December, and January and February in the next year), the diurnal variations are gentler than in the other three seasons.

Figure 6 shows a comparison of our monthly mean $\mathrm{CO}_{2}$ and $\mathrm{CH}_{4}$ concentrations with those observed at Nanjing University of Information Science and Technology (NUIST; $32.20^{\circ} \mathrm{N}, 118.72^{\circ}$ E), about $170 \mathrm{~km}$ to the northwest of the MLW site. The concentrations observed during the same time period at Mt. Waliguan (WLG, $36.28^{\circ} \mathrm{N}, 100.90^{\circ} \mathrm{E}, 3810 \mathrm{~m}$ above the mean sea level), a WMO baseline station representing the background atmosphere for Asia, are also shown [66,67]. NUIST is located at the outskirt of Nanjing, surrounded by residential areas and traffic roads and in the vicinity of two industrial complexes [68]. The atmospheric $\mathrm{CO}_{2}$ molar fraction is highest at NUIST, followed by MLW and lowest at WLG. Among the three sites, the strongest seasonality of the atmospheric $\mathrm{CO}_{2}$ molar fraction occurs at the MLW site, with low values in the summer and high values in the winter. The atmospheric $\mathrm{CH}_{4}$ molar fraction at the MLW site shows an opposite seasonality to $\mathrm{CO}_{2}$, with high values in the summer and low values in the winter. 


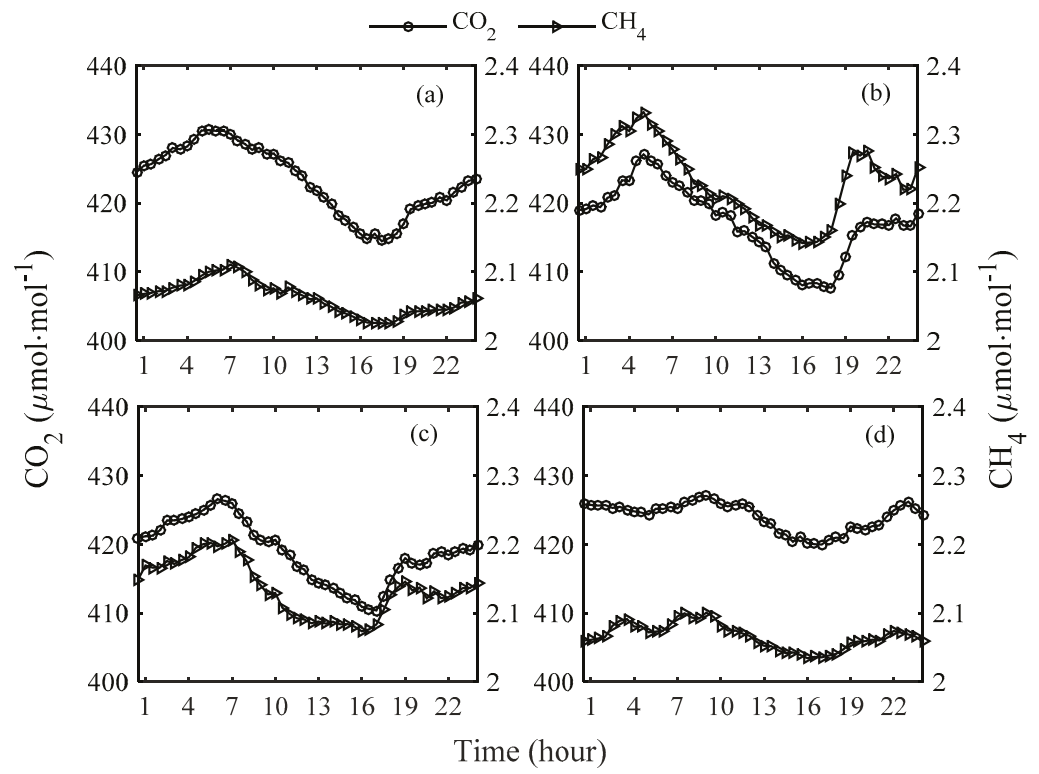

Figure 5. Diurnal variations of the molar fraction of $\mathrm{CH}_{4}$ and $\mathrm{CO}_{2}$ in the atmosphere in the four seasons in 2014: (a) spring; (b) summer; (c) autumn; and (d) winter.

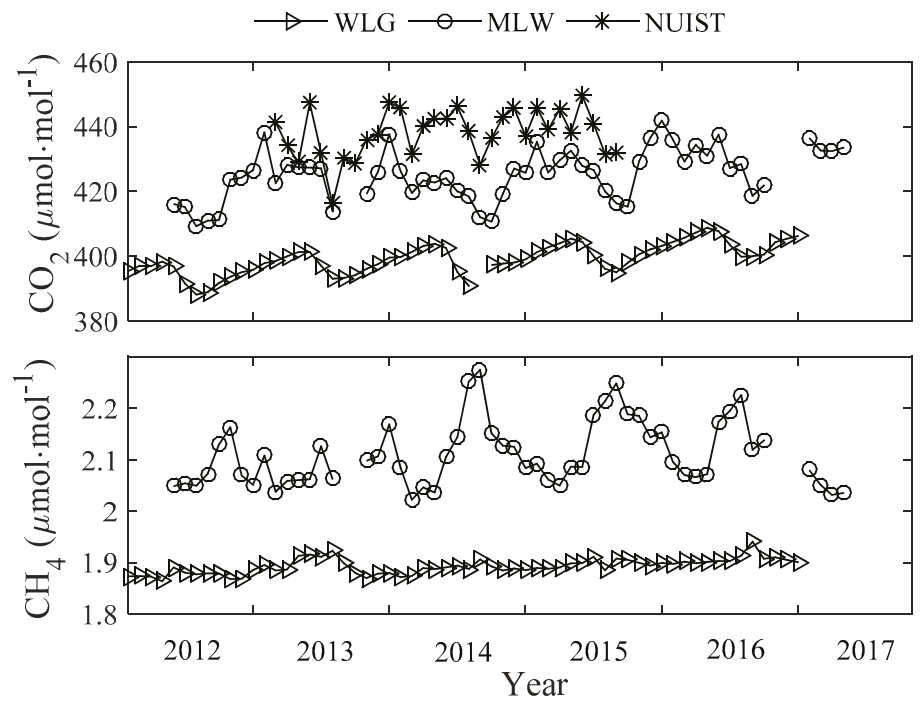

Figure 6. Variations of monthly molar fraction of $\mathrm{CO}_{2}$ in the atmosphere at Nanjing University of Information Science and Technology (NUIST), WLG and MLW and monthly molar fraction of $\mathrm{CH}_{4}$ at WLG and MLW from 2012 to 2017.

The monthly time series were deseasonalized to avoid the interference of seasonality of $\mathrm{CH}_{4}$ and $\mathrm{CO}_{2}$. A relative anomaly of $\mathrm{CH}_{4}$ and $\mathrm{CO}_{2}$ in a particular month of a given year was computed as the difference between the given concentration and the average of all years in that month, divided by the standard deviation of all the concentrations during the research period for that specific month. 
Then, the least square method was used to obtain the growth rates of $\mathrm{CO}_{2}$ and $\mathrm{CH}_{4}$. At the MLW site, the growth rates are $2.5 \pm 0.7 \mathrm{ppm}$ year $^{-1}$ for $\mathrm{CO}_{2}$ and $9.5 \pm 4.7 \mathrm{ppb}^{-1} \mathrm{ear}^{-1}$ for $\mathrm{CH}_{4}$. These rates are higher than those at WLG (2.3 $\pm 0.2 \mathrm{ppm}$ year $^{-1}$ for $\mathrm{CO}_{2}$ and $6.2 \pm 1.7 \mathrm{ppb}$ year $^{-1}$ for $\left.\mathrm{CH}_{4}\right)$.

\subsection{Diurnal and Inter-Annual Variations of the $\mathrm{CH}_{4}$ Versus $\mathrm{CO}_{2}$ Regression Slope}

Figure 7 shows the diurnal variations of the $\mathrm{CH}_{4}$ versus $\mathrm{CO}_{2}$ regression slope and their linear correlation coefficients $(\mathrm{R})$ for the summer and the winter in 2015. The slope value was determined for each half-hour period of the day, using all the data collected in the same half-hourly period. In the summer, the regression slope is marked by a sudden rise at around 18:00, coinciding with the onset of the surface inversion layer. The summertime $\mathrm{R}$ is high at night but has very low values in the afternoon. In the winter, the slope value is generally smaller than the summer value, and its diurnal variation is weak. The wintertime $\mathrm{R}$ fluctuates around 0.8 . The fact that the regression slope is stable and that the $\mathrm{R}$ value is high in the winter is not a surprise. In the winter months, biological sources of $\mathrm{CO}_{2}$ and $\mathrm{CH}_{4}$ are much weaker than the anthropogenic sources. For this reason, the data in winter were selected for further study.
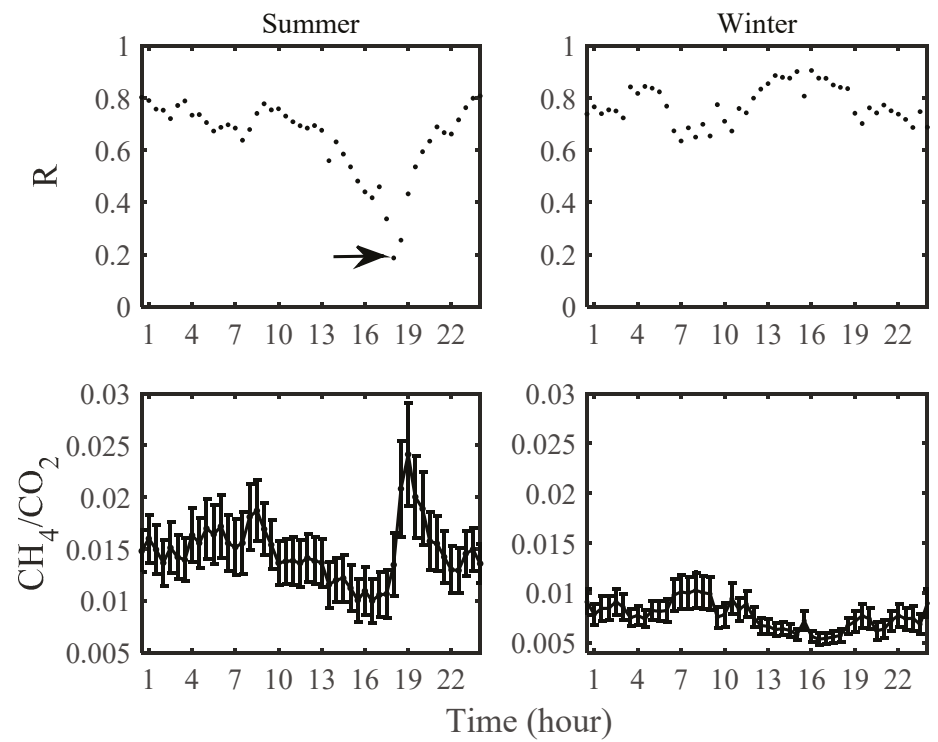

Figure 7. Diurnal variation of $\mathrm{CH}_{4}: \mathrm{CO}_{2}$ emission ratio in the summer (June, July, and August) in 2014 and in the winter (December, January and February) during 2014-2015. The arrow indicates the linear correlation at the $p$ value of 0.05 .

An important biological $\mathrm{CH}_{4}$ source is wetland, including natural wetlands (offshore, coastal, swamp, lakes and rivers) and constructed wetlands. The total wetland area in the YRD is $5.4 \times 10^{4} \mathrm{~km}^{2}$ (2013 value) [36], or 15\% of the total area of the YRD. However, wintertime wetland $\mathrm{CH}_{4}$ flux is generally weak. A study found that the methane emission rate in a freshwater wetland in Australia is less than $0.01 \mathrm{mmol} \mathrm{m}^{-2} \mathrm{~h}^{-1}$ in the winter, which is much lower than that in the summer (1.3-3.3 mmol $\mathrm{m}^{-2} \mathrm{~h}^{-1}$ ) [69]. Similarly, $\mathrm{CH}_{4}$ emissions from natural wetlands in the YRD are $1.98 \times 10^{8} \mathrm{~kg}$ [51], far less than anthropogenic emissions in winter $\left(3.10 \times 10^{9} \mathrm{~kg}\right.$, Section 3.3). The Xixi wetland, one of the four major wetlands in the YRD, even becomes a weak sink of $\mathrm{CH}_{4}$ in the winter $\left(0.0019 \mathrm{mg} \mathrm{m}^{-2}\right.$ $\mathrm{h}^{-1}$ ) [70]. Thus, $\mathrm{CH}_{4}$ emissions from wetlands could be omitted when we compared the "top-down" and "bottom-up" estimates using wintertime observations. 
Rice paddies are another important biological $\mathrm{CH}_{4}$ source, contributing about 3.3-7.0\% $\left(18.3 \times 10^{9} \mathrm{~kg}\right.$ year ${ }^{-1}$ to $8.8 \times 10^{9} \mathrm{~kg}$ year $\left.^{-1}, 1901-2010\right)$ [71] of the global $\mathrm{CH}_{4}$ emissions $\left(5.58 \times 10^{11} \mathrm{~kg}\right.$ year $\left.^{-1}, 2003-2012\right)$ [72]. China accounts for $20 \%$ of the rice production area in the world and the rice planting area in the YRD accounts for $18 \%$ of the China's total [35-38]. The important conditions for $\mathrm{CH}_{4}$ production are organic matter applied (such as rice straw) and anoxic soils established in flooded paddies. As a typical monsoon climate zone in southeastern China, the growth period for rice is from May to October [73]. During non-rice growing season in the winter, $\mathrm{CH}_{4}$ emissions from non-permanently flooded rice paddies are about $4-6 \%$ of the emissions in the growth season [74], and were ignored in the comparison with our "top-down" estimation.

Figures 8 and 9 are regression results using winter time observations made during 2012-2016. The regression was done separately for daytime (10:00-17:00 Beijing time) and nighttime (23:00-05:00 Beijing time) periods for consideration of different mixing conditions and source regions during the day and at night. In this regression, each data sample is a daytime or nighttime mean value. Taking the maximum drift over $24 \mathrm{~h}$ in $\mathrm{CO}_{2}$ and $\mathrm{CH}_{4}$ values $\left(<120 \mathrm{ppb}\right.$ for $\mathrm{CO}_{2}$ and $<1 \mathrm{ppb}$ for $\mathrm{CH}_{4}$ ) for each point caused by the observational instrument into consideration, the slope was affected by $<0.0001$ ppm:ppm, which can be ignored comparing with the standard error caused by the fitting method (0.0005 in 2013). The daytime regression slope fluctuates between $0.0055 \pm 0.0006$ and $0.0068 \pm 0.0005$ ppm $\mathrm{CH}_{4}$ per ppm $\mathrm{CO}_{2}$ without an obvious interannual trend. The correlation coefficient $\mathrm{R}$ is greater than 0.8 , and all four winters passed the 0.01 significance test.

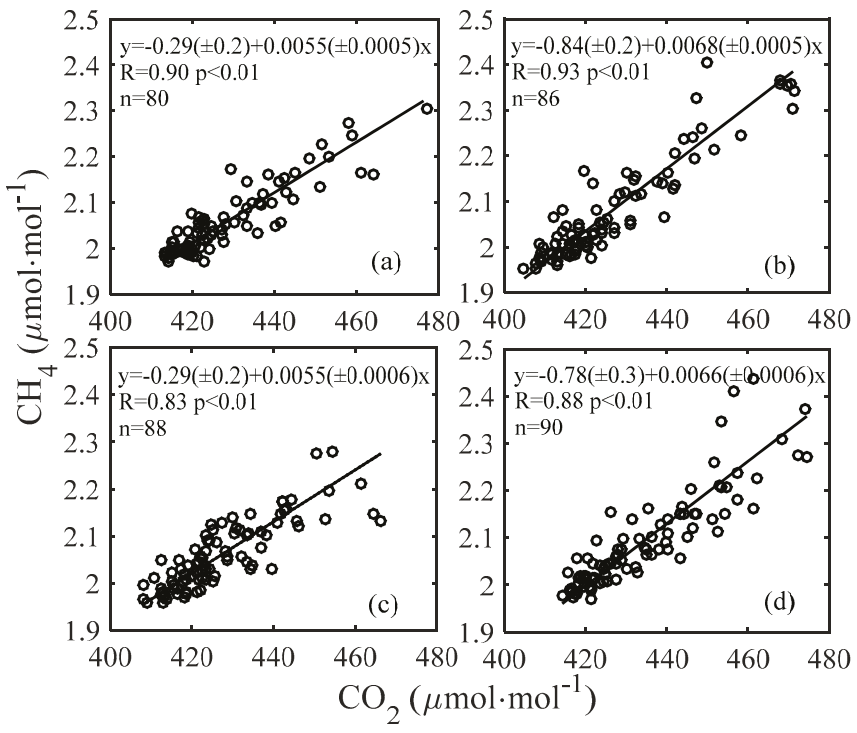

Figure 8. Scatter plots of winter (December-February) daytime $\mathrm{CH}_{4}$ and $\mathrm{CO}_{2}$ concentrations at MLW from 2012 to 2016. Each data point represents one daytime mean value. Regression statistics (regression equation, linear correlation $\mathrm{R}$ and number of samples) are also shown. Parameter ranges in the parentheses are 95\% confidence bounds: (a) December 2012-February 2013; (b) December 2013-February 2014; (c) December 2014-February 2015; and (d) December 2015-February 2016. 


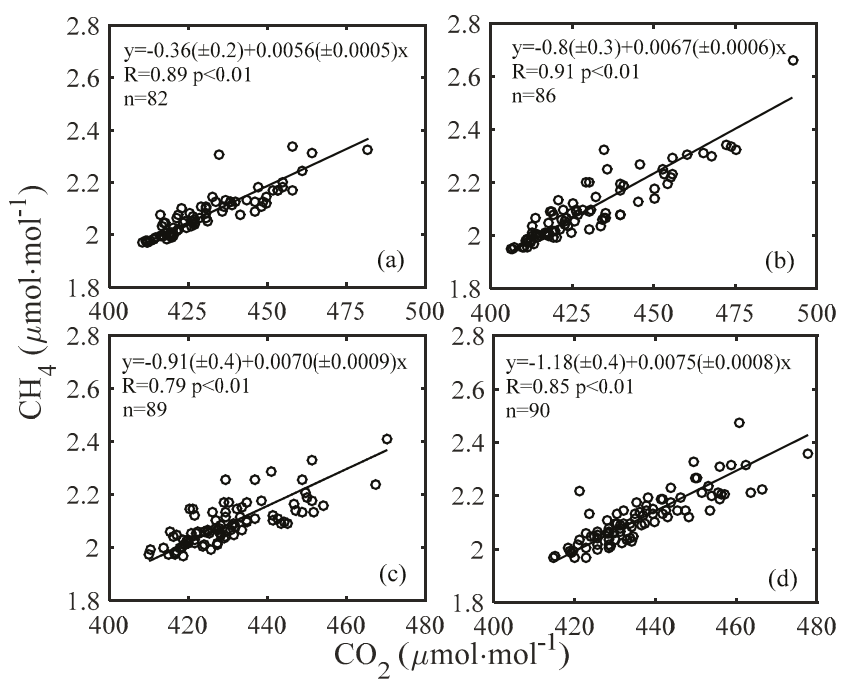

Figure 9. Same as Figure 8 except for winter (December-February) nighttime: (a) December 2012-February 2013; (b) December 2013-February 2014; (c)December 2014-February 2015; and (d) December 2015-February 2016.

The nighttime slope value increases from $0.0056 \pm 0.0005 \mathrm{ppm} / \mathrm{ppm}$ for the winter of 2012-2013 to $0.0075 \pm 0.0008 \mathrm{ppm} / \mathrm{ppm}$ for the winter of 2015-2016. With the exception of winter 2013-2014, the nighttime slope values are greater than the daytime values, implying more $\mathrm{CH}_{4}$ emission per mole of $\mathrm{CO}_{2}$ release by local anthropogenic sources than by regional sources. The correlation also passed the 0.01 significance test but the $R$ values are slightly lower than the daytime $R$ values.

An alternative approach to obtain the emissions ratio is to divide the $\mathrm{CH}_{4}$ concentration enhancement over a background value by the $\mathrm{CO}_{2}$ concentration enhancement. Here, we defined the clean background as the concentration at the 5 th percentile. The emissions ratio, calculated as $\left(\mathrm{CH}_{4}\right.$, mean $\left.-\mathrm{CH}_{4,5 \%}\right) /\left(\mathrm{CO}_{2 \text {, mean }}-\mathrm{CO}_{2,5}\right)$ for the winter, is in good agreement with the slope of the $\mathrm{CH}_{4}$ concentration versus $\mathrm{CO}_{2}$ concentration (Figure $\mathrm{S} 2$ ).

In this study, we assumed that the daytime observations were influenced by sources located in the YRD. We used the EDGARv4.3.2 inventory data (2012) to understand the sensitivity of the emissions ratio to the spatial footprint. We found that by expanding the source region by $100 \mathrm{~km}$ from all sides of the YRD boundary, the $\mathrm{CH}_{4}: \mathrm{CO}_{2}$ emissions ratio changed by less than $1 \%$.

\subsection{Inventory Results}

Table 1 shows the results of the $\mathrm{CO}_{2}$ emission in the YRD in 2012. Industrial energy consumption is the largest emitter, followed by industrial processes, and the residential sector is the smallest emitter. The emission estimate for the transportation sector has the largest relative uncertainty, mainly due to the lack of accurate data on the annual driving range and the emission factor for different vehicle types and driving conditions [75]. The total emission amount was $19.18 \times 10^{11} \mathrm{~kg}$ in 2012. The Monte Carlo method gives an overall uncertainty of 10\%. For comparison the total emission amount in 2009 was $15.35 \times 10^{11} \mathrm{~kg}[51]$. 
Table 1. Anthropogenic $\mathrm{CO}_{2}$ emissions in the YRD in 2012.

\begin{tabular}{ccc}
\hline Sector & Emission $\left(\times \mathbf{1 0}^{\mathbf{1 1}} \mathbf{~ k g}\right)$ & Percent of Total (\%) \\
\hline Industrial energy consumption $^{1}$ & $13.03( \pm 11 \%)$ & 67.9 \\
Industrial processes & $4.40( \pm 10 \%)$ & 23.0 \\
Transportation & $1.35( \pm 18 \%)$ & 7.0 \\
Household & $0.40( \pm 8 \%)$ & 2.1 \\
Total & $19.18( \pm 10 \%)$ & 100 \\
\hline
\end{tabular}

\footnotetext{
${ }^{1} \mathrm{CO}_{2}$ emissions in manufacturing, commerce, and construction are also included in this sector.
}

The annual $\mathrm{CO}_{2}$ emission for 2012-2015 is shown in Figure 10. The growth rate was 3\% from 2012 to 2013 and decreased to $0.5 \%$ from 2014 to 2015 . The reduced growth was mainly caused by the decrease in the industrial energy emission.

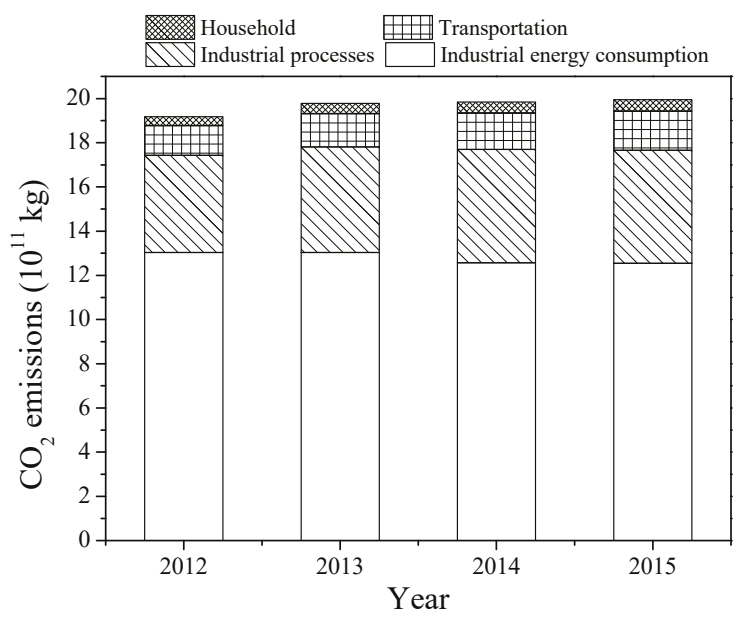

Figure 10. Annual anthropogenic $\mathrm{CO}_{2}$ emissions from different sectors in the YRD from 2012 to 2015, based on the IPCC inventory method.

Similarly, Table 2 shows the anthropogenic $\mathrm{CH}_{4}$ emissions in the YRD in 2012. Rice cultivation and coal mining are the major sources of anthropogenic $\mathrm{CH}_{4}$ emissions. Emission estimates for landfills, wastewater treatment and fuel burning (traffic) emissions have large uncertainties. The total regional emission was $5.78 \times 10^{9} \mathrm{~kg}$ in 2012, increasing by $9.7 \%$ compared to that reported for 2009 [51]. The uncertainty of the total estimate $(21 \%)$ is much greater than the uncertainty $(10 \%)$ of the $\mathrm{CO}_{2}$ emission estimate (Table 1), supporting the use of $\mathrm{CO}_{2}$ as a tracer gas to calculate the $\mathrm{CH}_{4}$ emission with the atmospheric method.

Table 2. Anthropogenic $\mathrm{CH}_{4}$ emissions in the Yangtze River Delta in 2012, based on the IPCC inventory method.

\begin{tabular}{ccc}
\hline Sector & Emission $(\times \mathbf{1 0} \mathbf{~} \mathbf{~ g})$ & Percent of Total (\%) \\
\hline Rice cultivation & $2.68( \pm 12 \%)$ & 46.3 \\
Landfill & $0.50( \pm 35 \%)$ & 8.7 \\
Wastewater treatment & $0.28( \pm 40 \%)$ & 4.8 \\
Livestock & $0.31( \pm 14 \%)$ & 5.4 \\
Fuel and Biomass burning & $0.32( \pm 17 \%)$ & 5.6 \\
Coal mining & $1.69( \pm 30 \%)$ & 29.2 \\
Total & $5.78( \pm 21 \%)$ & 100 \\
\hline
\end{tabular}


Figure 11 shows the annual anthropogenic $\mathrm{CH}_{4}$ emission in the YRD from 2012 to 2015. There was a slight downward trend during the study period, but there was a slight increase from 2014 to 2015.

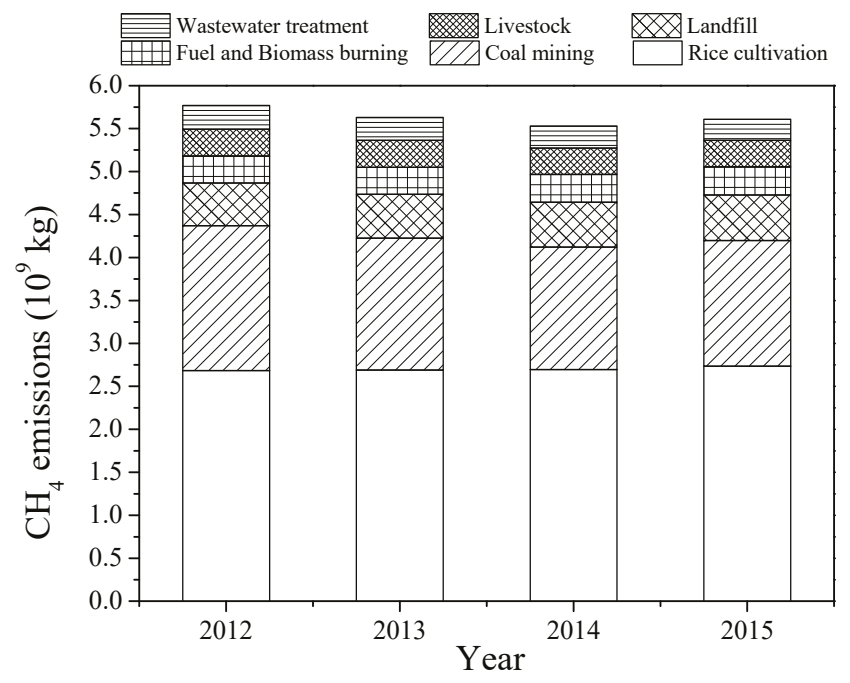

Figure 11. Annual anthropogenic $\mathrm{CH}_{4}$ emissions from different sectors in the YRD from 2012 to 2015, based on the IPCC inventory method.

\subsection{Comparison of $\mathrm{CH}_{4}$ Emission Estimates between the Methods}

Figure 12 shows the comparison of the annual anthropogenic $\mathrm{CH}_{4}$ emissions obtained with the two methods. In this comparison, emissions from rice cultivation were excluded from the IPCC estimate because no rice is grown in the winter months. The "top-down" atmospheric estimate fluctuates year by year, in the range from $3.84 \times 10^{9} \mathrm{~kg}$ to $4.89 \times 10^{9} \mathrm{~kg}$, which is $1.2-1.7$ times the IPCC result.

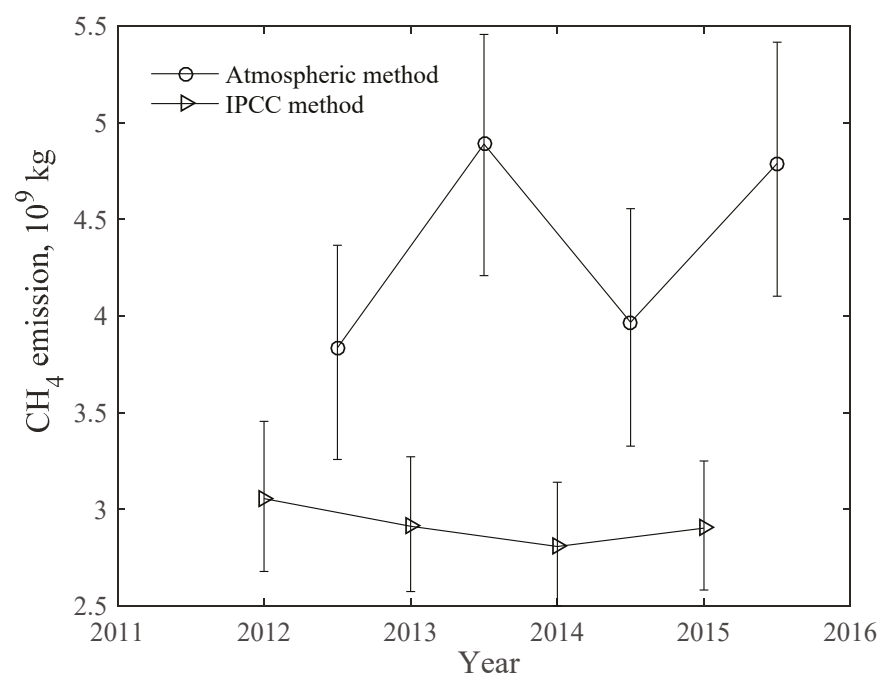

Figure 12. Annual anthropogenic $\mathrm{CH}_{4}$ emissions (excluding rice cultivation) in the YRD from 2012 to 2015. Error bars indicate the uncertainty at a confidence level of $97.5 \%$. 


\section{Discussion}

\subsection{Annual Growth Rates of $\mathrm{CH}_{4}$ and $\mathrm{CO}_{2}$ Concentrations}

The observation lasted nearly five years. Due to the lack of data in some months, the annual average is not representative, thus the linear increase rate of monthly averages was used to characterize the annual growth rate. The $\mathrm{CO}_{2}$ growth rate at the MLW site from 2012 to 2017 was $2.5 \pm 0.7 \mathrm{ppm}$ year $^{-1}$, which is $9 \%$ higher than observed at the WLG background station $\left(2.3 \pm 0.2 \mathrm{ppm}\right.$ year $\left.{ }^{-1}\right)$. A similar result was obtained from observations near Beijing, showing a $24 \%$ higher growth rate than at WLG [76]. The large growth rate is consistent with the anthropogenic $\mathrm{CO}_{2}$ emissions trend in the YRD with an increase of $30 \%$ from $15.35 \times 10^{11} \mathrm{~kg}$ in 2009 [51] to $19.95 \times 10^{11} \mathrm{~kg}$ in 2015 (Figure 10). In this period, emissions from the transport sector increased by $88 \%$, in line with the increasing car ownership, while emissions from industrial processes were nearly unchanged [51].

The annual growth rate of $\mathrm{CH}_{4}$ at MLW $\left(9.5 \pm 4.7 \mathrm{ppb}^{-1} \mathrm{ar}^{-1}\right)$ is nearly twice that at WLG $\left(6.2 \pm 1.7 \mathrm{ppb}\right.$ year $\left.^{-1}\right)$. The increasing trend at MLW is close to that in the Lin'an station in Zhejiang Province, which is also located in the center of YRD, with a growth rate of $8.0 \pm 1.2 \mathrm{ppb}$ year $^{-1}$ from 2009 to 2011 [77]. The growth rate at WLG from 2012 to 2016 was quite similar to global mean growth rate (about 6 ppb year $\left.{ }^{-1}, 2010-2014\right)[78,79]$. The annual trend of $\mathrm{CH}_{4}$ is $4.8 \mathrm{ppb}^{-10 a r^{-1}}$ (2008-2013) at the Zhongshan station in Antarctica, which is the least influenced by human activities [80,81]. At the Shangdianzi regional background station in Beijing, atmospheric $\mathrm{CH}_{4}$ concentration influenced by airmasses passing through the highly developed Beijing Municipality, Tianjin Municipality and Hebei Province increased at a rate of $10 \pm 0.1$ ppb year $^{-1}$ from 2009 to 2013, whereas atmospheric $\mathrm{CH}_{4}$ concentrations influenced by airmasses originating from Russia, Mongolia, and the Inner Mongolia Autonomous Region of China increased at a rate of $6 \pm 0.1 \mathrm{ppb}$ year $^{-1}$ over the same period [82].

One reason for the high $\mathrm{CH}_{4}$ growth rate at the MLW site is the steady increase in anthropogenic emissions according to the inventory data, although the "top-down" estimate does not reveal such a trend in anthropogenic emissions. Another reason may be related to the expansion of wetland areas. According to two national surveys of wetland resources, the total wetland area in the YRD obtained by the second census (2009-2013) increased by 54\% in comparison with the first (1995-2003), from $3.5 \times$ $10^{4} \mathrm{~km}^{2}$ to $5.4 \times 10^{4} \mathrm{~km}^{2}$ [36]. About $67 \%$ of this growth is contributed by constructed wetlands, which increased by nearly $700 \%$. In natural wetlands around the world, the $\mathrm{CH}_{4}$ emission flux, ranging from $7.0 \times 10^{3}$ to $2.8 \times 10^{4} \mathrm{~kg} \mathrm{~km}^{-2}$ year ${ }^{-1}$ with an average of $2.1 \times 10^{4} \mathrm{~kg} \mathrm{~km}^{-2}$ year $^{-1}$ [83,84] is lower than in constructed wetlands (ranging from $1.3 \times 10^{3}$ to $1.5 \times 10^{5} \mathrm{~kg} \mathrm{~km}^{-2} \mathrm{year}^{-1}$, with an average of $4.7 \times 10^{4} \mathrm{~kg} \mathrm{~km}^{-2}$ year ${ }^{-1}$ ) [85]. The annual total emissions by wetlands for the two time periods (1995-2003 and 2009-2013) aere $1.89 \times 10^{8} \mathrm{~kg}^{-1}$ year $^{-1}$ (range $1.6 \times 10^{8}$ to $14.8 \times 10^{8} \mathrm{~kg}$ year ${ }^{-1}$ ) and $2.98 \times 10^{8} \mathrm{~kg}$ year $^{-1}$ (range $2.5 \times 10^{8}$ to $23.3 \times 10^{8} \mathrm{~kg}$ year ${ }^{-1}$ ), respectively, using the Tier 1 approach provided by 2006 IPCC guidelines for moist and warm climates [8]. This method only considers diffusive emissions for natural wetlands during ice-free periods. Emissions from wetlands in two national surveys were $6.1 \%$ and $9.6 \%$ anthropogenic emission (excluding rice cultivation) in $2012\left(3.1( \pm 0.5) \times 10^{9} \mathrm{~kg}\right.$, Table 2$)$.

\subsection{Comparison of the $\mathrm{CH}_{4} / \mathrm{CO}_{2}$ Emissions Ratio}

Some sources, such as transportation and landfills, release both $\mathrm{CH}_{4}$ and $\mathrm{CO}_{2}$, but their $\mathrm{CH}_{4} / \mathrm{CO}_{2}$ emissions ratios are very different. The average $\mathrm{CH}_{4} / \mathrm{CO}_{2}$ emissions ratio of vehicle traffic is $4.6( \pm 0.2)$ $\times 10^{-5} \mathrm{ppm} / \mathrm{ppm}$ according to observations in traffic tunnels in Switzerland [86], indicating that $\mathrm{CH}_{4}$ emissions from traffic emissions account for only a small fraction of the anthropogenic emission. In a study of eight cities in China, the traffic emissions ratio is $7.0( \pm 3.6) \times 10^{-3} \mathrm{ppm} / \mathrm{ppm}$ [87]. The ratio is much larger than that in Switzerland. In comparison, $\mathrm{CH}_{4}$ comprises up to $61 \%$ (median: $34 \%$ ) of the total volume of landfill gas, with the remaining $3 \%$ to $69 \%$ (median: $33 \%$ ) being $\mathrm{CO}_{2}[88,89]$. In the case of wetlands, the emissions ratio varies with the type of wetlands and sometimes is negative 
because they act as sources of $\mathrm{CH}_{4}$ but sinks of $\mathrm{CO}_{2}$ [90-92]. The emissions ratio estimated from the regression slope is a composite signal of all the sources at the regional scale.

Table S1 summarizes the $\mathrm{CH}_{4} / \mathrm{CO}_{2}$ emissions ratio observed in different parts of the world. All these values were obtained as the regression slope of atmospheric $\mathrm{CH}_{4}$ concentration against the $\mathrm{CO}_{2}$ concentration. Some of these slope values were given by the cited literature, while others were estimated from the original concentration data. Our emissions ratio is close to those observed in Los Angeles and Pasadena, USA, but is higher than that observed in the daytime in Nanjing, China. The highest values occur in northern latitude remote sites far away from major industrial activities, such as Barrow, USA and Alert, Canada, due to abundant wetlands at these latitudes ( $>50 \%$ land area) [93]. About $60 \%$ of the total $\mathrm{CH}_{4}$ emission from natural wetlands come from those between latitude $50^{\circ} \mathrm{N}$ to $70^{\circ} \mathrm{N}$ [83].

\subsection{Comparison between the IPCC Method and the Atmospheric Method}

Shen et al. measured atmospheric $\mathrm{CO}_{2}$ and $\mathrm{CH}_{4}$ molar fraction at a suburban site in Nanjing from June 2010 to April 2011 [51]. They argued that the regression slope from daytime data represents emissions ratio of sources in the YRD, and the regression slope from nighttime data represents emissions ratio of the local sources in the Nanjing Municipality. Their atmospheric estimate for $\mathrm{CH}_{4}$ emission for sources in Nanjing is $200 \%$ higher than the IPCC estimate [51]. If we assume that the nighttime data in this study are also indicative of local sources in the Wuxi Municipality, our atmospheric estimate of the $\mathrm{CH}_{4}$ emission in the winter would be $1.8 \times 10^{8}-2.3 \times 10^{8} \mathrm{~kg}$, which is 4.4-5.7 times as large as the value calculated with the IPCC method (after exclusion of rice paddy emissions; Table 3). The IPCC method is far more uncertain at the urban scale than at the regional scale, for several reasons. First, cities do not have clear boundaries and direct emissions calculated based on urban statistics ignore some emissions of cities, such as aviation and waterways, so the total emission will be underestimated [94]. As the spatial scale increases, the dependence of the accounting area on cross-boundary transport of energy and material is smaller, and errors due to indirect emissions are reduced [95]. Second, emission factors at the cities are not measured accurately. Third, wastewater treatment and landfill are the two largest source categories in Wuxi, accounting for $45.6 \%$ of the city's total $\mathrm{CH}_{4}$ emissions; these two sources have the largest uncertainty.

Table 3. Anthropogenic $\mathrm{CH}_{4}$ emissions in Wuxi in 2012 based on the IPCC inventory method.

\begin{tabular}{ccc}
\hline Sector & Emission $(\times \mathbf{1 0} \mathbf{7 g})$ & Percent of Total (\%) \\
\hline Rice cultivation & $3.05( \pm 13 \%)$ & 42.8 \\
Landfill & $1.81( \pm 38 \%)$ & 25.4 \\
Wastewater treatment & $1.45( \pm 40 \%)$ & 20.3 \\
Livestock & $0.48( \pm 22 \%)$ & 6.7 \\
Fuel and Biomass burning & $0.34( \pm 21 \%)$ & 4.8 \\
Coal mining & - & - \\
Total & $7.13( \pm 26 \%)$ & 100 \\
\hline
\end{tabular}

In comparison with the IPCC estimate for the YRD in the winter, the "top-down" atmospheric estimate in this study is 1.2-1.7 times the IPCC result. Shen et al.'s estimate of $\mathrm{CH}_{4}$ emission from the atmospheric method is $20 \%$ lower [51] than the IPCC estimate, even though their measurement and our measurement both took place in the same region (YRD) and not too far from each other (170 km apart). One possible reason for the difference is that Shen et al.'s observation site is not far away from industrial complexes and traffic roads. Traffic $\mathrm{CH}_{4} / \mathrm{CO}_{2}$ emissions ratio is generally much lower than regional emissions ratios, as noted above. According to the "bottom-up" results provided by the Emissions Database for Global Atmospheric Research (EDGAR), the global $\mathrm{CH}_{4} / \mathrm{CO}_{2}$ emissions ratios in the chemical production sector, the metal production sector, and the public electricity and heat production sector were $1.2 \times 10^{-3}, 6.4 \times 10^{-4}$ and $7.6 \times 10^{-5} \mathrm{ppm} / \mathrm{ppm}$, respectively in 2012 (http://edgar.jrc.ec.europa.eu/overview.php? $\mathrm{v}=432 \&$ SECURE=123) [96]. The situation is 
a little different in China. The $\mathrm{CH}_{4} / \mathrm{CO}_{2}$ emissions ratio is bigger for the chemical production sector $\left(1.8 \times 10^{-3} \mathrm{ppm} / \mathrm{ppm}\right)$, and is smaller for the metal production sector $\left(4.7 \times 10^{-4} \mathrm{ppm} / \mathrm{ppm}\right)$ and the public electricity and heat production sector $\left(3.4 \times 10^{-5} \mathrm{ppb} / \mathrm{ppm}\right)$. Thus, the $\mathrm{CH}_{4} / \mathrm{CO}_{2}$ emissions ratio for industrial complexes should be lower than regional emissions ratios. Because our measurement was made at a rural system not directly impacted by local traffic and industrial emissions (Figure S1), our emissions ratio should be more representative than that reported in [51].

Another reason for the difference between our study and the study by Shen et al. [51] is different source areas between Nanjing and MLW. Hu et al. [97] simulated the atmospheric $\mathrm{CO}_{2}$ concentration in Nanjing City using the WRF-STILT model. They found that the NUIST site is mainly affected by the central and eastern regions of Anhui Province and the central and western regions of Jiangsu Province, with greater concentration contribution weights than other regions in the YRD.

Previous studies have also reported that estimates of $\mathrm{CH}_{4}$ emission based on the "top-down" atmospheric method are higher than the "bottom-up" inventory estimates. In the Los Angeles metropolitan area in California, USA, anthropogenic $\mathrm{CH}_{4}$ emissions calculated from two "top-down" approaches are 1.3-1.8 and 1.2-1.6 times, respectively, of the "bottom-up" estimates [20,98]. The US EPA inventory and EDGAR, two "bottom-up" methods, are shown to underestimate $\mathrm{CH}_{4}$ emissions in the United States by a factor of about 1.5 and 1.7, with the underestimation coming from two sectors: livestock and fossil fuel extraction and processing [99]. That "bottom-up" results are generally smaller indicate that there are unknown emission sources or underestimates of the emission capacity of known sources, such as landfills, coal mining and wastewater treatment. Some scholars have found that based on carbon isotope observations, $\mathrm{CH}_{4}$ emissions from landfills and ruminants are underestimated by the IPCC method [100]. In China, the methane emission rate is reported to be eight times the IPCC emission estimate for natural gas vehicles [78]. If this result is taken into consideration, the anthropogenic $\mathrm{CH}_{4}$ emissions in the YRD would increase by $2.4 \%$ in 2015. In the urban Boston area, USA, natural gas loss rate from transmission, distribution and end use was $2.7 \pm 0.6 \%$ of the total delivered gas, which is more than twice the result of the emission inventory [101]. In 2016, the length of natural gas pipeline reached $5.51 \times 10^{5} \mathrm{~km}$ in China, although the $\mathrm{CH}_{4}$ concentration measurements along urban street transects in eight Chinese cities show no evidence of pipeline leakage [87].

\section{Conclusions}

Continuous observation of atmospheric $\mathrm{CO}_{2}$ and $\mathrm{CH}_{4}$ mole fraction was made at the MLW station near Wuxi at Lake Taihu from May 2012 to April 2017. These measurements were combined with anthropogenic $\mathrm{CO}_{2}$ emission data in a "top-down" method to obtain an estimate of the anthropogenic $\mathrm{CH}_{4}$ emission in the YRD. For comparison, the $\mathrm{CH}_{4}$ emission was also calculated with the IPCC inventory method. The key results are as follows:

(1) The growth rates of the $\mathrm{CO}_{2}$ and $\mathrm{CH}_{4}$ molar fractions at the MLW site were $2.5 \pm 0.7 \mathrm{ppm}$ year $^{-1}$ and $9.5 \pm 4.7$ ppb year $^{-1}$, respectively, which are $9 \%$ and $53 \%$ higher than that observed at WLG over the same period.

(2) To avoid the interference of biological sources, we used the wintertime $\mathrm{CO}_{2}$ and $\mathrm{CH}_{4}$ concentration data to obtain the $\mathrm{CH}_{4} / \mathrm{CO}_{2}$ emissions ratio. Results indicate that the emissions ratio fluctuates between $0.0055 \pm 0.0006 \mathrm{ppm} / \mathrm{ppm}$ (winters of 2012-2013 and 2014-2015) and $0.0068 \pm 0.0005 \mathrm{ppm} / \mathrm{ppm}$ (winter of 2013-2014). These ratios are similar to those observed in Los Angeles and Pasadena, USA.

(3) According to the "top-down" method, the annual average anthropogenic emission of $\mathrm{CH}_{4}$ in the YRD from 2012 to 2015 is $4.37( \pm 0.61) \times 10^{9} \mathrm{~kg} \mathrm{year}^{-1}$ (excluding rice cultivation), which is $1.2-1.7$ times the result from the IPCC inventory.

(4) The "top-down" method also suggests that at the local scale, the IPCC inventory estimate for anthropogenic $\mathrm{CH}_{4}$ emission in the Wuxi municipality may be biased low by $4.4-5.7$ times.

Supplementary Materials: Figure S1: Prevailing wind direction measured at the MLW site in winter (December 2015-February 2016). Figure S2: $\mathrm{CH}_{4} / \mathrm{CO}_{2}$ emissions ratio (ppm/ppm) estimated with different methods in 
different regions, Table S1: Summary of $\mathrm{CH}_{4} / \mathrm{CO}_{2}$ emissions ratio (ppb/ppm) estimated with the atmospheric method found in the literature. Supplementary data file is available at: https:/ /yncenter.sites.yale.edu/dataaccess.

Author Contributions: Data curation, W.H., J.X. and Y.H.; Formal analysis, W.H.; Investigation, W.H.; Methodology, W.H.; Resources, W.X., J.X., Y.H. and S.L.; Supervision, W.X., M.Z., W.W., C.H. and X.L.; Validation, C.H. and X.L.; Writing — original draft, W.H.; and Writing-review and editing, X.L.

Funding: This research was supported by internal grants from NUIST-Wuxi Research Institute.

Acknowledgments: We are grateful to all of the staff who work at the WMO/GAW stations in China for collecting the data, and to the Greenhouse Gases Research Laboratory of the China Meteorological Administration (CMA) for data analysis. We appreciate Ed Dlugokencky, Andy Crotwell, and Kirk Thoning of NOAA for their help and support of the research measurements.

Conflicts of Interest: The authors declare no conflict of interest.

\section{References}

1. World Meteorological Organization (WMO). Greenhouse Gas Bulletin: The State of Greenhouse Gases in the Atmosphere Based on Global Observations through 2017; WMO: Geneva, Switzerland, 2018.

2. IPCC. The IPCC Fifth Assessment Report_Climate Change 2013: The Physical Science Basis; Working Group I, IPCC Secretariat: Geneva, Switzerland, 2013.

3. Solomon, S.; Intergovernmental Panel on Climate Change. Working Group I, Climate Change 2007: The Physical Science Basis: Contribution of Working Group I to the Fourth Assessment Report of the Intergovernmental Panel on Climate Change; Cambridge University Press: Cambridge, UK; New York, NY, USA, 2007.

4. Dlugokencky, E.J. NOAA/ESRL. Available online: www.esrl.noaa.gov/gmd/ccgg/trends_ch4/ (accessed on 24 March 2019).

5. Dlugokencky, E.J.; Bruhwiler, L.; White, J.W.C.; Emmons, L.K.; Novelli, P.C.; Montzka, S.A.; Masarie, K.A.; Lang, P.; Crotwell, A.M.; Miller, J.B.; et al. Observational constraints on recent increases in the atmospheric $\mathrm{CH}_{4}$ burden. Geophys. Res. Lett. 2009, 36, 252-260. [CrossRef]

6. Forster, P.; Ramaswamy, V.; Artaxo, P.; Bernsten, T.; Betts, R.; Fahey, D.W.; Haywood, J.; Lean, J.; Lowe, D.C.; Myhre, G.; et al. Changes in Atmospheric Constituents and in Radiative Forcing. Chapter 2. Climate Change 2007: The Physical Science Basis; Cambridge University Press: Cambridge, UK, 2007; pp. 129-234.

7. Aydin, M.; Verhulst, K.R.; Saltzman, E.S.; Battle, M.O.; Montzka, S.A.; Blake, D.R.; Tang, Q.; Prather, M.J. Recent decreases in fossil-fuel emissions of ethane and methane derived from firn air. Nature 2011, 476, 198-201. [CrossRef] [PubMed]

8. IPCC. 2006 IPCC Guidelines for National Greenhouse Gas Inventories, Prepared by the National Greenhouse Gas Inventories Programme; Eggleston, HS., Buendia, L., Miwa, K., Ngara, T., Tanabe, K., Eds.; IGES: Kanagawa, Japan, 2006.

9. Yue, Q.; Zhang, G. Preliminary estimation of methane emission and its distribution in China. Geogr. Res. 2012, 31, 1561-1570. (In Chinese) [CrossRef]

10. Boon, A.; Broquet, G.; Clifford, D.J.; Chevallier, F.; Butterfield, D.M.; Pison, I.; Ramonet, M.; Paris, J.D.; Ciais, P. Analysis of the potential of near ground measurements of $\mathrm{CO}_{2}$ and $\mathrm{CH}_{4}$ in London, $\mathrm{UK}$ for the monitoring of city-scale emissions using an atmospheric transport model. Atmos. Chem. Phys. 2016, 16, 6735-6756. [CrossRef]

11. Chen, C.; Liu, C.; Li, Z.; Wang, H.; Zhang, Y.; Wang, L. Uncertainty analysis for evaluating methane emissions from municipal solid waste landfill in Beijing. Environ. Sci. 2012, 33, 208-215. (In Chinese)

12. Pei, Z.; Ou Yang, H.; Zhou, C. A study on carbon fluxes from alpine grassland ecosystem on Tibetan Plateau. Acta Ecol. Sin. 2003, 23, 231-236. (In Chinese) [CrossRef]

13. Minamikawa, K.; Yagi, K.; Tokida, T.; Sander, B.O.; Wassmann, R. Appropriate frequency and time of day to measure methane emissions from an irrigated rice paddy in Japan using the manual closed chamber method. Greenh. Gas Meas. Manag. 2012, 2, 118-128. [CrossRef]

14. Winton, R.S.; Richardson, C.J. A cost-effective method for reducing soil disturbance-induced errors in static chamber measurement of wetland methane emissions. Wetl. Ecol. Manag. 2016, 24, 419-425. [CrossRef]

15. Lee, X. Fundamentals of Boundary-Layer Meteorology; Springer International Publishing: Cham, Switzerland, 2018.

16. Conway, T.J.; Steele, L.P. Carbon dioxide and methane in the Arctic atmosphere. J. Atmos. Chem. 1989, 9, 81-99. [CrossRef] 
17. Conway, T.J.; Steele, L.P.; Novelli, P.C. Correlations among atmospheric $\mathrm{CO}_{2}, \mathrm{CH}_{4}$, and $\mathrm{CO}$ in the Arctic, March 1989. Atmos. Environ. Part A Gen. Top. 1993, 27, 2881-2894. [CrossRef]

18. Hansen, A.D.A.; Conway, T.J.; Strele, L.P.; Bodhaine, B.A.; Thoning, K.W.; Tans, P.; Novakov, T. Correlations among combustion effluent species at Barrow, Alaska: Aerosol black carbon, carbon dioxide, and methane. J. Atmos. Chem. 1989, 9, 283-299. [CrossRef]

19. Wunch, D.; Wennberg, P.O.; Toon, G.C.; Keppel-Aleks, G.; Yavin, Y.G. Emissions of greenhouse gases from a North American megacity. Geophys. Res. Lett. 2009, 36, 139-156. [CrossRef]

20. Wong, K.W.; Fu, D.; Pongetti, T.J.; Newman, S.; Kort, E.A.; Duren, R.; Hsu, Y.K.; Miller, C.E.; Yung, Y.L.; Sander, S.P. Mapping $\mathrm{CH}_{4}$ : $\mathrm{CO}_{2}$ ratios in Los Angeles with CLARS-FTS from Mount Wilson, California. Atmos. Chem. Phys. 2015, 15, 241-252. [CrossRef]

21. Lelieveld, J.; Crutzen, P.J.; Dentener, F.J. Changing concentration, lifetime and climate forcing of atmospheric methane. Tellus Ser. B Chem. Phys. Meteorol. 1998, 50, 128-150. [CrossRef]

22. Zhao, Y.; Nielsen, C.P.; Mcelroy, M.B. China's $\mathrm{CO}_{2}$ emissions estimated from the bottom up: Recent trends, spatial distributions, and quantification of uncertainties. Atmos. Environ. 2012, 59, 214-223. [CrossRef]

23. Lee, X.; Bullock, O.R.; Andres, R.J. Anthropogenic emission of mercury to the atmosphere in the northeast United States. Geophys. Res. Lett. 2001, 28, 1231-1234. [CrossRef]

24. Wang, Y.; Munger, J.W.; Xu, S.; McElroy, M.B.; Hao, J.; Nielsen, C.P.; Ma, H. $\mathrm{CO}_{2}$ and its correlation with CO at a rural site near Beijing: Implications for combustion efficiency in China. Atmos. Chem. Phys. 2010, 10, 8881-8897. [CrossRef]

25. Suntharalingam, P.; Jacob, D.J.; Palmer, P.I.; Logan, J.A.; Yantosca, R.M.; Xiao, Y.; Evans, M.J. Improved quantification of Chinese carbon fluxes using $\mathrm{CO}_{2} / \mathrm{CO}$ correlations in Asian outflow. J. Geophys. Res. 2004, 109, 159-172. [CrossRef]

26. Zhu, T.; Yang, G.; Su, W.; Wan, R. Coordination evaluation between urban land intensive use and economic society development in the Yangtze River Delta. Resour. Sci. 2009, 31, 1109-1116. (in Chinese).

27. Lee, X.; Liu, S.; Xiao, W.; Wang, W.; Gao, Z.; Cao, C.; Hu, C.; Hu, Z.; Shen, S.; Wang, Y.; et al. The Taihu eddy flux network: an observational program on energy, water, and greenhouse gas fluxes of a large freshwater lake. Bull. Am. Meteorol. Soc. 2014, 95, 1583-1594. [CrossRef]

28. Xiao, W.; Liu, S.; Li, H.; Xiao, Q.; Wang, W.; Hu, Z.; Hu, C.; Gao, Y.; Shen, J.; Zhao, X.; et al. A flux-gradient system for simultaneous measurement of the $\mathrm{CH}_{4}, \mathrm{CO}_{2}$, and $\mathrm{H}_{2} \mathrm{O}$ fluxes at a lake-air interface. Environ. Sci. Technol. 2014, 48, 14490-14498. [CrossRef] [PubMed]

29. Flores, E.; Viallon, J.; Choteau, T.; Moussay, P.; Wielgosz, R.I.; Kang, N.; Kim, B.M.; Zalewska, E.; van der Veen, A.M.H.; Konopelko, L.; et al. International comparison CCQM-K82: Methane in air at ambient level (1800 to 2200) nmol/mol. Metrologia 2015, 52, 1-129. [CrossRef]

30. Flores, E.; Viallon, J.; Choteau, T.; Moussay, P.; Idrees, F.; Wielgosz, R.I.; Lee, J.; Zalewska, E.; Nieuwenkamp, G.; van der Veen, A.; et al. CCQM-K120 (Carbon dioxide at background and urban level). Metrologia 2019, 56, 1-178. [CrossRef]

31. State Statistical Bureau. China Energy Statistical Yearbook 2012; China Statistical Press: Beijing, China, 2013. (In Chinese)

32. State Statistical Bureau. China Energy Statistical Yearbook 2013; China Statistical Press: Beijing, China, 2014. (In Chinese)

33. State Statistical Bureau. China Energy Statistical Yearbook 2014; China Statistical Press: Beijing, China, 2015. (In Chinese)

34. State Statistical Bureau. China Energy Statistical Yearbook 2015; China Statistical Press: Beijing, China, 2016. (In Chinese)

35. State Statistical Bureau. China Statistical Yearbook 2012; China Statistical Press: Beijing, China, 2013. (In Chinese)

36. State Statistical Bureau. China Statistical Yearbook 2013; China Statistical Press: Beijing, China, 2014. (In Chinese)

37. State Statistical Bureau. China Statistical Yearbook 2014; China Statistical Press: Beijing, China, 2015. (In Chinese)

38. State Statistical Bureau. China Statistical Yearbook 2015; China Statistical Press: Beijing, China, 2016. (In Chinese) 
39. State Statistical Bureau. China Rural Statistical Yearbook 2012; China Statistical Press: Beijing, China, 2013. (In Chinese)

40. State Statistical Bureau. China Rural Statistical Yearbook 2013; China Statistical Press: Beijing, China, 2014. (In Chinese)

41. State Statistical Bureau. China Rural Statistical Yearbook 2014; China Statistical Press: Beijing, China, 2015. (In Chinese)

42. State Statistical Bureau. China Rural Statistical Yearbook 2015; China Statistical Press: Beijing, China, 2016. (In Chinese)

43. Cao, G.; Zhang, X.; Zhen, F.; Wang, Y. Estimating the quantity of crop residues burnt in open field in China. Resour. Sci. 2006, 28, 9-13. (in Chinese). [CrossRef]

44. Qiu, L.; Yang, G.; Bi, Y. Discussion on the conditions and countermeasures of developing marsh gas in rural areas of west China. Agric. Res. Arid Areas 2005, 23, 200-204. (In Chinese) [CrossRef]

45. Scheutz, C.; Kjeldsen, P.; Bogner, J.E.; Visscher, A.D.; Gebert, J.; Hilger, H.A.; Huber-Humer, M.; Spokas, K. Microbial methane oxidation processes and technologies for mitigation of landfill gas emissions. Waste Manag. Res. 2009, 27, 409-455. [CrossRef] [PubMed]

46. Cai, B. Analysis of the features of methane emissions from landfills of China in 2012. Environ. Eng. 2016, 34, 1-4. (In Chinese) [CrossRef]

47. Chen, D.; Wang, M.; Shang Guan, X.; Huang, J.; Rasmussen, R.A.; Khalil, M.A.K. Methane emission from rice fields in the south-east China. Adv. Earth Sci. 1993, 8, 47-54. (in Chinese).

48. Wang, M. Methane emission and mechanisms of methane production, oxidation, transportation in the rice fields. Chin. J. Atmos. Sci. 1998, 22, 600-612. (In Chinese) [CrossRef]

49. Min, J.; Hu, H. Calculation of greenhouse gases emission from agricultural production in China. China Popul. Resour. Environ. 2012, 22, 21-27. (In Chinese) [CrossRef]

50. Zhao, B. The Research on the Surface Mine Group Development \& Design Theory and Engineering Optimization; China University of Mining \& Technology: Beijing, China, 2015. (In Chinese)

51. Shen, S.; Dong, Y.; Wei, X.; Liu, S.; Lee, X. Constraining anthropogenic $\mathrm{CH}_{4}$ emissions in Nanjing and the Yangtze River Delta, China, using atmospheric $\mathrm{CO}_{2}$ and $\mathrm{CH}_{4}$ mixing ratios. Adv. Atmos. Sci. 2014, 31, 1343-1352. [CrossRef]

52. Yang, D.; Shen, S.; Zhang, M.; Lee, X.; Xiao, W. Uncertainty analysis on the estimation of $\mathrm{CO}_{2}$ and $\mathrm{CH}_{4}$ emission inventory over Nanjing and Yangtze River Delta. J. Meteorol. Sci. 2014, 34, 325-334. (In Chinese) [CrossRef]

53. Ramírez, A.; Keizer, C.D.; Sluijs, J.P.V.D.; Olivier, J.; Brandes, L. Monte Carlo analysis of uncertaintes in the Netherlands greenhouse gas emission inventory for 1990-2004. Atmos. Environ. 2008, 42, 8263-8272. [CrossRef]

54. Rypdal, K.; Winiwarter, W. Uncertainties in greenhouse gas emission inventories evaluation, comparability and implications. Environ. Sci. Policy 2001, 4, 107-116. [CrossRef]

55. Amstel, A.R.V.; Olivier, J.G.J.; Ruyssenaars, P.G. Monitoring of greenhouse gases in the Netherlands: Uncertainty and priorities for improvement. In Proceedings of the National Workshop, Bilthoven, The Netherlands, 1 September 1999.

56. Winiwarter, W.; Rypdal, K. Assessing the uncertainty associated with national greenhouse gas emission inventories: A case study for Austria. Atmos. Environ. 2001, 35, 5425-5440. [CrossRef]

57. Wehr, R.; Saleska, S.R. The long-solved problem of the best-fit straight line: Application to isotopic mixing lines. Biogeosciences 2016, 14, 17-29. [CrossRef]

58. Rotty, R.M. Estimates of seasonal variation in fossil fuel $\mathrm{CO}_{2}$ emissions. Tellus 1987, 39, 184-202. [CrossRef]

59. Li, Y.; Deng, J.; Mu, C.; Xing, Z.; Du, K. Vertical distribution of $\mathrm{CO}_{2}$, in the atmospheric boundary layer: Characteristics and impact of meteorological variables. Atmos. Environ. 2014, 91, 110-117. [CrossRef]

60. Winderlich, J.; Gerbig, C.; Kolle, O.; Heimann, $\mathrm{M}$. Inferences from $\mathrm{CO}_{2}$ and $\mathrm{CH}_{4}$ concentration profiles at the Zotino Tall Tower Observatory (ZOTTO) on regional summertime ecosystem fluxes. Biogeosciences 2014, 10, 15337-15372. [CrossRef]

61. Wang, Y. MeteoInfo: GIS software for meteorological data visualization and analysis. Meteorol. Appl. 2014, 21,360-368. [CrossRef] 
62. Wang, Y.; Zhang, X.; Draxler, R.R. TrajStat: GIS-based software that uses various trajectory statistical analysis methods to identify potential sources from long-term air pollution measurement data. Environ. Model. Softw. 2009, 24, 938-939. [CrossRef]

63. Sigler, J.M.; Lee, X. Recent trends in anthropogenic mercury emission in the northeast United States. J. Geophys. Res. Atmos. 2006, 111, 3131-3148. [CrossRef]

64. Zhang, F.; Fukuyama, Y.; Wang, Y.; Fang, S.; Li, P.; Fan, T.; Zhou, L.; Liu, X.; Meinhardt, F.; Emiliani, P. Detection and attribution of regional $\mathrm{CO}_{2}$ concentration anomalies using surface observations. Atmos. Environ. 2015, 123, 88-101. [CrossRef]

65. Obrist, D.; Conen, F.; Vogt, R.; Siegwolf, R.; Alewell, C. Estimation of $\mathrm{Hg}^{0}$ exchange between ecosystems and the atmosphere using ${ }^{222} \mathrm{Rn}$ and $\mathrm{Hg}^{0}$ concentration changes in the stable nocturnal boundary layer. Atmos. Environ. 2006, 40, 856-866. [CrossRef]

66. Zhou, L.; Tang, J.; Wen, Y.; Li, J.; Yan, P.; Zhang, X. The impact of local winds and long-range transport on the continuous carbon dioxide record at Mount Waliguan, China. Tellus B 2003, 55, 145-158. [CrossRef]

67. Zhang, F.; Zhou, L.; $\mathrm{Xu}, \mathrm{L}$. Temporal variation of atmospheric $\mathrm{CH}_{4}$ and the potential source regions at Waliguan, China. Sci. China Earth Sci. 2013, 56, 727-736. (In Chinese) [CrossRef]

68. Xu, J.; Lee, X.; Xiao, W.; Cao, C.; Liu, S.; Wen, X.; Xu, J.; Zhang, Z.; Zhao, J. Interpreting the ${ }^{13} \mathrm{C} /{ }^{12} \mathrm{C}$ ratio of carbon dioxide in an urban airshed in the Yangtze River Delta, China. Atmos. Chem. Phys. 2017, 17, 3385-3399. [CrossRef]

69. Boon, P.I.; Mitchell, A. Methanogenesis in the sediments of an Australian freshwater wetland, Comparison with aerobic decay, and factors controlling methanogenesis. Fems. Microbiol. Ecol. 1995, 18, 175-190. [CrossRef]

70. Qin, S.; Tang, J.; Pu, J.; Xu, Y.; Dong, P.; Jiao, L.; Guo, J. Fluxes and influencing factors of $\mathrm{CO}_{2}$ and $\mathrm{CH}_{4}$ in Hangzhou Xixi wetland, China. Earth Environ. 2016, 44, 513-519. (In Chinese) [CrossRef]

71. Zhang, B.; Tian, H.; Ren, W.; Tao, B.; Lu, C. Methane emissions from global rice fields: Magnitude, spatiotemporal patterns, and environmental controls. Glob. Biogeochem. Cycle 2016, 30, 1246-1263. [CrossRef]

72. Saunois, M.; Bousquet, P.; Poulter, B.; Peregon, A.; Ciais, P.; Canadell, J.G.; Dlugokencky, E.J.; Etiope, G.; Bastviken, D.; Houweling, S.; et al. The global methane budget 2000-2012. Earth Syst. Sci. Data 2016, 8, 697-751. [CrossRef]

73. Wang, X.; Ciais, P.; Li, L.; Ruget, F.; Vuichard, N.; Viovy, N.; Zhou, F.; Chang, J.; Wu, X.; Zhao, H.; et al. Management outweighs climate change on affecting length of rice growing period for early rice and single rice in China during 1991-2012. Agric. For. Meteorol. 2017, 233, 1-11. [CrossRef]

74. Jiang, C.; Wang, Y.; Zheng, X.; Zhu, B.; Huang, Y.; Hao, Q. Methane and nitrous oxide emissions from three paddy rice based cultivation systems in southwest China. Adv. Atmos. Sci. 2006, 23, 415-424. [CrossRef]

75. Song, X.; Xie, S. Development of vehicular emission inventory in China. Environ. Sci. 2006, 27, 1041-1045. (In Chinese) [CrossRef]

76. Liu, Q.; Wang, Y.; Wang, M.; Li, J.; Li, G. Trends of greenhouse gases in recent 10 years in Beijing. China J. Atmos. Sci. 2005, 29, 267-271. (in Chinese).

77. Fang, S.; Zhou, L.; Masarie, K.A.; Xu, L.; Rella, C.W. Study of atmospheric $\mathrm{CH}_{4}$ mole fractions at three WMO/GAW stations in China. J. Geophys. Res. Atmos. 2013, 118, 4874-4886. [CrossRef]

78. WMO Data Summary. WMO World Data Centre for Greenhouse Gases (WDCGG) Data Summary: Greenhouse Gases and Other Atmospheric Gases, No.38. Japan Meteorological Agency. Available online: http://ds.data.jma.go.jp/gmd/wdcgg/pub/products/summary/sum38/sum38.pdf (accessed on 13 May 2018).

79. World Meteorological Organization (WMO). Greenhouse Gas Bulletin: The State of Greenhouse Gases in the Atmosphere Based on Global Observations through 2016; WMO: Geneva, Switzerland, 2016.

80. Bian, L.; Gao, Z.; Sun, Y.; Ding, M.; Tang, J.; Schnell, R. CH $\mathrm{CH}_{4}$ Monitoring and Background Concentration at Zhongshan Station, Antarctica. Atmos. Clim. Sci. 2015, 6, 135-144. [CrossRef]

81. Wang, Y.; Bian, L.; Ma, Y.; Tang, J.; Zhang, D.; Zheng, X. Surface Ozone Monitoring and Background Characteristics at Zhongshan Station over Antarctica. Chin. Sci. Bull. 2011, 56, 1011-1019. [CrossRef]

82. Fang, S.; Tans, P.P.; Dong, F.; Zhou, H.; Luan, T. Characteristics of atmospheric $\mathrm{CO}_{2}$ and $\mathrm{CH}_{4}$ at the Shangdianzi regional background station in China. Atmos. Environ. 2016, 131, 1-8. [CrossRef]

83. Matthews, E.; Fung, I. Methane emission from natural wetlands: Global distribution, area, and environmental characteristics of sources. Glob. Biogeochem. Cycle 1987, 1, 61-86. [CrossRef] 
84. Aselmann, I.; Crutzen, P.J. Global distribution of natural freshwater wetlands and rice paddies, their net primary productivity, seasonality and possible methane emissions. J. Atmos. Chem. 1989, 8, 307-358. [CrossRef]

85. Mander, Ü.; Dotro, G.; Ebie, Y.; Towprayoon, S.; Chiemchaisri, C.; Nogueira, S.F.; Jamsranjav, B.; Kasak, K.; Tournebize, J.; Mitsch, W.J. Greenhouse gas emission in constructed wetlands for wastewater treatment: A review. Ecol. Eng. 2014, 66, 19-35. [CrossRef]

86. Popa, M.E.; Vollmer, M.K.; Jordan, A.; Brand, W.A.; Pathirana, S.L.; Rothe, M.; Röckmann, T. Vehicle emissions of greenhouse gases and related tracers from a tunnel study: $\mathrm{CO}: \mathrm{CO}_{2}, \mathrm{~N}_{2} \mathrm{O}: \mathrm{CO}_{2}, \mathrm{CH}_{4}: \mathrm{CO}_{2}, \mathrm{O}_{2}$ : $\mathrm{CO}_{2}$ ratios, and the stable isotopes ${ }^{13} \mathrm{C}$ and ${ }^{18} \mathrm{O}$ in $\mathrm{CO}_{2}$ and CO. Atmos. Chem. Phys. 2014, 14, 2105-2123. [CrossRef]

87. Hu, N.; Liu, S.; Gao, Y.; Xu, J.; Zhang, X.; Zhang, Z.; Lee, X. Large methane emissions from natural gas vehicles in Chinese cities. Atmos. Environ. 2018, 187, 374-380. [CrossRef]

88. Nagamori, M.; Isobe, Y.; Watanabe, Y.; Wijewardane, N.K.; Mowjood, M.I.M.; Koide, T.; Kawamotok, K. Characterization of Major and Trace Components in Gases Generated from Municipal Solid Waste Landfills in Sri Lanka. In Proceedings of the 14th International Waste Management and Landfill Symposium, Cagliari, Italy, 30 September-4 October 2013.

89. Ma, Z.; LI, H.; Yue, B.; Gao, Q.; Dong, L. Study on emission characteristics and correlation of GHGs $\mathrm{CH}_{4}$ and $\mathrm{CO}_{2}$ in MSW landfill cover layer. J. Environ. Eng. Technol. 2014, V4, 399-405. (In Chinese) [CrossRef]

90. Brix, H.; Sorrell, B.K.; Lorenzen, B. Are Phragmites-dominated wetlands a net source or net sink of greenhouse gases? Aquat. Bot. 2001, 69, 313-324. [CrossRef]

91. Hu, H.; Wang, D.; Li, Y.; Chen, Z.; Wu, J.; Yin, Q.; Guan, Y. Greenhouse gases fluxes at Chongming Dongtan phragmites australis wetland and the influencing factors. Res. Environ. Sci. 2014, 27, 43-50. (In Chinese) [CrossRef]

92. Van, d.B.R. Restoration of former wetlands in the Netherlands; effect on the balance between $\mathrm{CO}_{2}$ sink and $\mathrm{CH}_{4}$ source. Neth. J. Geosci. 2016, 82, 325-331. [CrossRef]

93. Wania, R. Modelling northern peatland surface processes, vegetation dynamics and methane emissions. Ph.D. Thesis, University of Bristol, Bristol, UK, 2007.

94. Chen, C.; Liu, C.; Tian, G.; Wang, H.; Li, Z. Progress in research of urban greenhouse gas emission inventory. Environ. Sci. 2010, 31, 2780-2787. (in Chinese). [CrossRef]

95. Cai, B. Advance and review of city carbon dioxide emission inventory research. China Popul. Resour. Environ. 2013, 23, 72-80. (in Chinese). [CrossRef]

96. Janssens-Maenhout, G.; Crippa, M.; Guizzardi, D.; Muntean, M.; Schaaf, E.; Dentener, F.; Bergamaschi, P.; Pagliari, V.; Olivier, J.G.J.; Peters, J.A.H.W.; et al. EDGAR v4.3.2 Global atlas of the three major greenhouse gas emissions for the period 1970-2012. Earth Syst. Sci. Data Discuss 2017. [CrossRef]

97. Hu, C.; Liu, S.; Cao, C.; Xu, J.; Cao, Z.; Li, W.; Xu, J.; Zhang, M.; Xiao, W.; Lee, X. Simulation of atmospheric $\mathrm{CO}_{2}$ concentration and source apportionment analysis in Nanjing City. Acta Sci. Circumstantiae 2017, 37, 3862-3875. (In Chinese) [CrossRef]

98. Jeong, S.; Hsu, Y.K.; Andrews, A.E.; Bianco, L.; Vaca, P.; Wilczak, J.M.; Fischer, M.L. A multitower measurement network estimate of California's methane emissions. J. Geophys. Res. 2013, 118, 11339-11351. [CrossRef]

99. Miller, S.M.; Wofsy, S.C.; Michalak, A.M.; Kort, E.A.; Andrews, A.E.; Biraud, S.C.; Dlugokencky, E.J.; Eluszkiewicz, J.; Fischer, M.L.; Janssens-Maenhout, G.; et al. Anthropogenic emissions of methane in the United States. Proc. Natl. Acad. Sci. USA 2013, 110, 20018-20022. [CrossRef] [PubMed]

100. Thompson, R.L.; Stohl, A.; Zhou, L.X.; Dlugokencky, E.; Fukuyama, Y.; Tohjima, Y.; Kim, S.Y.; Lee, H.; Nisbet, E.G.; Lowry, D.; et al. Methane emissions in East Asia for 2000-2011 estimated using an atmospheric Bayesian inversion. J. Geophys. Res. 2015, 120, 4352-4369. [CrossRef]

101. McKain, K.; Down, A.; Raciti, S.M.; Budney, J.; Hutyra, L.R.; Floerchinger, C.; Herndon, S.C.; Nehrkorn, T.; Zahniser, M.S.; Jackson, R.B.; et al. Methane emissions from natural gas infrastructure and use in the urban region of Boston, Massachusetts. Proc. Natl. Acad. Sci. USA 2015, 112, 1941-1946. [CrossRef] [PubMed]

(c) 2019 by the authors. Licensee MDPI, Basel, Switzerland. This article is an open access article distributed under the terms and conditions of the Creative Commons Attribution (CC BY) license (http:/ / creativecommons.org/licenses/by/4.0/). 



\title{
Article \\ Seasonal and Interannual Variation Characteristics of Low-Cloud Fraction in Different North Pacific Regions
}

\author{
Qian Wang ${ }^{1,2}$, Haiming Xu ${ }^{1,2, *}$, Leying Zhang ${ }^{3}$ and Jiechun Deng ${ }^{1,2}$ \\ 1 Key Laboratory of Meteorological Disaster, Ministry of Education (KLME)/Joint International Research \\ Laboratory of Climate and Environment Change (ILCEC)/Collaborative Innovation Center on Forecast and \\ Evaluation of Meteorological Disasters (CIC-FEMD), Nanjing University of Information Science \& \\ Technology, Nanjing 210044, China; w_qian_qian@163.com (Q.W.); jcdeng@nuist.edu.cn (J.D.) \\ 2 School of Atmospheric Sciences, Nanjing University of Information Science \& Technology, \\ Nanjing 210044, China \\ 3 Joint Innovation Center for Modern Forestry Studies, College of Biology and Environment, Nanjing Forestry \\ University, Nanjing 210037, China; zhangleyingzi@126.com \\ * Correspondence: hxu@nuist.edu.cn; Tel.: +86-25-5873-1166
}

Received: 18 February 2019; Accepted: 2 March 2019; Published: 7 March 2019

\begin{abstract}
In this study, we use the long-term satellite data to investigate seasonal and interannual variation of low-cloud fraction (LCF) and the associated controlling factors over the eastern and western North Pacific. On the seasonal time scale, the enhanced LCF over the eastern North Pacific in summer is actively coupled with strong estimated inversion strength (EIS) and 700-hPa relative humidity, and the LCF over the western North Pacific in winter is large and mainly caused by increased sensible heat flux and tropospheric low-level cold advection. On the interannual time scale, the increased LCF over the eastern North Pacific in summer is associated with increased EIS and decreased sea surface temperatures, in which the El Niño plays an important role; the enhanced LCF over the western North Pacific in spring and winter has a positive correlation with enhanced sensible heat flux (SHF) and tropospheric low-level cold advection, which can be partly explained by the subpolar frontal zone (SPFZ) intensity.
\end{abstract}

Keywords: low-level clouds; North Pacific; seasonal variation; interannual variation

\section{Introduction}

Low-level clouds play an important role in the global radiation balance, which includes longwave radiation emission, as well as absorption and reflection of solar shortwave radiation [1]. Garrett and Zhao found that where thin water clouds and pollution are coincident, there is an increase in cloud longwave emissivity resulting from elevated haze levels. This results in an estimated surface warming under cloudy skies [2]. They also found that in Alaska, the cloud radiative impact on the surface is a net warming effect between October and May and a net cooling in summer. During episodes of high surface haze aerosol concentrations and cloudy skies, both the net warming and net cooling are amplified. Thus the low cloud has an important influence on global climate change [3]. A small change in fractional coverage of low-level clouds can exert significant influences on weather and climate [4]. For example, the marine stratocumulus has a potential positive feedback to global warming [5]. However, since the formation of low-level clouds is governed by small-scale turbulent processes, the associated controlling factors of low-cloud fraction (LCF) are complex. Although Ma et al. has found a prognostic method of cloud-cover calculation (PROGCS) which has significant advantage over the conventional diagnostic one, the complex controlling factors still are the main sources of the uncertainty in state-of-the-art models [6]. For example, Fan et al. found that the aerosol errors 
have a certain contribution to cloud fraction biases in Coupled Model Intercomparison Project Phase 5 (CMIP5) simulations [7]. As a result, the variation of LCF has been poorly simulated in present climate projections $[8,9]$. Thus, it is very important to investigate the controlling factors of LCF for climate research $[10,11]$.

Low-level clouds are frequently observed over the cool oceans where deep convection is unlikely to occur. Due to their significant potential impacts on the Earth's energy balance, low-level clouds have been intensively investigated at various time scales [12]. At the seasonal time scale, it is well known that the LCF is positively related to the inversion strength of lower-tropospheric temperature. In previous studies, the estimated inversion strength (EIS) was defined as a refinement of lower-tropospheric stability (LTS), and there is a linear relationship between LCF and EIS over the subtropical and mid-latitude oceans [13]. In fact, the EIS can only explain the seasonality of LCF over the eastern area of an ocean basin, which is located east of the western Pacific subtropical high that accompanies persistent mid-tropospheric subsidence and equatorward surface winds [14,15]. Besides the subtropical and mid-latitude oceans, large LCF also appears over the high-latitude and subpolar oceans. In these regions, one of the important factors that affect LCF is a prominent ocean front [16]. Over the ocean front, the sea surface temperature (SST) anomalies are controlled by surface temperature advection, resulting in a source of sensible heat flux (SHF) anomalies [17]. The upward SHF destabilizes the surface layer and facilitates shallow convection in the boundary layer to further increase LCF. In addition, the decreased relative humidity $(\mathrm{RH})$ at $700-\mathrm{hPa}$ acts to reduce cloudiness $[18,19]$. Besides, the seasonal variation of low clouds is also affected by aerosol and haze [20,21].

At the interannual time scale, the variation of LCF is considered to be associated with different environmental fields [22]. Previous studies focused on the variation of LCF and its relationship with SST anomalies (SSTA). Norris and Leovy [23] showed that LCF is negatively correlated with the SSTA in the eastern subtropical oceans, especially during summer [24]. They further noted that surface cold advection may play an important role in the interannual variation of LCF. The summertime interannual variation of LCF over the North Pacific is the largest in the central and western regions along $35^{\circ}$ $\mathrm{N}$ and in the eastern region near $15^{\circ} \mathrm{N}$. The LCF over these two regions are in good relationship with local SST and sea-level pressure (SLP) field [25]. Over the North Atlantic, the North Atlantic subtropical high (NASH) also plays an important role in the interannual variation of summertime LCF. A stronger NASH is often accompanied by increased LCF and cooler SSTs along the southeast of the NASH. The northeasterly surface wind anomalies associated with an intensified NASH tend to induce colder advection and stronger coastal upwelling in the LCF region, acting to decrease surface temperature. Meanwhile, the anomalous warm advection associated with the easterly wind anomalies from Africa leads to a warming at $700 \mathrm{hPa}$ over the LCF region. Such warming and surface cooling increase atmospheric static stability, favoring the growth of LCF. The anomalous diabatic cooling associated with the growth of LCF dynamically excites an anomalous anticyclone to its north and enhances the NASH in turn. Besides the subtropical high, the El Niño-Southern Oscillation (ENSO) is a primary variability of interannual time scale in the Pacific Ocean, which has a positive relationship with summertime-enhanced LCF over the southeastern North Pacific [26].

The seasonal and interannual variations of LCF have been investigated in many studies. However, due to limited observation data, the data range used in previous studies is very short. In addition, previous studies showed that the EIS can only explain the variation of LCF over the eastern side of an ocean basin, while it is weakly related to the LCF over the western side [12]. Thus, different controlling factors of LCF between the eastern and western sides need to be studied. In this study, we use long-term satellite data to explore seasonal and interannual variations of low-level clouds over the North Pacific, where the associated controlling factors exhibit significant differences in the eastern and western regions.

The rest of this paper is organized as follows. In Section 2, we introduce the data and methods used in this study. In Section 3, we investigate the seasonal distribution of LCF over the North Pacific 
and its associated controlling factors. Multiple linear regression model analysis is used. Interannual variation of LCF is also explored in Section 3 and a conclusion is given in Section 4.

\section{Data and Methods}

\subsection{Data}

The cloud data used in this study are the collection 06 Level-3 monthly cloud product of the Moderate Resolution Imaging Spectroradiometer (MODIS), which has a horizontal resolution of $1^{\circ} \times 1^{\circ}$, and cover the period from January 2003 to December $2015[27,28]$. It is noteworthy that time representation errors exist for cloud fraction observed by MODIS, since it only observes clouds twice a day. The correlation coefficient between MODIS monthly cloud fraction (CF) and continuous day-and-night radar/lidar CF is 0.97 . This small error will not affect our results [21,29]. MODIS cloud data include cloud fraction and cloud top pressure. Clouds with top pressure higher than $700 \mathrm{hPa}$ are considered as low-level clouds [30]. Since the MODIS instruments cannot detect low-level clouds that are overlapped with mid- and high-level clouds, the random overlap assumption is used to reduce the influence of mid- and high-level clouds [31]. It is a reasonable assumption outside the areas of deep convection and landmass [32,33].

The meteorological fields used in this study are ERA-Interim global atmospheric reanalysis at $1^{\circ} \times 1^{\circ}$ grid from European Centre for Medium-Range Weather Forecasts (ECMWF) [34], including 700-hPa subsidence (W), 700-hPa RH, 700-hPa potential height (Z), 2-m surface air temperature (SAT), dew point temperature $\left(\mathrm{T}_{\mathrm{d}}\right), 10-\mathrm{m}$ surface wind, and SLP. All variables used cover the period from January 2003 to December 2015.

In addition, the SST at $1^{\circ} \times 1^{\circ}$ grid from the Hadley Center [35], the SHF at $1^{\circ} \times 1^{\circ}$ grid from the Woods Hole Oceanographic Institution (WHOI), and the Niño-3.4 index provided by the National Oceanic and Atmospheric Administration (NOAA) are used in this study [36,37]. For consistency, all variables used cover the period from January 2003 to December 2015.

\subsection{Methods}

The EIS defined by Wood and Bretherton [13] is used as a measure of inversion layer strength at the top of the boundary layer:

$$
E I S=\left(\theta_{700}-\theta_{s f c}\right)-\gamma_{m}^{850}\left(Z_{700}-Z_{L C L}\right)
$$

where $\theta_{700}$ and $\theta_{\text {sfc }}$ are the potential temperatures at $700 \mathrm{hPa}$ and surface, respectively. $Z_{700}$ is the $700-\mathrm{hPa}$ height, $\mathrm{Z}_{\mathrm{LCL}}$ is the lifting condensation level, and $\gamma_{m}^{850}$ is the $850-\mathrm{hPa}$ moist adiabatic lapse rate. $Z_{\mathrm{LCL}}$ is calculated by using $S A T$ and $T_{\mathrm{d}}$ :

$$
Z_{\mathrm{LCL}}=123 \times\left(S A T-T_{\mathrm{d}}\right)
$$

The near-surface temperature advection $(\operatorname{advT})$ is calculated by using $-V_{s f c} \cdot \nabla \mathrm{SST}$, where $V_{s f c}$ represents surface zonal and meridional winds, and $\nabla$ SST are the zonal and meridional SST gradients [38-40].

We also define the subpolar frontal zone (SPFZ) to measure SST gradient strength in the subpolar

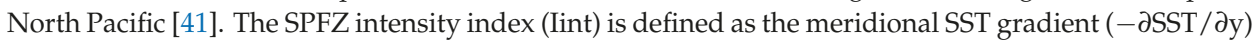
averaged over the climatological SPFZ area $\left(145^{\circ}-170^{\circ} \mathrm{E}, 35^{\circ}-47^{\circ} \mathrm{N}\right)$.

To quantify the relative importance of the associated controlling factors in seasonal variation of LCF, LCF dependence on these factors is derived using multiple linear regression. Although the multiple linear regression method cannot perfectly extract the impact of individual large-scale forcing, the derived local dependence is useful for quantifying their local controls on LCF [5]. 
In this study, spring refers to the period of March, April and May; summer refers to the period of June, July, August; autumn refers to the period of September, October, November; winter refers to the period of December, next January, next February.

\section{Results}

\subsection{Climatological Distribution of LCF}

Figure 1a,b displays the distributions of climatological LCF over the North Pacific in summer and winter, respectively. Winter is defined from December to the following February, and summer is defined from June to August. The LCF over the North Pacific is zonally inhomogeneous in both winter and summer, and exhibits obvious seasonal difference. In summer, the LCF over the eastern North Pacific is larger than that over the western North Pacific, with a local maximum around $20^{\circ} \mathrm{N}$ (Figure 1a). In contrast, the LCF maximum in winter appears over the western North Pacific (Figure 1b). Note that the LCF over the Bering Sea is large in both summer and winter.

(a)LCF\&T1000

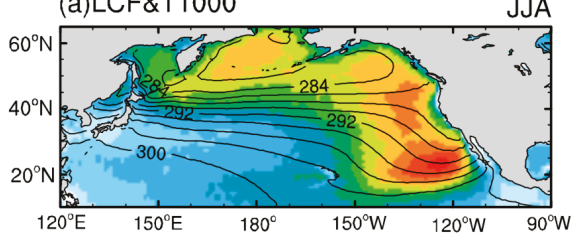

(c)EIS\&T700
(b)LCF\&T1000

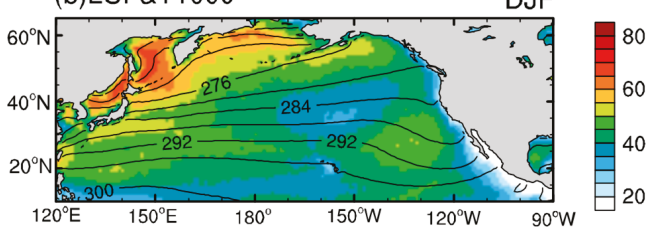

(d)EIS\&T700
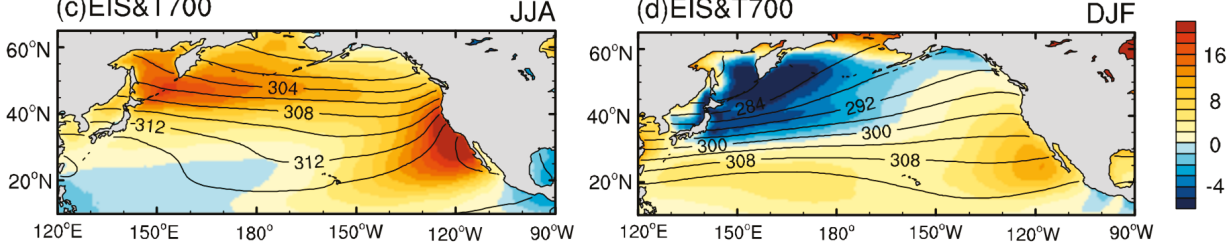

Figure 1. Climatological low-cloud fraction (LCF; shading; units: \%) and surface potential temperature (contour interval: $2 \mathrm{~K}$ ) in summer (a) and in winter (b); (c,d) are the same as (a,b), but for estimated inversion strength (EIS; shading; units: $\mathrm{K}$ ) and 700-hPa potential temperature (contour interval: $4 \mathrm{~K}$ ).

Previous studies indicated that the climatological distribution of LCF and the seasonality of LCF can be well explained by the EIS, whose enhancement acts to increase LCF [42,43]. Atmospheric circulation also make contribution to the variation of LCF, such as subtropical high, Hadley-Walker circulation, and mesoscale waves [12,44]. However, EIS was proved to be the dominating factor in the seasonal variation of the LCF in previous studies [12,31]. Thus, EIS is focused on in our study. Hence, the climatological EIS defined in Equation (1) is shown in Figure 1c,d for summer and winter, respectively. Across the summertime subtropical basin (Figure 1c), the EIS is maximal off the west coast of North America around $125^{\circ} \mathrm{W}$, in good correspondence with the spatial pattern of LCF (Figure 1a). Compared to the summertime situation, the EIS in winter exhibits a zonal minimum (negative center) distribution over the mid-latitude western North Pacific (Figure 1d), where a maximum LCF dominates. This is in contrast to the well-known liner relationship between EIS and LCF [13]. The enhancement of EIS could maintain a strong temperature inversion at the top of the boundary layer, inhibiting cloud-top entrainment of dry air, further contributing to LCF increase. Overall, the LCF over the eastern North Pacific is positively associated with the EIS, while the relationship between LCF and EIS over the western North Pacific is negative. Thus, the EIS alone is not sufficient to explain the observed LCF. Next, we will discuss the possible factors dominating the seasonal cycles of LCF over the eastern and western North Pacific, respectively. 


\subsection{Seasonal Cycle of $L C F$}

According to previous studies, the EIS, cool advT, SHF, 700-hPa subsidence, and 700-hPa RH are the main factors affecting the formation of low-level clouds over the oceans. Overall, the enhancements of these factors contribute to LCF increase [45]. The enhancement of EIS could maintain a strong temperature inversion at the top of the boundary layer, inhibiting cloud-top entrainment of dry air, further contributing to LCF increase. The cool advT could expand the difference value between SST and SAT, further increasing SHF. The increased SHF could destabilize the surface layer, and thereby facilitate shallow convection in the boundary layer, to further increase LCF. The enhanced 700-hPa W acts to warm the mid-troposphere, inhibiting cloud-top entrainment of dry air, further increasing LCF. The 700-hPa RH could contribute to the increase of LCF by increasing the water vapor content in the air. To discuss the seasonality of LCF and its distribution over the eastern and western North Pacific, longitude-time sections of climatological LCF and the associated controlling factors along $25^{\circ} \mathrm{N}$ and $45^{\circ} \mathrm{N}$ are shown in Figures 2 and 3, respectively.

(a) LCF

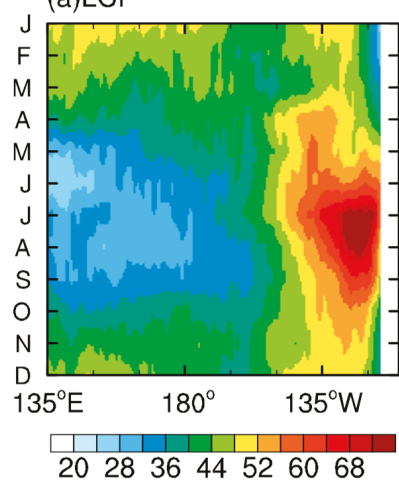

(d) $\mathrm{RH}$

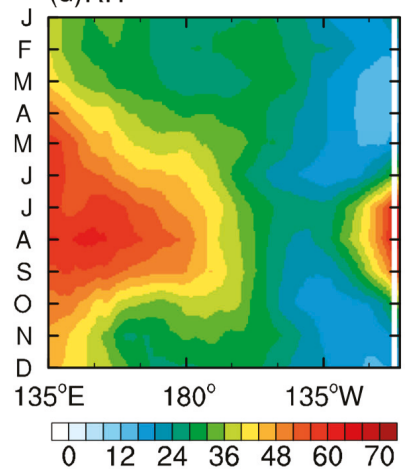

(b)EIS

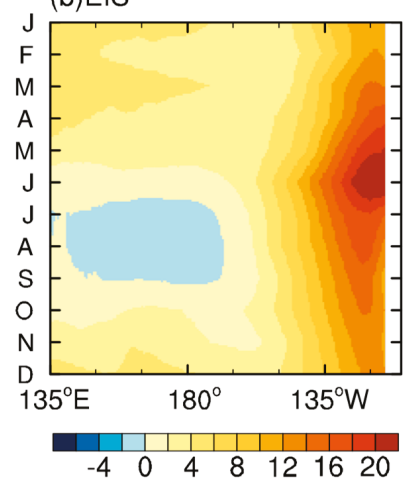

(e)W

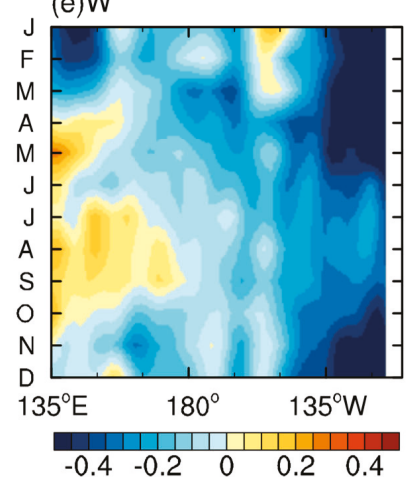

(c)advT

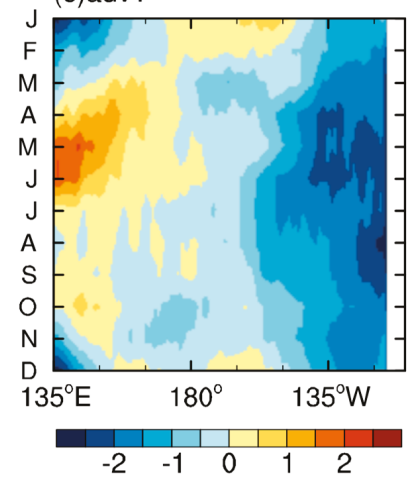

(f) SHF

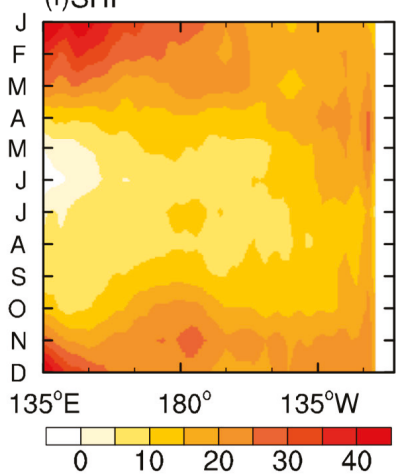

Figure 2. Time-longitude section of climatological (a) LCF (shading; units: \%), (b) EIS (shading; units: $\mathrm{K})$, (c) near-surface temperature advection (advT; shading; units: K/day), (d) 700-hPa relative humidity (RH; shading; units: \%), (e) 700-hPa subsidence (W; shading; units: $\mathrm{m} / \mathrm{s}$ ), and (f) sensible heat flux (SHF; shading; units: $\mathrm{W} / \mathrm{m}^{2}$ ) along $25^{\circ} \mathrm{N}$. 
(a) LCF

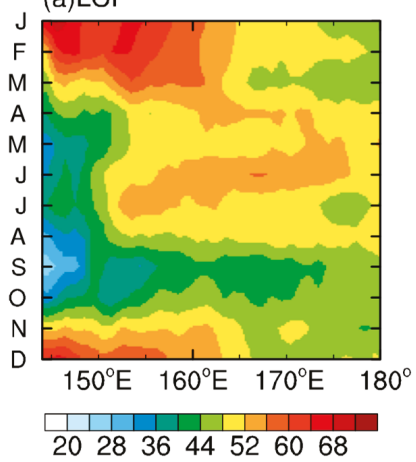

(d) $\mathrm{RH}$

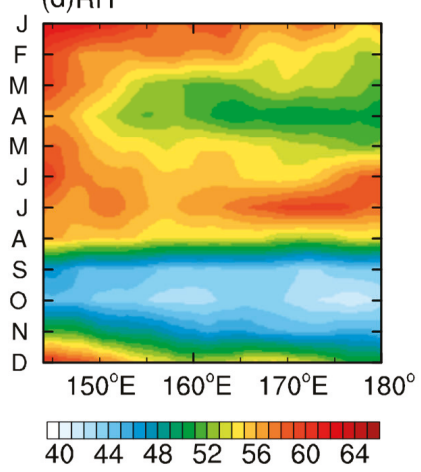

(b)EIS

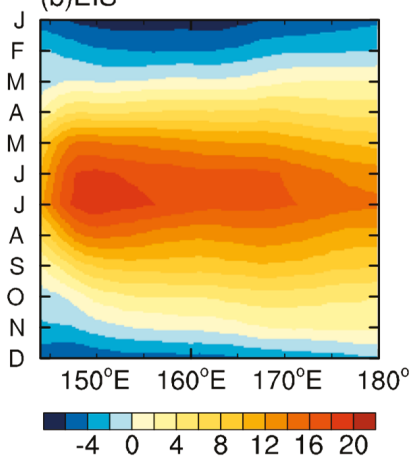

(e)W

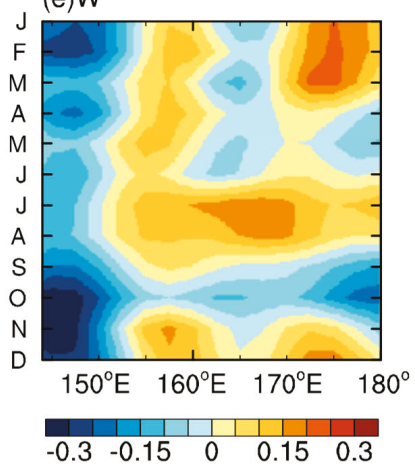

(c)advT

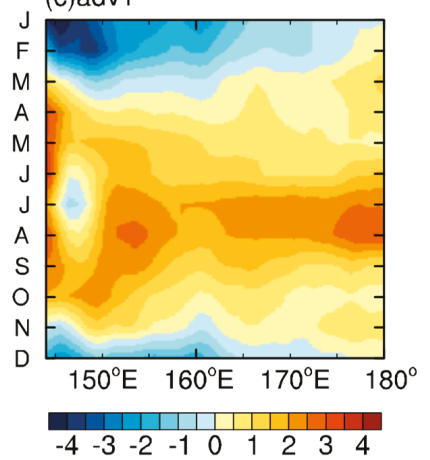

(f) SHF

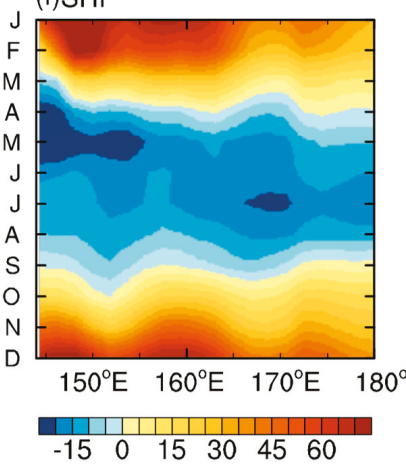

Figure 3. Time-longitude section of climatological (a) LCF (shading; units: \%), (b) EIS (shading; units: K), (c) near-surface advT (shading; units: K/day), (d) 700-hPa RH (shading; units: \%), (e) 700-hPa W (shading; units: $\mathrm{m} / \mathrm{s}$ ), and (f) SHF (shading; units: $\mathrm{W} / \mathrm{m}^{2}$ ) along $45^{\circ} \mathrm{N}$.

These figures reveal complex relationships of LCF with its controlling factors in the course of seasonal cycles over the North Pacific. At $25^{\circ} \mathrm{N}$ (Figure 2a), LCF is larger in summer than in winter over the eastern subtropics $\left(115^{\circ}-135^{\circ} \mathrm{W}\right)$, which is consistent with the winter-summer difference of the EIS shown in Figure 2b. As evident in Figure 2c,d, the distributions of cold temperature advection and 700-hPa RH are also in good accordance with LCF. However, 700-hPa W and SHF are relatively weaker in summer, which is in contrary to the seasonality of LCF (Figure 2e,f). Therefore, the EIS, cold advection, and 700-hPa RH have great contributions to the enhancement of LCF over the eastern North Pacific in summer. In summer, LCF prevails over the eastern portion of the subtropical North Pacific, which is located east of the surface subtropical high that accompanies persistent mid-troposphere subsidence and equatorward surface winds. The equatorward winds induce coastal upwelling (west coast of Mexico), upper-ocean mixing, and surface evaporation, acting to maintain relatively low SST. Meanwhile, the mid-troposphere subsidence associated with the subtropical high acts to warm the mid-troposphere. The combination of cool SST and warm mid-troposphere maintains a strong temperature inversion at the top of the boundary layer, inhibiting cloud-top entrainment of dry air, further increasing LCF. Thus, the EIS can explain the summertime enhancement of LCF to a certain extent. Note that the EIS reaches its maximum in spring, while the maximum of LCF is in summer (Figure 2a,b). This may be due to both EIS and RH being large in summer, while only the EIS is large in spring. Thus, LCF reaches its maximum in summer, resulting from the combined contribution of EIS and $\mathrm{RH}$, rather than in spring, when only the EIS is the strongest, suggesting the essential influence of RH on the seasonal variability of LCF over the eastern North Pacific. RH may lead to a time-lag 
correlation between EIS and LCF in the subtropics. The enhanced RH indicates an increase in vapor concentration in summer, which provides positive condition to the formation of low-level clouds in summer, despite the EIS being maximum in spring [46].

Figure 3 is the same as Figure 2, except along $45^{\circ} \mathrm{N}$. Over the western North Pacific $\left(145^{\circ}-160^{\circ}\right.$ E), the EIS is larger in summer than in winter (Figure 3b), while LCF is larger in winter than in summer (Figure 3a). This is in contrast to the well-known liner relationship between EIS and LCF [47]. Meanwhile, cold advection, 700-hPa RH, 700-hPa W, and SHF are enhanced in winter over the western portion (Figure 3c-f), which is in accordance with the distribution of LCF (Figure 3a). Therefore, the wintertime enhanced LCF over the western North Pacific may be due to the enhancement of cold advection, SHF, 700-hPa W, and 700-hPa RH. On the one hand, the cold advection in winter over the western region destabilizes the surface layer, increasing the difference between SST and SAT, further resulting in large upward SHF. The wintertime enhancement of upward SHF facilitates shallow convection in the boundary layer, and further increases LCF. On the other hand, the enhanced storm track activity also contributes to the wintertime enhancement of SHF over the western North Pacific (not shown). In this area, the wintertime enhanced 700-hPa W acts to warm the mid-troposphere, inhibiting cloud-top entrainment of dry air to further increase LCF to a certain extent [20]. Moreover, similar to the situation over the eastern North Pacific, the wintertime enhancement of 700-hPa RH may also have positive effects on enhancing LCF.

As shown in the preceding section, the factors favoring increased LCF are different over the eastern and western North Pacific regions. One may question the relative importance of contributions from the EIS, advT, SHF, 700-hPa W, and 700-hPa RH to the enhancement of LCF. To further quantify their relative contributions, we reconstruct LCF using a multiple linear regression model. In this study, the regression model is constructed from climatological LCF and the factors over the eastern $\left(115^{\circ}-136^{\circ} \mathrm{W}, 1^{\circ}-28^{\circ} \mathrm{N}\right)$ and western $\left(140^{\circ}-155^{\circ} \mathrm{E}, 47^{\circ}-60^{\circ} \mathrm{N}\right)$ North Pacific, respectively. To describe the relative importance of cloud controlling factors, the annual mean has been removed. The regression slope of LCF variation against each predictor is given in Table 1.

Table 1. Regression slope for each predictor (EIS: estimated inversion strength; advT: surface temperature advection; SHF: sensible heat flux; W: 700-hPa subsidence; RH: 700-hPa relative humidity).

\begin{tabular}{|c|c|c|c|c|c|}
\hline Area & $\begin{array}{c}\partial \mathrm{LCF} / \partial \mathrm{EIS} \\
\left(\% \mathrm{~K}^{-1}\right)\end{array}$ & 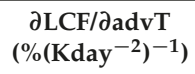 & $\begin{array}{c}\partial \mathrm{LCF} / \partial \mathrm{SHF} \\
\left(\%\left(\mathrm{Wm}^{-2}\right)^{-1}\right)\end{array}$ & $\begin{array}{c}\partial \mathrm{LCF} / \partial W \\
\left(\%\left(\mathrm{~m}^{-1}\right)^{-1}\right)\end{array}$ & $\begin{array}{c}\partial \mathrm{LCF} / \partial \mathrm{RH} \\
\left(\% \%^{-1}\right)\end{array}$ \\
\hline Western North Pacific & -0.08 & -0.19 & 0.12 & 48.6 & -0.14 \\
\hline Eastern North Pacific & 0.47 & -2.86 & 0.16 & 58.89 & 0.27 \\
\hline
\end{tabular}

Figures 4 and 5 show the longitude-time distributions of the predicted climatological seasonal cycles\# of LCF along $25^{\circ} \mathrm{N}$ and $45^{\circ} \mathrm{N}$, respectively. Besides, the corresponding LCF predicted by the multiple linear regression model is also shown in Figures $4 \mathrm{~b}$ and $5 \mathrm{~b}$, named "Total". At $25^{\circ} \mathrm{N}$, the multiple linear regression model explains $71 \%$ of the total variance of LCF regionality and its seasonal cycle, whereas the root mean square error (RMSE) between observed and predicted LCF is $8 \%$. The model reproduces the summertime LCF maximum from July to September over the eastern subtropics (Figure 4a,b). The reconstruction indicates that the EIS (Figure 4c) and RH (Figure 4e) make the greatest contributions to the summertime enhancement of LCF, and the contribution from cold advection is also important (Figure 4d). In contrast, the $700-\mathrm{hPa}$ W and SHF act to reduce LCF in summer (Figure 4f,g). 

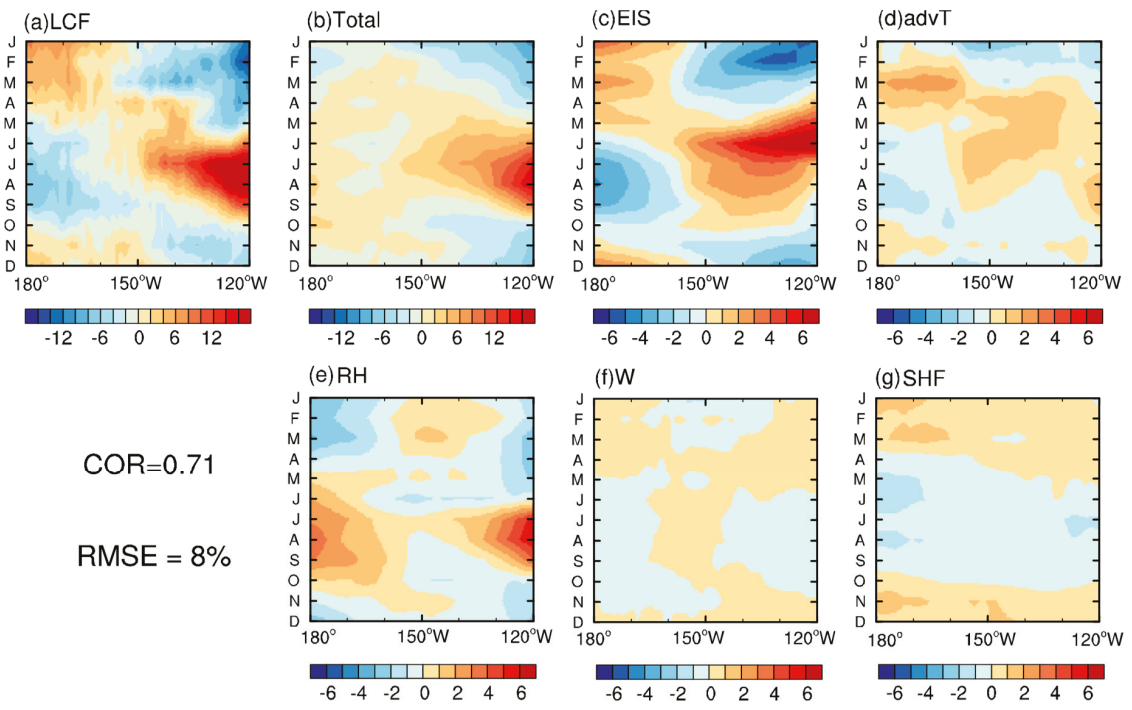

Figure 4. (a) Same as Figure 2a, except that the annual-mean LCF (\%) has been removed. (b) Same as (a), except for the corresponding LCF (\%) predicted by the multiple linear regression model. The correlation and root mean square error (RMSE) between $(\mathbf{a}, \mathbf{b})$ are shown below (a). (c-g) Same as (b), except for individual contributions from EIS, advT, 700-hPa RH, 700-hPa subsidence, and SHF to (b), respectively.

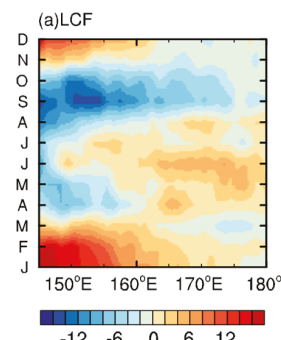

$\begin{array}{lllll}-12 & -6 & 0 & 6 & 12\end{array}$
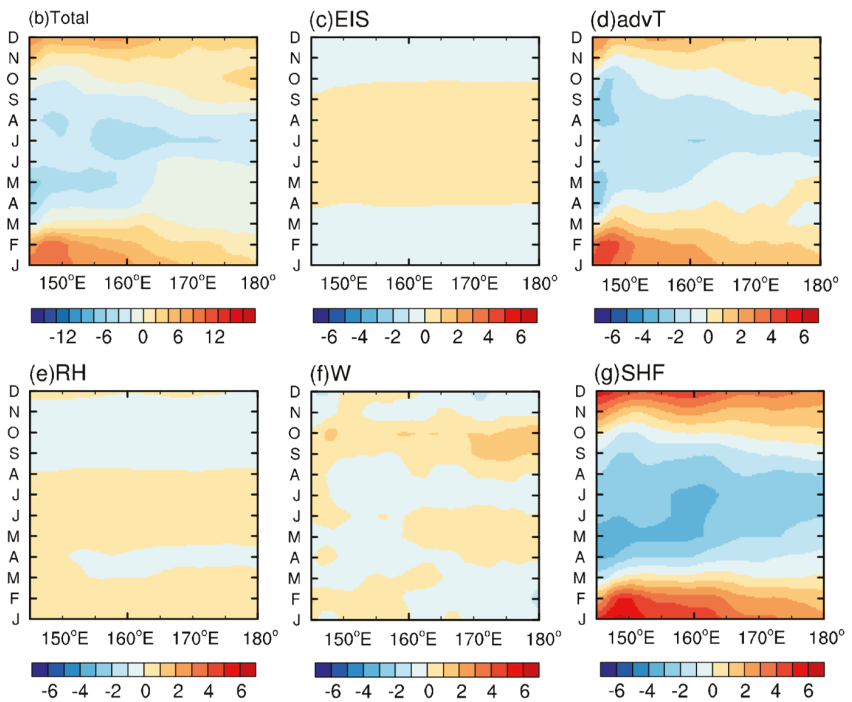

Figure 5. (a) Same as Figure 3a, except that the annual-mean LCF (\%) has been removed. (b) Same as (a), except for the corresponding LCF (\%) predicted by the multiple linear regression model. The correlation and root mean square error (RMSE) between $(\mathbf{a}, \mathbf{b})$ are shown below (a). (c-g) Same as (b), except for individual contributions from EIS, advT, 700-hPa RH, 700-hPa subsidence, and SHF to (b), respectively. 
At $45^{\circ} \mathrm{N}$, the reconstructed LCF can also reproduce LCF well. In this area, the reconstruction explains $68 \%$ of the total variance of LCF, and the RMSE between observed and predicted LCF is $9 \%$ (Figure 5a,b). The wintertime LCF enhancement over the western North Pacific is mostly attributable to enhanced cold advection and SHF (Figure $5 \mathrm{~d}, \mathrm{~g}$ ). Nevertheless, the EIS in this area acts to suppress the wintertime enhancement of LCF (Figure 5c), and the direct impacts of 700-hPa RH and W are negligible (Figure 5e,f).

Overall, the dominating factors associated with the seasonal cycle of LCF are different over the eastern and western North Pacific regions. Over the eastern North Pacific, the EIS dominates the enhancement of LCF in summer, together with the 700-hPa RH. Over the western North Pacific, the enhancement of LCF in winter is mostly due to enhanced SHF and cold advection.

\subsection{Association with Meteorological Parameters}

In this subsection, we examine the interannual variability of EIS, 700-hPa $\mathrm{W}$, advT, SHF, and SST to investigate the possible factors associated with the interannual variability of LCF over eastern and western North Pacific regions, respectively. We calculated the interannual variance of LCF in different seasons. We first choose three regions over the eastern North Pacific where the variances are large. However, in order to investigate the different factors of LCF between eastern and western North Pacific, we also choose three regions over the western North Pacific where the variances of LCF are also large (Figure 6). The six different regions are defined as follows: the Okhotsk Sea (OS; $\left.140^{\circ}-155^{\circ} \mathrm{E}, 47^{\circ}-60^{\circ} \mathrm{N}\right)$, the Kuroshio Extension (KE; $\left.142^{\circ}-180^{\circ} \mathrm{E}, 37^{\circ}-44^{\circ} \mathrm{N}\right)$, the south basin of Japan (SJ; $124^{\circ}-145^{\circ}$ E, $25^{\circ}-31^{\circ} \mathrm{N}$ ), the center of the North Pacific (CE; $136^{\circ}-165^{\circ} \mathrm{W}, 26^{\circ}-37^{\circ} \mathrm{N}$ ), the southeastern North Pacific (SE; $115^{\circ}-136^{\circ} \mathrm{W}, 15^{\circ}-28^{\circ} \mathrm{N}$ ), and the northeastern North Pacific (NE; $\left.124^{\circ}-148^{\circ} \mathrm{W}, 26^{\circ}-43^{\circ} \mathrm{N}\right)$.

(a)MAM

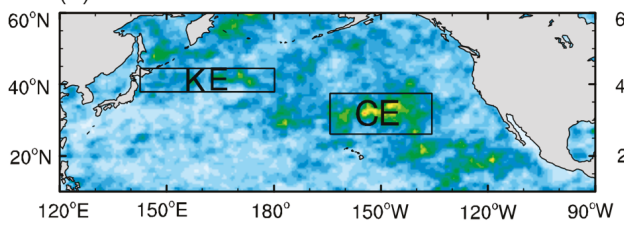

(c) SON
(b)JJA

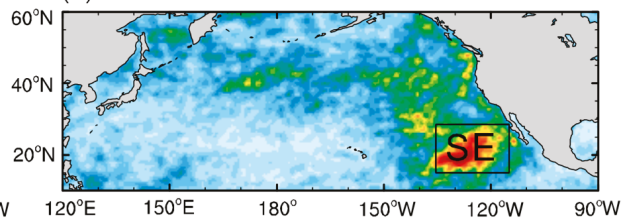

(d)DJF

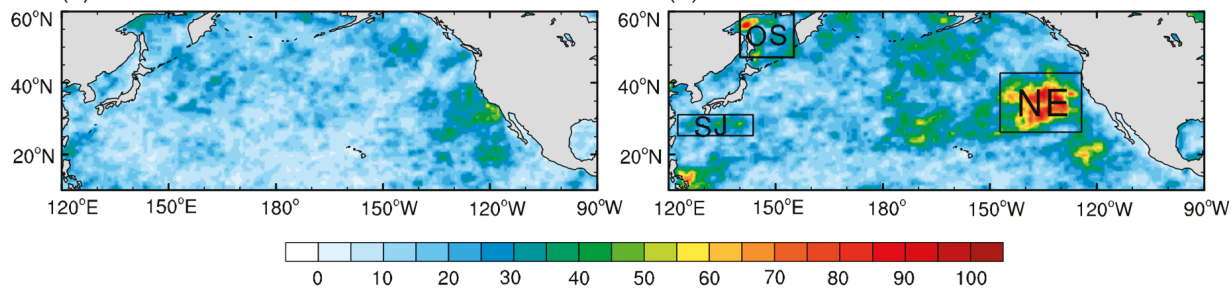

Figure 6. Interannual LCF variance (shading; units: $\%{ }^{2}$ ) in (a) spring, (b) summer, (c) autumn, and (d) winter. Thick solid rectangles designate different regions discussed in Section 4.

First, we calculated the correlation coefficients between regional-mean LCF and corresponding meteorological variables for each region. Table 2 lists these correlation coefficients. For the correlation coefficients of different regions and seasons, we use the method of significance test of correlation coefficients [48]. According to the significance test table of correlation coefficient, we can see that when the degree of freedom $n=11$, the correlation coefficient (COR) which is larger than 0.553 $(\mathrm{COR}<-0.553)$ exceeds a $95 \%$ confidence level; the COR which is less than $0.476(-0.476<\mathrm{COR}<0)$ cannot exceed a $90 \%$ confidence level. 
Table 2. Correlation coefficients of regionally-averaged interannual anomalies of various meteorological parameters with those of LCF. The bold type exceed a 95\% confidence level, while the parentheses indicate that the correlation coefficient is not statistically significant. (SE: the southeastern North Pacific; NE: the northeastern North Pacific; CE: the center of the North Pacific; OS: the Okhotsk Sea; KE: the Kuroshio Extension; SJ: the south basin of Japan).

\begin{tabular}{|c|c|c|c|c|c|c|}
\hline Area & Season & $\begin{array}{c}\text { Estimated } \\
\text { Inversion } \\
\text { Strength } \\
\text { (EIS) }\end{array}$ & $\begin{array}{c}\text { 700-hPa } \\
\text { Subsidence } \\
\text { (W) }\end{array}$ & $\begin{array}{l}\text { Surface } \\
\text { Temperature } \\
\text { Advection } \\
\text { (advT) }\end{array}$ & $\begin{array}{c}\text { Sensible } \\
\text { Heat Flux } \\
\text { (SHF) }\end{array}$ & $\begin{array}{c}\text { Sea } \\
\text { Surface } \\
\text { Temperature } \\
\text { (SST) }\end{array}$ \\
\hline \multirow{4}{*}{$\mathrm{SE}$} & Spring & 0.49 & $(-0.25)$ & $(0.04)$ & $(-0.24)$ & $(-0.41)$ \\
\hline & Summer & 0.57 & -0.64 & $(-0.11)$ & $(-0.07)$ & -0.57 \\
\hline & Autumn & $(0.36)$ & $(0.04)$ & $(-0.07)$ & -0.61 & -0.72 \\
\hline & Winter & 0.55 & -0.65 & $(0.12)$ & $(0.21)$ & $(-0.43)$ \\
\hline \multirow{4}{*}{ NE } & Spring & $(0.25)$ & -0.51 & -0.73 & $(0.46)$ & -0.64 \\
\hline & Summer & 0.73 & -0.60 & $(-0.38)$ & $(-0.39)$ & -0.74 \\
\hline & Autumn & 0.56 & $(-0.45)$ & -0.66 & $(-0.02)$ & $(-0.12)$ \\
\hline & Winter & 0.57 & -0.81 & -0.85 & 0.54 & -0.57 \\
\hline \multirow{4}{*}{$\mathrm{CE}$} & Spring & 0.71 & -0.91 & -0.81 & 0.68 & $(-0.37)$ \\
\hline & Summer & 0.71 & $(-0.41)$ & $(-0.37)$ & $(0.42)$ & -0.59 \\
\hline & Autumn & 0.59 & -0.81 & $(-0.29)$ & $(0.001)$ & $(-0.25)$ \\
\hline & Winter & 0.60 & -0.84 & -0.48 & $(0.40)$ & $(0.35)$ \\
\hline \multirow{4}{*}{ OS } & Spring & $(-0.34)$ & $(-0.41)$ & $(0.05)$ & $(0.15)$ & $(0.07)$ \\
\hline & Summer & $(0.07)$ & $(-0.35)$ & $(0.16)$ & 0.51 & $(-0.24)$ \\
\hline & Autumn & -0.48 & $(-0.35)$ & $(-0.35)$ & $(0.39)$ & $(-0.37)$ \\
\hline & Winter & $(-0.36)$ & -0.58 & -0.65 & 0.61 & $(0.02)$ \\
\hline \multirow{4}{*}{$\mathrm{KE}$} & Spring & $(-0.16)$ & -0.59 & -0.56 & 0.61 & $(-0.08)$ \\
\hline & Summer & $(0.21)$ & $(-0.42)$ & -0.62 & 0.67 & $(-0.05)$ \\
\hline & Autumn & $(-0.28)$ & $(-0.32)$ & -0.48 & $(0.27)$ & $(0.02)$ \\
\hline & Winter & $(-0.30)$ & -0.62 & -0.60 & $(0.45)$ & $(-0.43)$ \\
\hline \multirow{4}{*}{ SJ } & Spring & $(-0.01)$ & $(-0.22)$ & $(-0.17)$ & $(0.38)$ & $(-0.10)$ \\
\hline & Summer & $(-0.24)$ & -0.55 & $(0.13)$ & $(0.31)$ & $(0.21)$ \\
\hline & Autumn & $(0.37)$ & -0.47 & $(-0.09)$ & 0.56 & $(-0.21)$ \\
\hline & Winter & $(-0.18)$ & -0.80 & -0.7 & 0.65 & -0.85 \\
\hline
\end{tabular}

Over the eastern portions (SE, NE, and CE), the LCF is positively correlated with the EIS and negatively correlated with the SST, especially in summer and winter; the 700-hpa W also plays a positive role in the interannual variation of LCF over the eastern portions. In NE and CE, there is a positive correlation between LCF and cold advection. Over the eastern portions, the correlation between LCF and SHF is not obvious.

In contrast to the eastern regions, the correlations between LCF and meteorological parameters over the western regions (OS, KE, and SJ) present radically different features. Over the western regions, the LCF is positively connected with cold advection and SHF, especially in winter and spring. Note that there is no relationship between LCF and EIS, or between LCF and SST. Over the western regions, the 700-hPa W also has a positive correlation with LCF, similar to that in the eastern regions.

These correlation coefficients reflect regional contrast at the interannual time scale. The LCF over the eastern North Pacific is positively correlated with both EIS and SST; the LCF over the western regions coincides well with SHF and cold advection. The 700-hPa $\mathrm{W}$ has positive relation with LCF over both western and eastern regions.

\subsection{Association with El Niño and SPFZ}

What causes the characteristic interannual variations in SST, EIS, advT, and SHF, which are closely linked with the interannual variation of LCF? In this subsection, we first discuss the possible relationship of LCF with the El Niño, which is the primary variability in the North Pacific at the interannual time scale. Figure 7 shows the interannual anomalies of LCF, SST, and EIS over the North 
Pacific regressed onto the synchronization Niño-3.4 index in different seasons. Usually, the El Niño occurs in the eastern equatorial Pacific. Warm SST anomalies simultaneously occur in the surrounding regions (Figure 7a-d), which are well-known as the typical SST anomaly distribution associated with the El Niño $[49,50]$. Meanwhile, the warm SST benefits warm surface potential temperature, corresponding to the overlying negative EIS. This is consistent with the negative correlation between EIS and El Niño over the eastern North Pacific. The negative EIS over the eastern North Pacific favors negative LCF. Thus, El Niño-related SSTs have negative feedback on the LCF over the eastern North Pacific, in which the EIS plays an important role. This is consistent with the results of previous studies [51].

(a)MAM

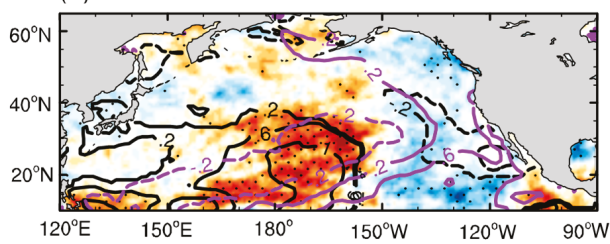

(c)SON

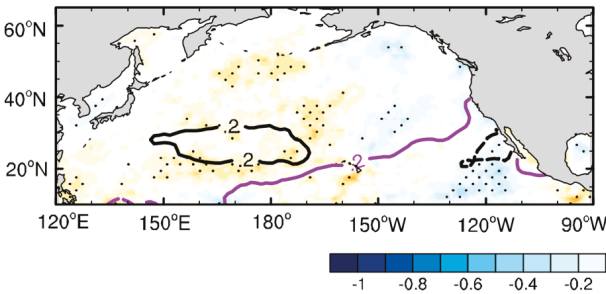

(b)JJA

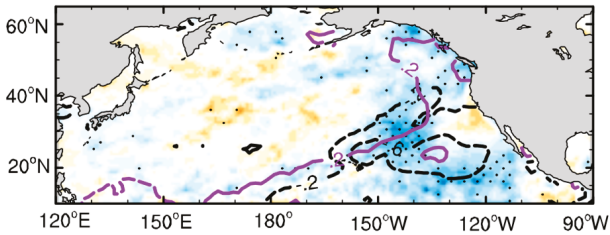

(d)DJF

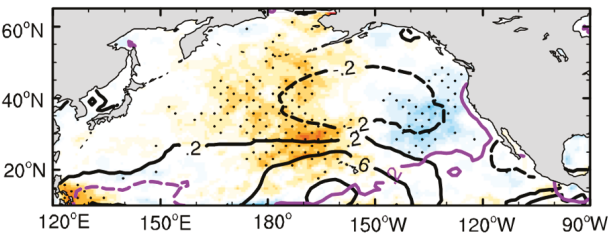

Figure 7. Coefficients of interannual LCF (shading; units: \%), SST (purple contour; units: K), and EIS (black contour; units: K) onto the synchronization Niño-3.4 index for (a) spring, (b) summer, (c) autumn, and (d) winter. Stippling indicates the $90 \%$ confidence level using the $t$ test. Contours indicate statistically significant positive (solid) and negative (dashed) differences.

The LCF over the western North Pacific does not have a clear relationship with the El Niño. This begs the question: Is there any possible link with other climate modes? From Table 2, we can see that the LCF over the western North Pacific is positively related to cold advection and SHF. Thus, in Figure 8, we show the maps of LCF, advT, and SHF anomalies regressed onto the normalized subpolar frontal zone (SPFZ) index, similar to Figure 7. The interannual LCF anomalies are positively correlated with the intensity of the SPFZ over the western North Pacific $\left(140^{\circ}-170^{\circ} \mathrm{W}, 40^{\circ}-60^{\circ} \mathrm{N}\right)$, especially in winter and spring (Figure 8a,d). At the same time, both cold advection and SHF present positive correlations with the SPFZ (Figure 8a,d). In spring and winter, the enhancement of the SPFZ over the western North Pacific can strengthen the cold advection through northerly wind, rendering SAT lower than the SST underneath, further resulting in large upward SHF [52]. The wintertime enhancement of SHF destabilizes the surface layer and facilitates shallow convection in the boundary layer, thus increasing the convective LCF. This implies that the SPFZ-related cold advection has a positive effect on the enhanced LCF by interacting with the SHF over the western North Pacific. 
(a)MAM

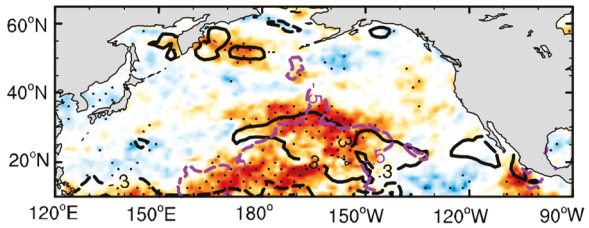

(c)SON

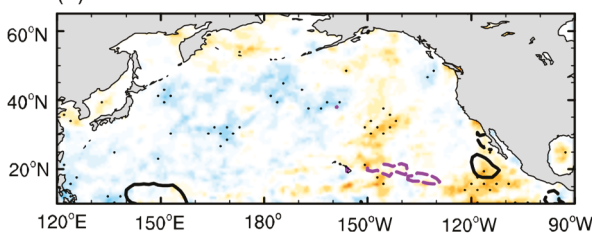

(b) JJA

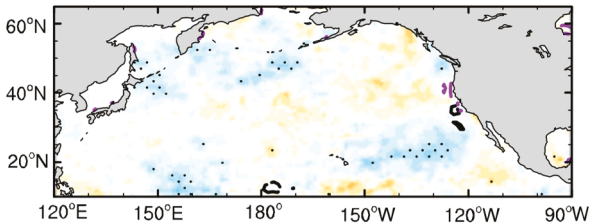

(d)DJF

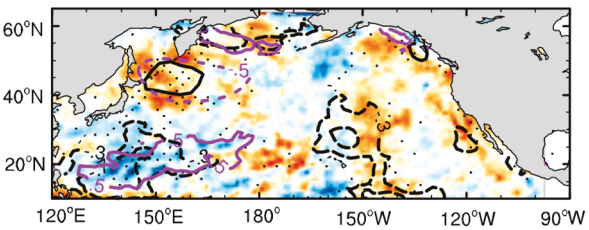

$\begin{array}{lllllllllll}-1 & -0.8 & -0.6 & -0.4 & -0.2 & 0 & 0.2 & 0.4 & 0.6 & 0.8 & 1\end{array}$

Figure 8. Regression coefficients of interannual LCF (shading; units: \%), advT (purple contour; units: $\mathrm{K} /$ day), and SHF (black contour; units: W/m2) onto the SPFZ index for (a) spring, (b) summer, (c) autumn, and (d) winter. Stippling indicates the $90 \%$ confidence level using the $t$ test. Contours indicate statistically significant positive (solid) and negative (dashed) differences at the $90 \%$ confidence level based on the $t$ test.

Overall, the interannual variation of LCF is different over the eastern and western North Pacific regions, due to different controlling factors and large-scale atmospheric processes. The increased LCF over the eastern North Pacific is associated with increased EIS and decreased SST, especially in summer. Our regression analysis signifies the El Niño contribution. Over the western North Pacific, the springtime and wintertime enhanced LCF has a positive correlation with enhanced SHF and cold advection, which can be partly explained by SPFZ intensity.

\section{Discussion and Concluding}

In this study, we investigate the seasonal and interannual variability of LCF and associated controlling factors over the eastern and western North Pacific. On the seasonal time scale, LCF shows obvious regional contrast. Over the eastern North Pacific, the EIS dominates the enhancement of LCF in summer, together with the 700-hPa RH. Over the western North Pacific, the enhancement of LCF in winter is mostly due to enhanced SHF and surface cold advection.

In terms of interannual variation, the increased LCF over the eastern North Pacific is associated with increased EIS and decreased SSTs, especially in summer. Our regression analysis indicates that El Niño contributes most. Over the western North Pacific, the springtime and wintertime enhanced LCF has a positive correlation with enhanced SHF and cold advection, which can be partly explained by SPFZ intensity.

This paper only discusses the factors that influence LCF variability in previous work. However, other factors, such as ocean or atmospheric circulation, may also play an important role in LCF changes, which need to be further studied in the future. Cloud microphysical processes and aerosol properties are also important for the formation of low-level clouds [53]. For example, oceanic aerosol productivity plays an important role in determining cloud condensation nuclei. Zhao et al. have found that if liquid water content (LWC) is high and aerosol amount is not too large, both cloud droplet number concentration (N) and effective radius (re) increase with increasing aerosols; if LWC is low or if LWC is high but aerosol amount is too large, cloud $\mathrm{N}$ increases but re decreases with increasing aerosols [54]. These aspects will be explored in our future study. 
Author Contributions: Conceptualization, H.X. Formal analysis, Q.W. Methodology, Q.W., H.X. and L.Z. Software, Q.W. Supervision, H.X. Validation, Q.W. and L.Z. Writing-original draft, Q.W. and L.Z. Writing-review and editing, Q.W., H.X., L.Z. and J.D.

Funding: This work was jointly supported by the Natural Science Foundation of China (41575077, 41490643, and 41705054), and the Priority Academic Program Development of Jiangsu Higher Education Institutions (PAPD). Deng was supported by the Natural Science Foundation of Jiangsu Province (BK20170942), the General Program of Natural Science Research of Jiangsu Province University (17KJB170012), and the China Scholarship Council (CSC).

Conflicts of Interest: The authors declare no conflict of interest.

\section{References}

1. Wood, R. Stratocumulus Clouds. Mon. Weather Rev. 2012, 140, 2373-2423. [CrossRef]

2. Garrett, T.J.; Zhao, C. Increased Arctic cloud longwave emissivity associated with pollution from mid-latitudes. Nature 2006, 440, 787. [CrossRef] [PubMed]

3. Zhao, C.; Garrett, T.J. Effects of Arctic haze on surface cloud radiative forcing. Geophys. Res. Lett. 2015, 42, 557-564. [CrossRef]

4. Randall, D.A.; Coakley, J.A., Jr.; Fairall, C.W.; Kropfli, R.A.; Lenschow, D.H. Outlook for research on subtropical marine stratiform clouds. Bull. Am. Meteorol. Soc. 1984, 65, 1290-1301. [CrossRef]

5. Oreopoulos, L.; Davies, R. Statistical dependence of albedo and cloud cover on sea surface temperature for two tropical marine stratocumulus regions. J. Clim. 1993, 6, 2434-2447. [CrossRef]

6. Ma, Z.; Liu, Q.; Zhao, C.; Shen, X.; Wang, Y.; Jiang, J.H.; Li, Z.; Yung, Y. Application and Evaluation of an Explicit Prognostic Cloud-Cover Scheme in GRAPES Global Forecast System. J. Adv. Model. Earth Syst. 2018, 10, 652-667. [CrossRef]

7. Fan, T.; Zhao, C.; Dong, X.; Liu, X.; Yang, X.; Zhang, F.; Shi, C.; Wang, Y.; Wu, F. Quantify contribution of aerosol errors to cloud fraction biases in CMIP5 Atmospheric Model Intercomparison Project simulations. Int. J. Climatol. 2018, 38, 3140-3156. [CrossRef]

8. Bony, S.; Dufresne, J.L. Marine boundary layer clouds at the heart of tropical cloud feedback uncertainties in climate models. Geophys. Res. Lett. 2005, 32, 023851. [CrossRef]

9. Zhai, C.; Jiang, J.H.; Su, H. Long-term cloud change imprinted in seasonal cloud variation: More evidence of high climate sensitivity. Geophys. Res. Lett. 2015, 42, 8729-8737. [CrossRef]

10. Trenberth, K.E.; Fasullo, J.T. Simulation of present-day and twenty-first-century energy budgets of the southern oceans. J. Clim. 2010, 23, 440-454. [CrossRef]

11. Grise, K.M.; Polvani, L.M.; Fasullo, J.T. Re-examining the relationship between climate sensitivity and the southern hemisphere radiation budget in cmip models. J. Clim. 2015, 28. [CrossRef]

12. Koshiro, T.; Yukimoto, S.; Shiotani, M. Interannual variability in low stratiform cloud amount over the summertime North Pacific in terms of cloud types. J. Clim. 2017, 30, 6107-6121. [CrossRef]

13. Wood, R.; Bretherton, C.S. On the relationship between stratiform low cloud cover and lower-tropospheric stability. J. Clim. 2006, 19, 6425-6432. [CrossRef]

14. Klein, S.A.; Hartmann, D.L. The seasonal cycle of low stratiform clouds. J. Clim. 1993, 6, 1587-1606. [CrossRef]

15. Myers, T.A.; Norris, J.R. Observational evidence that enhanced subsidence reduces subtropical marine boundary layer cloudiness. J. Clim. 2013, 26, 7507-7524. [CrossRef]

16. Miyasaka, T.; Nakamura, H. Structure and formation mechanisms of the northern hemisphere summertime subtropical highs. J. Clim. 2005, 18, 5046-5065. [CrossRef]

17. Deser, C.; Wahl, S.; Bates, J.J. The influence of sea surface temperature gradients on stratiform cloudiness along the equatorial front in the Pacific Ocean. J. Clim. 1993, 6, 1172-1180. [CrossRef]

18. Dong, S.; Gille, S.T.; Sprintall, J. An assessment of the Southern Ocean mixed layer heat budget. J. Clim. 2007, 20, 4425-4442. [CrossRef]

19. Bretherton, C.S.; Blossey, P.N.; Jones, C.R. Mechanisms of marine low cloud sensitivity to idealized climate perturbations: A single-les exploration extending the cgils cases. J. Adv. Model. Earth Syst. 2013, 5, 316-337. [CrossRef]

20. Garrett, T.J.; Zhao, C.; Dong, X.; Mace, G.G.; Hobbs, P.V. Effects of varying aerosol regimes on low-level Arctic stratus. Geophys. Res. Lett. 2004, 31. [CrossRef] 
21. Zhao, C.; Chen, Y.; Li, J.; Letu, H.; Su, Y.; Chen, T.; Wu, X. Fifteen-year statistical analysis of cloud characteristics over China using Terra and Aqua Moderate Resolution Imaging Spectroradiometer observations. Int. J. Climatol. 2018. [CrossRef]

22. Seethala, C.; Norris, J.R.; Myers, T.A. How has subtropical stratocumulus and associated meteorology changed since the 1980s? J. Clim. 2015, 28. [CrossRef]

23. Tselioudis, G.; Rossow, W.B.; Rind, D. Global patterns of cloud optical thickness variation with temperature. J. Clim. 1992, 5, 1484-1495. [CrossRef]

24. Van der Dussen, J.J.; De Roode, S.R.; Dal Gesso, S.; Siebesma, A.P. An les model study of the influence of the free tropospheric thermodynamic conditions on the stratocumulus response to a climate perturbation. J. Adv. Model. Earth Syst. 2015, 7, 670-691. [CrossRef]

25. Norris, J.R.; Leovy, C.B. Interannual variability in stratiform cloudiness and sea surface temperature. J. Clim. 1994, 7, 1915-1925. [CrossRef]

26. Norris, J.R. On trends and possible artifacts in global ocean cloud cover between 1952 and 1995. J. Clim. 1999, 12, 1864-1870. [CrossRef]

27. Norris, J.R. Interannual and interdecadal variability in the storm track, cloudiness, and sea surface temperature over the summertime North Pacific. J. Clim. 2000, 13, 422-430. [CrossRef]

28. Remer, L.A.; Kaufman, Y.J.; Tanré, D.; Mattoo, S.; Chu, D.A.; Martins, J.V. The modis aerosol algorithm, products, and validation. J. Atmos. Sci. 2005, 62, 947-973. [CrossRef]

29. Wang, Y.; Zhao, C. Can MODIS cloud fraction fully represent the diurnal and seasonal variations at DOE ARM SGP and Manus sites? J. Geophys. Res. Atmos. 2017, 122, 329-343. [CrossRef]

30. Ackerman, S.A.; Strabala, K.I.; Menzel, W.P.; Frey, R.A.; Moeller, C.C.; Gumley, L.E. Discriminating clear sky from clouds with modis. J. Geophys. Res. 1998, 103, 32141. [CrossRef]

31. Miyamoto, A.; Nakamura, H.; Miyasaka, T. Influence of the subtropical high and storm track on low-cloud fraction and its seasonality over the south Indian Ocean. J. Clim. 2018, 31, 4017-4039. [CrossRef]

32. Weare, B.C. Near-global observations of low clouds. J. Clim. 2000, 13, 1255-1268. [CrossRef]

33. McCoy, D.T.; Burrows, S.M.; Wood, R.; Grosvenor, D.P.; Elliott, S.M.; Ma, P.L.; Hartmann, D.L. Natural aerosols explain seasonal and spatial patterns of Southern Ocean cloud albedo. Sci. Adv. 2015, 1, e1500157. [CrossRef] [PubMed]

34. Li, J.; Huang, J.; Stamnes, K.; Wang, T.; Lv, Q.; Jin, H. A global survey of cloud overlap based on calipso and cloudsat measurements. Atmos. Chem. Phys. 2015, 15, 519-536. [CrossRef]

35. Dee, D.P.; Uppala, S.M.; Simmons, A.J.; Berrisford, P.; Poli, P.; Kobayashi, S.; Bechtold, P. The ERA-Interim reanalysis: Configuration and performance of the data assimilation system. Q. J. R. Meteorol. Soc. 2011, 137, 553-597. [CrossRef]

36. Wei, W.; Li, W.; Deng, Y.; Yang, S.; Liu, W.T. Dynamical and thermodynamical coupling between the north atlantic subtropical high and the marine boundary layer clouds in boreal summer. Clim. Dyn. 2017, 19, 1-13. [CrossRef]

37. Yu, L.; Weller, R.A. Objectively analyzed air-sea heat fluxes for the global ice-free oceans (1981-2005). Bull. Am. Meteorol. Soc. 2007, 88, 527-539. [CrossRef]

38. Bunge, L.; Clarke, A.J. A verified estimation of the El Niño index Niño-3.4 since 1877. J. Clim. 2009, 22, 3979-3992. [CrossRef]

39. Klein, S.A.; Hartmann, D.L.; Norris, J.R. On the relationships among low-cloud structure, sea surface temperature, and atmospheric circulation in the summertime northeast pacific. J. Clim. 1995, 8, 2063-2078. [CrossRef]

40. Norris, J.R.; Iacobellis, S.F. North pacific cloud feedbacks inferred from synoptic-scale dynamic and thermodynamic relationships. J. Clim. 2005, 18, 4862-4878. [CrossRef]

41. Mansbach, D.K.; Norris, J.R. Low-level cloud variability over the equatorial cold tongue in observations and models. J. Clim. 2007, 20, 1555-1570. [CrossRef]

42. Yao, Y.; Zhong, Z.; Yang, X.Q. Impacts of the subarctic frontal zone on the North Pacific storm track in the cold season: An observational study. Int. J. Climatol. 2018, 38, 2554-2564. [CrossRef]

43. Qu, X.; Hall, A.; Klein, S.A.; Deangelis, A.M. Positive tropical marine low-cloud cover feedback inferred from cloud-controlling factors. Geophys. Res. Lett. 2015, 42, 7767-7775. [CrossRef]

44. Bony, S.; Stevens, B.; Frierson, D.M.; Jakob, C.; Kageyama, M.; Pincus, R.; Shepherd, G. Clouds, circulation and climate sensitivity. Nat. Geosci. 2015, 8, 261-268. [CrossRef] 
45. Koshiro, T.; Shiotani, M. Relationship between low stratiform cloud amount and estimated inversion strength in the lower troposphere over the global ocean in terms of clouds. J. Meteorol. Soc. Jpn. Ser. II 2014, 92, 107-120. [CrossRef]

46. Eastman, R.; Warren, S.G.; Hahn, C.J. Variations in cloud cover and cloud types over the ocean from surface observations, 1954-2008. J. Clim. 2011, 24, 5914-5934. [CrossRef]

47. Xu, H.; Xie, S.P.; Wang, Y. Subseasonal variability of the southeast Pacific stratus cloud deck. J. Clim. 2005, 18, 131-142. [CrossRef]

48. Van der Dussen, J.J.; De Roode, S.R.; Ackerman, A.S.; Blossey, P.N.; Bretherton, C.S.; Kurowski, M.J.; Lock, A.P. The gass/euclipse model intercomparison of the stratocumulus transition as observed during astex: Les results. J. Adv. Model. Earth Syst. 2013, 5, 483-499. [CrossRef]

49. Lau, N.C.; Nath, M.J. Impact of ENSO on SST variability in the north pacific and north atlantic: Seasonal dependence and role of extratropical sea-air coupling. J. Clim. 2001, 14, 2846-2866. [CrossRef]

50. Zhu, P.; Hack, J.J.; Kiehl, J.T.; Bretherton, C.S. Climate sensitivity of tropical and subtropical marine low cloud amount to ENSO and global warming due to doubled $\mathrm{CO}_{2}$. J. Geophys. Res. Atmos. 2007, 112. [CrossRef]

51. Park, S.; Leovy, C.B. Marine low-cloud anomalies associated with ENSO. J. Clim. 2004, 17, 3448-3469. [CrossRef]

52. Lana, A.; Bell, T.G.; Simó, R.; Vallina, S.M.; Ballabrera-Poy, J.; Kettle, A.J.; Johnson, J.E. An updated climatology of surface dimethlysulfide concentrations and emission fluxes in the global ocean. Glob. Biogeochem. Cycles 2011, 25. [CrossRef]

53. Zhao, C.; Qiu, Y.; Dong, X.; Wang, Z.; Peng, Y.; Li, B.; Wu, Z.; Wang, Y. Negative Aerosol-Cloud re Relationship from Aircraft Observations Over Hebei, China. Earth Space Sci. 2018, 5, 19-29. [CrossRef]

54. Yang, Y.; Zhao, C.; Dong, X.; Fan, G.; Zhou, Y.; Wang, Y.; Zhao, L.; Lv, F.; Yan, F. Toward understanding the process-level impacts of aerosols on microphysical properties of shallow cumulus cloud using aircraft observations. Atmos. Res. 2019. [CrossRef]

(C) 2019 by the authors. Licensee MDPI, Basel, Switzerland. This article is an open access article distributed under the terms and conditions of the Creative Commons Attribution (CC BY) license (http:/ / creativecommons.org/licenses/by/4.0/). 



\title{
Article \\ Diurnal Variations in Surface Wind over the Tibetan Plateau
}

\author{
Yufei Zhao ${ }^{1, *}$, Jianping $\mathrm{Li}^{2,3}$, Qiang Zhang ${ }^{1}$, Xiaowei Jiang ${ }^{1}$ and Aixia Feng ${ }^{1}$ \\ 1 National Meteorological Information Centre, China Meteorological Administration, Beijing 100081, China; \\ zhangq@cma.gov.cn (Q.Z.); jiangxw@cma.gov.cn (X.J.); fengax@cma.gov.cn (A.F.) \\ 2 College of Global Change and Earth System Science, Beijing Normal University, Beijing 100875, China; \\ ljp@bnu.edu.cn \\ 3 Laboratory for Regional Oceanography and Numerical Modeling, Qingdao National Laboratory for Marine \\ Science and Technology, Qingdao 266237, China \\ * Correspondence: zhaoyf@cma.gov.cn
}

Received: 26 January 2019; Accepted: 26 February 2019; Published: 2 March 2019

\begin{abstract}
This study uses hourly surface wind direction and wind speed observations from 53 meteorological stations on the Tibetan Plateau (TP) $\left(70-105^{\circ}\right.$ E, 25-45 N) between 1995 and 2017 to investigate diurnal variations in the surface wind. The results show large diurnal variations in surface wind on the TP. The minimum wind speed occurs in the morning and the maximum in the afternoon. In all four seasons, the prevailing meridional wind is a southerly, and this is typically evident for more than two-thirds of each day. However, in the mornings during December-February and September-November, this southerly wind is replaced by a northerly, but remains southerly in the afternoon. The TP shows remarkable regional characteristics with respect to diurnal variations in wind speed. In the eastern region, the minimum and maximum daily wind speeds occur about $1 \mathrm{~h}$ later than in the west. Among the 53 meteorological stations, 79\% observed that it took less time for the minimum speed to rise to the maximum speed than for the maximum to drop to the minimum. The blocking effect of the high surrounding terrain causes the diurnal variations seen in the surface winds at the three stations in the Qaidam Basin to differ significantly from those observed at the other stations elsewhere on the plateau. These Qaidam Basin stations recorded their maximum wind speeds around noon, with the minimum at dusk, which is around 1900 LST. The EOF1 (EOF = empirical orthogonal function) of the hourly wind speed on the TP indicates the key daily circulation feature of the region; i.e., the wind speed is high in the afternoon and low in the morning. The EOF2 reflects the regional differences in the diurnal variations of wind speed on the TP; i.e., the eastern region reaches the daily maximum and minimum wind speeds slightly later than the western region.
\end{abstract}

Keywords: Tibetan Plateau; surface wind; diurnal variation

\section{Introduction}

Research into diurnal variations in meteorological parameters is important in improving our understanding of weather and climate systems. There has been much research into diurnal variations in global or local meteorological parameters (e.g., precipitation and surface winds). However, the limited amount of available observational data meant that early studies of these diurnal variations focused mainly on tropical areas. Infrared satellite data have been used to investigate the diurnal variations in convective activity using cloud cover, cloud crest brightness temperature, and water vapor (e.g., [1-4]). Studies in tropical regions have shown that the daily cycle of convective activity is strongly dependent on geographical location, and that topography plays a crucial role in the daily cycle of weather patterns $[1,5]$. 
The Tibetan Plateau (TP), also known as the third pole, is the world's largest landform and has an average elevation of about $4500 \mathrm{~m}$. The TP has a significant effect on its surroundings through thermal and dynamic processes [6,7]. Wind is an important indicator of atmospheric circulation, and changes in wind speed are an indication of circulation changes caused by natural or anthropogenic processes [8]. The wind is known to be distinctively turbulent and non-stationary. As a consequence, the wind velocity varies rather randomly on many different time scales [9]. Previous studies have examined the surface wind regime on the TP. For example, analysis of daily wind speed data from ground observation stations on the TP has shown seasonal differences in the surface wind, with the wind speed dropping most significantly during March-May [10]. Other research has found that changing wind speed is the most important meteorological control on trends in potential evapotranspiration on the TP [11].

There are limited observational data to study diurnal variations in meteorological elements over the TP. This has led to some studies having to rely on data with a low temporal resolution, or data obtained from indirect observations, to analyze such variations. For example, data with a temporal resolution of $3 \mathrm{~h}$ have been used to analyze diurnal variations in precipitation, thunderstorms [12], and surface winds [13]. Other studies have used satellite and radar data to explore the changing weather and climate on the TP (e.g., [14-17]).

Following the rapid deployment of automatic weather stations across China in recent years, hourly observational data are now available. However, these automatic weather stations are typically about 10 years old, so their records are short. Before the establishment of automatic weather stations, various self-recording instruments were widely used for hourly and even minute-by-minute observations, such as self-recording rain gauges and self-registering anemometers, but most of these datasets were recorded on paper, which is more difficult to collate and analyze than digital data, thereby restricting the application of these valuable data. In 2017, the China Meteorological Administration (CMA), after nearly 10 years of data processing work that included integrating the surface wind data observed by automatic weather stations, established the first hourly wind series from 2400 Chinese stations covering the period since 1951. The CMA also developed suitable quality control procedures, based on the characteristics of hourly wind data, to check the accuracy and completeness of the hour-by-hour wind series, and so established the Hourly Surface Wind dataset (HSW dataset) for mainland China [18].

The reliability of various reanalysis data is relatively low (e.g., $[19,20])$. Observational data recorded at meteorological stations are fundamental to the data processing and analysis that underpins climate research. The direction and speed of surface wind are major elements of China's meteorological observational dataset. However, few studies have used the long sequence of hourly wind data observed by the stations to analyze diurnal variations in surface winds on the TP. Accordingly, this study uses hourly wind direction and speed data from the TP in the HSW dataset to analyze diurnal variations in surface winds on the TP.

\section{Data and Methodology}

We used the HSW dataset from mainland China, which was developed, collated, and quality controlled by the National Meteorological Information Center (NMIC) of the CMA (Zhao et al., 2017 [18]). In this study, the TP region is defined as that bounded by $70-105^{\circ} \mathrm{E}$ and $25-45^{\circ} \mathrm{N}$. Our study area in west China encompasses Qinghai Province, Tibet, and parts of neighboring Xinjiang, Gansu, Yunnan, and Sichuan provinces. To avoid biases introduced by missing data, we limited our analysis to the 53 stations on the TP that provide a complete hourly wind speed series from 1995 to 2017 and are located at altitudes above $2000 \mathrm{~m}$ (figure omitted).

In China, the standard time (Beijing time) is UTC +8 , and this is the time used for meteorological observations. However, because of its vast size, China is divided into five time zones, and the TP alone spans three time zones (UTC +5 to UTC +7 ). Therefore, using LST to analyze diurnal variations on the TP avoids the difference in diurnal variations in wind speed caused by the gap between LST and Beijing time. In the diurnal cycle of surface wind speed at each station, the hour when the wind speed reached 
its maximum is defined as the 'max-hour', and the hour when the wind speed reached its minimum is defined as the 'min-hour'. The difference between the maximum and minimum is the daily range of wind speed. The 'max-dir' is the wind direction in the hour when the wind speed reached its daily maximum, and the 'min-dir' is the wind direction in the hour when the wind speed reached its daily minimum. For our analysis, we divided the year into four equal periods: December-February (DJF), March-May (MAM), June-August (JJA), and September-November (SON).

\section{Diurnal Variations in Wind Speed}

Figure 1 shows the seasonal and annual mean wind speed, variances of wind speed, zonal wind speed, and meridional wind speed on the TP. The maximum wind speed occurs during MAM, with the average wind speeds at all hours being higher than those of the other three seasons. MAM also sees the largest range in wind speed of up to $2.7 \mathrm{~m} \cdot \mathrm{s}^{-1}$, whereas JJA sees the smallest range of $1.8 \mathrm{~m} \cdot \mathrm{s}^{-1}$. The minimum wind speeds on the TP in DJF, MAM, JJA, and SON were recorded at 0800, 0600, 0600, and 0600 LST, respectively, and the maximum wind speeds at 1500, 1600, 1600, and 1500 LST, respectively. It is suggested that increased downward turbulent mixing of momentum during the day could be one of the main causes for the early afternoon maximum of surface wind speed [13]. In DJF, the wind speed takes the shortest time to rise from the daily minimum to the daily maximum, of up to $7 \mathrm{~h}$, meaning it takes $17 \mathrm{~h}$ to drop from the maximum to the minimum. In MAM and JJA, it takes $10 \mathrm{~h}$ for the wind speed to rise from the lowest in the morning to the highest in the afternoon, compared with $9 \mathrm{~h}$ in SON. Previous research has shown that in eastern China, wind speed drops to its minimum at 0500 LST and rises to its maximum at 1500 LST each day [21], with a variation of $1.2 \mathrm{~m} \cdot \mathrm{s}^{-1}$. On the TP, however, the wind speed reaches its minimum at 0600 LST and maximum at 1500 LST, with an annual average diurnal variation of $2.2 \mathrm{~m} \cdot \mathrm{s}^{-1}$. Therefore, the minimum wind speed in the daily cycle of wind speed on the TP arrives $1 \mathrm{~h}$, on average, later than in the eastern part of China, whereas the maximum wind speed arrives at the same time. The amplitude of the variation in the former is nearly twice that in the latter.

The change in wind speed is large when the wind speed is high (Figure 1a,b). In addition, although in the daily cycle of wind speed the hourly wind speeds during SON are lower than those during MAM, the changes in SON wind speed are larger than those in MAM between 1200 and 1500 LST. The maximum hourly wind speed variation during MAM and SON arrives $1 \mathrm{~h}$ earlier than the maximum hourly wind speeds.

In the zonal wind diagram (Figure 1c), the prevailing wind alternates between an easterly and a westerly in JJA and SON. In most cases, a westerly wind prevails in JJA, and the westerly component reaches a maximum at 2000 LST of only up to $0.52 \mathrm{~m} \cdot \mathrm{s}^{-1}$ which is much smaller than the maxima in other seasons. The zonal wind speed is compensated in averaging on multiple station data, not weakened at each station (figure omitted). The effect of large terrain on airflow movement is mainly manifested in blocking and diverting. On the one hand, these effects of mountain ranges on airflow will lead to asymmetric distribution of surface pressure on windward and leeward slopes, which usually results in a gradient of pressure from the windward slope to the leeward slope. On the other hand, the southwest monsoon from the Indian Ocean can affect southeastern Tibet and southwestern Sichuan province in JJA. Therefore, the zonal wind at some of the 53 stations is westerly in JJA (Figure 1), and the weaker westerly wind will appear in most hours of a day by being compensated in averaging on multiple stations which are not affected by the southwest wind. An east wind prevails during SON, with the zonal wind speeds all above $0.5 \mathrm{~m} \cdot \mathrm{s}^{-1}$ between 1200 and $1700 \mathrm{LST}$, reaching a maximum at 1400 LST of up to $1.1 \mathrm{~m} \cdot \mathrm{s}^{-1}$. During DJF and MAM, the average zonal wind for all hours on the TP is an easterly. During DJF, the zonal wind speeds between 1200 and 1700 LST exceed $1.0 \mathrm{~m} \cdot \mathrm{s}^{-1}$, reaching a maximum at $1500 \mathrm{LST}$ of up to $2.1 \mathrm{~m} \cdot \mathrm{s}^{-1}$. During MAM, the zonal wind speeds between 1100 and $1700 \mathrm{LST}$ exceed $1.0 \mathrm{~m} \cdot \mathrm{s}^{-1}$, reaching a maximum at $1400 \mathrm{LST}$ of up to $1.6 \mathrm{~m} \cdot \mathrm{s}^{-1}$.

The diurnal variations in the average meridional wind speed during each season and the annual mean can be divided into two groups (Figure 1d): 2000-0800 and 0800-2000 LST. Overall, the prevailing 
meridional wind in each season is a southerly. To be specific, a southerly and northerly wind alternate during DJF and SON, with the southerly being replaced by a northerly at about 0800-0900 LST, returning to a southerly at 1500-1600 LST. Over the $24 \mathrm{~h}$ of each day, the north wind prevails for about $7 \mathrm{~h}$ in DJF and SON, while the south wind prevails for the remaining $17 \mathrm{~h}$. During MAM and JJA, the south wind is replaced by a weak northerly for only the $2-3 \mathrm{~h}$ before noon, and the southerly prevails for the remaining $21-22 \mathrm{~h}$ of each day.

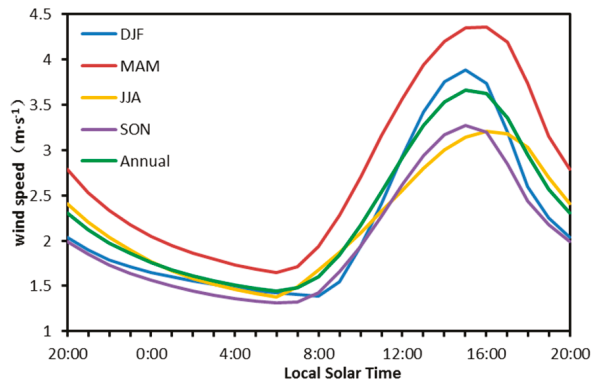

(a)

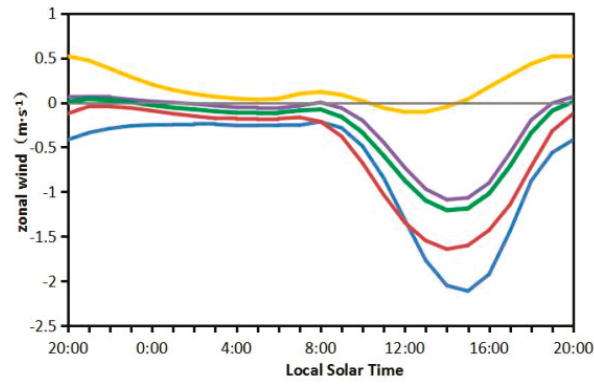

(c)

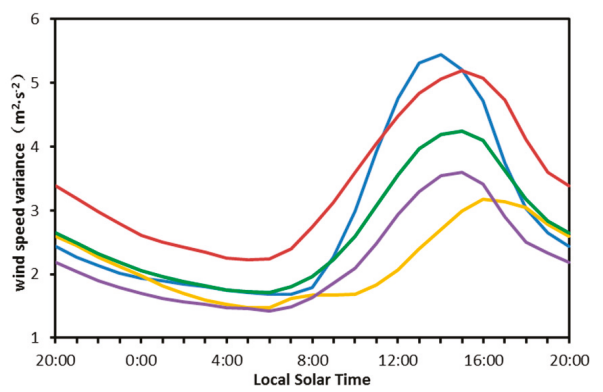

(b)

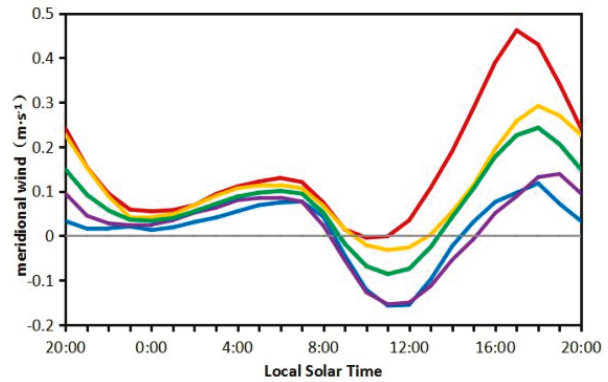

(d)

Figure 1. Diurnal variations in seasonal and annual mean wind speed (a), variances of wind speed (b), zonal wind speed (c), and meridional wind speed (d) averaged over the TP.

The max-hour and min-hour in the average diurnal wind speed cycle for each station on the TP are shown in Figure 2. The eastern region typically experiences the maximum wind speed about $1 \mathrm{~h}$ later than the western region. Among the 53 stations, 10, 15, and 15 stations reach their peak values at 1400,1500 , and $1600 \mathrm{LST}$, respectively, indicating that most stations $(57 \%)$ reach the maximum wind speed between 1500 and 1600 LST each day. In contrast to most other stations, Xiaozaohuo $\left(93.2^{\circ} \mathrm{E}\right.$, $36.9^{\circ} \mathrm{N}$ ) in Qinghai Province reaches its peak wind speed at $0900 \mathrm{LST}$, the earliest among the stations, Nuomuhong $\left(96.5^{\circ} \mathrm{E}, 36.4^{\circ} \mathrm{N}\right)$ in Qinghai Province reaches its peak at $1100 \mathrm{LST}$, while Huajialing $\left(105.0^{\circ} \mathrm{E}, 35.4^{\circ} \mathrm{N}\right)$ in Gansu Province and Jianzha $\left(102.0^{\circ} \mathrm{E}, 35.9^{\circ} \mathrm{N}\right)$ in Qinghai Province reach their peaks at 2100 and $1900 \mathrm{LST}$, respectively.

Similarly, according to Figure $2 b$, the eastern region attains a daily minimum wind speed about $1 \mathrm{~h}$ later than the western region. Thirty six stations (68\% of the total) reach the daily valley at 0600-0700 LST. The Xiaozaohuo, Delingha $\left(97.4^{\circ} \mathrm{E}, 37.4^{\circ} \mathrm{N}\right)$, and Nuomuhong stations (all in Qinghai Province) differ from the other stations, reaching their daily minimum wind speed at 1900 LST. Anduo $\left(91.1^{\circ} \mathrm{E}, 32.4^{\circ} \mathrm{N}\right)$ in Tibet and Tianjun $\left(99.0^{\circ} \mathrm{E}, 37.3^{\circ} \mathrm{N}\right)$ in Qinghai Province reach their daily minimum wind speed at 0100 LST. 


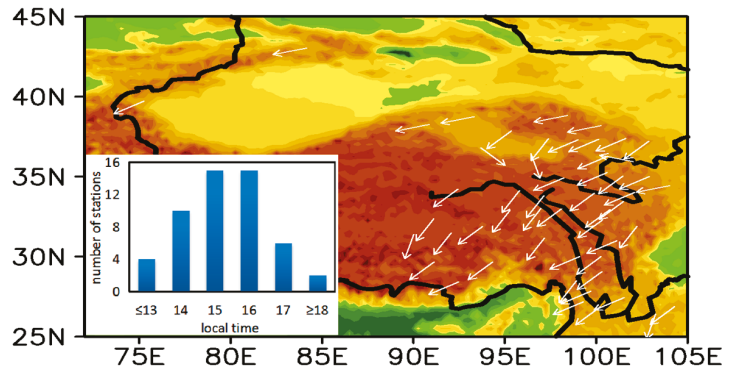

(a)

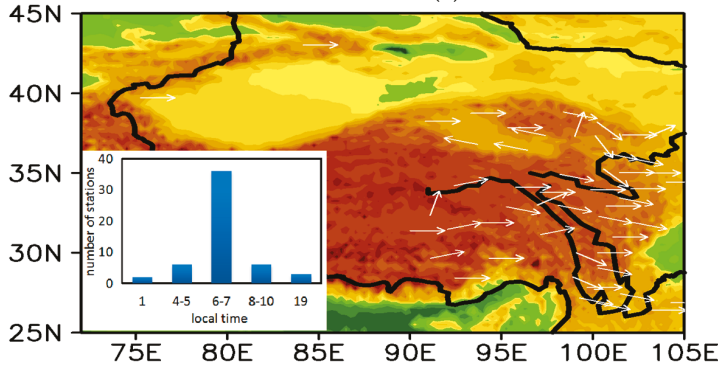

(b)

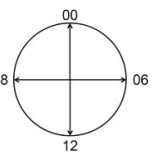

Figure 2. Timing of daily maximum (a) and minimum (b) surface wind speeds (vectors according to key at right, LST). Shading denotes elevation (m). The insets show histograms of the peak (a) and valley (b) hours.

The time interval between the min-hour and max-hour for the stations on the TP varies between $6 \mathrm{~h}$ ( 3 stations) and $19 \mathrm{~h}$ ( 2 stations). A total of 30 stations take $8-10 \mathrm{~h}$ to see the wind speed rise from the minimum to the maximum, and 42 stations need less than $12 \mathrm{~h}$ (Table 1 ). That is, $79 \%$ of the stations take a shorter time to see the wind speed rise from the minimum to the maximum than to see the wind speed drop from the maximum to the minimum. It takes $12 \mathrm{~h}$ for three stations to see their wind speed rise from the lowest to the highest, so $6 \%$ of the stations take an equal time to see the wind speed go from the lowest to the highest and from the highest to the lowest. A total of eight stations take more than $12 \mathrm{~h}$ to see their wind speed rise from the lowest to the highest, so $15 \%$ of the stations take longer to see their wind speed rise from the lowest to the highest than to see the wind speed drop from the highest to the lowest.

Table 1. Frequency distribution of the time (hours) required from the lowest to the highest daily wind speeds among the stations.

\begin{tabular}{ccccccccccccc}
\hline Number of hours & 6 & 7 & 8 & 9 & 10 & 11 & 12 & 13 & 14 & 15 & 16 & 19 \\
\hline Number of stations & 2 & 5 & 9 & 14 & 11 & 5 & 2 & 1 & 1 & 1 & 1 & 1 \\
\hline Percentage (\%) & 3.8 & 9.4 & 17.0 & 26.4 & 20.8 & 9.4 & 3.8 & 1.9 & 1.9 & 1.9 & 1.9 & 1.9 \\
\hline
\end{tabular}

\section{Diurnal Variations in Surface Wind Directions and Diurnal Range of Wind Speed}

Figure 3 and Table 2 show that the peak wind directions at each station differ, being northeasterly, southeasterly, northwesterly, and min-hour southwesterly for 24, 22, 4, and 3 stations, respectively. For $87 \%$ of the stations, the max-dir is easterly and for $13 \%$ it is westerly (Figure 3 ). For $55 \%$ of the stations, the min-dir is easterly. In the min-hour, 10, 19, 15, and 9 stations recorded northeasterly, southeasterly, northwesterly, and southwesterly winds, respectively. For $74 \%$ of the stations, the average wind 
direction is easterly, and $17,22,6$, and 8 stations have an average wind direction of northeast, southeast, northwest, and southwest, respectively.

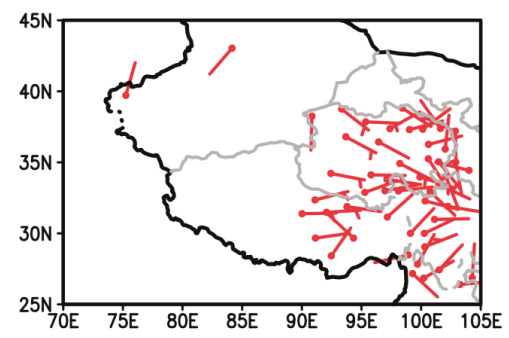

Figure 3. Surface wind direction and speed at the max-hour for each station.

Next, we consider the daily range of wind speed at the stations. Figure $4 a, b$ shows the daily range of annual average wind speed and wind speed variance for all stations. The variation in hourly wind speed is greater in the areas with a larger daily range. Tuotuohe $\left(92.6^{\circ} \mathrm{E}, 34.0^{\circ} \mathrm{N}\right)$ station in Qinghai Province has the largest daily range of wind speed, reaching $4.2 \mathrm{~m} \cdot \mathrm{s}^{-1}$, and Delingha station in Qinghai Province in the northerly part of the TP has the smallest daily range of wind speed, at about $0.7 \mathrm{~m} \cdot \mathrm{s}^{-1}$. The average daily range of wind speed across the TP is $2.4 \mathrm{~m} \cdot \mathrm{s}^{-1}$. The daily range of wind speed for all stations on the TP varies significantly from one season to another (Figure 4c-f). The high-value zone with a daily range over $3.6 \mathrm{~m} \cdot \mathrm{s}^{-1}$ moves northwestward from DJF to MAM. From MAM to JJA, the high-value zone continues to move northwestward. The spatial distribution of the wind speed daily range in $\mathrm{SON}$ is similar to that in DJF, but with a smaller daily range.
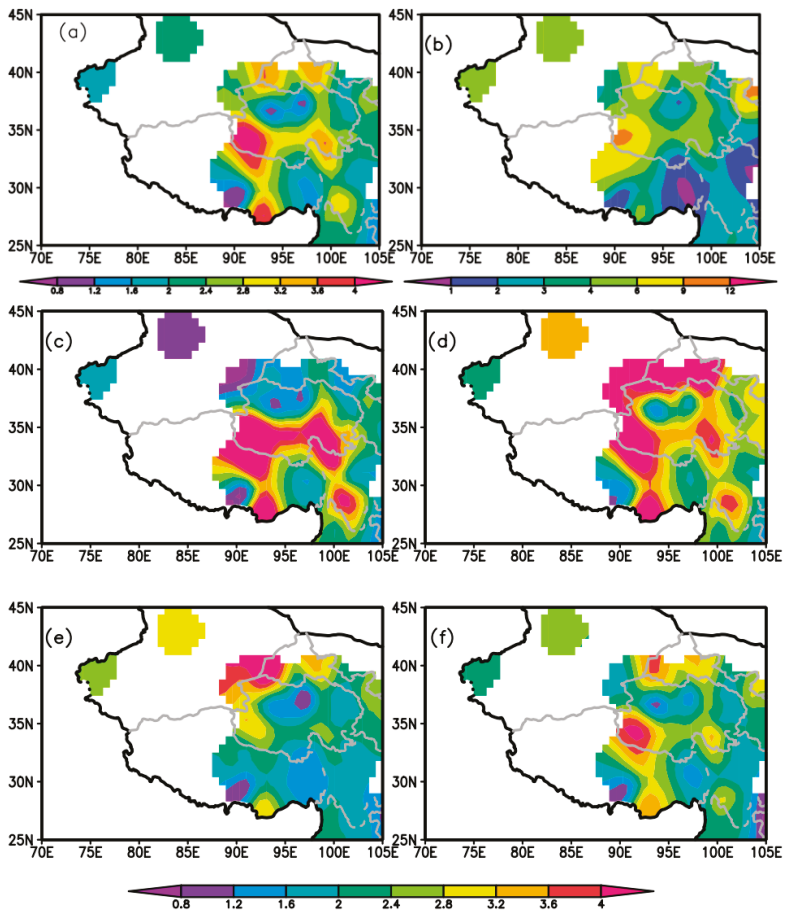

Figure 4. Daily range of annual average wind speed (a) $\left(\mathrm{m} \cdot \mathrm{s}^{-1}\right)$, hourly wind speed variance (b), and daily range of wind speed $\left(\mathrm{m} \cdot \mathrm{s}^{-1}\right)$ in December-February (DJF) (c), March-May (MAM) (d), June-August (JJA) (e), and September-November (SON) (f). 
Table 2. The numbers of stations which recorded northeasterly, southeasterly, northwesterly, and southwesterly winds in max-dir, min-dir, and average wind direction.

\begin{tabular}{cccc}
\hline \multirow{2}{*}{ Wind Direction } & \multicolumn{3}{c}{ The Numbers of Stations } \\
\cline { 2 - 4 } & Max-Dir & Min-Dir & Average Wind Direction \\
\hline Northeast & 24 & 10 & 17 \\
Southeast & 22 & 19 & 22 \\
Northwest & 4 & 15 & 6 \\
Southwest & 3 & 9 & 8 \\
\hline
\end{tabular}

\section{Diurnal Cycle of Surface Winds in Different Zones}

As mentioned above, the diurnal cycles of surface winds recorded in Xiaozaohuo, Delingha, and Nuomuhong are strikingly different from the other zones of the TP, and these three stations are all located in the Qaidam Basin. In this section, we analyze these diurnal variations by treating the three stations as a 'basin area' and the remaining 50 stations as a 'plateau area'. Figure 5 shows the annual average diurnal wind speed variations for the basin area and the plateau area. The diurnal wind speed variations of the two areas are obviously different. The wind speed in the basin area features a broad peak that reaches a maximum either side of noon and with a minimum at 1900 LST. In contrast, the plateau area sees a maximum wind speed at 1500 LST and a minimum wind speed at 0600 LST. At this time (0600 LST), the wind speed in the basin area is not at its minimum, but shows a small reduction compared with the wind speeds in the adjacent periods. Yu et al. (2009) [21] found a similar reversed day-night phase in the surface wind speed between mountain regions and plain regions of China. Based on a single year of wind data from television towers, Crawford and Hudson (1973) [22] concluded that the wind speed of the lower (higher) layers reached a minimum around midnight (noon) and a maximum in the afternoon (midnight). Their research target was diurnal wind speed variations on large plains and high mountain stations. In the present study, most of the stations from which data were collected on the TP are located in large high-altitude terrain, other than the stations at Xiaozaohuo, Delingha, and Nuomuhong, which are located in the Qaidam Basin at lower altitudes than the surrounding stations. Consequently, we suggest that the clear differences in the diurnal variations of the surface winds at these three stations are caused by the blocking effect of the surrounding mountainous terrain.
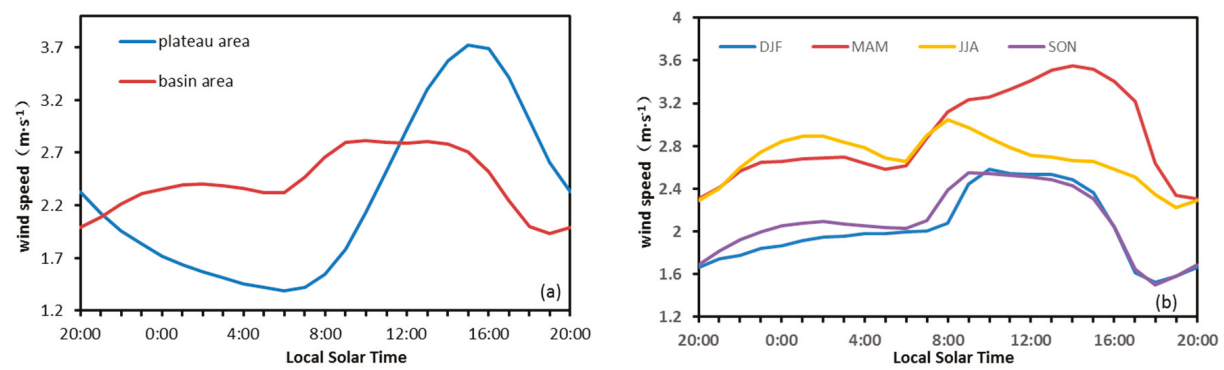

Figure 5. (a) Diurnal variations in annual mean wind speed averaged over the plateau area (blue line) and the basin area (red line). (b) Diurnal variations in seasonal mean wind speed averaged over the basin area.

In MAM, DJF, and SON the Qaidam Basin shows similar diurnal variations in wind speed to the annual mean (Figure 5b). The difference is that the wind speeds in MAM (SON and DJF) are higher (lower) than the annual mean wind speed. The diurnal variation in surface wind speed during JJA is different to that in the other three seasons. In JJA, the wind speed gradually decreases from 0800 to 1900 LST and reaches a daily minimum at 1900 LST. In the other three seasons, however, the diurnal variations in wind speed feature a gradual rise (in MAM) or continuous high speeds (in SON and DJF) from 0800 LST to about 1400 LST. In JJA afternoons on the TP the prevailing wind is a southwesterly. 
In the afternoons of the other seasons, however, the prevailing wind is a southeasterly (Figure 1c,d). As the TP is higher in the northwest and lower in the southeast, and the Qaidam Basin is aligned northwest-southeast, the blocking effect of the surrounding terrain on the Qaidam Basin is more pronounced in JJA, when a southwest wind prevails, than in the other seasons when a southeasterly prevails. In other words, because the dominant wind direction is aligned with the basin except in JJA, the blocking effect would not play a major role in DJF, MAM, and SON like JJA.

We applied empirical orthogonal function (EOF) analysis to the hourly wind speed data of the TP (51 stations, excluding two remote stations in Xinjiang Province). The hourly wind speed series from each station was standardized prior to the EOF decomposition. The first and second leading EOF (EOF1 and EOF2) passed the North test [23]. EOF1 and EOF2 account for $83 \%$ and $13 \%$ of the total variance, respectively. EOF1 shows mainly positive values, with weakly negatives in the Qaidam Basin (Figure 6a). The time coefficient curve of EOF1 (Figure 6c) is similar to the series in Figure 1a, with both featuring a single peak. The peak in diurnal wind speed occurs between 1400 and 1500 LST, and the wind speed at night tends to decrease slowly. EOF1 reflects mainly the diurnal variation of wind speed in most areas of the TP, and the diurnal variations that differ between the Qaidam Basin and the much larger plateau area. EOF2 (Figure $6 \mathrm{~b}$ ) varies between positive and negative values with an east-west dipole pattern, while the corresponding time coefficient features a single peak (Figure 6d). EOF2 is negative in the Qilian Mountains in Gansu Province, eastern Qinghai Province, western Sichuan Province, and southeast Tibet (the eastern region), and is positive in mid-west Qinghai Province, eastern Sichuan Province, and central Tibet (the western region). This suggests that EOF2 indicates that the eastern region reaches the peak and valley of diurnal wind speed slightly later than the western region, which is consistent with the conclusion drawn above. The branching effect of the TP on airflow makes the surface wind of the eastern edge of the TP different from that of the western part of the TP. The northerly airflow generated by the circulation of the plateau forms a "leeward wake zone" on the eastern edge of the plateau, and the anticyclone vortex is very strong, while westerly winds prevail in the western part of the plateau [24]. The difference of atmospheric circulation pattern will inevitably lead to the difference of surface wind diurnal variation between the eastern and western regions.

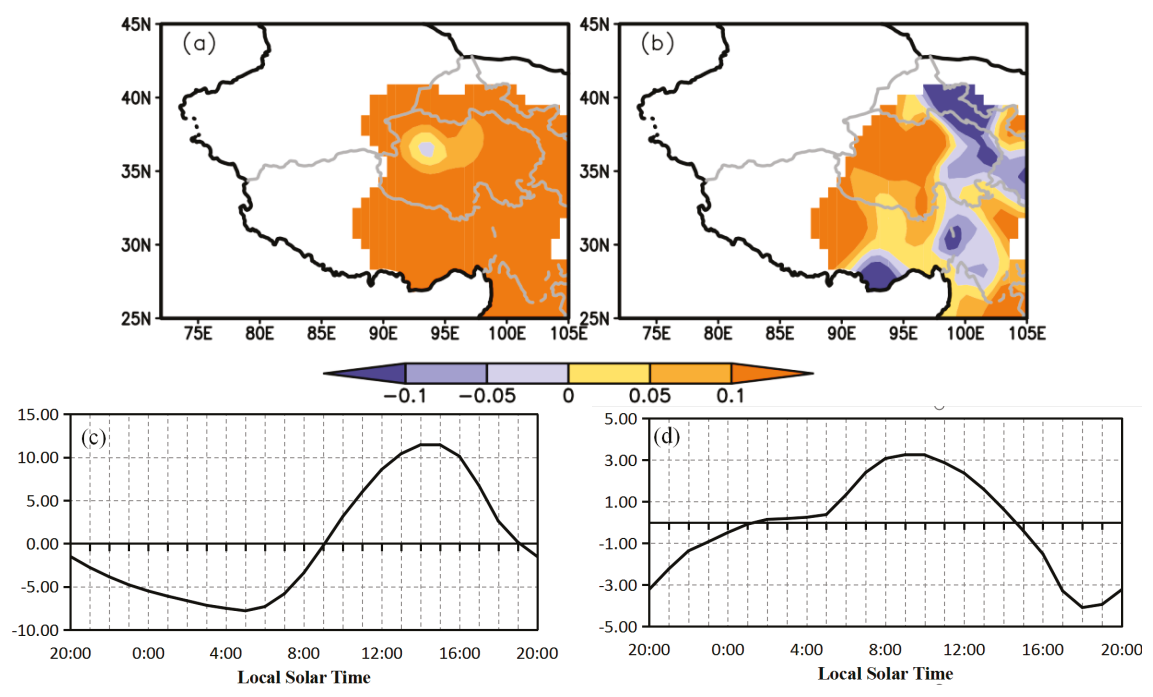

Figure 6. (a) The first leading empirical orthogonal function (EOF1) pattern of climatological hourly wind speeds on the Tibetan Plateau (TP). (b) As for (a), but for the second leading empirical orthogonal function (EOF2). (c) Time series corresponding to EOF1. (d) Time series corresponding to EOF2. 


\section{Summary and Discussion}

The diurnal cycle of surface wind speed on the TP was analyzed using hourly wind observation data from 53 meteorological stations with 23 years (1995-2017) of complete data. Our results reveal some novel spatial and temporal characteristics. The main conclusions are summarized as follows.

(1) The surface wind speed shows large diurnal variation. MAM has the highest wind speed and largest daily range of wind speed. On the TP, the minimum wind speed occurs in the early morning at 0600 LST and the maximum in the afternoon at 1500 LST. It is understandable that during daytime, as a response to surface solar heating, the downward vertical turbulent transport of momentum reaches its strongest in the afternoon. During night time, as a response to nocturnal cooling in the boundary layer, the eddy viscosity is reduced and less momentum is transported to the lower level. The surface wind slows down gradually due to the surface friction [21]. When the wind speed is high, the variation in wind speed is also large. On the TP the daily minimum wind speed arrives $1 \mathrm{~h}$ later than that recorded in eastern China by Yu et al. (2009) [21]. The two regions analyzed see the peak hourly wind speed in the same hour. The average daily range of wind speed on the TP is $2.4 \mathrm{~m} \cdot \mathrm{s}^{-1}$, nearly twice that in eastern China.

(2) The surface winds were decomposed into meridional and zonal winds, and their diurnal variation analyzed. The south wind dominated the meridional winds in each season, accounting for more than two-thirds of each day. In the mornings during DJF and SON, the south wind changes to a north wind, changing back to a south wind in the afternoon. In JJA and SON, east and west winds alternate as the prevailing wind direction. During DJF and MAM, the average wind direction on the TP is easterly throughout the day.

(3) The seasonal variation in the daily wind speed range of each station on the TP is well defined. The area of high diurnal range moved to the northwest with seasonal changes from DJF to MAM and from MAM to JJA. The hourly wind speed at $57 \%$ of the stations takes $8-10 \mathrm{~h}$ to develop from the lowest to the highest speed. At $79 \%$ of the stations the wind speed rises from the lowest to the highest in less time than it takes to change from the highest to the lowest.

(4) The diurnal variation of wind speed over the TP is noticeable [13]. At 0600-0700 LST, $68 \%$ of the stations experienced their lowest wind speed, and 57\% recorded their highest wind speeds at 1500 or 1600 LST. The lowest and highest daily wind speeds in the eastern part of the TP were recorded $1 \mathrm{~h}$ later than in the western part. The diurnal variation in surface winds in the Qaidam Basin differs significantly from that at the other plateau stations due to the blocking effect of the surrounding terrain. In addition to the hilly area, mountain-valley breeze can also occur on the edge of the plateau and the basin, and there is a significant diurnal variation in wind speed and wind direction. During the daytime, the wind often blows from the valley to the mountainside and the mountaintop. At nighttime, the wind often blows from the mountaintop and the mountainside to the valley. Based on decomposing the observed wind into the system wind and the mountain-valley breeze, researchers could carry out research on the diurnal variation of the surface wind and the mountain-valley breeze. This may contribute to analyzing the causes of diurnal variation of surface wind on the TP, however, more detailed mechanisms are to be further explored in future studies.

(5) The EOF of the hourly wind speeds reflects the high wind speeds in the afternoon and lower wind speeds in the morning over most of the TP (except for the Qaidam Basin). It also reflects that the wind speed in the eastern part of the TP reaches a diurnal maximum later than that in the western part. It may be reasonable that EOF2 may be related to the different atmospheric circulation systems [25], topographic characteristics, snow cover and vegetation cover in the eastern and western parts of the TP. 
Author Contributions: Conceptualization, Y.Z. and J.L.; Data curation, Y.Z. and Q.Z.; Formal analysis, Y.Z.; Funding acquisition, Y.Z.; Investigation, Q.Z.; Methodology, J.L.; Project administration, Q.Z. and X.J.; Resources, Y.Z.; Software, X.J. and A.F.; Supervision, J.L.; Writing—Original Draft, Y.Z. and X.J.; Writing-Review \& Editing, Y.Z. and J.L.

Funding: This research received no external funding.

Acknowledgments: This work was supported by the Chinese National Natural Science Foundation 'Development of Data Sharing Platform of the Tibetan Plateau's Multi-Source Land-Atmosphere System Information' under grant number 91637313 and the National Natural Science Foundation of China (NSFC) Project (41530424).

Conflicts of Interest: The authors declare no conflict of interest.

\section{References}

1. Yang, G.-Y.; Slingo, J. The diurnal cycle in the tropics. Mon. Weather Rev. 2001, 129, 784-801. [CrossRef]

2. Nesbitt, S.-W.; Zipser, E.-J. The diurnal cycle of rainfall and convective intensity according to three years of TRMM measurements. J. Clim. 2003, 16, 1456-1475. [CrossRef]

3. Liu, C.-H.; Moncrieff, M.-W. A numerical study of the diurnal cycle of tropical oceanic convection. J. Atmos. Sci. 1998, 55, 2329-2344. [CrossRef]

4. Bowman, K.-P.; Collier, J.-C.; North, G.-R.; Wu, Q.; Ha, E.; Hardin, J. Diurnal cycle of tropical precipitation in Tropical Rainfall Measuring Mission (TRMM) satellite and ocean buoy rain gauge data. J. Geophys. Res. 2005, 110, 1-14. [CrossRef]

5. Zuidema, P. Convective clouds over the Bay of Bengal. Mon. Weather Rev. 2003, 131, 780-798. [CrossRef]

6. Xiao, D.; Zhao, P.; Wang, Y.; Tian, Q.-H.; Zhou, X.-J. Millennial-scale phase relationship between North Atlantic deep-level temperature and Qinghai-Tibet Plateau temperature and its evolution since the Last Interglaciation. Chin. Sci. Bull. 2014, 59, 75-81. [CrossRef]

7. Nan, S.-L.; Zhao, P.; Chen, J.-M. Variability of summertime Tibetan tropospheric temperature and associated precipitation anomalies over the central-eastern Sahel. Clim. Dyn. 2018. [CrossRef]

8. Guo, H.; Xu, M.; Hu, Q. Changes in near-surface wind speed in China: 1969-2005. Int. J. Climatol. 2011, 31, 349-358. [CrossRef]

9. Fu, Z.-T.; Li, Q.-L.; Yuan, N.-M.; Yao, Z.-H. Multi-scale entropy analysis of vertical wind-speed series in atmospheric boundary-layer. Commun. Nonlinear Sci. 2014, 19, 83-91. [CrossRef]

10. Guo, X.-Y.; Wang, L.; Tian, L.-D.; Li, X.-P. Elevation-dependent reductions in wind speed over and around the Tibetan Plateau. Int. J. Climatol. 2017, 37, 1117-1126. [CrossRef]

11. Chen, S.-B.; Liu, Y.-F.; Thomas, A. Climatic change on the Tibetan Plateau: Potential evapotranspiration trends from 1961-2000. Clim. Chang. 2006, 76, 291-319.

12. Dai, A.-G. Global precipitation and thunderstorm frequencies. Part II: Diurnal variations. J. Clim. 2001, 14, 1112-1128. [CrossRef]

13. Dai, A.-G.; Deser, C. Diurnal and semidiurnal variations in global surface wind and divergence fields. J. Geophys. Res. 1999, 104, 109-126. [CrossRef]

14. Murakami, M. Analysis of the deep convective activity over the Western Pacific and Southeast Asia. Part I: Diurnal variation. J. Meteorol. Soc. Jpn. 1983, 61, 60-76. [CrossRef]

15. Bhatt, B.-C.; Nakamura, K. Characteristics of monsoon rainfall around the Himalayas revealed by TRMM precipitation Radar. Mon. Weather Rev. 2005, 133, 149-165. [CrossRef]

16. Liu, L.-P.; Feng, J.-M.; Chu, R.-Z.; Zhou, J.-J. The diurnal variation of precipitation in Monsoon season in the Tibetan Plateau. Adv. Atmos. Sci. 2002, 19, 365-378.

17. Bai, A.-J.; Liu, C.-H.; Liu, X.-D. Diurnal variation of summer rainfall over the Tibetan Plateau and its neighboring regions revealed by TRMM Multisatellite Precipitation Analysis. Chin. J. Geophys. 2008, 51, 704-714. (In Chinese) [CrossRef]

18. Zhao, Y.-F.; Zhang, Q.; Yu, Y.; Yang, G. Development of hourly wind speed dataset in China and application on Qinghai Tibetan Plateau. Plat. Meteorol. 2017, 36, 930-938.

19. Zhang, W.-J.; Jin, F.-F.; Zhao, J.-X.; Li, J.-P. On the bias in simulated ENSO SSTA meridional width of CMIP3 models. J. Clim. 2013, 26, 3173-3186. [CrossRef]

20. He, W.-P.; Zhao, S.-S. Assessment of the quality of NCEP-2 and CFSR reanalysis daily temperature in China based on long-range correlation. Clim. Dyn. 2018, 50, 493-505. [CrossRef] 
21. Yu, R.-C.; Li, J.; Chen, H.-M. Diurnal variation of surface wind over central eastern China. Clim. Dyn. 2009, 33, 1089-1097. [CrossRef]

22. Crawford, K.-C.; Hudson, H.-R. The diurnal wind variation in the lowest $1500 \mathrm{ft}$ in Central Oklahoma: June 1966-May 1967. J. Appl. Meteorol. 1973, 12, 127-132. [CrossRef]

23. North, G.-R.; Bell, T.-L.; Cahalan, R.-F.; Moeng, F.-J. Sampling errors in the estimation of empirical orthogonal functions. Mon. Weather Rev. 1982, 110, 699-706. [CrossRef]

24. Qin, Q.-C.; Shen, X.-S. An estimate of surface pressure drag of the Tibetan Plateau and its characteristic analysis. Acta. Meteorol. Sin. 2015, 73, 93-109. (In Chinese)

25. Yang, K.; Wu, H.; Qin, J.; Lin, C.-G.; Tang, W.-J.; Chen, Y.-Y. Recent climate changes over the Tibetan Plateau and their impacts on energy and water cycle: A review. Glob. Planet Chang. 2014, 112, 79-91. [CrossRef]

(C) 2019 by the authors. Licensee MDPI, Basel, Switzerland. This article is an open access article distributed under the terms and conditions of the Creative Commons Attribution (CC BY) license (http:/ / creativecommons.org/licenses/by/4.0/). 



\title{
Article \\ Sub-Mode Aerosol Volume Size Distribution and Complex Refractive Index from the Three-Year Ground-Based Measurements in Chengdu China
}

\author{
Chi Zhang ${ }^{1,2}$, Ying Zhang ${ }^{1}$, Zhengqiang $\mathrm{Li}^{1, *}$, Yongqian Wang ${ }^{3}$, Hua Xu ${ }^{1}$, Kaitao $\mathrm{Li}^{1}{ }^{1}$, \\ Donghui Li ${ }^{1}$, Yisong Xie ${ }^{1}$ and Yang Zhang ${ }^{3}$ \\ 1 State Environmental Protection Key Laboratory of Satellite Remote Sensing, Institute of Remote Sensing and \\ Digital Earth, Chinese Academy of Sciences, Beijing 100101, China; zhangchi@radi.ac.cn (C.Z.); \\ zhangying02@radi.ac.cn (Y.Z.); xuhua@radi.ac.cn (H.X.); likt@radi.ac.cn (K.L.); lidh@radi.ac.cn (D.L.); \\ xieys@radi.ac.cn (Y.X.) \\ 2 University of Chinese Academy of Sciences, Beijing 100049, China \\ 3 College of Resources and Environment, Chengdu University of Information Technology, \\ Chengdu 610103, China; wyqq@cuit.edu.cn (Y.W.); zhangyang@cuit.edu.cn (Y.Z.) \\ * Correspondence: lizq@radi.ac.cn; Tel.: +86-10-6485-7437
}

Received: 9 January 2019; Accepted: 22 January 2019; Published: 26 January 2019

\begin{abstract}
Chengdu is a typical basin city of Southwest China with rare observations of remote sensing measurements. To assess the climate change and establish a region aerosol model, a deeper understanding of the separated volume size distribution (VSD) and complex refractive index (CRI) is required. In this study, we employed the sub-mode VSD and CRI in Chengdu based on the three years observation data to investigate the sub-mode characteristics and climate effects. The annual average fraction of the fine-mode aerosol optical depth $\left(\mathrm{AOD}_{\mathrm{f}}\right)$ is $92 \%$, which has the same monthly tendency as the total $\mathrm{AOD}$. But the coarse-mode aerosol optical depth $\left(\mathrm{AOD}_{\mathrm{c}}\right)$ has little variation in different months. There are four distinguishing modes of VSD in Chengdu; the median radii are $0.17 \mu \mathrm{m} \pm 0.05$, $0.31 \mu \mathrm{m} \pm 0.12,1.62 \mu \mathrm{m} \pm 0.45,3.25 \mu \mathrm{m} \pm 0.99$, respectively. The multi-year average and seasonal variations of fine- and coarse-mode VSD and CRI are also analyzed to characterize aerosols over this region. The fine-mode single scattering albedos (SSAs) are higher than the coarse-mode ones, which suggests that the coarse-mode aerosols have a stronger absorbing effect on solar light than the small-size aerosol particles in Chengdu.
\end{abstract}

Keywords: Chengdu; aerosol; sub-mode volume size distribution; sub-mode complex refractive index; remote sensing

\section{Introduction}

As one component of the terrestrial atmosphere, aerosol is an important factor in global climate change, with direct effects and indirect effects. Direct effects include changing the radiation balance of the Earth-atmosphere system by absorbing and scattering sunlight [1,2]. On the other hand, aerosol serves as cloud condensation nuclei (CCN) involved in cloud microphysics processes, referred to as indirect effects [3]. Moreover, as one major constituent of haze, aerosol particles endanger public health [4].

Chengdu, located in the central region of the Sichuan basin (Chengdu Plain) with a population of $\sim 16$ million (the resident population of Chengdu was counted in 2016), is the economic center and transportation hub in southwest China. Due to the special topography of the basin, the average wind speed is low $[5,6]$. Coupled with the development economy in Chengdu, a large amount of pollutants associated with regional industrial emissions are easy to accumulate. Abundant water vapor 
is conducive to the formation of aerosol particulates, which has made Chengdu become one of the regions in China with serious haze pollution [7-10]. The special topography and climate in Sichuan basin leads to a kind of wet, rainy and cloudy weather condition [11]. Therefore, it is difficult to obtain a large number of measurements through optical remote sensing observations in Chengdu. Sampling method of atmospheric particulates is one kind of Chengdu air pollution study $[7,9,10,12]$, which fails to acquire the aerosol's larger-scale spatial characteristics. The spatial characteristics of aerosols can be obtained by remote sensing, one kind of non-contact method [13-15]. For instance, some studies analyzed the spatial-temporal distribution of aerosol optical depth (AOD) in Sichuan basin using satellite remote sensing [16,17]. Besides, aerosol optical parameters obtained by the ground-based remote sensing observation were statistically analyzed in this area [18-21].

Although the above-mentioned research studies focus on the total-column aerosol properties by remote sensing methods, it still remains a big challenge to obtain the characteristics of sub-mode aerosol (fine- and coarse-mode) in Chengdu. The fine- and coarse-mode particles are related to the different sources and compositions. Fine-mode aerosols are mainly dominated by anthropogenic emissions and are related to the fog or low-altitude cloud dissipated events [22,23]. Coarse-mode particles are determined by the sea salt, dust and other natural sources. Therefore, the knowledge of aerosol sub-mode properties plays a role in the research on regional climate and the improvement of the aerosol model used in the satellite retrieval algorithms.

In this study, the sub-mode volume size distribution (VSD) and complex refractive index (CRI) in Chengdu area were investigated based on three years of measurements of the Sun-sky radiometer Observation NETwork (SONET). Section 2 presents the observation data and the method to separate VSD and CRI into sub mode (fine and coarse mode). Section 3 shows the seasonal characteristics of sub-mode VSD and CRI. The sub-mode optical properties (AOD, single scattering albedo (SSA)) and the climate effect of sub-mode aerosol in Chengdu are discussed in Section 4. The results are summarized in Section 5 .

\section{Data and Method}

\subsection{Observation Site and Data}

SONET Chengdu site (Figure 1 red dot) is located in Chengdu, Sichuan province, a developing urban area. The CE318 (Cimel Electronique, Pairs France) is an automatic instrument for long-term continuous observation of direct solar radiation and diffused sky radiation in the Chengdu site with nine individual spectral channels: $340 \mathrm{~nm}, 380 \mathrm{~nm}, 440 \mathrm{~nm}, 500 \mathrm{~nm}, 675 \mathrm{~nm}, 870 \mathrm{~nm}, 1020 \mathrm{~nm}, 1640 \mathrm{~nm}$ and $940 \mathrm{~nm}$. The parameters include AOD, Angstrom Exponent (AE), VSD, CRI and SSA, and so on [24-26]. To ensure data quality, SONET instruments are calibrated by a routine process of laboratory and field calibration experiments. The direct sun measurements are calibrated every year in a field, located on Ling Mountain ( $1600 \mathrm{~m}, \mathrm{MSL})$, and compared with a master instrument that is regularly calibrated by Langley plot method with high precision $[27,28]$. For the calibration of sky radiance measurements, SONET adopts the method of vicarious/transfer calibration, which is different from the AErosol RObotic NETwork (AERONET) calibration method [29].

The accuracy assessment of SONET products is based on the Distributed Regional Aerosol Gridded Observational Network (DRAGON)-Korea-United States Air Quality Study (KORUS-AQ) 2016 campaign [30]. The aerosol optical and microphysical parameters were inverted by SONET and AERONET algorithm at the same time. The differences of two network products can reflect the accuracy and data acquisition of SONET products. It turned out that the Level 1.5 data amount of two kinds of products are all above $85 \%$, and the average AOD difference between SONET and AERONET is $0.002 \pm 0.0001$, less than AERONET AOD uncertainty [28]. The VSD difference between SONET and AERONET is $1.5 \% \pm 26 \%$ (radius range from 0.1 to $7 \mu \mathrm{m}$ ) and $18 \% \pm 85 \%$ (radius more than $7 \mu \mathrm{m}$ ) [28]. The real part of CRI has a difference of $0.007 \pm 0.04$ from AERONET, and the imaginary 
part has a difference value of $18 \% \pm 46 \%$. The average difference on SSA is slightly higher, but other parameters are close to or less than AERONET normal uncertainties [28].

The products of SONET are graded into three level (Level 1.0, Level 1.5, Level 2.0), defined following the AERONET data level protocols of version 2.0. In detail, Level 1.0 is raw data calculated from measurement and calibration coefficient. The Level 1.5 is based on Level 1.0 with automatic cloud screening procedures [31]. Level 2.0 has the additional application of pre- and post-calibration coefficient and expert checking. This paper is based on Level 2.0 data of SONET Chengdu site from June 2013 to December 2016.
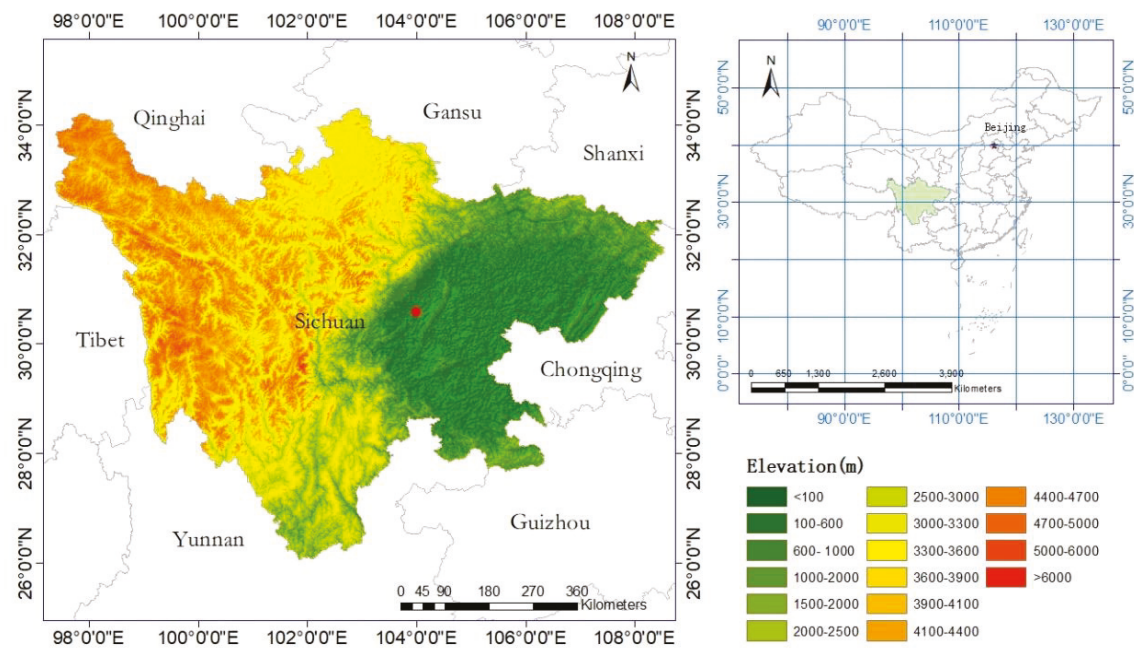

Figure 1. Topographic map of Sichuan province and location of the Sun-sky radiometer Observation NETwork (SONET) Chengdu site (marked with red dot). Data source is ASTER GDEM (Advanced Spaceborne Thermal Emission and Reflection Radiometer Global Digital Elevation Model).

\subsection{Method}

In this paper, the sub-mode VSDs and CRIs were retrieved by the aerosol products [24,26], following by Zhang et al. (2016) and Zhang et al. (2017). The method developed by Cuesta et al. (2008) is employed to separate VSD into a single Log-Normal Modes (LNM). Each LNM parameters have three parameters: the modal concentration, geometric standard deviation and modal radius [32,33]. The sub-mode VSD can be modeled by the following function:

$$
\frac{\mathrm{dV}(\mathrm{r})}{\mathrm{d} \ln r}=\sum_{\mathrm{i}=1}^{\mathrm{m}} \frac{\mathrm{C}_{\mathrm{i}}}{\sqrt{2 \pi}\left|\ln \sigma_{\mathrm{i}}\right|} \exp \left[-\frac{1}{2}\left(\frac{\ln r-\ln \mathrm{r}_{\mathrm{i}}}{\ln \sigma_{\mathrm{i}}}\right)^{2}\right]
$$

where $C_{i}\left(\mu \mathrm{m}^{3} / \mu \mathrm{m}^{2}\right)$ is the volume modal concentration, $r_{i}(\mu \mathrm{m})$ is the median radius, $\sigma_{i}$ is standard deviation, $\mathrm{m}$ is the total number of modes, $\mathrm{dV} / \mathrm{dlnr}\left(\mu \mathrm{m}^{3} / \mu \mathrm{m}^{2}\right)$ is aerosol volume particle size distribution.

The modes of VSD with radius less than $1 \mu \mathrm{m}$ can be considered as the fine mode and others belong to the coarse mode.

CRI can describe the scattering and absorption properties of atmospheric particulates. Most research analyzed aerosol total-columnar CRI, but fine- and coarse-mode particles are associated with different composition and source of pollution. So, in this study we recalculated the complex refractive indices for both of fine and coarse mode, following Zhang et al. (2017). For the calculation of the 
sub-mode CRI, we also choose the same radius limit $(1 \mu \mathrm{m})$ as the sub-mode VSD. The separated results of CRI have their own fine and coarse modes in different wavelength as follow:

$$
\begin{array}{r}
\mathrm{n}_{\mathrm{f} / \mathrm{c}}(\lambda)=\mathrm{n}_{\mathrm{f} / \mathrm{c}} \lambda=440,675,870,1020 \mathrm{~nm} \\
\mathrm{k}_{\mathrm{f}, \mathrm{c}}(\lambda)=\left\{\begin{array}{lc}
\mathrm{k}_{\mathrm{f}, \mathrm{c}} 440 & \lambda=440 \mathrm{~nm} \\
\mathrm{k}_{\mathrm{f}, \mathrm{c}} & \lambda=675,870,1020 \mathrm{~nm}
\end{array}\right.
\end{array}
$$

where $n$ is real part of CRI, $\mathrm{k}$ is imaginary part of CRI, $\lambda$ denotes the standard wavelengths of AERONET products, the subscripts $f$ and $c$ represent the fine and coarse modes, respectively.

The input parameters are the VSD, spectral AOD, and absorbing AOD. The initial guesses of sub-mode CRIs are from the inversion CRIs of measurements [34]. The effective CRIs are corresponding to each VSD bin, following the volume average rule [35]:

$$
\begin{gathered}
\mathrm{n}(\mathrm{r})=\frac{n_{f} V_{f}(r)+n_{c} V_{c}(r)}{V_{f}(r)+V_{c}(r)} \\
\mathrm{k}(\lambda, \mathrm{r})=\frac{k_{f} V_{f}(r)+k_{c} V_{c}(r)}{V_{f}(r)+V_{c}(r)}
\end{gathered}
$$

Then the fine- and coarse-mode CRIs are found by iterative fitting of the input AODs and the calculated AODs by the CRIs (Equations (4) and (5)) and VSDs.

With regard to the test of error estimation, the error of real part of CRI is less than 0.046 and that of imaginary part is less than 0.003 in three typical modal (WS: water soluble, BB: biomass burning, DU: dust). As this algorithm applied to AERONET measurements, the total uncertainties are $\Delta \mathrm{n}_{\mathrm{f} / \mathrm{c}}=0.11, \Delta \mathrm{k}_{\mathrm{f} / \mathrm{c}}=78 \%$ by considering all possible input of AERONET parameter errors together.

\section{Results}

\subsection{Fine- and Coarse-Mode $A O D$}

O'Neil et al. (2003) developed a spectral deconvolution algorithm (SDA) that utilizes spectral total extinction AOD data with the assumption of bimodal aerosol size distribution to infer the fine and coarse mode contributions to atmospheric AOD. SONET employs the algorithm's ability to separated coarse and fine mode AOD that used in Figure $2[25,36]$. As illustrated in Figure 2, we find that the fine-mode $\mathrm{AOD}\left(\mathrm{AOD}_{\mathrm{f}}\right)$ has the same monthly tendency with the total $\mathrm{AOD}$. The annual $\mathrm{AOD}_{\mathrm{f}}$ percent is $92 \%$, which varies from $86 \%$ to $96 \%$. Nevertheless, the coarse-mode AOD $\left(\mathrm{AOD}_{\mathrm{c}}\right)$ has little variation in different month. It is demonstrable that the fine-mode aerosols are the principal pollutant in Chengdu area, which lead to the change of AOD. In summer, rainfall affected by the typical subtropical monsoon basin climate is significantly higher than that in winter [37]. The increasing precipitation can play a role in the removal of atmospheric pollutants. As a result, AOD decreases in summer, which reaches the lowest value of 0.64 in June. However, the average AOD in summer is 0.89 , which still acts as a pollutant. There are two main reasons: firstly, the average surface wind speed all over the basin is low under the control of subtropical anticyclone in summer [38], which makes aerosol transport to other regions difficult. In addition, high temperature can cause the increasing formation of secondary organic aerosol particles [39]. In winter, the large variation of temperature from day to night leads to the rapid condensation of water vapor, which is conducive to the concentration of water and particulate matter. And the cold air is not conductive to the diffusion of aerosol because of the enclosed basin [16]. Therefore, AOD is the highest in winter (Winter: AOD =1.12). 


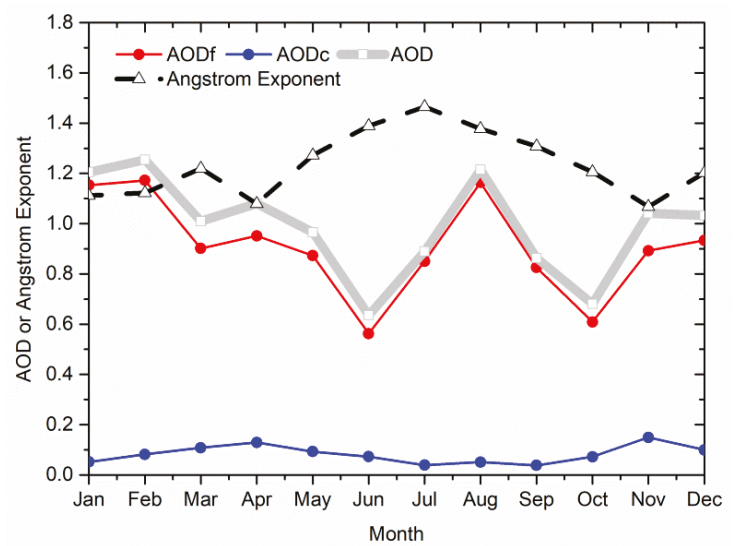

Figure 2. Monthly mean of aerosol optical depth (AOD), $\mathrm{AOD}_{\mathrm{f}}, \mathrm{AOD}_{\mathrm{c}}$ at $440 \mathrm{~nm}$ and Angstrom Exponent (440-870 nm) in SONET Chengdu site from 2013 to 2016.

$\mathrm{AE}(440-870 \mathrm{~nm})$ changes little with the value more than 1.0, which is similar to the previous research $[12,20]$. Convective precipitation occurs frequently in summer that the majority of coarse particles have been eliminated by wet settlement, but the fine particles remained in atmosphere with long suspension times [20,40-42]. Also, in Figure 2, it also can be illustrated by that the difference between $\mathrm{AOD}_{\mathrm{f}}$ and $\mathrm{AOD}$ is lowest in summer. The average AE is less than 1.2 in each month of spring. The main reason for the high AOD and low AE in spring is the long-distance transport of dust pollution from North China $[43,44]$. In addition, another reason may be the wind speed increasing, by which it can be speculated that large particles are emitted to the atmosphere or transported from other regions by strong wind $[20,45]$.

The AOD can be separated into fine- and coarse-mode and the different mode has the obviously distinguishing extinction for solar light in Chengdu. Therefore, it is important to explore the more sub-mode properties to research on the climate effect of different mode aerosols.

\subsection{Sub-Mode VSD}

VSD is one of the important aerosol microphysical properties. Although the particle size changes constantly, atmospheric aerosol particles exist in three-mode VSD stably. According to particle radius, the modes can be divided into nuclear mode (less than $0.1 \mu \mathrm{m})$, accumulation mode $(0.1-1 \mu \mathrm{m})$ and coarse mode (larger than $1 \mu \mathrm{m}$ ) [46]. The process of nuclear mode is concentrated in nanometer scale, and the accumulation mode and coarse mode can be shown in VSDs [47,48]. According to Eck et al. (2012), large fine mode-dominated aerosols (submicron radius) were observed after the fog or low-altitude cloud dissipated events. As cloud condensation nuclei or ice nuclei, the smaller coarse mode-dominated aerosols (supermicron radius) are involved in the fog/cloud formation and dissipation [49]. Li, et al. (2014) found that an unusual increase of submicron fine modes is an important mechanism for haze growth in the polluted region. As identified in Figure 3, there are four modes of the aerosol VSD in Chengdu area and the corresponding parameters are listed in Table 1. The different color lines are the average of each mode and the values of $\mathrm{N}$ in the legend are the amounts of data involved in averaging. The modes can be clearly distinguished. As the median radius is less than $1 \mu \mathrm{m}$, there are two peaks: the fine mode and submicron fine (SMF) mode. Furthermore, there are two peaks as the radius more than $1 \mu \mathrm{m}$ : supermicron coarse (SMC) mode and coarse mode. In the figure, the fine mode has an almost equal amount of data as the coarse mode, but the fine-mode with one addition, which is one record with only one-peak VSD. The SMC mode has the least data amount of all $(N=133)$. The median radius of each mode is obviously different. As to the fine mode, the average median radius is $0.17 \mu \mathrm{m} \pm 0.05$ and the volume modal concentration is $0.10 \pm 0.07$, that is, the largest 
value of all modes. The median radii of the SMF modes are mainly in the range of $0.2-0.5 \mu \mathrm{m}$, which can indicate fog dissipation and haze growth, as previously mentioned. The SMC mode has a median radius of $1.62 \mu \mathrm{m} \pm 0.45$ and the volume modal concentration of $0.07 \pm 0.05$. The coarse mode has an average median radius of $3.25 \mu \mathrm{m} \pm 0.99$.

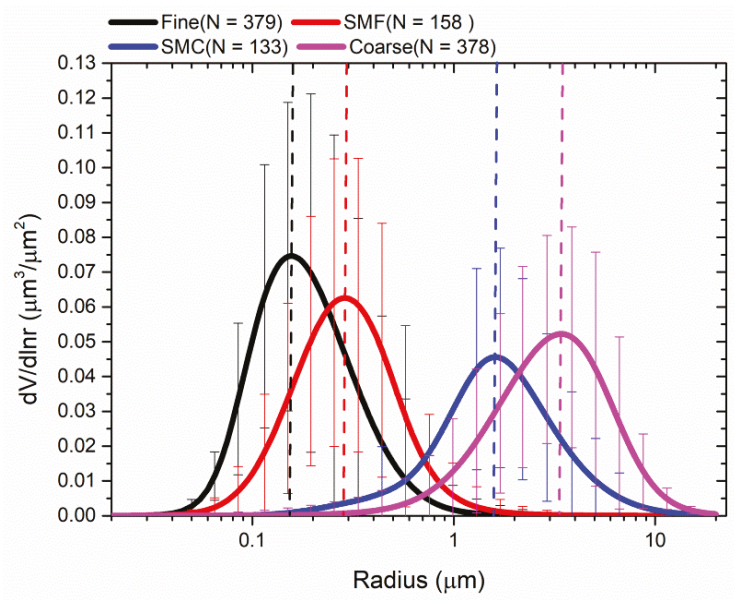

Figure 3. The average sub-mode volume size distribution in Chengdu.

Table 1. The parameters of sub-mode volume size distribution.

\begin{tabular}{cccc}
\hline & $\mathbf{R}(\boldsymbol{\mu m})$ & $\sigma$ & $\mathbf{V}\left(\mu \mathbf{m}^{3} / \mu \mathbf{m}^{2}\right)$ \\
\hline Fine & $0.17 \pm 0.05$ & $1.55 \pm 0.18$ & $0.10 \pm 0.07$ \\
SMF & $0.31 \pm 0.12$ & $1.69 \pm 0.28$ & $0.09 \pm 0.05$ \\
SMC & $1.62 \pm 0.45$ & $1.83 \pm 0.35$ & $0.07 \pm 0.05$ \\
Coarse & $3.25 \pm 0.99$ & $1.82 \pm 0.29$ & $0.09 \pm 0.05$ \\
\hline
\end{tabular}

\subsection{Fine- and Coarse-Mode VSD and CRI}

The primary focus of Section 3.2 shows that the VSD can be separated into four distinguishing modes. However, in general, the natural aerosols, which are predominately coarse mode particles $(\mathrm{r}>1 \mu \mathrm{m})$, and combustion-produced and anthropogenic emissions particles, which are predominately fine mode particles $(\mathrm{r}<1 \mu \mathrm{m})$, of various mixed relative fractions are the mixtures in the aerosols. Furthermore, the fine mode and coarse mode particles are from different components. Also, at the same time, the CRI can only be separated into fine- or coarse-mode due to technical and precision limitations. Therefore, we focus on the fine- and coarse-mode VSD and CRI in Chengdu in this section.

In Figure 4, we present the multi-year average separated CRIs and the breakdown results of VSDs. It can be seen the fine- and coarse-mode VSD are well separated. The pictures (a) and (b) in the first row are the average values retrieved from the ground-based Sun-sky radiometer over multiple years. The second and third rows are the average of fine- and coarse-mode VSD and CRI. The sub-mode real part of CRI has non variation of wavelengths referring to Equation (2). The total CRI and sub-mode CRI are from different algorithms $[21,32,34]$, but the sub-mode CRI is related to the volume modal concentration in the iterative algorithm of estimation of CRI for fine and coarse mode [34].

The fine-mode volume modal concentration is clearly higher than the coarse-mode one. The fineand coarse-mode real parts of CRI exhibit little difference $\left(n_{\mathrm{f}}=1.43, \mathrm{n}_{\mathrm{c}}=1.46\right)$. However, the coarse mode has a lower imaginary part of CRI at $440 \mathrm{~nm}$ than that of fine mode $\left(\mathrm{k}_{\mathrm{f} 440}=0.0106, \mathrm{k}_{\mathrm{c} 440}=\right.$ 0.0072). At longer wavelengths, the imaginary part of CRI has little variation between fine- and coarse-mode $\left(\mathrm{k}_{\mathrm{f}}=0.0121, \mathrm{k}_{\mathrm{c}}=0.0112\right)$. 

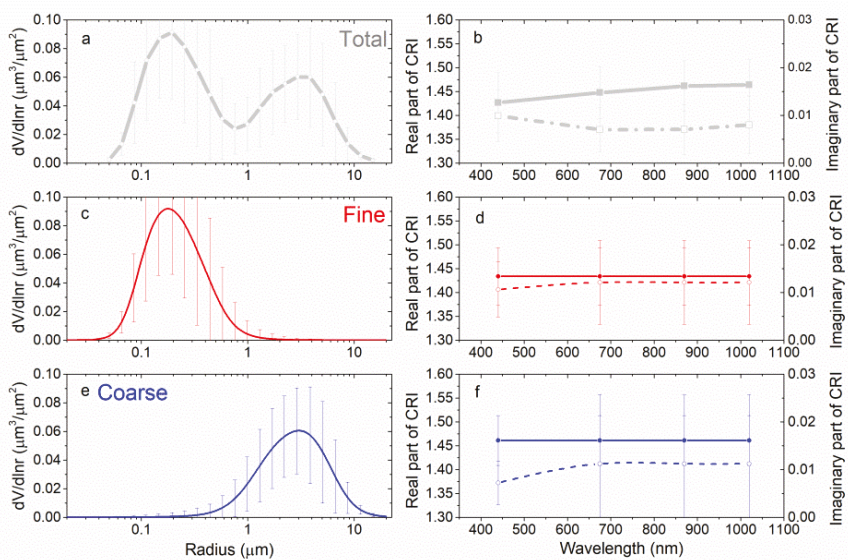

Figure 4. The separated volume size distribution and sub-mode complex refractive index of multi-year average. The data source of $(\mathbf{a})$ and $(\mathbf{b})$ for total modes are from the inversion algorithm of SONET, and others (c-f) are from the sub-mode algorithms. (a) Total volume size distribution (b) Total complex refractive index in four wavelengths; (c) Fine-mode volume size distribution; (d) Fine-mode complex refractive index; (e) Coarse-mode volume size distribution; (f) Coarse-mode complex refractive index; The solid lines in figure $(\mathbf{b}),(\mathbf{d}),(\mathbf{f})$ are the real parts of complex refractive index, and the dash lines are the imaginary parts. The corresponding parameters are listed in Table 2.

Figure 5 shows the fine-mode VSDs and CRIs in different seasons. The corresponding parameters are listed in Table 2. The typical bimodal or multimodal VSDs in all seasons imply a fine-coarse mixed-size distribution in the Chengdu area, similar to the urban-industrial aerosol type [50]. The fine-mode volume concentration is higher in summer, followed by winter, spring and autumn (Table 2). Furthermore, the fine-mode median radii are higher in summer $(0.21)$ and winter $(0.21)$. This can be explained by the increasing precipitation in summer and the low wind speed in winter that would lead to the high relative humidity and hygroscopic growth [22,23].
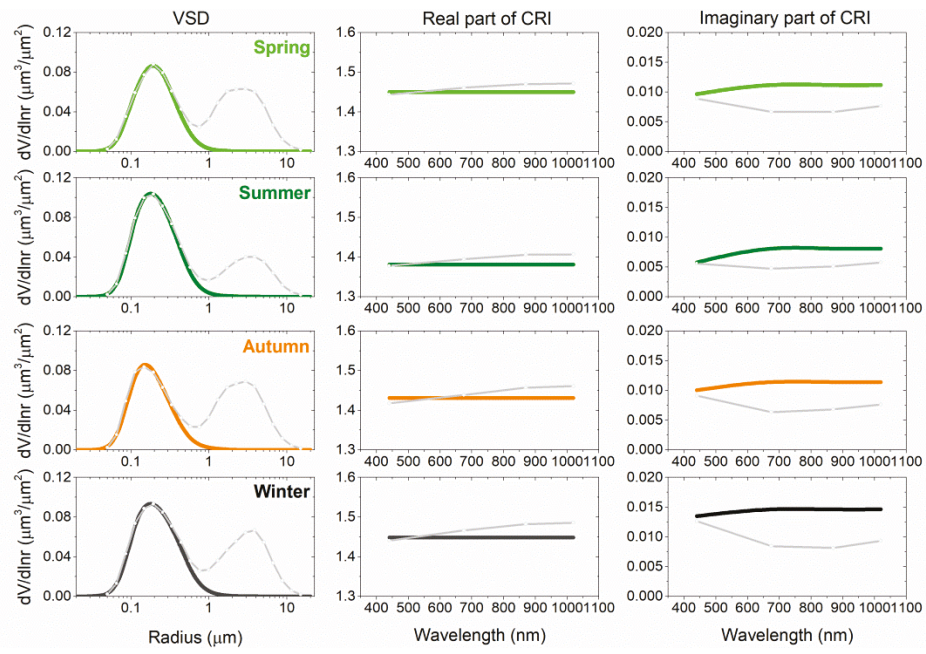

Figure 5. Seasonal variation of fine-mode volume size distribution (VSD) and complex refractive index (CRI) in SONET Chengdu site. The grey line refers to the total parameters. The corresponding parameters are listed in Table 2. 


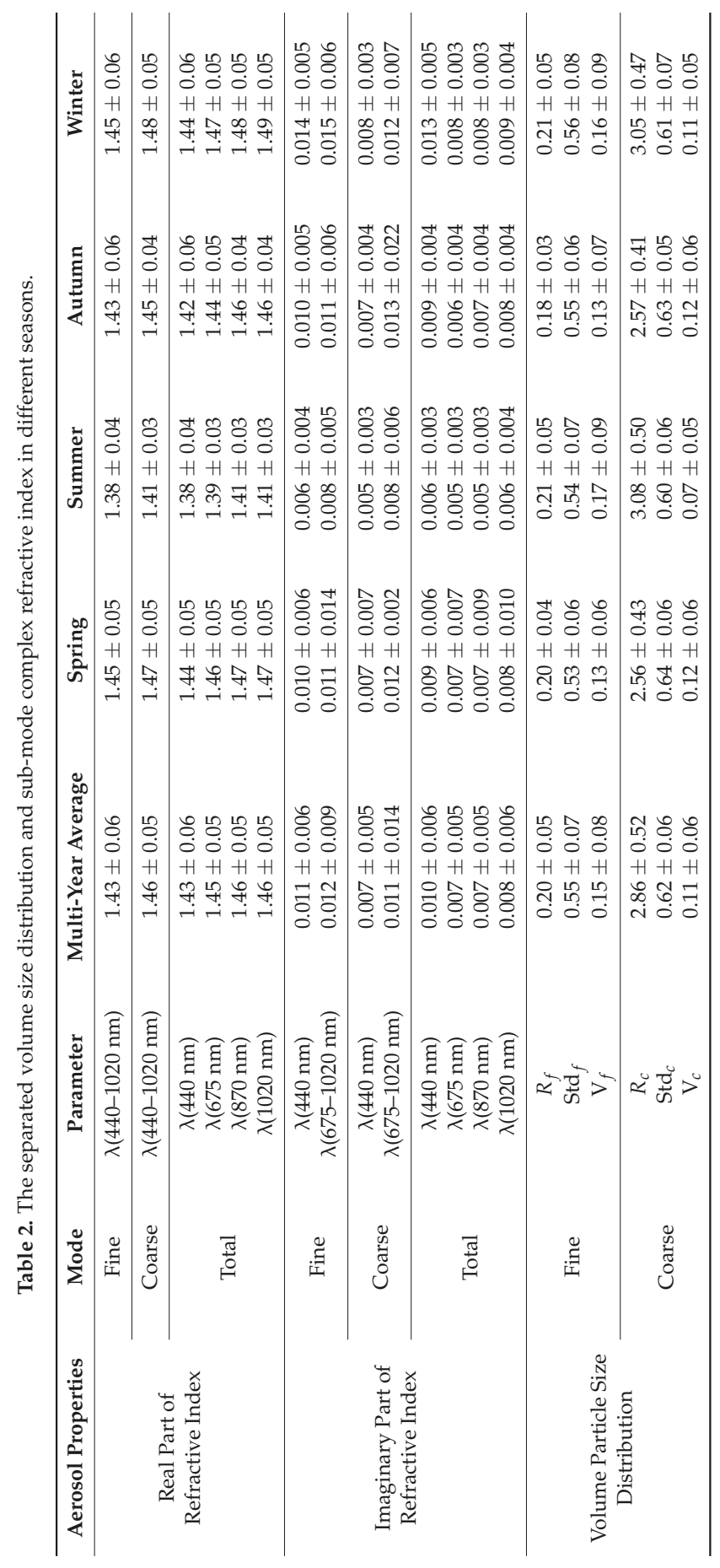


The CRI can reflect the aerosol chemical composition. The real part indicates the aerosol refractivity and scattering characteristics. Specifically, the real part of CRI of water is generally considered to be 1.33 [51], much lower than other dry matters. Therefore, the real part can also reflect the water content in aerosol. The total real part of CRI in summer is the lowest, which is associated with the high humidity and water content in summer. Moreover, the fine-mode real part of CRI is also the lowest $\left(\mathrm{n}_{\mathrm{f}}=1.38\right)$. As shown in Table 2, the fine-mode real parts of CRIs are all lower than the coarse-mode ones, which suggests that the water content in fine-mode particles play a leading role in Chengdu aerosols.

The imaginary part of CRI is related to the absorption characteristics of aerosol. The fine-mode imaginary part of CRI generally indicates that the fine-mode absorption component, that is, Black carbon (BC) or Brown carbon (BrC) [52].

Figure 6 presents the coarse-mode VSDs and CRIs in different seasons. The coarse-mode volume concentration is obviously less than the fine-mode. In particular, the volume concentration in summer gets the lowest $\left(\mathrm{V}_{\mathrm{c}}=0.069\right)$, which is associated with the wet removal of coarse particles. In summer, the coarse-mode real part is the lowest value over the four seasons, but also higher than the fine-mode one in Figure 5 that suggests the coarse particles are weakly hygroscopic $\left(\mathrm{n}_{\mathrm{f}}=1.38, \mathrm{n}_{\mathrm{c}}=1.41\right)$. For all seasons, the coarse-mode imaginary part of CRI is quite constant (Table 2). In contrast, the fine-mode imaginary part has great seasonal variation. That demonstrates the coarse particle components are relatively stable. The spectral difference of the imaginary part (between $440 \mathrm{~nm}$ and longer wavelength) has a discrepancy between fine- and coarse-mode. It should be mentioned that the imaginary part reflects the aerosol absorbing property, and its spectral pattern can reveal the relative fractions of absorbing aerosols, that is, BC and DU [52-54].
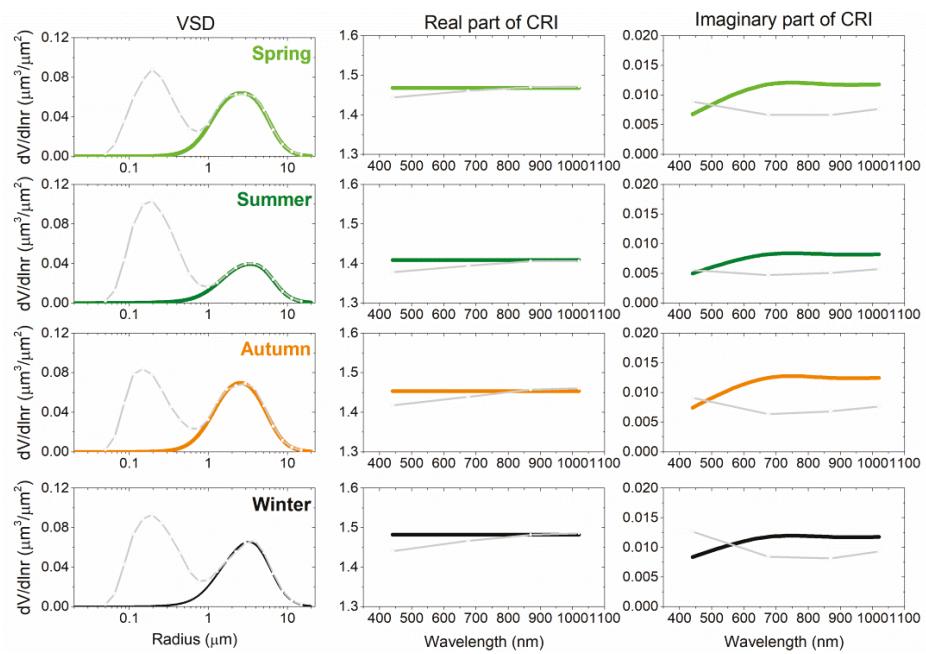

Figure 6. Seasonal variation of coarse-mode VSD and CRI in SONET Chengdu site. The grey line refers to the total parameters. The corresponding parameters are listed in Table 2.

\section{Discussion}

In order to evaluate the overall analysis scheme, a numerical experiment was used to assess the performance of sub-mode results. In Figure 7, we illustrated the recovery of AOD in four wavelengths by the sub-mode VSD and CRI. It can be seen that the correlation coefficients are all larger than 0.98 . The absolute deviations in four wavelengths are $0.04,0.02,0.03$ and 0.03 , corresponding relative standard deviations are $0.03,0.03,0.06,0.09$, respectively. These biases are basically close to the claimed 
uncertainties of SONET products (AOD), which demonstrate that the sub-mode VSD and CRI results are acceptable in understanding of optical closure.

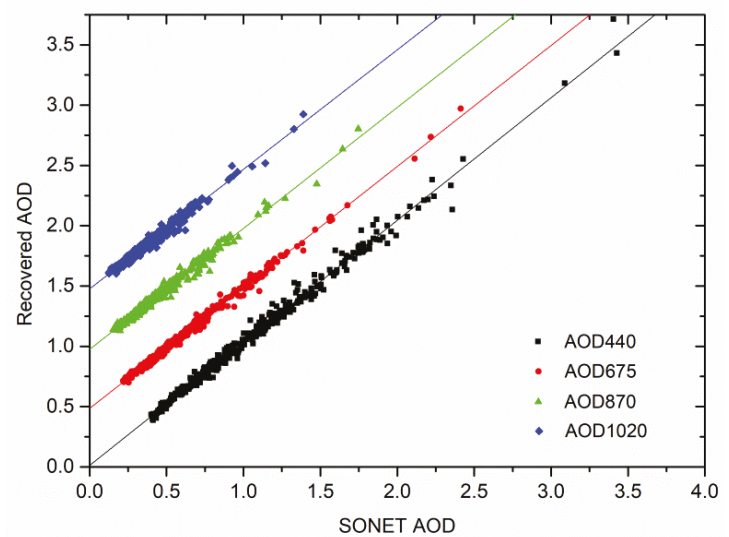

Figure 7. Recovery of AOD at different wavelength based on the separated volume size distribution and sub-mode complex refractive index. $N=380$ and curves (at $675 \mathrm{~nm}, 870 \mathrm{~nm}, 1020 \mathrm{~nm}$ ) are shifted for a better viewing.

For further details of the climate effect, the sub-mode SSAs were taken into account. SSAs could reflect the aerosol absorption and scattering of solar lights, which is an important parameter in climate modeling $[55,56]$. Hansen et al. (1997) noted that a change in SSA from 0.9 to 0.8 can change the radiative forcing from negative to positive depending on the reflectance of the underlying surface and the altitude of the aerosols. Moreover, strongly absorbing aerosols may have a large impact on the regional climate and heating the atmosphere $[57,58]$.

In Figure 8, the sub-mode SSA is calculated by the separated VSD and sub-mode CRI under ignoring the influence of nonsphericity on dust aerosols. The total SSAs are all larger than 0.9 in the four seasons and the fine-mode SSAs are closed to the total SSAs that indicates the scattering properties are mainly dominated by fine-mode aerosol. Higher SSA at $675 \mathrm{~nm}$ could indicate the main absorption component BrC [52,53], but the high value of SSA indicates the absorbing effect is obvious less than scattering effect of solar lights. The SSA spectral trends from $675 \mathrm{~nm}$ to $870 \mathrm{~nm}$ show different patterns: the increasing pattern is usually corresponding to the absorbing coarse particles (e.g., Dust); the decreasing pattern is usually corresponding to the absorbing fine particles (e.g., BC, $\mathrm{BrC}$ ) [52]. The fine-mode SSAs decrease and the coarse-mode SSAs increase with the increase of wavelength, which indicates the different absorbing component in different modes. Furthermore, the coarse-mode SSAs are lower than that of the fine-mode that suggests the absorption of coarse-mode particles is likely stronger than that of the small size aerosol particles. In this regard, the absorbing component in large-size aerosols (such as mineral dust, biomass burning, etc.) is possibly more than that of small-size aerosols. 

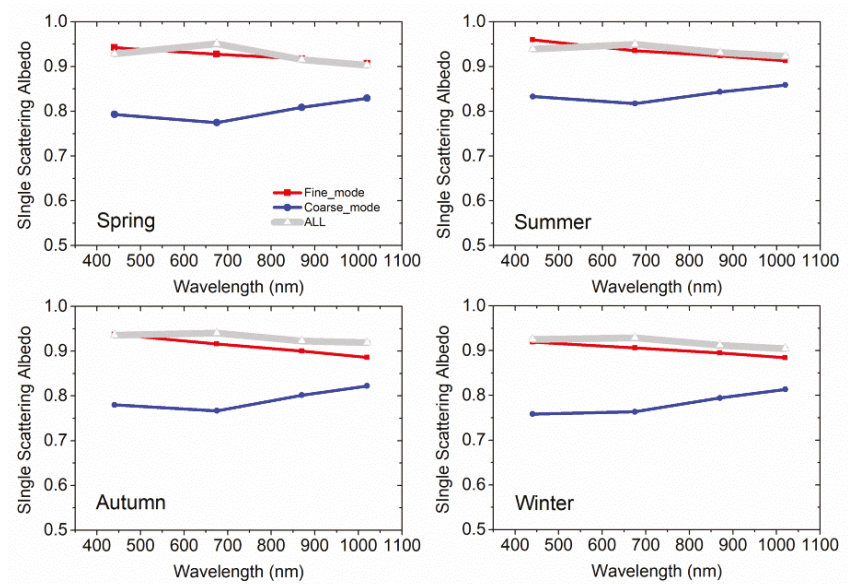

Figure 8. The sub-mode single scattering albedo in different season based on the separated volume size distribution and sub-mode complex refractive index (ignore the influence of nonsphericity on dust aerosols). The grey, red, blue lines are the whole-, fine- and coarse-mode single scattering albedos (SSAs), respectively.

\section{Conclusions}

In this study, we investigated the sub-mode VSD and CRI for fine- or coarse-mode in the Chengdu area. The annual average of $\mathrm{AOD}_{\mathrm{f}}$ percentage is $92 \%$, which has the same monthly tendency with the total $\mathrm{AOD}$, but $\mathrm{AOD}_{\mathrm{c}}$ has little variation in different months. The typical bimodal or multimodal VSDs employ a fine-coarse mixed-size distribution in Chengdu area. There are four distinguishing modes of VSD in Chengdu that the median radii are $0.17 \mu \mathrm{m} \pm 0.05,0.31 \mu \mathrm{m} \pm 0.12,1.62 \mu \mathrm{m} \pm 0.45,3.25 \mu \mathrm{m} \pm$ 0.99 , respectively.

The fine-mode annual average volume modal concentration is clearly higher than the coarse-mode one. The fine-mode volume concentration and median radius are higher in summer and winter. In particular, the coarse-mode volume concentration gets lowest in summer $\left(\mathrm{V}_{\mathrm{c}}=0.069\right)$, which is associated with the wet removal of large-size particles. For multi-year average results of CRI, the fine-mode and coarse-mode real parts show little difference. However, the coarse mode has a lower imaginary part at $440 \mathrm{~nm}$ than the fine-mode $\left(\mathrm{k}_{\mathrm{f} 440}=0.0106, \mathrm{k}_{\mathrm{c} 440}=0.0072\right)$. At longer wavelengths, the imaginary part of CRI has little variation between fine and coarse mode $\left(\mathrm{k}_{\mathrm{f}}=0.0121, \mathrm{k}_{\mathrm{c}}=0.0112\right)$. In summer, both fine- and coarse-mode real parts get the lowest value respectively because of the high humidity $\left(\mathrm{n}_{\mathrm{f}}=1.38, \mathrm{n}_{\mathrm{c}}=1.41\right)$. For all seasons, the coarse-mode imaginary part of CRI is quite constant, but the fine-mode imaginary part has great seasonal variations. It indicates the coarse particle components are relatively stable.

In order to assess the performance of the sub-mode results, we illustrated the recovery of AOD by the sub-mode VSD and CRI. It can be seen that all the correlation coefficients are larger than 0.98 . The sub-mode SSAs are calculated by sub-mode VSD and CRI under the condition of neglecting the non-sphericity. The total SSAs are all larger than 0.9 in the four seasons and the fine-mode SSAs are closed to the total SSAs that indicates the scattering properties are mainly dominated by fine-mode aerosols. The coarse-mode SSAs are lower than fine-mode, which suggests the absorbing effect of coarse-mode particles is likely stronger than that of the small size aerosol particles.

Author Contributions: Z.L. conceived and designed this study, and participated in drafting and revising the article. C.Z. substantially contributed to the analysis and interpretation of data, and drafted the articles. H.X. reviewed and edited the manuscript. Y.Z. and Y.W. undertook a part of the instrument maintenance job. D.L., K.L. and Y.X. contributed to the calibration of the sun-sky radiometer and analyses of the observation data. Y.Z. do formal analysis and investigation. 
Acknowledgments: This work was supported by the National Key Research and Development Program of China under Grant 2016YFE0201400, the National Natural Science Foundation of China under Grant 41671364,41671367, 41771396, and Science and Technology Service network initiative (STS) Project of Chinese Academy of Sciences (KFJ-STS-QYZD-022).

Conflicts of Interest: The authors declare no conflict of interest.

\section{References}

1. Twomey, S. Pollution and the planetary albedo. Atmos. Environ. (1967) 1974, 8, 1251-1256. [CrossRef]

2. Kazil, J.; Stier, P.; Zhang, K.; Quaas, J.; Kinne, S.; O'donnell, D.; Rast, S.; Esch, M.; Ferrachat, S.; Lohmann, U. Aerosol nucleation and its role for clouds and Earth's radiative forcing in the aerosol-climate model ECHAM5-HAM. Atmos. Chem. Phys. 2010, 10, 10733-10752. [CrossRef]

3. Albrecht, B.A. Aerosols, cloud microphysics, and fractional cloudiness. Science 1989, 245, 1227-1231. [CrossRef] [PubMed]

4. Pöschl, U. Atmospheric Aerosols: Composition, Transformation, Climate and Health Effects. Angew. Chem. Int. Ed. 2005, 44, 7520-7540. [CrossRef] [PubMed]

5. Liao, W.; Wang, X.; Fan, Q.; Zhou, S.; Chang, M.; Wang, Z.; Wang, Y.; Tu, Q. Long-term atmospheric visibility, sunshine duration and precipitation trends in South China. Atmos. Environ. 2015, 107, 204-216. [CrossRef]

6. Pan, L.; Che, H.; Geng, F.; Xia, X.; Wang, Y.; Zhu, C.; Chen, M.; Gao, W.; Guo, J. Aerosol optical properties based on ground measurements over the Chinese Yangtze Delta Region. Atmos. Environ. 2010, 44, 2587-2596. [CrossRef]

7. Tao, J.; Cheng, T.; Zhang, R.; Cao, J.; Zhu, L.; Wang, Q.; Luo, L.; Zhang, L. Chemical composition of PM 2.5 at an urban site of Chengdu in southwestern China. Adv. Atmos. Sci. 2013, 30, 1070-1084. [CrossRef]

8. Tao, M.; Chen, L.; Wang, Z.; Tao, J.; Che, H.; Wang, X.; Wang, Y. Comparison and evaluation of the MODIS Collection 6 aerosol data in China. J. Geophys. Res. Atmos. 2015, 120, 6992-7005. [CrossRef]

9. Deng, L.; Qian, J.; Liao, R.; Tong, H. Pollution characteristics of atmospheric particulates in Chengdu from August to September in 2009 and their relationship with meteorological conditions. China Environ. Sci. 2012, 32, 1433-1438.

10. Li, X.; Yang, Z.; Fu, P.; Yu, J.; Lang, Y.-c.; Liu, D.; Ono, K.; Kawamura, K. High abundances of dicarboxylic acids, oxocarboxylic acids, and $\alpha$-dicarbonyls in fine aerosols $\left(\mathrm{PM}_{2.5}\right)$ in Chengdu, China during wintertime haze pollution. Environ. Sci. Pollut. Res. 2015, 22, 12902-12918. [CrossRef]

11. Yong, L.; Allen, P.A.; Densmore, A.L.; Qiang, X. Evolution of the Longmen Shan foreland basin (western Sichuan, China) during the Late Triassic Indosinian orogeny. Basin Res. 2003, 15, 117-138. [CrossRef]

12. Wang, Q.; Cao, J.; Shen, Z.; Tao, J.; Xiao, S.; Luo, L.; He, Q.; Tang, X. Chemical characteristics of PM $_{2.5}$ during dust storms and air pollution events in Chengdu, China. Particuology 2012, 11, 70-77. [CrossRef]

13. Hsu, N.C.; Tsay, S.-C.; King, M.D.; Herman, J.R. Deep Blue Retrievals of Asian Aerosol Properties during ACE-Asia. IEEE Trans. Geosci. Remote Sens. 2006, 44, 3180-3195. [CrossRef]

14. Remer, L.; Kaufman, Y.; Tanré, D.; Mattoo, S.; Chu, D.; Martins, J.; Li, R.; Ichoku, C.; Levy, R.; Kleidman, R. The MODIS Aerosol Algorithm, Products and Validation. J. Atmos. Sci. 2005, 62, 947-973. [CrossRef]

15. Remer, L.; Mattoo, S.; Levy, R.; Munchak, L. MODIS 3 km aerosol product: Algorithm and global perspective. Atmos. Meas. Tech. 2013, 6, 1829-1844. [CrossRef]

16. Liu, X.; Chen, Q.; Che, H.; Zhang, R.; Gui, K.; Zhang, H.; Zhao, T. Spatial distribution and temporal variation of aerosol optical depth in the Sichuan basin, China, the recent ten years. Atmos. Environ. 2016, 147, 434-445. [CrossRef]

17. Shi, G.; Liu, R.; Wang, D.Y.; Yang, F. Evaluation of the MODIS C6 Aerosol Optical Depth Products over Chongqing, China. Atmosphere 2017, 8, 227. [CrossRef]

18. Lin, M.; Tao, J.; Chan, C.-Y.; Cao, J.-J.; Zhang, Z.-S.; Zhu, L.-H.; Zhang, R.-J. Characterization of Regression Relationship between Recent Air Quality and Visibility Changes in Megacities at Four Haze Regions of China. Aerosol Air Qual. Res. 2012, 12, 1049-1061. [CrossRef]

19. Tao, J.; Zhang, L.; Cao, J.; Hsu, S.-C.; Xia, X.; Zhang, Z.; Lin, Z.; Cheng, T.; Zhang, R. Characterization and source apportionment of aerosol light extinction in Chengdu, southwest China. Atmos. Environ. 2014, 95, 552-562. [CrossRef] 
20. Tao, R.; Che, H.; Chen, Q.; Tao, J.; Wang, Y.; Sun, J.; Wang, H.; Zhang, X. Study of Aerosol Optical Properties Based on Ground Measurements over Sichuan Basin, China. Aerosol Air Qual. Res. 2014, 14, 905-915. [CrossRef]

21. Dubovik, O.; King, M.D. A flexible inversion algorithm for retrieval of aerosol optical properties from Sun and sky radiance measurements. J. Geophys. Res. 2000, 105, 20673-20696. [CrossRef]

22. Eck, T.F.; Holben, B.N.; Reid, J.; Giles, D.; Rivas, M.; Singh, R.P.; Tripathi, S.; Bruegge, C.; Platnick, S.; Arnold, G. Fog-and cloud-induced aerosol modification observed by the Aerosol Robotic Network (AERONET). J. Geophys. Res. Atmos. 2012, 117, 107-116. [CrossRef]

23. Li, Z.; Eck, T.; Zhang, Y.; Zhang, Y.; Li, D.; Li, L.; Xu, H.; Hou, W.; Lv, Y.; Goloub, P. Observations of residual submicron fine aerosol particles related to cloud and fog processing during a major pollution event in Beijing. Atmos. Environ. 2014, 86, 187-192. [CrossRef]

24. Dubovik, O.; Smirnov, A.; Holben, B.; King, M.; Kaufman, Y.; Eck, T.; Slutsker, I. Accuracy assessments of aerosol optical properties retrieved from Aerosol Robotic Network (AERONET) Sun and sky radiance measurements. J. Geophys. Res. Atmos. 2000, 105, 9791-9806. [CrossRef]

25. O'Neill, N.; Eck, T.; Holben, B.; Smirnov, A.; Dubovik, O.; Royer, A. Bimodal size distribution influences on the variation of Angstrom derivatives in spectral and optical depth space. J. Geophys. Res. 2001, 106, 9787-9806. [CrossRef]

26. Dubovik, O.; Sinyuk, A.; Lapyonok, T.; Holben, B.N.; Mishchenko, M.; Yang, P.; Eck, T.F.; Volten, H.; Muñoz, O.; Veihelmann, B. Application of spheroid models to account for aerosol particle nonsphericity in remote sensing of desert dust. J. Geophys. Res. Atmos. 2006, 111. [CrossRef]

27. Holben, B.N.; Eck, T.; Slutsker, I.; Tanre, D.; Buis, J.; Setzer, A.; Vermote, E.; Reagan, J.; Kaufman, Y.; Nakajima, T. AERONET-A federated instrument network and data archive for aerosol characterization. Remote Sens. Environ. 1998, 66, 1-16. [CrossRef]

28. Li, Z.; Xu, H.; Li, K.; Li, D.; Xie, Y.; Li, L.; Zhang, Y.; Gu, X.; Zhao, W.; Tian, Q. Comprehensive Study of Optical, Physical, Chemical, and Radiative Properties of Total Columnar Atmospheric Aerosols over China: An Overview of Sun-Sky Radiometer Observation Network (SONET) Measurements. Bull. Am. Meteorol. Soc. 2018, 99, 739-755. [CrossRef]

29. Li, Z.; Blarel, L.; Podvin, T.; Goloub, P.; Buis, J.P.; Morel, J.P. Transferring the calibration of direct solar irradiance to diffuse-sky radiance measurements for CIMEL Sun-sky radiometers. Appl. Opt. 2008, 47, 1368-1377. [CrossRef]

30. Holben, B.N.; Kim, J.; Sano, I.; Mukai, S.; Eck, T.F.; Giles, D.M.; Schafer, J.S.; Sinyuk, A.; Slutsker, I.; Smirnov, A. An overview of mesoscale aerosol processes, comparisons, and validation studies from DRAGON networks. Atmos. Chem. Phys. 2018, 18, 1-23. [CrossRef]

31. Smirnov, A.; Holben, B.; Eck, T.; Dubovik, O.; Slutsker, I. Cloud-screening and quality control algorithms for the AERONET database. Remote Sens. Environ. 2000, 73, 337-349. [CrossRef]

32. Zhang, Y.; Li, Z.; Zhang, Y.; Chen, Y.; Cuesta, J.; Ma, Y. Multi-peak accumulation and coarse modes observed from AERONET retrieved aerosol volume size distribution in Beijing. Meteorol. Atmos. Phys. 2016, 128, 537-544. [CrossRef]

33. Cuesta, J.; Flamant, P.H.; Flamant, C. Synergetic technique combining elastic backscatter lidar data and sunphotometer AERONET inversion for retrieval by layer of aerosol optical and microphysical properties. Appl. Opt. 2008, 47, 4598-4611. [CrossRef] [PubMed]

34. Zhang, Y.; Li, Z.; Zhang, Y.; Li, D.; Qie, L.; Che, H.; Xu, H. Estimation of aerosol complex refractive indices for both fine and coarse modes simultaneously based on AERONET remote sensing products. Atmos. Meas. Tech. 2017, 10, 1-17. [CrossRef]

35. Heller, W. Remarks on Refractive Index Mixture Rules. J. Phys. Chem. 1965, 69, 1123-1129. [CrossRef]

36. O'Neill, N.; Eck, T.; Smirnov, A.; Holben, B.; Thulasiraman, S. Spectral discrimination of coarse and fine mode optical depth. J. Geophys. Res. Atmos. 2003, 108. [CrossRef]

37. Chen, Y.; Xie, S.-D. Characteristics and formation mechanism of a heavy air pollution episode caused by biomass burning in Chengdu, Southwest China. Sci. Total Environ. 2014, 473, 507-517. [CrossRef] [PubMed]

38. Liu, Y.M.; Wu, G.X.; Liu, H.; Liu, P. Condensation heating of the Asian summer monsoon and the subtropical anticyclone in the Eastern Hemisphere. Clim. Dyn. 2001, 17, 327-338. [CrossRef]

39. Kroll, J.H.; Seinfeld, J.H. Chemistry of secondary organic aerosol: Formation and evolution of low-volatility organics in the atmosphere. Atmos. Environ. 2008, 42, 3593-3624. [CrossRef] 
40. Gobbi, G.P.; Kaufman, Y.J.; Koren, I.; Eck, T.F. Classification of aerosol properties derived from AERONET direct sun data. Atmos. Chem. Phys. 2007, 7, 8713-8726. [CrossRef]

41. Kaufman, Y.J. Aerosol optical thickness and atmospheric path radiance. J. Geophys. Res. Atmos. 1993, 98, 2677-2692. [CrossRef]

42. King, M.D.; Byrne, D.M.; Herman, B.M.; Reagan, J.A. Aerosol Size Distributions Obtained by Inversion of Spectral Optical Depth Measurements. J. Atmos. Sci. 1978, 35, 2153-2167. [CrossRef]

43. Gong, S.L.; Zhang, X.Y.; Zhao, T.L.; Mckendry, I.G.; Jaffe, D.A.; Lu, N.M. Characterization of soil dust aerosol in China and its transport and distribution during 2001 ACE-Asia: 2. Model simulation and validation. J. Geophys. Res. 2003, 108. [CrossRef]

44. Wang, Y.; Sun, Y.; Xin, J.; Li, Z.; Wang, S.; Wang, P.; Hao, W.M.; Nordgren, B.L.; Chen, H.; Wang, L. Seasonal variations in aerosol optical properties over China. Atmos. Chem. Phys. Discuss. 2008, 8, 8431-8453. [CrossRef]

45. Che, H.; Xia, X.; Zhu, J.; Li, Z.; Dubovik, O.; Holben, B.; Goloub, P.; Chen, H.; Estelles, V.; Cuevas-Agulló, E. Column aerosol optical properties and aerosol radiative forcing during a serious haze-fog month over North China Plain in 2013 based on ground-based sunphotometer measurements. Atmos. Chem. Phys. 2014, 14, 2125-2138. [CrossRef]

46. Willeke, K.; Whitby, K. Atmospheric Aerosols: Size Distribution Interpretation. J. Air Pollut. Control Assoc. 1975, 25, 529-534. [CrossRef]

47. Kulmala, M.; Vehkamäki, H.; Petäjä, T.; Maso, M.D.; Lauri, A.; Kerminen, V.M.; Birmili, W.; Mcmurry, P.H. Formation and growth rates of ultrafine atmospheric particles: A review of observations. J. Aerosol Sci. 2004, 35, 143-176. [CrossRef]

48. Liu, X.; Li, J.; Qu, Y.; Han, T.; Hou, L.; Gu, J.; Chen, C.; Yang, Y.; Liu, X.; Yang, T. Formation and evolution mechanism of regional haze: A case study in the megacity Beijing, China. Atmos. Chem. Phys. 2013, 13, 4501-4514. [CrossRef]

49. Hammer, E.; Gysel, M.; Roberts, G.C.; Elias, T.; Hofer, J.; Hoyle, C.R.; Bukowiecki, N.; Dupont, J.C.; Burnet, F.; Baltensperger, U. Size-dependent particle activation properties in fog during the ParisFog 2012/13 field campaign. Atmos. Chem. Phys. 2014, 14, 9475-9516. [CrossRef]

50. Su, X.; Cao, J.; Li, Z.; Li, K.; Xu, H.; Liu, S.; Fan, X. Multi-Year Analyses of Columnar Aerosol Optical and Microphysical Properties in Xi'an, a Megacity in Northwestern China. Remote Sens. 2018, 10, 1169. [CrossRef]

51. Dubovik, O.; Holben, B.; Eck, T.F.; Smirnov, A.; Kaufman, Y.J.; King, M.D.; Tanré, D.; Slutsker, I. Variability of Absorption and Optical Properties of Key Aerosol Types Observed in Worldwide Locations. J. Atmos. Sci. 2002, 59, 590-608. [CrossRef]

52. Li, Z.; Gu, X.; Wang, L.; Li, D. Aerosol physical and chemical properties retrieved from ground-based remote sensing measurements during heavy haze days in Beijing winter. Atmos. Chem. Phys. 2013, 13, 10171-10183. [CrossRef]

53. Wang, L.; Li, Z.-Q.; Li, D.-H.; Li, K.-T.; Tian, Q.J.; Li, L.; Zhang, Y.; Lv, Y. Retrieval of Dust Fraction of Atmospheric Aerosols Based on Spectra Characteristics of Refractive Indices Obtained from Remote Sensing Measurements. Spectrosc. Spectral Anal. 2012, 32, 1644.

54. Schuster, G.L.; Dubovik, O.; Holben, B.N.; Clothiaux, E.E. Inferring black carbon content and specific absorption from Aerosol Robotic Network (AERONET) aerosol retrievals. J. Geophys. Res. Atmos. 2005, 110. [CrossRef]

55. Bodhaine, B.A. Aerosol absorption measurements at Barrow, Mauna Loa, and the South Pole. J. Geophys. Res. Atmos. 1995, 100, 8967-8975. [CrossRef]

56. Lee, K.H.; Li, Z.; Man, S.W.; Xin, J.; Wang, Y.; Hao, W.M.; Zhao, F. Aerosol single scattering albedo estimated across China from a combination of ground and satellite measurements. J. Geophys. Res. Atmos. 2007, 112. [CrossRef]

57. Surabi, M.; James, H.; Larissa, N.; Yunfeng, L. Climate effects of black carbon aerosols in China and India. Science 2002, 297, 2250-2253.

58. Hansen, J.E.; Sato, M.; Ruedy, R. Radiative forcing and climate response. J. Geophys. Res. Atmos. 1997, 102, 6831-6864. [CrossRef]

(c) 2019 by the authors. Licensee MDPI, Basel, Switzerland. This article is an open access article distributed under the terms and conditions of the Creative Commons Attribution (CC BY) license (http:/ / creativecommons.org/licenses/by/4.0/). 


\title{
Article \\ Summertime Urban Mixing Layer Height over Sofia, Bulgaria
}

\author{
Ventsislav Danchovski \\ Department of Meteorology and Geophysics, Faculty of Physics, Sofia University, Sofia 1164, Bulgaria; \\ danchovski@phys.uni-sofia.bg; Tel.: +359-2-8161-413
}

Received: 7 November 2018; Accepted: 9 January 2019; Published: 17 January 2019

\begin{abstract}
Mixing layer height (MLH) is a crucial parameter for air quality modelling that is still not routinely measured. Common methods for MLH determination use atmospheric profiles recorded by radiosonde but this process suffers from coarse temporal resolution since the balloon is usually launched only twice a day. Recently, cheap ceilometers are gaining popularity in the retrieval of MLH diurnal evolution based on aerosol profiles. This study presents a comparison between proprietary (Jenoptik) and freely available (STRAT) algorithms to retrieve MLH diurnal cycle over an urban area. The comparison was conducted in the summer season when MLH is above the full overlapping height of the ceilometer in order to minimize negative impact of the biaxial LiDAR's drawback. Moreover, fogs or very low clouds which can deteriorate the ceilometer retrieval accuracy are very unlikely to be present in summer. The MLHs determined from the ceilometer were verified against those measured from the radiosonde, which were estimated using the parcel, lapse rate, and Richardson methods (the Richardson method was used as a reference in this study). We found that the STRAT and Jenoptik methods gave lower MLH values than radiosonde with an underestimation of about $150 \mathrm{~m}$ and $650 \mathrm{~m}$, respectively. Additionally, STRAT showed some potential in tracking the MLH diurnal evolution, especially during the day. A daily MLH maximum of about $2000 \mathrm{~m}$ was found in the late afternoon (18-19 LT). The Jenoptik algorithm showed comparable results to the STRAT algorithm during the night (although both methods sometimes misleadingly reported residual or advected layers as the mixing layer (ML)). During the morning transition the Jenoptik algorithm outperformed STRAT, which suffers from abrupt changes in MLH due to integrated layer attribution. However, daytime performance of Jenoptik was worse, especially in the afternoon when the algorithm often cannot estimate any MLH (in the period 13-16 LT the method reports MLHs in only 15-30\% of all cases). This makes day-to-day tracing of MLH diurnal evolution virtually impracticable. This problem is possibly due to its early version (JO-CloVis $8.80,2009$ ) and issues with real-time processing of a single profile combined with the low signal-to-noise ratio of the ceilometer. Both LiDAR-based algorithms have trouble in the evening transition since they rely on aerosol signature which is more affected by the mixing processes in the past hours than the current turbulent mixing.
\end{abstract}

Keywords: mixing layer; urban area; ceilometer; radiosonde

PACS: 01.30.-y; 01.30.Ww; 01.30.Xx

\section{Introduction}

The effect of air quality on human health is a serious problem, especially in densely populated areas. Hence, a lot of effort is being made to better understand the processes controlling pollution levels, particularly in numerical modelling. Key input parameters of these models are meteorological variables, which are needed to be identified in order to calculate the production, diffusion, transport and scavenging of atmospheric pollutants. These harmful substances are dispersed vertically within 
the mixing layer (ML) due to its inherent turbulence. According to Seibert et al. [1], ML is “... the layer adjacent to the ground over which pollutants or any constituents emitted within this layer or entrained into it become vertically dispersed by convection or mechanical turbulence within a time scale of about an hour". However, one should bear in mind that there are situations when time-scales of the dominant processes (such as diabatic processes like radiative cooling in the evening transition, or unsteadiness of pressure gradients, or intermittent turbulence due to breaking gravity waves, just to name a few) are much longer so that the ML is unsteady [2]. Obviously, near-ground pollution levels will depend on the mixing layer height $(\mathrm{MLH})$ since it constrains the dispersion volume. Thus, the MLH is vitally important to be identified especially in urban areas where pollution sources and inhabitants are much greater [3-10]. Moreover, urban MLH can be characterized by enormous temporal and spatial variability due to inhomogeneity in surface roughness and heating in cities [11]. Therefore, MLH is worthwhile to be continuously monitored and also compared with parametrizations in numerical weather and/or pollution prediction models [12-14].

Despite its importance, MLH is not a part of routine measurements. Furthermore, because it is associated with the spatial distribution of turbulence, we need turbulence profiles to determine MLH. Consequently, TKE (turbulent kinetic energy)-based criteria (MLH is marked by the level where TKE drops below a predefined threshold) are often used in numerical models with turbulence closure of order 1.5 or higher for MLH determination [1,15]. Moreover, profiles of the TKE and its dissipation rate can be measured by remote sensing instruments [16,17]. Therefore, Doppler LiDARs [18] and sodars $[19,20]$ can serve as "turbulence profilers" but the former are quite expensive and the latter have limited vertical range. Fortunately, vertical profiles of non-reactive scalar meteorological variables should be nearly constant with height within a well-mixed boundary layer [21], so we can detect the MLH by looking for abrupt changes in the uniformly distributed profiles of these tracers [22,23].

Regardless of the wide variety of remote sensing methods, the most used instrument for MLH detection is the radiosonde, which is still used as a reference. The derivation of the MLH from the radiosonde profiles of the atmospheric temperature, humidity, and wind dates back to 1960s [24]. Moreover, these radiosonde-based methods are still used independently [25] or as a reference for validating MLH measurements from remote sensing instruments [26]. However, the radiosonde also has some drawbacks as it measures atmospheric properties along its flight, which is slant instead of vertical, due to horizontal wind. Therefore, the radiosonde profiles do not coincide with rising thermal or vertical profiles derived from the remote sensing instruments. Additionally, the radiosondes' main limitation is their coarse temporal resolution since they are usually launched no more than twice a day.

The necessity of continuous MLH monitoring can be met by operating ground-based remote sensing instruments. A comprehensive review of existing techniques for MLH determination through ground-based remote sensing instruments, along with their advantages and limitations, can be found in Wiegner et al. [27] and Emeis et al. [28]. It is worthwhile to note that individual disadvantages of each instrument in the MLH diurnal cycle determination can be overcome if apparatuses are used together [29].

One should note that relying on ground-based remote sensing instruments in MLH estimation cannot provide good spatial representativeness, especially over areas with non-homogeneous land-use and/or complex topography. Fortunately, this lack of information can be filled if space-based remote sensing instruments are used. Among them are the Cloud-Aerosol LiDAR with Orthogonal Polarization (CALIOP) [30] and the Moderate Resolution Imaging Spectroradiometer (MODIS) [31], which are the most used for determination of the atmospheric boundary layer height over continents and oceans [32-35]. The radio occultation method based on global position system signals can provide vertical profiles of the refractivity index that can be used in MLH retrieval [36,37].

In recent years, laser-based remote sensing instruments, especially automatic LiDARs and ceilometers (ALC), have become more affordable and widely used in the field of atmospheric research, particularly for MLH determination [38-45]. We should also note the considerable efforts made in the COST Action ES 1303 TOPROF [46] which provides standards for calibrated profiles of the aerosols, 
winds, temperature, and humidity to fill the observational gap in the lower troposphere. These quality controlled observations are delivered in near real-time through the EUMETNET Composite Observing System (EUCOS) network E-PROFILE [47] to the national weather services in order to improve numerical weather prediction.

Different LiDAR-based methods for MLH retrieval from the range corrected signal are summarized in Haeffelin et al. [48]. These methods are the basis of many proprietary [49,50] and in-house [51-54] algorithms explicitly designed for MLH retrieval from ceilometers' data. Possible performance improvement of these LiDAR-based techniques can be achieved by monitoring diurnal variations in Radon-222 [55] or it can be used alone to evaluate MLH [56].

The objectives of the present study are to evaluate the performance of a proprietary algorithm as well as a popular, freely available algorithm in detecting of MLH from ceilometer data over an urban area. Both methods are evaluated against MLHs retrieved using radiosonde profiles as a reference. The structure and evolution of the mixing layer over Sofia in summertime is also discussed. To highlight the advantages and disadvantages of both algorithms, an analysis was performed in the summer when MLH is high enough to minimize the negative effects due to incomplete overlapping in the near-field range of the ceilometer. The paper is organized as follow: measurement sites and specifications of the instruments used for observations, as well as details about the collected data and methods applied to determine the MLH, are in Section 2. Inter-comparison of the three radiosonde-based methods is in Section 3.1. Verification of the MLH retrieved from the ceilometer compared to the MLH measured from the radiosonde is in Section 3.2. Diurnal evolution of the MLH over Sofia derived from the ceilometer data by both the proprietary and the freely available algorithm, as well as a discussion of their main benefits and drawbacks and suggestions for performance improvement, are in Section 3.3. Statistical analysis of the MLH diurnal cycle is discussed in Section 3.4. The article ends with summary of findings.

\section{Data and Methodology}

Sofia is the largest and the most densely populated city in Bulgaria with roughly 1,400,000 inhabitants. The city is located in a valley that is almost fully encircled by mountains; therefore, the micro- and meso-scale processes, as well as the ML dynamics, are heavily influenced by both complex orography and urban territory. To perform our analysis of urban MLH we used 3 months of intensive measurements, from 1 June until 31 August 2015. The data used in this study were obtained from a continuously operating ceilometer, Jenoptik CHM 15k (in 2014, the company G. Lufft Mess- und Regeltechnik GmbH acquired the product segment of ceilometers from Jenoptik and now the ceilometer is known as Lufft CHM 15k), and a balloon sounding launched on a daily basis at 12:00 UTC (14:00 LT).

The CHM15k (firmware version 0.63) is operated by the Department of Meteorology and Geophysics, Sofia University. The ceilometer is situated in the city centre on the territory of the University Astronomical Observatory in the park "Borisova gradina" (Figure 1). The CHM15k is an eye-safe biaxial LiDAR system equipped with an Nd: YAG solid-state near-infra-red laser operating at $1064 \mathrm{~nm}$. It emits pulses with an energy of $8 \mu \mathrm{J}$ and a repetition frequency of $5-7 \mathrm{kHz}$. The ceilometer provides data with a vertical resolution of $15 \mathrm{~m}$, the maximum height of the signal is 15,000 $\mathrm{m}$ and the temporal resolution is set up to $60 \mathrm{~s}$. As CHM15k is a biaxial LiDAR it suffers from incomplete overlap in the near range since only a small portion of the laser beam gets into the receiver field of view. According to the manufacturer, the overlapping is $\sim 1 \%$ at 15 th bin $(225 \mathrm{~m}), \sim 10 \%$ at 24 th bin $(360 \mathrm{~m}), \sim 50 \%$ at 40 th bin $(600 \mathrm{~m}), \sim 90 \%$ at 57 th bin $(855 \mathrm{~m}), \sim 99 \%$ at 78 th bin $(1170 \mathrm{~m})$ and full overlap is achieved at 120th bin $(1800 \mathrm{~m})$. Further details about the instrument can be found in [57].

The MLH was retrieved from the ceilometer profiles by supposing that aerosol concentration is rapidly adapted to the thermal stratification of the ML and that aerosol loading above the city is not dominated by advection. The manufacturer's software includes a proprietary algorithm for automatically deriving the MLH every minute (software JO-CloVis version 8.80) [58]. Because the Jenoptik algorithm is proprietary not much is known about it. Haeffelin et al. [48] reported that the 
algorithm uses vertical derivatives and wavelet transforms on the range-corrected signal to identify local minima which are used as MLH, however, it is not specified which version is referred to and there is no information on how signal-to-noise ratio is enhanced in the pre-processing. A freely available Structure of the Atmosphere (STRAT) algorithm [52], which is designed for the retrieval of aerosol vertical profiles in the atmospheric boundary layer and free troposphere, is used for comparison. In contrast to the Jenoptik algorithm that is based on vertical gradients of backscatter signal in a single profile, STRAT uses both temporal and vertical gradients $\left(G_{t}\right.$ and $\left.G_{v}\right)$ by using Sobel 2-D derivation operators. The global gradient is calculated as $G=\sqrt{G_{t}{ }^{2}+G_{v}{ }^{2}}$. The edges in backscatter are kept if $G$ is greater than predefined thresholds. Additionally, edges in low signal-to-noise ratio zones are rejected. Finally, minimum (450 $\mathrm{m}$ due to overlapping) and maximum (here, $3000 \mathrm{~m}$ during the day and $1500 \mathrm{~m}$ at night are used) allowed heights are applied and three global gradients-the strongest, the second strongest, and the lowest-height-are reported as MLH candidates [48]. The MLH is then determined as the lowest-height candidate at night, during day quality control based on relative change in backscatter around each candidate is performed and the first existing one in the line strongest, second strongest and lowest is selected as MLH [18].

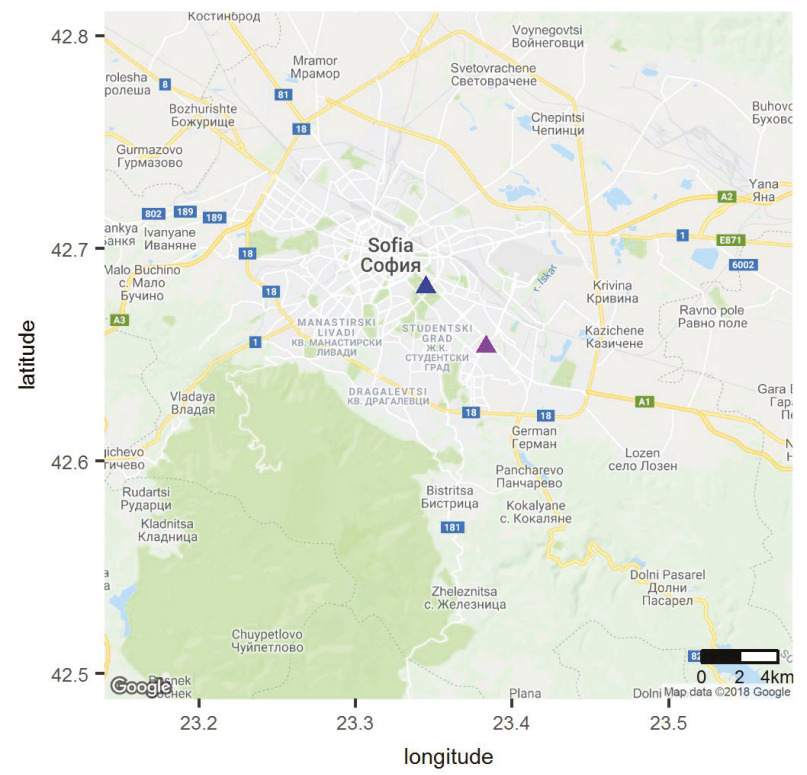

Figure 1. The locations of the ceilometer and the radiosonde indicated by a blue and a purple triangle in the Sofia valley. (Source of the map is Google LLC).

The atmospheric sounding system is the Vaisala's MW41 which is located in the Central Aerological Observatory on the territory of the National Institute of Meteorology and Hydrology, which is about $4.4 \mathrm{~km}$ south-east from the ceilometer (Figure 1). In this study, low resolution radiosonde data are used, which are freely available at Integrated Global Radiosonde Archive (IGRA) [59]. Archived radiosonde data consist of atmospheric parameters recorded at mandatory and significant levels which were used to restore the atmospheric profiles by linear interpolation.

Following de Haij et al. [60], three different MLH detecting algorithms were applied to the radiosonde data. The Bulk Richardson ( $\mathrm{Ri}$ ) method is based on the Richardson number which is the ratio of thermally and mechanically driven turbulence. According to this method, MLH is the level where the bulk Richardson number exceeds predefined threshold values [61-63]. In this study, 
the commonly recommended value of 0.21 was used. It is worth noting that the Ri method is suitable for both convective and stable conditions. In the parcel method [24,64], the MLH is determined by extending dry-adiabatically surface temperature to its intersection point with temperature profile. However, this method provides reliable results only for unstable convective boundary layer as it neglects wind shear effects on vertical mixing. The last method for MLH determination from radiosonde data is the lapse rate method [21,65]. It is based on threshold values of vertical gradients of potential temperature $(\theta)$ and relative humidity (RH). Adhering to de Haij et al. [60], negative gradients of $\mathrm{RH}$ and a gradient of $\theta>2 \mathrm{~K} / \mathrm{km}$ were used as the basis for this study. As the selected critical value of potential temperature gradient is more or less subjectively chosen, the performance of lapse rate values of $0.5,1,1.5,2.5,3,3.5$, and $4 \mathrm{~K} / \mathrm{km}$ was also tested.

As main synoptic-scale systems are associated with the suppression or stimulation of parcel ascending, it is interesting to examine their role on mixing layer height [66]. Therefore, the difference $(\Delta p)$ of surface layer atmospheric pressure $(p)$ and its smoothed value $\left(p_{\text {smooth}}\right.$, which is obtained by low pass filter with cut-off 6 days) is calculated by Equation (1). Then $\Delta p$ is standardized by Equation (2), i.e., the $\Delta p$ is rescaled to have a mean of zero (subtraction of the mean value $\overline{\Delta p}$ ) and a standard deviation of one (division by the standard deviation $\sigma_{\Delta p}$ ).

$$
\begin{gathered}
\Delta p=p-p_{\text {smooth }} \\
\Delta p_{\text {std }}=\frac{\Delta p-\overline{\Delta p}}{\sigma_{\Delta p}}
\end{gathered}
$$

Finally, the atmospheric pressure (atm.press) is classified as "Low" if $\Delta p_{s t d}$ is smaller than -0.5 while it is marked as "High" if $\Delta p_{s t d}$ is higher than 0.5 . If the $\Delta p_{s t d}$ values are greater than -0.5 but less than 0.5 , atmospheric pressure is marked as "Normal".

\section{Results and Discussions}

\subsection{Inter-Comparison of Radiosonde-Based MLH Retrieval Methods}

The three aforementioned radiosonde-based algorithms-Richardson, parcel and lapse-ratewere applied on the dataset for a total of 92 days (for 28 days the atmospheric pressure was "High", for 43 "Normal", and for 21 "Low"). MLH values were successfully estimated at 92, 92, and 81 days, respectively. The estimated MLHs were then compared against one another on Figure 2. The perfect correlation between the Richardson and parcel method indicates that in summer at 14:00 LT (12:00 UTC) the urban mixing layer over Sofia is dominated by thermally driven turbulence. It is a fairly expected result since the study period took place in summer and radiosonde launching occurred in the early afternoon. The box-plot shows that slightly higher MLH values are related to prevailing low atmospheric pressure and that when atmospheric pressure is marked as normal or high, MLHs are slightly decreased; however, the observed difference is not statistically significant (Wilcoxon-Mann-Whitney test with a significance level of 5\% was performed).

The lapse rate method shows worse alignment with the Richardson and parcel methods, therefore, we tested how a threshold value of vertical gradient $\theta$ influences concurrence with the other two approaches. We found that lapse rate values of $1,1.5$ and $2 \mathrm{~K} / \mathrm{km}$ perform similarly and Pearson correlation coefficients with respect to the Ri method are about 0.89 . However, the correlation diminishes if smaller or higher threshold values are used. It is also worth mentioning that a negative vertical gradient of the relative humidity is not changed because it agrees with the mixing layer conception (the Earth's surface is the water vapour source and free atmosphere is low in humidity, so the humidity gradient should be negative at MLH). Keeping in mind that the Ri method incorporates both mechanical and buoyancy production of turbulent mixing we choose it as a reference in the following analysis. Performance of the parcel and lapse rate methods using the set of critical values mentioned above were evaluated against the Richardson method and is summarised in Table 1. 
(a)

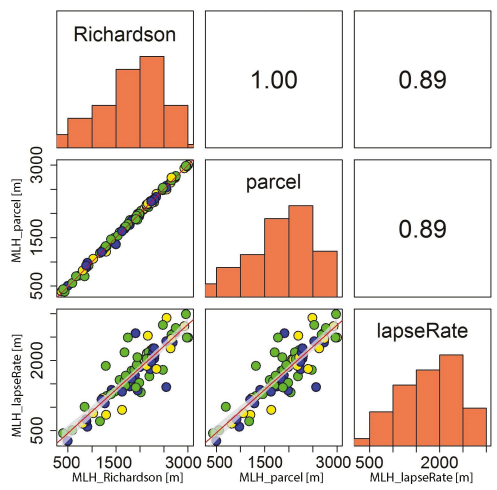

(b)

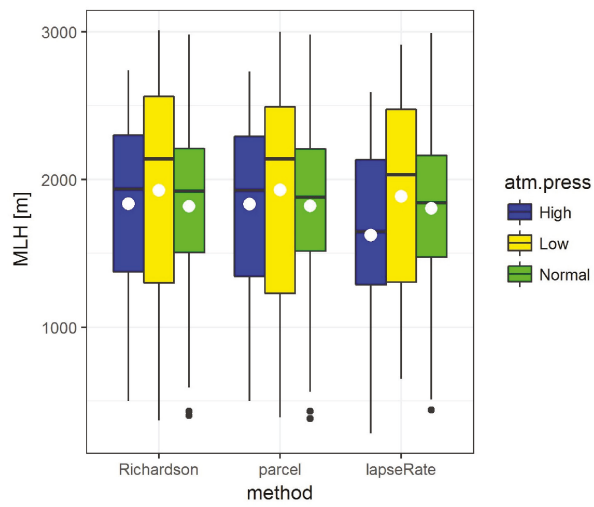

Figure 2. Inter-comparison of the three radiosonde-based MLH methods. The correlation matrix (a) shows correlation coefficients in the upper-right triangle, the diagonal shows a histogram of each method, and the lower-left triangle shows scatter-plots and linear regression lines with corresponding $95 \%$ confidence intervals. The box and whisker plot (in the style of Tukey) is on plot (b). The box lines correspond to the 25, 50 and 75 percentiles. The lower and upper whiskers represent the lowest values still within $1.5 \mathrm{IQR}$ (inter-quantile range) of the lower quartile, and the highest values still within 1.5 IQR of the upper quartile. The data beyond the end of the whiskers signify outliers and are plotted as black dots. White dots indicate mean values. In both figures, atmospheric pressure is color-coded as "High" (blue), "Low" (yellow), “Normal” (green).

Table 1. Skill scores (MD—mean deviation; RMSD—root-mean-square deviation, $\mathrm{r}$-Pearson correlation coefficient, slope - linear regression slope, intercept-linear regression intercept) of parcel and lapse rate methods compared against the Richardson method as a reference in the MLH determination.

\begin{tabular}{cccccc}
\hline Method & MD [m] & RMSD [m] & r & Slope & Intercept [m] \\
\hline parcel & 1 & 37 & 1.00 & 0.99 & 11 \\
lapse rate $0.5 \mathrm{~K} / \mathrm{km}$ & -215 & 396 & 0.85 & 0.82 & 520 \\
lapse rate $1.0 \mathrm{~K} / \mathrm{km}$ & -200 & 351 & 0.89 & 0.88 & 402 \\
lapse rate $1.5 \mathrm{~K} / \mathrm{km}$ & -194 & 342 & 0.89 & 0.89 & 388 \\
lapse rate $2.0 \mathrm{~K} / \mathrm{km}$ & -153 & 330 & 0.89 & 0.85 & 417 \\
lapse rate $2.5 \mathrm{~K} / \mathrm{km}$ & -87 & 403 & 0.81 & 0.75 & 554 \\
lapse rate $3.0 \mathrm{~K} / \mathrm{km}$ & -40 & 431 & 0.78 & 0.70 & 601 \\
lapse rate $3.5 \mathrm{~K} / \mathrm{km}$ & 39 & 493 & 0.75 & 0.61 & 719 \\
lapse rate $4.0 \mathrm{~K} / \mathrm{km}$ & 106 & 543 & 0.73 & 0.57 & 773 \\
\hline
\end{tabular}

\subsection{Inter-Comparison of MLHs Derived from Ceilometer and Radiosonde Data}

MLHs calculated from radiosonde data are often used for reference since they are based on the thermodynamic structure of the lowest atmosphere that directly reflects changes in the surface forcing. However, since routine balloon launching usually occurs only twice a day so it does not allow for MLH diurnal evolution to be tracked. Low-cost ceilometers that provide backscatter power profiles are a tempting alternative because they operate continuously.

To evaluate the overall performance of the ceilometer-based methods in the MLH determination, the calculated values are compared against the Richardson method estimates from the radiosonde data. Since the radiosonde in Sofia is launched once a day at 12:00 UTC (14:00 LT), the ceilometer-retrieved MLHs from within a 20 min timespan are averaged and used in the comparison. After this procedure the size of the STRAT's datasets at "High", "Normal" and "Low" atmospheric pressure is reduced to $18(64 \%), 24(56 \%)$ and $10(48 \%)$ days, respectively. The Jenoptik algorithm successfully estimates 
MLHs in 13 (46\%), 17 (40\%) and 11 (52\%) days at "High", "Normal" and "Low" atmospheric pressure, respectively. In other words, both ceilometer-based algorithms cannot estimate MLHs in about half of the days with "Low" atmospheric pressure. The percentage of the Jenoptik-retrieved MLHs becomes even lower at "Normal" and "High" pressure, while the performance of STRAT is slightly increased. The left and right panels of Figure 3 show a correlation matrix and box and whiskers plots of the MLH determined by STRAT, Jenoptik and Ri methods at different atmospheric pressures. It is evident that both LiDAR-based algorithms tend to underestimate MLH compared to radiosonde (Richardson). We should bear in mind that MLH estimation from the ceilometer and the radiosonde data rely on different tracers, which may contribute to the observed discrepancy. When optically thick clouds or rain are presented the backscatter signal can be strong enough to saturate the ceilometers receiver so the cloud base or somewhere under the cloud within the rain column is reported as the MLH. To prove the hypothesis, the data was spited to rainy (if nonzero ceilometer's precipitation index is registered from 11:20 to 11:40 UTC) and dry cases. The analysis showed that the difference between Ri and STRAT, and between Ri and Jenoptik are statistically non-significant (t-test with a significant level of 0.05 is performed) in rainy days. In the rest of the days the Ri method reports about $180 \mathrm{~m}(750 \mathrm{~m})$ higher MLH than STRAT (Jenoptik) and the results are statistically significant. Additionally the role of low clouds was tested. In days with low clouds (if cloud base height is $<1500 \mathrm{~m}$ ) the difference between $\mathrm{Ri}$ and STRAT and between Ri and Jenoptik are evaluated as a statistically non-significant. In the rest of the days radiosonde estimates are $212 \mathrm{~m}$ and $493 \mathrm{~m}$ higher than STRAT and Jenoptik respectively and t-test showed that both results are statistically significant. The observed underestimation of the MLH by the ceilometer could be attributed to the difference in land surface type. The ceilometer is situated in the park (while the radiosonde is in a built-up area) so one can expect that some of the solar energy is consumed during evapotranspiration; therefore the rest of the energy that would produce the thermally driven turbulence, and thus MLH raising, is reduced. To prove this, the number of consecutive days with no precipitation (ceilometer's precipitation index is used for the classification) are used to split the data into categories. It was found that the difference between Ri and STRAT methods (the Jenoptik is not included since it shows significant deviation from the Richardson method, see Figure 3) increases with the number of consecutive droughty days, which is supposed to be a result of the lack of available water for evaporation in a built-up zone. Additionally, if the drought period is long, MLH becomes higher and the ceilometer-based method experiences difficulties that are supposed to be a result of diminished backscatter due to the increased volume for aerosol dispersion (Figure 4).

(a)

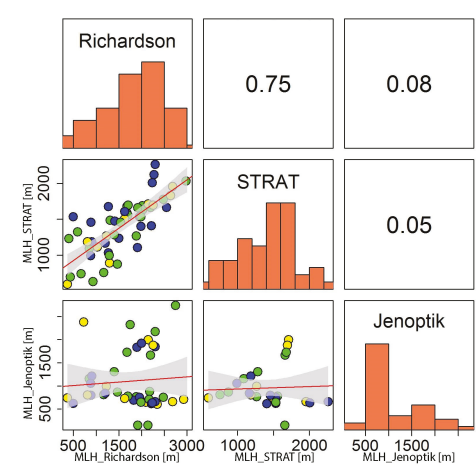

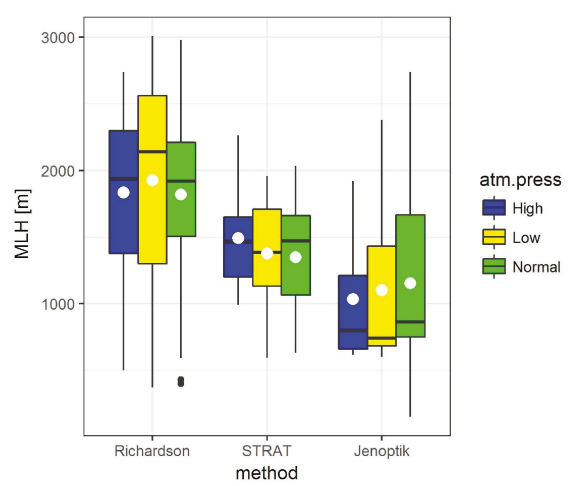

Figure 3. A correlation matrix (a) and Tukey's box and whiskers plot (b) of radiosonde-(Richardson) and LiDAR-based (STRAT and Jenoptik) algorithms for MLH detection. Conventions are the same as in Figure 2. 


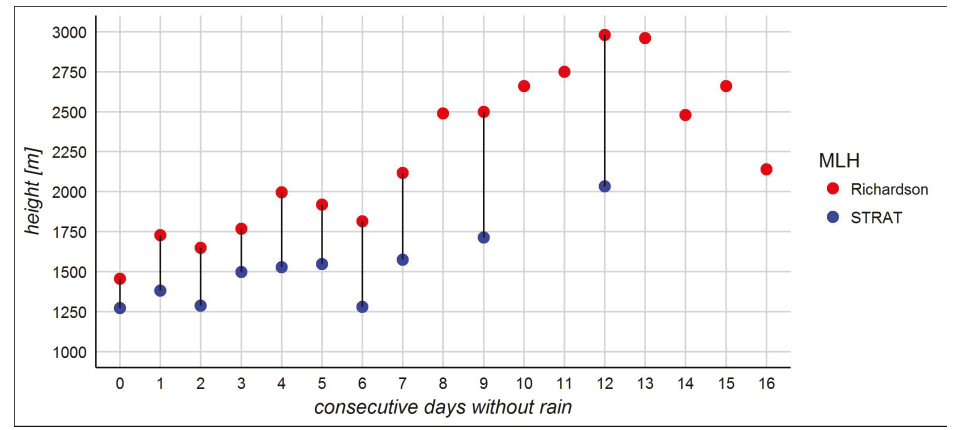

Figure 4. The dependence of drought duration (in number of dry days) on the mean MLH determined by Richardson and STRAT methods.

Skill scores of LiDAR-based algorithms against the Ri method are listed in Table 2. It can be seen that the average underestimation of MLH by STRAT and Jenoptik is $\sim 160 \mathrm{~m}$ and $\sim 660 \mathrm{~m}$ respectively. The STRAT-estimated values of MLH are reasonably comparable with those retrieved from radiosonde profiles, but Jenoptik's performance is quite unpromising and needs further clarification.

Table 2. Skill scores (MD—mean deviation; RMSD—root-mean-square deviation, r-Pearson correlation coefficient, slope-linear regression slope, intercept-linear regression intercept ) of aerosol-based algorithms (Jenoptik and STRAT) compared against the Richardson method as a reference in the MLH determination.

\begin{tabular}{cccccc}
\hline Method & MD $[\mathrm{m}]$ & RMSD $[\mathrm{m}]$ & $\mathbf{r}$ & Slope & Intercept $[\mathrm{m}]$ \\
\hline Jenoptik & -665 & 1086 & 0.08 & 0.0 .7 & 970 \\
STRAT & -162 & 467 & 0.75 & 0.45 & 701 \\
\hline
\end{tabular}

\subsection{Diurnal Evolution of the MLH Determined by the Ceilometer-A Case Study}

To elucidate the above-mentioned ceilometer's capacity to track the MLH diurnal cycle, a case study is first considered. In Figure 5 diurnal evolution of the range-corrected ceilometer signal $\left(\mathrm{PR}^{2}\right)$ on July 24 is presented along with MLHs determined according to STRAT and Jenoptik algorithms. Radiosonde-derived MLH by the Richardson method is also plotted for comparison.

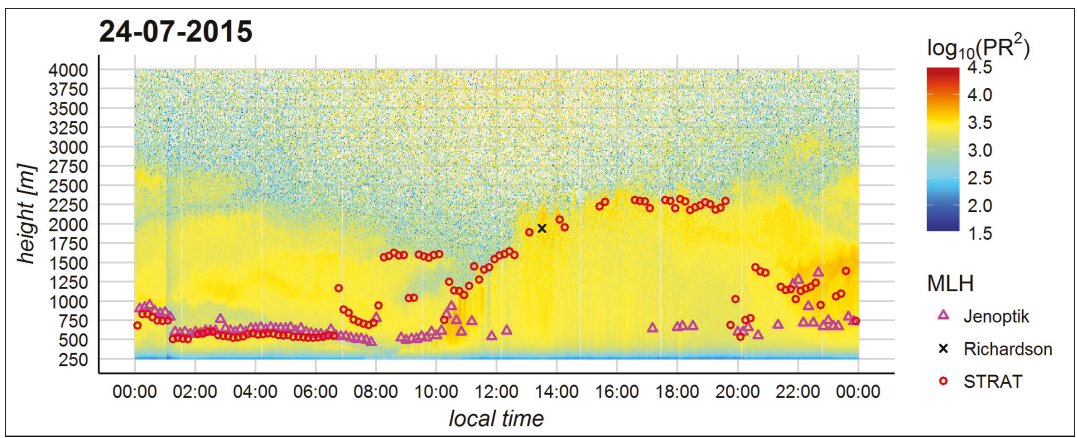

Figure 5. Time-height cross section of the ceilometer's range-corrected backscatter power ( $\mathrm{PR}^{2}$ in arbitrary units) on 24 July 2015. The MLH retrieved from ceilometer's data by Jenoptik and STRAT algorithms are marked by magenta triangles and red circles, respectively (for clarity, the Jenoptik MLHs are plotted with the same temporal resolution as STRAT-10 min). Radiosonde-based MLH according to the Ri method is presented by black " $x$ " marks. 
As observed, the range corrected ceilometer's signal reveals some characteristic features in the MLH diurnal evolution. The backscatter power within the first 500-700 $\mathrm{m}$ is high in the early hours of the night which can be associated with mechanically mixed aerosols within the nocturnal boundary layer. As seen, the layer was shrinking and at 8:00 LT (less than $2 \mathrm{~h}$ after sunrise) it had disappeared. One may expect a new convective layer to be identifiable at that moment but we should keep in mind that the ceilometer has virtually zero overlapping in the first $\sim 200 \mathrm{~m}$ (overlapping is $<1 \%$ ) so that the first signs of the rising thermals are visible at $\sim 9: 00$ LT. Above the nocturnal layer, there is a zone with decreased signal that is capped by a high backscatter layer, which most likely outlines aerosol burden air in the residual layer, or it is a result of advection at that elevation. The ceilometer's signal also depicts the daytime evolution of the MLH with its typical growth due to the solar heating of the surface. After sunrise, thermals start forming and rising due to positive buoyancy. These updrafts produce turbulent mixing so that the diminished vertical backscatter within ML in the afternoon results from an increased volume for aerosol dispersion. An enhanced signal close to the ML top in the afternoon can be attributed to hygroscopic growth of aerosols due to increased relative humidity. As can be seen, MLH reached its maximum $(\sim 2250 \mathrm{~m})$ at $\sim 16: 00$ LT and remains almost constant until 19:00 LT. In the evening, the thermals cease to form (in the absence of cold air advection), allowing turbulence to decay in the formerly well mixed layer. A new nocturnal layer starts forming and overhead air associated with the new residual layer becomes decoupled from the mechanical source of turbulence on the ground. However, the evening transition period is non-stationary as heat fluxes decrease over a few hours after sunset so that the aerosol vertical distribution does not respond to surface forcing within an hour [2]. At that part of the day the ceilometer profiles are mostly a result of the turbulence dynamics in the recent periods, therefore, they do not reveal the present ML but its history. That problem is inherent to all remote sensing instruments which use aerosol backscatter to trace the ML but can be overcome if a "true turbulence profiler" is used. As observed, the MLH determined by the Ri method is $\sim 1940 \mathrm{~m}$ which corresponds very well to the aerosol distribution depicted by the ceilometer backscatter signal at the moment of balloon launching (at 13:30 LT that day).

It is also noticeable that the STRAT algorithm plausibly represents the diurnal evolution of the MLH. However, in the time interval from sunrise (6:09 LT) to approximately 10:30 LT, which corresponds to the morning transition period, STRAT misleadingly reports an overhead backscatter gradient (associated with the residual layer) as MLH instead of the one closest to the ground. Similar behaviour is found across all days and seems to be due to the layer attribution technique implemented in STRAT. According to Haeffelin et al. [48] the algorithm reports the strongest, second strongest, and the lowest gradients in backscatter and then, depending on the local time, it constructs a diurnal evolution of its "best estimate" (used here as MLH) which is the lowest gradient during the night and the strongest gradient during the day. Thus, the STRAT method reports abrupt changes in MLH around sunrise and sunset instead of smooth transitions from the nocturnal to convective boundary layer, and vice versa. Possible improvement of layer attributions and representations of the MLH diurnal evolution can be achieved through the use of statistical analysis [67] or graph theory [68].

It can be seen that the overall consistency of the MLHs reported by the Jenoptik algorithm with the observed aerosol distribution and evolution is relatively poorer than the consistency of the STRAT's MLHs. However, Jenoptik outperforms STRAT in the morning transition, although neither method can track the MLH from 8 to $9 \mathrm{LT}$ when the MLH is in the zone of incomplete overlapping. The performance of the Jenoptik method during daytime is much worse and it cannot represent the MLH evolution. The method cannot report MLH from 13 to 17 LT and it significantly underestimates ML depth around noon and in the late afternoon. It should be noted that STRAT also locates these aerosol gradients at intermediate levels (Figure 6) but reports them as the lowest and the second strongest candidates, which are then successfully filtered out by the attribution procedure in the algorithm. This worsened performance of the Jenoptik method is likely to be a result of the immaturity of the outdated version of the algorithm used. Additionally, the Jenoptik method operates in real-time so it is likely to use only the current backscatter profile without taking into account previous measurements. Therefore, 
the signal-to-noise ratio (SNR) will be lower, which may result in poor performance compared to STRAT. Consequently, the poorer daytime performance of the Jenoptik can be attributed to reduced backscatter signal within the increased depth of the MLH (and enlarged volume for aerosol dispersion) and augmented background signal due to the higher sun elevation angle. Data shows the STRAT method also has similar troubles with backscatter gradient detection from $\sim 13: 00$ LT to $\sim 15: 00$ LT when only a few MLHs are reported. However, the process of smoothing incorporated within the algorithm enhances the SNR, enabling the MLH evolution to be tracked against the Jenoptik algorithm.

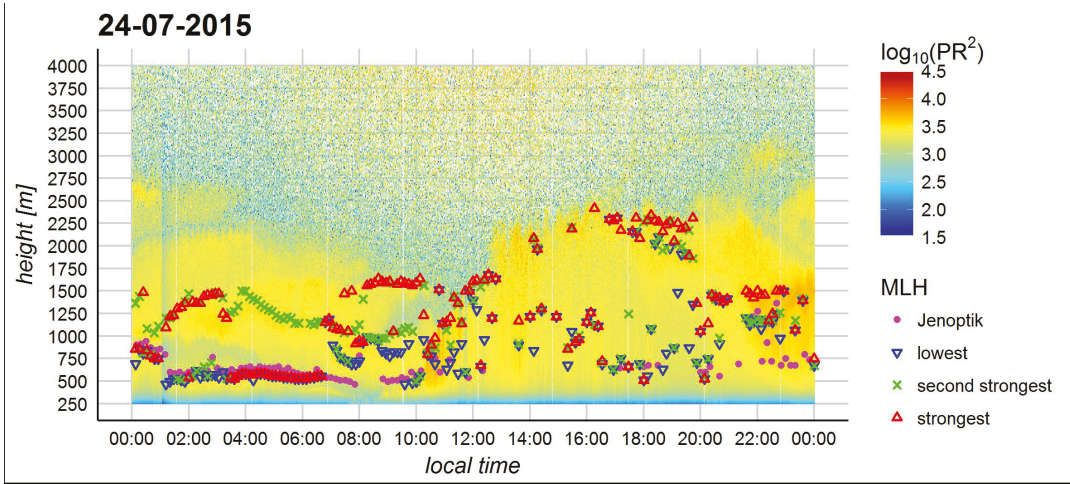

Figure 6. Time-height cross section of the ceilometer's range-corrected backscatter power ( $\mathrm{PR}^{2}$ in arbitrary units) on 24 July 2015. The MLH calculated by the Jenoptik algorithm (magenta dots) and STRAT's candidates (the strongest gradient—red triangles, the second strongest gradient—green " $x^{\prime}$ marks, and the lowest gradient—-blue upside down triangles) are also shown.

\subsection{Diurnal Evolution of the MLH Determined by Ceilometer-A Statistical Analysis}

To compare the performance of both LiDAR-based algorithms we first make the datasets comparable. Since the Jenoptik algorithm has a 1-min resolution but STRAT's temporal resolution is $10 \mathrm{~min}$, Jenoptik-derived MLHs are averaged in 10-minute intervals. The availability of STRATand Jenoptik-derived MLHs after applying the described procedure is presented in Figure 7. As seen, MLH data availability of both methods show similar patterns related to the diurnal cycle. The STRAT algorithm manages to estimate MLHs in about 70-95\% of the cases but in the afternoon its availability drops to $50-70 \%$ with minimum of $\sim 45 \%$ at 14 LT. In contrast, the Jenoptik method provides MLHs in about $60-85 \%$ of the cases but in the afternoon it hardly reaches even $35-40 \%$ with a minimum of $\sim 15 \%$ at 15 LT. The observed diurnal pattern in MLH availability in both LiDAR-based methods is closely related to decreased SNR due to reduced aerosol concentration (due to increased volume for aerosol dispersion) and increased background signal (due to higher solar radiation) in the afternoon. Neither of the two applied algorithms show a clear atmospheric pressure dependency.
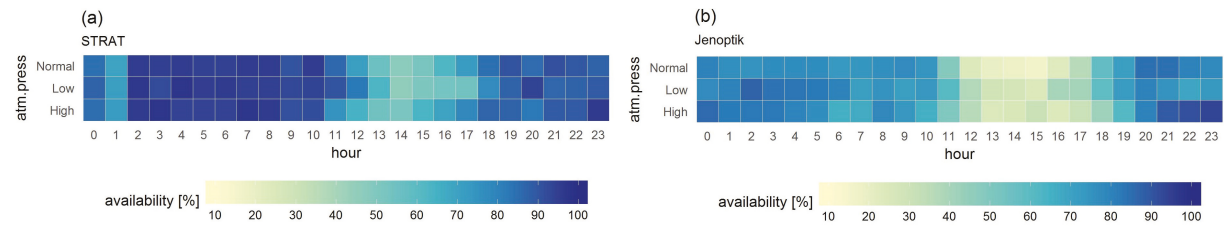

Figure 7. Diurnal evolution of the availability of MLH determined by STRAT (a) and Jenoptik (b) algorithms at "Normal", "Low" and "High" atmospheric pressure in summer of 2015.

The aforementioned features of both LiDAR-based techniques are also visible if all data for the MLH daytime progress are summarised and presented as box-plots (Figure 8). From midnight to 
7 LT STRAT and Jenoptik algorithms provide comparable MLHs and most of the estimated values are in the range of 500-1000 m. However, the Jenoptik also shows several quite large values marked as outliers (most of them in the range 1500-3500 m) which are a result of improper selection of high aerosol layers that cannot be related to the near-ground turbulence. When atmospheric pressure is "Normal" the Jenoptik algorithm also reports a few quite low MLH in the ceilometer's incomplete overlapping zone which should be treated as incorrect values (most likely they are result of multiple scattering). The morning transition is marked by STRAT as an abrupt jump that is a result of its layer attribution criterion, while the Jenoptik represents the transition less steeply. Daytime performance of both algorithms is, thus, easily distinguishable. The MLHs retrieved by Jenoptik are often in the first $1 \mathrm{~km}$ and rarely reach $2 \mathrm{~km}$. As was noted, the algorithm tends to report mid-level gradients that are also marked by STRAT lowest-height and/or second strongest gradients. However, in STRAT these mid-level gradients in the ML are successfully filtered out by the successive layer attribution. The daily maximum of MLH (sometimes more than $2000 \mathrm{~m}$ ) is registered in the late afternoon ( 18:00 LT), a few hours before sunset and, more importantly, during peak car traffic, which can help against excessive concentrations of air pollution. The evening transition is hard to be correctly traced by the LiDAR's backscatter profile as the aerosol signature is more related to turbulent mixing in the past than the current state. Therefore, although showing different behaviours, it is difficult to designate one of the two methods as more reliable. It is worth noting that there are a large number of outliers in the retrieved MLHs by the Jenoptik algorithm; most of them are related to high aerosol layers due to advection or residual layers at night. As seen, both methods report lower daytime MLHs in "Low" atmospheric pressure, especially Jenoptik algorithm, whose estimates do not reach $1 \mathrm{~km}$ in $50 \%$ of cases.

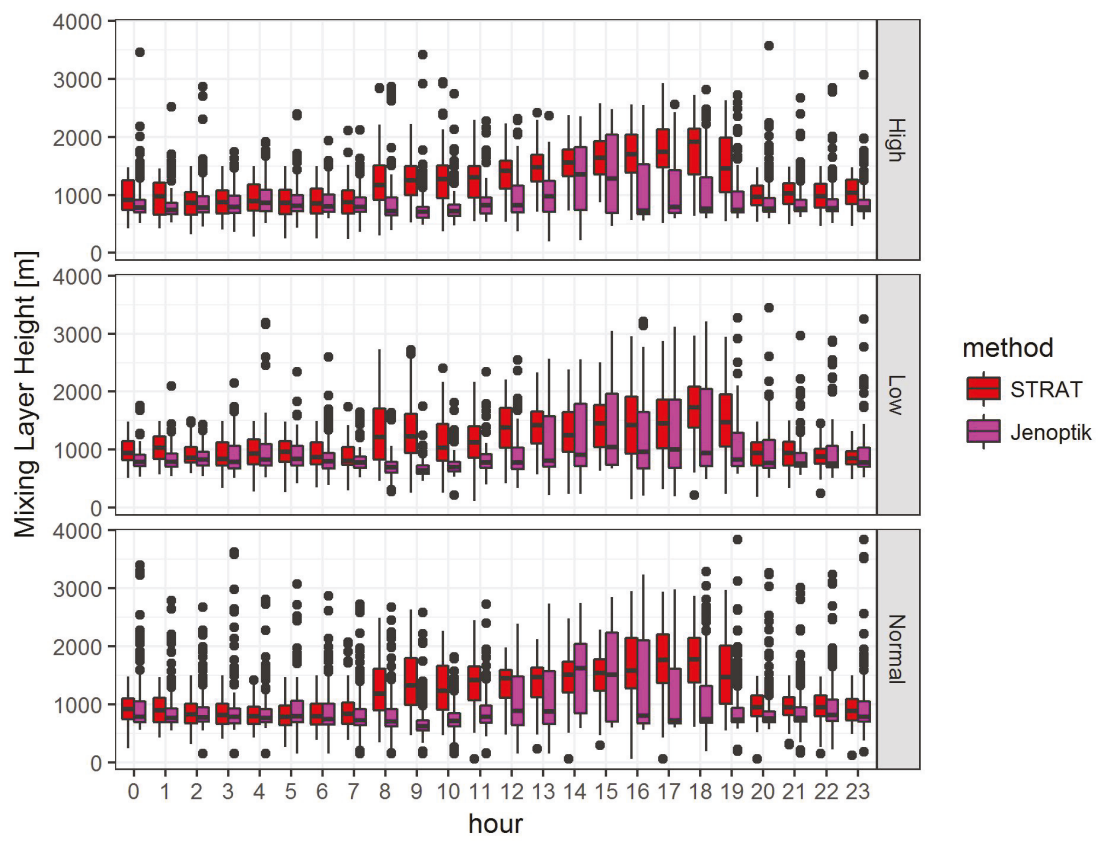

Figure 8. Diurnal cycle of the MLH over Sofia determined by STRAT (red) and Jenoptik (magenta) algorithms as a box and whiskers plot (in Tukey's style) at "High", "Low" and "Normal" atmospheric pressure in summer of 2015 . 


\section{Conclusions}

In this paper, MLHs derived by different algorithms over three summer months from radiosonde and ceilometer data were analysed and compared. It was shown that the Richardson and parcel methods produce identical MLHs which indicates that ML is primarily thermally driven while the lapse-rate method underestimates the MLH. It was also found that threshold values for potential temperature higher than $2 \mathrm{~K} / \mathrm{km}$ or smaller than $1 \mathrm{~K} / \mathrm{km}$ deteriorate the agreement of lapse rate with the Richardson and parcel methods. Based on performed comparison against the Richardson method, it was shown that the ceilometer tends to underestimate the MLH. The observed discrepancy was mainly attributed to different land surface types where the instruments are situated and the distance between the sites. Additionally, the proprietary algorithm has difficulty with the low SNR of the ceilometer and frequently cannot report any MLH. In contrast, STRAT handles this better in that it incorporates SNR enhancement. It was shown that the ceilometer-derived aerosol profiles provide consistent with expected MLH information, which can be used to trace the urban MLH dynamics during day. However, the Jenoptik algorithm has difficulty (low availability of reported MLH due to reduced SNR when ML is high) primarily due to the early version of the software used in this work. The hampered tracking of the MLH by the proprietary algorithm may also be a result of the real-time operation on a single profile without making use of the previously collected data. The primary issues of both LiDAR-based techniques were identified as layer attribution, particularly at night and during transition periods when high aerosol layers were mistakenly used by the algorithms. It was underlined that incomplete overlapping of the ceilometer impacts the detection of low MLH at night. Based on the performed statistical analysis it was shown that the STRAT algorithm reconstructs expected MLH dynamics during the day, with maximums in the late afternoon. On the other hand, the Jenoptik method rarely reports MLH values in daytime, which embarrasses the tracking of the MLH diurnal evolution.

Funding: This research and publication costs were funded by the Bulgarian National Science Fund grant number DM 04/1 2016.

Acknowledgments: This study would not be possible without TOPROF-European COST action ES1303 and the advices and recommendations of all TOPROF members. The author is also grateful to NOAA's National Centers for Environmental Information for providing the IGRA. Acknowledgements are due to all contributors to the $\mathbf{R}$ project. The author would also like to thank anonymous readers whose valuable comments and corrections significantly improved paper quality.

Conflicts of Interest: The author declares no conflict of interest.

\section{References}

1. Seibert, P.; Beyrich, F.; Gryning, S.E.; Joffre, S.; Rasmussen, A.; Tercier, P. Review and intercomparison of operational methods for the determination of the mixing height. Atmos. Environ. 2000, 34, 1001-1027. [CrossRef]

2. Momen, M.; Bou-Zeid, E. Analytical reduced models for the non-stationary diabatic atmospheric boundary layer. Bound.-Layer Meteorol. 2017, 164, 383-399. [CrossRef]

3. Schäfer, K.; Emeis, S.; Hoffmann, H.; Jahn, C. Influence of mixing layer height upon air pollution in urban and sub-urban areas. Meteorol. Z. 2006, 15, 647-658. [CrossRef]

4. Schäfer, K.; Wagner, P.; Emeis, S.; Jahn, C.; Muenkel, C.; Suppan, P. Mixing layer height and air pollution levels in urban area. In Proceedings of SPIE-Remote Sensing of Clouds and the Atmosphere XVII; SPIE: Bellingham, WA, USA, 2012; Volume 8534, p. 853409. [CrossRef]

5. Yuan, J.; Bu, L.; Huang, X.; Gao, H.; Sa, R. Particulate Characteristics during a Haze Episode Based on Two Ceilometers with Different Wavelengths. Atmosphere 2016, 7, 20. [CrossRef]

6. Zang, Z.; Wang, W.; Cheng, X.; Yang, B.; Pan, X.; You, W. Effects of Boundary Layer Height on the Model of Ground-Level PM2.5 Concentrations from AOD: Comparison of Stable and Convective Boundary Layer Heights from Different Methods. Atmosphere 2017, 8, 104. [CrossRef] 
7. Geiß, A.; Wiegner, M.; Bonn, B.; Schäfer, K.; Forkel, R.; Schneidemesser, E.v.; Münkel, C.; Chan, K.L.; Nothard, R. Mixing layer height as an indicator for urban air quality? Atmos. Meas. Tech. 2017, 10, 2969-2988. [CrossRef]

8. Mues, A.; Rupakheti, M.; Münkel, C.; Lauer, A.; Bozem, H.; Hoor, P.; Butler, T.; Lawrence, M.G. Investigation of the mixing layer height derived from ceilometer measurements in the Kathmandu Valley and implications for local air quality. Atmos. Chem. Phys. 2017, 17, 8157-8176. [CrossRef]

9. Zeng, S.; Zhang, Y. The Effect of Meteorological Elements on Continuing Heavy Air Pollution: A Case Study in the Chengdu Area during the 2014 Spring Festival. Atmosphere 2017, 8, 71. [CrossRef]

10. Kotthaus, S.; Halios, C.H.; Barlow, J.F.; Grimmond, C. Volume for pollution dispersion: London's atmospheric boundary layer during ClearfLo observed with two ground-based lidar types. Atmos. Environ. 2018, 190, 401-414. [CrossRef]

11. Li, X.X.; Britter, R.E.; Norford, L.K.; Koh, T.Y.; Entekhabi, D. Flow and pollutant transport in urban street canyons of different aspect ratios with ground heating: Large-eddy simulation. Bound.-Layer Meteorol. 2012, 142, 289-304. [CrossRef]

12. Baklanov, A. The mixing height in urban areas-A review. Mix. Heights Invers. Urban Areas COST Action 2002, 715, 9-28.

13. Schäfer, K.; Emeis, S.; Jahn, C.; Münkel, C.; Schrader, S.; Höß, M. New results from continuous mixing layer height monitoring in urban atmosphere. In Proceedings of SPIE-Remote Sensing of Clouds and the Atmosphere XIII; SPIE: Bellingham, WA, USA, 2008; Volume 7107, p. 71070A. [CrossRef]

14. Vishnu, R.; Kumar, Y.B.; Sinha, P.R.; Rao, T.N.; Samuel, E.J.J.; Kumar, P. Comparison of mixing layer heights determined using LiDAR, radiosonde, and numerical weather prediction model at a rural site in southern India. Int. J. Remote Sens. 2017, 38, 6366-6385. [CrossRef]

15. Banks, R.F.; Tiana-Alsina, J.; Rocadenbosch, F.; Baldasano, J.M. Performance evaluation of the boundary-layer height from lidar and the Weather Research and Forecasting model at an urban coastal site in the north-east Iberian Peninsula. Bound.-Layer Meteorol. 2015, 157, 265-292. [CrossRef]

16. Kumer, V.M.; Reuder, J.; Dorninger, M.; Zauner, R.; Grubišić, V. Turbulent kinetic energy estimates from profiling wind LiDAR measurements and their potential for wind energy applications. Renew. Energy 2016, 99, 898-910. [CrossRef]

17. O'Connor, E.J.; Illingworth, A.J.; Brooks, I.M.; Westbrook, C.D.; Hogan, R.J.; Davies, F.; Brooks, B.J. A method for estimating the turbulent kinetic energy dissipation rate from a vertically pointing Doppler lidar, and independent evaluation from balloon-borne in situ measurements. J. Atmos. Ocean. Technol. 2010, 27, 1652-1664. [CrossRef]

18. Schween, J.; Hirsikko, A.; Löhnert, U.; Crewell, S. Mixing-layer height retrieval with ceilometer and Doppler lidar: From case studies to long-term assessment. Atmos. Meas. Tech. 2014, 7, 3685-3704. [CrossRef]

19. Lokoshchenko, M.A. Long-term sodar observations in Moscow and a new approach to potential mixing determination by radiosonde data. J. Atmos. Ocean. Technol. 2002, 19, 1151-1162. [CrossRef]

20. Emeis, S.; Türk, M. Frequency distributions of the mixing height over an urban area from SODAR data. Meteorol. Z. 2004, 13, 361-367. [CrossRef]

21. Stull, R.B. An Introduction to Boundary Layer Meteorology; Springer Science \& Business Media: Berlin, Germany, 1988. [CrossRef]

22. Sicard, M.; Perez, C.; Comeren, A.; Baldasano, J.M.; Rocadenbosch, F. Determination of the mixing layer height from regular lidar measurements in the Barcelona area. In Remote Sensing of Clouds and the Atmosphere VIII; SPIE: Bellingham, WA, USA, 2004; Volume 5235, pp. 505-517. [CrossRef]

23. Cimini, D.; De Angelis, F.; Dupont, J.C.; Pal, S.; Haeffelin, M. Mixing layer height retrievals by multichannel microwave radiometer observations. Atmos. Meas. Tech. 2012, 6, 2941-2951. [CrossRef]

24. Holzworth, G.C. Estimates of mean maximum mixing depths in the contiguous United States. Mon. Weather Rev. 1964, 92, 235-242. [CrossRef]

25. Wang, X.; Wang, K. Estimation of atmospheric mixing layer height from radiosonde data. Atmos. Meas. Tech. 2014, 7, 1701-1709. [CrossRef]

26. Hennemuth, B.; Lammert, A. Determination of the atmospheric boundary layer height from radiosonde and lidar backscatter. Bound.-Layer Meteorol. 2006, 120, 181-200. [CrossRef] 
27. Wiegner, M.; Emeis, S.; Freudenthaler, V.; Heese, B.; Junkermann, W.; Münkel, C.; Schäfer, K.; Seefeldner, M.; Vogt, S. Mixing layer height over Munich, Germany: Variability and comparisons of different methodologies. J. Geophys. Res. Atmos. 2006, 111. [CrossRef]

28. Emeis, S.; Schäfer, K.; Münkel, C. Surface-based remote sensing of the mixing-layer height-A review. Meteorol. Z. 2008, 17, 621-630. [CrossRef] [PubMed]

29. Beyrich, F.; Görsdorf, U. Composing the diurnal cycle of mixing height from simultaneous sodar and wind profiler measurements. Bound.-Layer Meteorol. 1995, 76, 387-394. [CrossRef]

30. Winker, D.M.; Vaughan, M.A.; Omar, A.; Hu, Y.; Powell, K.A.; Liu, Z.; Hunt, W.H.; Young, S.A. Overview of the CALIPSO mission and CALIOP data processing algorithms. J. Atmos. Ocean. Technol. 2009, 26, 2310-2323. [CrossRef]

31. Kaufman, Y.J.; Tanré, D.; Remer, L.A.; Vermote, E.; Chu, A.; Holben, B. Operational remote sensing of tropospheric aerosol over land from EOS moderate resolution imaging spectroradiometer. J. Geophys. Res. Atmos. 1997, 102, 17051-17067. [CrossRef]

32. Luo, T.; Yuan, R.; Wang, Z. Lidar-based remote sensing of atmospheric boundary layer height over land and ocean. Atmos. Meas. Tech. 2014, 7, 173-182. [CrossRef]

33. Zhang, W.; Guo, J.; Miao, Y.; Liu, H.; Zhang, Y.; Li, Z.; Zhai, P. Planetary boundary layer height from CALIOP compared to radiosonde over China. Atmos. Chem. Phys. 2016, 16, 9951-9963. [CrossRef]

34. Liu, Z.; Mortier, A.; Li, Z.; Hou, W.; Goloub, P.; Lv, Y.; Chen, X.; Li, D.; Li, K.; Xie, Y. Improving Daytime Planetary Boundary Layer Height Determination from CALIOP: Validation Based on Ground-Based Lidar Station. Adv. Meteorol. 2017, 2017, 5759074. [CrossRef]

35. Feng, X.; Wu, B.; Yan, N. A method for deriving the boundary layer mixing height from modis atmospheric profile data. Atmosphere 2015, 6, 1346-1361. [CrossRef]

36. Sokolovskiy, S.; Kuo, Y.H.; Rocken, C.; Schreiner, W.; Hunt, D.; Anthes, R. Monitoring the atmospheric boundary layer by GPS radio occultation signals recorded in the open-loop mode. Geophys. Res. Lett. 2006, 33. [CrossRef]

37. Guo, P.; Kuo, Y.H.; Sokolovskiy, S.; Lenschow, D. Estimating atmospheric boundary layer depth using COSMIC radio occultation data. J. Atmos. Sci. 2011, 68, 1703-1713. [CrossRef]

38. García-Franco, J.; Stremme, W.; Bezanilla, A.; Ruiz-Angulo, A.; Grutter, M. Variability of the Mixed-Layer Height Over Mexico City. Bound.-Layer Meteorol. 2018, 167, 493-507. [CrossRef]

39. Knepp, T.N.; Szykman, J.J.; Long, R.; Duvall, R.M.; Krug, J.; Beaver, M.; Cavender, K.; Kronmiller, K.; Wheeler, M.; Delgado, R.; et al. Assessment of mixed-layer height estimation from single-wavelength ceilometer profiles. Atmos. Meas. Tech. 2017, 10, 3963. [CrossRef] [PubMed]

40. Peng, J.; Grimmond, C.S.B.; Fu, X.; Chang, Y.; Zhang, G.; Guo, J.; Tang, C.; Gao, J.; Xu, X.; Tan, J. Ceilometer-Based Analysis of Shanghai's Boundary Layer Height (under Rain-and Fog-Free Conditions). J. Atmos. Ocean. Technol. 2017, 34, 749-764. [CrossRef]

41. Nemuc, A.; Nicolae, D.; Talianu, C.; Carstea, E.; Radu, C. Dynamic of the lower troposphere from multiwavelength LIDAR measurements. Roman. Rep. Phys. 2009, 61, 313-323.

42. Ungureanu, I.; Stefan, S.; Nicolae, D. Investigation of the cloud cover and planetary boundary layer (PBL) characteristics using ceilometer CL-31. Roman. Rep. Phys. 2010, 62, 396-404.

43. Wang, W.; Gong, W.; Mao, F.; Pan, Z. An improved iterative fitting method to estimate nocturnal residual layer height. Atmosphere 2016, 7, 106. [CrossRef]

44. Li, H.; Yang, Y.; Hu, X.M.; Huang, Z.; Wang, G.; Zhang, B. Application of Convective Condensation Level Limiter in Convective Boundary Layer Height Retrieval Based on Lidar Data. Atmosphere 2017, 8, 79. [CrossRef]

45. Caicedo, V.; Rappenglück, B.; Lefer, B.; Morris, G.; Toledo, D.; Delgado, R. Comparison of aerosol lidar retrieval methods for boundary layer height detection using ceilometer aerosol backscatter data. Atmos. Meas. Tech. 2017, 10, 1609-1622. [CrossRef]

46. Illingworth, A. TOPROF (COST Action ES1303)—Towards Operational Ground Based Profiling with Ceilometers, Doppler Lidars and Microwave Radiometers for Improving Weather Forecasts. Available online: http:/ / www.toprof.imaa.cnr.it/ (accessed on 30 November 2018).

47. EUMETNET Composite Observing System-E-PROFILE. Available online: http://eumetnet.eu/activities/ observations-programme/current-activities/e-profile/ (accessed on 30 November 2018). 
48. Haeffelin, M.; Angelini, F.; Morille, Y.; Martucci, G.; Frey, S.; Gobbi, G.; Lolli, S.; O'dowd, C.; Sauvage, L.; Xueref-Rémy, I.; et al. Evaluation of mixing-height retrievals from automatic profiling lidars and ceilometers in view of future integrated networks in Europe. Bound.-Layer Meteorol. 2012, 143, 49-75. [CrossRef]

49. Münkel, C.; Eresmaa, N.; Räsänen, J.; Karppinen, A. Retrieval of mixing height and dust concentration with lidar ceilometer. Bound.-Layer Meteorol. 2007, 124, 117-128. [CrossRef]

50. Uzan, L.; Egert, S.; Alpert, P. Ceilometer evaluation of the eastern Mediterranean summer boundary layer height-First study of two Israeli sites. Atmos. Meas. Tech. 2016, 9, 4387-4398. [CrossRef]

51. Stachlewska, I.; Piądłowski, M.; Migacz, S.; Szkop, A.; Zielińska, A.; Swaczyna, P. Ceilometer observations of the boundary layer over Warsaw, Poland. Acta Geophys. 2012, 60, 1386-1412. [CrossRef]

52. Morille, Y.; Haeffelin, M.; Drobinski, P.; Pelon, J. STRAT: An automated algorithm to retrieve the vertical structure of the atmosphere from single-channel lidar data. J. Atmos. Ocean. Technol. 2007, 24, 761-775. [CrossRef]

53. Poltera, Y.; Martucci, G.; Collaud Coen, M.; Hervo, M.; Emmenegger, L.; Henne, S.; Brunner, D.; Haefele, A. PathfinderTURB: An automatic boundary layer algorithm. Development, validation and application to study the impact on in-situ measurements at the Jungfraujoch. Atmos. Chem. Phys. Discuss. 2017. [CrossRef]

54. Kotthaus, S.; Grimmond, C.S.B. Atmospheric boundary-layer characteristics from ceilometer measurements. Part 1: A new method to track mixed layer height and classify clouds. Q. J. R. Meteorol. Soc. 2018, 144, 1525-1538. [CrossRef]

55. Griffiths, A.; Parkes, S.; Chambers, S.; McCabe, M.; Williams, A. Improved mixing height monitoring through a combination of lidar and radon measurements. Atmos. Meas. Tech. 2013, 6, 207-218. [CrossRef]

56. Galeriu, D.; Melintescu, A.; Stochioiu, A.; Nicolae, D.; Balin, I. Radon, as a tracer for mixing height dynamicsAn overview and RADO perspectives. Roman. Rep. Phys. 2011, 63, 115-127.

57. Heese, B.; Flentje, H.; Althausen, D.; Ansmann, A.; Frey, S. Ceilometer lidar comparison: Backscatter coefficient retrieval and signal-to-noise ratio determination. Atmos. Meas. Tech. 2010, 3, 1763-1770. [CrossRef]

58. Jenoptik. Cloud Height Meter CHM 15k-User Manual; JENOPTIK Laser, Optical Systems GmbH: Jena, Germany, 2009.

59. Durre, I.; Vose, R.S.; Wuertz, D.B. Overview of the integrated global radiosonde archive. J. Clim. 2006, 19, 53-68. [CrossRef]

60. De Haij, M.; Wauben, W.; Baltink, H.K. Continuous Mixing Layer Height Determination Using the LD-40 Ceilometer: A Feasibility Study; Royal Netherlands Meteorological Institute (KNMI): De Bilt, The Netherlands, 2007.

61. Vogelezang, D.; Holtslag, A. Evaluation and model impacts of alternative boundary-layer height formulations. Bound.-Layer Meteorol. 1996, 81, 245-269. [CrossRef]

62. Menut, L.; Flamant, C.; Pelon, J.; Flamant, P.H. Urban boundary-layer height determination from lidar measurements over the Paris area. Appl. Opt. 1999, 38, 945-954. [CrossRef] [PubMed]

63. Sicard, M.; Pérez, C.; Rocadenbosch, F.; Baldasano, J.; García-Vizcaino, D. Mixed-layer depth determination in the Barcelona coastal area from regular lidar measurements: Methods, results and limitations. Bound.-Layer Meteorol. 2006, 119, 135-157. [CrossRef]

64. Holzworth, G.C. Mixing depths, wind speeds and air pollution potential for selected locations in the United States. J. Appl. Meteorol. 1967, 6, 1039-1044. [CrossRef]

65. Garrett, A. Comparison of Observed Mixed-Layer Depths to Model Estimates Using Observed Temperatures and Winds, and MOS Forecasts. J. Appl. Meteorol. 1981, 20, 1277-1283. [CrossRef]

66. Dang, R.; Li, H.; Liu, Z.; Yang, Y. Statistical analysis of relationship between daytime Lidar-derived planetary boundary layer height and relevant atmospheric variables in the semiarid region in Northwest China. Adv. Meteorol. 2016, 2016. [CrossRef]

67. Lotteraner, C.; Piringer, M. Mixing-height time series from operational ceilometer aerosol-layer heights. Bound.-Layer Meteorol. 2016, 161, 265-287. [CrossRef]

68. de Bruine, M.; Apituley, A.; Donovan, D.P.; Klein Baltink, H.; de Haij, M.J. Pathfinder: Applying graph theory to consistent tracking of daytime mixed layer height with backscatter lidar. Atmos. Meas. Tech. 2017, 10, 1893-1909. [CrossRef]

(c) 2019 by the author. Licensee MDPI, Basel, Switzerland. This article is an open access article distributed under the terms and conditions of the Creative Commons Attribution (CC BY) license (http:/ / creativecommons.org/licenses/by/4.0/). 

MDPI

St. Alban-Anlage 66

4052 Basel

Switzerland

Tel. +41 616837734

Fax +4161302 8918

www.mdpi.com

Atmosphere Editorial Office

E-mail: atmosphere@mdpi.com

www.mdpi.com/journal/atmosphere

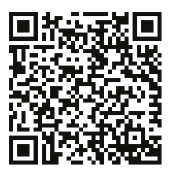



MDPI

St. Alban-Anlage 66

4052 Basel

Switzerland

Tel: +41 616837734

Fax: +41 613028918 